\title{
Des ressources et des hommes en montagne
}

\section{Jean Duma (dir.)}

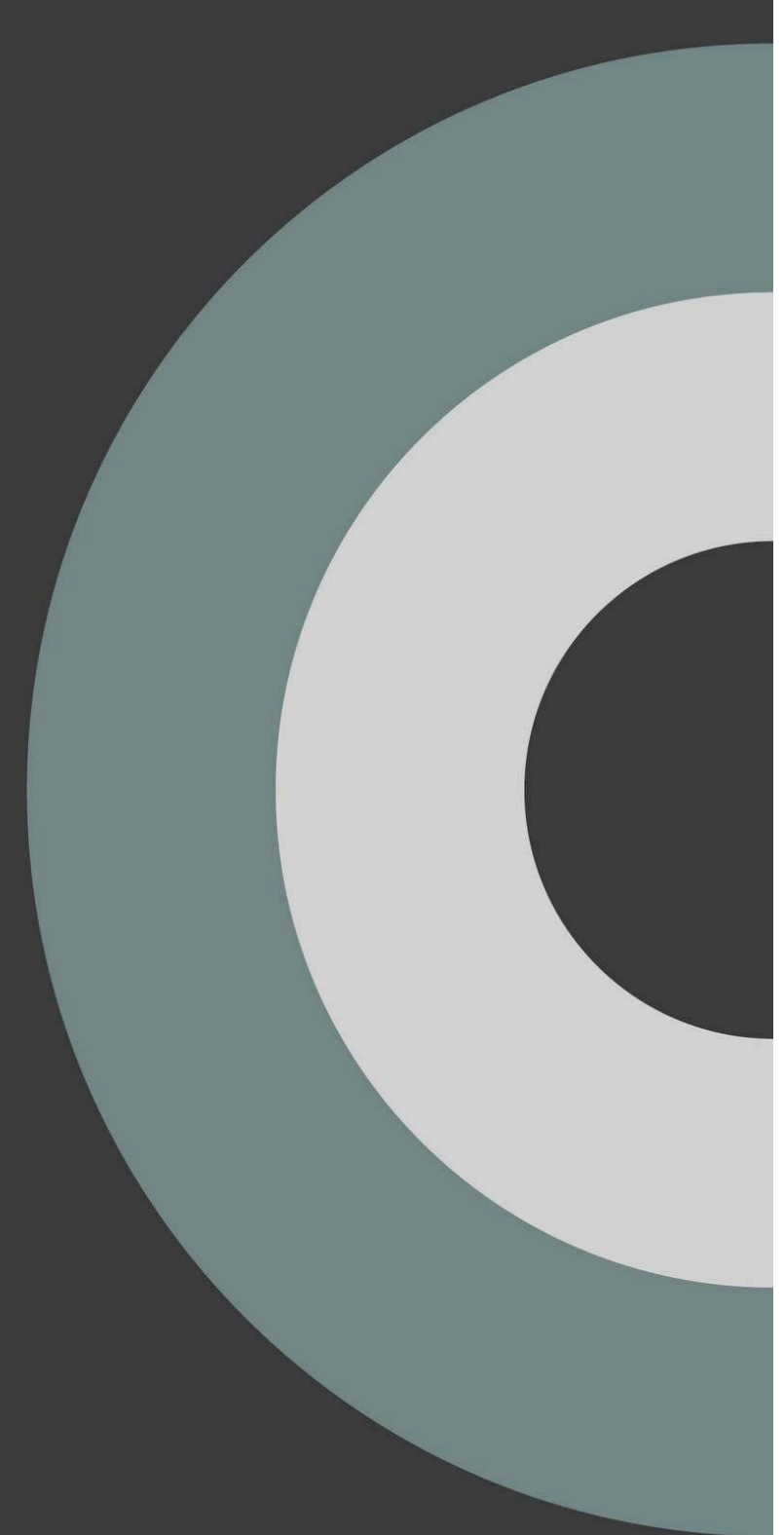




\section{Des ressources et des hommes en montagne}

\section{Jean Duma (dir.)}

DOI : $10.4000 /$ books.cths. 5628

Éditeur : Éditions du Comité des travaux historiques et scientifiques Année d'édition : 2019

Date de mise en ligne : 18 juin 2019

Collection : Actes des congrès nationaux des sociétés historiques et scientifiques

ISBN électronique : 9782735508884

\section{Sbooks}

http://books.openedition.org

\section{Référence électronique}

DUMA, Jean (dir.). Des ressources et des hommes en montagne. Nouvelle édition [en ligne]. Paris

Éditions du Comité des travaux historiques et scientifiques, 2019 (généré le 10 décembre 2020). Disponible sur Internet : <http://books.openedition.org/cths/5628>. ISBN : 9782735508884 . DOI : https://doi.org/10.4000/books.cths.5628.

Ce document a été généré automatiquement le 10 décembre 2020.

(C) Éditions du Comité des travaux historiques et scientifiques, 2019

Conditions d'utilisation

http://www.openedition.org/6540 
La montagne peut paraître à première vue étrangère aux circulations des hommes comme des ressources. Pourtant, l'espace montagnard, lieu de départ ou de refuge depuis toujours, se caractérise par des circulations permanentes qui, en dépit des difficultés imposées par des contraintes naturelles qui peuvent être fortes, se caractérisent par leur ampleur et leur diversité : diversité des objets, diversité dans le temps, diversité des modalités humaines. La montagne, en dépit de certaines apparences, est un espace marqué par des mutations avec des rythmes d'évolution diversifiés, du temps long des périodes préhistoriques aux mutations d'aujourd'hui, plus brutales et plus radicales.

Le Congrès national des sociétés historiques et scientifiques rassemble chaque année universitaires, membres de sociétés savantes et jeunes chercheurs. Ce recueil est issu de travaux présentés lors du $142^{\mathrm{e}}$ Congrès sur le thème "Circulations montagnardes, circulations européennes ».

\section{JEAN DUMA}

Professeur émérite des universités 
SOMMAIRE

Introduction

Jean Duma

\section{Aux Temps anciens}

Les outils macrolithiques : 5000 ans d'exploitation dans les Vosges

Florent Jodry

Les bases de données

Les sources d'approvisionnement en matériaux lithiques et les modes d'acquisition

Les outils lithiques adaptés aux besoins

Du vin antique sur un versant haut-savoyard? Le vignoble et le pressoir de Versoie à Thonon-les-Bains

Christophe Landry

Une unité rurale de l'Antiquité tardive au Genevray, sur les rives du marais de Versoie

Les fosses de plantation, premiers témoins de l'implantation de la vigne sur la rive sud du Léman au

$\mathrm{IV}^{\mathrm{e}}$ siècle apr. J.-C.

Les fondations d'un pressoir

Quelle production viticole? Du vitis allobrogica de Pline au Chasselas moderne

\section{La période médiévale}

Rôle méconnu d'une brèche rouge brun à clastes schisteux et à ciment silico-ferrugineux dans le bâti médiéval des Pyrénées catalanes

Michel Martzluff, Pierre Giresse, Aymat Catafau, Caroline de Barrau et Cécile Respaut

Historique des recherches

Gisements et zones d'extraction

La brèche à clastes schisteux des églises de haute Cerdagne

Bilan de la recherche

Les étangs de Grandmont : aménagement et exploitation hydrauliques des monts d'Ambazac (Haute-Vienne)

Christophe Cloquier

Des monts d'Ambazac aux vallons humides

De la découverte fortuite à l'étude exhaustive

Aménagement triple du territoire : irrigation, meunerie et pisciculture

La hiérarchisation des espaces ruraux : famille, migrations et luttes politiques à la frontière des royaumes de Valence et d'Aragon pendant le Moyen Âge Vicent Royo Pérez

La construction d'un espace frontalier

Famille et affaires au-delà des frontières politiques

La lutte pour l'espace local 
Remploi et mobilité des bois de construction dans le bâti subalpin médiéval et moderne : le cas du massif du Mercantour (Alpes françaises)

Vincent Labbas

Méthodes et outils

Bois de construction et provenance des arbres

Le réemploi de bois d'œuvre

La circulation de la mémoire lignagère dans un espace de moyenne montagne : nobles et confrères du Saint-Esprit en Forez au XIII siècle

Alexis Fontbonne

Le Forez : un milieu montagnard franchissable

La naissance d'une frontière politique

La circulation des vassaux : l'implantation forézienne des vassaux du comte

Les confréries du Saint-Esprit : un espace d'intégration idéal?

Être noble et confrère du Saint-Esprit : une stratégie d'implantation

Les lignages non-nobles : la memoria au village et entre villages

Un parallèle éclairant : les confréries des Alpes

\section{Aux Temps modernes}

Le bois de construction des Alpes du sud : une ressource mise en œuvre localement et exportée

Lisa Shindo

Utilisation locale du bois de construction

Exportation du bois de construction

Les bois importés en Basse Provence et leurs marques

Conclusions et perspectives

Le contrôle du faîte des Vosges : aspects politiques et économiques à l'aube des Temps modernes

Jean-Marie Yante

Le franchissement routier du massif vosgien

L'enjeu des gîtes métallifères

Marchands du Dauphiné à Bayonne et dans sa région au milieu du XVII siècle Francis Brumont

Installation

Des compagnies familiales

Un négoce bien réglé et profitable

Mobilité et ancrage local : les enjeux des confréries à Turin au XVIII siècle Nicoletta Rolla

La ville s'agrandit

L'importance d'habiter Turin

Les associations des métiers du bâtiment

Sacré et profane

La «nation »

Des Alpes à Saint-Domingue : les commerçants du Haut-Dauphiné et les colonies caribéennes au XVIII siècle

Boris Deschane

Les milieux commerçants dans le Haut-Dauphiné

Circulations montagnardes, circulations atlantiques

Un groupe social multi-situé? 
Le pasteur Oberlin au Ban de la Roche (1740-1826) : un homme des Lumières pionnier de l'économie de montagne

Marie-Noële Denis

Le Ban de la Roche

Les conditions naturelles

La situation économique

Le pasteur Oberlin et son univers

La révolution agricole au Ban de la Roche

Développement de l'industrie

Un modèle architectural

L'instruction

Histoire de la migration marchande de la Vallée de Barcelonnette : une première esquisse Laurent Surmely

L’âge du " grand commerce » $\left(\mathrm{XV}^{\mathrm{e}}\right.$-début du XVII ${ }^{\mathrm{e}}$ siècle)

L'âge des réseaux marchands en Piémont et dans les États génois (début XVII ${ }^{\mathrm{e}}$ siècle-années 1740)

L'âge du colportage (années 1740-première moitié du XIX ${ }^{\mathrm{e}}$ siècle)

L'âge des Amériques (années 1840-Xx ${ }^{\mathrm{e}}$ siècle)

Des Pyrénées à la Sierra Maestra: aux origines du modèle caféier cubain, Casamajor et les Béarnais dans l'Oriente

Jacques de Cauna

Les Casamajor, une vieille famille béarnaise aux Îles

De Prudent de Casamajor à Prudencio Casamayor : Cuba, le café, les Béarnais

L'aventure cubaine des cousins Dufourcq et ses étonnantes destinées familiales

\section{AuX XIX et $X X^{e}$ siècles}

Les circulations de bois dans le Vercors-nord au XIX ${ }^{e}$ siècle : l'histoire d'une dépossession? Gilles Della-Vedova

Des circulations héritées

Des circulations entravées

Lutte des masses/lutte des classes

Des circulations de bois négociées

Le développement en co-construction par les migrations familiales (canton de Villard-deLans $X I X^{e}-X X^{e}$ siècle)

Gilles Della-Vedova

Le départ des « pauvres gens »?

Des destinations bien différentes

Tisser le lien entre la montagne et la ville

La montagne, lieu d'arrivées

La mobilité des Savoyards aux portes de la Maurienne (1860-1914)

Jean-Marc Villermet

Une ouverture sur le monde

Des destinations très variées

Constitution progressive de réseau

Une race écartelée ? Les enjeux sociaux, économiques et politiques des bovins de Villard-deLans (Isère) du milieu du XIX ${ }^{e}$ siècle à 1914

Gilles Della-Vedova

Une race au cœur d'un jeu d'acteurs multiples

Une race venue d'en bas (socialement), c'est-à-dire d'en haut (géographiquement) 


\section{Aujourd'hui}

Encadrer la coutume migratoire : l'exemple de la transhumance pyrénéenne dans la première moitié $\mathrm{du} \mathrm{XX}^{e}$ siècle

Henri Pinoteau

La progressive mise en place d'un encadrement juridique

De la logistique à la politique étrangère

Bergers de Cize contre vétérinaires du Valcarlos : exemple d'un incident diplomatique pastoral

Les figues d'exportation en Kabylie (1930-1953) : réussite ou échec du colonisateur?

Isabelle Chiavassa

Initiative et étapes

Longueurs et résistances

La montagne touristique française : une démographie en panne?

Christophe Gauchon

Quelques préalables méthodologiques

Le constat

Explications et implications 


\section{NOTE DE L'ÉDITEUR}

Les articles de cet ouvrage ont été validés par le comité de lecture des Éditions du Comité des travaux historiques et scientifiques dans le cadre de la publication des actes du $142^{\mathrm{e}}$ Congrès national des sociétés historiques et scientifiques tenu à Pau en 2017. 


\title{
Introduction
}

\author{
Jean Duma
}

1 La montagne - obstacle et refuge à la fois - peut paraître à première vue étrangère aux circulations des hommes comme des ressources. Pourtant, et c'est surtout l'intérêt des contributions réunies ici à l'occasion du $142^{\mathrm{e}}$ congrès CTHS qui s'est tenu à Pau en 2017 et consacré aux Circulations montagnardes et aux circulations européennes, l'espace montagnard, lieu de départ ou de refuge depuis toujours, se caractérise par des circulations permanentes qui, en dépit des difficultés imposées par des contraintes naturelles qui peuvent être fortes, se caractérisent par leur ampleur et leur diversité : diversité des objets, diversité dans le temps, diversité des modalités humaines.

2 Il faut noter également l'importance des phénomènes de rupture, des allers et retours aussi bien spatiaux que temporels. La montagne, en dépit de certaines apparences, est un espace marqué par des mutations avec des rythmes d'évolution diversifiés qui va du temps long des périodes préhistoriques aux mutations d'aujourd'hui plus brutales et plus radicales. Le regroupement chronologique des vingt-deux contributions présentées ici rend compte de cette réalité.

3 Deux contributions abordent les premiers temps de l'homme. Cela concerne les évolutions lentes des temps préhistoriques avec notamment la contribution de Florent Jodry soulignant la richesse des contacts qui existent déjà, dès le Néolithique, entre les populations et comment cela révèle l'émergence d'un artisanat de plus en plus qualifié et disposant des outils nécessaires à son activité C'est aussi l'approche des frémissements plus sensibles de la période antique avec l'étude de la viticulture alpine conduite par Christophe Landry. Croisant données archéologiques et sources classiques, il met en évidence l'ancienneté de l'activité viticole dans une zone de montagne.

4 La période médiévale voit à la fois le maintien d'évolutions lentes et de permanences (Les Étangs de Grandmont de Christophe Cloquier) et des changements plus contrastés et plus dynamiques, voire plus conflictuels. C'est le cas des rapports entre les communautés rurales et les oligarchies urbaines des royaumes de Valence et d'Aragon étudiés par Vicent Royo-Perez. C'est la mise en évidence des stratégies des nobles foréziens pour rester au centre du pouvoir comtal abordé par Alexis Fontbonne. 
5 Les périodes modernes et contemporaines rassemblent un plus grand nombre de contributions. C'est le signe d'une recherche plus ample et plus diversifiée qui se caractérise par une multiplication des approches et des problématiques. En effet ces circulations ne sont pas seulement diverses dans le temps, elles le sont aussi dans leurs objets et dans leurs modalités humaines. L'accessibilité et la mobilité croissantes des personnes et des biens en montagne, au cours des deux derniers siècles, ont produit de grandes mutations aussi bien au niveau des objets que sur le plan humain.

6 Les objets sont nombreux et tiennent compte des spécificités économiques de ces zones et de leurs ressources. Sans pouvoir, ni vouloir être exhaustif, un regard a été jeté sur quelques cas particuliers: les bovins, essentiels dans des régions marquées par des économies agropastorales avec l'étude de Gilles Della-Vedova sur les bovins de Villardde-Lans dans l'Isère de la fin du xix siècle; les figues d'exportation en Kabylie présentées par Isabelle Chiavassa, qui témoignent de l'activité des colonisateurs et de leurs difficultés ; le bois un produit important et permanent que l'on trouve aussi bien au Moyen Âge - Vincent Labbas s'intéresse notamment aux formes de réemploi, à la croisée du Moyen Âge et des Temps modernes, Lisa Shindo met en évidence la diversité de la circulation des bois liée à la diversité des usages - que dans les périodes plus récentes avec les circulations de bois dans le Vercors-nord au XIX siècle, dont Gilles Della-Vedova souligne les enjeux socio-politiques.

7 La pluriactivité générale et ancienne en montagne s'accompagne de migrations aux rythmes et à l'ampleur divers. La question est abordée de façon diversifiée par plusieurs contributions où se manifestent des jeux d'échelles multiples. Certaines de ces migrations sont de faible ampleur, constituent une mobilité de proximité, souvent saisonnière et fort éloignée d'une migration de la misère. C'est ce que mettent en évidence Jean-Marc Villermet lorsqu'il se penche sur le sort des Savoyards du canton d'Aiguebelle aux portes de la Maurienne, Henri Pinoteau qui traite de la transhumance pyrénéenne dans la première moitié $\mathrm{du} \mathrm{xx}^{\mathrm{e}}$ siècle ou Gilles Della-Vedova qui met bien en valeur, par une microanalyse du canton de Villard-de-Lans aux $\mathrm{xIx}^{\mathrm{e}}$ et $\mathrm{xx}^{\mathrm{e}}$ siècles, la complexité du phénomène et le rôle essentiel des liens familiaux et des logiques de groupe qui organisent ces mouvements.

8 Ces mouvements peuvent se développer à l'échelle d'un pays, la France ou de l'Italie. Francis Brumont analyse le cas de ces marchands dauphinois qui «s'expatrient " à Bayonne où ils se livrent à des activités diversifiées qui les insèrent dans les circuits commerciaux locaux sans qu'ils oublient pour autant leurs racines alpestres. De son côté, Nicoletta Rolla montre comment, en prenant appui sur la réalité complexe des confréries, les entrepreneurs du bâtiment qui jouent au rôle essentiel dans l'agrandissement de Turin au XVIII ${ }^{e}$ siècle, sont au centre de circulations qui associent toutes les régions voisines de la capitale.

9 Les échanges, enfin, s'effectuent entre des aires géographiques plus éloignées, vers des milieux considérés comme plus cléments et générateurs de profits à l'image de la contribution de Boris Deschanel sur les rapports entre les commerçants du HautDauphiné et les colonies caribéennes au XvIII ${ }^{\mathrm{e}}$ siècle et sur les stratégies familiales qui les accompagnent, celle de Laurent Surmely qui traite de la classique migration marchande de la vallée de Barcelonnette ou Jacques de Cauna qui reconstitue les liens de Casamajor et des Béarnais avec l'Oriente cubain dans la moyenne durée. 
10 Cette mobilité des hommes s'accompagne d'un effort de contrôle des routes et la montagne, se confronte ainsi à la naissance d'entités politiques en devenant limites d'États et longtemps des communautés montagnardes ont voulu jouer le rôle de portiers, de gardiens de frontières incertaines et disputées avec la volonté de maintenir leurs avantages pastoraux et commerciaux. Le contrôle du faite des Vosges étudié par Jean-Marie Yante en fournit un bon exemple et en souligne bien les enjeux politiques et économiques.

Enfin, le souci de valorisation des espaces montagnards a conduit à mettre l'accent sur des aspects particuliers où la dimension économique est prise dans sa globalité avec la réflexion de Marie-Noële Denis sur le pasteur Oberlin et ses efforts, au Ban de la Roche, pour expérimenter et développer une économie de montagne prenant appui sur une agriculture spécifique, sur l'industrie et sur l'instruction, qui en fait un pionnier au temps des Lumières. Ou bien le travail plus actuel de Christophe Gauchon qui, faisant le bilan des politiques d'aménagement touristique lancées dans les années 1950-1960, est conduit à s'interroger sur l'impact démographique réel de ces politiques dont il souligne finalement l'effet réduit, au bout d'un certain temps, pour enrayer le déclin démographique qui se manifeste dans certaines régions de montagne où l'attractivité est plus touristique que résidentielle.

Enfin, il convient aussi de noter la dimension et l'apport méthodologiques de plusieurs de ces contributions qui témoignent aussi de l'importance des renouvellements rendus possibles par la mise en œuvre des nouvelles techniques de recherche. Plusieurs contributions en témoignent : dans le domaine de l'archéologie, avec la contribution de Christophe Landry pour l'Antiquité et celle de Christophe Cloquier pour la période médiévale; le recours à la dendrochronologie, notamment par Lisa Shindo et Vincent Labbas ou l'étude des roches (Michel Martzluff) et des objets lithiques qu'elles ont généré (Florent Jodry). Au total, la diversité et la qualité des études rassemblées ici soulignent la fécondité des problématiques qui ont irriguées ce Congrès.

\section{AUTEUR}

\section{JEAN DUMA}

Professeur émérite des universités 
Aux Temps anciens 


\title{
Les outils macrolithiques : 5000 ans d'exploitation dans les Vosges
}

\author{
Florent Jodry
}

1 L'étude des outils macrolithiques mis au jour sur les sites dont la fourchette chronologique comprise entre le Néolithique et le début de l'Antiquité, révèle la diversité des roches acquises et illustre la richesse des contacts entre les populations. La multiplication des points d'acquisition montre la capacité de l'Homme à s'affranchir des distances afin de mettre en place des circuits d'approvisionnement temporaires ou pérennes. Il est donc prêt à parcourir de longues distances ou plus pragmatiquement à utiliser un réseau commercial afin de se procurer le matériau ad hoc. L'acquisition locale, bien que relevant d'un réflexe humain tout à fait compréhensible, n'est donc pas forcément le seul mode opératoire.

2 Cette gestion des ressources lithiques induit la recherche de la roche la plus efficace dans les conditions optimales de ramassage et de transport, ce qui conditionne l'aspect de ces outils, transportés sous leur forme brute, semi-finie ou achevée. En effet, tandis que la proximité entre la zone d'extraction et le site d'utilisation permet de constituer des stocks importants de matière brute, traitée ultérieurement ou employée telle quelle, l'éloignement semble entraîner deux types de traitement dans la réalisation des objets. Le premier concerne le dégrossissage de pièces brutes sur le site d'approvisionnement, afin de limiter les quantités de matière à transporter, le second repose sur la valorisation du transport de produits semi-finis ou finis afin de limiter la fracture d'outils plus complexes à réaliser.

3 Afin de mettre en valeur ce potentiel géologique très riche, révélé par la variété des outils élaborés et leur répartition chronologique, nous avons construit deux bases de données dont la première "ressources lithiques » a été mise au point pour enregistrer les zones d'extraction et la caractérisation de la roche, en lien avec Philippe Duringer, géologue à l'IPG-EOST de Strasbourg et Gilles Fronteau, géologue au Gegenaa de l'Université de Reims. La seconde base de données, « outils lithiques », est construite à partir des inventaires des rapports de diagnostics et de fouilles. Cette base de données prend en considération le type d'outil, la matière première et la fourchette chronologique des sites. Le croisement de ces données constitue les clés d'entrée pour 
bâtir une cartographie des sites importateurs ${ }^{1}$ et ainsi dessiner les flux de circulation des ressources minérales.

\section{Les bases de données}

Cette première enquête menée sur les "ressources lithiques" intègre les zones potentielles de prélèvement qui sont à l'heure actuelle peu nombreuses puisque leur découverte est soumise aux prospections pédestres. Toutefois, à l'heure actuelle 41 points d'acquisition sont enregistrés et positionnés sur un fond de carte géologique grâce aux données collectées par un appareil de géolocalisation utilisant la technologie GPS $\odot / G L O N A S S \odot$. Les points d'acquisition se situent dans les zones d'affleurement gréseux autour des sites archéologiques répertoriés dont certains sont fouillés et étudiés (Goubet et al. 2015 ; Farget, Fronteau 2011). Cependant dans l'état actuel de la recherche, l'attribution chronologique de nombreuses zones de prélèvements reste floue.

5 Toutefois ces zones sont reconnues à l'aide de deux critères : présence d'une halde (Hal) et d'un ou plusieurs objets en cours de taille et abandonnés ou brisés, isolés (OI) ou dans un contexte d'exploitation visible (OC). Ce contexte d'acquisition se fait sur matériaux de surface $(\mathrm{COL})$ ou directement sur la roche mère $(\mathrm{EXT})$. Les pièces sont très fréquemment réalisées à partir de petits blocs déplaçables par l'Homme (COL_i ; Jodry \& Holderbach, 2017) et plus rarement à partir de gros blocs de surface (EXT_b) non transportables (fig. 1).

Fig. 1. - Exemple de gros bloc de surface non transportable (EXT_b) exploité pour l'acquisition de matériaux.

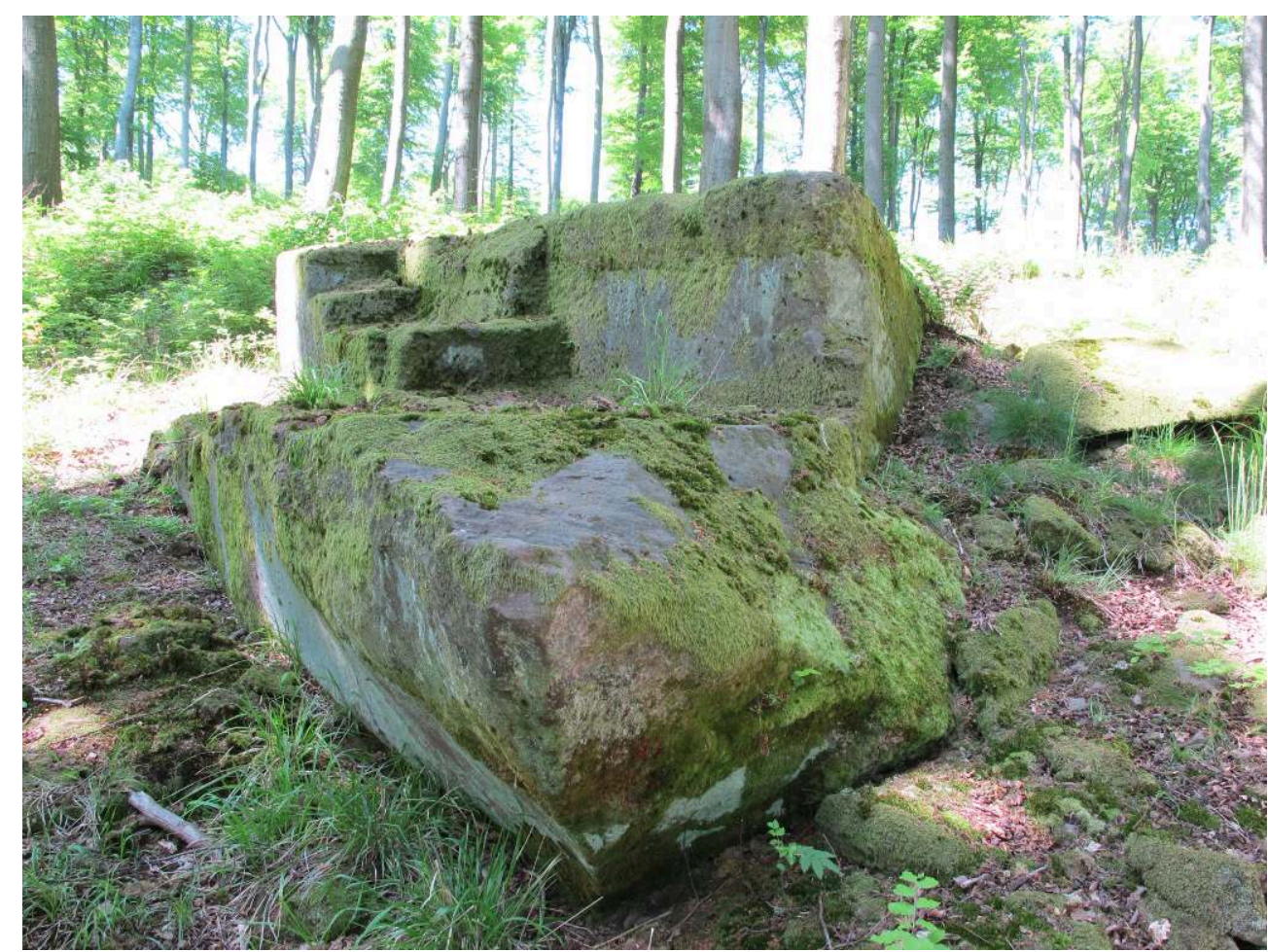

(c) Cliché : Jodry-Inrap 2010. 
Parallèlement à cette première base de données " ressources lithiques ", une seconde est construite. Cette base de données "outils lithiques » intègre jusqu'à présent 25 sites, la plupart diachroniques, dont la fourchette chronologique s'inscrit sur la période du Néolithique ancien au début du Haut Empire (premier siècle). Une forte variation peut se lire dans la chronologie des sites enregistrés jusqu'à présent et il est souhaitable à l'avenir de corriger ces différences afin d'affiner les comparaisons puisqu'une grande amplitude se lit au sein de certaines périodes. L'exemple le plus flagrant concerne le Néolithique où l'on enregistre un seul site du Néolithique ancien pour 10 sites du Néolithique récent. Une amplitude identique a été mise en valeur pour les implantations protohistoriques où sept sites de l'âge du Bronze côtoient dans l'inventaire 24 sites de l'âge du Fer (fig. 2).

Fig. 2. - Chronologie du décompte des sites enregistrés dans l'étude (état août 2017).

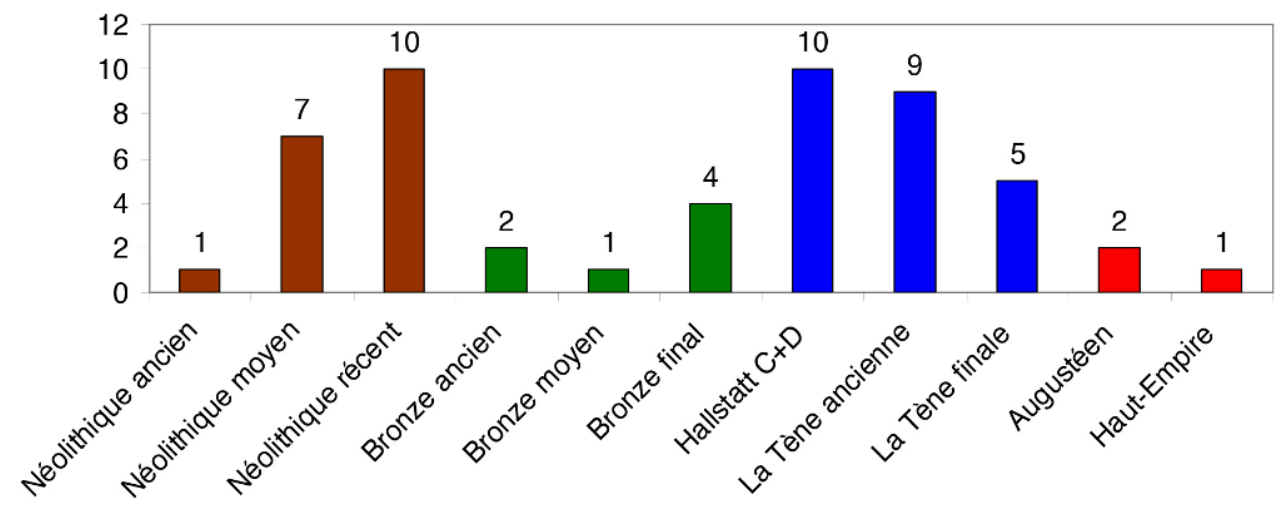

(C) Jodry, Inrap, 2017

7 La base de données « outils lithiques » rassemble plus de 1200 outils : 1039 réalisés dans les roches sédimentaires, 117 dans les roches magmatiques et 97 dans les roches métamorphiques. Ils se répartissent principalement sur la période du Néolithique avec 828 pièces (692 outils pour la période centrale du Néolithique moyen ${ }^{2}$ ) puis sur la période protohistorique avec 367 pièces (96 outils pour l'âge du Bronze, 91 pour la période Hallstatt et 180 pour le second âge du fer). Enfin, 58 outils ont été inventoriés pour la période antique.

8 Dans cet ensemble d'outils lithiques, différents groupes peuvent être répertoriés. Ce sont principalement des pièces destinées à la transformation de produits alimentaires parmi lesquelles les outils de mouture arrivent en tête avec 832 pièces (toutes périodes confondues). D'autres éléments, appartenant à des activités artisanales, sont également retenus parmi lesquels les percuteurs, enclumes, polissoirs, lissoirs et aiguisoirs rassemblent 333 pièces sur l'ensemble des périodes.

\section{Les sources d'approvisionnement en matériaux lithiques et les modes d'acquisition}

9 Ces deux banques de données permettent de construire un tableau chronologique des principales sources lithiques exploitées. Il indique, par le plébiscite de certaines roches au détriment d'autres ou au contraire par leur absence, qu'une sélection semble être à l'origine de ce choix. Cette sélection semble obéir à un schéma d'acquisition commandé 
soit par une connaissance aiguë des affleurements lithiques, soit en utilisant un maillage de sites intermédiaires qui importent certaines pièces lithiques sur de longues distances (tabl. 1).

Le massif vosgien se développe sur près de 300 kilomètres de long et s'étend sur 35 kilomètres dans sa plus petite largeur. Dans sa partie méridionale, il entre en contact avec l'Arc Jurassien à la hauteur de Bâle et s'étend jusqu'aux massifs du Hunsrück et de l'Eifel en Allemagne à son extrémité septentrionale. La complexité des dépôts sédimentaires vosgiens impose qu'on les qualifie davantage afin d'éviter qu'ils soient mal identifiés et résumés par une terminologie triviale comme "grès rose " ou " grès des Vosges ». L'intervention de Philippe Duringer et Gilles Fronteau dans ce domaine a particulièrement aidé les archéologues à modifier cette vision simpliste et la caractérisation pétrographique précise des roches, doublée par la réalisation de lames minces, a contribué à valoriser la richesse lithologique présente dans le massif Vosgien.

Tabl. 1. - Tableau chronologique des principales roches exploitées.

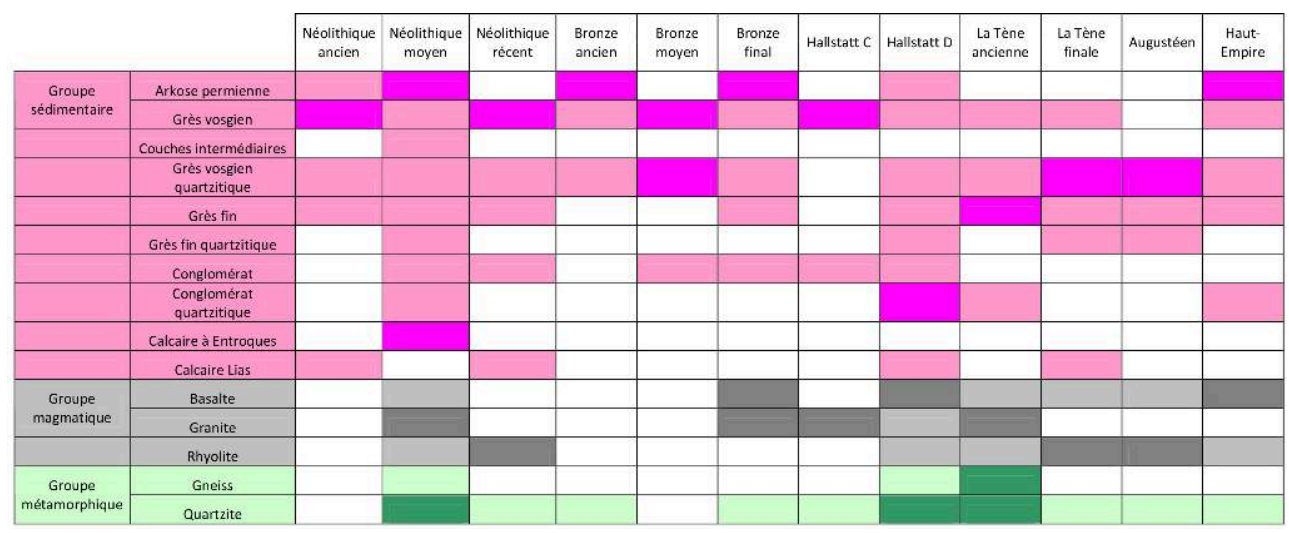

La couleur foncée indique la roche plébiscitée pour la période selon le groupe lithologique. La couleur claire et blanche sa présence ou son absence.

(c) Jodry, Inrap, 2017.

11 La recherche d'une roche aux bonnes compétences mécaniques induit des déplacements locaux (entre 0 et $20 \mathrm{~km}$ ), régionaux (déplacement supérieur à $20 \mathrm{~km}$ mais inférieur à $100 \mathrm{~km}$ ) ou extra-régionaux (déplacement supérieur à $100 \mathrm{~km}$ ) montrant un investissement humain lourd dédié à la recherche de blocs le plus fréquemment préformés (Fronteau et al. 2015 ; Jodry \& Duringer 2016a).

Le prélèvement sur matériaux de surface de petite dimension ( $\left.\mathrm{COL}_{-} \mathrm{i}\right)$ est la technique la plus représentée et cette dernière se décline selon des emplacements topographiques spécifiques où l'accumulation de roches de surface permet leur prélèvement sans difficulté. Ils peuvent être acquis au sein d'une minière (COL_m), dans des éboulis ( $\left.\mathrm{COL}_{-} \mathrm{e}\right)$ et dans les alluvions ( $\mathrm{COL}_{-} \mathrm{a}$ ) que ces dernières soient issues d'une rivière vosgienne ou du Rhin. Ce type de sélection permet au tailleur de pierre de transporter un élément de qualité testé sur la zone de prélèvement.

La minière est, selon le lexique élaboré par le PCR «Évolution typologique et technique des meules du Néolithique au Moyen Âge " (rapport de l'année 2014), est «une exploitation ou extraction par terrassement à ciel ouvert, sous forme de fosse, de matière première minérale ». Ce système observé à plusieurs reprises sur les hauteurs de Gueberschwihr lors d'une série de prospections facilite l'accès aux matériaux de 
surface sans avoir à dégager une zone et creuser pour son exploitation. Ces petites zones dépressionnaires possèdent des dimensions dont la variation montre qu'elles sont adaptées aux besoins (fig. 3). Ces dimensions sont comprises entre $4 \mathrm{~m}^{2}$ et $20 \mathrm{~m}^{2}$ et leur profondeur ne dépasse pas le mètre. Les supports lithiques récupérés dans ces minières sont des blocs ou des galets relativement préformés économisant ainsi au tailleur de pierre certaines étapes comme celle de l'équarrissage, de l'épannelage durant lesquelles la fracture de bloc est fréquente. L'intérêt de ce type de prélèvement est le gain de temps et le transport de pièces de qualité.

Les prospections menées sur les affleurements gréseux quartzitiques proches de la faille vosgienne ont permis de déterminer les lieux d'acquisition de galets ou de plaques de même format (pour la réalisation d'outils de mouture et enclumes) que ceux découverts sur le site néolithique de Dambach-la-Ville-PAAC (Jodry \& Duringer 2016a) et distants de $40 \mathrm{~km}$ induisant un déplacement régional.

Fig. 3. - Exemple de minière creusée dans la partie supérieure d'une terrasse gréseuse sur la commune de Gueberschwihr.

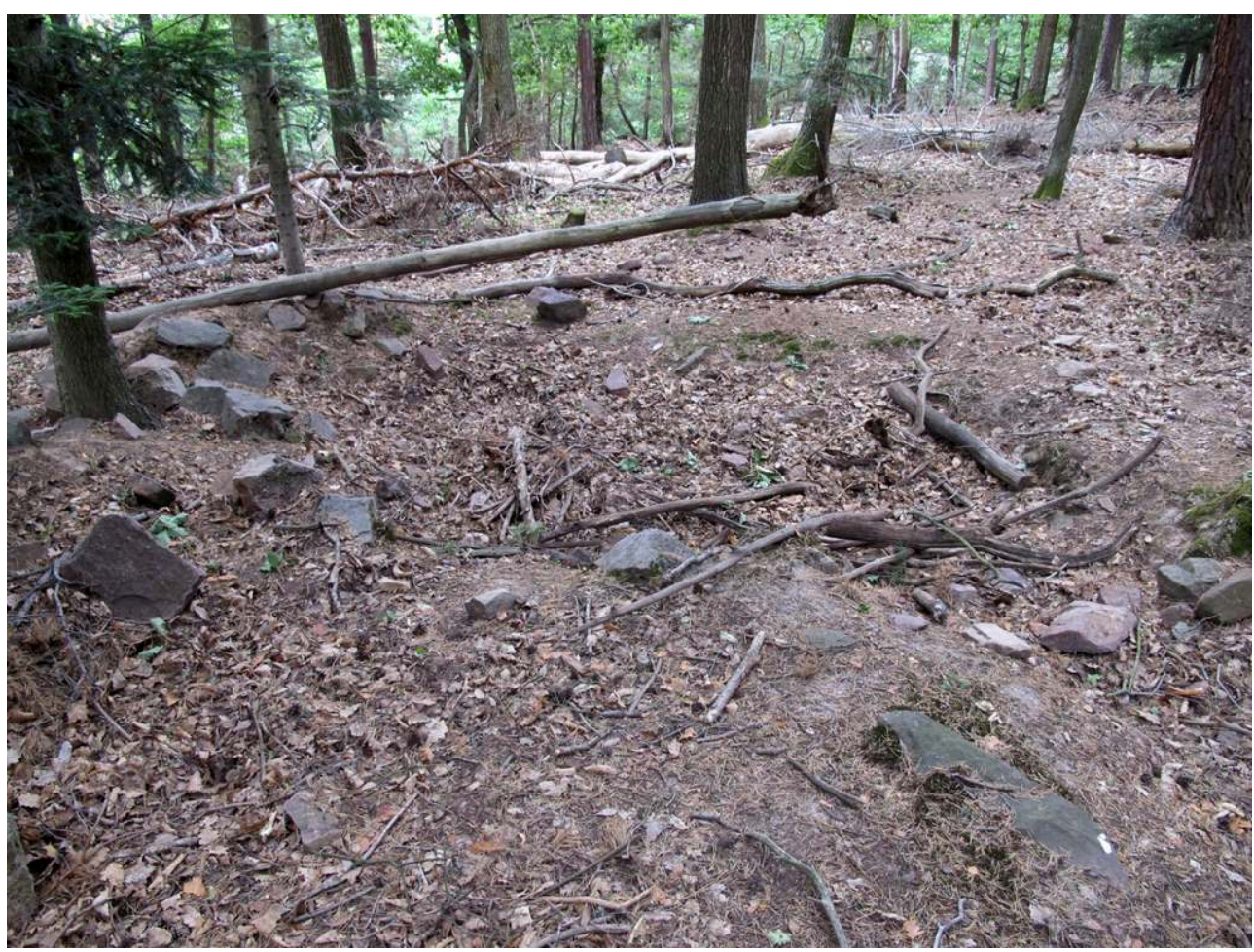

(C) Cliché : Jodry-Inrap, 2015

Le deuxième mode de prélèvement, observé en flanc de montagne ou dans les vallées, est l'exploitation de matériaux sur les éboulis ( $\left.\mathrm{COL}_{-} \mathrm{e}\right)$. Ce dernier peut avoir plusieurs origines, naturelle ou anthropique, comme le démantèlement de parois rocheuses, cas observé dans le gigantesque amas de blocs, converti en carrière, qui couvre les flancs du Purpurkopf à Rosheim.

Les prospections récentes engagées en 2014 ont permis de découvrir mêlées à la construction de l'enceinte qui domine la montagne, le Purpurschloss, quatre ébauches de meules rotatives (Jodry \& Holderbach, 2017). À l'extérieur de cette enceinte, dans la carrière, deux autres ébauches brisées et abandonnées ont été retrouvées. Même si l'imposant diamètre $(1,20 \mathrm{~m})$ d'une pièce en cours d'élaboration permet de l'attribuer 
avec prudence à la période médiévale (probablement postérieure à l'édification du château-tour), les autres pièces peuvent être associées, en fonction de leur diamètre, à la fin de la période gauloise ou au début de la période antique. Quoi qu'il en soit, les meules découvertes sur ce site sont taillées dans des blocs qui gisent au sol. Ces blocs entaillés pour en extraire une meule ou mis en forme pour leur donner le format désiré (fig. 4) sont quasiment identiques aux meules gauloises découvertes sur le site d'Obernai-PAEI distant de $12 \mathrm{~km}$ impliquant par conséquent un déplacement local.

Fig. 4. - Ébauche de meule abandonnée mise en forme à partir d'un bloc isolé dans un éboulis.

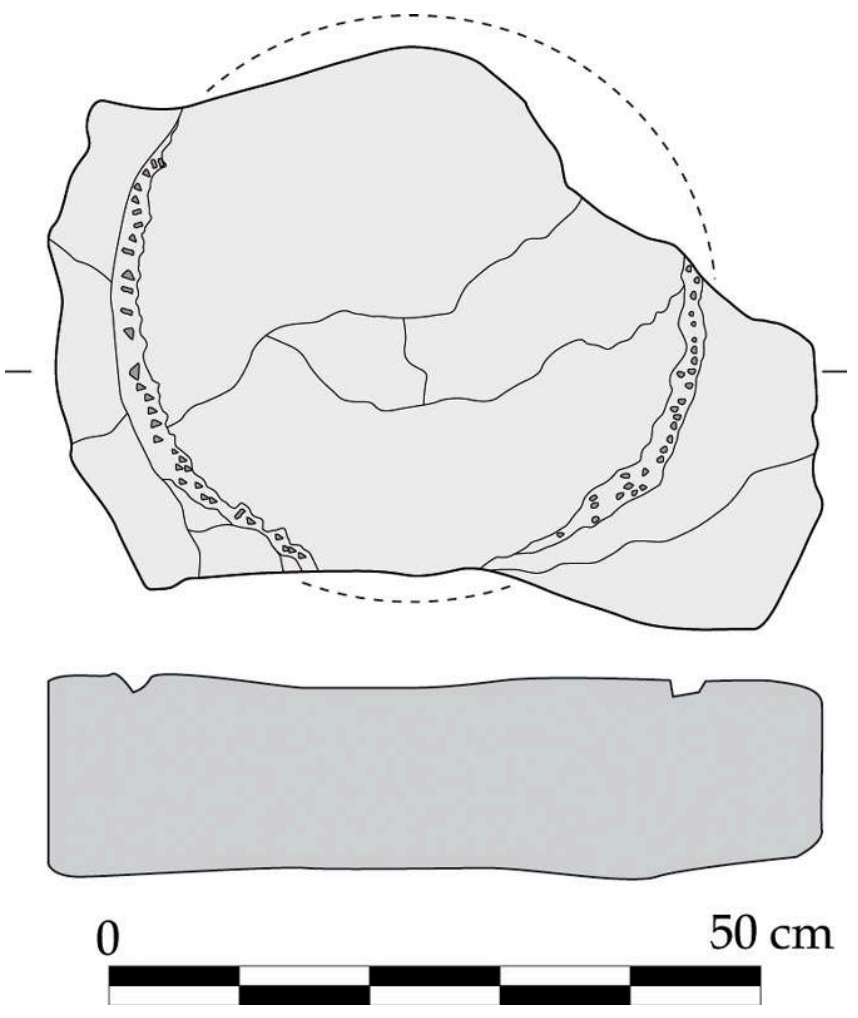

(c) DAO : Jodry-Inrap 2014

Le troisième système d'acquisition ( $\left.\mathrm{COL}_{-} a\right)$, le procédé de prélèvement dans les alluvions (rhénanes ou vosgiennes), semble le plus répandu. Les alluvions d'origine rhénane déposées au cours du Quaternaire sont majoritairement formées de galets, graviers et sables. Dans un mouvement récent de repli en rive droite de la vallée, le Rhin a localement façonné des terrasses, dont la surface est formée de plusieurs niveaux, séparées par des talus d'érosion. Parmi ces alluvions, les galets rhénans possèdent des dimensions variant de quelques centimètres à 20 ou 30 centimètres de longueur, en fonction de la compétence du fleuve. Leur dimension décroît en direction de l'aval du fleuve, de $20 \mathrm{~cm}$ de longueur aux environs de Colmar, les galets n'excèdent pas $10 \mathrm{~cm}$ aux alentours de Strasbourg. Ces alluvions forment par conséquent des réserves immenses, stockées sur une grande épaisseur qui, une fois examinées par l'Homme et ramassées, sont aptes à être utilisées le plus souvent en outils de percussion. Ces derniers étant préférentiellement sélectionnés parmi les galets de quartzite.

Les alluvions des rivières vosgiennes permettent également d'obtenir des galets massifs et de grande dimension ou plus modestes comme sur le site hallstattien d'Odratzheim, 
par exemple, où les structures ont fourni de gros galets entre 0,300 et $0,600 \mathrm{~kg}$ et de petits dont la masse n'excède pas quelques dizaines de grammes. Les galets de quartzite proviennent du sous-sol même du site (Jodry 2017) mais en l'absence d'accès à cette « réserve naturelle » le prélèvement peut être effectué dans le lit des rivières alentour où de nombreux galets aux tailles variées sont détachés par l'érosion naturelle de la matrice des couches du Conglomérat principal.

19 La cible du ramassage alluvionnaire concerne aussi le prélèvement de blocs roulés volumineux à l'image de ceux qui tapissent certains flancs de vallées vosgiennes encaissées. La fouille du site de Weyersheim, qui a livré de gros éléments d'enclumes brisées en granite, a permis de déclencher une recherche pour en déterminer la provenance.

20 Ces éléments pondéreux en granite dont le plus lourd pèse $31 \mathrm{~kg}$ ont été très certainement prélevés dans l'environnement de Gunsbach dans la vallée de la Fecht (fig. 5) à environ 100 kilomètres au sud-ouest du site de Weyersheim. Les flancs de cette vallée sont des sources potentielles d'approvisionnement facilement accessibles, d'après Pierre Fluck (Université de Haute Alsace), ce qui présente un schéma de prélèvement régional.

Fig. 5. - Vue champêtre de la vallée de la Wormsa.

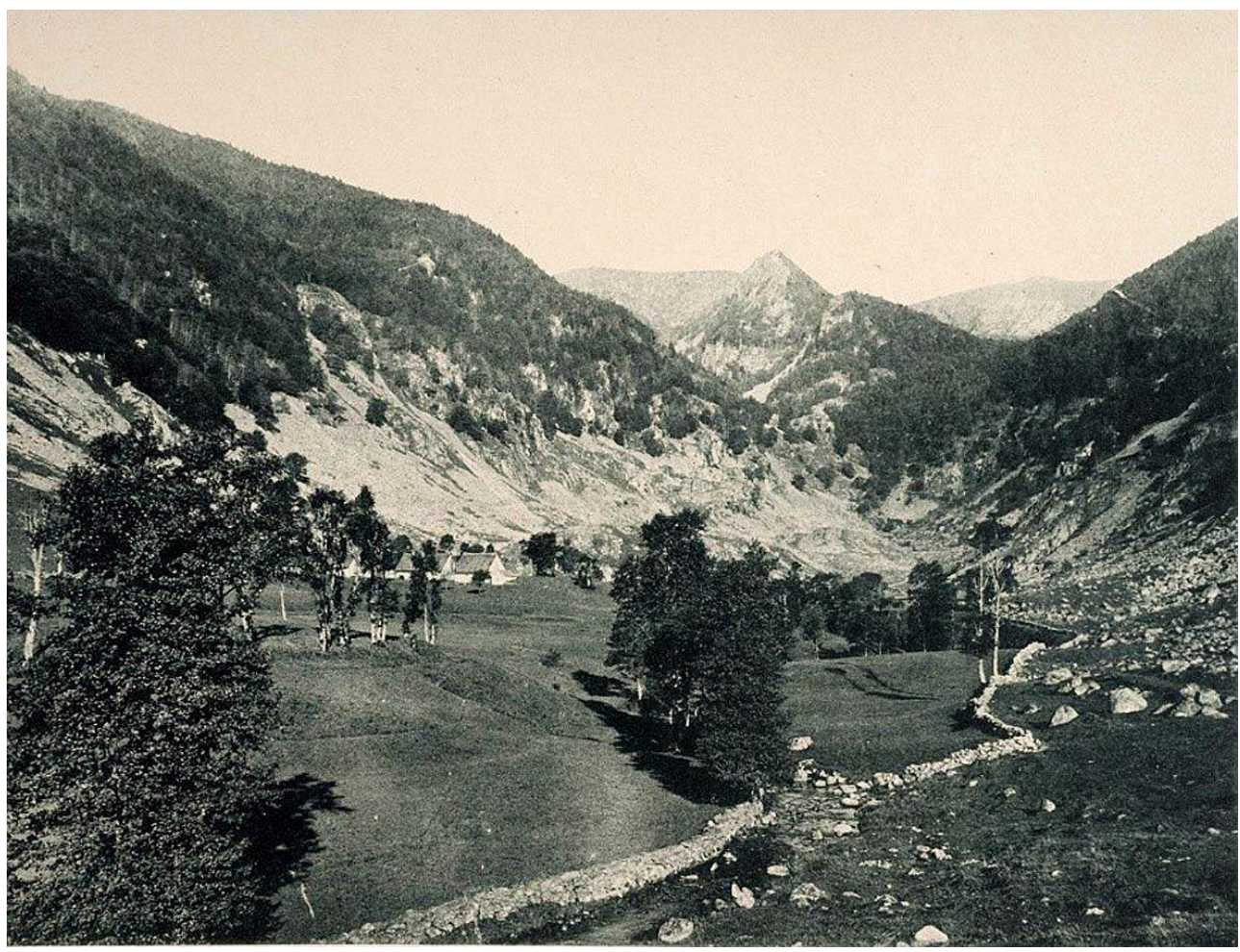

(c) F.-X. Saile; document BNUS.

21 Le quatrième mode d'acquisition se fait directement sur les haldes (COL_hal) qui accumulent les déchets de carrières ouvertes. C'est dans les carrières des Stampfloecher sur la commune de Saint-Jean Saverne que les Couches Intermédiaires (Trias) ont fait l'objet d'exploitations à destination des sites vosgiens proches (approvisionnement local). Les prospections réalisées en 2004 (Ring 2004) puis en 2016 ont permis d'étudier des meules taillées à partir d'éléments dont l'origine géologique 
reste inédite puisque c'est la première mention de l'exploitation de ces strates gréseuses. Deux raisons peuvent être invoquées pour comprendre la décision qui préside au choix de la roche exploitée dans ces carrières. Les prospections géologiques pédestres effectuées avec Philippe Duringer couplées à l'observation de la carte géologique de Saverne permettent de mieux les comprendre (Jodry \& Duringer 2016b).

22 Tout d'abord, une raison géographique: dans ce secteur, le grès grossier s'étend essentiellement sur les flancs de vallons, propices aux érosions, et n'apparaît pas sous la forme d'affleurement notable dont l'accès pourrait faciliter l'ouverture d'une carrière.

La seconde raison est d'ordre géologique. Le grès grossier est dans ce secteur une roche de très mauvaise qualité qui cumule des défauts. En effet, le premier de ces défauts réside dans sa texture composée d'éléments fins et d'éléments argileux qui rendent ce grès très friable, empêchant son exploitation pour la fabrication de meules. Par ailleurs, attribués à la formation de Karlstal, ces grès sont par nature bien moins cimentés que toutes les autres formations du Buntsandstein, car une grande partie des grès est d'origine éolienne.

24 Le second défaut que nous pouvons invoquer est que ce grès se présente aux rares endroits visibles sous la forme d'une roche totalement diaclasée par les fissures verticales et obliques et clivée horizontalement par de très nombreux joints de stratification typiques de ces couches de Karlstal (fig. 6).

Fig. 6. - Grès vosgien apparaissant diaclasé sur le versant ouest de la zone prospectée.

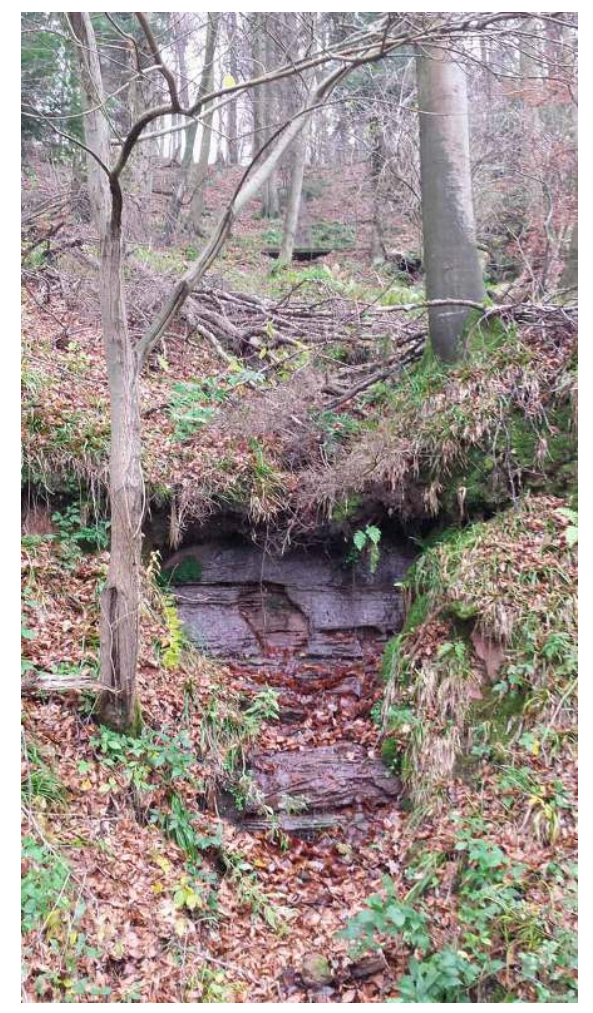

(c) Cliché : Jodry-Inrap 2016.

Nous disposons à l'heure actuelle de deux d'exemples d'extraction directement sur la roche mère (EXT). Il s'agit pour le premier de quelques traces de pic d'extraction d'une 
potentielle meule observées sur un front de taille sur la commune d'Eckartswiller (information Nicolas Meyer-Inrap, fig.7). Le second exemple est la découverte d'affleurements de calcaire à Entroques proche de la commune de Bergheim et exploités pour en retirer des blocs destinés à être transformés en percuteurs pour le site néolithique de Dambach-la-Ville-PAAC (Duringer \& Kucharski 2016) distant de $15 \mathrm{~km}$, induisant ici un approvisionnement local.

Fig. 7. - Exemple de contexte d'acquisition sur roche mère de type acquisition sur paroi (EXT_f).

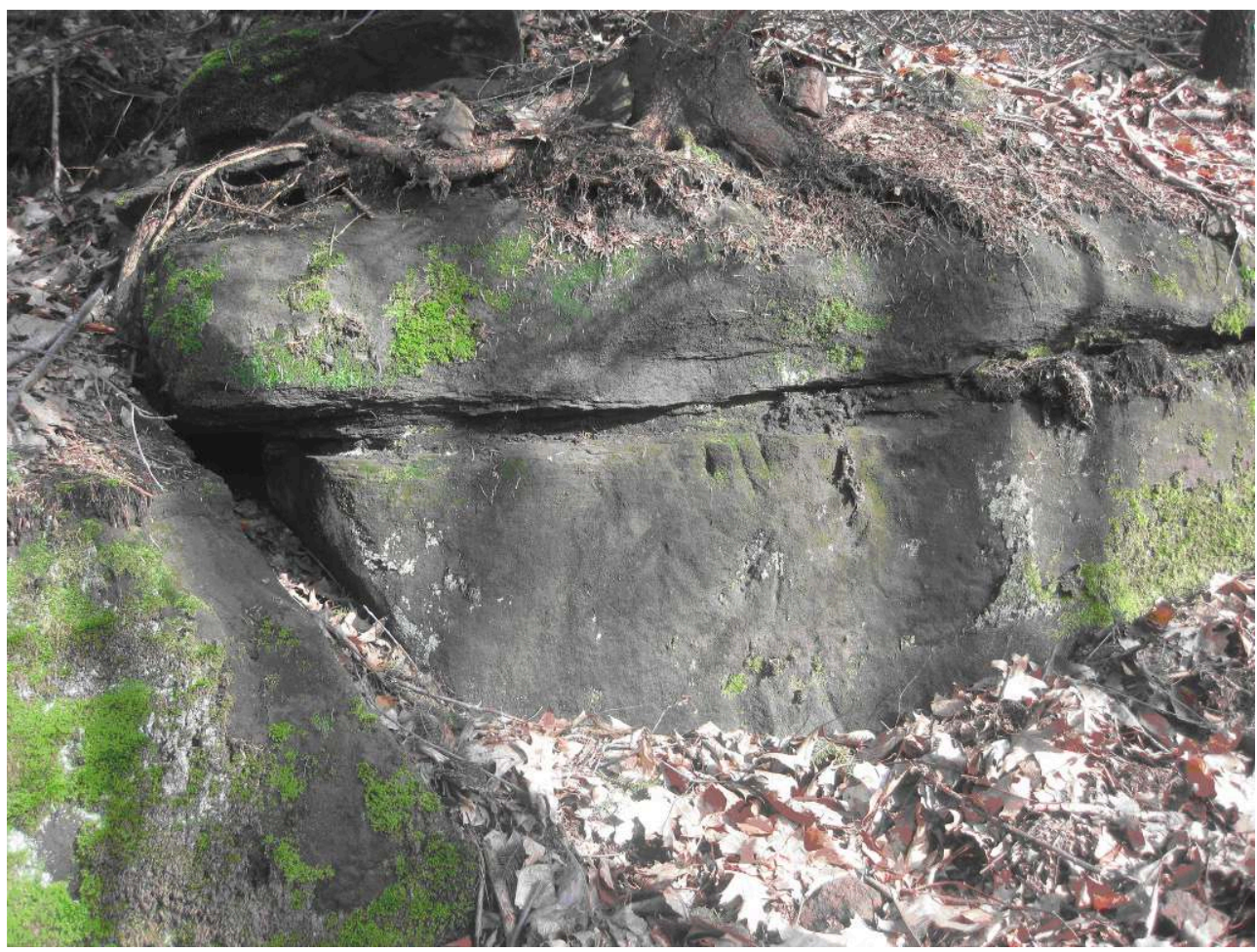

(c) Cliché : Meyer 2013

\section{Les outils lithiques adaptés aux besoins}

La variété lithologique du massif vosgien (Vosges cristallines au Sud, constituant le socle vosgien, et des Vosges gréseuses au Nord, constituant la couverture sédimentaire) a séduit les différentes cultures, dès le Néolithique ancien, pour l'élaboration de nombreux outils, à commencer par ceux de la sphère alimentaire représentée par les moulins. Le système du moulin va-et-vient composé d'un élément fixe (meule) sur lequel travaille un élément mobile, libre (molette) est connu depuis le Paléolithique pour le broyage de pigments (Archambaud de Beaune 2000). Cependant cet appareil ne se généralise qu'à l'avènement de l'agriculture pour la transformation des céréales en farine panifiable ou en composants de bouillies. Dans le cas le plus répandu d'une activité de mouture céréalière, cet outil fonctionne en plaçant le grain sur la meule, sur laquelle est actionnée manuellement la molette dans une course rectiligne. L'appui généré par l'utilisateur sur la molette va participer, avec le concours de la texture de la roche, à l'ouverture de l'enveloppe des céréales. 

enclumes (broyage minéral ou traitement de produits métalliques) nécessitant des roches résistantes à la percussion, des polissoirs, galets ou blocs de roche choisis pour leur qualité abrasive comme le grès grossier mais aussi des lissoirs. Ces derniers se présentent sous la forme de petits galets de quartzite dont la masse est comprise entre 50 et 100 gr. Leur morphologie générale fait penser à de petits galets roulés et ramassés de manière opportuniste, sans pouvoir certifier s'ils sont d'origine alluvionnaire ou issus de la désagrégation de blocs de Conglomérat Principal. Ces lissoirs sont utilisés de manière active et peuvent servir à lisser la surface des peaux ou d'objets en bois ou en os. Nous pouvons également suggérer une fonction de lissage de la surface des céramiques afin d'homogénéiser leurs parois. Les différentes roches employées pour l'élaboration d'outils lithiques (mouture, broyage, percussion, polissage ou lissage,...) 
sont choisies en fonction de leurs formes, leurs qualités mécaniques, leurs résistances à l'usure et l'accessibilité des gisements (Fronteau \& Boyer 2011).

Ainsi l'abrasivité du granite (roche magmatique-plutonique) a entrainé sa sélection dès le Néolithique moyen pour la réalisation d'outils de mouture, comme ceux du site de Dambach-la-Ville par exemple (Jodry \& Duringer 2016a). Mais c'est également sa résistance et l'aspect roulé des galets qui semblent être recherchés pour la réalisation d'enclumes notamment à La Tène ancienne ; Michler et $a l$, à paraître).

En revanche, peu de roches métamorphiques ont été employées pour la réalisation d'outils lithiques hormis le gneiss, réservé aux moulins va-et-vient de La Tène ancienne. Nous ne connaissons pas exactement la raison de ce choix, cette roche foliée restant tout de même fragile, mais il n'est pas exclu que son utilisation relève d'une fonction précise. L'épaisse couche gréseuse des Vosges est assise sur les dernières séries permiennes caractérisées par des roches volcaniques (rhyolite) ou sédimentaires (arkose). Ces roches sont exploitées pour la réalisation de moulins va-et-vient et rotatifs (Féliu \& Jodry 2017 et Jodry \& Duringer 2016a). La rhyolite est présente au Néolithique récent mais c'est surtout sur l'axe chronologique laténien que cette roche est exploitée. En effet, l'ouverture des carrières de La Salle, où sont extraits des minières une roche grenue de très bonne qualité abrasive, se situe à l'extrémité de la période Hallstatt.

Choisie sans doute pour ses capacités abrasives identiques à celles de la rhyolite et sa disponibilité, l'arkose permienne est exploitée dès le Néolithique moyen puis ponctuellement durant l'âge du Bronze et le Haut Empire où elle est taillée pour la réalisation de grandes meules rotatives. Ici son action abrasive est sans doute à mettre en parallèle à celle du gneiss, offrant peut-être une roche de qualité pour traiter les céréales vêtues. Toutefois ce matériau, présent sur toute la frise chronologique du Néolithique à l'Antiquité, n'aura pas une aura identique à celle des grès triasiques.

Ces grès triasiques recouvrent le massif Vosgien, du moins dans la partie septentrionale de la chaîne. Cette accumulation de sédiments détritiques, maximale dans le nord des Vosges où l'épaisseur atteint $400 \mathrm{~m}$, forme l'essentiel des affleurements du Buntsandstein. Ce sous-étage du Trias inférieur se compose de subdivisions stratigraphiques dont les plus importantes sont le Buntsandstein moyen, composé du grès vosgien, grossier et du conglomérat principal. Même si le conglomérat propose une efficacité abrasive potentiellement inférieure due à la présence de dragées de quartzite dans sa matrice, il n'en reste pas moins une roche présente sur la totalité de l'axe chronologique. Cependant c'est le grès grossier qui reste la roche «par excellence " puisqu'elle agglomère les différents critères d'une bonne pierre meulière. C'est en effet la fonction principale qui lui est assignée depuis le Néolithique ancien jusqu'au Haut Empire.

36 L'étage supérieur du Trias divisé en couches intermédiaires sur lesquelles est assis le grès à Voltzia, est reconnaissable grâce à la texture fine de ses composants. Cette texture fine est recherchée notamment pour la réalisation de polissoirs et aiguisoirs principalement durant La Tène ancienne où la métallurgie du fer prend son essor. Contrairement à l'hypothèse que nous avancions en 2012 (Jodry 2012) le niveau des Couches Intermédiaires et les strates calcaires sous-jacentes ont bien fait l'objet d'exploitations (Duringer \& Kucharski 2016). Les Couches Intermédiaires ont été exploitées pour pallier la défaillance mécanique du grès grossier (Jodry \& Duringer 
2016b) mais ses capacités abrasives (destinées aux outils de mouture) doivent être tout de même soulignées (Jodry \& Fronteau, en cours).

Les bancs calcaires dont il est question désormais grâce aux découvertes récentes faites sur le site de Dambach-la-Ville sont ceux de l'étage triasique moyen appelé Muschelkalk (calcaire à Entroques; destiné aux percuteurs au Néolithique moyen) et jurassique inférieur où ont été prélevées les «ovoïdes» du Lias (exploitées pour la réalisation de percuteurs). Globalement, ces blocs de calcaire très présent sur la partie septentrionale des Vosges où se succèdent les vallonnements des collines sousvosgiennes ont été prélevés pour la réalisation de percuteurs, de lissoirs ou de projectiles destinés à la chasse ou aux affrontements entre belligérants (Jodry \& Cousseran-Néré 2015). Cependant l'absence de calcaire peut être remplacée par les galets de quartzite dont le ramassage s'effectue dans les alluvions rhénanes (fig. 8). Ces percuteurs sont néanmoins découverts la plupart du temps en relation avec la fabrication du matériel de mouture (fabrication et entretien de la surface active des meules).

Fig. 8. - Exemple de percuteur sur galet rhénan.

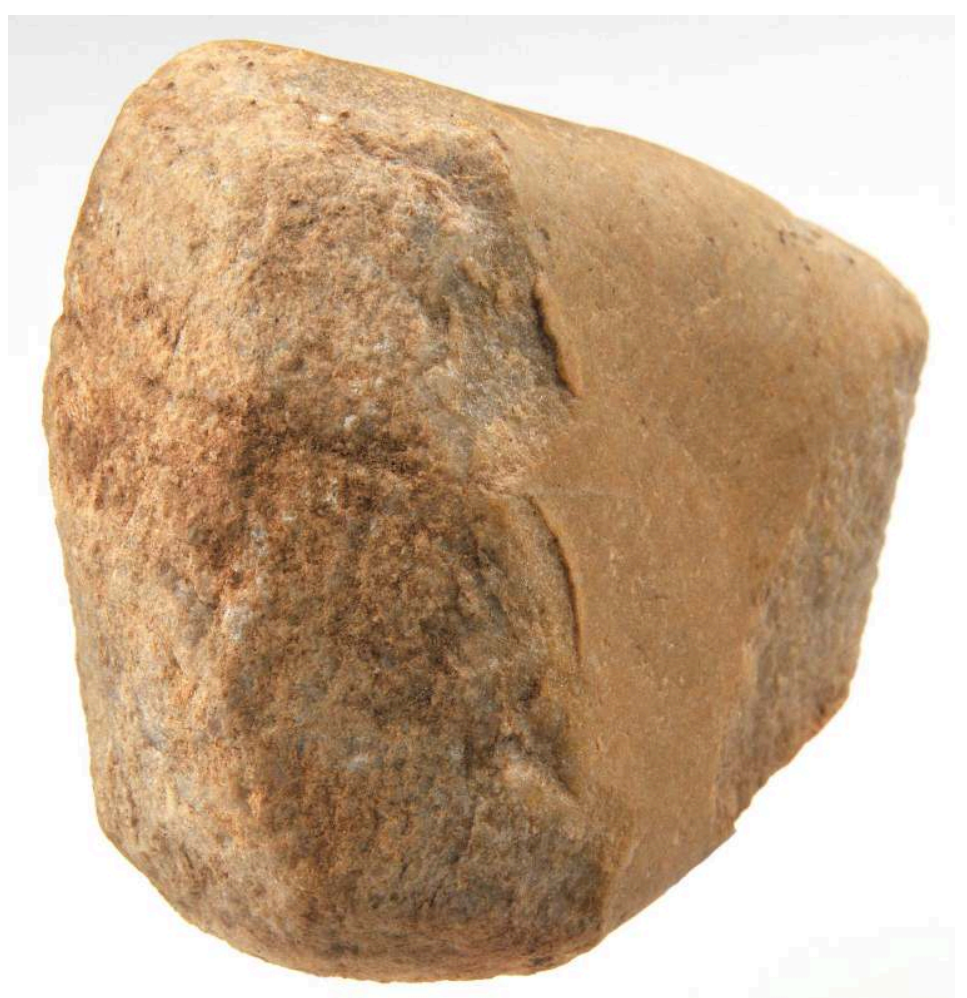

(c) Cliché : Schneikert-Inrap 2009.

Précédant ces dépôts alluviaux, durant l'ère tertiaire, le volcanisme de l'Eifel en Rhénanie-Palatinat (Allemagne) a permis de former des coulées basaltiques compactes qui offrent une matière première aux compétences mécaniques indéniables pour la réalisation de moulins rotatifs durant le Haut Empire. Plébiscitée durant le Haut Empire, devenue la roche synonyme de meule rotative militaire, le basalte de l'Eifel, exploité depuis le Néolithique, n'est présent dans la région de Basse-Alsace que depuis la période romaine. 
Les principaux gisements destinés à l'extraction de meules rotatives dont la standardisation est facilitée par la morphologie des colonnes basaltiques se situent dans le massif volcanique de l'Osteifel où les principales coulées de lave de Mayen, de Kottenheim et d'Ettringen ont été exploitées. Cependant, les coulées de lave du groupe de cratères du Bellerberg offrent également la possibilité d'extraire une roche compacte de très bonne qualité aux compétences mécaniques indéniables, depuis le début du premier millénaire avant notre ère (Mangartz \& Harms 2002). L'acquisition de cette roche lointaine induit un approvisionnement extra-régional utilisant très certainement un maillage de sites ou d'ateliers intermédiaires.

Durant les cinq millénaires qui précèdent la période romaine, les matières premières lithiques des grandes entités géologiques présentées dans cette recherche ont fait l'objet d'exploitations et d'importants échanges sur des distances variant de l'approvisionnement local à l'acquisition extra-régionale. Cet article vient apporter un éclairage supplémentaire sur les décisions qui président aux choix des roches et met en valeur l'exploitation des ressources vosgiennes.

41 Tandis que les grès permiens et triasiques restent les principales roches exploitées depuis le Néolithique pour la réalisation de matériel de mouture, les roches magmatiques comme le granite restent en retrait. Mais contrairement à ce que nous avancions en 2012, faute d'indices, d'autres roches, comme le basalte et la rhyolite, apparaissent dans les assemblages dès cette période, mais restent tout de même anecdotiques. Cette émergence de «nouvelles » roches dans les assemblages est peutêtre due à une volonté d'ouvrir de nouveaux réseaux afin de pallier une fluctuation dans les axes d'approvisionnement ou constituent des «monnaies d'échanges » afin d'affirmer son influence.

C'est à la transition Bronze final/Hallstatt que les nouveaux circuits d'approvisionnement se dessinent: cette période charnière annonce les grandes options à venir dans le choix des roches exploitées. Dès cette phase, la représentation des matières premières locales, principalement sédimentaires, se stabilisent voire diminuent et les «nouveaux " matériaux s'affirment. Le développement de ces roches exogènes est un phénomène vraisemblablement soutenu par l'éclosion d'un artisanat de plus en plus qualifié, utilisant des outils métalliques adaptés à l'exploitation des roches dures (Bessac 1986, Féliu \& Jodry 2016). C'est ensuite à la fin de la période laténienne et la charnière augustéenne que va s'affirmer l'hégémonie du basalte. Pour des raisons d'homogénéité des sources d'approvisionnement lithique et d'uniformisation dans les méthodes d'extraction, cette roche supplantera alors le grès durant tout le Haut Empire (Jodry 2016). 


\section{BIBLIOGRAPHIE}

ALONSO-MARTINEZ N., 2002 - «Le moulin rotatif manuel au nord-est de la Péninsule ibérique : une innovation technique dans le contexte de la mouture des céréales ", dans Moudre et broyer, $\mathrm{H}$. PROCOPIOU et R. TREUIL (dir.), Éditions du Comité des Travaux Historiques et Scientifiques, p. 111 à 127,4 fig.

ARCHAMBAULT DE BEAUNE S., 2000 - Pour une archéologie du geste, broyer, moudre, piler, des premiers chasseurs aux premiers agriculteurs, 231 pages, 8 planches, CNRS Éditions, Paris.

BAUDAIS D., LUNDSTRÖM-BAUDAIS K., 2002 - «Enquête ethnoarchéologique dans un village du NordOuest du Népal : les instruments de mouture et de broyage », dans Moudre et Broyer, Archéologie et Histoire, vol. I, colloque de Clermont-Ferrand (1995), p. 155-180, CTHS.

BESSAC J.-Cl., 1986 - L'outillage traditionnel du tailleur de pierre de l'Antiquité à nos jours, CNRS, Paris, $319 \mathrm{p}$.

CAROZZA L., 2006 - « Les percuteurs et l'outillage en roches dures », dans CAROZZA L. et GEORJON C. (dir.), La fin du néolithique et les débuts de la métallurgie en Languedoc central : contrôle social du territoire et pratiques économiques entre 3200 et 2400 av. J.-C. dans la moyenne vallée de l'Hérault. Archives d'écologie préhistorique.

DURINGER Ph. \& KUCHARSKI M., 2016 - «Étude des percuteurs ", dans CROUTSCH Ch. -Dambach-la-VillePAAC. Rapport final d'opération de fouille préventive, PAIR, Strasbourg, SRA Alsace.

FARGET V., FRONTEAU G., 2011 - « Les carrières de meules de La Salle (Vosges) - Les Fossottes », dans BUCHSENSCHUTZ O., JACCOTTEY L., JODRY F. et BLANCHARD J.-L. (dir.), Évolution typologique et technique des meules du Néolithique à l'an mille sur le territoire français, Table ronde de Saint-Julien-sur-Garonne (F) du 2 au 4 octobre 2009, 23 supplément Aquitania, p. 137-145.

FÉLIU Cl., JODRY Fl., 2017 - «Un atelier de production de meules rotatives de La Tène finale à Obernai (67); réflexions sur l'organisation de la fabrication et du commerce des moulins à la fin de l'âge du Fer », dans MARION S., DEFFRESSIGNE S., KAURin J., BATAILlE G. (éd.), Production et protoindustrialisation aux âges $\mathrm{du}$ Fer ; perspectives sociales et environnementales, actes du $39^{\mathrm{e}}$ colloque international de l'AFEAF, Nancy 2015. Mémoires, 47, s.l. : Ausonius Éditions, p. 605-618.

FRONTEAU G., BOYER Fr., 2011 - « Roches meulières : de la classification pétrographique à la classification texturale d'un potentiel "mécanique" ", dans BUCHSENSCHUTZ O., JACCOTTEY L., JODRY F. et BLANCHARD J.-L. (dir.), Évolution typologique et technique des meules du Néolithique à l'an mille sur le territoire français, Table ronde de Saint-Julien-sur-Garonne (F) du 2 au 4 octobre 2009, 23 ème supplément Aquitania, p. 111-120.

FRONTEAU G. \& TURMEL A. \& PiCHARD Cl. \& DeCRock B. \& DEVOS A. \& O. LejeUne \& MÉNIVAL D. \& CHALUMEAU L. \& COMBAUD A., 2014 - « Les approvisionnements en pierre de construction à Reims : des choix marqués par de fortes contraintes géologiques, géographiques et socio-économiques ", dans J. LORENZ, F. BLARY et J.-P. GÉLY, Construire la Ville. Histoire de la pierre à bâtir, actes du $137^{\text {ème }}$ Congrès national du CTHS. 23-28 avril 2012 (Tours), Paris, Éditions du CTHS, 2014, p. 235-250.

GOUBET F., JODRY F., MEYER N., WEISS N., 2015 - Au « grès » du temps : Collections lapidaires celtes et galloromaines du Musée archéologique de Saverne, SHASE, Saverne, 372 p.

JODRY F. \& CARZON J.-L., 2012 - De la roche à l'outil : les matières premières lithiques en Alsace du Néolithique à La Tène finale. Premiers résultats. CAAAH 55, p. 11-26. 
JODRY F., 2006 - « Les meules rotatives en Alsace (La Tène finale-III ${ }^{\mathrm{e}}$ siècle ap. J.-C.) », dans CAAAH, t. 49, Société pour la Conservation des Monuments Historiques d'Alsace, p. 17-29.

JODRY F., 2012 - « Le matériel de mouture en Alsace du Néolithique à La Tène finale. Le potentiel géologique des Vosges et les “ importations " sur les sites d'habitat ", dans Roches et sociétés de la Préhistoire, entre massifs cristallins et bassins sédimentaires dans MARCHAND G., QUERRE G., (dir.) - Roches et Sociétés, entre massifs cristallins et bassins sédimentaires, colloque de Rennes (2009), p. 251-261, PUR, 2012.

JODRY Fl. \& DURINGER Ph., 2016a - «Étude des outils macrolithiques », dans CROUTSCH Ch., Dambachla-Ville-PAAC. Rapport final d'opération de fouille préventive, PAIR, Strasbourg, SRA Alsace.

JODRY F. \& DURINGER Ph., 2016b - Rapport de prospection 2016 « Production d'outils de mouture dans le massif vosgien », Strasbourg, SRA Alsace.

JODRY Fl. \& COUSSERAN, NÉRÉ S., 2015 - «Étude des outils macrolithiques », dans RICHE C., Choisy au Bac-La Bouche d'Oise. Rapport final d'opération de fouille préventive, Canal Seine-Nord, fouille 42. JODRY Fl., 2017 - «Étude des outils macrolithiques », dans MICHLER M., Rosheim-Rittergass. Rapport final d'opération de fouille préventive, Inrap Strasbourg, SRA Alsace.

JODRY Fl., HOLDERBACH J.-M., 2017 - La carrière d'extraction de meules en grès vosgien du Purpurkopf à Rosheim (Bas-Rhin), $2^{\mathrm{e}}$ colloque, Les meules à grain du Néolithique à l'époque Médiévale technique, culture et diffusion, Reims 2014, RAE.

JODRY F. \& FRONTEAU G., 2018. Rapport de prospection 2017 « Production d'outils de mouture dans le massif vosgien », Strasbourg, SRA Alsace.

MANGARTZ F., HARMS E., 2002 - Vom Magma zum Mühlstein, eine zeitreise durch die lavaströme des Bellerberg-Vulkans, RGZM 5, 107 p.

MICHLER M., JODRY Fl., CLERC P. BADEY S., à paraître - « La forge hallstattienne de Weyersheim (BasRhin, France) - Hallstatt D3/La Tène ancienne », dans The metalworker and his tools, Conférence Belfast juin 2016.

POISSONNIER B., 2002 - «Pilon, broyeurs, bouchardes, marteaux et autres percuteurs : les interprétations fonctionnelles au risque de l'expérimentation », dans Moudre et Broyer, Archéologie et Histoire, tome I, colloque de Clermont-Ferrand (1995), p. 141-154, CTHS, 2002.

Rapport du PCR «Évolution typologique et technique des meules du Néolithique au Moyen Âge » 2014.

RING J.-J., 2004 - « L'établissement gallo-romain des Stampfloecher-Rothlach, Site inédit des sommets vosgiens, dans la Forêt Indivise de Saint-Jean », dans Pays d'Alsace, Bulletin de la Société d'Archéologie de Saverne et Environs, $\mathrm{n}^{\circ}$ 207, p. 15-24.

\section{NOTES}

1. Cette recherche est en cours et reste conditionnée, dans sa partie " outils lithiques ", aux prescriptions faites par le Service Régional de l'Archéologie. La base de données « ressources lithiques » est soumise, de son côté, aux autorisations de prospections annuelles attribuées à l'auteur, délivrées par ce même service. Par conséquent, il convient de considérer ce travail comme un "état des lieux », puisqu'il résulte d'un dépouillement progressif en constante évolution. 
2. L'exceptionnel site de Dambach-la-Ville-PAAC (fouillé par Ch. Croutsch-AA) a livré plus de 700 outils lithiques.

\section{RÉSUMÉS}

Cet article fait écho à celui publié à l'issue du colloque organisé à Rennes en 2012 dont la thématique générale concernait les «Roches et sociétés " (Jodry 2012). Le travail présentait une synthèse cartographiée des sites importateurs de matériaux lithiques en Alsace et faisait un rappel des matériaux exploités. Une des lacunes de cet article résidait dans le manque d'information concernant les modes d'acquisition et leur situation. Nous avons décidé de compléter et enrichir cette recherche grâce à l'analyse couplée des ressources lithiques et des outils macrolithiques. Par conséquent, cette analyse met en valeur la richesse lithologique du massif vosgien, non seulement par la diversité des roches acquises, mais aussi par le biais des outils et leurs typologies fonctionnelles, qu'ils soient liés à la transformation alimentaire ou à l'artisanat.

\section{AUTEUR}

\section{FLORENT JODRY}

Archéologue macrolithicien, institut national de recherches archéologiques préventives (INRAP) de Strasbourg, membre du laboratoire Archéologie et histoire ancienne, Méditerranée, Europe (ARCHIMEDE, UMR 7044, Université de Strasbourg / CNRS) 


\title{
Du vin antique sur un versant haut- savoyard? Le vignoble et le pressoir de Versoie à Thonon-les-Bains
}

\author{
Christophe Landry
}

\section{Une unité rurale de l'Antiquité tardive au Genevray, sur les rives du marais de Versoie}

1 Les vestiges du site gallo-romain du Genevray ont suscité l'intérêt pour la question de la conquête des piémonts alpins, du côté de la province de Narbonnaise, par la vigne cultivée. La viticulture, emblématique de l'expansion romaine dès la période laténienne, n'échappe pas à la logique des relations transalpines. La fouille de 2014 fut l'occasion de traiter de pratiques culturales en milieu alpin, à la lumière des avancées en paléogénétique des cépages.

2 Le site du Genevray se trouve dans la région du Bas-Chablais, à proximité de la rive méridionale du lac Léman et de l'agglomération antique de Thonon-les-Bains, occupée $d u \mathrm{I}^{\mathrm{er}}$ au IV ${ }^{\mathrm{e}}$ siècle de notre ère (fig. 1). Dans l'état actuel des connaissances, les sources ne nous renseignent pas sur le statut de cette agglomération. Son cœur a pu être partiellement appréhendé dans les années 1970 grâce aux travaux de rénovation urbaine qui ont révélé des ateliers de potiers des $\mathrm{II}^{\mathrm{e}}$ et $\mathrm{III}^{\mathrm{e}}$ siècle apr. J.-C. Dans la moitié orientale de la ville actuelle semble se développer un quartier artisanal, dont l'activité $\mathrm{au} \mathrm{I}^{\mathrm{er}}$ siècle apr. J.-C. commence à être perçue grâce aux fouilles et sondages préventifs de ces dernières années. L'intérêt porte également sur les hameaux périphériques que la tradition considère comme les héritiers de villae suburbaines. Celles-ci ont conduit à émettre l'hypothèse, impossible à confirmer à l'heure actuelle, de l'existence d'une aristocratie tirant une partie de sa fortune des productions artisanales de l'agglomération ${ }^{1}$. 
Fig. 1. - Localisation du site du Genevray/Versoie à Thonon-les-Bains, sur une vue satellite du Chablais.

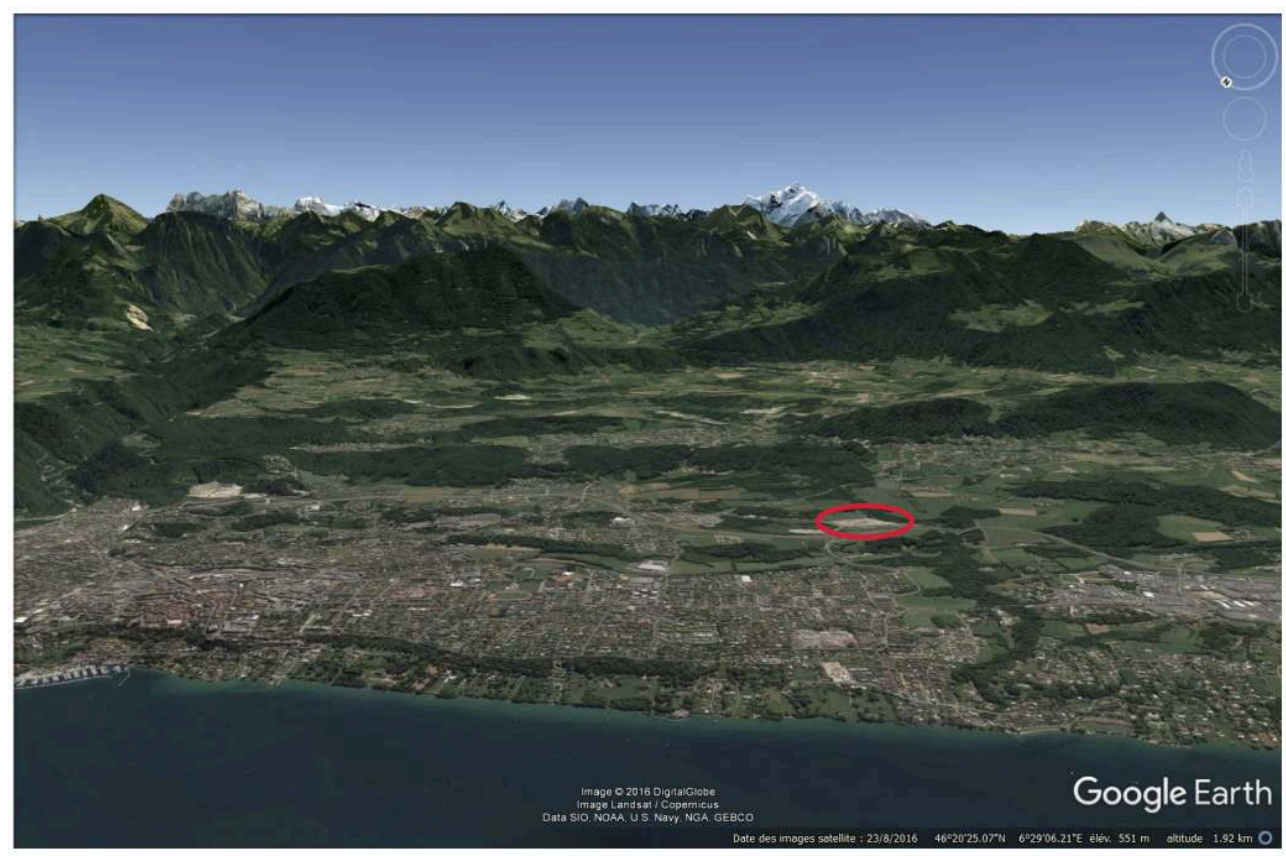

(c) Google Earth 3D.

3 L'opération de fouille de 2014, "Genevray, Route de Versoie " ${ }^{2}$, sur une surface de $5255 \mathrm{~m}^{2}$, fait suite à plusieurs interventions archéologiques menées dans ce secteur de la commune (fig. 2). De 2001 à 2005, les sondages et fouilles préalables au projet de construction du contournement routier de Thonon mettaient en évidence l'existence au Genevray d'un important site pré et protohistorique (Néolithique, Bronze final, Hallstatt, Haut-Empire). Par la suite, le projet de construction d'une caserne de pompiers par le Conseil général a entraîné la découverte en 2011 par J.-L. Gisclon (Inrap) de l'occupation de l'Antiquité tardive dont il est question ici. 
Fig. 2. - Plan général du site du Genevray, avec historique des opérations d'archéologie préventive.

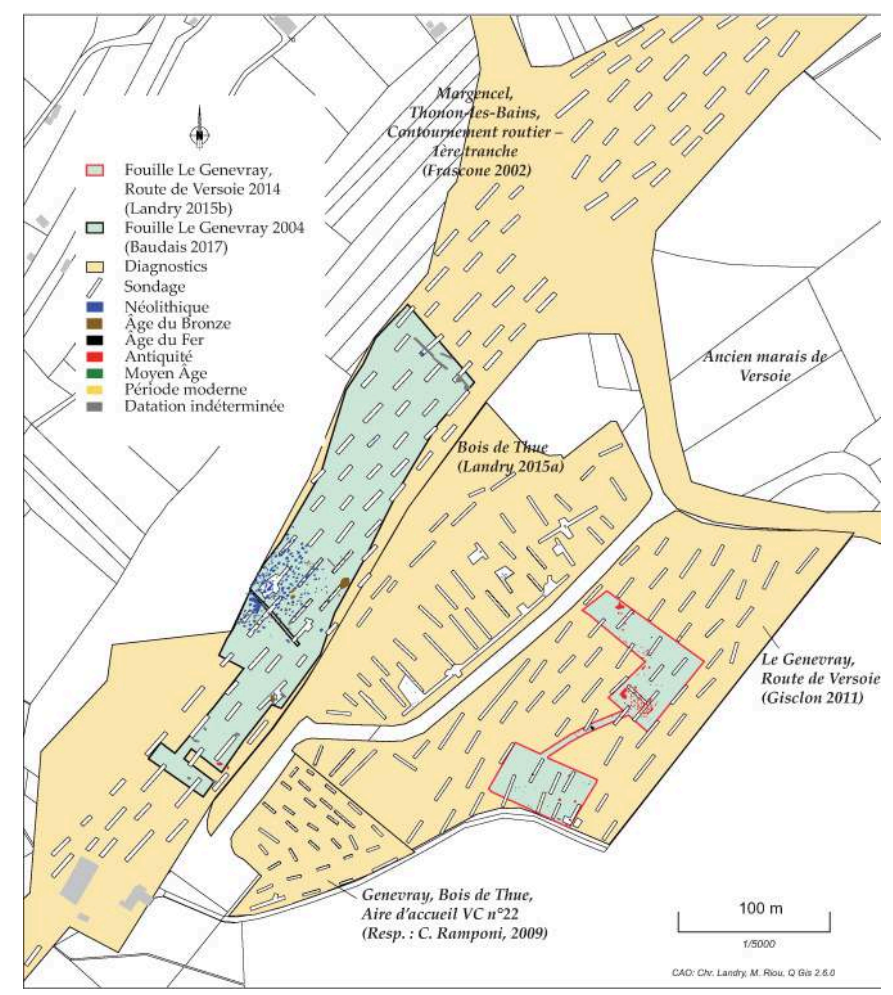

(c) Chr. Landry, M. Riou.

4 Le site se trouve en rive droite du vallon du Pamphiot, ruisseau incisant et drainant les formations morainiques et fluvio-glaciaires qui composent le complexe des terrasses de Thonon-les-Bains, et aux pieds du versant couronné par les châteaux d'Allinges qui dominent la plaine littorale. La terrasse sur laquelle est implanté le site se trouve à $460 \mathrm{~m}$ d'altitude, soit $88 \mathrm{~m}$ au-dessus du niveau actuel du lac. Les vestiges s'étendent au bord d'un ancien plan d'eau associé à une doline périglaciaire, le marais de Versoie, qui a été scellé depuis le Moyen Âge par des apports colluviaux détritiques ${ }^{3}$. Les carottages ${ }^{4}$ et l'étude palynologique ${ }^{5}$ ont révélé un fort hiatus sédimentaire caractérisant le passage brutal de l'âge du Bronze au Moyen Âge. L'exploitation de la tourbe, avant les $\mathrm{IX}^{\mathrm{e}}$-XI ${ }^{\mathrm{e}}$ siècle, pourrait ainsi avoir entraîné l'ablation des séquences susceptibles de fournir les pollens de vigne recherchés.

Le secteur qui nous intéresse ici concerne une surface de $800 \mathrm{~m}^{2}$ (fig. 3). Les vestiges désignent une occupation rurale centrée sur le $\mathrm{IV}^{\mathrm{e}}$ siècle de notre ère. Ce sont les émissions monétaires qui nous donnent les termini les plus précis : 270-280 d'une part et 392-394 d'autre part. La vie quotidienne des paysans travaillant sur le site est documentée grâce aux restes céramiques, fauniques (l'élevage ne peut être démontré malgré l'inhumation d'un équidé), métallurgiques (affutage, réfection de l'outillage,...) et à l'instrumentum (aiguisoir/polissoir en grès, houe-pioche en fer,...). Les résultats archéobotaniques permettent d'esquisser le tableau d'un paysage agraire varié, illustrant plusieurs espèces, arbres fruitiers, céréales, légumineuses, qui ne s'adaptent guère aux formes de traces agraires rencontrées sur le site. Ces résultats décrivent de préférence des restes de consommation, mais renseignent néanmoins le paysage environnant. 
Fig. 3. - Plan général de la fouille du Genevray/Route de Versoie de 2014.

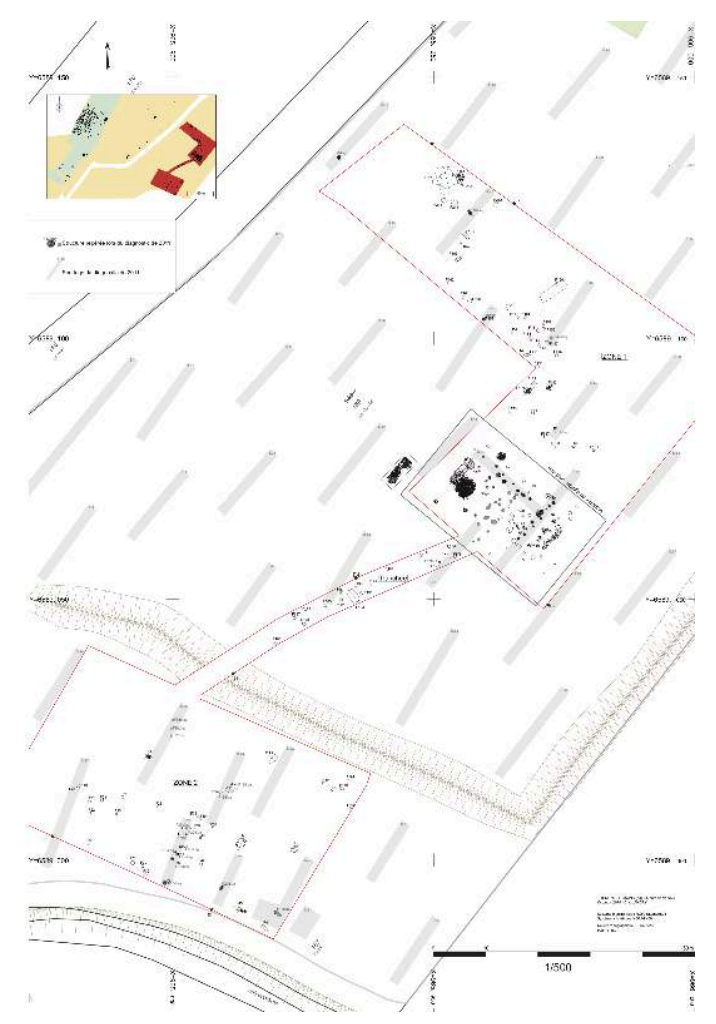

(c) Équipe Inrap.

\section{Les fosses de plantation, premiers témoins de l'implantation de la vigne sur la rive sud du Léman au IV siècle apr. J.-C.}

6 L'exercice d'identification des espèces cultivées et du mode de conduite se heurte sur ce site à diverses limites (nature du substrat, arasement important,...). Ainsi, tous les protocoles d'étude des traces agraires antiques ${ }^{7}$ ne sont pas pertinents ici, et seul fait sens, afin de proposer une hypothèse de restitution recevable, un travail classique d'analyse métrologique relative, où les mesures retenues ne sont que des ordres de grandeur.

\section{La technique du marcottage}

7 La partie est du site se prête particulièrement bien à cette analyse (fig. 4). Trois types de fosses sont représentés (fig. 5) : des fosses quadrangulaires aux contours irréguliers et à fond plat, assez rares (F131, F114 et F115 par exemple), des fosses circulaires ou ovales d'un module proche de 0,60 $\mathrm{m}$ de diamètre (comme F258 et F118), et des fosses circulaires ou ovales plus petites (comme F110). Presque toutes les fosses rondes ou ovales de cette zone ont un profil en cuvette, les plus grandes étant généralement les plus profondes (de 0,1-0,2 m en moyenne). Les formes des négatifs parfois observés en coupe s'apparentent à des fantômes de mottes racinaires. La technique du marcottage peut expliquer les différences de module entre les creusements. 
Fig. 4. - Plan et coupes des traces agraires de vignoble, dans la zone est.

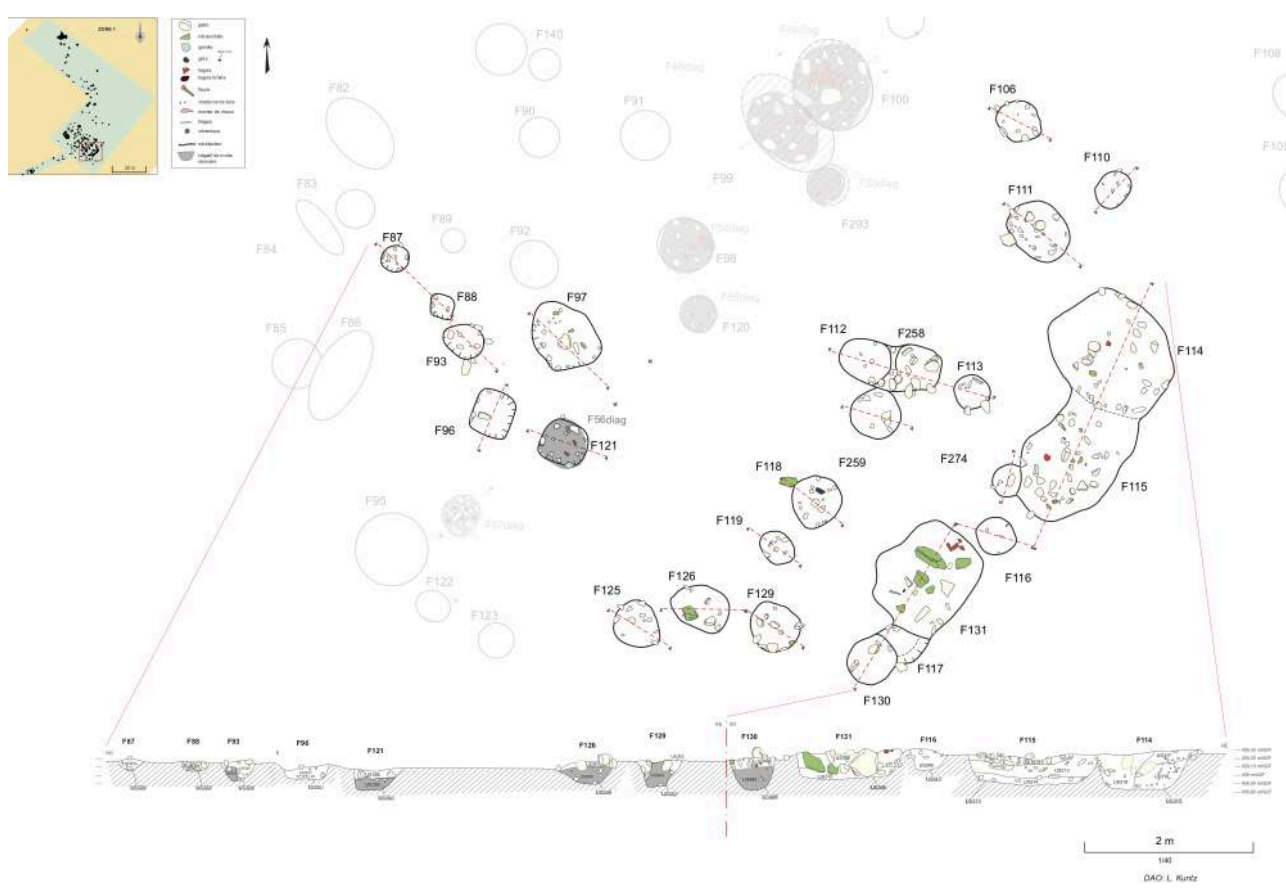

(c) Équipe Inrap.

Fig. 5. - Vue de fosses de plantation.

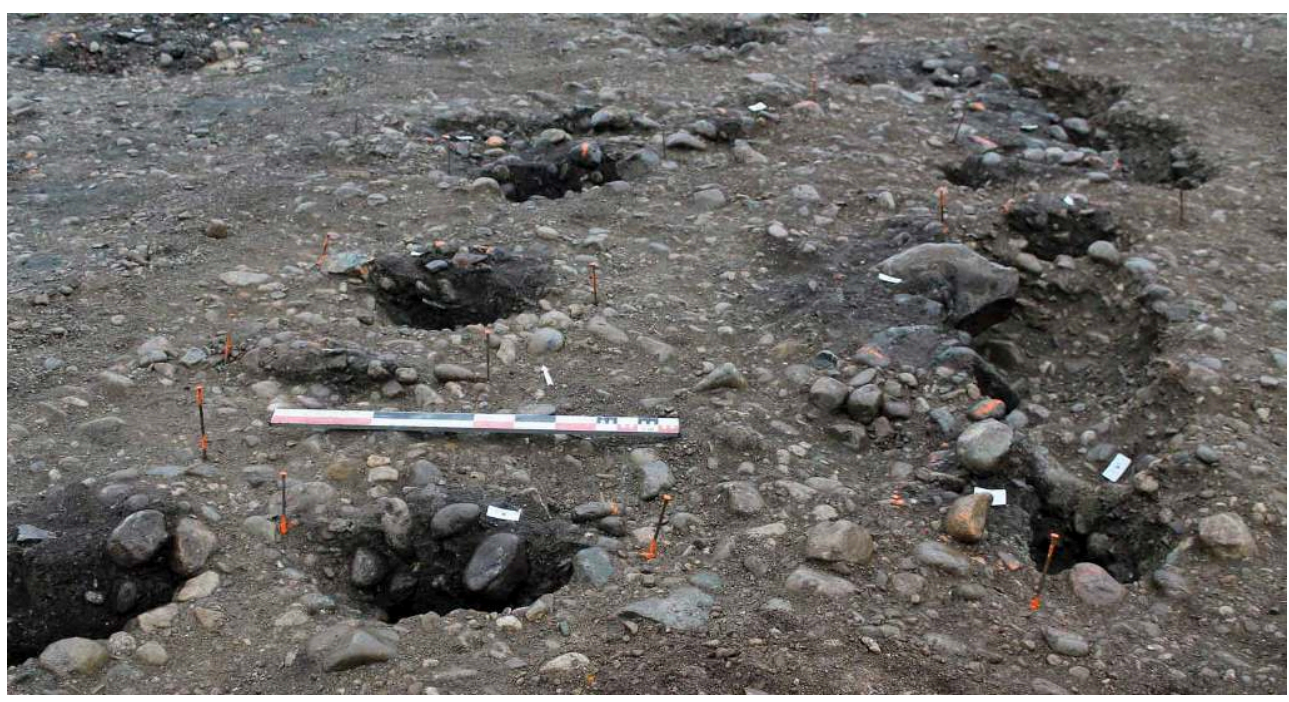

(c) G. AckX.

8 Les trois fosses quadrangulaires situées à la limite orientale de la zone pourraient de par leur taille $(1,60 \times 1,15 \mathrm{~m})$ avoir accueilli des arbres ou des arbustes. La forte présence de taxons de pomme dans les analyses carpologiques laisse envisager la culture sur le site de quelques pommiers, mais les espacements mesurés ne correspondent pas. En revanche, la forme de ces fosses peut concorder avec le provignage de pieds de vigne: cette technique de marcottage souterrain consiste à coucher un cep de vigne dans une fosse et à faire pousser plusieurs de ses sarments pour en faire de nouveaux pieds. 
Le marcottage consiste à reproduire un végétal en faisant prendre racine à l'une de ses ramifications, que l'on désolidarise par la suite du plant-mère. Le marcottage peut être aérien si l'on enfouit à distance une ramification que l'on fait ressortir de terre. Cette technique est utilisée pour reproduire plusieurs types de végétaux (glycine, chèvrefeuille, fraisier,...) mais c'est pour la vigne qu'elle s'emploie à plus grande échelle, et qu'elle nécessite de véritables fosses pour accueillir les marcottes (les futurs pieds reproduits).

10 L'exemple de F131 et de F117-F130 est symptomatique d'une telle technique (fig. 6). En effet, la trace enregistrée F117 n'est visible qu'en plan. Le creusement n'apparaît presque plus en coupe. Il pourrait s'agir de la trace laissée par l'enfouissement d'une ramification du pied-mère, ou plant vif, planté dans la fosse F131. Cette ramification serait plongée dans la fosse F130, où se développerait alors la marcotte.

Fig. 6. - Exemple de fosses illustrant la reproduction par provignage.

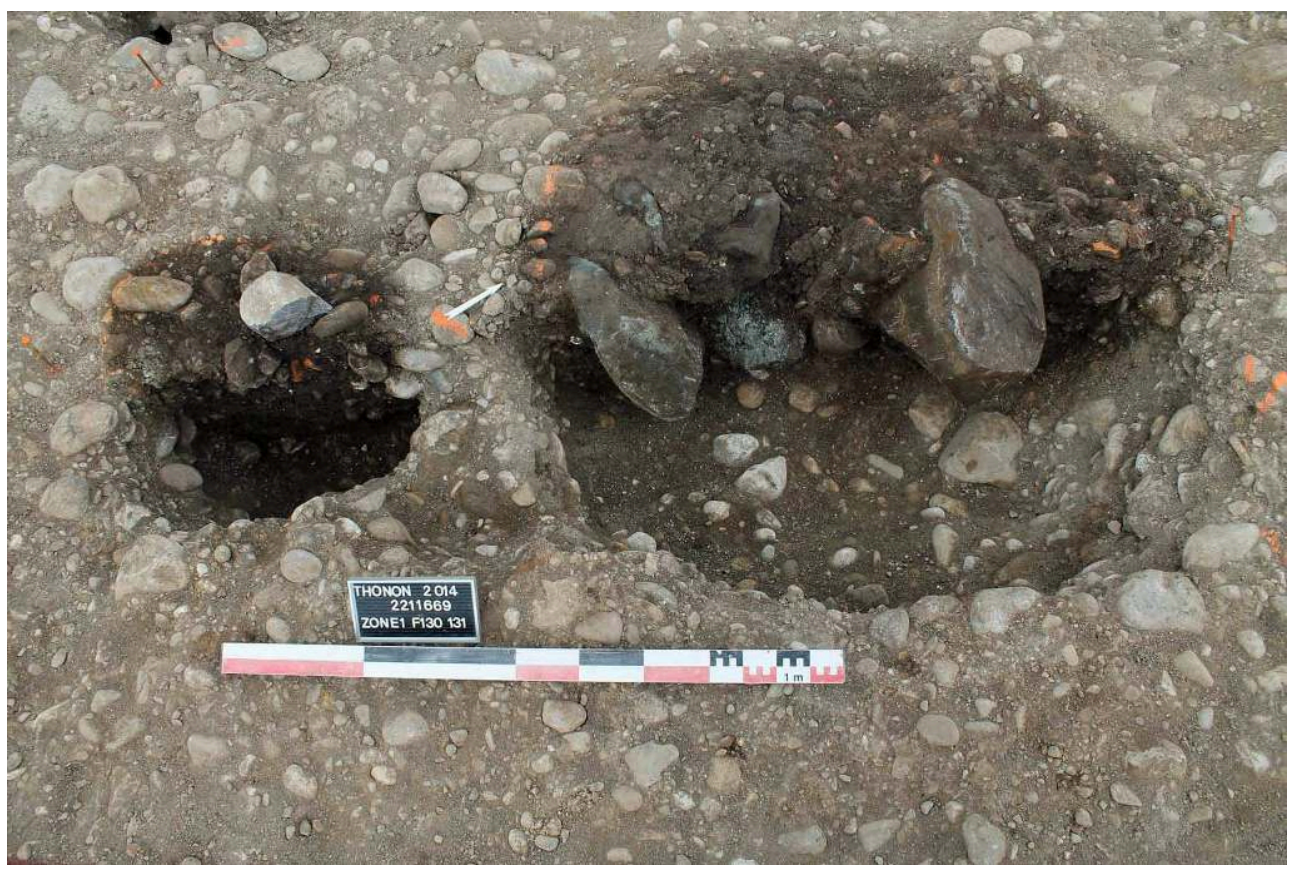

(c) G. Ackx.

11 Le marcottage aérien ne laisse pas de traces au sol, mais les associations constatées entre des fosses de $0,60 \mathrm{~m}$ et des fosses plus petites gravitant à proximité sont des illustrations assez classiques des configurations que peuvent engendrer des reproductions par marcottage aérien. Les traces observées ici évoquent ainsi à la fois le provignage et le marcottage aérien. Or la mise en évidence de la technique du marcottage, et surtout du provignage, constitue le plus fidèle argument permettant d'interpréter ces traces comme les vestiges d'une vigne cultivée.

\section{Datation des fosses, vers un ensemble homogène}

12 La fosse F263 apporte un indice de chronologie relative grâce à son scellement par un fin niveau de sol, qui renferme exclusivement du mobilier de l'Antiquité tardive. La plantation n'a donc pas perduré au Moyen Âge. La datation des comblements des fosses apporte un terminus post quem à situer également dans l'Antiquité tardive : les remblais 
nous renseignent sur les matériaux en place ou à proximité au moment du creusement des fosses et de la plantation des mottes à enraciner. Six fosses livrent du mobilier céramique datant (33 tessons tardo-antiques), fait assez rare pour des plantations. Les charbons de bois scellés dans quatre fosses ont permis des datations au radiocarbone :

-F118 : $1715 \pm 30$ BP soit 249-394 apr. J.-C. cal. à $2 \sigma$ (Poz-73320, Oxcal v4.2.3./IntCall13) ;

-F110 : $1710 \pm 30$ BP soit 251-397 (Poz-73319, idem);

-F130 : $1660 \pm 30$ BP soit 325-430 (Poz-73321, idem) ;

- F258 : $1635 \pm 30$ BP soit 340-438 (Poz-73343, idem).

13 Deux groupes d'intervalles se dessinent, qui se chevauchent largement, ayant en commun une bonne part $\mathrm{du} \mathrm{IV}^{\mathrm{e}}$ siècle, moment où cette vigne a très probablement été plantée.

Il faut néanmoins également intégrer le fait que certains pieds ont pu être renouvelés des années après la plantation des premiers plants vifs. La vigne est par définition vivace, mais également très sensible aux variations et aléas climatiques. Or le BasChablais possède un climat contrasté, avec des taux d'humidité assez forts en matinée, que la vigne n'apprécie que modérément, ce qui explique que les vignes y aient été élevées traditionnellement en hautains sur arbres (pour protéger les grappes de l'humidité du sol, Landry à paraître). Cette technique de conduite n'est pas celle adoptée sur le site du Genevray/Versoie. Aussi peut-on envisager les difficultés rencontrées sur le site pour maintenir saine une vigne basse ou sur échalas simples, ce qui devait entraîner le renouvellement fréquent des ceps morts.

Néanmoins, en considérant la courte période de mise en culture considérée (un siècle ?), ces renouvellements doivent avoir respecté la trame d'implantation initiale de la parcelle de vigne.

\section{Quelques préconisations des agronomes antiques}

Concernant la vigne, les agronomes antiques évoquent la plantation de ceps dans différents types de fosses. En effet, ils préconisent, soit de planter le vignoble sur des terrains entièrement défoncés ${ }^{8}$, technique dont les traces archéologiques ne peuvent être perçues, soit dans des tranchées de défoncement linéaires appelées sulci ${ }^{9}$, soit dans des fosses isolées désignées sous le terme de scrobes ${ }^{10}$. Columelle décrit ces scrobes comme des fosses allongées, dans lesquelles deux pieds de vigne poussent aux extrémités. Pline désigne ces fosses sous le terme d'alvei ${ }^{11}$. Ce sont les fosses que l'on retrouve le plus souvent en Gaule. Pline mentionne également des fosses cubiques de 3 pieds de côté ${ }^{12}$.

P. Boissinot a établi une typologie des formes de défoncement préalables à la plantation des ceps de vigne ${ }^{13}$. Il ressort de ce travail que les petites fosses rondes appartiennent au Type 2, et les fosses qu'il désigne sous le qualificatif de «ramassées", au Type 3. Celui-ci rassemble des fosses quadrangulaires ou subquadrangulaires de tailles diverses, ainsi que des fosses oblongues moins allongées que les alvei du Type 4, qui ne doivent accueillir a priori qu'un seul cep. F131, F114 et F115 pourraient s'apparenter à ce type de fosses, tandis que toutes les autres fosses de la zone est appartiennent plutôt au Type 2.

En métrologie, on constate au premier abord des espacements entre les fosses, centre à centre, proches de 3 pieds (soit presque $1 \mathrm{~m}$, si l'on considère le pied classique romain, 
le pes monetalis, dont la valeur est établie à $0,2957 \mathrm{~m}$ ). Ces espacements coïncident bien avec certaines préconisations, notamment de l'agronome référent pour l'Antiquité tardive, Palladius :

«Quand la terre est grasse, on laisse de grands intervalles entre eux, et de petits espaces quand elle est maigre. C'est pour cela que, en alignant des ceps sur la surface entière d'un terrain façonné, quelques-uns laissent entre eux trois pieds dans tous les sens. D'après cette méthode, on plantera par arpent 3600 ceps. $»^{14}$

Palladius nous explique :

«[...] En province on fait les vignes de beaucoup de manières; mais la meilleure consiste à dresser les ceps sur une jambe courte, comme des arbustes. Un roseau leur sert d'appui jusqu'à ce qu'ils se soient affermis. $»^{15}$

À Versoie, aucune trace de tuteur n'a été observée. Un fin tuteur planté dans la terrasse würmienne ne laisse pas de trace en se décomposant ou en étant arraché, car gravier et cailloux s'infiltrent alors dans les espaces laissés vacants. Dès lors, aucune restitution de l'échalassage ne saurait être proposée. Les fosses de plantation de vignes de Versoie sont donc rondes ou légèrement ovales, et correspondent au Type 2. Ce Type de vigne se rencontre fréquemment en Narbonnaise, même s'il est nettement moins répandu que les alvei.

21 De telles plantations de vigne sont notamment mentionnées sur le site de MontpellierMultiplexe dans l'Hérault ${ }^{16}$, où la vigne est datée du début du $\mathrm{II}^{\mathrm{e}}$ siècle apr.J.-C., sur le site de Mayran dans le Gard ${ }^{17}$, où les fosses sont attribuables à l'Antiquité tardive, tout comme les deux parcelles de fosses du Type 7 du Grand Palais à Châteauneuf-duRhône ${ }^{18}$.

\section{Hypothèse de restitution d'une parcelle de vigne (fig. 7)}

22 La technique des projections linéaires s'avère relativement fiable dans une logique de cultures romaines. Les arpenteurs, agronomes et agriculteurs romains, font généralement preuve d'une rigueur et d'une précision extrême dans leur exploitation du terroir. Les innombrables cas de traces de vignes fouillées en Gaule et dans le reste $\mathrm{du}$ monde romain le démontrent notamment ${ }^{19}$. Dans le cas de plantations en fosses, on parvient donc vite en planimétrie à aligner plusieurs fosses et à déterminer une trame. Dans le cas des vignes, une seule orientation est généralement privilégiée (contrairement à certains vergers). 
Fig. 7. - Hypothèses de restitution planimétrique du vignoble et du pressoir du Genevray/Versoie.

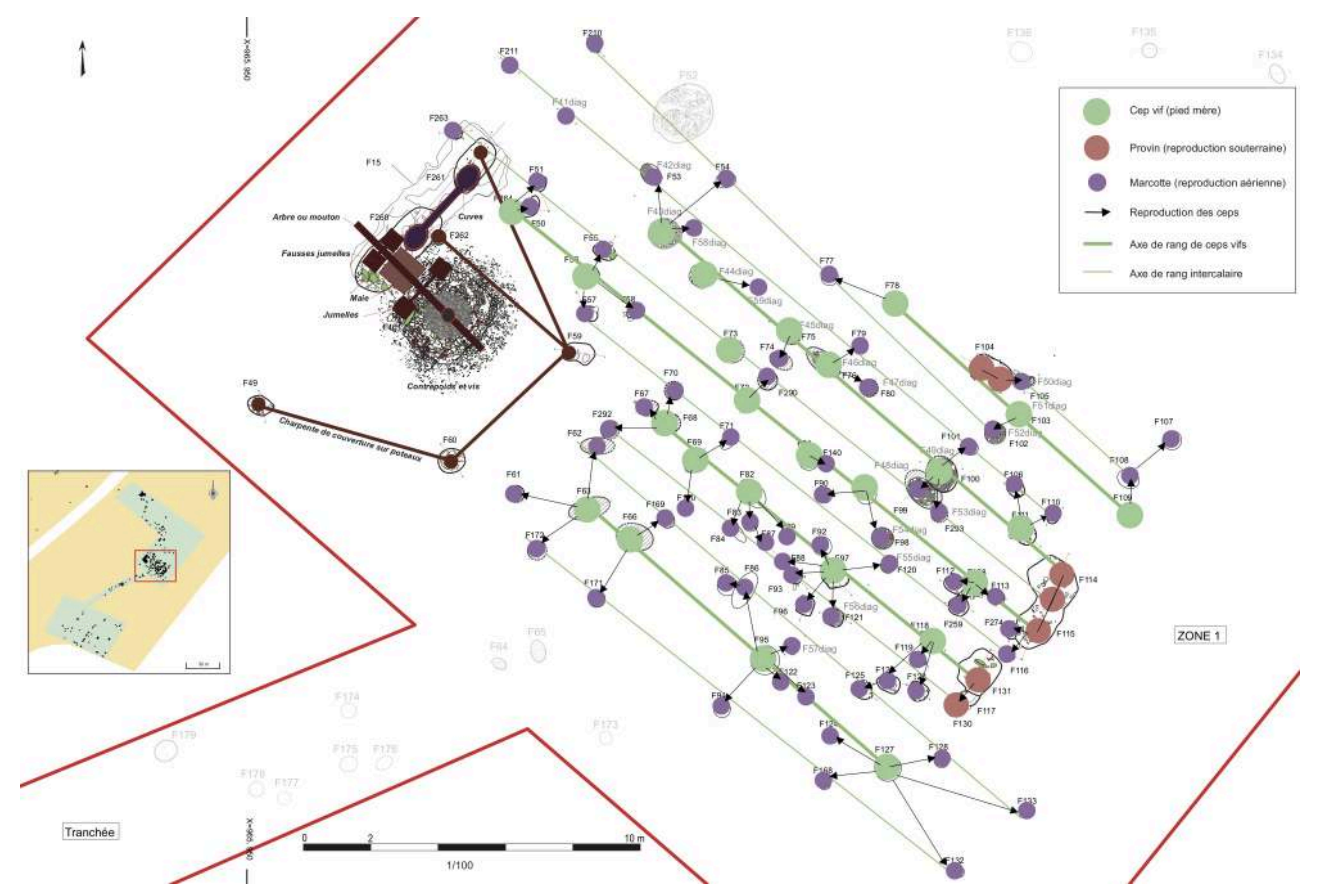

(c) Chr. Landry.

La méthode consiste ici à définir des alignements intégrant le maximum de grandes fosses les plus profondes. Nous proposons de voir dans ces lignes l'implantation des premiers ceps de la parcelle : les plants vifs, déjà adultes, à partir desquels seront marcottés les autres pieds afin de densifier la trame. On constate très vite une orientation sud-est/nord-ouest. Le calage de la trame en angle mathématique n'a pas été entrepris car les distances sont très faibles, ce qui contraint à une trop forte imprécision. En outre aucun fossé antique n'a été mis au jour au Genevray et pour l'heure à Thonon, les éventuels parcellaires gallo-romains de l'agglomération et de ses environs n'ont jamais été démontrés.

Nous obtenons ainsi cinq rangs de plants vifs, espacés d'axe en axe de 2,16 m, 2,2 m, $2,7 \mathrm{~m}$ et 3,37 $\mathrm{m}$. Les espacements sur un même rang varient de $1,5 \mathrm{~m}$ à environ $4 \mathrm{~m}$. On constate la présence de fosses plus petites intercalées entre les rangs, et parfois même entre deux pieds vifs sur un même rang. Elles peuvent correspondre aux emplacements des pieds marcottés. On comprend dès lors la logique de densification de la plantation : un à deux rangs intercalaires de marcottes ont été ajoutés entre les rangs de ceps vifs. Columelle, entre autres, nous explique la logique d'une telle méthode :

«On introduit des marcottes entre les plants : il sera suffisant d'en piquer dans le milieu de l'intervalle vacant entre les vignes et sur la même ligne. Les marcottes ainsi disposées pousseront mieux, et il se trouvera assez d'espace pour que l'on puisse cultiver le plant qui est dans les rangées. Ensuite dans la même ligne que les marcottes enracinées, il sera, en cas que quelqu'une des jeunes vignes vienne à y mourir, une ressource pour la remplacer. On doit planter cinq marcottes dans l'espace d'un pied, et ce pied est pris à partir du milieu de l'intervalle, de manière que, de chaque côté, la distance soit égale. $»^{20}$

Il s'agit de théorie et la même rigueur n'est pas toujours observée. Ici la métrologie appliquée souffre d'irrégularité, aggravée certainement par la nature du substrat et les conditions de l'étude déjà évoquées. Nous retiendrons donc que les fosses des plants 
vifs obéissent globalement à un module de 2 pieds pour les rondes, et de 3 par 4 pieds pour les quadrangulaires. En revanche, les marcottes sont enfouies dans des fosses d'un module inférieur de l'ordre d'1 à 1,5 pied. L'espacement moyen entre les axes est abaissé: nous obtenons une moyenne d'1 $\mathrm{m}$, ce qui équivaut à un peu moins de 3,5 pieds, et reste cohérent par rapport aux préconisations agronomiques romaines.

Le nombre de marcottes autour des ceps vifs, et leurs espacements, ne sont pas des données très déterminantes puisque nous ne pouvons démontrer, à cause de la logique de remplacement déjà évoquée, que tous ces pieds marcottés ont donné du raisin au même moment. Aussi n'est-ce pas surprenant de voir autant de marcottes provenant d'un même plant vif, puisque la gestion de la parcelle doit être considérée sur plusieurs années.

La question de la surface mise en culture n'est là non plus guère pertinente, puisque les traces de l'ensemble du vignoble ne sont à l'évidence pas conservées partout sur le site. Néanmoins, la notion de parcelle peut être proposée pour l'ensemble étudié, qui semble relativement concentré et délimité. La gestion parcellaire du vignoble ne peut être occultée totalement, et l'on se doit d'évoquer de possibles alternances de formes de cultures, de cépages, d'axes de circulation. Columelle conseille de diviser les vignes en quartiers, séparés par des chemins d'accès sur le rythme du demi-jugère ${ }^{21}$, c'est-à-dire un arpent $\left(1260 \mathrm{~m}^{2}\right)$. La zone de concentration des fosses de vigne de Versoie couvre seulement $250 \mathrm{~m}^{2}$, mais il n'y a rien de surprenant à cela puisque le contexte particulier des terrasses des piémonts alpins n'autorise à l'évidence pas les mises en cultures extensives observées dans les plaines et les régions de collines.

Quant à la densité maximale de plantation, si l'on compte les 100 fosses retenues, elle est de l'ordre de 8000 ceps à l'hectare, ce qui s'avère raisonnable, si l'on recherche la qualité, et faible si l'on privilégie le rendement. Mais ces notions sont à relativiser, car le rendement dépend davantage du nombre de grappes par cep, et donc de la technique de taille employée. Naturellement, sans connaître le mode de conduite et la technique de taille, et en l'absence de chai, l'ampleur de la production ne peut être estimée. On considère aujourd'hui qu'un rendement moyen de $40 \mathrm{hl} / \mathrm{ha}$, pour une parcelle dont la densité est de l'ordre de 10000 ceps/ha, constitue une production raisonnable permettant d'obtenir une qualité de vin correcte. Aussi, si l'on table sur le même objectif de qualité, on peut envisager un rendement moyen de $32 \mathrm{hl} / \mathrm{ha}$ pour la vigne du Genevray/Versoie. En supposant une taille permettant d'obtenir un tel rendement, la production totale sur une récolte n'excéderait pas 80 litres, ce qui ne représente que 3 amphores. On est donc très loin de pouvoir remplir un tonneau ${ }^{22}$. Et même si le vigneron du Genevray parvenait à respecter le rendement que Columelle estime raisonnable pour une vigne romaine bien tenue, soit 3 culei $^{23}$ par jugera $^{24}(60 \mathrm{hl} / \mathrm{ha})$, la production de cette parcelle serait encore assez faible. Tous ces arguments suggèrent deux hypothèses d'interprétation pour ce vignoble. Il peut s'agir d'une parcelle à vocation vivrière : elle accompagne d'autres cultures ou d'autres vignes aux alentours.

L'autre hypothèse consiste à envisager cette vigne, et ses probables installations connexes (équipements, habitat d'un fermier), comme partie intégrante d'un domaine dont la production agricole serait diversifiée et répartie entre plusieurs unités plus ou moins indépendantes disséminées sur le versant, des fermes ou des propriétés de membres de la clientèle (au sens romain) d'un aristocrate détenant une villa suburbaine (à Morcy? Marclaz ?). 
Dans les deux cas, ce vignoble ne traduit pas une exploitation intensive, et ne semble pas avoir été géré avec la même rigueur que celle qu'on observe archéologiquement sur les domaines des autres régions de Narbonnaise ${ }^{25}$, et même dans les autres provinces gauloises $^{26}$.

\section{Les fondations d'un pressoir}

31 Un ensemble de structures, situé à la limite occidentale de la parcelle de vigne, pose question quant à son interprétation. Nous proposons d'y voir les traces de l'installation d'un pressoir.

\section{Description des structures excavées}

L'ensemble exposé ici se compose de neuf faits ${ }^{27}$.

- F262 est un trou de poteau circulaire à parois verticales et fond plat, $(\mathrm{L}=0,42 \mathrm{~m}, \mathrm{P}=0,10 \mathrm{~m})$.

- F261 est une fosse quadrangulaire ( $\mathrm{L}=1,70 \mathrm{~m}, \mathrm{l}=0,85 \mathrm{~m}, \mathrm{P}=0,13 \mathrm{~m})$.

- Les trois creusements F49, F60 et F59 se distinguent de toutes les structures de forme similaire en plan, interprétées comme des fosses de plantation. Ces trois faits présentent un surcreusement circulaire marquant l'empreinte d'un poteau, au fond plat ( $D=0,60 \mathrm{~m}, 0,30 \mathrm{~m}$ et $0,50 \mathrm{~m} \mathrm{P}=0,25 \mathrm{~m}, 0,45 \mathrm{~m}$ et $0,48 \mathrm{~m}$ ).

- La structure F260, associée à F12, est une fosse oblongue ( $\mathrm{L}=3,15 \mathrm{~m}, 1=1,23 \mathrm{~m}, \mathrm{P}=0,24 \mathrm{~m})$ aux parois verticales et au fond plat au nord, présentant un surcreusement ovalaire (L $=1,70 \mathrm{~m}, 1=1,23 \mathrm{~m}, \mathrm{P}=0,72 \mathrm{~m}$ ) dans sa moitié sud. F260, F261, F262, ainsi que F12, sont scellés par des remblais tardo-antiques.

- F12 est une large fosse quadrangulaire aux angles arrondis (fig. 8 et 9) $(\mathrm{L}=2,62 \mathrm{~m}, \mathrm{l}=2,56 \mathrm{~m}$, $\mathrm{P}=0,88 \mathrm{~m}$, surface au sol $: 6,7 \mathrm{~m}^{2}$ ) ; elle est orientée $\mathrm{N}$-E/SO et flanquée de 2 trous de poteaux $(\mathrm{D}=0,60 \mathrm{~m})$ dans les angles nord et ouest (F276 et F461). Le creusement présente des parois verticales sauf à l'ouest où il s'évase comme une rampe. Le fond est plat, tapissé par un fin dépôt limoneux. Après l'abandon de la structure, les parois du creusement semblent avoir légèrement raviné, puis trois niveaux de remblais de démolition viennent la combler, contenant de nombreux mobiliers (céramique, objets, monnaies, faune, scories de fer...). Ces matériaux proviennent à l'évidence d'un bâtiment détruit ou en ruine situé dans un faible rayon.

- Les deux négatifs circulaires F276 et F461 ( $D=0,60 \mathrm{~m}, \mathrm{P}=0,46 \mathrm{~m})$ ont un fond plat et des parois obliques. De gros blocs de micaschiste scellent leur comblement après avoir servi de calage à l'installation. 
Fig. 8. - Vue de la fosse F12 avant sa fouille.

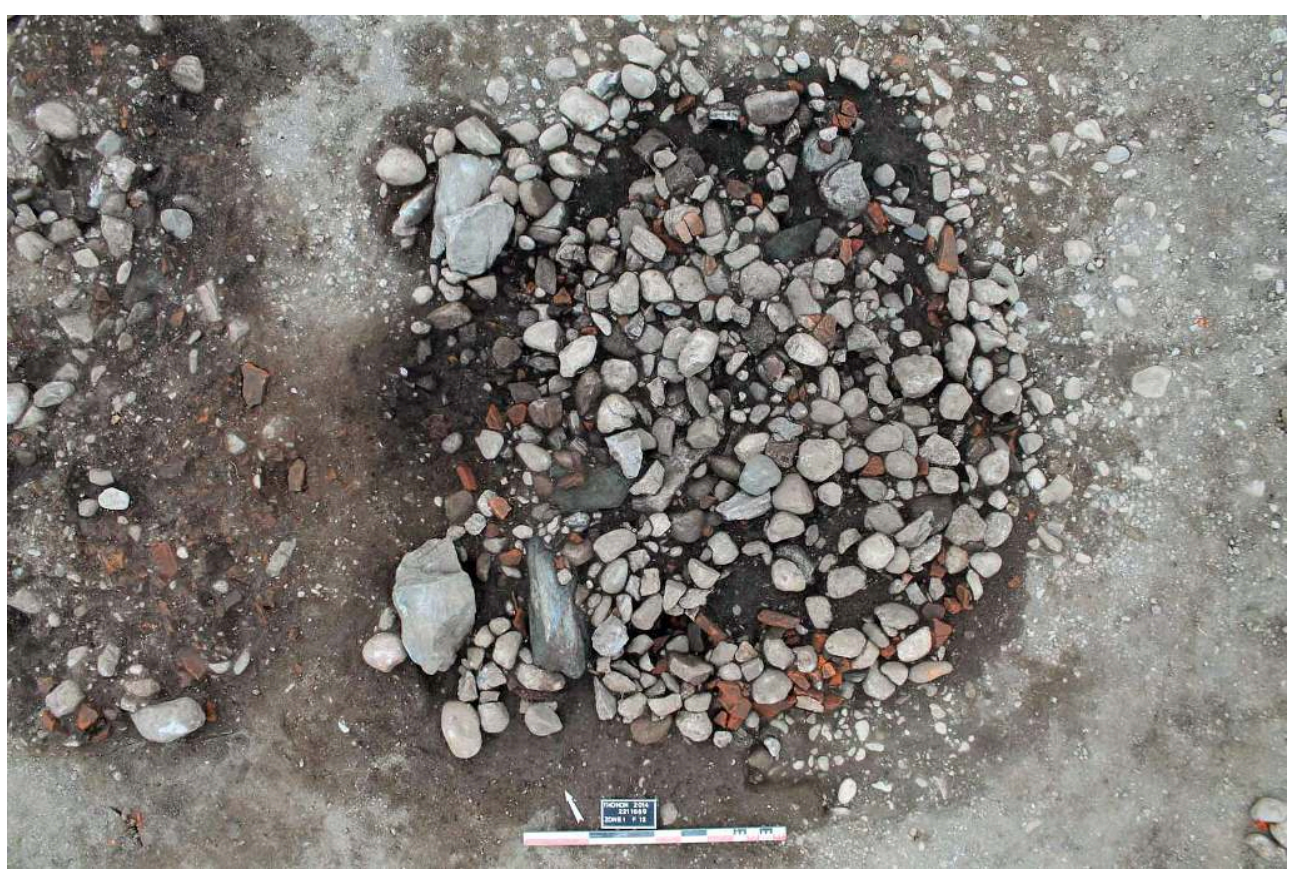

(C) Chr. Landry.

Fig. 9. - Plan et coupe de la fosse F12.

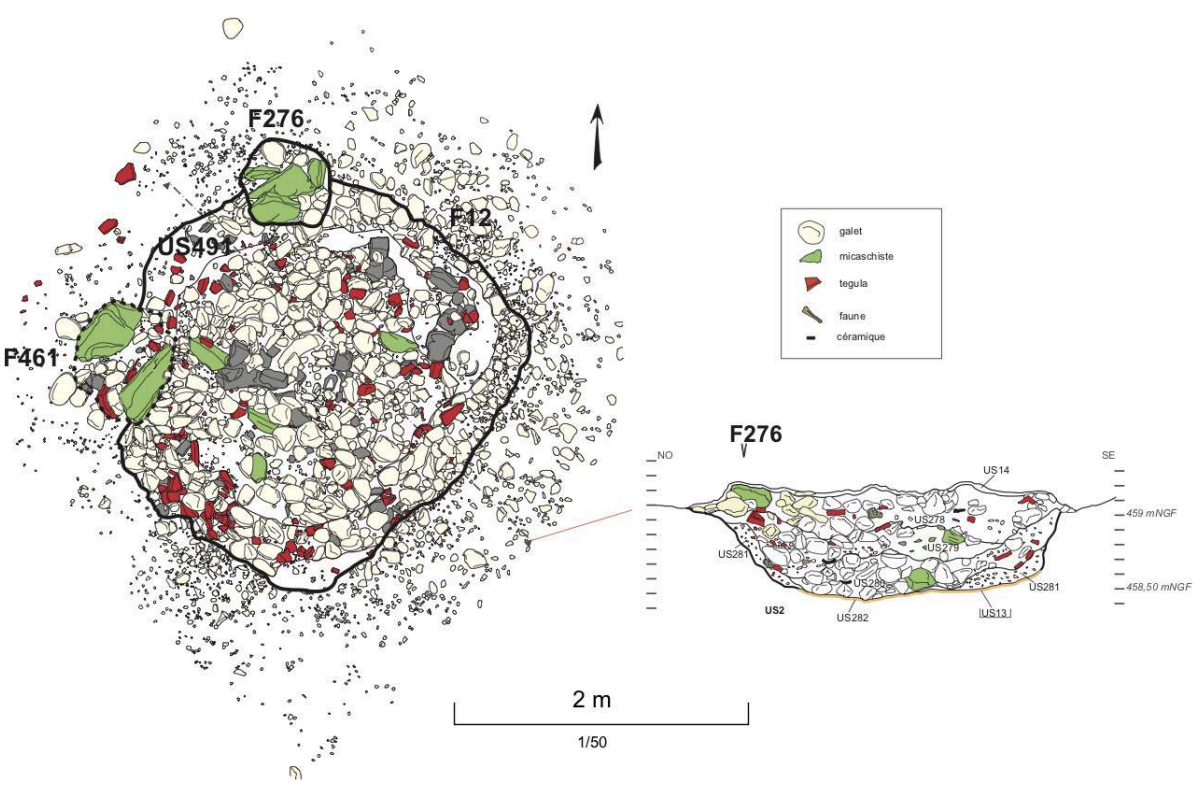

(c) L. Kuntz.

\section{Hypothèse d'interprétation}

Les premières hypothèses qui viennent à l'esprit pour interpréter le creusement de F12 (fosse d'extraction, maison semi-enterrée, sur le modèle alpin, comme en livre le site 
valaisan de Brigue ${ }^{28}$, cave, vide sanitaire) ne sont pas convaincantes ni étayées par le contexte immédiat.

Il faut donc envisager l'association de F12 avec les différents négatifs environnants comme formant une seule installation. Les deux creusements profonds de F260 et F12 situés de part et d'autre de deux négatifs quasi symétriques évoquent la disposition des pièces composant un petit pressoir à levier. Les deux négatifs centraux, espacés d'1 m, peuvent avoir servi d'ancrage aux fausses jumelles, et la partie la plus profonde de F260 à caler les deux poutres jumelles. Une surface d'un peu plus $\mathrm{d}^{\prime} 1 \mathrm{~m}^{2}$ serait alors disponible dans l'espace circonscrit par ces quatre éléments en bois, pour accueillir la cage où le raisin est écrasé. Le moût pourrait alors être recueilli dans un baquet placé en contrebas, dans la moitié nord du creusement de F260. La fosse F12 aurait dès lors servi à enfouir le contrepoids auquel était fixée la vis servant à abaisser l'arbre. L'ensemble de l'installation mesurerait dès lors au minimum $4 \mathrm{~m}$ de longueur. Tous les trous de poteau environnants peuvent avoir supporté une charpente et une toiture couvrant la machinerie en bois. Il faut envisager que d'autres vestiges se trouvent plus à l'ouest hors de l'emprise fouillée, qui pourraient compléter l'ossature des installations proposées ici.

Les données font trop défaut pour une reconstitution architecturale exhaustive. Nous en restons donc à une hypothèse de restitution graphique en plan (fig. 7).

Les pressoirs antiques trouvés en fouille sont légion depuis les travaux notamment de J.-P. Brun ${ }^{29}$. Les restitutions qui en sont données vont toutes plus ou moins dans le même sens, rejoignant l'image que nous en donnent certaines représentations figurées, comme la mosaïque des saisons de Saint-Romain-en-Gal, et les auteurs antiques comme Caton l'Ancien ${ }^{30}$, Vitruve ${ }^{31}$ et Héron ${ }^{32}$. La plupart des sites fouillés disposent d'indices indéniables : cuves et fouloirs maçonnés, socles de jumelles en pierre, contrepoids en place ou en remploi, chais à dolia, concentrations de pépins, maçonneries du bâtiment... Les quelques exemples reposant sur l'analyse des fosses d'ancrage d'éléments en matériaux périssables, notamment hors Narbonnaise, reprennent généralement les modèles des installations « en dur ». C'est le cas entre autres du pressoir de Boulazac en Dordogne $^{33}$, de celui de Piriac-sur-Mer en Loire-Atlantique ${ }^{34}$, de ceux de Lagarel à SaintAndré-de-Sagonis ${ }^{35}$ et de Tourbes dans l'Hérault ${ }^{36}$, ou de celui de Parville dans l'Eure ${ }^{37}$. Ce dernier était associé à un bâtiment sur poteaux adjacents. Cette association n'est pas sans rappeler le site de Versoie, où les poteaux observés appartiennent plus vraisemblablement à une superstructure de protection du pressoir, mais où l'existence d'un bâtiment est très probable, hors de l'emprise de fouille.

37 La présence d'un pressoir, même de taille modeste, au plus près des vignes, fait sens dans un secteur de piémont comme celui du marais de Versoie. Le paysage actuel ne retranscrit guère le relief ayant préexisté avant les travaux de construction du contournement de Thonon. Du site au hameau de Morcy, où se trouve la plus proche villa prônée par la tradition historiographique locale, il devait exister un dénivelé de près de $30 \mathrm{~m}$. Aussi conçoit-on tout à fait l'intérêt, d'un point de vue logistique, de presser sur place les raisins produits sur cette terrasse lémanique, afin de n'avoir plus qu'à descendre le moût vers les installations de stockage d'un établissement mieux équipé. 


\section{Quelle production viticole? Du vitis allobrogica de Pline au Chasselas moderne} par les agronomes, réside donc dans une bonne adaptation à un climat froid et humide. Cette conduite convient particulièrement aux régions de Piémont que sont le Chablais et le Comminges (la production de Jurançon se fait encore aujourd'hui dans des vignes conduites en hautains). Mais, on l'a vu, le vignoble du Genevray n'adopte pas ce mode de conduite. traditionnellement admise passionnent les archéologues ${ }^{45}$. Les sites de production de ce breuvage au fort potentiel commercial ne devaient pas se trouver dans des régions comme le Bas-Chablais savoyard, aussi enclavées par rapport aux grands axes de circulation de la Viennoise. La recherche penche aujourd'hui pour une région plus centrale de la cité de Vienne, vers les contreforts du Dauphiné. En effet, l'Allobrogique pourrait correspondre à une proto-Mondeuse ${ }^{46}$. Dès le xix siècle avait été constatée la superposition des zones de culture de la Mondeuse noire et de la Syrah avec le territoire allobroge. Aujourd'hui les analyses paléogénétiques réalisées par des équipes de l'Inra à Montpellier et de l'université de Neuchâtel ${ }^{47}$, permettent de relier les cépages entre eux. Ainsi, la Mondeuse et la Syrah auraient pour ancêtre le Pinot noir, originaire du nord-est de la France et implanté plus au sud par les Romains. La Syrah est un croisement entre la Mondeuse blanche de Savoie et la Dureza originaire 
d'Ardèche, mais fille du Pinot, tout comme le Teroldego qui provient du Trentin en Italie. La mise en évidence de la relation entre Dureza et Teroldego représente la première preuve d'un lien génétique direct entre deux cépages transalpins. Mondeuse, Syrah et Teroldego auraient ainsi un ancêtre commun, apparenté au Pinot: l'Allobrogique pourrait se situer quelque part sur leur arbre généalogique. L'analyse génétique de pépins archéologiques pourrait s'avérer décisive dans cette problématique.

Rien n'empêche au final que ce soit le cépage allobroge qui ait été introduit sur la rive sud du Léman, même s'il ne s'y est pas pérennisé, et que de tout autres productions y ont été privilégiées par la suite. En effet, la tradition fait remonter au XI ${ }^{\mathrm{e}}$ siècle sur la rive sud du Léman la culture en « crosses » (hautains), introduite par des moines, et qui est maintenue aujourd'hui à Marin. Les archives d'Yvoire mentionnent en $1334^{48}$ des celliers et des vignes qui jouxtaient les fossés de la ville neuve, et le cépage Chasselas n'aurait été généralisé dans tout le Bas-Chablais savoyard que dans la première moitié $\mathrm{du} \mathrm{Xv} \mathrm{v}^{\mathrm{e}}$ siècle $^{49}$ (fig. 10). Le croisement des sources historiques et des analyses génétiques démontre que ce cépage est bien originaire de l'arc lémanique, probablement du canton de Vaud en Suisse ${ }^{50}$. Ainsi, le village de Chasselas, en Bourgogne, où ce raisin est attesté en 1612 , s'il se trouve bien dans la zone d'affinité génétique du cépage, ne constituerait qu'une zone de transition. Le lien génétique entre le Chasselas lémanique et les cépages gallo-romains élevés dans le piémont chablaisien reste à établir, mais nécessitera la découverte de pépins conservés in situ. Seules de telles avancées permettront de savoir si le vignoble du $\mathrm{IV}^{\mathrm{e}}$ siècle s'apparentait au vin des Allobroges ou plutôt à un parent précoce des raisins vaudois.

Fig. 10. - Le site du Genevray est couvert de vignes au XVIII siècle, sans doute du " Chasselas ».

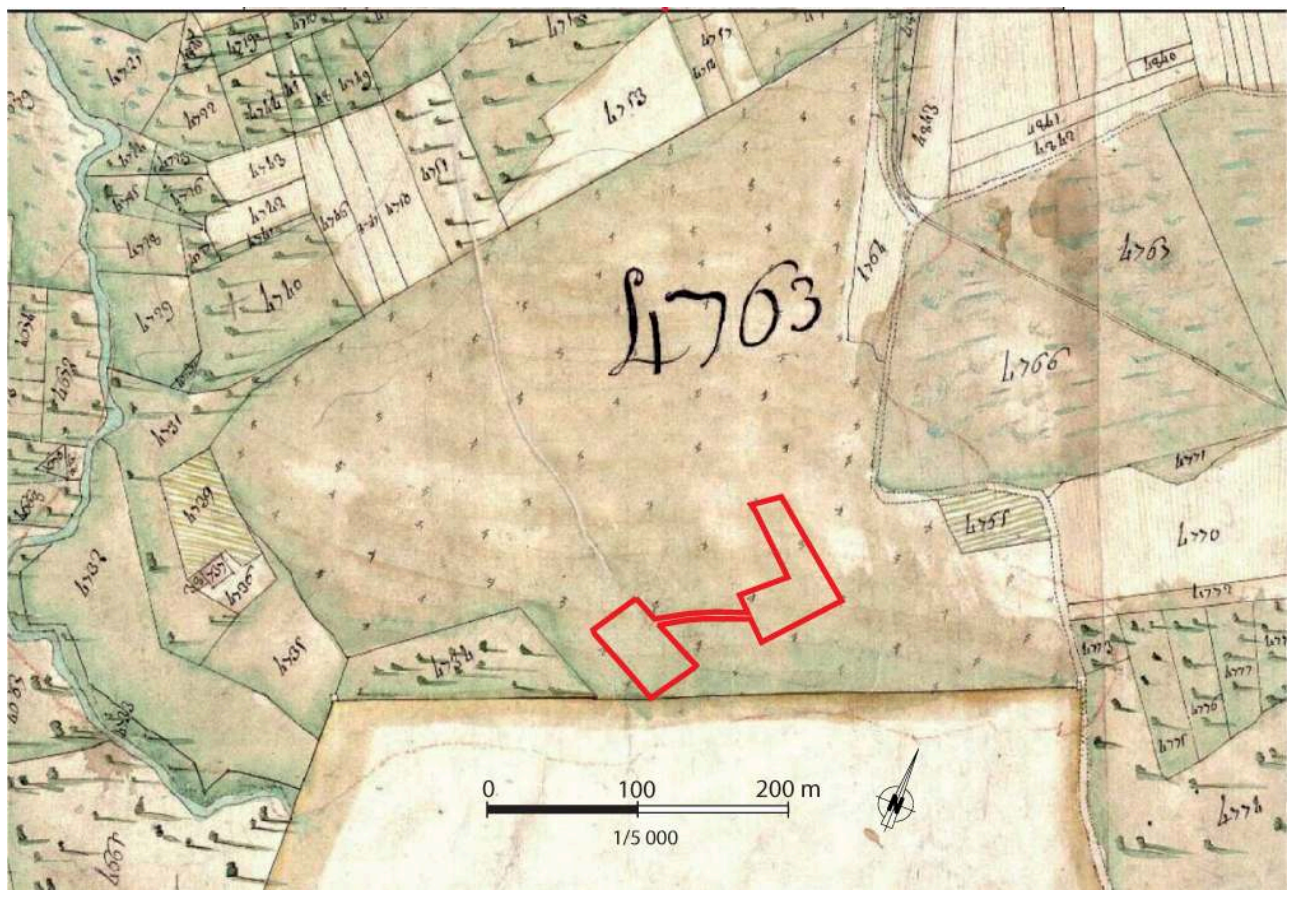

(Mappe sarde, Archives départementales de Haute-Savoie, Annecy, cote 1 C d 16, Copie, 1728-1738). 
ignoble et le pressoir du Genevray appartiennent donc vraisemblablement à une petite unité rurale implantée au $\mathrm{IV}^{\mathrm{e}}$ siècle apr. J.-C. en périphérie de l'agglomération antique de Thonon. Ses cultures et installations peuvent faire partie intégrante d'un domaine dont la production agricole serait diversifiée et répartie entre plusieurs fermes sur le versant chablaisien. Le moût issu de la pressurée pouvait être ensuite descendu rapidement vers la plaine littorale ou les terrasses basses, en direction d'installations de stockage plus proches des débarcadères et des axes routiers ${ }^{51}$.

\section{BIBLIOGRAPHIE}

ANDRÉ J., LEVADOUX L., « La vigne et le vin des Allobroges », Journal des Savants, vol. 3, nº 1, p. $169-181$.

BÉAL J.-C., LANDRY Chr. (dir.), La villa antique du Palais à Châteauneuf-du-Rhône, DARA, à paraître.

BÉAL J.-C., LUCAS G., 2011, « La viticulture dans la partie occidentale du territoire allobroge », dans pouX M. et al., Dossier : La vigne et le vin dans les Trois Gaules, Gallia, 68-1, p. 215-235.

BOHNY J., BOST Chr., 2017, « Les installations de vinification d'un chai aquitain : la cella vinaria du « Lieu-Dieu » à Boulazac (Dordogne), $\mathrm{I}^{\mathrm{er}}$-II ${ }^{\mathrm{e}}$ siècle apr. J.-C. », in TRÉMENT F. (dir.), Produire, transformer et stocker dans les campagnes des Gaules romaines. Problèmes d'interprétation fonctionnelle et économique des bâtiments d'exploitation et des structures de production agro-pastorale, actes du XI colloque de l'Association d'étude du monde rural gallo-romain - colloque AGER, Clermont-Ferrand, 11 au 13 juin 2014, RACF, 2017.

BOISSINOT P., 2001, «Archéologie des vignobles antiques du sud de la Gaule », dans BRUN J.-P., LAUBENHEIMER F. (dir), Dossier : La viticulture en Gaule, Gallia, 58, p. 45-68.

BRUN J.-P., 2003, Le vin et l'huile dans la Méditerranée antique, Viticulture, oléiculture et procédés de fabrication, Paris, Errance, 2003, 240 p.

BRUN J.-P., 2004, Archéologie du vin et de l'huile dans l'Empire romain, Errance, Paris, 316 p.

BRUN J.-P., 2005, Archéologie du vin et de l'huile en Gaule romaine, Errance, Paris, 271 p.

BRUN J.-P., 2010, « Viticulture et oléiculture en Gaule », dans OUZOULIAS P., TRANOY L., Comment les Gaules devinrent romaines, La Découverte, Paris, p. 231-253.

BRUN J.-P., LAUBENHEIMER F. (dir.), 2001, Dossier : La viticulture en Gaule, Gallia, 58, CNRS Éditions, 2001, 376 p.

BUFFAT L., PETITOT H., VIDAL L., 2006, « Un centre domanial dans la vallée de la Tave : la villa de Mayran (Saint-Victor-la-Coste, Gard) », Revue archéologique de Narbonnaise, vol. 38-39, Montpellier, p. 225-282.

CHARTRAIN A., 2007, « A proper study of mankind is dot, and dash. Parcellaires fossiles et faits funéraires sur le territoire rural de Montpellier », congrès « Medieval Europe » (6-8 sept. Paris), session, publié dans les pré-actes [www.archeogeographie.org]et dans les actes [http://medieval-europeparis-2007.univ-paris1.fr/A.Chartrain.pdf] 
COLUMELLE, De l'agriculture, Livres I à XII, trad. par M. Louis DU BOIS, C. L. F. PANCKOUCKE, Bibliothèque latine-française, Seconde série, 1844, en ligne : [http://remacle.org/]

COMPAN M., 2011, Les établissements agricoles de Mont Ferrier durant le Haut Empire à Tourbes : "d'une ferme à l'autre ": autoroute A75, section Béziers - Pézenas, secteur 1 : Hérault, Tourbes, Mont Ferrier, Rapport final d'opération de fouille archéologique préventive, Nîmes, Inrap Méditerranée, 407 p. FRITSCH R., 1990, « Examen de macrorestes végétaux sur le site de Portout 2 », dans J. et Chr. PERNON, Les potiers de Portout, productions, activités et cadre de vie d'un atelier au ve siècle ap. J.-C., Paris, (20 è̀me $^{2}$ uppl. à la RAN),1990, p. 32-36.

HERVÉ-MONTEIL M.-L., LUKAS D., MONTEIL M., DIETSCH-SELLAMI M.-F., 2011, « La viticulture dans l'ouest de la Gaule Lyonnaise : les pressoirs de Parville (Eure) et de Piriac-sur-Mer (Loire-Atlantique) », Gallia, $\mathrm{n}^{\circ} 68,1$, p. 163-214.

LACOMBE T., BOURSIQUOT J.-M., LAUCOU V., DI VECCHI-STARAZ M., PÉROS J.-P., THIS P., 2012, « Large-scale parentage analysis in an extended set of grapevine cultivars (Vitis vinifera L.) », Theoretical and Applied Genetics, International Journal of Plant Breeding, vol. 125, $\mathrm{n}^{\circ} 2$.

LANDRY Chr., 2015b, Thonon-les-Bains (Haute-Savoie), Le Genevray, route de Versoie, Rapport final d'opération de fouille, Inrap, SRA Rhône-Alpes, Lyon, 365 p.

LANDRY Chr., à paraître, « La question de la conduite de la vigne en hautain en Gaule. Le cas des premières traces de culture à Châteauneuf-du-Rhône ", dans BÉAL J.-C., LANDRY Chr. (dir.), La villa antique du Palais à Châteauneuf-du-Rhône, DARA.

LANDRY Chr., 2019, «La voie de la Doie à Thonon-les-Bains, témoin de la circulation entre Bas et Haut-Chablais aux premiers temps de l'occupation romaine ", dans LEMAîTRE N. (ed.), Des routes et des hommes : la construction des échanges par les itinéraires et les transports, éd. numérique, Paris, Ed. du Comité des Travaux Historiques et Scientifiques, p. 30-47. [https://books.openedition.org/ cths/4383]

LANDRY Chr., MOULIN B., 2016, « When GIS goes to the Countryside: Detecting and Interpreting Roman Orchards from the 'Grand Palais' (Drôme, France) », dans CAMPANA S., SCOPIGNO R., CARPENTIERO G., CIRILLO M. (ed.), CAA2015 Keep the Revolution going, Proceedings of the 43rd Annual Conference on Computer Applications and Quantitative Methods in Archaeology, Siena (Italy), March 30 th- April 3rd 2015, Archaeopress Publishing LTD, Oxford, p. 499-515.

LAUBENHEIMER F., 2015, Boire en Gaule, CNRS Éditions, Paris, 192 p.

LEVEAU P., RÉMY B., CANAL A., SEGARD M., 2005, « Aix-les-Bains, vicus thermal et bourg rural », Revue archéologique de Narbonnaise, tome 38-39, p. 85-103.

LUKAS D., 2009, « Un pressoir gallo-romain », Archéopages, n² 29, p. 80-81.

MARLIÈRE É., 2001, « Le tonneau en Gaule romaine », dans Gallia, 58, p. 181-201.

Palladius, L'économie rurale, Livres I à XIV, trad. par M. CABARET-DUPATY, C. L. F. PANCKOUCKE, Bibliothèque latine-française, seconde série, 1843, en ligne :[http://remacle.org/]

PASQUET O., 2014, Étude géo-historique du vignoble et des paysages viticoles savoyards, "VIN’ALP », action du programme Interreg IV A ALCOTRA France-Italie, document disponible sur vignobles.tourisme.coeurdesavoie.fr/

PAULUS L., 1999, La vigne et le vin en Savoie (XIV et début du XVe siècle), Mémoire de DEA d'Histoire sous la direction de Christian GUILLERÉ, Université Lyon II, 146 p. 
Pline l'Ancien, Histoire Naturelle, Livres XIV à XVIII, Paris : Dubochet, 1848-1850, édition d'Émile Littré, en ligne :[http://remacle.org/]

POMARÈDES H., 2008, coll. COMPAN M., GINOUVEZ O., JUNG C., « Viticulture et équipements de production dans la cité de Lodève durant le haut Empire : apport des découvertes récentes autour de Clermont-L’Hérault », dans Revue archéologique de Narbonnaise, vol. 41, n 1, p. 7-41.

POUX M., BRUN J.-P., HERVÉ-MONTEIL M.-P. (dir.), 2011, Dossier : La vigne et le vin dans les Trois Gaules, Gallia, 68.1, CNRS Éditions.

RÉMY B. (dir.), 2005, Inscriptions Latine de Narbonnaise, vol. 1. Vienne, Tome 74, supplément à Gallia, Paris, CNRS.

SEGARD M., 2009, Les Alpes occidentales romaines, Bibliothèque d'Archéologie Méditerranéenne et Africaine, Éditions Errance, Centre Camille Jullian, 285 p.

vouillamoz J.-F., ARNOLD C., 2009, «Étude historico-génétique de l'origine du “Chasselas" », Revue suisse de Viticulture, Arboriculture et Horticulture, vol. 41 (5), p. 299-307.

VOUILLAMOZ J.-F., GRANDO M.-S., 2006, « Genealogy of wine grape cultivars: "Pinot" is related to "Syrah" ", Heredity, 97, p. 102-110.

\section{NOTES}

1. Segard 2009, p. 64.

2. Landry $2015 b$.

3. Étude géomorphologique par E. Morin, dans Landry, Ibid.

4. Laboratoires Carrtel et Chrono-environnement.

5. David Etienne, Élise Doyen, dans Landry, Ibid.

6. Études spécialisées dans Landry, Ibid. par Ch. Cécillon, D. Lalaï, A. Rebiscoul, J.L. Gisclon, S. Bigot, M. Cabanis, Chr. Bonnet avec la collaboration de M. Riou.

7. Landry, Moulin 2016.

8. Columelle, De l'agriculture, III, 13.

9. Ibid.

10. Ibid.

11. Pline l'Ancien, Histoire naturelle, XVII, 35.

12. Ibid.

13. Boissinot 2001, p. 52.

14. Palladius, De re rustica, III, 9.

15. Ibid., III, 11.

16. Fouille de L. Sauvage et B. Dedet, 1998 ; le plan est repris dans Chartrain 2007, fig. 9.

17. Buffat et al. 2006, p. 246.

18. Béal, Landry à paraître.

19. Landry, Moulin 2016.

20. De l'Agriculture, III, 16.

21. De l'agriculture, Livre IV, 18. 
22. Marlière 2001, p. 185-186.

23. Le culeus désigne la contenance d'une peau de bœuf entière, soit l'équivalent de 20 amphores ou 500 litres.

24. Le jugère correspond à un quart d'hectare, soit $2500 \mathrm{~m}^{2}$.

25. Brun, Laubenheimer 2001.

26. Poux et al. 2011.

27. $\mathrm{L}$ = longueur, $\mathrm{l}=$ largeur, $\mathrm{D}=$ diamètre, $\mathrm{P}=$ profondeur.

28. Segard 2009, p. 29.

29. Brun 2003, 2004, 2005 et 2010.

30. De agricultura, 18 et 19.

31. De architectura, VI, 6, 3 .

32. Mechanica, III, dans Baron Carra De Vaux, 1894, Les Mécaniques ou l'Élévateur de Héron d'Alexandrie, publiées pour la première fois sur la version arabe de Qostâ ibn Lûqà et traduites en français. Paris, Leroux, 194 pages de texte français, 115 de texte arabe.

33. Bohny, Bost 2017.

34. Hervé-Monteil et al. 2011.

35. Pomarèdes 2008, p.29-34.

36. Compan 2011.

37. Lukas 2009, Hervé-Monteil et al. 2011.

38. Segard 2009, p. 124.

39. Rémy 2005 : ILN, Vienne, 666.

40. Fritsch 1990 ; Pernon, Pernon 1990 ; Leveau et al. 2005, p. 99.

41. H.N., XIV, 5.

42. De re rustica, XII, 23.

43. Epigrammes, XIII, Xenia, 107.

44. H.N., XIV, 6.

45. Laubenheimer 2015; Béal, Lucas 2011.

46. André, Levadoux 1964.

47. Lacombe et al. 2012 ; Vouillamoz, Grando 2006.

48. Source non vérifiée.

49. Paulus 1999 ; Pasquet 2014.

50. Vouillamoz, Arnold 2009.i

51. Landry, 2019. 


\section{RÉSUMÉS}

Les vestiges d'une petite occupation rurale des $\mathrm{IV}^{\mathrm{e}}$ et $\mathrm{V}^{\mathrm{e}}$ siècle apr. J.-C. ont été fouillés en 2014 au bord de l'ancien marais de Versoie, au nord du massif du Chablais. L'étude du site permet de restituer une parcelle de vigne et un bâtiment abritant un pressoir à levier. Il s'agit d'un nouveau jalon dans l'histoire de la viticulture alpine, à l'heure où les données archéologiques savoyardes sont encore très lacunaires. Doit-on voir le vignoble de Versoie comme une attestation du fameux cépage vitis allobrogica ou vitis picata dont Pline nous dit qu'il est productif et affectionne les lieux froids, alors que les sites de production sont plutôt attendus aujourd'hui dans une région plus centrale de la cité de Vienne? Ce cépage pourrait ne pas s'être pérennisé dans le Chablais, les moines introduisant la culture du Chasselas en «crosses » (hautains) au XI ${ }^{\mathrm{e}}$ siècle sur la rive sud du Léman, et ce cépage ne s'y généralisant que dans la première moitié du $\mathrm{XV}^{\mathrm{e}}$ siècle.

\section{AUTEUR}

\section{CHRISTOPHE LANDRY}

Chargé d'opération et de recherche à l'INRAP et au laboratoire Archéologie et archéométrie («ArAr », UMR 5138), CNRS/université Lumière - Lyon II 
La période médiévale 


\title{
Rôle méconnu d'une brèche rouge brun à clastes schisteux et à ciment silico-ferrugineux dans le bâti médiéval des Pyrénées catalanes
}

\author{
Michel Martzluff, Pierre Giresse, Aymat Catafau, Caroline de Barrau et \\ Cécile Respaut
}

Ces travaux, menées dans le cadre du Programme Collectif de Recherches (PCR) PETRVS: "Identification et localisation des roches et des carrières utilisées dans la construction en Roussillon au Moyen Âge ", ont reçu un financement de l'Université de Perpignan-Via Domitia et de la Direction Régionale des Affaires Culturelles.

1 La roche qui nous intéresse ici est une brèche riche en débris schisteux du Paléozoïque, parfois émoussés, emballés dans un ciment siliceux et vivement colorée en rouge brun ou ocre jaune par les oxydes de fer. Elle n'a pas de nom vernaculaire dans les Pyrénées catalanes, preuve que son usage s'est perdu depuis très longtemps.

\section{Historique des recherches}

2 Cette roche fut signalée pour la première fois dans le "Répertoire géologique des églises du Conflent", inventaire exhaustif des matériaux composant les églises médiévales d'une large part du bassin de la Têt, établi sur la base de lames minces et publié en 2004 par Bernard Laumonier ${ }^{1}$. Identifiée dans l'église romane Saint-Pierre de Belloc, près de Vinça, en tant que «brèche sédimentaire miocène » (mais avec un point d'interrogation et pas de localisation connue), cette roche participe au décor bicolore du portail (fig. 1). Le monument fut pour l'essentiel bâti au XII ${ }^{\mathrm{e}}$ sì̀cle $^{2}$ à la limite entre bas Conflent et plaine du Roussillon dans un environnement strictement granitique. Or, bien que le substrat géologique de la moyenne et de la haute vallée du Conflent soit largement constitué par des formations paléozoïques qui ont donné leur nom aux séries régionales du Précambrien à l'Ordovicien ("schistes de Canaveilles» et « de Jujols»), 
aucune autre église de cette vaste contrée n'a utilisé de brèche composée de débris schisteux issus de ces formations et aucun affleurement de cette brèche n'est répertorié sur la nouvelle édition de la carte géologique.

Fig. 1. - Portails romans de la chapelle Saint-Pierre de Belloc, à Vinça (à gauche) et de Sainte-Marie du Mercadal, à Castelnou.
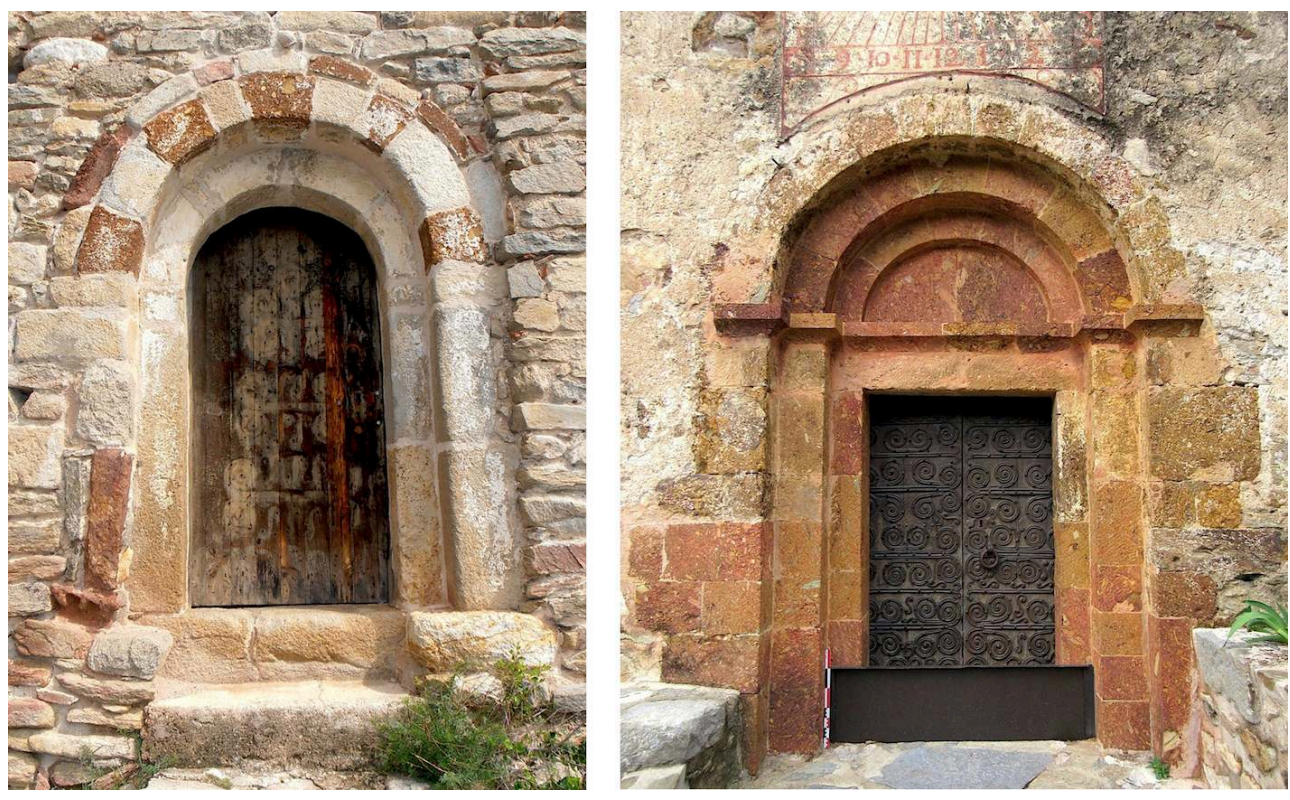

(C) C. Respaut.

3 C'est plus récemment et à Banyuls-sur-Mer, dans le massif des Albères, que la restauration de l'église Saint-Jean-l'Évangéliste (dite Rectoria) a attiré notre attention sur cette roche colorée qui armait les lésènes et l'encadrement des baies, composant le décor roman conservé dans l'abside, décor particulièrement spectaculaire lorsque le reste des murs restaurés fut enduit de chaux en $2015^{3}$. C'est là qu'a commencé notre recherche sur ce matériau d'origine inconnue. Mais c'est en amont de Banyuls, dans la vallée de la Baillaury, que se trouvent, vers $150 \mathrm{~m}$ d'altitude, les vestiges les plus parlants de cette roche où ils ornent le chevet de Sainte-Marie des Abeilles, datée du XI siècle.

4 La toute nouvelle carte géologique au 50000 des Albères (feuille Argelès) ne signalant pas de brèche semblable à l'affleurement, nous nous sommes tournés vers le monastère de Sant Quirze de Colera, situé en Ampourdan, au pied du versant méridional des Albères, car cette abbaye initia les noyaux de peuplement du versant nord à l'époque carolingienne. C'est l'un des plus anciens Monuments d'Intérêt National de Catalogne qui, longtemps laissé à l'abandon, fait désormais l'objet de restaurations et de fouilles archéologiques depuis une vingtaine d'années". S'il ne reste pas grand-chose hors sol des constructions primitives des $\mathrm{VIII}^{\mathrm{e}}-\mathrm{IX}^{\mathrm{e}}$ siècles et de la vaste église à nef unique du $\mathrm{X}^{\mathrm{e}}$ siècle, une grande partie du monument, reconstruit à la fin $\mathrm{du} \mathrm{XI}^{\mathrm{e}}$ siècle sur un plan basilical et consacré en 1123, est fort bien conservée. Tous les chaînages des angles, les arcatures, les lésènes, l'entourage des portails et des baies, ainsi que les chapiteaux du cloître, sont alors réalisés avec une brèche rouge sombre ou ocrée, brunie par la patine, qui lui donne un cachet exceptionnel (fig. 2). Par contre, suite à une probable secousse sismique $^{5}$, les reconstructions de la façade occidentale et d'une partie de la clôture du 
prieuré, à partir de la fin du XII ${ }^{\mathrm{e}}$ siècle, ne font plus appel qu'au seul schiste du substrat primaire, soigneusement taillé au ciseau et à la gradine, technique bien attestée avec les mêmes outils et sur la même roche pour construire, dans le massif des Aspres, l'église du prieuré de Serrabone, fondée en 1081, consacrée en 1151.

Fig. 2. - Abside de Sant Quirze de Colera.
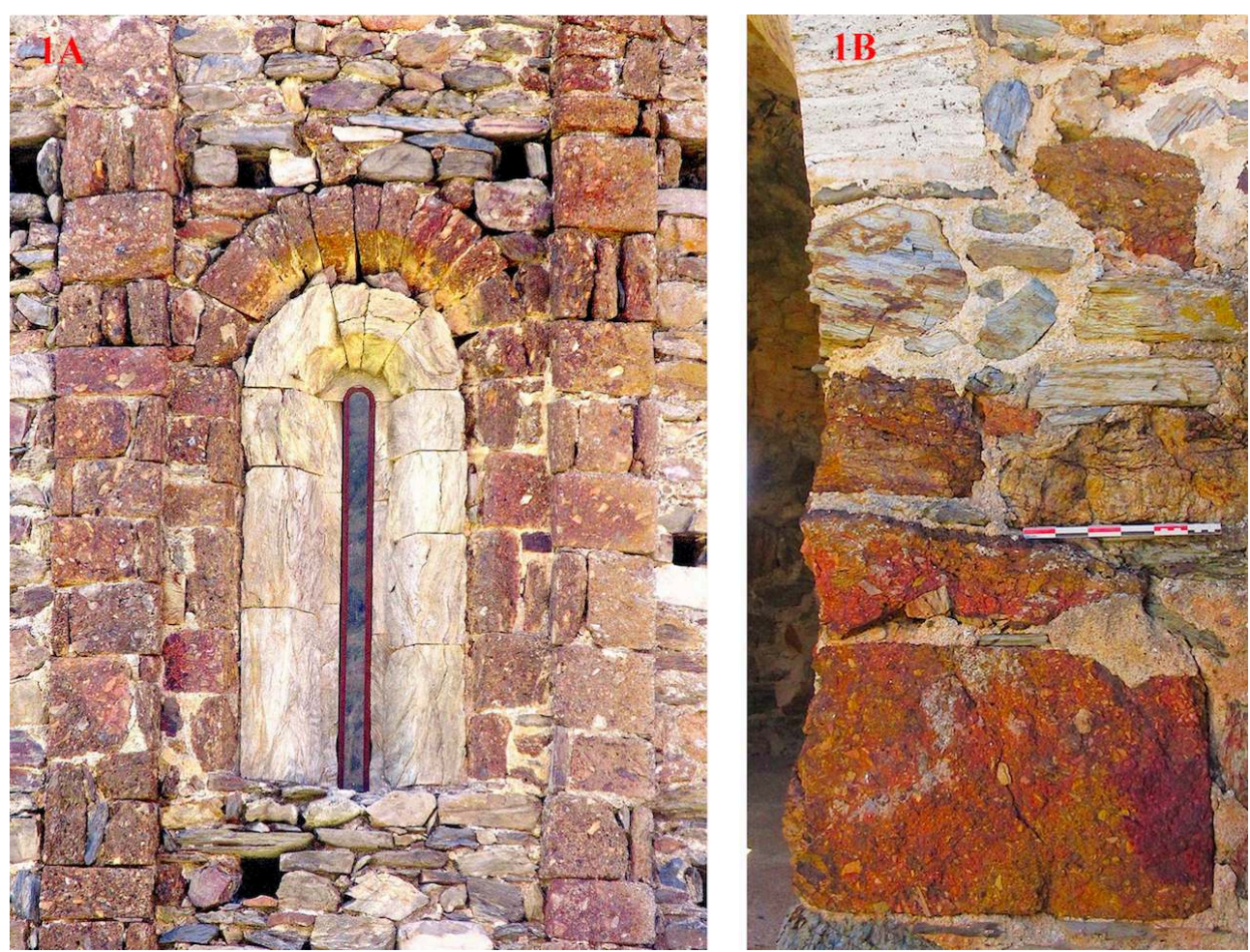

Contraste entre la brèche des lésènes, couleur rouille (1A), et l'étroite baie taillée dans un schiste pélitique local choisi pour sa pâleur ; arc triomphal de Sant Genis del Terrer où les montants en brèche rouge contrastent pareillement avec les travertins de l'arcature, ici restaurée (1B), le matériau patiné d'origine étant plus beige à gris.Contraste entre la brèche des lésènes, couleur rouille (1A), et l'étroite baie taillée dans un schiste pélitique local choisi pour sa pâleur ; arc triomphal de Sant Genis del Terrer où les montants en brèche rouge contrastent pareillement avec les travertins de l'arcature, ici restaurée (1B), le matériau patiné d'origine étant plus beige à gris.

(c) C. Respaut.

5 Étrangement, la plupart des églises romanes des $\mathrm{XI}^{\mathrm{e}}-\mathrm{XII}^{\mathrm{e}}$ siècles situées à proximité de Sant Quirze dans ce même contexte paléozoïque schisteux, en particulier celle du village voisin de Rabos, ne recèlent pas le moindre fragment de cette brèche colorée (fig. 3). Parmi les très rares églises qui en ont conservé la trace dans cette région, nous retiendrons la petite chapelle préromane de Sant Genis del Terrer, perchée sur une crête face au port de Llança, non loin du prieuré de Sant Pere de Rodes. Cet édifice de la fin du $\mathrm{x}^{\mathrm{e}}$ siècle a conservé un arc triomphal armé de montants soigneusement taillés dans une brèche rouge locale à clastes schisteux, très chargée en oxydes de fer (fig. 2). 
Fig. 3. - Répartition des affleurements et des sites ayant utilisé la brèche dans les anciens comtés catalans.

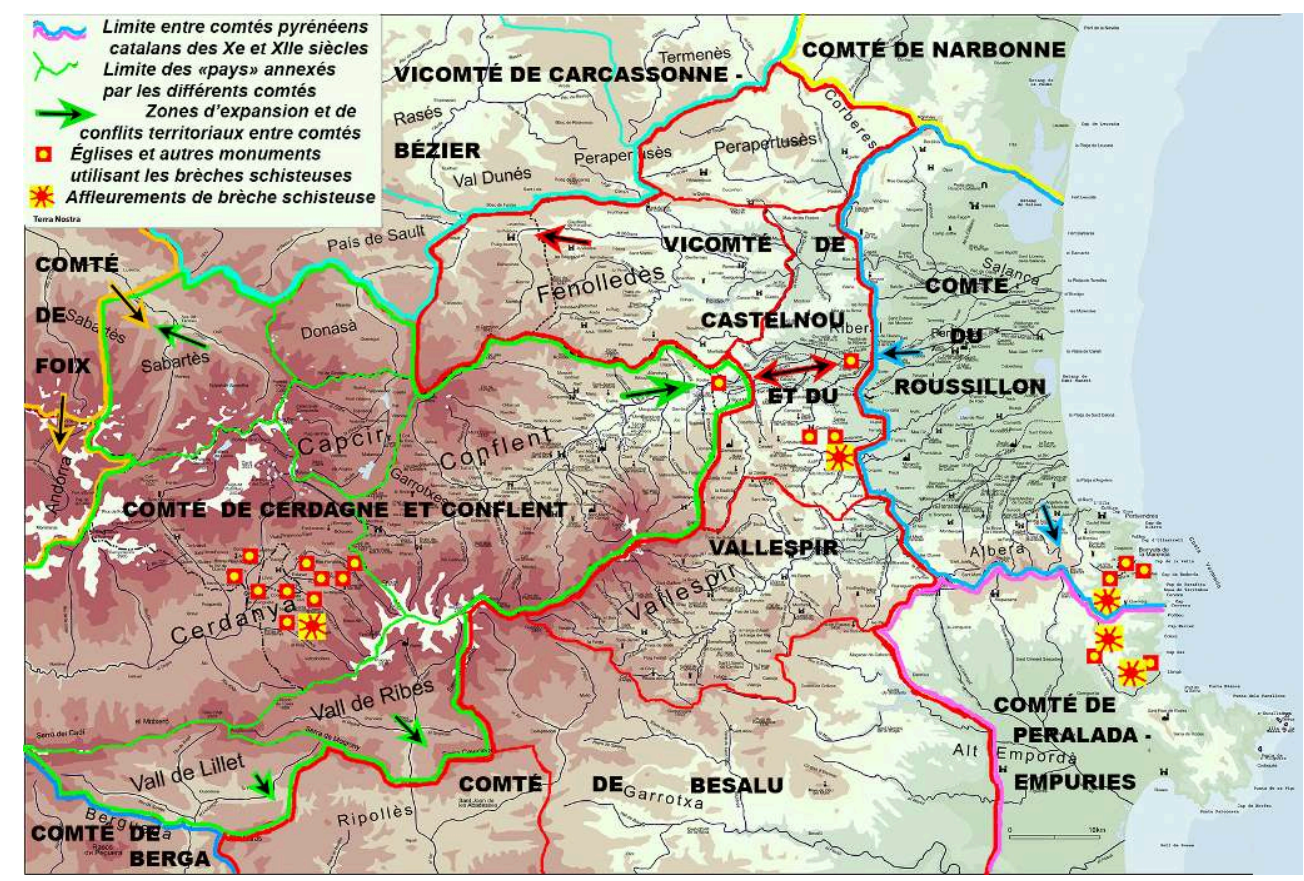

D’après Conseil départemental des P.-O., modifié. (c) DAO : M. Martzluff.

6 Sur le versant nord de la chaîne, aucune église de la plaine sédimentaire de l'ancien comté du Roussillon ne recèle ce type de matériau. Par contre, dans la région des Aspres, au pied du Canigou, les vestiges de la fortification primitive du château vicomtal de Castelnou, attestée aux $\mathrm{x}^{\mathrm{e}}$ et $\mathrm{xI}^{\mathrm{e}}$ siècle, comportent de très nombreux parements de brèche brun rouge à clastes schisteux. Il en est de même pour une tour située face à la forteresse (alt. $250 \mathrm{~m}$ ), et aussi pour l'église, Sainte-Marie du Mercadal, dont le beau portail roman est tout entier taillé dans cette roche (fig. 1). Curieusement, aucun des sanctuaires de cette zone schisteuse des Aspres qui, jusqu'en 1286, dépendait des vicomtes de Castelnou (avec le Vallespir), n'a conservé le moindre bloc de cette brèche dans ses murs. Toutefois, deux églises associables à ce comté, celle de SainteMarie de Belloc, déjà citée, et celle de Saint-André de Saint-Feliu-d'Avall, font exception. Éloignée du substrat schisteux, sur les berges de la Têt, bâtie sur les alluvions quaternaires, l'église de Saint-André a conservé, dans sa nef romane réutilisée comme transept lors d'un agrandissement $d u x{ }^{2}{ }^{e}$ siècle, toute une corniche réalisée en brèche à débris schisteux issue de Castelnou. Ce site se trouve dans un étranglement entre trois grands comtés : Besalu (dont dépendait la vicomté de Castelnou-Vallespir), Roussillon et Cerdagne-Conflent (fig. 3). Ce passage, convoité par les comtes du Roussillon et de Conflent, était très important pour les vicomtes de Castelnou, car il leur permettait de circuler librement vers leurs possessions des Corbières, en Fenouillèdes et vers le Perapertusès.

7 En montagne, alors que les églises du Capcir sont totalement dépourvues de cette brèche à clastes schisteux, c'est en Cerdagne que nous avons retrouvé les plus nombreux vestiges de l'emploi de ce type de matériau (fig. 4 et tabl. 1). Aux côtés de l'église de Sainte-Léocadie, qui en a conservé les traces préromanes les plus nettes, d'autres sanctuaires des $\mathrm{XI}^{\mathrm{e}}$ et $\mathrm{XII}^{\mathrm{e}}$ siècles ont réutilisé cette roche et assez nombreux sont ceux qui, remaniés ou reconstruits dans les temps modernes, en conservent 
encore quelques vestiges. À Err et à Sainte-Léocadie, près de gisements de matière première du Puigmal, il existe aussi quelques très rares fermes des $\mathrm{XVIII}^{\mathrm{e}}$ et $\mathrm{XIX}^{\mathrm{e}}$ siècles qui ont employé dans un portail ou dans des murs quelques parements d'une brèche semblable, quoique souvent violacée à noirâtre et comportant de nombreux fragments de quartz.

Fig. 4. - Carte de répartition des sites médiévaux ayant utilisé la brèche en haute Cerdagne, autour du massif du Puigmal.

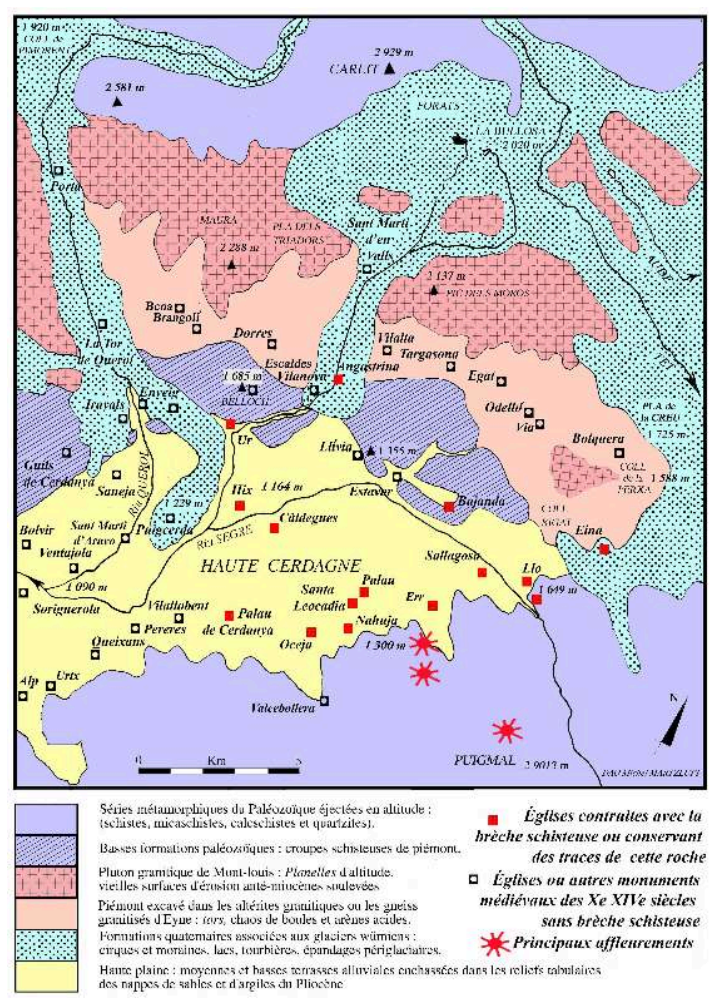

(c) DAO : M. Martzluff. 
Tabl. 1. - Liste des monuments médiévaux des P.-O. comportant la brèche brun rouge à ocre jaune à clastes schisteux et à ciments ferrugineux et siliceux.

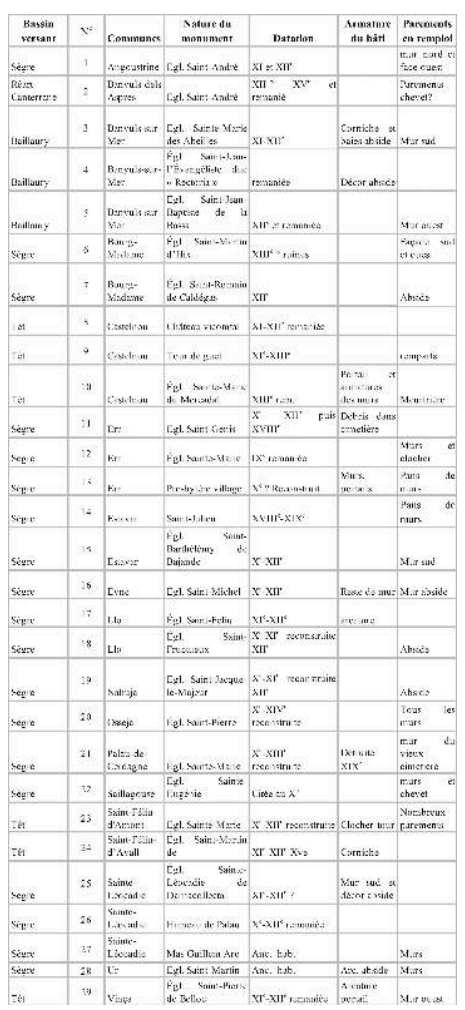

(c) M. Martzluff.

\section{Gisements et zones d'extraction}

La publication des travaux de fouilles menés à Sant Quirze de Colera ne mentionne pas l'origine des roches. Or, la rivière qui traverse le site charrie quelques petits galets de même nature que la brèche du monument. C'est légèrement en amont, de part et d'autre du cours d'eau, que nous avons identifié de petits affleurements résiduels de brèche, à la surface du socle schisteux. Dans ces affleurements d'origine sédimentaire, guère plus épais que $50 \mathrm{~cm}$, existent quelques fronts de taille très discrets et des blocs taillés épars.

Nous avons procédé de la même façon pour tenter de trouver cette roche sur le versant nord des Albères. Près de la chapelle Sainte-Marie des Abeilles, dans la vallée de la Baillaury, la rivière livre de nombreux galets de brèche identique à celle de Sant Quirze. Vers l'amont, alors que la rivière recoupe des affleurements de marbre cipolins gris du Précambrien et quelques amas de travertins quaternaires, les galets de brèche sont plus nombreux et de volume plus important (quelques-uns dépassent le mètre). Les versants étant fermés par un dense maquis, nous n'avons pu localiser les gîtes qui se trouvent sous le col de Banyuls. En réalité, les galets de brèche sont assez nombreux et de dimension suffisante dans l'alluvion de cette vallée pour satisfaire au volume des roches taillées dans les édifices médiévaux.

Dans les Aspres schisteuses, le ruisseau qui coule en contrebas du site de Castelnou comporte de petits galets de la même brèche et traverse en l'érodant un des affleurements qui a été exploité de façon opportuniste (un gros bloc comportant des 
traces de débitage est conservé dans le lit). À quelques mètres au-dessus, sur le versant de la rive droite, une coupe longeant la route laisse apparaître ces brèches. D'autres gisements existent sans doute dans le secteur où un maquis très dense rend la prospection difficile.

11 En Cerdagne, deux affleurements d'une brèche à clastes schisteux colorée par un ciment ferrugineux avaient été cartographiés sur la carte au 50000 (feuille de Saillagouse) ${ }^{6}$. Situés sur le flanc nord du massif du Puigmal, les gisements de cette roche, qui est bien plus dense qu'un travertin, sont trop éloignés en altitude pour avoir pu servir de source d'approvisionnement entre le $\mathrm{x}^{\mathrm{e}}$ et le $\mathrm{XII}^{\mathrm{e}}$ siècle. La rivière d'Err ayant livré quelques rares galets de brèche de même composition que ceux trouvés dans les Albères, galets absents des couvertures sédimentaires de la haute plaine cerdane, nous avons vite découvert une des sources d'extraction, tout près du village d'Err, au lieu-dit Fonts de la Devesa (fig. 5). Les affleurements se trouvent à moins de $10 \mathrm{~m}$ en surplomb du cours d'eau, sur un versant très abrupt qui a conservé des lambeaux de remplissage formés d'éboulis de pente et de galets alluviaux. Les parties cimentées, parfois épaisses de deux mètres, se trouvent au voisinage des sources ferrugineuses et sont en contact direct avec le substrat contre la pente du versant, alors qu'ils surmontent ailleurs des sédiments détritiques peu ou pas consolidés. L'exploitation a surtout raclé les zones les moins hétérogènes situées contre le substrat grésopélitique schisteux où les débris sont moins volumineux et le ciment plus solide. 
Fig. 5. - Zone d'extraction à Err.

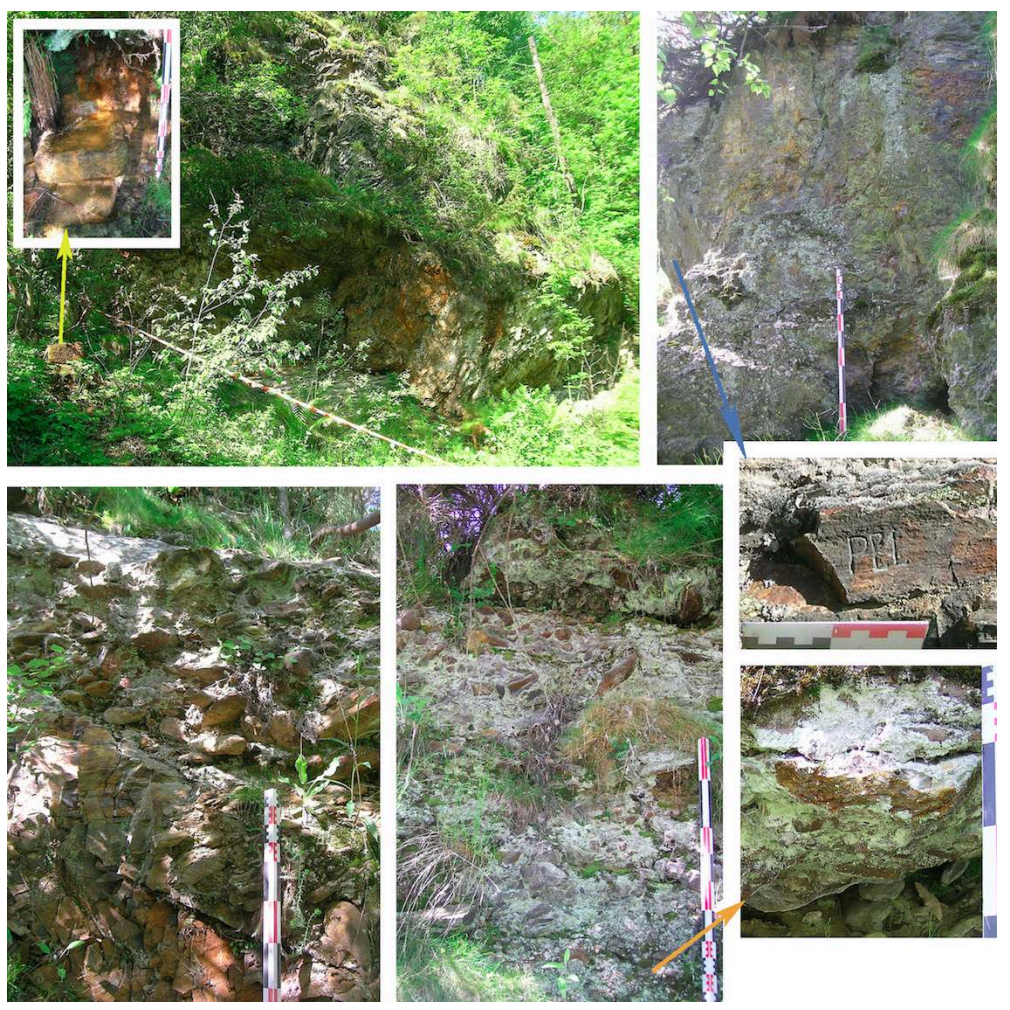

En haut à gauche, aspect général des affleurements sur un versant proche d'Err et, en médaillon, l'une des sources ferrugineuses captées dans un bassin. À droite, reste d'une excavation qui s'est arrêtée à l'encaissant schisteux et, en médaillon, une inscription sur celui-ci. En bas à gauche, front de taille dans une nappe de cailloutis et de galets cimentés qui repose sur le substrat schisteux. Au centre, vue du front de taille le plus épais où se mêlent des passées grossières et des passées plus graveleuses (en médaillon à droite où l'on aperçoit aussi la partie sédimentaire inférieure qui n'est pas indurée).

(c) C. Respaut.

Dans tous les sites, Banyuls, Sant Quirze de Colera, Castelnou et Err, la brèche étudiée est observée à la surface d'un substratum de schistes gris, lustrés, assez altérés et tendres avec des lits quartzeux intercalés. Ce substratum présente des caractères pétrographiques sensiblement identiques qu'il s'agisse des formations de l'Édiacarien, comme dans le lit de la Baillaury, de leur prolongement transfrontalier comme à Sant Quirze de Colera où ils sont cartographiés indistinctement d'âge cambro-ordovicien sur la carte géologique de Catalogne (2007), ou bien des schistes sériciteux de l'Ordovicien à Castelnou ou encore des schistes sériciteux et chloriteux également d'âge ordovicien de la région d'Err dans le sud de la Cerdagne. C'est donc sur des roches mères assez pareillement composées et dégradées et faiblement silicifiées que se sont accumulées les brèches dont le faciès et la composition sont presque invariables, c'est-à-dire des clastes schisteux gris clair à gris foncé dans un ciment généralement rouge sombre de nature à la fois ferrugineuse et siliceuse. Ce sont les mêmes brèches qui, à quelques faibles variantes près, ont été utilisées dans les monuments médiévaux des différents comtés pyrénéens catalans.

13 Une difficulté d'approche du terrain rend difficile l'observation d'une coupe complète de l'accumulation brèchique au-dessus de son substratum schisteux. Une opportunité nous est offerte près de Castelnou où un sol rouge atteignant $1,70 \mathrm{~m}$ d'épaisseur affleure au-dessus des schistes ordoviciens qui sont ici à la fois sériciteux et chloriteux. 
Une cuirasse rouge de $30 \mathrm{~cm}$, incluant de nombreuses plaquettes de schistes gris ordoviciens, est nettement individualisée et forme une banquette en relief au-dessus du saprolite. Le toit de cette même cuirasse affleure aussi à la surface du lit de la petite rivière en contrebas, à quelques centaines de mètres en allant vers Castelnou.

La cuirasse rouge brique, globalement bréchoïde, présente de nombreux clastes de schistes sériciteux gris clair de dimension millimétrique à centimétrique, généralement anguleux, parfois faiblement émoussés où se mêlent d'assez rares clastes quartzeux (fig. 6b). Latéralement, on trouve parfois des grands clastes de schistes noirs de près de $10 \mathrm{~cm}$ de diamètre qui ont résisté à l'altération. Dans la matrice, on observe fréquemment des cavités de glébules avec des cortex sombres violacés ou noirâtres, peut-être composés d'hématite. Ces pellicules sombres sont aussi reconnues à la surface de certaines masses indurées. La matrice est très fine avec des micro-parcelles de séricite. Par zone, on peut observer un peu en relief des micro-amas quartzeux parfois millimétriques qui constituent la charpente de cette brèche.

Le saprolite est assez bien exprimé sur une épaisseur d'environ $140 \mathrm{~cm}$ mais latéralement n'atteint plus que quelque $50 \mathrm{~cm}$. Il a été le site de quatre prélèvements sous la carapace : $-20 \mathrm{~cm},-60 \mathrm{~cm},-110 \mathrm{~cm}$ et $-160 \mathrm{~cm}$. C'est une accumulation assez indurée, mais pas très pierreuse (lithomarge ?). Ces prélèvements ont fait l'objet d'une granulométrie sommaire par voie humide permettant de séparer cinq fractions : les graviers (> $2 \mathrm{~mm}$ ), les sables grossiers ( 0,2 à $2 \mathrm{~mm}$ ), les sables fins (63 à 200 microns), les limons ( 2 à 63 microns) et les argiles ( $<2$ microns). La texture est toujours dominée par les graviers proches de $40 \%$, suivis par les sables grossiers proches de $20 \%$, les sables fins sont moins abondants ( 2 à $10 \%$ ) que les limons ( 20 à $25 \%$ ). Les argiles (en dessous de $2 \mu \mathrm{m}$ ) représentent moins de $5 \%$ de l'ensemble. La distribution verticale de ces fractions est assez homogène, si ce n'est à hauteur de $140 \mathrm{~cm}$ où l'on note une concentration des fractions fines (limons et argiles) qui passe de $27-29 \%$ à près de $46 \%$. 
Fig. 6. - Étude pétrographique.

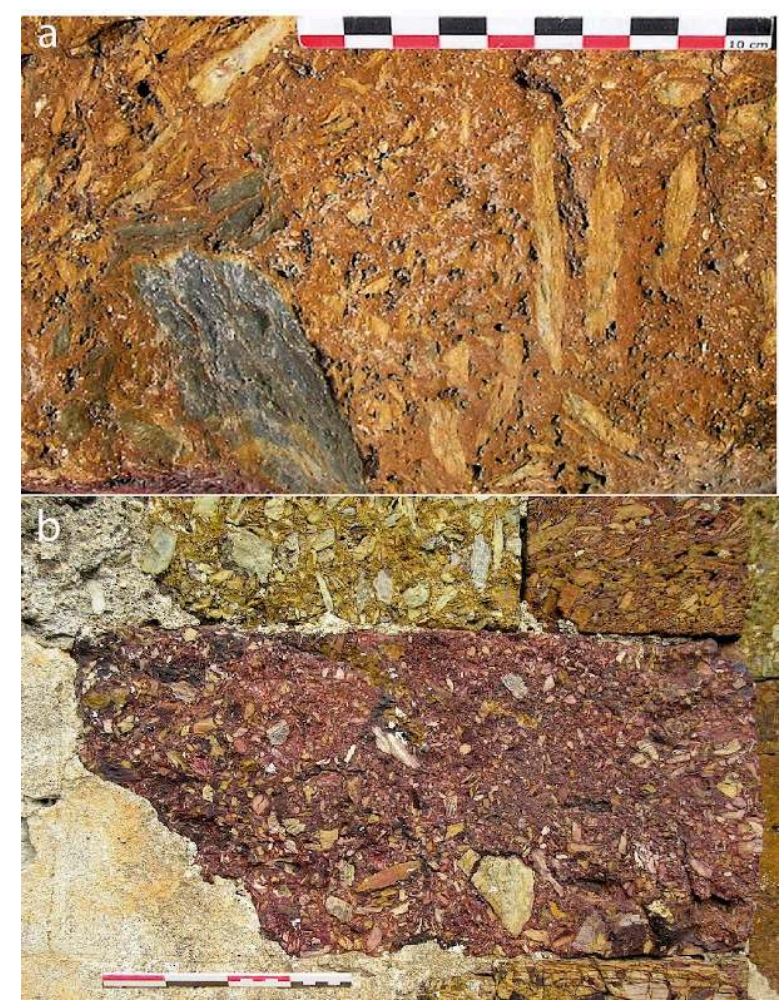

a : Baillaury. Distribution quelconque des clastes schisteux beige ocre (altérés) et gris foncé dans du ciment ferro-siliceux, nombreuses cavités ; b : Castelnou, église de Sainte-Marie du Mercadal ( $\|^{\mathrm{e}}$ siècle), le hasard de l'architecture superpose des pierres avec des ciments ferro-siliceux plus ou moins hydratés allant du rouge sanguin à l'ocre jaune.

(C) C. Respaut, DAO : P. Giresse.

16 La nature homogène de ces faciès brèchiques de Castelnou, observée en première approche macroscopique, se trouve confirmée par l'observation au microscope. À côté des clastes centimétriques, on trouve de nombreux petits clastes schisteux allongés et disposés de manière parfois parallèle, mais le plus souvent irrégulière (fig. $6 \mathrm{~b}$ et 7 ). Les schistes sont parfois dégradés (gris pâle) ou parfois bien conservés (gris foncé ou verdâtre) et sont accompagnés par des petits quartz. La matrice, opaque en lumière polarisée, est une argile fortement ferruginisée, de teinte ocre à rouge sombre, avec de nombreuses enveloppes (coatings) qui isolent des îlots ou qui définissent des micronodules pisolithiques à cortex multicouches (fig. $7 \mathrm{a}, 7 \mathrm{~b}$ et $8 \mathrm{a}$ ). Des amas de silice plus ou moins amorphe (fig. 7c) se sont développés dans le champ poral de l'horizon, donc après le processus de ferrallitisation. Mais celui-ci a pu se prolonger aussi après l'accumulation siliceuse comme en témoigne la présence de cutanes autour de plusieurs amas siliceux. 
Fig. 7. - Étude pétrographique.

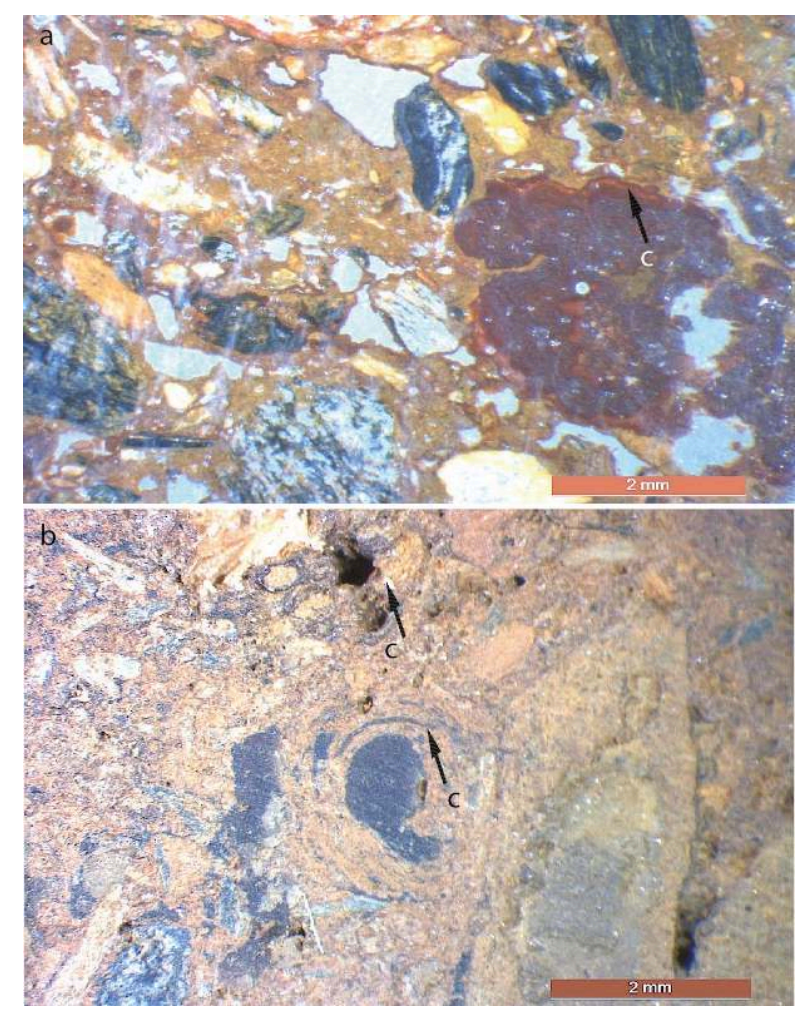

a : Sant Quirze de Colera, lumière polarisée, cutane (c) de goethite et d'hématite autour d'un granule hématitique ; $b$ : Baillaury, lumière naturelle, cutanes enveloppant des granules de diverses tailles dont le noyau a parfois disparu.

(c) P. Giresse. 
Fig. 8. - Étude pétrographique.

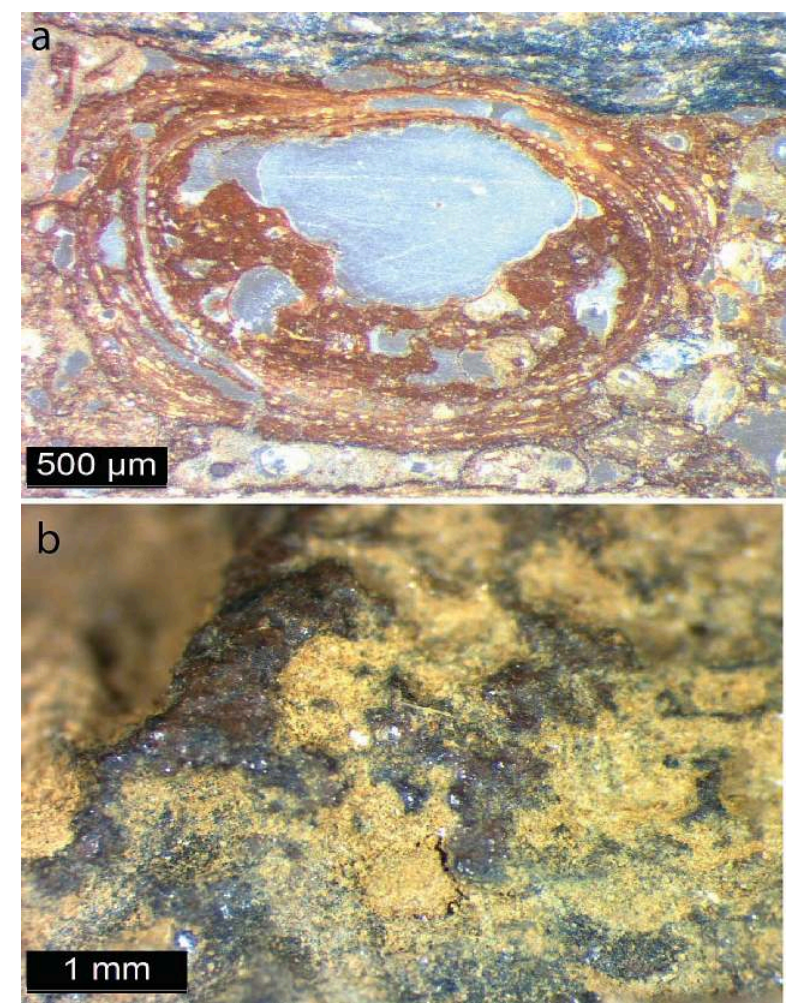

a : Baillaury, exemple de pisolithe ferrugineux à cortex multicouches, le noyau résiduel caverneux a été envahi secondairement par des dépôts siliceux (Si) ; b : Sant Quirze, de Colera, accumulation siliceuse (Si) en chou-fleur sub-affleurante sous la matrice.

(c) P. Giresse.

17 À Sant Quirze de Colera, on peut discerner différents types de structures plus ou moins plissotées des schistes, des débris quartzeux assez abondants et plusieurs concrétions ferralitiques à structure pisolithique, demeurant opaque en lumière polarisée. Le ciment peut-être localement siliceux et généralement amorphe, des îlots sont localement ourlés par des cutanes ferrugineux. La porosité de la roche est assez développée, les cavités mimant les formes allongées des clastes disparus.

Dans la haute vallée de la Baillaury, le microfaciès observé ressemble à première vue au précédent. Cependant le champ poral y est plus développé, les cavités sont celles d'anciens débris de schistes ou de nodules pisolithiques disparus (fig. 6b, 7c). Dans ces conditions, la trame siliceuse en toile d'araignée (fig. 8b) se trouve mise en évidence. Les cutanes figurent des structures en boxworks autour des vides libérés par les anciens noyaux. Localement, la matrice siliceuse est fortement développée avec une accumulation bothryoidale en forme de chou-fleur de taille presque millimétrique, la surface peut être blanc laiteux ou pigmentée par le fer ferrique (fig. 8), ou même recouverte par une pellicule ferrugineuse. Cette matrice parait généralement amorphe, mais parfois, on peut distinguer une nébuleuse de très petits cristaux de quartz.

L'âge de cette accumulation ferrifère et silicifiée observée sur plusieurs pentes schisteuses paléozoïques demeure une question latente à cette étude. L'instabilité des oxydes de fer et leur hydratation variable rendent a priori assez improbable des mesures isotopiques ou paléomagnétiques. En conséquence, c'est en fonction des acquis relativement récents sur l'évolution paléoclimatique méso-cénozoïque et plus 
particulièrement cénozoïque de la région que nous aborderons cette approche. Le dossier peut s'appuyer à la fois sur plusieurs observations régionales des surfaces d'érosion post-orogéniques au sommet des reliefs et de leurs sols altérés, des successions de processus karstiques et de quelques études de paléosols qui ont notamment donné naissance aux accumulations du Sidérolithique.

Pour Grandin et Thiry ${ }^{7}$, le Tertiaire n'a connu qu'une seule période de bauxitisation généralisée qui s'achève à l'oligocène inférieur et dont les témoins sont rencontrés jusqu'aux latitudes $40^{\circ} \mathrm{N}$ et $40^{\circ} \mathrm{S}$. Une grande période de ferruginisation a affecté la zone intertropicale entre le Miocène supérieur et le Pliocène supérieur. L'encroûtement siliceux affecte les pédiplaines qui tronquent des altérations et passent aux surfaces de dépôt des bassins. Deux grandes périodes de silicification sont connues au Tertiaire, l'une à l'Éocène supérieur-Oligocène et l'autre entre le Miocène supérieur et le Villafranchien. Cuirasses ferrugineuses et siltcrètes sont des formations à saisons contrastées s'inscrivant respectivement dans une séquence de l'aride vers l'humide et dans une séquence de l'humide vers l'aride.

Sur plusieurs hauts-reliefs des Pyrénées, surtout dans sa partie orientale, les restes de surface d'érosion ont été plusieurs fois observés ${ }^{8}$. Sur la base d'une approche stratigraphique et de mesures de thermochronologie dans des zones proches, il est conclu que surfaces et sols sont post-orogéniques, c'est-à-dire postérieurs à la dénudation éocène-oligocène ${ }^{9}$. Le développement de ces sols d'altération pourrait ainsi avoir été contrôlé par l'orogenèse pyrénéenne, leur développement ou leur conservation ont pu cesser autour de $10 \mathrm{~mA}$ où ils ont été l'objet d'une importante érosion assez générale, ce qui peut expliquer la très grande rareté de leurs témoins conservés.

\section{La brèche à clastes schisteux des églises de haute Cerdagne}

Sur une soixantaine de sites médiévaux cerdans connus sur ces hautes terres (ponts et fortifications compris), nous avons pu répertorier une quinzaine d'églises où les blocs de brèche ouvragés sont présents (tabl.1). Toutes sont situées en haute Cerdagne, c'està-dire dans la zone orientale qui fait partie du département des Pyrénées-Orientales (fig. 3). En basse Cerdagne, ce sont d'autres types de roches colorées qui sont employées dans les parties conservées des édifices préromans et du premier art roman, tout comme sur le versant sud de la chaîne, dans les Valls de Llilet et de Ribes, aujourd'hui situées dans le Ripollès et le Bergueda, mais à l'époque compris dans le comté de Cerdagne (fig. 2). Ce lot d'églises cerdanes ayant conservé les restes de brèche est plus dense à proximité du Puigmal d'Err où se trouve la source de matière première. Il constitue l'ensemble le plus important des Pyrénées catalanes et peut se diviser en cinq groupes :

- les rarissimes monuments qui conservent une partie de leur structure originelle des $\mathrm{x}^{\mathrm{e}}$ ou XI siècles employant la brèche colorée à clastes schisteux ;

- les églises citées au $\mathrm{x}^{\mathrm{e}}$ siècle dans l'acte de consécration de la Seu d'Urgell, mais reconstruites au $\mathrm{Xl}^{\mathrm{e}}$ siècle en remployant des blocs de cette brèche uniquement dans certaines parties de leur bâti le plus sacré, généralement le chevet, peut-être en « hommage » aux édifices antérieurs ; 
- les églises rebâties aux XII ${ }^{\mathrm{e}}$ et XIII ${ }^{\mathrm{e}}$ siècles, les plus nombreuses et qui, parementées en pierres de taille, principalement du granite, ne conservent dans leurs murs que quelques blocs de brèche épars ;

- les églises du piémont du Puigmal, profondément transformées à partir du XVII ${ }^{\mathrm{e}}$ siècle pour abriter de grands retables, qui ont réutilisé la brèche des structures médiévales antérieures dans le nouvel édifice ;

- les églises complètement détruites et reconstruites sur place ou ailleurs à la fin $\mathrm{du} \mathrm{XVIII}^{\mathrm{e}}$ et au XIX ${ }^{\mathrm{e}}$ siècle, mais dont il reste encore des éléments du bâti en brèche dans les murs ou dans le sol du cimetière qui les jouxtait.

Dans le premier groupe se placent l'église de Sainte-Léocadie et l'église paroissiale d'Err (Saint-Génis). Le hameau de Sainte-Léocadie est cité sous le vocable de Darnacollecta au $\mathrm{X}^{\mathrm{e}}$ siècle. L'église apparaît sous le nom de Santa Léocaia en 1034. L'édifice, remanié au $\mathrm{XIII}^{\mathrm{e}}$ siècle et par la suite, conserve d'importantes structures préromanes et du premier art roman qui font intervenir la brèche du Puigmal en élément décoratif (fig. 9). SaintGénis d'Err, l'une des deux églises du lieu citées au $\mathrm{x}^{\mathrm{e}}$ siècle, fut entièrement reconstruite à la fin $\mathrm{du} \mathrm{XVIII}^{\mathrm{e}}$, mais garde dans son chevet des éléments complets d'architecture en brèche correspondant à l'ancien bâti (fig. 10, n²).

Fig. 9. - Sainte-Léocadie.
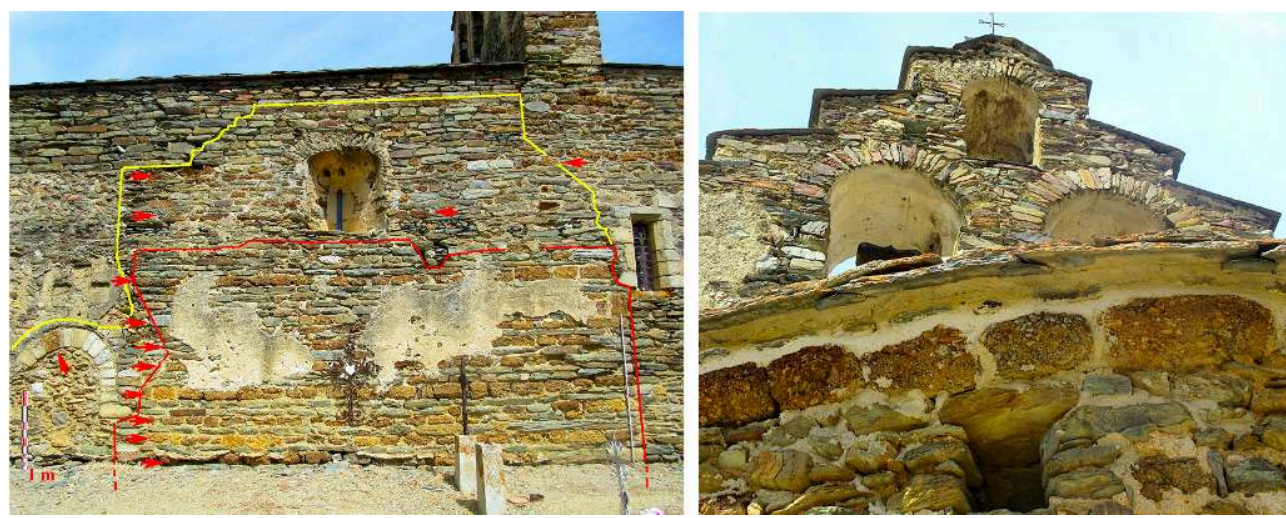

Sur le mur gouttereau sud de l'église Sainte-Léocadie de Dernacollecta, la surface encadrée en rouge correspond au mur primitif préroman conservé qui comporte des bandes de brèche (flèches rouges) alternant avec des assises de grésopélites primaires plus claires. La partie entourée en jaune, dont le portail, correspond à la construction citée en 1050 qui réutilise encore les rangées de parements de brèche, mais moins systématiquement, sauf sur la corniche du chevet (à droite). Remployant encore quelques blocs de brèche, le reste est remanié postérieurement.

(c) C. Respaut.

Au centre de la plaine, l'église Saint-Romain de Caldégas, fortement remaniée pendant les Temps modernes, mais qui conserve d'importants éléments architecturaux d'une reconstruction $\mathrm{au} \mathrm{XI}^{\mathrm{e}}$ siècle, entre dans le second groupe (fig. 10, $\mathrm{n}^{\mathrm{o}}$ 1). Plusieurs fragments de brèche sont épars dans le mur gouttereau nord et dans l'abside où la corniche a même été volontairement réalisée dans cette roche, peu visible après les restaurations. Des travertins et des briques sont également remployés pour assurer le décor des arcatures aveugles. Il en est de même pour Saint-Martin d'Ur et, dans une moindre mesure, pour Saint-Barthélemy de Bajande, très remaniée. 
Fig. 10. - Caldégas, Angoustrine, Err, Hix.

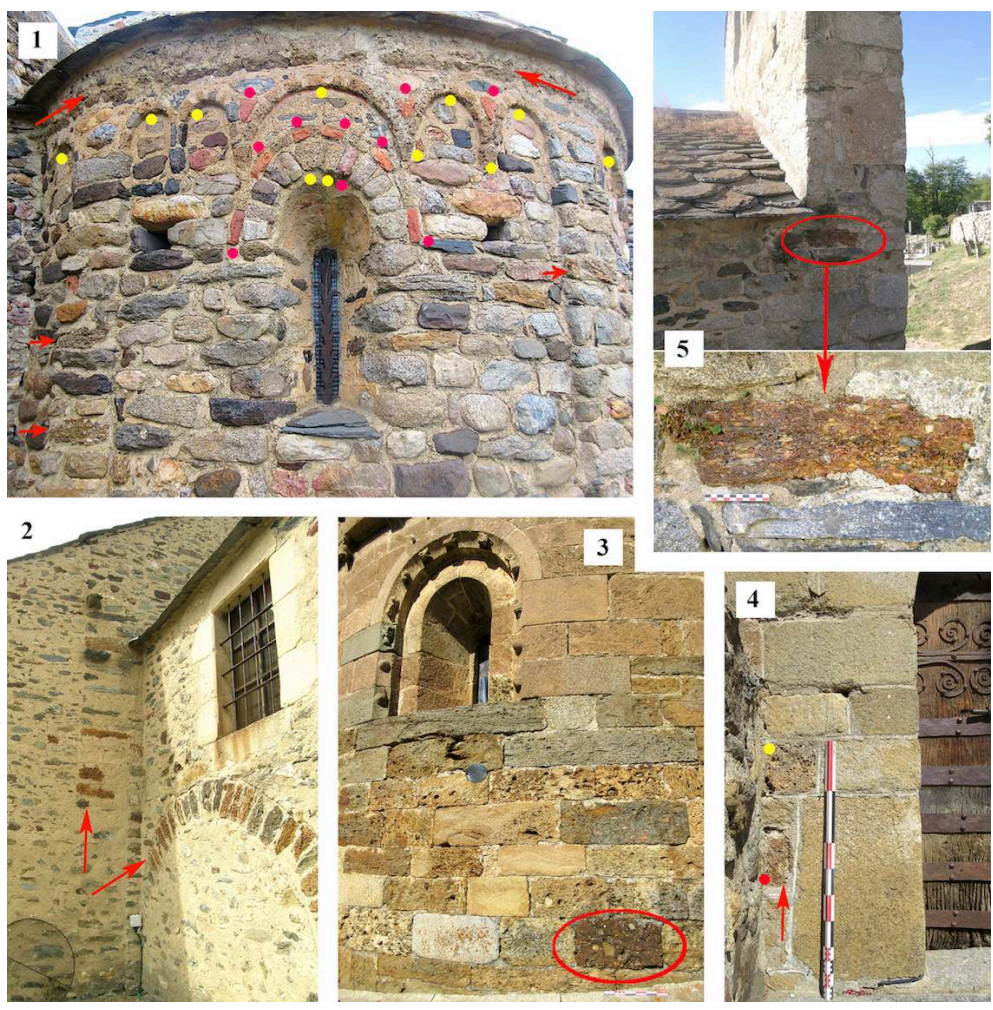

№ 1 : abside de l'église Saint-Romain de Caldégas faite de galets cassés au marteau et réutilisant au $\mathrm{xl}^{\mathrm{e}}$ siècle plusieurs roches de l'église antérieure : la brèche schisteuse sur toute la corniche et dans les lésènes (flèches rouges), les travertins des arcatures (ronds jaunes), matériaux qui furent associés à des briques (ronds rouges) pour créer un effet décoratif. № 2 : mur sud du chevet de l'église SaintGénis d'Err comportant les éléments en bréche de l'ancienne structure romane (flèches rouges). № 3 : l'abside romane de Saint-Fructueux de Llo, totalement parementée avec le calcaire dévonien local au $\mathrm{x}^{\mathrm{e}}$ siècle, expose en son centre un parement de brèche (cerclé de rouge) d'un probable sanctuaire antérieur. № 4 : près du portail de l'église de Saint-Martin d'Hix, un bloc de brèche (rond rouge) et un parement de travertin évoquent la construction antérieure, totalement refaite au xıe siècle. № 5 : parement de brèche (en médaillon) sur mur gouttereau nord de l'église romane de Saint-André d'Angoustrine, reconstruite au $x \|^{\mathrm{e}}$ siècle.

(C) C. Respaut.

Dans le groupe 3, les églises Saint-Fructueux de Llo (fig. 10, $\mathrm{n}^{\circ}$ 3), bâtie sous un piton calcaire, et Saint-Martin d'Hix (site de plaine sédimentaire où siégeait le pouvoir comtal ; fig. 10, $\mathrm{n}^{\circ} 4$ ), ainsi que Saint-André d'Angoustrine, située sur une moraine granitique (fig. $10, \mathrm{n}^{\circ}$ ) sont loin des substrats schisteux du Paléozoïque où se trouve la source de la brèche. Entièrement rebâties au XII ${ }^{e}$ siècle, leur architecture parementée avec des roches compactes et décorée de sculptures laisse peu de place à de rares parements en brèche à clastes schisteux, qui se trouvent en remploi. En l'absence de fouilles, ce sont sans doute les seuls témoins des édifices antérieurs cités par les textes.

Sainte-Marie d'Err (qui conserve sa pierre de consécration datée de 930), SainteEugénie de Saillagouse, Saint-Pierre d'Osséja et Saint-Jacques de Nahuja, sont toutes situées près du piémont schisteux du Puigmal et ont été entièrement reconstruites pendant les Temps modernes. Les remplois de brèche qui émaillent leurs murs, tout comme les éclats qui jonchent la surface de leurs cimetières, sont les seuls témoignages des sanctuaires primitifs. À Err et Nahuja toutefois, les plus grands parements de brèche schisteuse des structures médiévales ont été retaillés pour réaliser des baies ou des éléments d'architecture qui correspondent à l'édifice moderne. 
Dans le dernier groupe se place l'église médiévale Saint-Michel d'Eyne, détruite à la fin $\mathrm{du}$ XVIII ${ }^{\mathrm{e}}$ siècle pour faire place à un édifice nouveau. À l'extérieur, contre le mur gouttereau sud, près du chevet, reste un lambreau de voute conservé dans le talus et peu lisible. Par contre, les parements en brèche de l'ancien édifice, qui n'ont rien à voir avec le substrat granitique et gneissique de cette partie du massif, se retrouvent dans le mur du cimetière qui est situé en contrebas. Le cas de Sainte-Marie de Palau-deCerdagne, au centre de la haute plaine, est tout aussi significatif. L'église, reconstruite au sommet du village au xix ${ }^{e}$ siècle, se trouvait à l'origine près du cimetière, dans un vallon en contrebas. Là encore, seuls quelques éclats de brèche répandus au sol et un bloc inséré dans le mur de clôture peuvent témoigner de cet édifice préroman disparu.

\section{Bilan de la recherche}

La brèche présentée ici offre plusieurs qualités favorables. D’une part, elle est facile à tailler en usant modérément d'un outil tranchant emmanché de type polka, éventuellement d'une scie, car elle est formée d'une bonne part de schistes tendres. Mais elle ne peut pas se tailler comme une roche compacte, au risque de fractures très aléatoires (si l'on pioche la surface au pic, les plus gros émoussés se déboîtent). D'autre part, le ciment siliceux révélé par les analyses pétrographiques est très solide et offre dans l'ensemble une bonne résistance à la compression. Enfin, la coloration par les oxydes de fer est attrayante. Elle a pu servir de contraste au XII ${ }^{\mathrm{e}}$ siècle avec la pâleur d'autres roches, comme à Saint-Pierre de Belloc, mais elle est appréciée à ce titre bien avant, dès les $\mathrm{X}^{\mathrm{e}}$ et $\mathrm{XI}^{\mathrm{e}}$ siècles, comme à Sant Genis del Terrer et à Sant Quirze de Colera ${ }^{10}$.

Par contre, elle est très rare à l'affleurement sur les substrats schisteux des séries paléozoïques, bien développés dans la zone axiale des Pyrénées catalanes. Elle se trouve dans des talwegs en bancs peu épais et limités en surface, et paraît totalement absente de la vallée de la Têt en Conflent, du bassin de l'Agly dans les Corbières et du haut bassin de l'Aude en Capcir. L'usage de ce matériau suppose donc une bonne connaissance du substrat local, sans doute en rapport avec des progrès de l'agriculture (défrichements) et des prospections faites pour exploiter les petits gisements de fer.

Elle est utilisée à partir $\mathrm{du} \mathrm{x}^{\mathrm{e}}$ siècle au moins, en association fréquente avec les travertins de source, pour bâtir quelques églises préromanes au sud des Albères, près de la côte. Il n'y a aucun décalage chronologique entre ces constructions et les plus vieux édifices cerdans. L'extrême rareté de vestiges archéologiques plus anciens ne permet cependant pas de savoir si cet usage monumental provient d'ateliers nouveaux impulsés par les abbayes carolingiennes ou d'une tradition technique antérieure largement répandue. Au XI siècle, à Sant Quirze de Colera, ces brèches sont façonnées en parements réguliers, voire en chapiteaux lisses, probablement avec un large outil taillant, de type polka.

31 Cette ressource disparaît sur ce site, passé le premier quart du XII siècle, remplacé par une taille des schistes gréso-péliteux du substrat immédiat avec de nouveaux outils percutés (ciseaux, gradines) qui permettent une taille plus soigneuse de ces roches feuilletées (comme au prieuré de Serrabone). Ce nouvel outillage, lié à l'essor de la métallurgie du fer, facilite le dressage des parements dans des roches compactes, ainsi que la sculpture des marbres (apparition des chapiteaux ouvragés au cloître de SaintMichel de Cuxa). D'autre part, l'introduction systématique du débitage par coins 
permet alors d'employer des roches plus compactes, surtout les granites, dont l'usage s'étend depuis la seconde moitié du $\mathrm{XI}^{\mathrm{e}}$ au $\mathrm{XIV}^{\mathrm{e}}$ siècle à partir des ateliers de la Seu d'Urgell et d'Elne. L'extraction et la taille des brèches schisteuses colorées semblent uniquement se poursuivre dans le XII ${ }^{\mathrm{e}}$ siècle sur le bas versant les Aspres, à Castelnou. En Cerdagne, cet emploi ne semble pas dépasser le $\mathrm{x}^{\mathrm{e}}$ siècle, sauf sous une forme résiduelle rappelant l'architecture antérieure dans les absides $\mathrm{du} \mathrm{XI}^{\mathrm{e}}$ siècle (corniches) et reste cantonné en haute Cerdagne, dans l'orbe de diffusion des gisements du piémont du Puigmal.

Il est difficile enfin de voir d'autres influences que celles d'ordre matériel pour expliquer la présence dans les édifices médiévaux de cette brèche typique, quoique très mal connue. Seul un monument de la vicomté de Castelnou - l'église de Saint-André à Saint-Feliu-d'Avall - pourrait témoigner, dans le cadre des âpres affrontements féodaux des $\mathrm{XI}^{\mathrm{e}}$ et $\mathrm{XII}^{\mathrm{e}}$ siècles pour gagner du territoire entre comtés voisins, de l'influence conjoncturelle d'un centre de pouvoir via l'apport de ce type de matériau exogène.

En l'état actuel de recherches à poursuivre, cette roche monumentale nouvellement identifiée est un traceur intéressant pour l'étude archéologique des édifices médiévaux.

\section{BIBLIOGRAPHIE}

BABAUlt J., VAN DEN DRIESSCHE J., BONNET, CASTELlTORT S., CRAVE A., « Origin of the highly elevated Pyrenean peneplain », Tectonics, 24 (2), 2005, DOI : 10.1029/2004TC001697

CALVET M., GUNNELL Y., « Planar landforms as markers of denudation chronology : an inversion of East Pyrenean tectonics based on landscape and sedimentary basin analysis ", Geol. Soc. Lond. Spec. Publ., édition numérique, 296, 2008, p. 147-166. [URL : http://dx.doi.org/10.1144/SP296.10] CODINA I REINA Dolors, FARGAS BIBIANA Augustí, TEIXIDOR I MURLÀ Mireia, « Primers resultats de l'escavació de Sant Quirze de Colera », Tribuna d'Arqueologia, 8, 1997-1998, p. 145-163, 8 fig. GRANDIN G., THIRY M., « Les grandes surfaces continentales tertiaires des régions chaudes. Succession des types d'altération », Cah. O.R.S.T.O.M., sér. Géol., XIII, 1, 1983, p. 3-18. LLAC François, Notice explicative, carte géologique France (1/50 000), Feuille Saillagouse (1098), BRGM. 1989, 75 p.

LAUMONIER Bernard, LAUMONIER Alexandre : 2004, « Géologie et art roman : pierres romanes du Conflent (Pyrénées-Orientales) », dans M. MARTZLufF (dir.), Roches ornées, roches dressées. Colloque en Hommage à Jean Abélanet, Presses Universitaires de Perpignan, p. 483-496, 3 fig., 3 tabl.

MALLET Géraldine, Églises romanes oubliées du Roussillon, Montpellier, Les Presses du Languedoc éd., 2003,334 p et ill.

MARTZluff Michel, GIRESSE Pierre, CATAFAu Aymat, BARRAu Caroline de, ResPAUt Cécile, « Les roches des Pyrénées catalanes employées dans l'architecture entre l'Antiquité et le haut Moyen Âge : état actuel de la question », Archéo 66, vol. 31, 2016, p. 97-112, 20 fig. 
MARTZluff Michel, CATAFAu Aymat, GIRESSE Pierre, BARRAu Caroline de, « Les roches ornementales dans le domaine pyrénéen des rois de Majorque. Sources et usages : approches pluridisciplinaires ", Les pedreres medievals a la Corona d'Aragó, actes del Simposi internacional de Barcelona, 2013, ESPAÑOL BERTRAN Francesca et VALERO Juan (dir.), Institut d'Estudis Catalans éd., Barcelona, 2018, p. 53-88, 2 fig.

MONOD B., REGARD V., CARCONE J., WYNS R., CHRISTOPHOUL F., « Postorogenic planar paleosurfaces of the central Pyrenees : weathering and neotectonic records », Comptes Rendus Geoscience, Elsevier Masson, 348 (3-4), 2016, p. 184-193.

ORTUÑO M., MARTí A., MARTÍN-CLOSAS C., JIMÉNEZ-MORENO G., MARTINETTO E., SANTANACH P., «Palaeoenvironments of the Late Miocene Prüedo Basin : implications for the uplift of the Central Pyrenees », éd. numérique, J. Geol. Soc., 170, 2013, 79-92. [URL : http://dx.doi.org/10.1144/ jgs2011-121]

VANDERHAEGEN Bruno, « Banuyls-sur-Mer. Église de la Rectorie », Archéo 66. Bull. de l'A.A.P.-0., n 30, 2015, p. 29-30, 4 fig.

\section{NOTES}

1. Géologue ayant coordonné la nouvelle carte au $50000^{\mathrm{e}}$ (feuille Prades). Voir B. Laumonier et A. Laumonier , "Géologie et art roman : pierres romanes du Conflent (Pyrénées-Orientales) », p. 487 à 489. Voir aussi le poster sur le site Internet : http:// www.geologie-des-pyrenees.com/architecture-prehistoire/geologie-art-roman-pierres-romanesdu-conflent-poster

2. Pour la chronologie des églises présentées ici, voir principalement G. Malet, Églises romanes oubliées du Roussillon, p. 119-120, p. 159, p. 239 à 250.

3. B. Vanderhaegen, «Banuyls-sur-Mer. Église de la Rectorie », p. 29-30.

4. D. Codina i Reina et al., "Primers resultats de l'escavació de Sant Quirze de Colera », p. 146.

5. Le monument est placé sur une faille, bien visible dans le fossé nord.

6. Au sein des «Formations holocènes et actuelles »: $F=$ «concrétionnements ferrugineux »; voir F. Llac, « Notice explicative », p. 24.

7. G. Grandin et M. Thiry, «Les grandes surfaces continentales tertiaires des régions chaudes. Succession des types d'altération ».

8. J. Babaut et al., "Origin of the highly elevated Pyrenean peneplain. Tectonics »; M. Calvet et Grunnell, «Planar landforms as markers of denudation chronology: an inversion of East Pyrenean tectonics based on landscape and sedimentary basin analysis »; M. Ortuño et al., "Palaeoenvironments of the Late Miocene Prüedo Basin: implications for the uplift of the Central Pyrenees ».

9. B. Monod et al., «Postorogenic planar paleosurfaces of the central Pyrenees: weathering and neotectonic records ».

10. Sur la question de l'attrait ancien pour les roches vivement colorées en rouge et leur contraste avec le blanc dès une phase régionale tardo-antique, voir M. Martzluff et al., «Les roches des Pyrénées catalanes employées dans l'architecture entre l'Antiquité et le haut Moyen Âge : état actuel de la question ", p. 101-102. Cet attrait pour le rouge est évident dans l'architecture préromane, pour le comté du Roussillon avec les grès 
arkosiques clansayésiens dits "d'Espira », employés dans les plus vieux édifices (église Saint-Étienne du prieuré de Saint-Estève) et aussi avec les grès rouges siliceux du Permo-Trias qui jouent la même fonction décorative dans les sanctuaires des $\mathrm{x}^{\mathrm{e}}$ et $\mathrm{xl}^{\mathrm{e}}$ siècles du versant sud de la chaîne, depuis la Seu d'Urgell (ancienne église Sant Pere) et le Bergueda (Sant Vincenç de Rus), jusqu'à la Garrotxa (bases de la façade de Sant Feliu de Rocabruna et du clocher de Santa Cecilia de Molló). Voir à ce sujet M. Martzluff et al., « Les roches ornementales dans le domaine pyrénéen des rois de Majorque. Sources et usages : approches pluridisciplinaires ", p. 5 à 7.

\section{RÉSUMÉS}

Issue de la surface de plusieurs formations schisteuses paléozoïques des Pyrénées catalanes, une brèche ocre à rouge sombre est signalée et définie ici pour la première fois. Elle est caractérisée par des clastes de schistes sériciteux inclus dans un ciment silico-ferrugineux dont plusieurs structures témoignent d'un processus de pédogenèse ferrallitique qui pourrait remonter au Miocène. Elle a visiblement joué, $d u x^{e}$ au $x^{e}{ }^{e}$ siècle, un rôle de premier plan dans l'ornementation d'un petit groupe d'édifices médiévaux proches des rarissimes gisements. Dans les Albères et les Aspres, entre 100 et $250 \mathrm{~m}$ d'altitude, se détache un groupe de monuments prestigieux (monastère de Sant Quirze de Colera, château vicomtal de Castelnou des comtés de Peralada-Empuries et de Besalu-Vallespir). Mais le groupe le plus important se trouve au cœur de la chaîne, entre 1400 et 2000 m d'altitude, dans le comté de Cerdanya-Conflent. L'apparition précoce de cette roche dans ces sanctuaires montagnards interroge sur les motifs de son usage localisé et de son abandon au cours du XII ${ }^{\mathrm{e}}$ siècle.

\section{AUTEURS}

\section{MICHEL MARTZLUFF}

Maître de conférences à l'université de Perpignan Via Domitia, HNHP, UMR 7194

\section{PIERRE GIRESSE}

Professeur émérite à l'UPVD, CEFREM, UMR CNRS 5110

\section{AYMAT CATAFAU}

Maître de conférences au CRESEM-CHRISM, UPVD

\section{CAROLINE DE BARRAU}

Maître de conférences au CRESEM-CHRISM, UPVD

\section{CÉCILE RESPAUT}

Contractuelle INRAP-Méditerranée 


\title{
Les étangs de Grandmont :
} aménagement et exploitation hydrauliques des monts d'Ambazac (Haute-Vienne)

\author{
Christophe Cloquier
}

1 Disséminés dans les vallons des monts d'Ambazac, les étangs du Limousin ponctuent des paysages au relief modeste mais caractéristique du nord-ouest du massif central. Témoins imposants des activités anthropiques passées, ils conservent divers éléments associés, en creux ou en élévation, en grande partie dissimulés par une végétation abondante. Établis dans des vallons humides dépourvus, le plus souvent, de ru ou ruisseau, ils s'opposent aux versants et monts granitiques plus arides.

2 En 2013, à l'occasion de prospections archéologiques terrestres spécifiques, réalisées dans le cadre des recherches pluridisciplinaires menées sur l'abbaye chef d'ordre de Grandmont, neuf étangs furent identifiés et localisés dans la vallée de Grandmont, entre les hameaux des Sauvages et de Malessart, sur la commune de Saint-Sylvestre. Répartis en amont et en aval du hameau de Grandmont, ils forment une chaîne continue mais non homogène sur 1,6 km de long. Au fil des années, ils livrent des éléments et vestiges, complémentaires et diversifiés, obtenus par la multiplication des approches aériennes, subaquatiques et terrestres.

3 Témoins discrets d'un aménagement anthropique aussi important qu'impressionnant, les étangs de la vallée de Grandmont constituent la partie visible d'un paysage de montagne largement modifié par les populations rurales successives. Ainsi, en fonction de la période considérée et de la hauteur d'eau, ils permettaient certainement l'élevage de poissons dulçaquicoles, l'alimentation en eau de moulins ou l'irrigation des pentes herbeuses des vallons au fond desquels ils furent aménagés. 


\section{Des monts d'Ambazac aux vallons humides}

4 Majoritairement localisés dans le département de la Haute-Vienne et plus modestement celui de la Creuse, les monts d'Ambazac constituent une petite portion des contreforts du Massif central. Plus précisément, ils forment un massif montagneux modeste au cœur des monts de la Marche. Ils s'étendent sur un peu plus de $45 \mathrm{~km}$ d'ouest en est, pris entre les communes de Nantiat et Bourganeuf, et $17 \mathrm{~km}$ du nord au sud, pris entre les communes de Bessines-sur-Gartempe et Ambazac. Caractérisés par des sommets marqués mais peu élevés, ils présentent, d'ouest en est, des altitudes qui varient de $587 \mathrm{~m}$, sur la commune de Compreignac, à $552 \mathrm{~m}$, sur la commune de Monboucher, et culminent à $701 \mathrm{~m}$, au niveau du puy de Sauvagnac, sur la commune de Saint-Léger-la-Montagne. Ils présentent un relief homogène peu prononcé.

5 Sur le plan géologique, les monts d'Ambazac sont constitués de granites et de leucogranites, des roches magmatiques particulièrement dures qui se distinguent des micaschistes et des schistes, constitutifs d'autres monts de la Marche. De ce fait, sur le plan géomorphologique, ils forment donc un petit massif isolé avec un modelé dominant de paysage alvéolaire dégagé et vallonné, constitué de petites cuvettes à fond souvent humide et tourbeux. Sur le plan hydrographique, ils sont dépourvus de rivière. Toutefois, sur la commune de Saint-Léger-la-Montagne, à $605 \mathrm{~m}$ d'altitude, ils abritent la source de la Couze, un affluent de la Gartempe. En alimentant la Couze, qui s'écoule vers l'ouest puis le nord-ouest, ils sont donc évités par le cours de la Gartempe au nord, celui du Rivalier, un affluent du Taurion, à l'est, et enfin celui du Taurion, un affluent de la Vienne, au sud. En revanche, ils sont parcourus par une multitude de rus et ruisseaux qui alimentent un semis de plans d'eau ou en partent. Indirectement, les monts d'Ambazac alimentent donc en eau les deux rivières qui les bordent au nord et au sud.

6 Toutefois, en étant soumis aux fortes précipitations du climat océanique, les monts d'Ambazac peuvent recevoir une moyenne de $1200 \mathrm{~mm}$ d'eau par an, avec des épisodes neigeux récurrents et plus importants que dans la vallée voisine de la Vienne, au niveau de Limoges, située à $20 \mathrm{~km}$ au sud. De ce fait, avec un climat hivernal froid et humide, ils contribuent à la formation de tourbières particulièrement étendues, constituant alors d'immenses écosystèmes aussi particuliers que notables, ou, au contraire, beaucoup plus réduites dans les petites cuvettes humides, constitutives du paysage alvéolaire avec les bois et les pâturages. Avec cette association de relief, paysage et climat, les monts d'Ambazac constituent également en creux, au cœur du Limousin, une zone vallonnée et humide particulière.

7 Lors des prospections terrestres, différents plans d'eau, dont certains appelés étangs, furent repérés ou découverts dans cette vallée largement pourvue de végétaux hygrophiles, caractéristiques des zones humides. De l'amont vers l'aval, se succèdent l'étang des Sauvages, l'étang des Chênes, le Petit étang des Chênes, l'étang des Chambres, l'étang $\mathrm{n}^{\circ} 5$, l'étang $\mathrm{n}^{\circ} 6$ et l'étang de Malessart auquel sont accolées deux autres structures, appelées étang $\mathrm{n}^{\circ} 7$ et étang $\mathrm{n}^{\circ} 8$ (fig. 1). Exceptés les deux derniers, ponctuellement en eau, les autres étangs sont tous en eau et constituent donc une chaîne continue de l'amont vers l'aval: les eaux du premier étang finissant inévitablement dans le dernier étang. Il convient de souligner que cette numérotation des étangs, faite depuis l'amont vers l'aval du tronçon prospecté et étudié, suit le sens de l'écoulement des eaux de surface. 
Fig. 1. - Localisation des étangs sur la carte topographique de l'Institut géographique national $\mathrm{n}^{\circ}$ 2030 Ambazac au $1: 25000$.

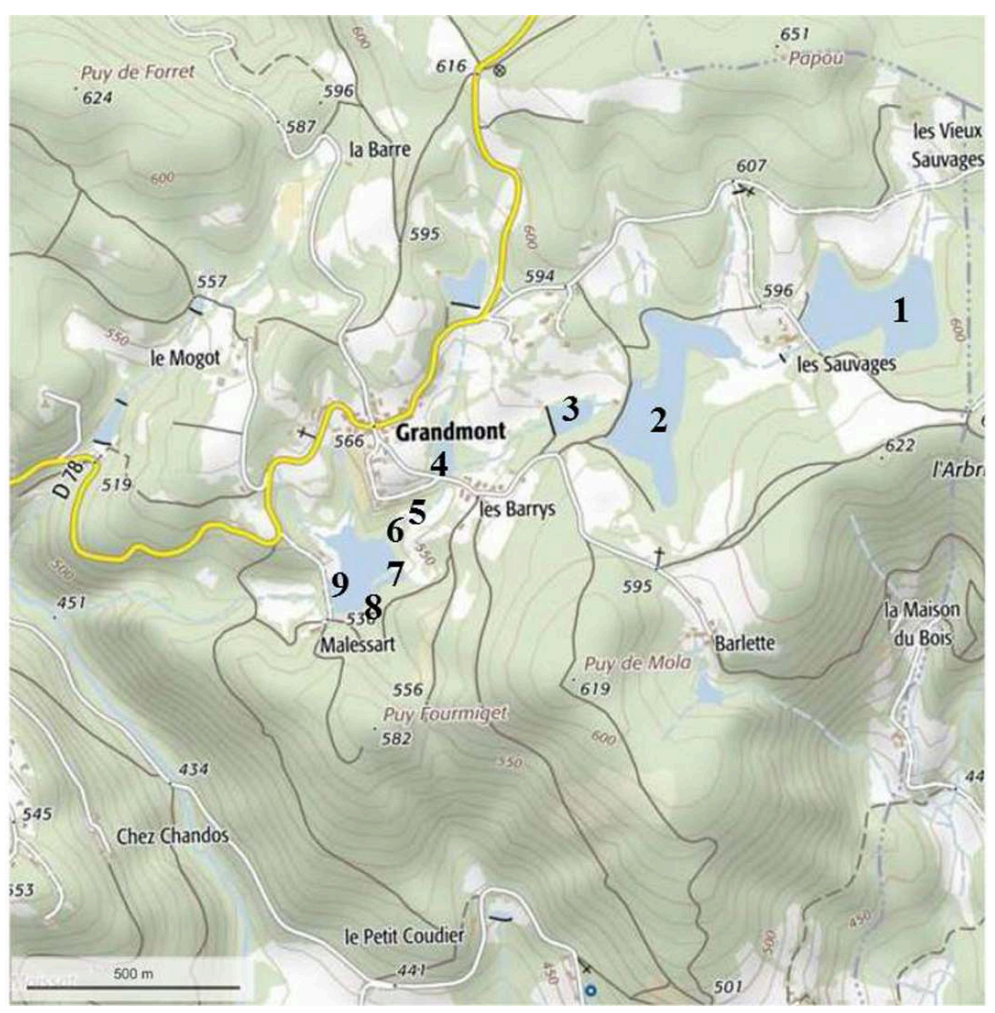

(C) IGN/Geoportail.

8 Alimentés par l'excès d'eau de l'étang immédiatement situé en amont, ces étangs sont naturellement remplis par les eaux pluviales et nivales voire, pour au moins deux d'entre eux, par les eaux du vallon humide qui les dominent. Ainsi, l'étang des Sauvages et l'étang des Chênes sont alimentés par les eaux qui sourdaient et sourdent encore dans le vallon humide, localisé en amont et au nord de chacun d'eux. Différents, aussi bien par la forme que par les caractéristiques, ces deux étangs, premiers maillons de cette chaîne, furent étroitement associés au vallon humide, qui les domine, par un réseau de drains, assurant le captage des eaux souterraines (fig. 2.). 
Fig. 2. - Vue aérienne du vallon humide, en amont de la queue de l'étang des Sauvages, avec le réseau de drains.

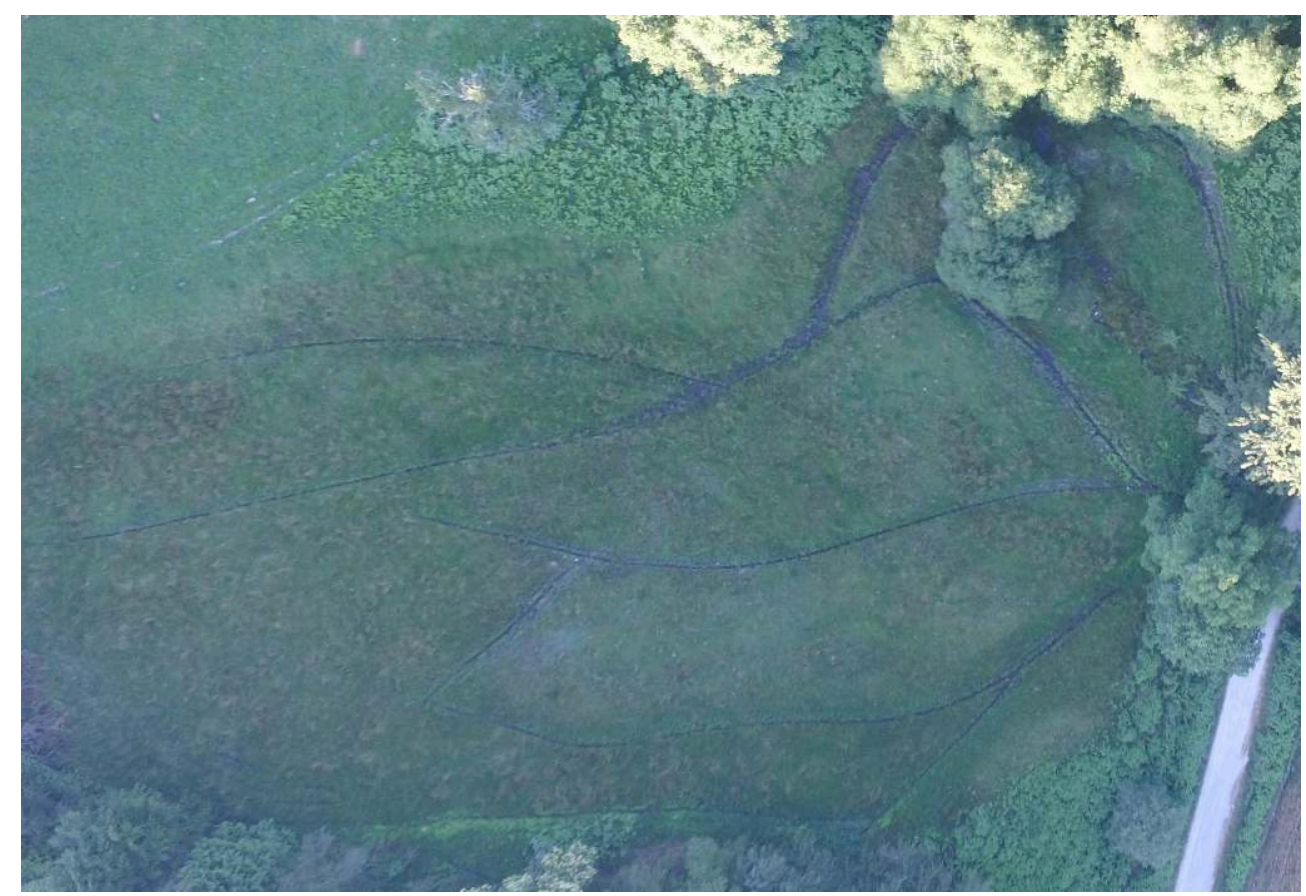

(c) Cliché S. Desruelles.

Peu visibles au sol, ces réseaux de drains furent réellement découverts et identifiés comme tels lors des prospections aériennes faites avec un drone au-dessus et autour de ces deux étangs. Éléments linéaires parallèles, ils sont établis dans le sens de la pente et convergent vers un collecteur unique qui descend ensuite, en suivant le fond du vallon, vers l'extrémité amont de chaque étang. En amont de l'étang des Sauvages, sur le versant ouest du vallon, l'un de ces drains fut partiellement dégagé de la végétation hygrophile en décomposition et des limons tourbeux pléistocènes. Il est constitué de deux rangées parallèles de blocs de granit, formant un conduit pour l'écoulement de l'eau, recouvertes de blocs de granit plats, formant une protection contre le comblement du conduit et le déchaussement des blocs. Manifestement, il servait au captage et à la collecte des eaux qui s'écoulent encore sur les pentes.

Sur le même versant mais plus au nord, un puit encore rempli d'eau fut découvert à la limite de la zone boisée. Entièrement constitué de petits blocs de granit maçonnés, il est doté d'une couverture qui le préserve des chutes de feuilles et brindilles. Difficilement datable, il pourrait être associé aux vestiges du hameau des Vieux Sauvages, localisés à l'est sur le versant opposé. Témoin discret et indirect de l'occupation humaine du versant de ce vallon humide, il pourrait toutefois illustrer la maîtrise du captage et l'utilisation des eaux souterraines pour la consommation humaine dans cette partie des monts granitiques, en amont de la vallée de Grandmont, réputée désertique lors de l'arrivée des disciples d'Étienne de Muret au début du XII ${ }^{\mathrm{e}}$ siècle.

11 Dans l'attente des résultats d'archéologie extensive, engagée par Philippe Racinet, autour de l'abbaye chef d'ordre de Grandmont, les sources documentaires constituent, en dépit des destructions massives de documents consécutives à la dissolution de l'ordre, un recours inévitable et nécessaire. De manière inégale et fragmentaire, elles 
livrent des informations ténues et dispersées ${ }^{1}$. Ainsi, sur le plan parcellaire cadastral de Saint-Sylvestre, daté de 1813, figurent le hameau des Sauvages, localisé au niveau de l'actuel hameau des Vieux Sauvages, l'étang des Sauvages, l'étang des Chênes, un canal de jonction, le Petit étang des Chênes, le hameau des Chênes, aujourd'hui disparu mais localisable au sud du Petit étang des Chênes, l'étang des Chambres, le hameau de Grandmont, un canal de jonction, l'étang de Malessart, le hameau de Malessard et un canal rectiligne qui méandre ensuite, appelé ruisseau de Malessard à Grandmont ${ }^{2}$.

Le 27 décembre 1790, lors de la mise en vente de la maison de l'abbaye de Grandmont avec les prés, terres, bois et la réserve, au titre des biens nationaux, trois étangs, appelés le Sauvage, le Malessart et les Chambres, avec un petit moulin au-dessous de ce dernier, furent mentionnés ${ }^{3}$. Le même jour, les deux étangs des Chênes, appartenant à la métairie des Chênes, furent également mentionnés et vendu en un seul $\operatorname{lot}^{4}$. Sur un plan de la matrice du rôle de la paroisse de Saint-Sylvestre pour les années 1780 à 1790, l'étang des Chambres, le canal d'évacuation des eaux et la partie supérieure de l'étang de Malessart, furent représenté avec une partie du hameau et du terroir de Grandmont ${ }^{5}$. Enfin, sur la carte de Cassini, établie et éditée en 1768, furent représentés le hameau des Sauvages, localisé au niveau de l'actuel hameau des Vieux Sauvages, les quatre premiers étangs, reliés entre eux par un canal de jonction, le hameau du Chêne, localisable au sud du troisième étang, le village et l'abbaye de Grandmont, et un dernier étang, à l'emplacement de l'étang de Malessart. Tous ces étangs étaient associés à une digue (fig. 3).

Fig. 3. - Extrait de la carte de Cassini, no 32 Le Dorat. Vers 1768.

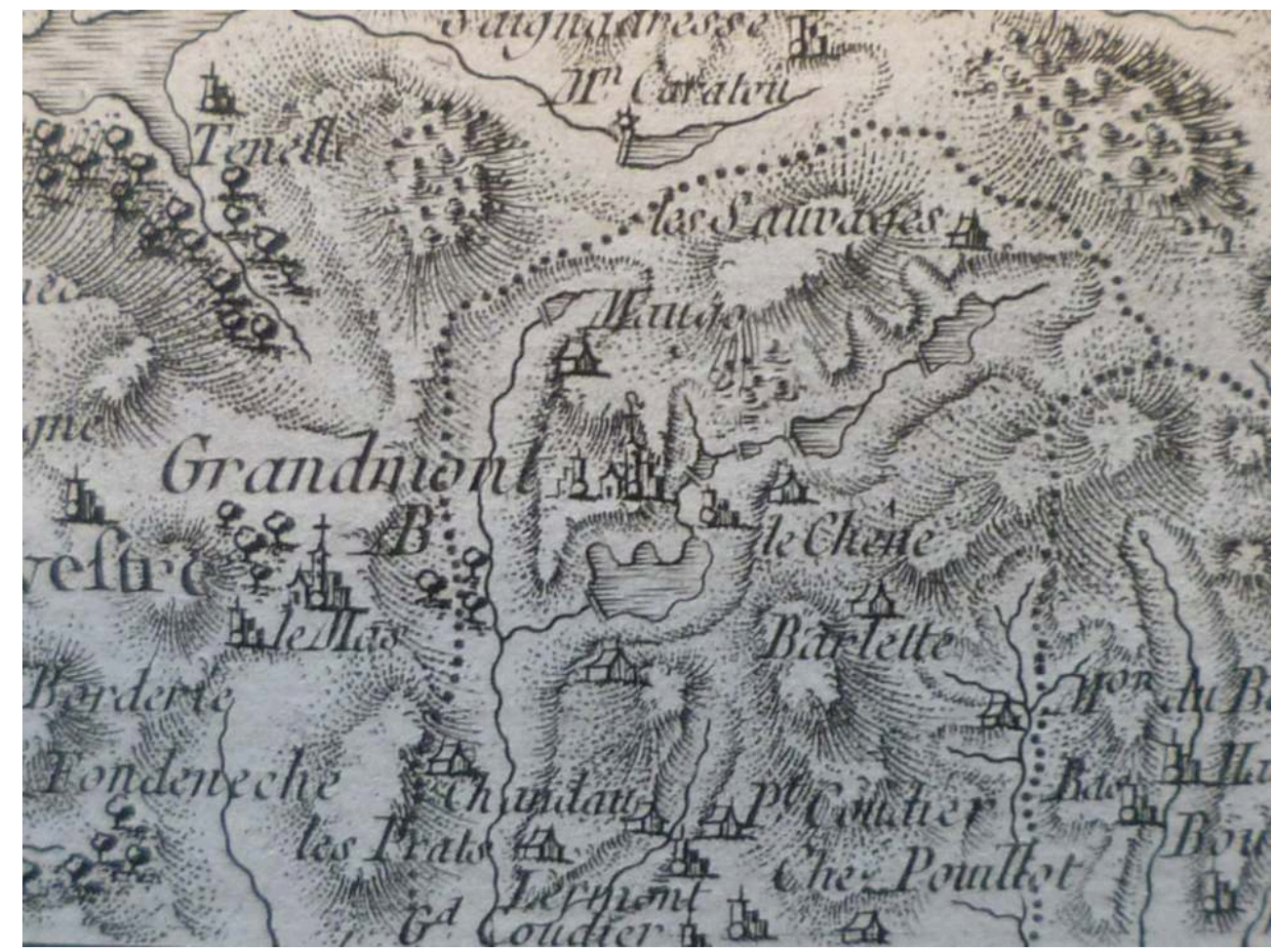

(c) Cliché C. Cloquier.

13 À ces informations de la seconde moitié $d u$ XVIII ${ }^{e}$ siècle et du début du xIXe siècle, doivent être ajoutées quelques informations antérieures. Après la mort d'Étienne de Muret, survenue le 8 février 1125, les religieux de Muret reçurent du seigneur de 
Montcocu les bois qui couvraient les montagnes de Grandmont pour leur installation dans la vallée ${ }^{6}$. Établis dans un premier monastère, ils reçurent ensuite de l'abbé de l'abbaye Saint-Martial de Limoges, probablement avant son décès en 1143, sa part de dîme sur le village et la tenure des Sauvages, assis et situés à côté des forêts et bois de Grandmont ${ }^{7}$. En 1194, ils reçurent également d'un bourgeois de Limoges, le mas et l'étang des Sauvages ${ }^{8}$. Avec ces quelques informations relatives au XII siècle, il est donc possible de restituer une partie du paysage, des habitats et des aménagements présents lors de l'arrivée des religieux de Muret dans la vallée de Grandmont, jusqu'à présent qualifiée de désert.

\section{De la découverte fortuite à l'étude exhaustive}

Lors des prospections archéologiques terrestres de 2013, neuf étangs furent donc identifiés dans la vallée de Grandmont. Étagés dans le fond de cette vallée, tous répondent à un schéma général comparable : un plan d'eau artificiel retenu par une digue, constituée de blocs de granit, avec une profondeur et une superficie proportionnelles à la hauteur et la largeur de cette digue. Toutefois, ils présentent tous des dimensions, des formes et des orientations différentes. Presque tous entourés ou dissimulés par de hauts arbres, ils sont difficilement visibles dans leur totalité, même par voie aérienne, et ne sont pas tous facilement accessibles, excepté au niveau de la digue. Si l'étang des Sauvages, l'étang des Chênes, le Petit étang des Chênes, l'étang $\mathrm{n}^{\circ} 5$ et l'étang de Malessart illustrent l'importance des aménagements en eau, l'étang des Chambres, les étangs $n^{\circ} 6,7$ et 8 sont le plus souvent à sec et largement encombrés d'une végétation abondante qui limite les mesures et observations.

Pour ces étangs, les longueur, largeur et superficie furent mesurées sur le plan parcellaire cadastral actuel, la profondeur fut mesurée en plongée ou estimée, la hauteur de la digue et la largeur du sommet de la digue furent mesurées sans enlèvement des végétaux. 
Tabl. 1. - Caractéristiques des étangs de la vallée de Grandmont.

\begin{tabular}{|c|c|c|c|c|c|c|}
\hline $\begin{array}{l}\text { Nom de } \\
\text { l'étang }\end{array}$ & $\begin{array}{l}\text { Longueur } \\
\text { maximale } \\
\text { en } \mathrm{m}\end{array}$ & $\begin{array}{c}\text { Largeur } \\
\text { maximale } \\
\text { en } \mathrm{m}\end{array}$ & $\begin{array}{l}\text { Profondeur } \\
\text { maximale } \\
\text { en } \mathrm{m}\end{array}$ & $\begin{array}{c}\text { Superficie } \\
\text { approximative } \\
\mathrm{en}^{2}\end{array}$ & $\begin{array}{c}\text { Hauteur de } \\
\text { la digue } \\
\text { en } m\end{array}$ & $\begin{array}{c}\text { Largeur de } \\
\text { la digue } \\
\text { en } m\end{array}$ \\
\hline $\begin{array}{l}\text { Étang des } \\
\text { Sauvages }\end{array}$ & 330 & $\begin{array}{c}250 \text { (amont) } \\
215 \text { (aval) }\end{array}$ & 6,5 & 45900 & 4,5 & 4 \\
\hline $\begin{array}{l}\text { Étang des } \\
\text { Chênes }\end{array}$ & 135 & 450 & 7,5 & 45700 & 6 & 6 \\
\hline $\begin{array}{l}\text { Petit étang } \\
\text { des Chênes }\end{array}$ & 105 & 65 & env. 3,5 & 5600 & 4 & 4 \\
\hline $\begin{array}{l}\text { Étang des } \\
\text { Chambres }\end{array}$ & 150 & 45 & env. 4 & 9800 & 5 & 9 \\
\hline Étang $n^{\circ} 5$ & 25 & 30 & env. 3 & 850 & 3 & 3 \\
\hline Étang $n^{\circ} 6$ & 15 & 20 & env. 1 & 830 & 1 & 3 \\
\hline Étang $n^{\circ} 7$ & 15 & 25 & env. 2 & 205 & 2 & 3,5 \\
\hline Étang $n^{\circ} 8$ & 20 & 25 & env. 2 & 830 & 2,5 & 3 \\
\hline $\begin{array}{l}\text { Étang de } \\
\text { Malessart }\end{array}$ & 175 & 185 & env. 5 & 19300 & 6 & 9 \\
\hline
\end{tabular}

() Réalisation C. Cloquier.

16 Les cinq premiers étangs et l'étang de Malessart sont contenus par une digue de section trapézoïdale, constituée de deux parements obliques de blocs de granit et d'un noyau imperméable non identifié. En revanche, les étangs $\mathrm{n}^{\circ} 7$ et $\mathrm{n}^{\circ} 8$ sont contenus par une digue de section rectangulaire, constituée de deux parements verticaux de blocs de granit et d'un noyau imperméable non identifié. Enfin, l'étang n ${ }^{\circ} 6$ est contenu par une digue de section trapézoïdale rectangle, constituée d'un parement vertical de blocs de granit, vers l'intérieur, et d'un talus de limons formant un noyau imperméable visible, sur toute la largeur, au niveau d'une brèche. Manifestement, ces trois derniers étangs présentent non seulement des dimensions, une profondeur et une superficie modestes mais sont également retenus par une digue au profil différent. Ils auraient pu avoir des fonctions différentes ou appartenir à une période d'aménagement différente; ils sont également dépourvus des éléments complémentaires.

En effet, un ou deux systèmes maçonnés, appelés vannes, équipaient et équipent encore la digue des cinq premiers étangs et de l'étang de Malessart afin d'en vidanger les eaux. À raison de deux par digue, ces vannes répondent toutes un schéma général comparable : deux murs, constitués de blocs de granit maçonnés, conduisent les eaux de l'étang vers un conduit de section quadrangulaire fermé par une pelle en bois, munie d'un long manche pour la manœuvrer depuis la surface. Toutefois, elles présentent toutes des dimensions, des formes et des implantations différentes en fonction des caractéristiques et dimensions de la digue et donc de l'étang associé. Cependant, la première, appelée vanne haute, affleure toujours à la surface de l'eau et la seconde, appelée vanne basse, atteint toujours la profondeur maximale de l'étang.

Ainsi, pour l'étang des Sauvages, la vanne haute, localisée dans la partie droite de la digue, est accessible depuis le chemin qui surmonte la digue (fig.4). Entièrement 
composée de blocs de granit maçonnés, elle forme un ensemble massif immergé de 3,30 $\mathrm{m}$ de haut. Elle présente sept parties distinctes, identifiées de la digue vers l'étang : la rampe d'accès, le sommet, la pelle, la chambre, le radier, l'aile droite et l'aile gauche (fig. 5). Accessible par une rampe inclinée de 3,8 de long, 0,43 à $0,46 \mathrm{~m}$ de large, la vanne haute possède un sommet composé de deux linteaux, assemblés par des agrafes métalliques scellées au plomb, qui maintiennent le manche de la pelle à la verticale. Cette vanne haute est repérable par le manche métallique de la pelle, à savoir un fer plat de $0,05 \mathrm{~m}$ de largeur et $0,02 \mathrm{~m}$ d'épaisseur, qui enserre une plaque en bois rectangulaire de $0,50 \mathrm{~m}$ de hauteur, $0,44 \mathrm{~m}$ de largeur et $0,05 \mathrm{~m}$ d'épaisseur destinée à fermer un conduit de vidange, de section quadrangulaire, positionné à $3,5 \mathrm{~m}$ de profondeur. Au niveau de ce conduit, elle est composée d'une chambre trapézoïdale, de $3,10 \mathrm{~m}$ de hauteur, 0,42 à $0,44 \mathrm{~m}$ de largeur et $0,62 \mathrm{~m}$ de profondeur, qui supporte les deux linteaux du sommet et possède un linteau horizontal à mi-profondeur. La vanne haute est également constituée d'un radier mixte, composé, de l'aval vers l'amont, d'un dallage, sur une longueur de 3,20 m, d'une rangée de blocs de 0,60 m de large et d'une couche compacte de cailloux et de sable, délimitée et stabilisée par une pièce de bois de $1,40 \mathrm{~m}$ de long et $0,60 \mathrm{~m}$ de large. Avec une aile gauche, constituée d'un mur de $8,20 \mathrm{~m}$ de long, 0,46 à $0,48 \mathrm{~m}$ de large et 2,70 à $0,55 \mathrm{~m}$ de haut, de l'aval vers l'amont, et une aile droite constituée d'un mur de 9,40 m de long, en deux segments de 4,90 et $4,50 \mathrm{~m}$ de long, $0,46 \mathrm{~m}$ de large et 2,65 à $0,35 \mathrm{~m}$ de haut, de l'aval vers l'amont, elle constitue, à ce jour, le système de vidange des eaux le plus complet. De ce fait, elle sert de modèle descriptif théorique pour toutes les vannes repérées sur les différentes digues d'étangs de la vallée de Grandmont.

Fig. 4. - Rampe d'accès et sommet de la vanne haute de l'étang des Sauvages.

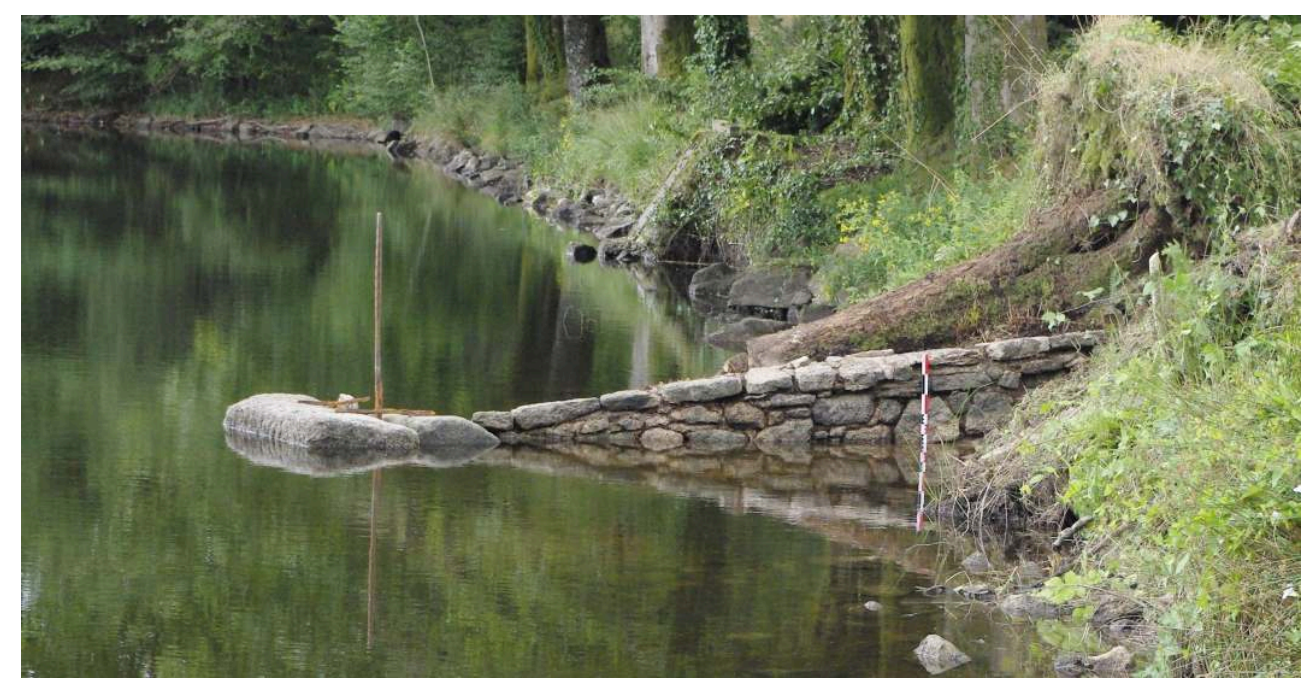

(c) Cliché O. Bauchet. 
Fig. 5. - Relevé en plan de la vanne haute de l'étang des Sauvages.

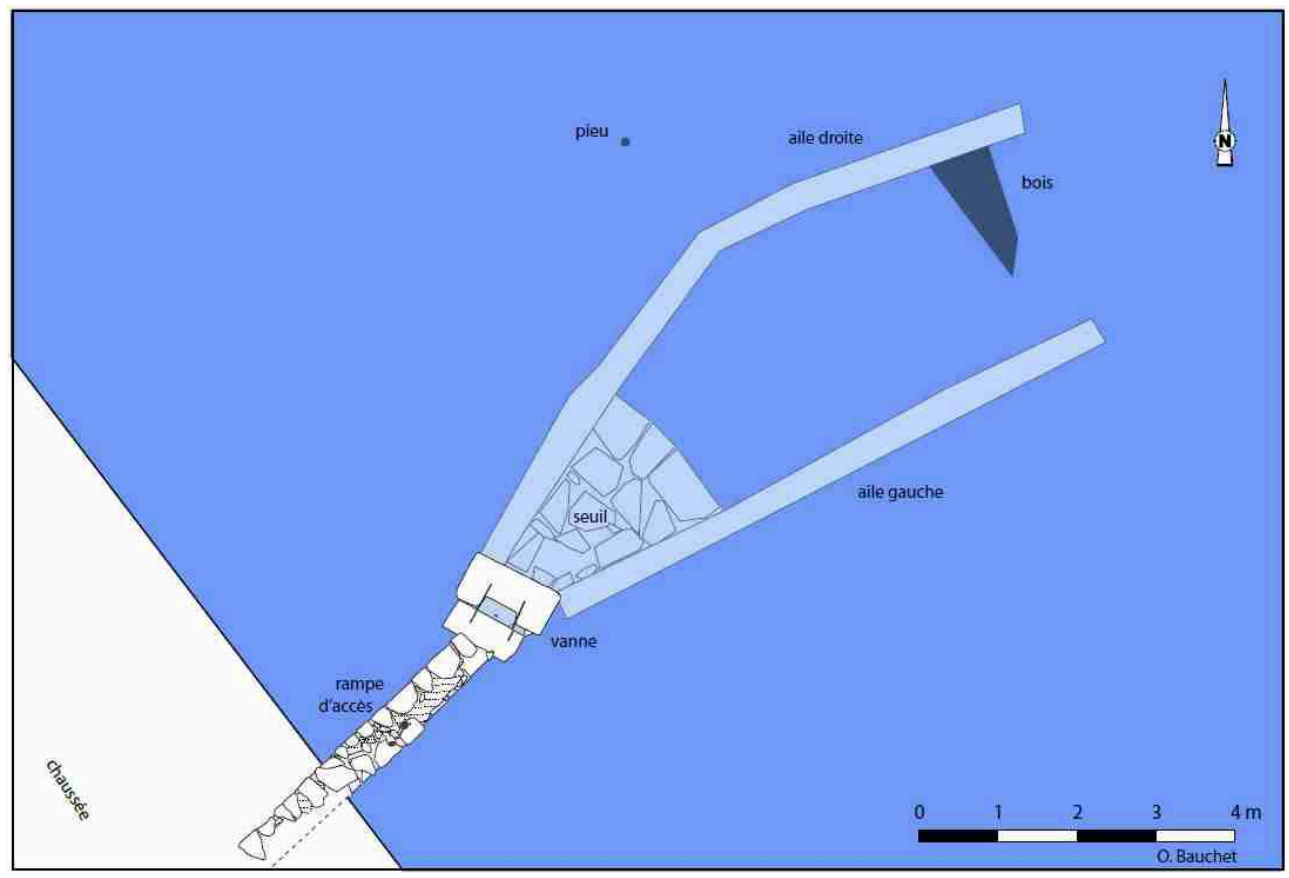

(C) Dessin O. Bauchet.

19 Toujours pour l'étang des Sauvages, la vanne basse, localisée dans la partie gauche de la digue, est établie à plus de $5 \mathrm{~m}$ de la digue et $2 \mathrm{~m}$ de profondeur; elle n'est donc pas accessible ou visible lorsque l'étang est rempli d'eau. Entièrement composée de blocs de granit maçonnés, elle constitue un ensemble immergé de 3,90 $\mathrm{m}$ de haut. Prise dans son ensemble, elle présente six parties distinctes, identifiées de la digue vers l'étang: le sommet, la pelle, la chambre, le radier, l'aile droite et l'aile gauche. Dépourvue de rampe d'accès, la vanne basse possède un sommet composé de deux gros blocs, reliés par un arceau métallique qui maintient, à la verticale, le manche métallique de la pelle en bois. Pourvue d'un conduit de vidange, de section quadrangulaire, positionné à $6 \mathrm{~m}$ de profondeur, elle est également composée, au niveau de ce conduit, d'une chambre trapézoïdale, renforcée par deux linteaux horizontaux, placés aux tiers de la hauteur. La vanne possède un radier mixte, composé de deux blocs, formant un seuil d'1 $\mathrm{m}$ de long environ, et, en amont, d'une couche compacte de cailloux et de sable. Avec une aile gauche, constituée d'un mur de 4,25 m de long et 0,45 m de large, et une aile droite, constituée d'un mur de 3,75 m de long et $0,45 \mathrm{~m}$ de large, qui reposent en partie sur un rondin de bois de près $\mathrm{d}^{\prime} 1 \mathrm{~m}$ de long, elle se distingue de la vanne haute par les caractéristiques.

De même, pour l'étang des Chênes, la vanne haute, localisée dans la partie droite de la digue, est accessible, depuis le chemin qui parcourt la digue. Entièrement composée de blocs de granit maçonnés, elle forme un massif immergé de 3,50 $\mathrm{m}$ de haut. Prise dans son ensemble, elle présente seulement quatre parties distinctes, identifiées de la digue vers l'étang : le sommet, la pelle, la chambre, le radier. Construite à moins de $1,5 \mathrm{~m} \mathrm{du}$ parement interne de la digue, la vanne haute possède un sommet composé de deux linteaux, assemblés par des agrafes métalliques scellées au plomb, qui maintiennent le manche de la pelle à la verticale. Cette vanne haute est également dotée d'un conduit de vidange, de section quadrangulaire, positionné à $3,5 \mathrm{~m}$ de profondeur. Au niveau de 
ce conduit, elle est composée d'une chambre trapézoïdale, également renforcée par un linteau horizontal à mi-profondeur, mais dotée de parois à degrés qui suivent la pente du talus de l'étang. La vanne possède un radier largement envasé.

21 Toujours pour l'étang des Chênes, la vanne basse, localisée dans la partie gauche de la digue, est éloignée de plus de $15 \mathrm{~m}$ de la digue à $3 \mathrm{~m}$ de profondeur; elle n'est donc pas accessible ou visible lorsque l'étang est rempli d'eau. Entièrement composée de blocs de granit maçonnés, elle constitue un massif de plus de $4 \mathrm{~m}$ de hauteur. Comme la vanne haute, elle présente quatre parties distinctes, identifiées de la digue vers l'étang: le sommet, la pelle, la chambre et le radier. Elle possède un sommet composé de deux linteaux, assemblés par des agrafes métalliques scellées au plomb, qui maintiennent le manche de la pelle à la verticale. Elle est composée d'une chambre trapézoïdale, renforcée par deux linteaux horizontaux, situés aux tiers de sa hauteur, et dotée de parois à degrés qui suivent la pente du talus de l'étang.

En revanche, pour le Petit étang des Chênes, la vanne haute et la vanne basse furent construites côte à côte, à moins de $2 \mathrm{~m}$ l'une de l'autre, dans la partie gauche de la digue (fig. 6). Entièrement composées de blocs de granit maçonnés, elles forment deux ensembles de 2,50 $\mathrm{m}$ de haut, intégrés dans le parement de la digue, pour la première, et le talus de l'étang, pour la seconde. Elles présentent seulement trois parties distinctes : la pelle, la chambre et le radier. Ces vannes sont également dotées d'un conduit de vidange, de section quadrangulaire, fermé par une pelle en bois. Elles sont constituées d'une chambre trapézoïdale, renforcée par un linteau horizontal, au premier tiers de la profondeur, pour la vanne haute. Cette vanne haute possède, comme probablement la vanne basse, un radier composé de dalles (fig. 7).

Fig. 6. - Vannes basse, à gauche, et haute, à droite, insérées dans la digue du Petit étang des Chênes.

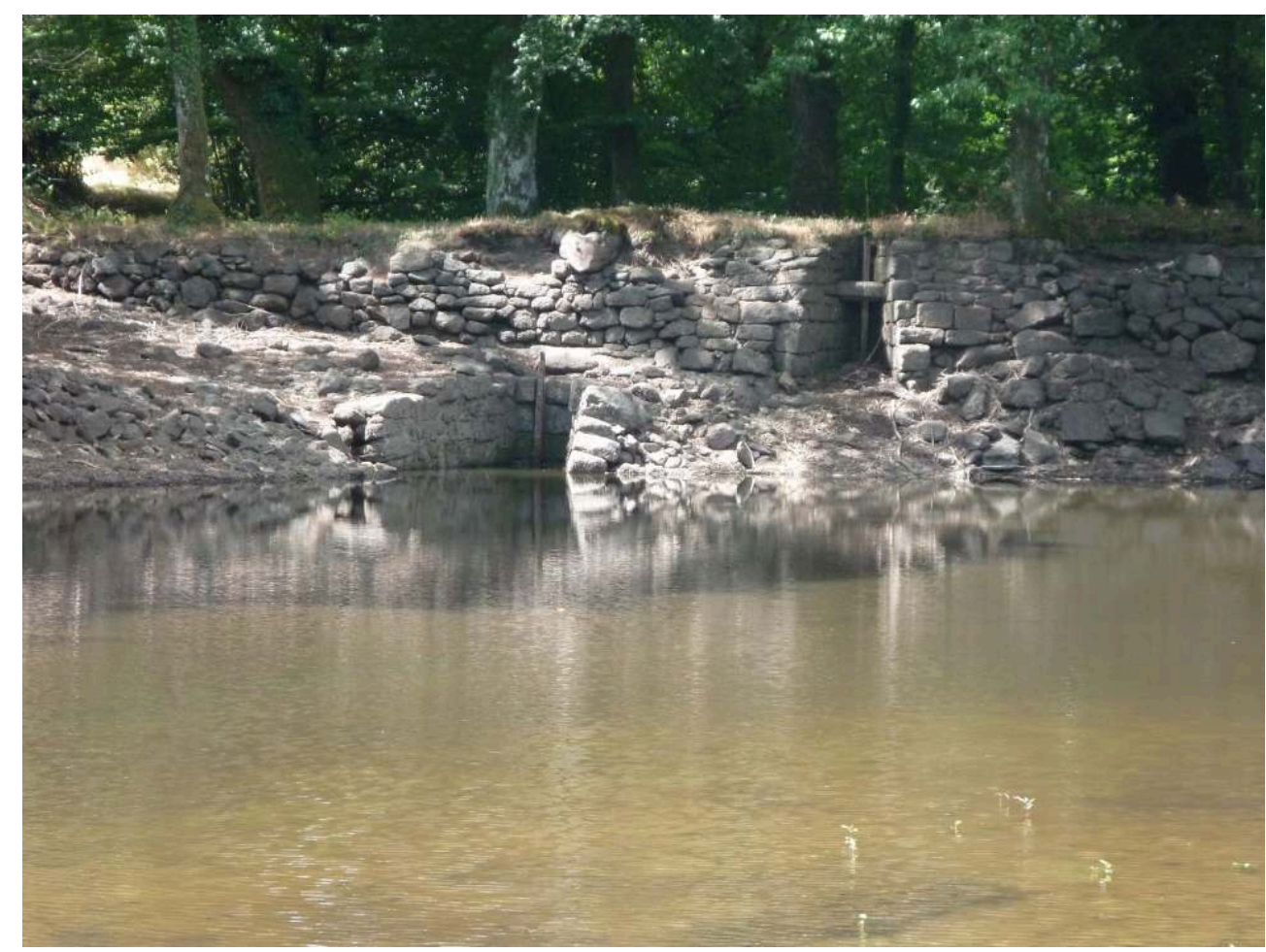


Fig. 7. - Chambre, pelle en bois, linteau horizontal et radier de la vanne haute du Petit étang des Chênes, à gauche, et entrée du conduit de la vanne haute du petit étang des Chênes, à droite.
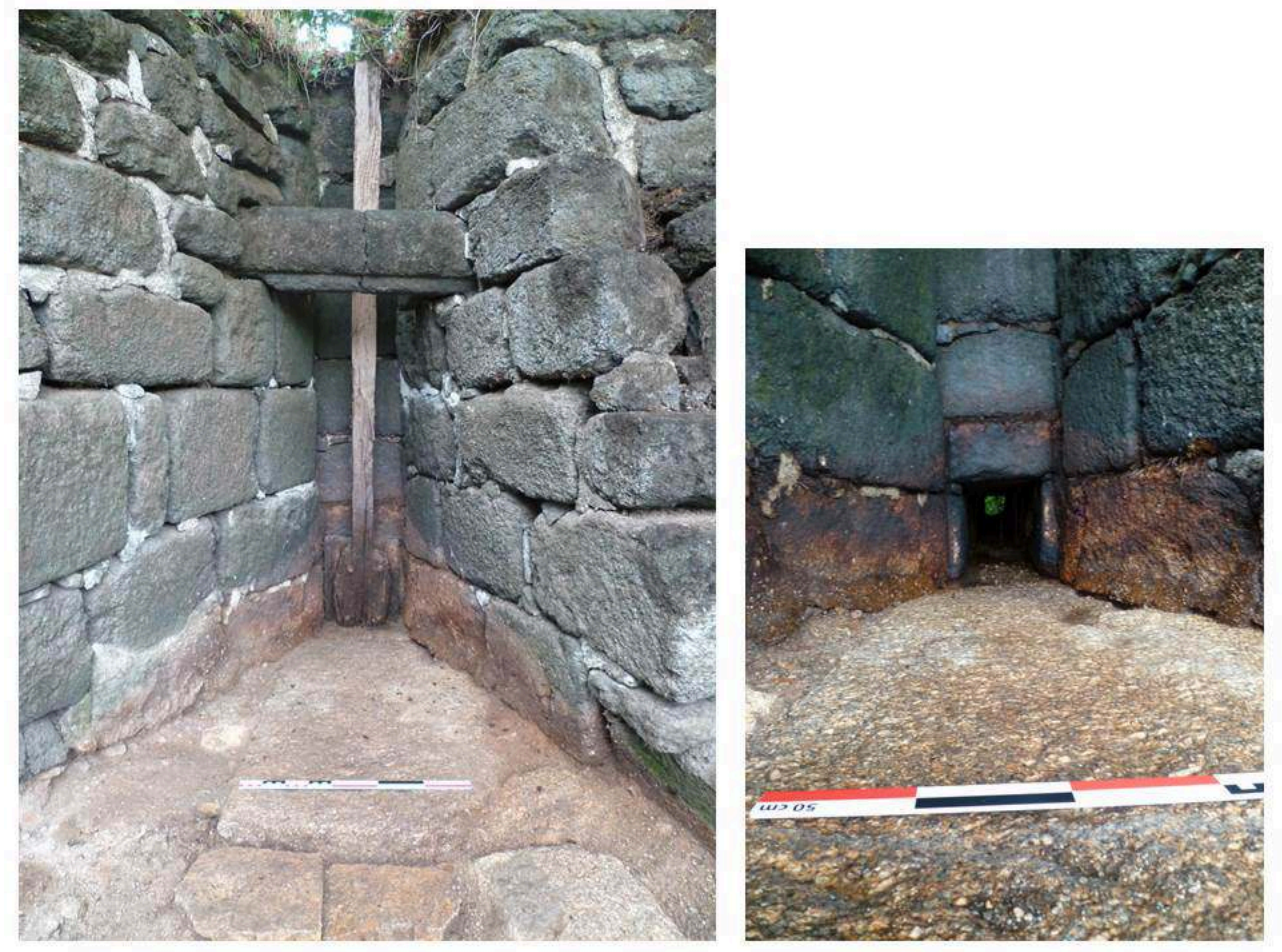

(C) Clichés C. Cloquier. doivent encore être localisées. En effet, en dépit d'un niveau d'eau très faible dans l'étang des Chambres, aucune vanne ne fut localisée en raison de l'envasement important de la totalité de celui-ci. Inversement, dans l'étang c 5 et l'étang de Malessart, totalement en eau, aucune vanne ne fut localisée ou repérée depuis la surface et aucune plongée ne fut tentée en raison de la qualité biologique incertaine des eaux, particulièrement chargée en particules organiques. Toutefois, il convient de préciser que des observations complémentaires, réalisées en aval de chacune des digues, ont permis d'avancer l'existence très probable de vannes pour ces trois étangs.

En effet, si des conduits, fermés par des pelles en bois, furent découverts au fond des chambres des vannes hautes et basses des trois premiers étangs, à savoir l'étang des Sauvages, l'étang des Chênes et le Petit étang des Chênes, les exutoires ou sorties de ces conduits furent également découverts et observés en aval de la digue de chacun de ces étangs. Ces exutoires, de section quadrangulaire, permettent donc de restituer des conduits, constitués de blocs de granit probablement maçonnés, qui traversent chaque digue, de l'amont vers l'aval, avec une pente évaluée à 2,16\% pour ceux de l'étang des Sauvages. Avec des dimensions supérieures ou égales à $0,3 \mathrm{~m}$ de côté, ils apparaissent comme des éléments suffisamment efficaces, pour évacuer les millions de litres d'eau de l'étang lors des vidanges, et suffisamment robustes, pour résister non seulement à la pression des tonnes de matériaux qui constituent chaque digue mais également à la vitesse des eaux évacuées.

En aval de la digue de l'étang des Sauvages, les eaux sortant de l'exutoire du conduit de la vanne haute se déversent dans un bassin trapézoïdal, recoupé par un bâtiment 
récent et doté d'un fond dallé en granit. Elles s'écoulent ensuite dans un caniveau ou rigole en pente douce qui longe la digue jusqu'à un canal perpendiculaire dans lequel s'écoulent également les eaux qui sortent du conduit de la vanne basse (fig. 8 et fig. 9). De même, en aval de la digue de l'étang des Chênes et du Petit étang des Chênes, les eaux sortant des conduits des vannes hautes et basses se déversent dans une structure quadrangulaire, construite avec des matériaux récents. En aval de la digue de l'étang des Chambres et de l'étang $\mathrm{n}^{\circ} 5$, les eaux sortent également d'un conduit quadrangulaire et se déversent également dans un bassin quadrangulaire, constitué de blocs et de dalles de granit. Évacuées de ces bassins par des ouvertures, elles se déversent ensuite dans un canal de liaison maçonné qui alimente l'étang situé en aval, formant un véritable réseau hydraulique anthropique.

Fig. 8. - Relevé en plan des vannes de l'étang des Sauvages, des bassin, caniveau, moulin (?) et canal dégagés en aval de la digue.

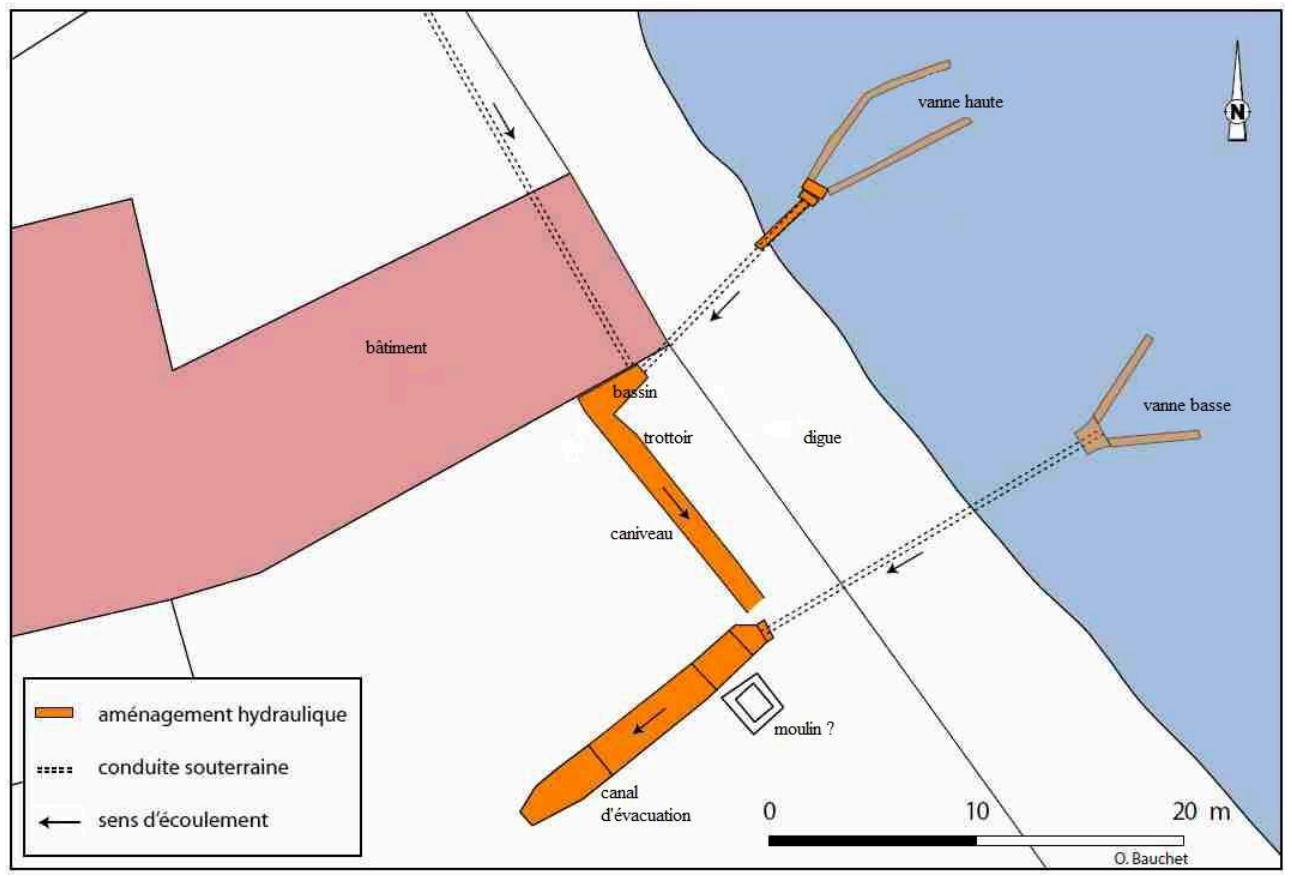

(c) Dessin O. Bauchet. 
Fig. 9. - Vue aérienne du bassin trapézoödal, du trottoir de circulation et du caniveau d'écoulement dégagés en aval de la digue de l'étang des Sauvages.

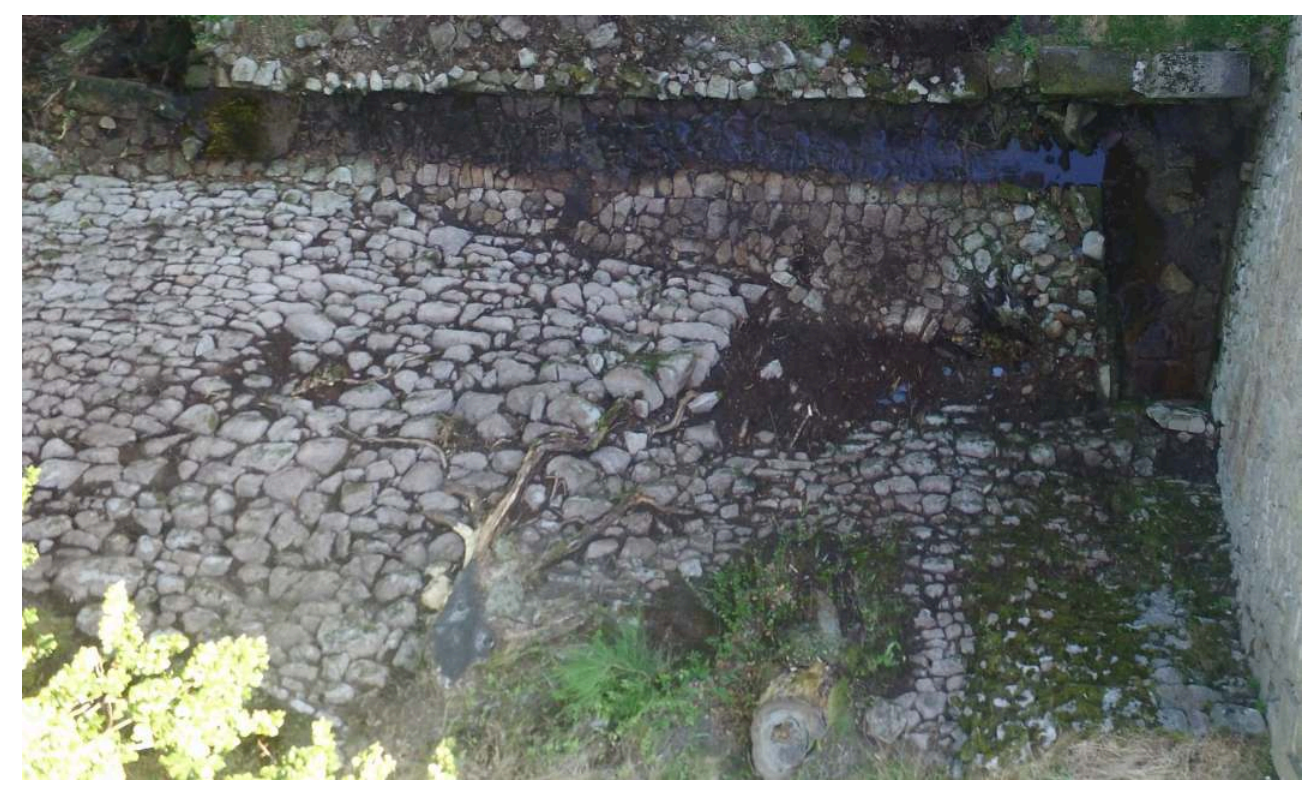

(C) Cliché S. Desruelles.

\section{Aménagement triple du territoire : irrigation, meunerie et pisciculture}

$26 \mathrm{Au}$ fil des prospections et sondages, les différents éléments découverts ont révélé l'existence d'aménagements anthropiques complexes. Délaissés par les hommes et ignorés par les chercheurs, ces constructions ne furent jamais appréhendées ni individuellement ni collectivement et demeurent inconnues dans la vallée de Grandmont. Ainsi, depuis le repérage terrestre initial des étangs, sur 1,6 km de long, ces éléments furent complétés par de nouvelles découvertes, faites lors des prospections aériennes par drone et réparties sur $300 \mathrm{~m}$ de plus vers l'amont.

Piloté depuis le sol par une seule personne, cet appareil permet de visualiser, photographier et filmer, à basse altitude, des zones étendues autour des plans d'eau en une vingtaine de minutes alors qu'il faudrait au moins une journée à pied pour cette même personne au niveau du sol. En plus du gain de temps, il offre, notamment comme avantage majeur, la prise de hauteur pour repérer des structures linéaires. Indéniablement, il a permis d'identifier le réseau de drains de captage des eaux souterraines, en partie dégagé, en amont de l'étang des Sauvages, et, à explorer, en amont de l'étang des Chênes. Alors que la carte topographique de l'Institut géographique national indique un tracé de cours d'eau temporaire, le drone offrit une vue exhaustive du vallon avec ce réseau anthropique.

28 À chaque extrémité de la digue de l'étang des Sauvages, une structure maçonnée fut identifiée comme l'avaloir d'un trop-plein. Insérée dans la partie émergée de la digue, elle est constituée de deux murets de 0,5 m d'épaisseur et de hauteur qui convergent, de l'amont vers l'aval, vers un conduit quadrangulaire de $0,3 \mathrm{~m}$ de section. Manifestement destinée à évacuer les eaux de l'étang, elle ne peut écouler que les eaux présentes au-dessus du sommet de la vanne haute, peu abondantes en période estivale. 
Dans la partie gauche de la digue, cette structure est prolongée par un conduit souterrain qui traverse la digue perpendiculairement, de part en part, puis par un canal, de 0,5 m de large, qui longe la pente sur plus de $70 \mathrm{~m}$ de long avant de disparaître au niveau d'un chemin d'accès. Dans la partie droite de la digue, cette structure est également prolongée par un conduit souterrain qui traverse la digue perpendiculairement, de part en part, puis change brusquement de direction afin de longer la digue et pour déboucher dans le bassin trapézoïdal, principalement alimenté par le conduit de la vanne haute. Si le trop-plein gauche, complété par le conduit et le canal d'évacuation des eaux, a manifestement conservé une certaine intégrité, le tropplein droit, complété par un conduit, qui change de direction une fois la digue passée, a très vraisemblablement subi des modifications avec la construction du bâtiment. Cette hypothèse est d'ailleurs renforcée par la présence d'un conduit d'évacuation des eaux dans le bassin trapézoïdal, parallèle au bâtiment adossé à cette digue.

À chaque extrémité de la digue de l'étang des Chênes, seul un conduit quadrangulaire, de $0,3 \mathrm{~m}$ de section, est présent dans la partie émergée de la digue. Protégé par deux grilles métalliques récentes, destinées à arrêter les débris végétaux ou les poissons, il permet également d'écouler les eaux présentes au-dessus du sommet de la vanne haute, non négligeables en période estivale. Dans la partie gauche de la digue, il traverse perpendiculairement la digue mais fut repris par une buse en béton. Dans la partie droite de la digue, ce conduit souterrain traverse la digue perpendiculairement et déverse les eaux dans une rigole, qui court à flanc de versant sur plus de $170 \mathrm{~m}$, en suivant une ligne de rupture de pente et en restant donc perpendiculaire à la pente générale du vallon herbeux.

Dans la continuité des apports aériens par drone, il convient d'ajouter les repérages et prises de vues faites au niveau du vallon, localisé en aval de l'étang des Chênes et donc en amont du Petit étang des Chênes. En effet, si les prospections terrestres et observations, faites depuis le sommet de la digue de l'étang des Chênes et dans ce vallon, avaient permis de repérer des anomalies au niveau de la végétation, elles n'offraient qu'une vision imprécise et partielle des deux drains ou rigoles, parallèles et rectilignes, qui courent à flanc de versant, perpendiculairement à la pente. Une fois encore, avec la complémentarité des approches, aériennes et terrestres, elles ont permis d'identifier des éléments peu visibles mais indissociables des eaux évacuées par le conduit de la vanne haute l'étang des Chênes.

31 À l'extrémité gauche de la digue du Petit étang des Chênes, seul un canal aérien, de $0,5 \mathrm{~m}$ de large, fut repéré dans la partie émergée de la digue. Fortement endommagé, il traverse perpendiculairement l'extrémité de la digue, longue la paroi granitique du versant avant d'entrer dans un conduit quadrangulaire souterrain, repris par une buse en béton sous le chemin d'accès à la digue. Comparé au trop-plein gauche de la digue de l'étang des Chênes, ce trop-plein pourrait être uniquement utilisé pour l'évacuation des eaux hivernales. En revanche, le trop-plein droit de la digue de l'étang des Chênes était et demeure manifestement établi afin d'arroser ou irriguer le versant droit ou septentrional du vallon, situé en aval de l'étang des Chênes et donc en amont du Petit étang des Chênes. Cette utilisation des eaux, évacuées par le trop-plein droit de la digue de l'étang des Chênes, pourrait être proposée pour les eaux, évacuées par le trop-plein droit de la digue de l'étang des Sauvages, avant la construction des différents bâtiments et un détournement du conduit d'évacuation vers le bassin trapézoïdal, établi en aval de cette digue. 

versants de vallons fut ponctuellement mais manifestement associée aux digues ou aux eaux issues des étangs. Cette pratique serait à associer au terme «levade » qui désigne une construction, une élévation ou une levée. Incontestablement, elle devra être appréhendée et précisée en ayant recours aux sources documentaires, conservées dans différents établissements de conservation dont les archives départementales de la Haute-Vienne, puis confrontée aux éléments observés en aval des digues et aux diverses informations topographiques collectées sur les versants des vallons.

En aval de la digue de l'étang des Sauvages, une structure maçonnée quadrangulaire, de $2 \mathrm{~m}$ de côté, fut découverte sur la berge gauche du grand canal d'évacuation des eaux, établi dans le prolongement du conduit d'évacuation des eaux de la vanne basse, perpendiculairement à la digue. Elle forme un ensemble homogène constitué de dalles de granit régulières et d'éléments plats irréguliers, disposés en assises sur une hauteur inférieure à $0,3 \mathrm{~m}$. Construite à $0,5 \mathrm{~m}$ du parement gauche du canal, elle se trouve à $1 \mathrm{~m}$ du départ de ce canal et $2 \mathrm{~m}$ de la base de la digue. Elle est positionnée au seul endroit que pouvait occuper un moulin à eau équipé d'une roue verticale en dessous.

En aval de la digue de l'étang des Chênes, un haut moulin à eau fut construit, vers l'extrême fin $d u x x^{e}$ ou le tout début $d u x^{e}$ siècle, afin de produire de l'électricité durant les premières années du $\mathrm{xx}^{\mathrm{e}}$ siècle. De plan rectangulaire, il mesure $13 \mathrm{~m}$ de longueur pour $7 \mathrm{~m}$ de largeur et possède un niveau accessible depuis la digue et un niveau inférieur. Manifestement alimenté en eau par le conduit de la vanne basse, il conserve encore sa turbine, en partie éventrée et largement corrodée, dans la partie inférieure de la cage. Cette construction particulièrement imposante fut implantée au milieu de la digue, dans le prolongement de la vanne basse. Vers l'aval, il est prolongé par un grand canal aux parois maçonnées, d' $1 \mathrm{~m}$ de profondeur et de près d'1,5 $\mathrm{m}$ de largeur, qui débouche au niveau de la partie amont du Petit étang des Chênes.

À $20 \mathrm{~m}$ en aval de l'extrémité de ce canal maçonné, en aval d'un bloc de granit oblong, d'au moins $4 \mathrm{~m}$ de long et $2 \mathrm{~m}$ de diamètre, une ébauche de meule fut découverte lors d'une prospection terrestre. Préservée des agressions climatiques dans une couche de limons, elle a conservé, sur la face supérieure, les traces d'un fer d'outil de 0,04 $\mathrm{m}$ de large. De forme nettement circulaire, elle mesure 1,37 à 1,41 $\mathrm{m}$ de diamètre pour une épaisseur irrégulière de 0,22 à $0,34 \mathrm{~m}$ (fig. 10). Étant donné sa position, elle fut vraisemblablement taillée dans le bloc de granit oblong voisin qui présente un front de taille très net. En revanche, elle ne fut apparemment pas travaillée sur l'autre face. Elle repose sur une couche de sable granitique grossier et hétérogène avec des inclusions de couleur rouille et des éclats de granit. Prise dans une succession de couches de sable fin, de limon sableux gris et de limon très argileux gris foncé, elle est associée à trois morceaux de tuiles plates et un tesson de céramique commune, de type écuelle, tournée à pâte grise et cuite en réduction, non datée. Associée aux quelques éléments archéologiques, cette ébauche de meule de moulin indique une activité humaine manifeste au niveau des blocs de granit présents dans la queue du petit étang des Chênes. 
Fig. 10. - Ébauche de meule de moulin du Petit étang des Chênes, avant et après dégagement.

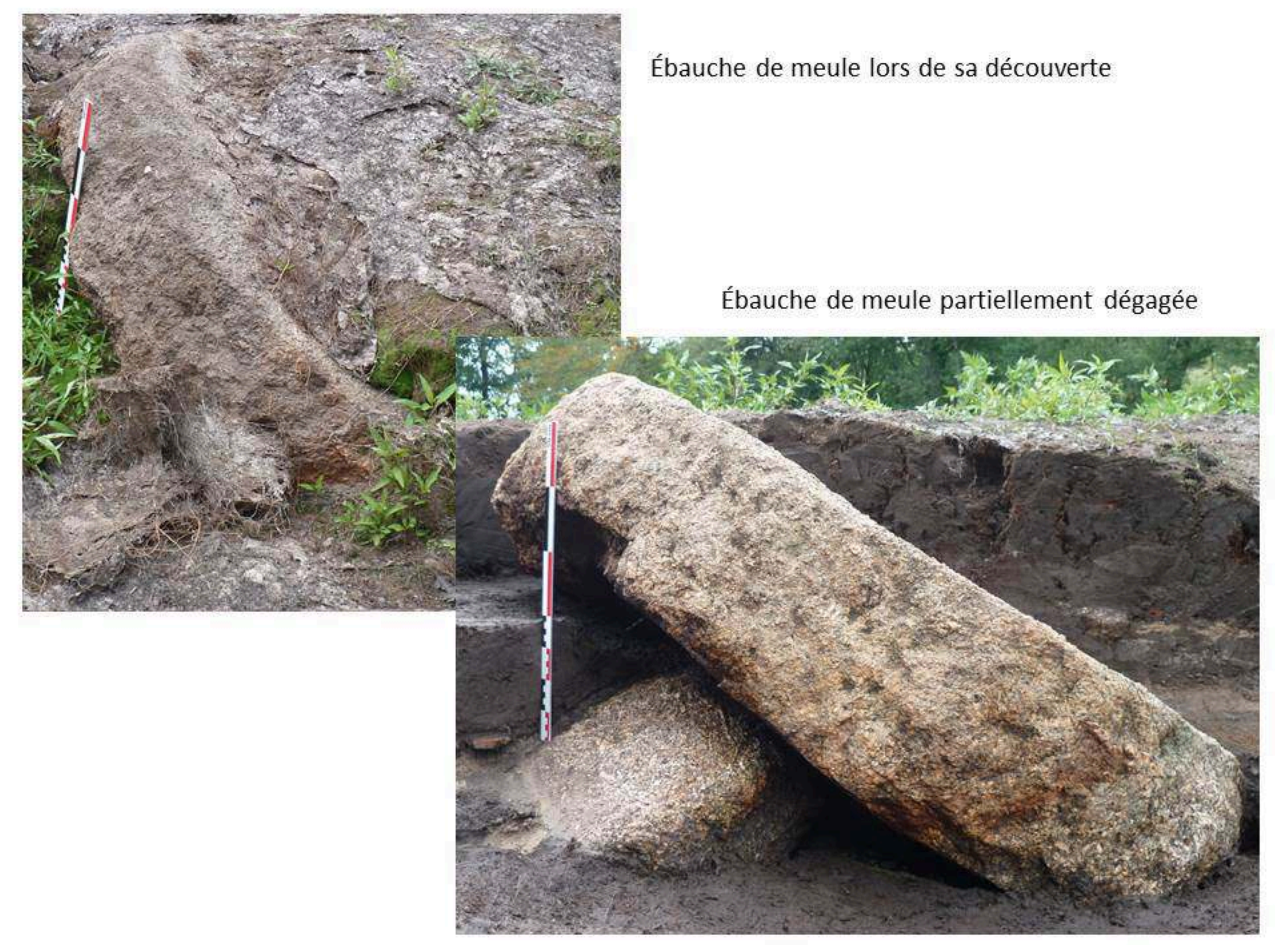

(C) Clichés C. Cloquier. dissimulés sous une végétation luxuriante, occupent un emplacement sur lequel un moulin à eau aurait pu être construit. Localisés au milieu de la base de la digue, ils forment un alignement repérable, à moins de $5 \mathrm{~m}$ du bassin dans lequel se déversent les eaux de l'étang. À ce jour, ces éléments lapidaires ne sont associables à aucune autre information susceptible de renforcer la présence d'un moulin à eau excepté un document produit à l'occasion des ventes de biens nationaux. Le 27 décembre 1790, lors de la mise en vente de l'abbaye de Grandmont, un petit moulin, construit au-dessous de l'étang des Chambres, fut mentionnés.

i la présence, médiévale ou moderne de moulins à eau semble plausible et possible, les vestiges, découverts en aval de la digue de l'étang des Sauvages et en aval de la digue de l'étang des Chambres, doivent encore être dégagés et étudiés afin de confirmer ou infirmer cette hypothèse. La présence de moulin à eau, avérée pour l'étang des Chambres à la fin du XVIII ${ }^{\mathrm{e}}$ siècle, est unique et limitée à cet étang. Elle indique une utilisation supplémentaire de l'eau et donc une activité complémentaire mais indéniablement liée à l'aménagement de la vallée et à l'étang. Reste à savoir si l'implantation de moulins à eau engendra la construction des digues et donc la mise en eau des espaces ainsi créés ou l'inverse.

Avec de telles profondeurs et superficies, les étangs de la vallée de Grandmont offraient et offrent encore des espaces aquatiques particulièrement importants avec des biotopes et des zonages variés et appréciables pour l'alimentation, le développement et la reproduction de diverses espèces de poissons dulçaquicoles. À l'image des étangs de la Brenne, la Dombes ou la Sologne, ils constituent, au niveau du Limousin, un ensemble de plans d'eau propices à la pisciculture, vraisemblablement pour des brochets (Esox 
lucius) et des carpes (Cyprinus carpio). Si aucun objet archéologique ne permet d'évoquer la capture de poissons, les étangs et les structures maçonnées, établies en amont et en aval des digues de retenue, permettent de proposer raisonnablement la pratique de la pisciculture, avec la capture de poissons dans les bassins construits en aval des digues, et donc l'exploitation d'une ou plusieurs espèces de poissons pour l'alimentation humaine durant les périodes médiévale ou moderne.

Initialement associés aux moines de Grandmont, installés dans ce lieu après la mort d'Étienne de Muret, survenue le 8 février 1125, les neuf étangs furent effectivement localisés en amont et en aval du hameau qui abrita le prieuré de Grandmont, érigé en abbaye chef d'ordre en 1317. Avec d'imposantes digues et des systèmes de régulation des eaux tout aussi imposants, ces étangs apparaissent donc comme des aménagements conséquents, pérennes et vraisemblablement onéreux. Dépourvus d'éléments architecturaux décoratifs, d'artefacts ou de stratigraphie exploitables pour une datation, ils s'avèrent difficilement datables, avec les seuls blocs de granit maçonnés. En exploitant les sources documentaires, ils peuvent, comme ce fut le cas pour l'étang des Sauvages, mentionné dans un acte de donation daté de l'année $1194^{10}$, être associés à une ou plusieurs dates qui confirment alors leur existence entre le $\mathrm{XII}^{\mathrm{e}}$ et le $\mathrm{XVIII}^{\mathrm{e}}$ siècle ou l'activité piscicole. En revanche, pour leur date ou période de construction, mise en eau ou exploitation initiale, ils ne peuvent livrer d'information ou d'indication pertinente ou précise.

Toutefois, les systèmes de régulation des eaux de l'étang des Sauvages ont livré des possibilités de datations particulièrement appréciables. Au niveau du radier, la vanne haute a livré une pièce de bois, datée par le dosage du carbone 14, entre les années 1029 et 1183. Sous son aile droite, la vanne basse conserve un rondin en bois, daté avec le même procédé, des années 1020 à 1155 . Enfin, sous son aile gauche, cette vanne conserve également un rondin en bois, encore daté avec le même procédé, des années 897 à 1024. Ainsi datées, les vannes de l'étang des Sauvages indiquent l'existence d'un aménagement de cette portion de la vallée de Grandmont dès le premier tiers du $\mathrm{XI}^{\mathrm{e}}$ siècle, et donc potentiellement avant l'arrivée des disciples d'Étienne de Muret, ou durant le XII ${ }^{\mathrm{e}}$ siècle, et donc contemporain de l'installation des religieux sur ce site.

Aménagés entre les vallons des monts d'Ambazac, les neuf étangs de la vallée de Grandmont ponctuent le relief modeste d'un paysage de montagnes. Manifestement alimentés par des réseaux de drains de captage, les deux premiers étangs alimentaient et alimentent toujours les étangs situés en aval. Adossés à de puissantes digues, constituées de blocs de granit, ils conservent des structures maçonnées à savoir les vannes, pour la régulation des eaux, et des trop-pleins, pour l'utilisation des eaux hivernales en irrigation. En aval des digues, ils sont complétés par des bassins quadrangulaires, vraisemblablement utilisés pour arrêter et capturer les poissons lors des lâchers d'eau, ou par des structures maçonnées, abritant probablement un moulin à eau, dont au moins un est attesté par les sources documentaires.

En effet, en l'absence de cours d'eau utilisable pour la capture de poissons et la production d'énergie hydraulique, les étangs apparaissent comme un véritable aménagement médiéval du territoire, jusqu'à présent délaissé ou ignoré par les archéologues et les historiens. Indéniablement, ils constituent une étape majeure dans 
l'occupation et l'exploitation d'un espace naturel comme la vallée de Grandmont. Depuis le captage des eaux souterraines dans le vallon situé en amont du premier étang jusqu'au canal d'évacuation des eaux du dernier étang, ils forment un ensemble cohérent et préservé, dans lequel plusieurs activités humaines furent manifestement exercées dès le $\mathrm{XI}^{\mathrm{e}}$ ou $\mathrm{XII}^{\mathrm{e}}$ siècle. Dans un souci d'enrichissement de la connaissance des étangs du Limousin et des activités associées, à savoir l'irrigation, la meunerie et la pisciculture, ils pourraient constituer un ensemble de référence.

En dépit de l'absence de mobilier archéologique, permettant de dater les différentes structures en élévation, de la ténuité et de l'éparpillement des informations, contenues dans les sources documentaires, l'étude archéologique et historique des étangs de la vallée de Grandmont permet de mettre en œuvre des approches et des techniques, complémentaires voire innovantes, en associant des prospections, sondages et relevés terrestres ou subaquatiques et des repérages aériens par drone. Elle permet donc une complémentarité maximale des approches et aboutit à des résultats inédits particulièrement encourageants. De ce fait, cette étude a permis de constituer, présenter et faire aboutir un dossier de demande protection au titre des Monuments historiques pour l'étang des Sauvages, l'étang des Chênes, le Petit étang des Chênes et l'étang des Chambres, avec les structures associées pour le captage des eaux souterraines, le transfert des eaux ou l'irrigation des versants. Avec cette reconnaissance patrimoniale des étangs et des structures associées, elle contribue ainsi au prolongement de l'action engagée sur un patrimoine bâti, en partie immergé, particulièrement imposant mais paradoxalement très fragile, dissimulé sous une importante végétation au cœur du Limousin.

\section{BIBLIOGRAPHIE}

CLOQUIER Christophe, « Apports des sources documentaires pour la connaissance des étangs piscicoles du Limousin : l'exemple des étangs de Grandmont, Saint-Sylvestre (87) », Archives en Limousin, $\mathrm{n}^{\circ} 46,2016$, p. 15-25.

LECLER André, Dictionnaire historique et géographique de la Haute-Vienne, Marseille, Laffitte reprints, 1976.

\section{NOTES}

1. C. Cloquier, «Apports des sources documentaires pour la connaissance des étangs piscicoles du Limousin », p. 15-25.

2. Arch. dép. Haute-Vienne, 3 P 193, feuilles des sections B1 et C1.

3. Arch. dép. Haute-Vienne, 1 Q 331, fol. 158 et 159-v.

4. Arch. dép. Haute-Vienne, 1 Q 331, fol. 158 et 161v.

5. Arch. dép. Haute-Vienne, $1 \mathrm{~J}$ 66, entre les fol. 15 et 16. 
6. A. Lecler, Dictionnaire historique et géographique de la Haute-Vienne, p. 20.

7. Arch. dép. Haute-Vienne, I sem 81, fol. 157v.

8. Arch. dép. Haute-Vienne, I sem 10, fol. 45.

9. Arch. dép. Haute-Vienne, 1 Q 331, fol. 158 et 159-v.

10. Arch. dép. Haute-Vienne, I sem 10, fol. 45.

\section{RÉSUMÉS}

Avec un relief modeste, les monts d'Ambazac (Haute-Vienne) livrent des paysages vallonnés parsemés d'étangs relativement vastes. Caractérisés par un substrat granitique, ils présentent toutefois une opposition manifeste entre des versants drainés et des vallons humides dépourvus, le plus souvent, de ru ou ruisseau. Forts de ces caractéristiques géomorphologiques et géographiques, ils conservent cependant les vestiges et traces d'importants aménagements anthropiques. Initialement repérés et identifiés lors de prospections archéologiques terrestres, les étangs de la vallée de Grandmont livrent, au fil de campagnes successives de travaux subaquatiques et terrestres, de multiples éléments, révélateurs de leur importance, dans un paysage de montagne modifié. Ainsi, les neuf étangs repérés et en cours d'étude s'avèrent être des plans d'eau artificiels, retenus par d'imposantes et puissantes digues en blocs de granit, majoritairement surmontées d'une chaussée carrossable ou d'une route. Attribués aux moines de l'abbaye-mère de Grandmont (XII ${ }^{\mathrm{e}}$ siècle), ces étangs formaient un ensemble conséquent qui s'étire sur près de $2 \mathrm{~km}$ de long. Alimentés par les eaux nivales et pluviales, ils recevaient également les eaux des étangs établis en amont. Ainsi, en fonction de la hauteur d'eau et de la période considérée, ils permettaient aussi l'irrigation des pentes herbeuses des vallons au fond desquels ils furent aménagés. Toutefois, certains étangs, à l'image de l'étang des Sauvages, furent dotés d'un réseau de captage des eaux, repéré lors de prospections aériennes par drone.

\section{AUTEUR}

\section{CHRISTOPHE CLOQUIER}

Conservateur de la bibliothèque centrale du service de santé des armées, chercheur associé au Lamop, Umr 8589, université de Paris 1 - Cnrs 


\title{
La hiérarchisation des espaces
} ruraux : famille, migrations et luttes politiques à la frontière des royaumes de Valence et d'Aragon
pendant le Moyen Âge

\author{
Vicent Royo Pérez
}

Ce travail a été soutenu par le Ministerio de Economía, Industria y Competitividad à l'occasion du programme de formation postdoctorale "Juan de la Cierva-Formación"

1 À l'époque médiévale, les contrées frontalières étaient considérées des endroits lointains. Une image incertaine, peaufinée par les centres de pouvoir, avait été forgée sur ces régions excentrées, où la complexité des gouvernements propres aux villes était improbable. En plus, ces régions périphériques se caractérisaient plutôt par une économie rudimentaire reposant sur le pâturage et sur une agriculture de subsistance. Le rayonnement était l'apanage des cités. Or, les études menées au cours des dernières décennies ont mis en évidence que cette vision traditionnelle des régions périphériques était très éloignée de la réalité, car elles étaient des zones plutôt dynamiques du fait de la vitalité découlant de leur position frontalière. Le va-et-vient et les échanges étaient constants sur les territoires limitrophes, devenant ainsi des zones où l'afflux de personnes, d'idées et de marchandises était incessant. Peu importaient les limites politiques et physiques, puisque la circulation s'y superposait et que des espaces de confluence s'y formaient dont le dynamisme était bien différent de celui des régions intérieures ${ }^{1}$.

2 Ce raisonnement peut être étendu aux territoires de la Couronne d'Aragon. L'expansion vers Al-Andalus au XII ${ }^{e}$ et au XIII ${ }^{e}$ siècles, ainsi que le processus de colonisation ultérieur, constituent une influence essentielle lors de la création des sociétés frontalières d'Aragon, de Catalogne et de Valence, lesquelles arrivent à maturité au cours des deux siècles qui s'ensuivent. Dans ces régions limitrophes, un réseau de peuplement se 
définit servant d'épine dorsale au territoire régional vers la partie sud-est du Système Ibérique, se distinguant par les chaînes de montagnes de Gudar-El Maestrat-Els Ports. Qui plus est, la tradition et les sources montrent que, même s'il y avait des limites politiques et de nombreuses barrières physiques, les territoires de montagne de ces trois entités étaient plutôt bien desservis. Voici donc ce que ce travail a pour but, à savoir, l'analyse des relations parmi les zones rurales des royaumes de Valence et d'Aragon au cours du XIII et XIV siècles. Pour des questions d'espace, on ne se penchera ici que sur ce côté de la frontière et, par ailleurs, la communauté rurale de Vilafranca, située dans la frontière septentrionale du Royaume de Valence et à peu de kilomètres du Royaume d'Aragon, nous servira de point de repère.

\section{La construction d'un espace frontalier}

3 Le processus de conquête et de colonisation du $\mathrm{XII}^{\mathrm{e}}$ et du XIII ${ }^{\mathrm{e}}$ siècle est à l'origine des caractéristiques exclusives des régions de montagne reliant les royaumes d'Aragon et de Valence. L'expansion débute par le rattachement de Tortosa (1148), Lleida (1149) et Alcañiz (1151), et prend fin entre 1231 et 1234, après la conquête des régions de Els Ports et El Maestrat. Tout au long de ce siècle et parallèlement à ces conquêtes, les chrétiens mettent en œuvre un processus de colonisation visant à attirer des centaines de familles et à étayer un réseau de peuplement permettant d'assembler ce territoire (fig. 1) $)^{2}$.

Fig. 1. - Le réseau de seigneuries entre 1280 et 1293.

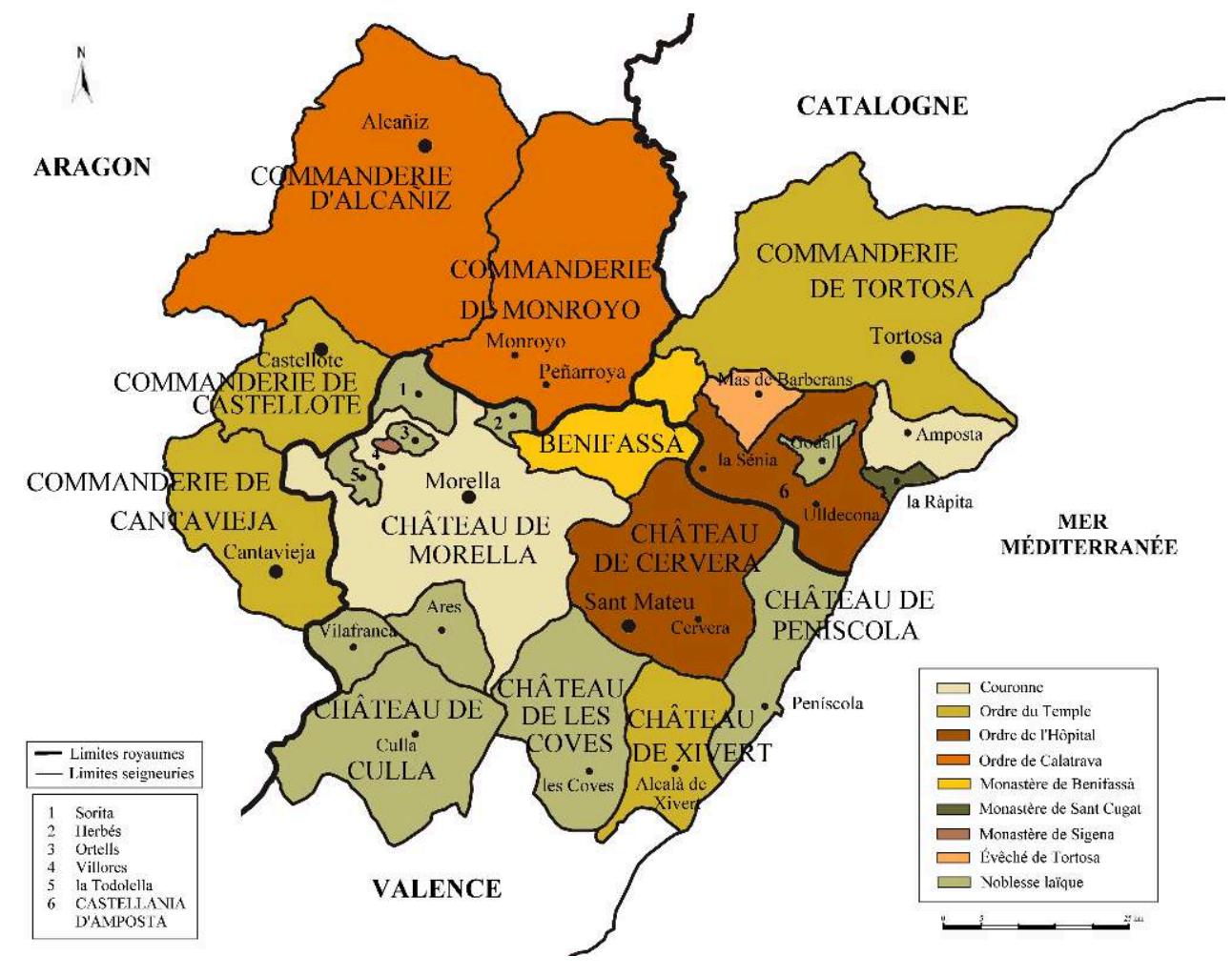

(c) Vicent Royo Pérez.

D'emblée, il faut souligner une complexe carte politique de la région dans laquelle coexistent les seigneuries des ordres militaires et la noblesse avec les biens de la 
Couronne. Ce morcellement juridictionnel n'empêche pas la continuité des formes de peuplement de part et d'autre de la frontière. En fait, de la moitié du XII siècle jusqu'à la fin du xiII e siècle, il s'articule entre les royaumes de Valence et d'Aragon un réseau de peuplement cohérent, appuyé par une soixantaine de communautés rurales, situées à peu de kilomètres les unes des autres, dont la démographie évolue d'une façon très variable au cours du XIV ${ }^{e}$ siècle - on compte alors quelques familles (250 à 300 maisons). Au-dessus de ces communautés, certaines villes deviennent les capitales des seigneuries, remplissent fonctions urbaines et font office de marchés régionaux, comme c'est le cas d'Alcañiz, Monroyo et Cantavieja ${ }^{3}$. Enfin, la vraie capitale de la région est la ville de Morella, dont le nombre d'habitants dépasse largement celui des autres, en atteignant 1539 maisons en 1373. En plus, c'est le siège des délégués de la Couronne et les deux foires annuelles qui s'y tiennent la convertissent, avec Tortosa, en principal nœud du commerce sur la frontière entre le Royaume de Valence, l'Aragon et la Catalogne (fig. 2$)^{4}$.

Fig. 2. - Le réseau de peuplement aux XIII et XIV siècles.

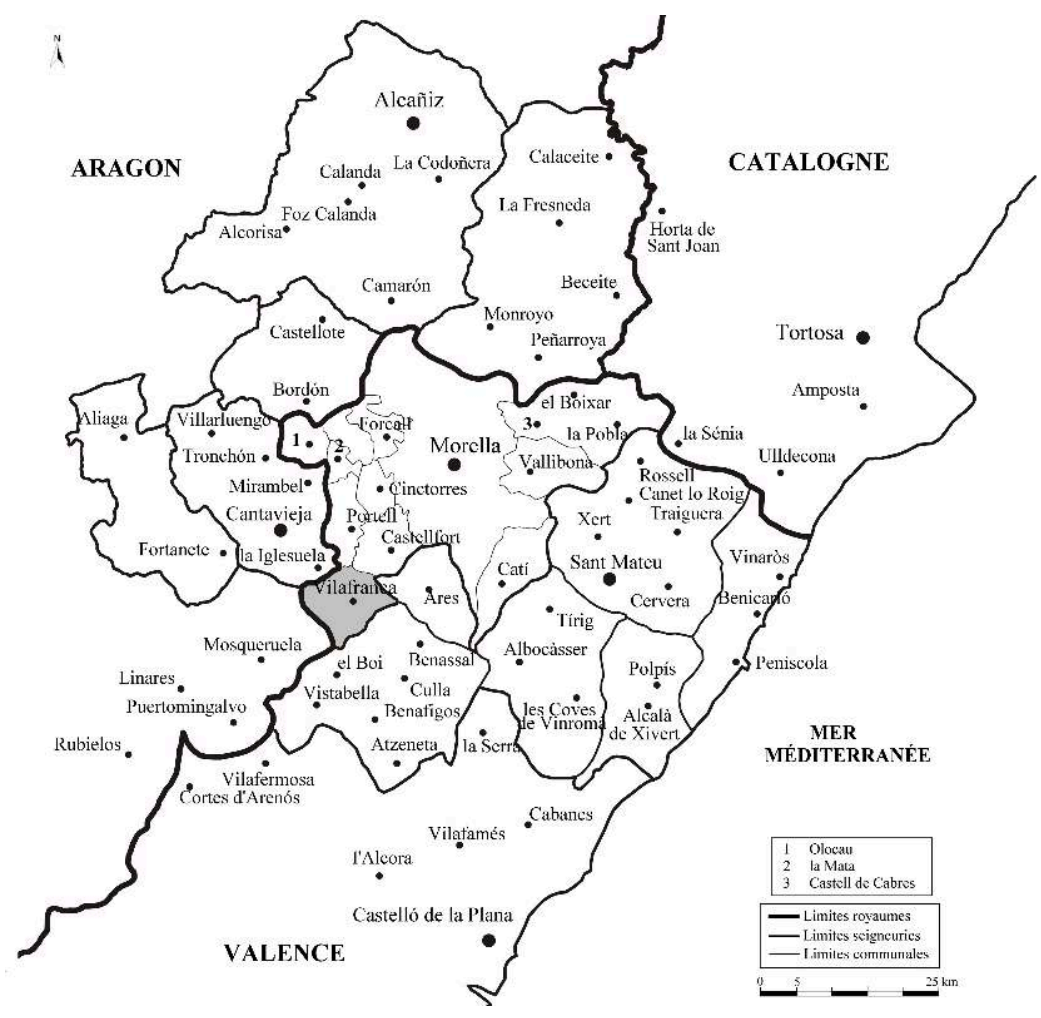

(c) Vicent Royo Pérez.

5 Au sein de ce réseau de centres, on pourrait penser que Vilafranca occupe une position secondaire par rapport aux villes. Cependant, cette communauté rurale jouit d'une position géographique qui lui confère un grand dynamisme. Depuis sa fondation en 1239, Vilafranca - qui appartient à plusieurs familles de la noblesse catalane et aragonaise pendant le XIII ${ }^{\mathrm{e}}$ siècle, et s'intègre dans le bailliage royal de Morella en 1303 - est le carrefour des routes reliant les zones de pâturage d'hiver de El Maestrat et de La Plana de Castelló avec les zones de pâturage d'été de Els Ports, Bajo Aragon et la région de montagne de Teruel. En conséquence, ce village devient un lieu de passage 
obligé dans cette transhumance de parcours moyen, ce qui convertit Vilafranca en nœud de ce réseau routier et lui permet de devenir un petit marché.

Grâce à cette situation privilégiée, le village attire davantage de colons que les autres communautés. En effet, entre vingt et quarante familles s'y installent après la conquête $\mathrm{du}$ XIII ${ }^{\mathrm{e}}$ siècle, au début du XIV ${ }^{\mathrm{e}}$ siècle, Vilafranca atteint 110 maisons. Cette croissance est possible grâce à l'affluence de colons en provenance de Catalogne et d'Aragon, comme en témoigne l'anthroponymie. Entre 1274 et 1319, 66 noms de famille ont pu être identifiés : $50 \%$ ont une origine catalane, alors que $35 \%$ ont une ascendance aragonaise ${ }^{5}$. L'anthroponymie démontre apparemment une légère prédominance de l'origine catalane, or si l'on tient compte des prénoms, il ressort de cette analyse un panorama plus diversifié. Durant ces années, 35 prénoms masculins ont été décortiqués et il en résulte une prédominance de l'origine aragonaise, aux alentours de $46 \%$. Par ailleurs, $34 \%$ des prénoms sont d'origine catalane, tandis que ceux utilisés indifféremment dans les deux territoires s'élèvent à $20 \%$. On pourrait donc affirmer qu'un important flux migratoire en provenance de Catalogne vers Vilafranca eut lieu, mais il ne faudrait pas non plus sous-estimer la forte affluence en provenance d'Aragon, ce qui contribua à établir des relations solides avec les communautés situées de l'autre côté de la frontière.

7 Il y a donc un flux intense de personnes qui donne un coup de fouet à Vilafranca et qui constitue le meilleur exemple d'une dynamique de croissance économique et sociale, qui s'étend depuis la moitié du XIII ${ }^{e}$ siècle jusqu'à la moitié du XIV ${ }^{e}$ siècle. Qui plus est, cette mobilité détermine profondément la structure sociale et professionnelle de Vilafranca. L'emplacement du village au cœur des routes du bétail et les conditions géographiques font en sorte que ses habitants se spécialisent dans l'élevage ovin, devenant ainsi la principale source de l'économie domestique, en plus de l'agriculture céréalière. De la même façon, l'abondance de matières premières a pour conséquence le développement d'une industrie textile qui, malgré son faible niveau de spécialisation jusqu'à la fin du XIV ${ }^{e}$ siècle, crée des emplois pour bien de familles.

8 D'autre part, la mobilité intense qu'entraîne la proximité de la frontière attire la présence de nombreux notaires - indispensables pour certifier de multiples transactions effectuées au sein de la communauté rurale -, ainsi que de membres du clergé. Ces deux métiers sont l'option privilégiée par les membres de l'élite rurale pour épargner à leurs enfants le travail agricole, un signe de plus de leur position prestigieuse au sein de la communauté. Car au début du XIV siècle, il est déjà possible de distinguer nettement l'existence d'un petit nombre de paysans qui accumulent un patrimoine agropastoral considérable et qui mettent sur pied une stratégie d'investissement diversifiée, ce qui leur permet de contrôler une grande partie des secteurs du marché local ${ }^{6}$.

Bref, Vilafranca devient un petit centre de marché à l'échelle régionale et joue un rôle essentiel à la frontière entre les royaumes de Valence et d'Aragon. Dans le village, un grand nombre de transactions est effectué habituellement - plus que dans les autres communautés rurales de la zone - et c'est pour cette raison qu'elle devient un pôle d'attraction dans les deux sens. D'un côté, elle constitue le débouché naturel pour les paysans des communautés rurales avoisinantes, qui y trouvent des chances de promotion. De l'autre côté, Vilafranca attire les investissements de chevaliers et bourgeois des villes, car son rôle en tant que nœud régional la transforme en plateforme d'accès aux zones rurales. En conséquence, Vilafranca occupe une position 
intermédiaire dans le réseau de peuplement de la région et a un rôle indispensable à l'articulation des routes existantes en reliant les zones de montagne du Royaume de Valence et d'Aragon.

\section{Famille et affaires au-delà des frontières politiques}

$10 \mathrm{Au}$ cours du XIII ${ }^{\mathrm{e}}$ siècle, les limites des frontières entre les royaumes de Valence et d'Aragon sont tracées, mais la délimitation politique n'empêche pas les habitants de franchir les confins dans les deux sens. Loin de là, l'anthroponymie révèle l'existence d'un important flux migratoire depuis l'Aragon jusqu'à Vilafranca. Même si les documents d'archives conservés de cette époque-là ne permettent point de suivre en détail ce processus, le flux en provenance d'Aragon se poursuit tout au long du XIII ${ }^{\mathrm{e}}$ siècle. En effet, quand les sources disponibles commencent à foisonner au début du xIV siècle, la présence de personnes venant d'Aragon est habituelle au point que certaines figures se distinguent par leur rôle essentiel dans le tissu social de la communauté.

11 En 1316, le roi Jacques II octroie une tour et un palais à Vilafranca à Jimeno Garcés de Uncastillo $^{7}$. Cet infanzón d'origine aragonaise jouit d'une étroite relation avec la monarchie - d'après les documents royaux, Jacques II indique que Garcés appartient à la camera nostra - et, grâce à ces dons, il met le cap sur Vilafranca, où il participe activement aux principales affaires de l'époque ${ }^{8}$. En fait, au moins depuis 1320, Garcés a le droit d'usage du secrétariat de la communauté, soit un monopole royal lui permettant de désigner le professionnel chargé de travailler pour le gouvernement local'. En 1327, Jacques II lui octroie une licence pour bâtir un nouveau moulin dans le territoire communal de Vilafranca et, une année plus tard, le notaire du village, Simó Bonfill, obtient l'autorisation nécessaire à la construction d'un autre ${ }^{10}$. Dès lors, Bonfill devient l'associé de Garcés et, grâce à cette relation, ils tiennent les rênes des affaires politiques et économiques du village pendant les années trente du XIV siècle.

Outre les affaires, l'autre mécanisme qui permet de renforcer les liens entre les étrangers et les voisins de la communauté rurale est la mise en application d'une politique de mariages soigneusement calculée, comme le font les Santpol, de Puertomingalvo - ville aragonaise qui appartient à l'évêché de Saragosse, située à 40 kilomètres de Vilafranca -, tout comme les Montsó, de Vilafranca. La famille Santpol est l'une des plus éminentes de la petite noblesse de la région de montagne de Teruel. En effet, elle compte parmi ses membres plusieurs membres de la cort del senyor rey, c'està-dire, des infanzones qui font partie de la cour du roi ${ }^{11}$. Une fois garantie leur domination à l'échelle locale, ils profitent des liens qui les rattachent à Jimeno Garcés et à la monarchie pour étendre leurs tentacules autour de Vilafranca pendant les années quarante du XIV siècle.

Grâce à une concession royale, le droit d'usage du four de Vilafranca est entre les mains de Juan de Santpol, qui contrôle de cette manière la production du pain ${ }^{12}$. D'autre part, Bernardo de Santpol achète à Jaume Montsó, de Vilafranca, le bétail, les céréales et les rentes dont le notable est le propriétaire en dehors de la communauté moyennant un prix de 5000 sous $^{13}$. C'est grâce à cette acquisition que Bernardo de Santpol étend son influence sur le milieu rural avoisinant, car il obtient les droits sur les prémices, les productions agricoles et les troupeaux que Montsó détient à Vistabella, El Boi et 
Benassal, soit des villages frontaliers ou très proches de Puertomingalvo (fig. 2). Or, les relations entre ces deux familles ne s'arrêtent pas là.

Durant ces années, le mariage dudit Jaume Montsó avec María, la sœur de Jaime de Santpol, est fort bénéfique pour Montsó, car il contribue à renforcer la position privilégiée dont il bénéficie au sein de la communauté ${ }^{14}$. Certains membres de cette lignée faisaient partie de l'armée du noble Blasco de Alagón, conquérant de Vilafranca, et s'y installèrent peu après sa conquête. Depuis lors, ses descendants amassèrent des richesses et bâtirent une renommée dont hérite le jeune Jaume au milieu du XIV siècle, comme l'atteste la fonction qu'il exerce en tant que lieutenant du bailli royal en $1344^{15}$. Il consolide cette position privilégiée à la suite de son mariage avec la fille des Santpol, car cette union lui permet de l'apparenter à une famille de la petite noblesse, ce qui le met sur la voie de la promotion sociale. Grâce à ce mariage, Montsó s'installe à Puertomingalvo ${ }^{16}$.

15 Les mariages deviennent un important mécanisme de promotion sociale pour les familles riches et les stratégies qu'elles mettent en place sont fort variées. Contrairement à Montsó, d'autres préfèrent s'allier à de puissantes lignées de la région par le biais du mariage de leurs filles, tandis que leurs fils héritent du patrimoine familial ou encore ils accèdent à d'autres métiers qui consolident leur prééminence, en travaillant comme notaire ou comme membre du clergé. C'est bien le cas de la famille Centelles, la lignée la plus puissante de Vilafranca à la fin du XIV siècle. Le chef de famille, Berenguer, amasse l'une des fortunes les plus grandes de la région et se marie avec María, fille de Juan Merlés, l'un des personnages les plus influents de Cantavieja, ville aragonaise située à 20 kilomètres de Vilafranca ${ }^{17}$. Cinq enfants naissent de ce mariage. L'aîné, Berenguer, travaille comme notaire à la ville valencienne de Morvedre. Le deuxième fils, Antoni, demeure à Vilafranca et hérite du patrimoine familial. Cependant, le succès des Centelles repose sur les mariages arrangés par les trois filles.

L'une d'elles, Llúcia, épouse Francesc Torres, un jurisconsulte de Cantavieja, conservant ainsi les liens avec la ville dont la mère était originaire. Centelles arrange le mariage de leur fille Caterina avec un habitant d'Alcalà de Xivert, Jaume Bri, ce qui permet au marchand du Vilafranca d'établir un réseau commercial fluide avec de nombreux habitants de cette communauté rurale de El Maestrat, appartenant à l'ordre de Montesa et située à 67 kilomètres de Vilafranca. Finalement, Berenguer apparente Orfresa à Nicolau Sorita, un jurisconsulte de Mosqueruela - ville située à 27 kilomètres de Vilafranca et encadrée dans le territoire communal de Teruel - et l'un des personnages les plus influents de la région, comme l'atteste le rôle qu'il joue pendant la période de l'Interrègne (1410-1412) ${ }^{18}$.

17 Ces exemples illustrent que les réseaux constitués par les familles aisées se situent audelà des frontières politiques et des classes sociales. Par cette stratégie, Vilafranca fait office de plateforme d'accès des influences urbaines au milieu rural, en raison du pôle d'attraction qu'elle constitue pour la petite noblesse et pour la bourgeoisie des villes aragonaises. La communauté est à la fois un centre de promotion pour les paysans des villages plus petits, lesquels cherchent de nouvelles opportunités loin de leur lieu de naissance. C'est le cas de Pere Miralles, un jeune éleveur appartenant à la famille la plus puissante de Culla, qui décide de tenter sa chance à Vilafranca au début du $\mathrm{XV}^{\mathrm{e}}$ siècle $^{19}$. Le village étant un centre stratégique dans le commerce de la laine, elle lui offre plus d'opportunités de s'enrichir. Après avoir s'installer à Vilafranca en 1401, Pere conserve 
son patrimoine agraire à Culla, mais il s'immisce dans la vie politique de Vilafranca et organise le réseau de liens nécessaire pour consolider sa position ${ }^{20}$.

En revanche, d'autres jeunes transforment Vilafranca en tremplin pour atteindre des villes plus grandes. Jaume Ferrer, né à Polpís - un hameau d'environ 30 maisons appartenant à l'ordre de Montesa et situé à 76 kilomètres de Vilafranca -, poursuit la voie traditionnelle reliant la région côtière de El Maestrat avec l'Aragon et se déplace jusqu'à Vilafranca pour y résider entre 1395 et $1401^{21}$. Durant ces années, il s'introduit dans les affaires relatives au bétail jusqu'au jour où il s'installe à la ville de Cantavieja, où il commence à exercer comme cardeur. C'est ainsi que les successifs changements de résidence lui permettent d'accéder à l'un des métiers les plus prestigieux du monde rural et de conserver une certaine mobilité économique qui s'étend sur toute la région, voilà donc deux des caractéristiques inhérentes aux élites rurales ${ }^{22}$.

\section{La lutte pour l'espace local}

Les exemples ayant été mentionnés jusqu'à présent témoignent de l'existence d'une intense mobilité dans la région frontalière reliant les royaumes de Valence et d'Aragon. Le va-et-vient des villageois est constant et, en plus des déplacements occasionnels, d'autres relations plus profondes sont aussi entamées. Contrairement à ce que l'on pourrait penser, l'arrivée des étrangers ne génère pas toujours un rejet de la société locale. Loin de là, les nouveaux arrivés et les voisins tissent un réseau de liens qui élargit les structures internes, articulant le tissu social du monde rural au-delà de l'espace strictement local.

Les cas de Jimeno Garcés et du notaire de Vilafranca Simó Bonfill illustrent parfaitement les trames de coopération tissées. À l'abri de l'union que tous les deux manigancent, une série de liens sont noués, dont les intérêts servent à articuler un réseau de sociabilité caractérisé par sa verticalité, dépassant le cadre local et intégrant des membres des différents degrés de l'échelle sociale. Ainsi, une faction est constituée par Garcés, à l'intérieur de laquelle s'insèrent des membres de plusieurs familles habitant différentes villes et communautés situées des deux côtes de la frontière. Parmi les lignées ayant tissé ces réseaux il y a les Santpol, de Puertomingalvo, qui ont une relation étroite avec Garcés et s'apparentent, à leur tour, aux Montsó, de Vilafranca. Se joignent à eux les Saera, de Mosqueruela, et les De l'Onso, de Vilafranca. Ils tissent tous des liens de parenté les uns avec les autres ${ }^{23}$.

21 En conséquence, la famille joue un rôle essentiel dans l'articulation de ces parentèles. Cependant, les affinités dans les affaires servent, elles aussi, à nouer une trame d'intérêts communs qui augmentent largement les chances d'enrichissement. En fait, Simó Bonfill s'allie à Jimeno Garcés, ce qui lui ouvre la voie du secrétariat local, qu'il loue systématiquement, et, en échange de quoi, il prend en charge la gestion des travaux de construction du moulin que Garcés détient à Vilafranca ${ }^{24}$. Une fois bâti, Garcés loue le moulin à Miquel de l'Onso et à Gonçalbo Montsó, tandis que le jeune Jaume Montsó décide de s'introduire dans l'affaire de la meunerie, même si l'entreprise n'aboutit pas $^{25}$. Dans leurs actions on entrevoit un partage des différents secteurs d'investissement parmi les différents membres du clan. Il ne faut pas oublier que les Santpol détiennent le droit d'usage du four de la communauté rurale, ce qui pourrait pousser les Montsó à s'aventurer sur les moulins afin de contrôler, à eux tous, les deux phases principales de la production du pain. 
Une stratégie d'investissement commune est donc mise en place ayant pour but de diversifier les domaines d'action et d'éviter des intérêts opposés entre les parents et les alliés. Toutefois, cette connivence articulée par certaines familles aisées de Vilafranca et d'autres familles étrangères est contestée par une autre faction. Le contrôle que tentent d'exercer les membres du clan dont Garcés est le chef suscite l'opposition d'un groupe de paysans riches de Vilafranca, lesquels s'organisent autour de la figure de Bernat Sanxo, l'habitant le plus influent du village au milieu du xIve siècle. Des membres des lignées des Espert, des Alberic, des Canet et des Salvador - entre autres se rallient à sa cause, et c'est ici que réside l'une des rares différences par rapport au clan mené par Garcés : tous les membres de la faction dirigée par Sanxo sont originaires de Vilafranca.

C'est ainsi que se dessinent les deux clans rivaux. Pourtant, il est à noter que la scission entre les deux factions est moins stricte qu'elle en a l'air. En réalité, les liens familiaux s'entrecroisent parmi les membres des deux clans. Par exemple, le notaire Simó Bonfill, allié de Garcés, est aussi en même temps une personne très proche du chef rival, parce que son fils Simonet est marié avec une fille de Bernat Sanxo ${ }^{26}$. De même, Ramon Canet est l'oncle de Jaume Montsó, et il prend même en charge la tutelle du jeune homme aussi longtemps qu'il est mineur ${ }^{27}$. La mise en œuvre d'une stratégie de mariages grandement endogamique est à l'origine d'innombrables conflits liés aux partages des héritages, car les droits des paysans appartenant à des factions opposées s'entrecroisent alors que personne ne veut céder le moindre pouvoir au clan rival.

Au-delà de la famille, les luttes des factions se répandent dans tous les domaines où se trouvent leurs membres. D'emblée, les nouveaux membres des deux factions rivales sont à l'origine de multiples échauffourées, lesquelles dégénèrent en agressions verbales et physiques, parfois mortelles. Il s'agit normalement d'actions spontanées, déclenchées par la tension liée à la rivalité existante et exécutées par des jeunes et des paysans d'origine humble. En revanche, d'autres actions sont bien planifiées par leurs exécuteurs et constituent la riposte à un plan bien échafaudé d'intimidation du rival, comme celle survenant en 1343. En septembre de cette année-là, Domingo Bernat rassemble un contingent de 44 hommes armés pour attaquer Juan Garcés de Uncastillo, fils de Jimeno, devant son palais de Vilafranca ${ }^{28}$. La violence, tout comme d'autres mécanismes de pression, est utilisée suivant un comportement codifié que les membres des factions connaissent par cœur.

Les disputes entre les factions rivales s'étendent aussi sur les secteurs prioritaires des investissements de leurs membres, car il existe une dispute sous-jacente pour obtenir le contrôle du marché. En 1343, Jaume Montsó acquiert un tiers des droits d'un moulin situé dans le territoire communal de Vilafranca, mais l'achat est saboté par son oncle Ramon Canet et Domingo Alberic, propriétaire des deux tiers du moulin. La faction de Garcés a déjà le contrôle d'un moulin et les alliés de Bernat Sanxo voient donc d'un mauvais œil qu'un membre de la faction rivale puisse acquérir les droits sur ce qu'ils contrôlent. C'est pourquoi ils commettent certaines infractions lorsque le contrat d'achat est envoyé, invalidant ainsi ce contrat. Par la suite, le moulin est fermé par le bailli royal de Morella et, après plusieurs actions en justice, Jaume Montsó renonce à son intention d'entrer dans les affaires de la meunerie. En 1345, le jeune homme cède finalement les droits qu'il avait acquis à Domingo Alberic et le notable de Vilafranca obtient ainsi la pleine propriété du moulin. Autrement dit, le moulin est sous le contrôle exclusif de la faction menée par Bernat Sanxo ${ }^{29}$. 

Évidemment, les magistratures sont l'apanage des voisins de Vilafranca, mais cela n'empêche pas les étrangers de contrôler la politique locale. Le moyen de riposte des chefs étrangers des factions consiste à promouvoir leurs membres à la tête des magistratures afin de favoriser leurs propres intérêts et ceux des alliés, et nuire aux clans adverses. En 1343, Domingo Alberic, allié de Bernat Sanxo, profite des postes au gouvernement que deux membres de sa faction occupent pour obtenir un moratoire qui lui permet de retarder le paiement des impôts locaux qu'il n'avait pas réglés. En revanche, au cours de l'exercice suivant, l'arrivée au gouvernement de deux membres de la faction opposée oblige Alberic à payer sur-le-champ les arriérés d'impôts ${ }^{30}$.

Ce cas met en évidence une autre des caractéristiques des luttes pour s'emparer du pouvoir politique. En réalité, l'alternance des factions aux magistratures locales est monnaie courante, de sorte que durant une année le gouvernement est contrôlé par une faction et durant l'année d'après l'autre clan en tient les rênes. Lorsque cela n'est pas possible - phénomène habituel -, les factions rivales se partagent les magistratures et, donc, la même année certains postes sont occupés par les membres d'une faction, et d'autres sont occupés par des membres du clan contraire. Cette distribution a tendance à entraîner de graves problèmes de gouvernement, étant donné que les prétentions des uns se heurtent à une forte opposition des autres, ce qui entrave la gestion des affaires communautaires.

Le meilleur exemple de cette alternance de gouvernements se trouve au début du $\mathrm{xv}^{\mathrm{e}}$ siècle. Au cours des deux dernières décennies du xive siècle, le riche marchand Berenguer Centelles dirige la faction qui contrôle le gouvernement local sans la moindre contestation. Toutefois, à la fin du siècle, Bartomeu Bonfill réussit à prendre la tête d'une solide alliance dans le but de lui faire face. Finalement, entre 1400 et 1402, le conflit entre les deux factions éclate dans un contexte de forte disette et de crise du fisc local. Confrontés à cette conjoncture, Bonfill et ses alliés parviennent à chasser les protecteurs de Centelles des magistratures. Une fois le pouvoir est sous leur contrôle, ils engagent une dure répression contre leur rival, qui a pour but de détruire les fondements sur lesquels repose la situation privilégiée du riche marchand.

D'une part, ils privent Centelles d'une des principales sources de revenus en lui interdisant de vendre des grains à Vilafranca - il avait profité de la pénurie de céréales pour y conclure des marchés spéculatifs - ; et, d'autre part, il est accusé de fraude fiscale, au moment précis où le fisc local est sur le point de faire faillite, afin de mettre fin aux abattements fiscaux dont il avait bénéficié lorsqu'il tenait les rênes du gouvernement. Face à cette offensive menée par Bonfill, Centelles finit par quitter Vilafranca et emménage à Portell - village valencien situé à 11 kilomètres -, où il décède en $1404^{31}$. Il existe donc un conflit latent pour s'emparer de la politique locale, étant donné qu'il s'agit d'un élément clé de réussite ou d'échec en les luttes des factions qui organisent la vie quotidienne de la communauté.

Au-delà des frontières politiques et physiques, il existe un flux constant entre les villes et les communautés rurales s'étendant de part et d'autre de la frontière qui sépare les royaumes d'Aragon et de Valence. Cette frontière n'entrave aucunement la circulation des individus, quel que soit l'échelon dans la hiérarchie. Ils circulent fréquemment à 
travers un réseau de peuplement qui remonte au processus de conquête et de colonisation des XII et XIII ${ }^{\mathrm{e}}$ siècles. Au milieu de ces réseaux, Vilafranca devient un pôle d'attraction de nobles et bourgeois des villes aragonaises, dont la présence symbolise la pénétration des influences urbaines dans le milieu rural. De la même manière, la communauté est le carrefour des paysans et des artisans des communautés rurales plus petites en quête d'opportunités de promotion sociale, tandis que les notables locaux profitent de cette conjoncture favorable pour tisser un large réseau de contacts dans toute la région. Les mécanismes qui permettent de rassembler tous les acteurs sont les investissements dans les différents secteurs du marché, ainsi que la mise en œuvre d'une politique de mariages stratégiquement mûrie, ce qui permet que les familles d'origine rurale puissent s'apparenter à des lignées de la petite noblesse.

31 La confluence d'intérêts des uns et des autres a des effets très bénéfiques pour tous, mais leur cohabitation n'est évidemment pas toujours dépourvue de conflits. Tant s'en faut, la concurrence à l'échelle locale finit par dégénérer en vive opposition. À l'abri des alliances forgées par le biais de mariages et affaires, des factions intègrent des acteurs des différents degrés de l'échelle sociale, et leurs membres se battent pour contrôler l'économie et la politique locales. Les conflits entre les factions, toujours à l'état latent, s'accentuent au cours des périodes de grandes difficultés, comme dans les années 1340 et au début $d u x^{e}$ siècle. À ces époques-là, la disette de céréales et l'épidémie de la peste entraînent une conjoncture très complexe au cours de laquelle la hiérarchie établie est contestée au sein de la communauté rurale. Cependant, au-delà de ce contexte commun, une différence substantielle peut s'entrevoir entre les deux époques. Jusqu'au milieu du xive siècle, l'influence de la petite noblesse aragonaise est incontournable pour comprendre le tissu social de la communauté. Depuis le XIII ${ }^{\mathrm{e}}$ siècle, grâce aux flux migratoires du processus de colonisation, la petite noblesse et les bourgeois des villes aragonaises ont un territoire privilégié d'expansion vers le nord du Royaume de Valence, région en plein processus de croissance démographique, sociale et économique depuis l'époque de la conquête. Toutefois, leur importance diminue à partir des décennies centrales $d u x^{e}{ }^{e}$ siècle, au moment précis où une série de bouleversements commencent à se manifester, lesquels traduisent la fin de la croissance précédente.

D'ores et déjà, la mobilité de la population rurale reste importante, et il y a même une intensification des migrations de courte ou de moyenne distance à la fin du XIV siècle, à la suite des difficultés résultant des épidémies et des disettes. De la même manière, les bourgeois des zones urbaines exercent un contrôle évident sur certains secteurs du marché, en mettant par exemple des fonds de crédit à la disposition des gouvernements locaux. Pourtant, à l'intérieur des communautés, les élites rurales ont consolidé leur position privilégiée et sont parvenues à fermer les marchés locaux aux investisseurs étrangers. Parallèlement, elles ont étendu leurs tentacules autour des zones rurales avoisinantes, tout en tenant compte des limites de leurs capacités. En conséquence, il n'est plus possible de trouver de factions dirigées par un étranger : la prééminence appartient aux notables de la communauté et ce sont eux qui sont à la tête des factions.

À partir de la moitié du XIve siècle, la société rurale de la frontière entre le Royaume de Valence et le Royaume d'Aragon se développe complètement, ce qui se manifeste par l'éclosion définitive des élites rurales. Les paysans riches des communautés rurales sont en mesure de faire face aux influences urbaines, ce qui contrebalance le partage des pouvoirs à l'échelle locale. Cependant, la crise démographique et économique qui 
secoue la région depuis la deuxième décennie $\mathrm{du} \mathrm{Xv}^{\mathrm{e}}$ siècle consolide la prédominance des villes et de leurs habitants, alors que les communautés rurales plongent dans une dépression qu'elles ne surmonteront qu'au xVI siècle. Durant ce laps de temps, il se produit un processus de réorganisation du réseau de peuplement, dont le résultat ressemble à peine à l'organisation précédente.

\section{BIBLIOGRAPHIE}

BÉAUR Gérard, «Stratigraphier le monde rural. Les catégories sociales en question », dans ANTOINE Annie (dir.), Campagnes de l'Ouest. Stratigraphie et relations sociales dans l'histoire, Rennes, 1999, p. 17-20.

GARCíA FITZ Francisco et JIMÉNEZ ALCÁZAR Juan Francisco (coord.), La Historia peninsular en los espacios de frontera : las "Extremaduras históricas” y la "Transierra” (siglos XI-XV), Cáceres-Murcia, 2012.

GUINOT Enric, Feudalismo en expansión en el norte valenciano. Antecedentes y desarrollo del señorío de la Orden de Montesa, siglos XIII-XIV, Castelló de la Plana, 1986.

GUINOT Enric, « Demografia medieval del nord del País Valencià », dans PÉREZ APARICIO Carmen (éd.), Estudis sobre la població del País Valencià, Valence, 1988, vol. I, p. 229-249.

GUINOT Enric, Els fundadors del Regne de València : repoblament, antroponímia i llengua a la València medieval, Valence, 1999, (2 vol.).

LALIENA Carlos, Sistema social, estructura agraria y organización del poder en el Bajo Aragón en la Edad Media (siglos XII-XV), Teruel, 1987.

LALIENA Carlos (coord.), Matarranya. Gentes y paisajes en la Edad Media, Valderrobres, 2016.

NAVARRo Germán et VILlanUeVA Concepción (éd.), Libro de la bailía de Cantavieja (1428-1470), Zaragoza, Instituto de Estudios Turolenses, 2009.

ROYO Vicent, Vilafranca (1239-1412). Conflictes, mediacions de pau i arbitratges en una comunitat rural valenciana, Castelló de la Plana, Universitat Jaume I, 2016.

ROYO Vicent, Els orígens del Maestrat històric. Identitat, convivència i conflictes en una societat rural de frontera (segles XIII-XV), Benicarló, Onada Edicions, 2017.

ROYO Vicent, Les arrels històriques de la comarca dels Ports. Societat, poder i identitat en una terra de frontera durant la Baixa Edat Mitjana, Benicarló, Onada Edicions, 2018.

VIRGILI Antoni, Ad detrimentum Yspanie. La conquesta de Turtusa i la formació de la societat feudal (1148-1200), Valence, 2001.

\section{NOTES}

1. Voilà l'image dépeinte à travers les derniers travaux réalisés sur les territoires frontaliers. Par exemple, F. García Fitz et J. F. Jiménez Alcázar (coord.), La Historia 
peninsular en los espacios de frontera: las "Extremaduras históricas" y la "Transierra" (siglos XI$\mathrm{xv})$.

2. Les cas catalan et valencien ont été étudiés dans A. Virgili, Ad detrimentum Yspanie. La conquesta de Turtusa i la formació de la societat feudal (1148-1200); et E. Guinot, Feudalismo en expansion en el norte valenciano. Antecedentes y desarrollo del señorío de la Orden de Montesa, siglos XIII-XIV.

3. Ainsi c'est montré par C. Laliena, Sistema social, estructura agraria y organización del poder en el Bajo Aragón en la Edad Media (siglos XI-XV); et C. Laliena (coord.), Matarranya. Gentes y paisajes en la Edad Media.

4. Une synthèse de ce complexe processus dans V. Royo, Els orígens del Maestrat històric. Identitat, convivència i conflictes en una societat rural de frontera (segles XIII-XV); et V. Royo, Les arrels històriques de la comarca dels Ports. Societat, poder $i$ identitat en una terra de frontera durant la Baixa Edat Mitjana.

5. $11 \%$ des noms de famille restants sont utilisés indifféremment dans les deux territoires, et $4 \%$ des noms de famille restants ont une origine incertaine. Ces chiffres diffèrent des autres communautés du nord du Royaume de Valence, où plus de $80 \%$ des noms de famille ont d'habitude une origine catalane, alors que l'ascendance aragonaise n'est que $10 \%$. E. Guinot, Els fundadors del Regne de València: repoblament, antroponímia $i$ llengua a la València medieval, vol. I, p. 136-141.

6. La description de la communauté rurale dans V. Royo, Vilafranca (1239-1412). Conflictes, mediacions de pau i arbitratges en una comunitat rural valenciana, p. 89-107.

7. Arxiu de la Corona d'Aragó, Cancelleria Reial, reg. 234, f. 61v.

8. Dans le Royaume d'Aragon, les infanzones, membres de la petite noblesse, ont droit à certaines exemptions fiscales grâce à une concession royale.

9. Arxiu de la Corona d'Aragó, Cancelleria Reial, reg. 219, f. 236.

10. Arxiu Històric Notarial de Morella, $n^{\circ} 9,04 / 04 / 1327$ et 22/06/1328.

11. C'est le cas de Juan de Santpol. Ibid., $\mathrm{n}^{\circ} 15,05 / 10 / 1344$.

12. Ibid., $\mathrm{n}^{\circ} 5,27 / 03 / 1341$.

13. Ibid., $\mathrm{n}^{0} 7,21 / 06 / 1344$.

14. Ibid., $\mathrm{n}^{\circ} 19,22 / 04 / 1363$

15. Ibid., $\mathrm{n}^{\circ} 16,22 / 12 / 1343$.

16. Ibid., $\mathrm{n}^{\circ} 7,04 / 07 / 1345$.

17. Cantavieja compte presque 370 maisons à cette époque et est à la tête d'un bailliage appartenant à l'ordre de l'Hôpital. G. Navarro et C. Villanueva (éd.), Libro de la bailía de Cantavieja (1428-1470).

18. En 1411, Sorita est nommé lieutenant du gouverneur du Royaume de Valence en raison de son ralliement à la cause de Jaume d'Urgell. V. Royo, Vilafranca (1239-1412). Conflictes, mediacions de pau $i$ arbitratges en una comunitat rural valenciana, p. 311 . Les références aux mariages des enfants de Berenguer et María sont disponibles dans Arxiu Històric Notarial de Morella, $\mathrm{n}^{\circ}$ 70, 19/08/1411.

19. Culla, une communauté rurale de El Maestrat située à 15 kilomètres de Vilafranca, avoisine les 100 maisons à la fin du XIV siècle, alors que Vilafranca en compte environ 130. E. Guinot, « Demografia medieval del nord del País Valencià », p. 248. 
20. Il occupe deux magistratures dans le gouvernement local entre 1405 et 1408 . Le notable Bartomeu Sala décide de le nommer son exécuteur testamentaire. Arxiu Històric Notarial de Morella, $\mathrm{n}^{\circ}$ 78, 30/10/1409.

21. La démographie de Polpís est disponible dans E. Guinot, «Demografia medieval del nord del País Valencià », p. 244.

22. G. Béaur, "Stratigraphier le monde rural. Les catégories sociales en question ", p. $17-20$.

23. En fait, Miquel de l'Onso est consanguineum de Jaume Montsó et beau-frère de Jaume Saera, lequel est une personne très proche de María de Santpol, épouse dudit Montsó. Arxiu Històric Notarial de Morella, nº 14, 29/04/1362; ibid., nº 19, 22/04/1363.

24. De même, Garcés lègue à Bonfill ses droits sur la moitié dudit moulin en guise de récompense pour sa gestion à la tête des travaux. Ibid, $n^{\circ}$ 9, 04/04/1327 et 04/10/1327.

25. Ibid., $\mathrm{n}^{\circ}$ 5, 17/06/1340; et ibid., $\mathrm{n}^{0} 16,13 / 12 / 1343$ et 19/12/1343.

26. Ibid., n ${ }^{\circ} 5,05 / 06 / 1339$.

27. Ibid., $\mathrm{n}^{\circ} 15,20 / 09 / 1342$.

28. Ibid., $\mathrm{n}^{\circ} 15,05 / 10 / 1344$.

29. Ibid., $\mathrm{n}^{\circ} 16,13 / 12 / 1343,19 / 12 / 1343,16 / 02 / 1344$ et 09/02/1345.

30. Ibid., $\mathrm{n}^{\circ} 6,03 / 01 / 1343$; et ibid., $\mathrm{n}^{\circ} 16,23 / 10 / 1343$.

31. Une analyse de la lutte engagée par les deux factions est disponible dans V. Royo, Vilafranca (1239-1412). Conflictes, mediacions de pau $i$ arbitratges en una comunitat rural valenciana, p. 561-607.

\section{RÉSUMÉS}

Cet article analyse les relations entre les zones de montagne des royaumes de Valence et d'Aragon pendant le Moyen Âge. L'étude se penche sur les relations établies entre le village de Vilafranca, situé à la frontière du Royaume de Valence, et les autres villages aragonais. À partir des sources notariales et des registres de la chancellerie royale, on analyse la colonisation de Vilafranca après la conquête $d u$ XIII ${ }^{e}$ siècle et les liens tissés entre les riches familles du village et l'oligarchie des villes d'Aragon, à travers les mariages, le commerce de produits agraires et l'échange de rentes pendant le XIV ${ }^{\mathrm{e}}$ siècle. On étudie précisément les conflits survenus entre les élites rurales de Vilafranca à la suite de l'ingérence des acteurs étrangers dans les affaires de la communauté rurale.

\section{AUTEUR}

\section{VICENT ROYO PÉREZ}

Docteur en Histoire 


\title{
Remploi et mobilité des bois de construction dans le bâti subalpin médiéval et moderne : le cas du massif du Mercantour (Alpes françaises)
}

\author{
Vincent Labbas
}

1 Le sujet est ici la mobilité du bois employé dans la construction subalpine, qu'il s'agisse de l'approvisionnement en matière première ou du réemploi des bois d'œuvre à chaque chantier de construction. Le réemploi, autrement dit la récupération de bois issus d'anciens chantiers, traduit une utilisation et un entretien régulier du bâti. Il apparaît comme une pratique basée sur l'économie des ressources ligneuses que l'on observe sur une longue durée, du XIV siècle jusqu'au début du $\mathrm{xx}^{\mathrm{e}}$ siècle. L'acte de recycler les matériaux tient par ailleurs une place importante dans la littérature historique, ${\text { archéologique }{ }^{1} \text { et architecturale }}^{2}$.

2 Recycler, récupérer, trier. Le réemploi ainsi réparti entre ces trois catégories par Yvan Lafarge $^{3}$, fait écho à la distinction proposée par Fabien Blanc ${ }^{4}$. Il distingue les réemplois polymorphes, matériaux mis en œuvre sans préférence particulière, les remplois anamorphes dont la forme est bien " adaptée à la construction d'éléments spécifiques ", sans pour autant correspondre à la fonction initiale, soit une réutilisation, et les remplois isomorphes, utilisation d'un élément à l'identique, dans la même fonction.

3 La mobilité des bois d'œuvre induit également celle de la provenance des arbres pour les besoins de la construction. Dans la mesure où la dendrochronologie occupe une place incontournable au sein de cette recherche, il est nécessaire de mentionner les recherches effectuées en " dendro-provenance ${ }^{5} »$ ou dendro-provenancing. Cette branche de la dendrochronologie émerge dans les années $1970^{6}$. Le terme apparaît à Tucson (Arizona) en 1994, à l'occasion d'une conférence internationale ${ }^{7}$. En Provence rhodanienne, la question de la provenance des fustes a été principalement abordée pour la construction urbaine au Moyen Âge et dans le cadre de travaux historiques et 
archéologiques. Les études montrent que les bois de conifère sont massivement importés depuis les Alpes du Sud, la Savoie ou le Vercors $8 / 9$.

4 Concernant l'histoire et l'archéologie de la montagne, sa chronologie et ses modes d'occupation, son économie, ses frontières et ses échanges, la littérature livre, pour le massif du Mercantour notamment, un décryptage précieux sur les communautés de montagne au Moyen Âge et à l'époque moderne ${ }^{10}$. Par ailleurs, les approches archéologiques récentes montrent que l'histoire de la montagne s'écrit aussi dans la longue durée ${ }^{11}$, de la Préhistoire jusqu'aux périodes sub-contemporaines. Les recherches dendrochronologiques conduites durant les années 2000 et 2010 par JeanLouis Édouard ont livré d'une part des longues chronologies de référence pour le mélèze dans les Alpes du Sud ${ }^{12}$ et d'autre part l'existence d'un bâti ancien en haute montagne $^{13}$, notamment dans les Hautes-Alpes mais aussi dans le massif du Mercantour. C'est également ce que tendent à mettre en évidence les recherches que j'ai menées dans le cadre d'une thèse de doctorat soutenue en 2016 sur le bâti de haute montagne dans le massif du Mercantour ${ }^{14}$. L'objectif de cette recherche était d'ancrer chronologiquement le bâti de haute montagne grâce à la dendrochronologie, qui fournit des dates absolues, et par l'archéologie du bâti, notamment à travers la lecture stratigraphique des structures en élévation. L'étude des modes et des techniques de construction de ces granges implantées au-dessus de $1500 \mathrm{~m}$ d'altitude occupe ici une place tout aussi importante. Ces constructions, dont la plupart sont montées en blockbau, ou pans-de-bois pleins, sont indissociables des forêts de mélèzes qui constituent la ressource principale en matière première. C'est pourquoi la question du rapport des hommes avec la forêt est inéluctable dans cette recherche.

Cette recherche interdisciplinaire nous conduit à exposer dans une première partie les méthodes utilisées, en particulier celles de la dendrochronologie, mais aussi le matériel. La provenance des bois d'œuvre fera l'objet d'une seconde partie. Un troisième et dernier point sera consacré au réemploi dans la construction subalpine.

\section{Méthodes et outils}

\section{Corpus}

6 La constitution du corpus de bâtiments procède tout d'abord d'une stratégie de sélection des sites. L'objectif était d'approcher un bâti le plus «préservé » possible de transformations récentes. Pour orienter les prospections, trois outils cartographiques ont été utilisés : les bases de données du Parc du Mercantour, les cartes topographiques et les photographies aériennes. Ces données actuelles ont été systématiquement confrontées aux cadastres napoléoniens ${ }^{15}$ établis au cours du siècle pour obtenir une première attestation de l'ancienneté d'un édifice. Plus de 200 bâtiments ont ainsi été observés. Sur cette base, 90 édifices, situés au-dessus de 1400 d'altitude et jusqu'à $2150 \mathrm{~m}$ d'altitude et repartis sur 58 sites (fig. 1, à gauche) ont été sélectionnés. Cette sélection s'est faite sur la base d'un potentiel archéologique en termes de chronologie relative et de techniques de construction, et sur la base d'un potentiel dendrochronologique en termes de nombre de bois à prélever.

7 Concernant l'échantillonnage dendrochronologique, 1150 prélèvements représentant 750 bois de construction ont été effectués. Cet échantillonnage livre 541 dates qui ont 
permis d'établir une longue chronologie de cernes qui couvrent quasiment mille ans, de l'année 958 jusqu'à 1933.

Fig. 1. - Carte du massif du Mercantour et des sites étudiés.

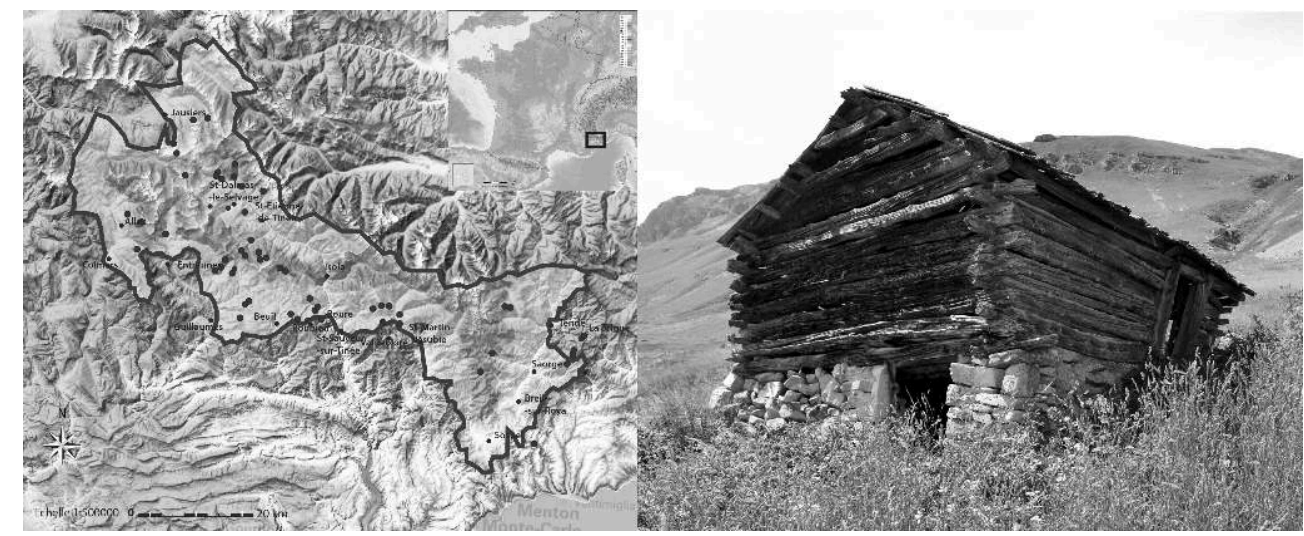

Photo d'une grange dans la vallée de la Tinée. Fond de carte : parc national du Mercantour et IGN

Photographies et DAO : V. Labbas (C).

\section{Méthodologie}

L'approche interdisciplinaire de cette recherche a nécessité aussi bien l'emploi des méthodes propres à l'archéologie du bâti (déconstruction stratigraphique des élévations, production de relevés, analyse des modes de construction) qu'à la dendrochronologie.

La dendrochronologie est la discipline qui étudie les variations interannuelles des cernes des arbres. Cependant, avant d'en présenter les principaux points méthodologiques, il est nécessaire de savoir de quoi est constitué un arbre (fig. 2, en haut à gauche). La moelle, au centre de l'arbre, correspond à la première année de la vie de l'arbre. Chaque année l'arbre crée du bois par couche successive : ces "couches » sont appelées des cernes de croissance. Les cernes d'aubier constituent une couronne périphérique de couleur plus claire. Ces cernes sont la partie «vivante » du bois, dans lesquels circule la sève. La présence des cernes d'aubier est essentielle en dendrochronologie dans la mesure où il s'agit des derniers cernes produits par l'arbre, celles qui permettent la datation la plus précise ${ }^{16}$. 
Fig. 2. - Méthodologie de la dendrochronologie.

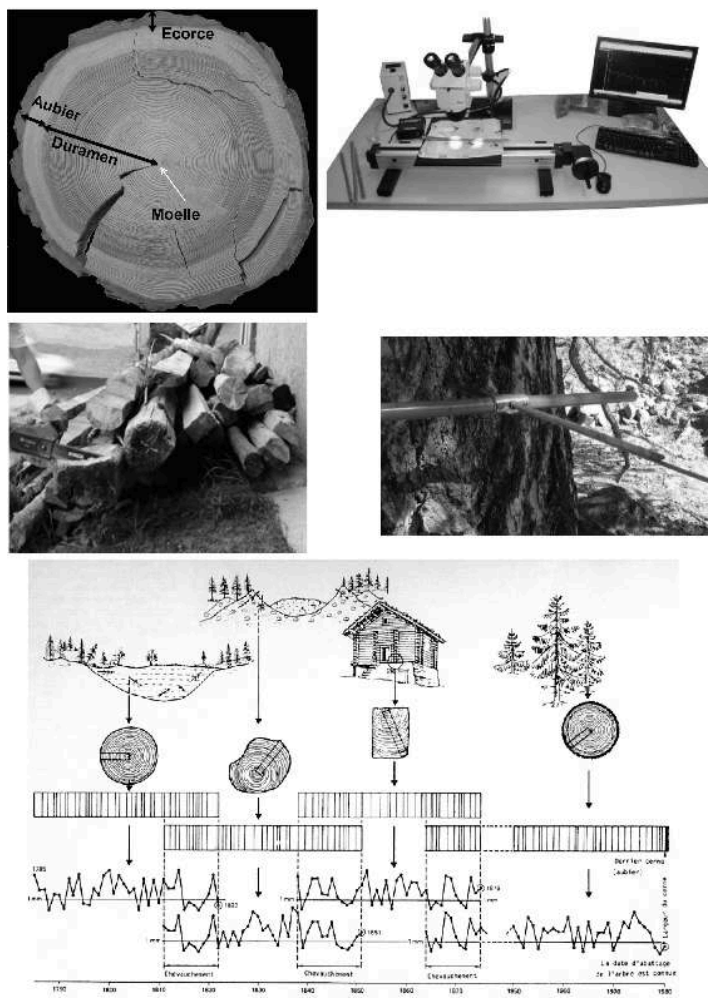

Coupe radiale d'un arbre ; loupe binoculaire et table de mesure ; bois déposé ; prélèvements à la tarière de Pressler ; schéma de la construction des référentiels.

(c) Clichés de L. Shindo, schéma de G.N. Lambert.

Les étapes qui procèdent de l'analyse dendrochronologique sont effectuées en laboratoire, la première étape étant la mesure des largeurs des cernes. Cette étape est effectuée à l'aide d'une loupe binoculaire et d'une table de mesure ${ }^{17}$ pilotée par un logiciel spécifique à la dendrochronologie ${ }^{18}$ (fig. 2, en haut à droite). Les largeurs de cernes mesurées permettent d'obtenir des séries chronologiques, sous forme de graphiques qui sont ensuite comparées lors de l'étape appelée «la synchronisation ». La synchronisation consiste à comparer une série avec une autre afin de déterminer une corrélation entre elles $^{19}$ grâce à différents tests statistiques, mais aussi par comparaisons visuelles. L'étape finale $\mathrm{du}$ processus de datation concerne la détermination des phases d'abattage qui fixent la date de la mort de l'arbre. Pour chaque bois, l'aubier conservé fournit une date d'abattage, ou une estimation dans le cas où l'aubier n'est pas complet, ce qui constitue la majorité des $\operatorname{cas}^{20}$. Les phases d'abattage, sont déterminées par la proximité chronologique et contextuelle des bois datés, c'est-à-dire par un intervalle commun entre plusieurs bois synchrones. La mise en relation entre l'ensemble des données conduit à restituer une partie de l'histoire d'un édifice.

\section{Bois de construction et provenance des arbres}

Dans le massif du Mercantour, la provenance des arbres est naturellement locale, c'est le mélèze qui est l'espèce majoritairement employée. Dans la partie inférieure de l'étage, autour de $1500 \mathrm{~m}$ d'altitude, le mélèze côtoie ponctuellement d'autres espèces, 
telles que le pin sylvestre ou le chêne dans les constructions. Au-delà de ce constat, nous proposons, grâce à des descripteurs dendrochronologiques et archéologiques, d'affiner cette provenance.

Dans un premier point, nous montrerons que l'usage des matrices carrées de corrélation livre des résultats permettant de différencier les bois d'œuvre provenant de plusieurs sites proches les uns des autres. Un second point sera consacré aux résultats obtenus par l'étude de deux chantiers de construction.

\section{La provenance des arbres qui fournissent le bois d'œuvre : une approche par l'utilisation des matrices carrées de corrélation}

13 Contrairement aux chênes en Europe du Nord, la dendro-provenance appliquée au mélèze s'avère délicate en raison de l'homogénéité du signal climatique commun aux mélèzes dans les Alpes du Sud. Cependant, le calcul des matrices carrées de corrélation ${ }^{21}$ met en évidence des individualisations correspondant à des sites précis. Ce calcul, systématiquement effectué pour chaque groupe de bois issus d'un édifice, a été testé afin de déterminer dendrochronologiquement la provenance des bois à plusieurs échelles : dans un premier temps, à l'échelle de plusieurs vallées du massif du Mercantour, dans un second temps, à l'échelle de trois vallons limitrophes (fig. 3). Le calcul des matrices carrées de corrélation permet d'apprécier la qualité des synchronismes entre plusieurs paires de séries individuelles, soit plusieurs bois au sein d'une structure, voire de plusieurs structures. La matrice calcule des coefficients de corrélation (entre 0 et 1 ; plus le résultat est proche de 1, plus la corrélation est bonne) qui sont ici traduits par des niveaux de gris, simplifiant la lecture et l'appréciation visuelle. Par ailleurs, ce calcul prend tout son sens dans l'analyse archéologique d'un édifice, dans la mesure où les groupes de bois synchrones sont comparés à l'analyse stratigraphique de la structure. Sur l'écran, on peut visualiser l'exemple d'une matrice calculée pour un édifice et rangée par couleur. De manière simple, plus les carrés sont foncés, plus le synchronisme entre deux individus est fort. 
Fig. 3. - Matrices carrées des corrélations.
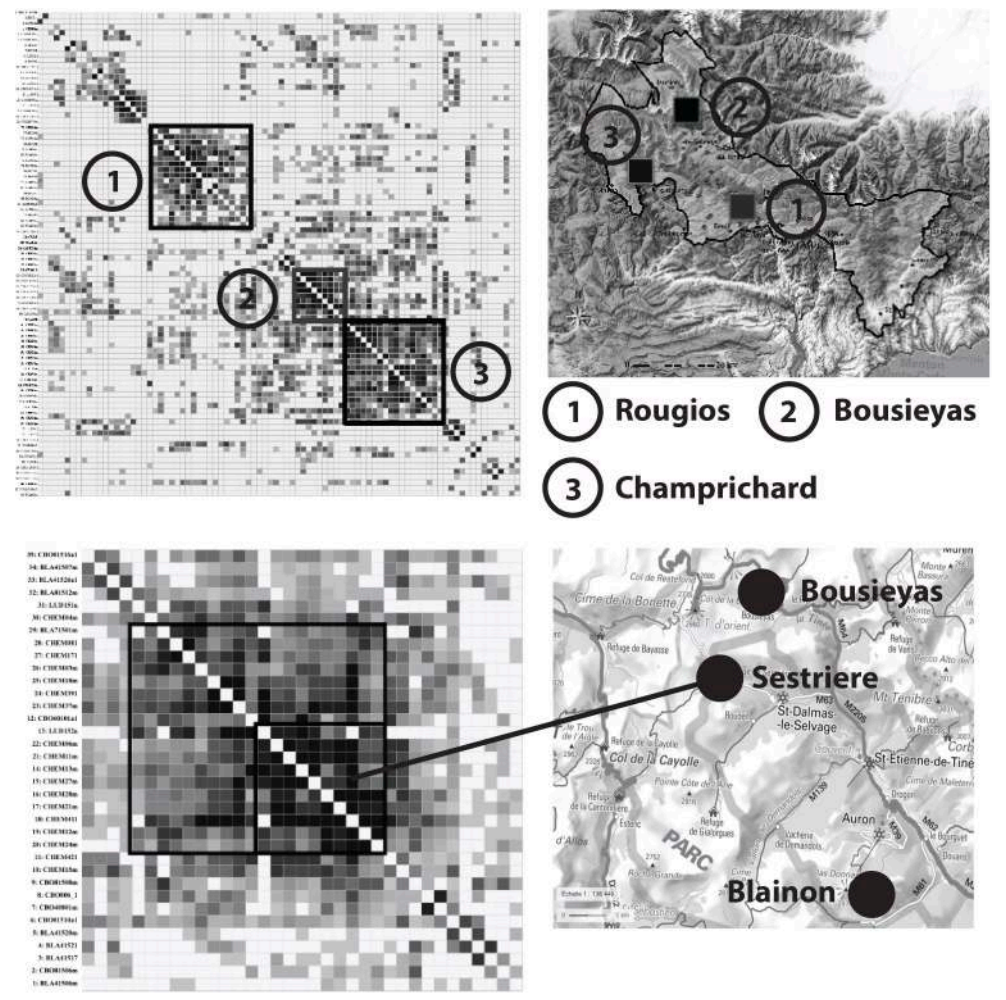

(c) DAO de V. Labbas; fonds de carte IGN

14 Ce que l'on observe sur la matrice ci-dessous (fig. 3, en haut) qui fait bien apparaître trois groupes contemporains représentant trois sites distincts. Cette matrice a été calculée avec 88 individus contemporains, tous abattus au XIX siècle. À une échelle plus restreinte, de trois vallons très proches géographiquement en l'occurrence, un calcul de matrice pour 35 individus abattus dans la première moitié du $\mathrm{XIX}^{\mathrm{e}}$ siècle et provenant de trois sites. L'objectif était de tester la possibilité de différencier ces vallons. On constate que tous les bois corrèlent entre eux plus ou moins fortement. Les individus situés dans le grand carré rouge viennent tous d'un même bâtiment, qui est une grange du vallon de Sestrière, donc un lot homogène de bois d'œuvre. Au sein de ce carré, dans lequel les corrélations sont les plus fortes, on remarque un petit groupe dans le petit carré rouge dans lequel les synchronismes sont les plus forts. Ces deux groupes de bois contemporains et issus d'un même contexte suggèrent deux terroirs dendrologiques différents. À la périphérie de la matrice, on trouve les bois provenant des deux autres sites, marqués par des synchronismes moins forts. Ces deux exemples tendraient à mettre en évidence des provenances différentes de groupes d'arbres issus d'un même secteur, en raison de la distance des points sur la matrice. En périphérie de la matrice, ces groupes d'arbres sont issus d'un territoire pourtant proche.

\section{Provenance des arbres dans un chantier de construction}

15 La question que nous abordons dans ce chapitre est celle de la provenance des arbres au sein d'un chantier de construction dans l'étage subalpin. L'utilisation des matrices carrées de corrélation est ici appliquée conjointement à l'analyse archéologique des élévations mais aussi à celle des sources d'archives. Les deux exemples présentés sont 
un hameau implanté dans la haute vallée du Verdon et une grange dans la vallée de la Tinée.

Un chantier d'urgence : La reconstruction du hameau de Champrichard (Allos, 04) suite à une avalanche en 1805

Le hameau de Champrichard est un hameau de montagne, aujourd'hui abandonné, situé à $1750 \mathrm{~m}$ d'altitude dans la haute vallée du Verdon, sur le territoire de la commune d'Allos dans les Alpes-de-Haute-Provence (fig. 4, en haut). Durant les $\mathrm{XVII}^{\mathrm{e}}$ et $\mathrm{XVIII}^{\mathrm{e}}$ siècles, il était situé sur une ancienne voie de communication qui reliait la vallée du Verdon à celle du Var. L'étude dendrochronologique et archéologique, conduite sur trois des cinq bâtiments du hameau, permet de dater ce hameau de l'époque moderne, à partir du milieu du $\mathrm{XVII}^{\mathrm{e}}$ siècle jusqu'à son abandon dans la première moitié $d u \mathrm{xx}^{\mathrm{e}}$ siècle.

Fig. 4. - Présentation du site de Champrichard (Allos, 04).
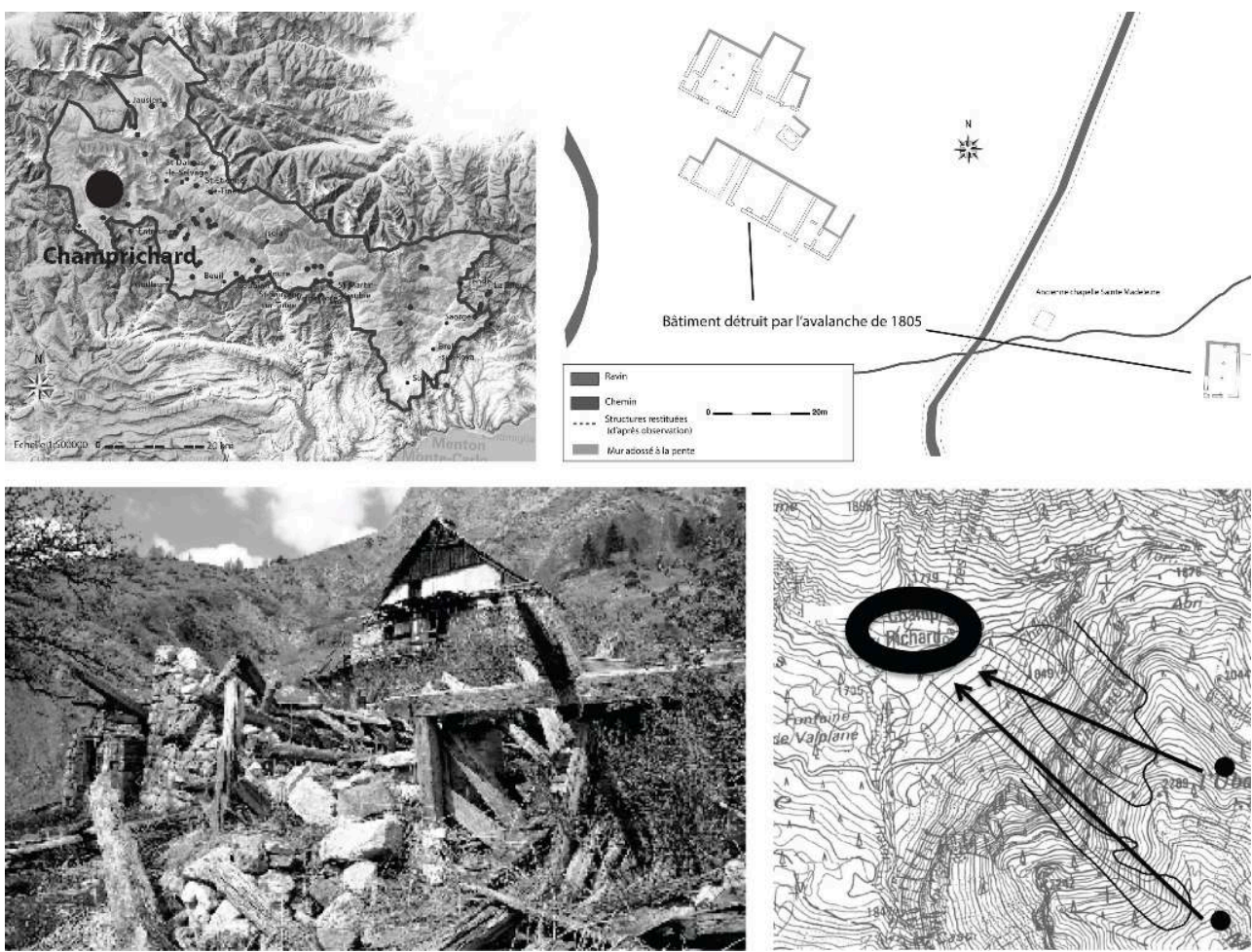

Plan du site, clichés depuis le sud ; carte des couloirs d'avalanches.

D'après IRSTEA.

Les sources d'archives étudiées par Joël Vallauri ${ }^{22}$ mentionnent deux épisodes d'avalanche qui ont détruit deux bâtiments du hameau et tué près d'une quinzaine de personnes en janvier 1805. L'analyse conjointe des sources dendrochronologiques, archéologiques et textuelles permet de déterminer que les deux avalanches sont parties du versant opposé au hameau, depuis l'ubac (fig. 4, en bas à droite). Seuls les bâtiments situés au sud font état d'une reconstruction durant l'année 1805. Par ailleurs, les victimes recensées dans la catastrophe habitaient effectivement ces bâtiments. Le maire d'Allos demande que 600 mélèzes soient coupés dans les forêts communales pour les besoins de la reconstruction cette même année. Le bloc-diagramme 
dendrochronologique (fig. 5, à gauche) met en évidence un important groupe de bois abattus en 1805. La majorité de ces arbres ont, par ailleurs, une centaine d'années au moment de leur abattage (ils ont commencé à pousser au début du xvIII ${ }^{\mathrm{e}}$ siècle). Le calcul de la matrice carrée des corrélations indique un fort synchronisme entre les bois coupés cette année-là (fig. 5, à droite). À l'intérieur de ce groupe, un sous-ensemble d'individus fait apparaître les plus fortes corrélations et mettrait en évidence un terroir dendrologique cohérent ${ }^{23}$, et par extension, une provenance commune. Au début du $\mathrm{XIX}^{\mathrm{e}}$ siècle, les bois communaux d'Allos sont manifestement proches du hameau : au nord-ouest et au sud dans le vallon du Chadoulin. Il est cependant difficile de déterminer avec précision si les arbres proviennent de l'une ou l'autre de ces forêts, voire des deux espaces forestiers.

Fig. 5. - Bloc-diagramme chronologique et matrice carrée du site de Champrichard.

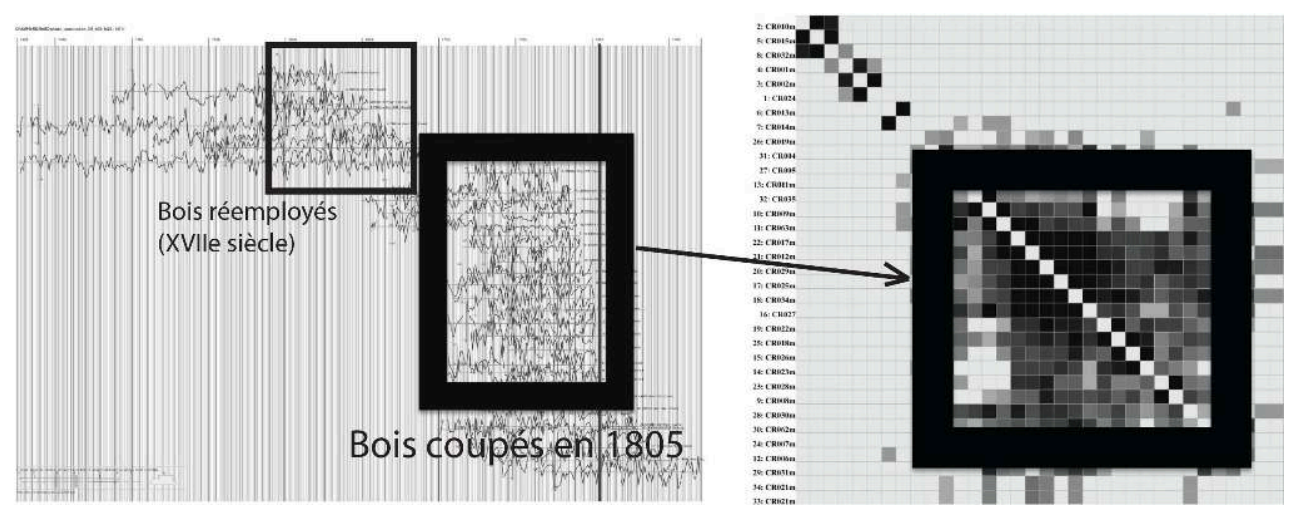

(c) DAO : V. Labbas

La grange et le logis : les chantiers de construction d'une grange à la fin du XVII siècle

18 Le second exemple nous conduit plus à l'est dans le massif du Mercantour, dans le vallon de Roya, affluent de la Tinée, sur la commune de Saint-Étienne-de-Tinée. Dans ce vallon axé est-ouest, le bâti est implanté à l'adret, au nord. On trouve les forêts de mélèzes sur le versant opposé à l'ubac (fig. 6, en haut).

Les 18 bâtiments étudiés dans le vallon de Roya livrent une chronologie de la construction depuis le xiII ${ }^{\mathrm{e}}$ siècle. Au centre du vallon, le hameau, est encore habité. Les granges construites dans les pentes, au nord et à l'ouest du hameau, sont majoritairement abandonnées, et constituent un témoignage des anciennes activités agropastorales, qui représentaient l'économie principale jusqu'au milieu du $\mathrm{xx}^{\mathrm{e}}$ siècle. L'édifice présenté ici est construit dans la pente, localement forte. Il est long de 25 mètres, large de $6 \mathrm{~m} 50$ et intégralement conservé en élévation. 
Fig. 6. - Présentation de la grange logis de Blainon (Saint-Étienne-de-Tinée, 06).

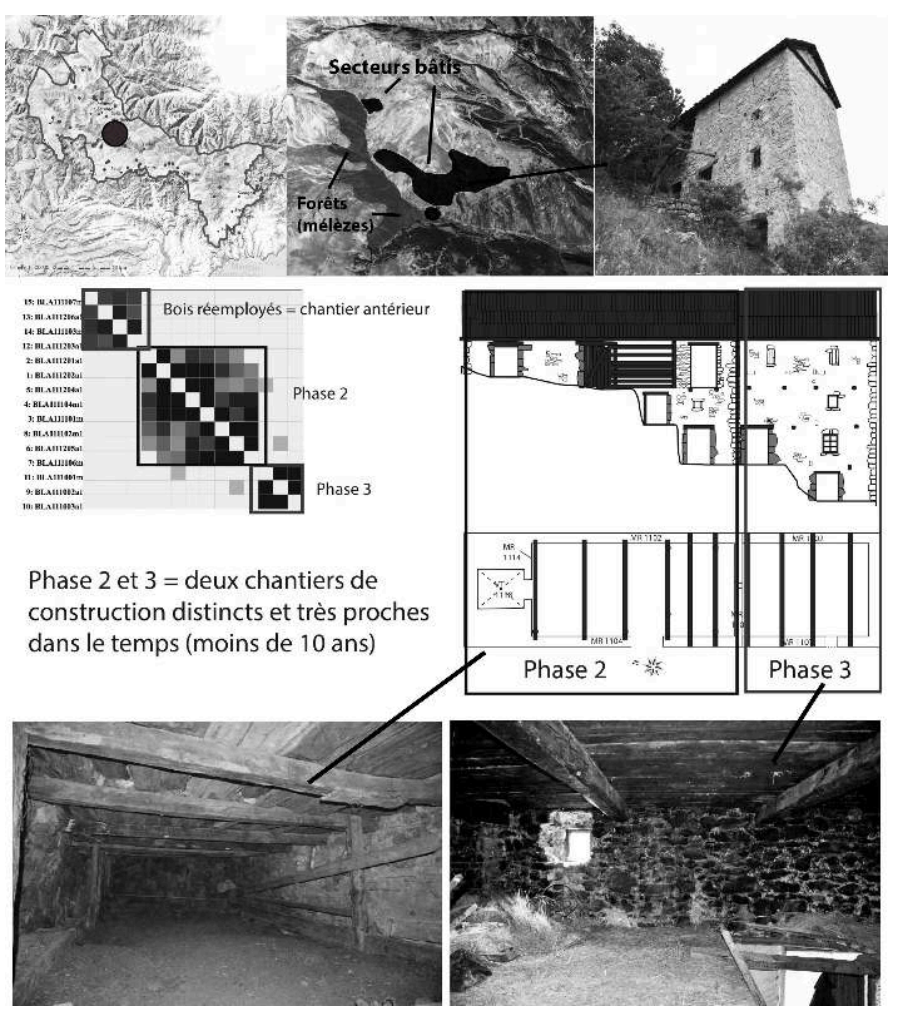

Plan, phasage chronologique, matrice carrée des corrélations et vues des plafonds.

Fonds de carte : parc national du Mercantour et IGN ; photographies et (c) DAO : V. Labbas.

20 L'analyse stratigraphique met en évidence deux grandes phases de construction: la première concerne la construction de la partie grange, en amont de la pente, pour parquer les bêtes et datée de 1679 par la dendrochronologie. La seconde phase de construction est une extension habitable de l'édifice vers l'aval, en 1682 (fig. 6, au centre). Bien que chronologiquement proche, la partie grange et le logis procèdent donc de deux chantiers de construction distincts. Les poutres employées dans les plafonds de la grange sont pour la plupart des bois simplement écorcés, alors que dans le logis les poutres sont équarries et plus soignées d'une manière générale. La matrice carrée de corrélation, calculée pour les bois de ce bâtiment, met ici en évidence trois groupes. Le premier groupe, encadré en vert en haut à gauche de la matrice, représente un ensemble de bois datés du début $d u \mathrm{xVI}^{\mathrm{e}}$ siècle qui ont été réemployés dans le chantier de construction de la grange. Au centre, le groupe encadré en rouge représente les bois employés dans la construction de la partie grange, bâtie en 1679 et schématisé à droite. Enfin, le groupe encadré en bleu, représente les bois employés dans le logis construit en 1682 .

21 Alors que les bois employés dans la grange et dans le logis sont synchrones - dans la mesure où les arbres ont poussé en même temps - la matrice fait pourtant apparaître une absence de synchronisme entre ces deux groupes, ce qui met bien en évidence des terroirs dendrologiques bien distincts et, par extension, des sources d'approvisionnements également distinctes. 


\section{Le réemploi de bois d'œuvre} matériellement l'adaptation des communautés humaines aux réglementations forestières, tout en mettant en évidence une économie des moyens pour transformer la ressource-bois en matériaux à bâtir.

Dans le bâti subalpin du massif du Mercantour, les bois d'œuvre sains et issus des chantiers de reconstruction antérieurs sont réutilisés à chaque nouveau chantier. Un chantier de reconstruction est, grâce à la dendrochronologie, daté par l'apport de bois neufs.

Les exemples présentés proviennent de deux sites de la vallée de la Tinée (Alpes Maritimes). Les bâtiments du premier site, Bousieyas (commune de Saint-Dalmas-leSelvage), introduisent le phénomène de réemploi systématique sur une longue durée, $\mathrm{du} \mathrm{XII}^{\mathrm{e}}$ siècle jusqu'au début du $\mathrm{xx}^{\mathrm{e}}$ siècle. Le second site, Blainon (Saint-Étienne-deTinée), éclaire également la pratique du réemploi, à la fin du XIII ${ }^{e}$ siècle et au début du XIV ${ }^{e}$ siècle, et conduit à s'interroger sur le déplacement des bois d'œuvre d'un édifice vers un autre, implanté à proximité.

\section{Réemploi et reconstruction : le site de Bousieyas (Saint-Dalmas-le- Selvage, 06)}

Bousieyas est un hameau au nord du massif, implanté à $2000 \mathrm{~m}$ d'altitude et dépendant de la commune de Saint-Dalmas-le-Selvage. Huit granges situées dans l'alpage au nordouest du hameau ont été étudiées. Les prélèvements et analyses dendrochronologiques livrent 145 dates, de l'année 1159 jusqu'à l'année 1927, formant une chronologie continue de 936 ans qui couvre la période 991-1927, c'est-à-dire quasiment l'ensemble du II ${ }^{\mathrm{e}}$ millénaire. Deux granges sont ici présentées à titre d'exemple (fig. 7 et 8). La première grange, à gauche, a livré des dates du milieu du XII ${ }^{\mathrm{e}}$ siècle jusqu'au premier tiers $\mathrm{du} \mathrm{xx}^{\mathrm{e}}$ siècle. La seconde est implantée sur un alpage au sud du hameau et a fourni des dates également du milieu du XII ${ }^{\mathrm{e}}$ siècle jusqu'au milieu du XVIII ${ }^{\mathrm{e}}$ siècle. 
Fig. 7. - Plusieurs clichés d'une grange ( $\mathrm{xll}^{\mathrm{e}}-\mathrm{xx}$ siècle) de l'alpage de Bousieyas (Saint-Dalmas-leSelvage, 06).

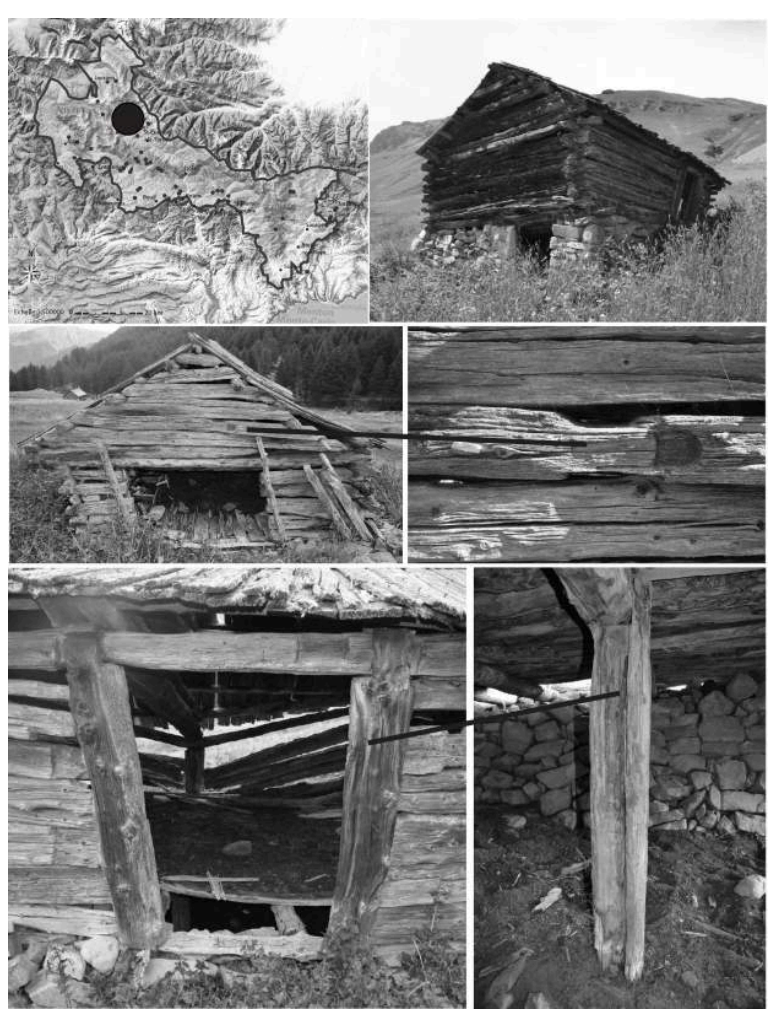

Fond de carte : parc national du Mercantour et IGN ; photographies et DAO @ : V. Labbas 
Fig. 8. - Seconde grange de l'alpage de Bousieyas (Saint-Dalmas-le-Selvage, 06).

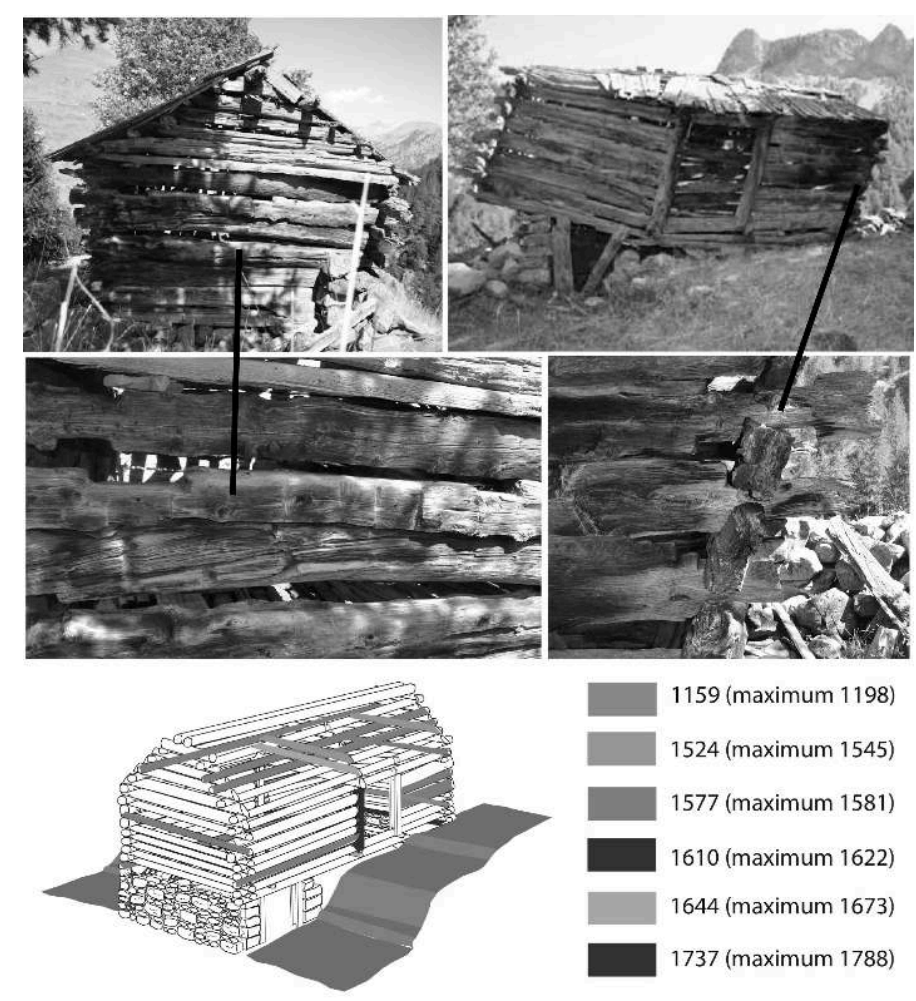

Clichés et phasage chronologiques ( $\mathrm{XII}^{\mathrm{e}}$-xVIII${ }^{\mathrm{e}}$ siècle).

(c) Photographies et DAO : V. Labbas.

Dans la première grange, sept phases de reconstruction ont pu être identifiées depuis l'année 1146 jusqu'en 1927, avec des phases beaucoup plus rapprochées entre elles durant les $\mathrm{XVII}^{\mathrm{e}}$, XVIII ${ }^{\mathrm{e}}$ et $\mathrm{XIX}^{\mathrm{e}}$ siècles (fig. 7). Le réemploi de bois issus des chantiers précédents s'observe à chaque nouveau chantier. Les mailles, qui forment les élévations en pans de bois pleins, sont démontées et acquièrent une nouvelle place, souvent une nouvelle fonction, comme l'illustre l'exemple de ce linteau identifié grâce à son encoche pour emboîter un piédroit et le trou façonné pour un gond de porte, ici refaçonné en maille de pan de bois (fig. 7, au centre). À l'étage inférieur de la grange, un piédroit de porte issu d'un chantier du milieu du XVII ${ }^{e}$ siècle est réemployé comme poteau lors de la dernière reconstruction de la grange en 1927, qui voit la fonction de l'étage supérieur, dédiée initialement au stockage du foin, modifiée pour parquer le bétail à l'instar du premier niveau.

La seconde grange (fig. 8) présente une construction et une fonction similaire à la précédente. Le soubassement est bâti en pierres sèches montées grossièrement et constitue un solin pour l'élévation, qui est montée en mailles de bois empilées formant des pans de bois pleins. L'étude de cette grange met en évidence six phases de construction et reconstruction depuis l'année 1159, qui pourrait représenter la construction initiale, jusqu'à 1737 , dernière phase de reconstruction identifiée. À l'instar de la grange précédente, les bois sains, issus des reconstructions précédentes, sont réemployés dans les chantiers ultérieurs. Tous les bois datés et antérieurs à 1737 sont ainsi des réemplois, comme un linteau daté de 1577, plusieurs fois refaçonné pour accueillir les piédroits de porte puis réemployé ici en simple maille dans l'élévation (fig. 8, au centre à gauche). Les mailles, que l'on peut observer sur l'image (fig. 8, au 
centre à droite), s'emboîtent grâce à des encoches à mi-bois, sont plusieurs fois refaçonnées, mettant ainsi en évidence que les bois ne sont pas numérotés ou marqués pour reprendre leur place d'origine, mais qu'au contraire ils sont mobiles dans l'édifice. La représentation schématique ci-dessous (fig. 8 , en bas) identifie la place de chaque bois daté dans l'édifice et dans son dernier état visible, dans la moitié du XVIII' siècle).

\section{Réemploi et mobilité des bois d'œuvre au Moyen Âge : le site de Blainon (Saint-Étienne-de-Tinée, 06)}

Un matériau de construction n'est pas systématiquement réemployé in situ. Un édifice ruiné ou abandonné peut devenir une source de matériaux à bâtir pour de nouvelles constructions. Il est, par exemple, fréquent de constater dans de nombreux villages que les pierres d'un ancien château sont réemployées dans les murs des habitations du village environnant.

Les études conduites dans l'alpage de Blainon, abordé précédemment, interroge ici l'hypothèse de transferts de bois d'œuvre d'un bâtiment vers un autre. Dans sa thèse, Jean Paul Boyer ${ }^{24}$ mentionne des déplacements de bois de grange à la fin du Moyen Âge, qu'il s'agisse de vol de bois mais aussi de granges démontées et reconstruites dans un autre secteur d'un même finage. Ces informations, livrées par l'étude des sources écrites, conduisent à nous questionner sur les traces matérielles (archéologiques et dendrochronologiques) de ces déplacements de bois d'œuvre d'un chantier vers un autre.

Les deux exemples présentés sont des témoins exceptionnels du bâti agropastoral du Bas Moyen Âge, partiellement conservés en élévation. Ces deux granges sont respectivement datées de l'extrême fin du XIII ${ }^{e}$ siècle (1298) pour la première (fig. 9) et du premier tiers du XIV siècle (1326) pour la seconde (fig. 10). Dans l'alpage ces deux structures sont distantes d'environ $300 \mathrm{~m}$ et à la même altitude, d'environ $1800 \mathrm{~m}$. 
Fig. 9. - Alpage de Blainon (Saint-Étienne-de-Tinée, 06).

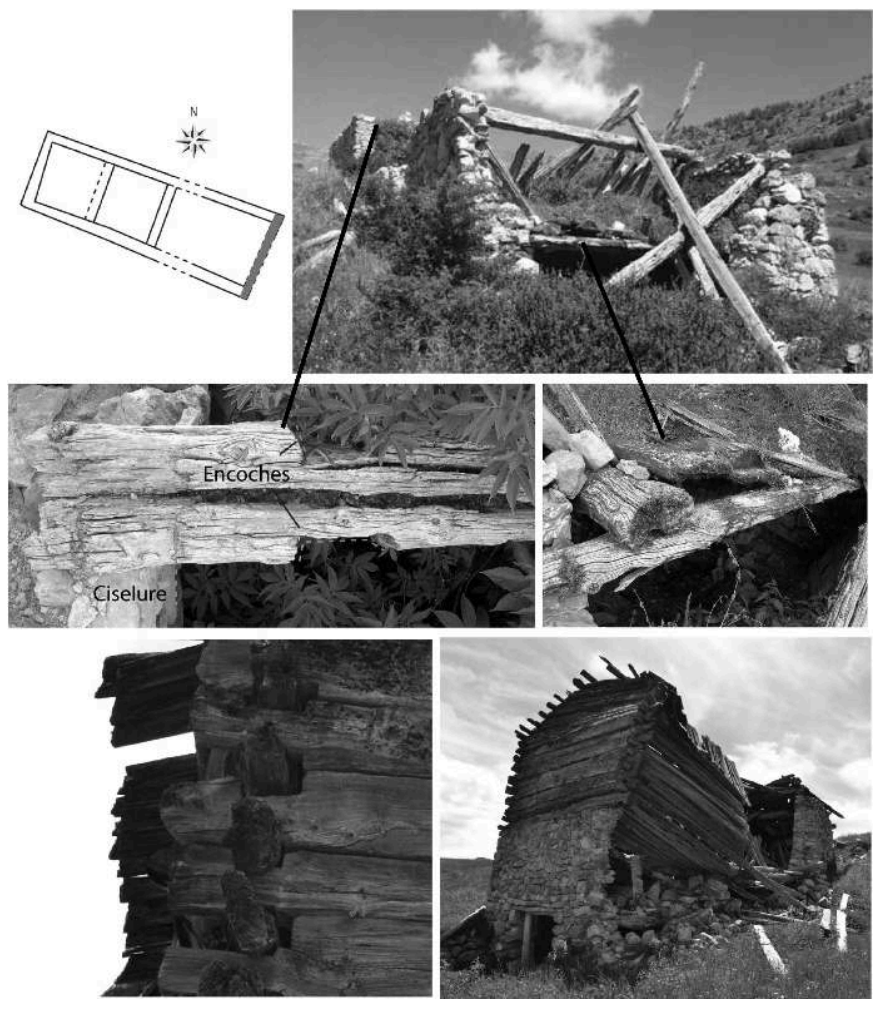

Plans et vues de la grange médiévale du xive siècle.

(c) Photographies et DAO : V. Labbas. 
Fig. 10. - Alpage de Blainon (Saint-Étienne-de-Tinée, 06).
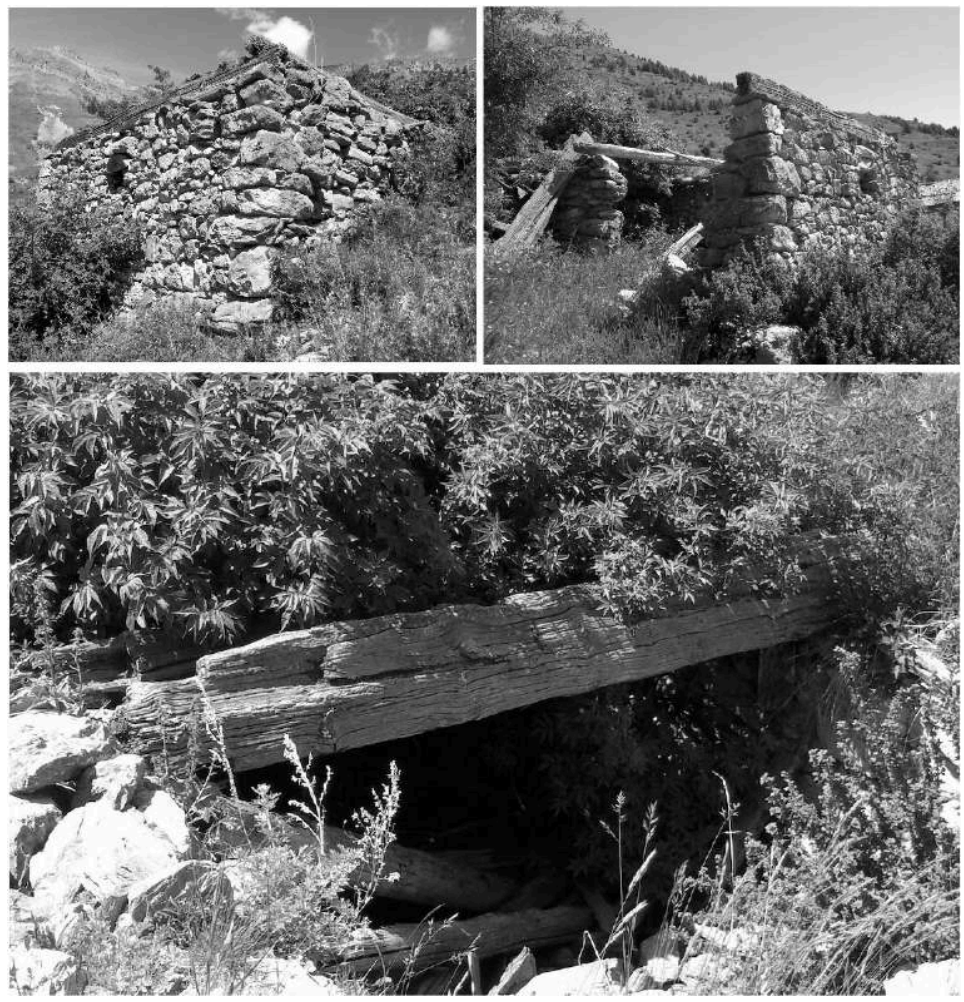

Plusieurs vues de la grange datée de 1298

(c) Photographies et DAO : V. Labbas.

\section{La grange de 1326}

31 Ce bâtiment est situé à $1795 \mathrm{~m}$ d'altitude dans la partie est de l'alpage de Blainon, au sud d'une chapelle Saint-Sébastien également en ruine. Les états de section du cadastre de 1875 indiquent que l'une des trois parcelles qui constituent l'édifice est mentionnée en tant que terre (culture), alors qu'elle est bien représentée comme la partie est du bâtiment et les deux autres décrites comme "bâtiment rural ». La fonction agricole (bâtiment rural) est certaine à la fin du $\mathrm{XIX}^{\mathrm{e}}$ siècle, sans exclure la fonction d'habitat, qu'il soit saisonnier ou permanent dans cet alpage exposé plein sud. Ce bâtiment est de plan rectangulaire, allongé d'est en ouest. Il mesure $15 \mathrm{~m} 80$ dans l'axe est-ouest et $4 \mathrm{~m}$ 90 dans l'axe nord-sud. Malgré l'état de ruine avancée, l'observation des élévations sur plusieurs mètres de hauteur et une moitié de plancher à l'est, est possible. On identifie trois niveaux de plafonds. Deux murs de refend scindent le bâtiment en trois parties, ce qui concorde avec la division parcellaire de la fin du XIX ${ }^{\mathrm{e}}$ siècle.

L'analyse archéologique livre une chronologie relative de la construction qui met en évidence plusieurs reconstructions. La dendrochronologie fournit 8 dates, de 1170 à 1326. Cette date de 1170 correspond à un bois sans aubier qui ne fournit ici qu'un terminus post quem. Il faut considérer la date de 1210 comme la plus ancienne de l'édifice, correspondant à un bois avec un aubier complet. Trois bois sont datés entre 1300 et 1326 et proviennent de deux des trois planchers partiellement conservés. 1326 étant la plus récente fournit par l'analyse, c'est celle qui date l'édifice. 

par des datations dendrochronologiques des bois disponibles. Sur deux des trois niveaux de plancher identifiés dans l'édifice, les poutres sont, dans un état antérieur, des mailles de pans-de-bois pleins que l'on identifie grâce à leur double encoche à mibois (fig. 9 , au centre). On peut, par ailleurs, constater que ces réemplois traduisent une pratique similaire à celle abordée dans le point précédent.

\section{La grange datée de 1298}

Le second bâtiment, également en ruine, est conservé sur un à deux mètres d'élévation, autrement dit le premier niveau bâti en pierres sèches qui soutient trois poutres du plancher qui permet de restituer un niveau supplémentaire.

L'analyse archéologique de ces éléments livre une chronologie relative simple: le soubassement en pierre est le produit d'une seule phase de chantier et une reprise ultérieure se traduit par une fenêtre obturée dans le mur oriental, au sud. Deux des trois poutres ont fait l'objet d'analyses dendrochronologiques, la troisième étant inaccessible. Ces bois livrent précisément la date de 1298, la flache des pièces de bois attestant la présence du dernier cerne de croissance. Ces poutres sont également des mailles réemployées (fig. 10, en bas) qui présentent les mêmes caractéristiques que celles du bâtiment précédent, dans leur façonnage (encoches taillées à mi-bois) et leurs dimensions (quatre à cinq mètres de long et 23 à 25 centimètres de diamètre). De prime abord, ces dates attestent l'existence de bâtiments agropastoraux sur ce site subalpin et dans ce secteur des Alpes du Sud. Ces pièces de bois médiévales, de la fin du XIII ${ }^{\mathrm{e}}$ siècle et du début du XIV siècle, réemployées en poutre, permettent de restituer dans les deux cas une élévation en pans-de-bois pleins dans un état antérieur et pour chacun de deux édifices. Sur le site de Blainon, la présence d'une grange conservée en élévation et présentant des caractéristiques proches de la première grange (dans ses dimensions et partition de l'espace intérieur), permet de proposer une restitution de l'élévation de la grange du XIV siècle.

Concernant l'origine des bois, il ne s'agit pas ici d'affirmer que les bois proviennent de l'une ou l'autre de ces deux granges, mais d'en évoquer la possibilité. Au regard des dates très proches livrées par la dendrochronologie (28 ans d'écart) mais aussi par le fait que la fonction initiale de ces bois soit la même (des mailles d'élévation), tout comme leur fonction en tant que réemploi (poutres de plancher), on peut s'interroger sur un transfert de bois d'œuvre d'une grange vers l'autre, mais aussi d'une grange disparue dont ces deux exemples auraient bénéficié.

Les approches dendrochronologique et archéologique du bâti pastoral livrent ici de nouvelles connaissances sur les activités humaines en montagne, au Moyen Âge et à l'époque moderne. Les exemples présentés mettent en évidence une dynamique dans la construction de haute montagne dans les Alpes du Sud.

L'approvisionnement en bois d'œuvre pour les besoins des chantiers reflète des stratégies d'exploitation des arbres, mais aussi une économie de la ressource. Ces pièces de bois, bien qu'ayant une origine locale, traduiraient également plusieurs sources locales d'approvisionnement. Le réemploi systématique de bois d'œuvre, que l'on 
perçoit et que l'on suit d'un chantier à l'autre de la fin du Moyen Âge jusqu'à l'abandon de ces activités durant la première moitié $d u x^{e}$ siècle, traduit une économie de la ressource. Cette économie s'explique en premier lieu par une logique de récupération des matériaux sains, dans la mesure où couper et façonner de nouveaux bois induit nécessairement plus de travail. En second lieu, cette pratique systématique pourrait faire écho à une réglementation limitant les coupes de bois. Ces aspects traduiraient le pendant matériel de cette réglementation stricte sur les bois déjà mise en lumière par les historiens. Cependant, les textes ne mentionnent que rarement la provenance. C'est pourquoi l'utilisation d'outils dendrochronologiques, tels que les matrices carrées, peut permettre d'entrevoir une manière de rendre compte des mobilités du bois d'œuvre dans le bâti subalpin. Ces travaux conduisent à proposer des perspectives de recherche. En premier lieu, la provenance des arbres constituerait un axe à développer de manière interdisciplinaire et en collaboration avec des historiens, géographes, écologues. De telles recherches permettraient d'approcher plus précisément les secteurs d'approvisionnement en bois d'œuvre ainsi que les trajets des arbres, de la forêt jusqu'au chantier. En second lieu, la systématisation des études archéodendrochronologiques sur ce patrimoine de montagne s'avère essentielle. Ces édifices, menacés de disparition principalement par l'absence d'entretien, témoignent d'une histoire complexe qui couvre le second millénaire de notre ère.

\section{BIBLIOGRAPHIE}

BERNARD Jean-François, BERNARDI Philippe, ESPOSITO Daniela (dir.), Il reimpiego in architettura. Recupero, trasformazione, uso. Rome, Collection de l'École Française de Rome (418), 2008.

BERNARDI Philippe, Métiers du bâtiment et techniques de construction à Aix-en-Provence à la fin de l'époque gothique (1400-1550). Aix-en-Provence, Publications de l'Université de Provence AixMarseille I, 1995.

BLANC Fabien, « Archéologie du bâti médiéval et moderne dans les Alpes-Maritimes en Provence Orientale ", thèse de doctorat d'Archéologie, université Paris 1 - Panthéon-Sorbonne, 2007.

BONDE Niels, TYERS Ian, WAZ'NY Tomasz, « Where does the Timber Come from? Dendrochronological Evidence of the Timber Trade in Northern Europe », Archceological Science, 1995, p. 201 - 204.

BOUTICOURT Émilien, Charpentes méridionales. Construire autrement : le midi rhodanien à la fin du Moyen Âge, Arles, Honoré Clair éditions, 2016.

BOYER Jean-Paul, Hommes et Communautés du haut pays niçois médiéval : La Vésubie (XIII ${ }^{e}-X V^{e}$ siècles), Nice, centre d'Étude Médiévale, 1990.

ECKSTEIN Dieter, WAZ'NY Tomasz, BAUCH J., KLEIN Peter, « New Evidence for the Dendrochronological Dating of Netherlandish Paintings ", Nature, 320, p. 465-466.

ÉDOUARD Jean-Louis, « Longue chronologie de cernes du mélèze et occupation humaine depuis plus de mille ans dans la vallée de la Clarée (Briançonnais, Alpes françaises) », Bibliothèque d'archéologie méditerranéenne et africaine, $\mathrm{n}^{\circ}$ 4, Errance, 2010, p. 325-333. 
ÉDOUARD Jean-Louis, « Datation dendrochronologique du bâti traditionnel et occupation humaine dans les Alpes françaises du sud au cours du dernier millénaire ", Panorama de la dendrochronologie en France, collection Edytem, $\mathrm{n}^{\circ} 11,2010$, p. 169-176.

HUYGEN Jean-Marc, La poubelle et l'architecte. Vers le réemploi des matériaux, Éditions Actes Sud, coll. L'Impensé, 2008.

LABBAS Vincent, « Archéologie et dendrochronologie du bâti subalpin dans le massif du Mercantour durant le second millénaire de notre ère ", thèse de doctorat de l'université AixMarseille, 2016, 4 vol., 1492 p.

LAFARGE Yvan, HUYGEN Jean-Marc, « De la récupération à la réversibilité en architecture », Archéopage 29, 2010, p. 68-73.

LAMBERT Georges-Noël « Dendrochronologie, histoire et archéologie, modélisation du temps. Le logiciel Dendron II et le projet Historik Oaks, V1 et V2 ", habilitation à diriger les recherches, Besançon, 2 vol., 152 p. et 206 p., 2006.

LAMBERT Georges-Noël, BERNARD Vincent, DUPOUEY Jean-Luc, FRAITURE Pascale, GASSMAN Patrick, GIRARDCLOS Olivier, LEBOURGEOIS François, LEDIGOL Yannick, PERRAULT Christophe, TEGEL Willy, « Dendrochronologie et dendroclimatologie du chêne en France, questions posées par le transfert de données de bois historiques vers la dendroclimatologie ", Panorama de la dendrochronologie en France, collection Edytem, $\mathrm{n}^{\circ} 11,2010$.

LASSALLE Juliette, « Litiges territoriaux et conflits d'alpages de la haute vallée de la Roya », thèse de doctorat en Histoire médiévale, université Paris I - Panthéon-Sorbonne, 2008, 3 vol.

PALMERo Béatrice, «Communautés, enjeux de pouvoir et maîtrise de l'espace pastoral aux confins du comté de Nice (Tende, La Brigue et Triora) à l'époque moderne. Une approche microhistorique : les alpes de proximité ", thèse de doctorat de l'université d'Aix-Marseille 1, novembre 2005, 2 vol.

RENDU Christine, La montagne d'Enveig. Une estive pyrénéenne dans la longue durée, Canet, Édition Trabucaïre, 2003, 606 p.

VALLAURI Joël, « L'avalanche de Champ Richard. Colmars-les-Alpes », L'Écho des remparts, Colmarsles-Alpes, $\mathrm{n}^{\circ}$ 6, Juillet, 2002.

SCHWEINGRUBER Fritz, Tree rings. Basics and Applications of dendrochronology, De Reidel, Publishing Company, 1988, $276 \mathrm{p}$.

WALSH Kevin, MOCCI Florence, PALET-MARTINEZ Jose, « Nine thousand years of human/landscape dynamics in the High altitude zone in the southern French Alps (Parc National des Écrins, Hautes Alpes) », Preistoria Alpina 42, 2007, p. 9 à 22.

\section{NOTES}

1. Voir notamment à ce sujet : J.F. Bernard, P. Bernardi, D. Esposito (dir.), Il reimpiego in architettura. Recupero, trasformazione, uso.

2. J.-M. Huygen, La poubelle et l'architecte. Vers le réemploi des matériaux.

3. Y. Lafarge, J.-M. Huygen, « De la récupération à la réversibilité en architecture ", p. 68-73. 
4. F. Blanc, «Archéologie du bâti médiéval et moderne dans les Alpes - Maritimes en Provence Orientale », $576 \mathrm{p}$.

5. Voir notamment : T. Waz ny, « Dendro-provenancing between the Baltic Sea and the East Mediterranean », p. 81-87.

6. Eckstein, Wazny, Bauch, Klein, «New Evidence for the Dendrochronological Dating of Netherlandish Paintings ", p. 465-466.

7. N. Bonde, I. Tyers I., T. Wazny, «Where does the Timber Come from? Dendrochronological Evidence of the Timber Trade in Northern Europe », p. 201-204.

8. P. Bernardi, Métiers du bâtiment et techniques de construction à Aix-en-Provence à la fin de l'époque gothique (1400-1550), $501 \mathrm{p}$.

9. E. Bouticourt, Charpentes méridionales. Construire autrement : le midi rhodanien à la fin $d u$ Moyen Âge, 355 p.

10. Voir à ce propos : J.P. Boyer, Hommes et Communautés du haut pays niçois médiéval : la Vésubie (XIII ${ }^{e}-X V^{e}$ siècle), J. Lassalle 2008, «Litiges territoriaux et conflits d'alpages de la haute vallée de la Roya » et B. Palmero, «Communautés, enjeux de pouvoir et maitrise de l'espace pastoral aux confins du comté de Nice (Tende, La Brigue et Triora) à l'époque moderne. Une approche micro-historique : les Alpes de proximité ».

11. Voir notamment pour les Pyrénées: C. Rendu, La montagne d'Enveig, Une estive pyrénéenne dans la longue durée, et pour les Alpes du Sud: K. Walsh, F. Mocci, J. PaletMartinez, "Nine thousand years of human/landscape dynamics in the High altitude zone in the southern French Alps (Parc National des Ecrins, Hautes Alpes) », p. 9-22.

12. J.L. Édouard, «Longue chronologie de cernes du mélèze et occupation humaine depuis plus de mille ans dans la vallée de la Clarée (Briançonnais, Alpes françaises) », p. 325-333.

13. J.L. Édouard, «Datation dendrochronologique du bâti traditionnel et occupation humaine dans les Alpes françaises du sud au cours du dernier millénaire ", p.169-176.

14. V. Labbas, "Archéologie et dendrochronologie du bâti subalpin dans le massif du Mercantour durant le second millénaire de notre ère ", $1492 \mathrm{p}$.

15. Les cadastres dits napoléoniens sont établis dans le premier tiers du XIX siècle (1824) pour les communes du PNM situées dans les Alpes-de-Haute-Provence et conservés aux Archives Départementales à Digne-les-Bains et autour des années 1875 dans les communes situées dans les Alpes-Maritimes et conservés aux Archives Départementales des Alpes-Maritimes.

16. Voir par exemple: F. Schweingruber, Tree rings. Basics and Applications of dendrochronology.

\section{LINNTAB@ RINNTECH}

18. TSAP@ RINNTECH

19. Cette étape a été effectuée grâce au logiciel Dendron IV, développé par GeorgesNoël Lambert, au Laboratoire Chrono-Environnement de Besançon. Voir notamment : G.N. Lambert, « Dendrochronologie, histoire et archéologie, modélisation du temps. Le logiciel Dendron II et le projet Historik Oaks, V1 et V2 ».

20. Pour le mélèze, l'estimation de l'aubier maximum est issue des travaux de thèse de Lisa Shindo (L. Shindo, «Bois de construction et ressources forestières dans les Alpes du sud au II millénaire. Dendrochrono-écologie et archéologie », 935 p.) 
21. Voir notamment : G.N. Lambert, V. Bernard, J.L. Dupouey, P. Fraiture, P. Gassman, O. Girardclos, F. Lebourgeois, Y. Ledigol, C. Perrault, W. Tegel, « Dendrochronologie et dendroclimatologie du chêne en France, Questions posées par le transfert de données de bois historiques vers la dendroclimatologie », p. 205-216.

22. J. Vallauri, «L'avalanche de Champ Richard ». Colmars-les-Alpes », p. 8-12.

23. La notion de terroir dendrologique indique des arbres ayant poussés avec des conditions similaires sans provenir nécessairement d'un même lieu.

24. J.P. Boyer, Hommes et Communautés du haut pays niçois médiéval : la Vésubie (XIII ${ }^{e} \mathrm{XV}^{e}$ siècles), $585 \mathrm{p}$.

\section{RÉSUMÉS}

L'approche dendrochronologique et archéologique des constructions subalpines agropastorales dans le massif du Mercantour met en évidence un bâti utilisé et reconstruit fréquemment du XII ${ }^{\mathrm{e}}$ siècle jusqu'au début $\mathrm{du} \mathrm{xx}^{\mathrm{e}}$ siècle en exploitant les ressources forestières environnantes. La pratique systématique du remploi dans ces édifices de haute montagne implique une mobilité des matériaux. Ce déplacement des pièces de bois induit une réutilisation de matières premières in situ, interne à un bâtiment, mais peut se traduire également par un déplacement des pièces pour construire d'autres bâtiments agropastoraux, qu'ils soient proches ou éloignés. Cette recherche interdisciplinaire met en évidence des pratiques de construction dans lesquelles la mobilité des matériaux transparaît autant que l'emploi de bois «neuf». Elle montre une économie dans les moyens mis en œuvre ainsi que dans l'usage des ressources forestières locales.

\section{AUTEUR}

\section{VINCENT LABBAS}

Docteur en archéologie et dendrochronologie, postdoctorant - Chaire IDEX Gragson - Laboratoire TRACES - UMR 5608 


\title{
La circulation de la mémoire
} lignagère dans un espace de moyenne montagne : nobles et confrères du Saint-Esprit en Forez au XIII ${ }^{\mathrm{e}}$ siècle

\author{
Alexis Fontbonne
}

1 À la fin $\mathrm{du} \mathrm{XII}{ }^{e}$ siècle, une transaction met fin au conflit qui oppose le comte et l'archevêque de Lyon pour le contrôle de la ville. La nouvelle base du pouvoir comtal devient alors le Forez, espace de moyenne montagne, et les vassaux du comte doivent migrer, séparés de leurs anciens domaines par les monts du Lyonnais. Nous allons étudier cette migration nobiliaire à la fois sous l'angle des stratégies d'implantation du pouvoir comtal et nobiliaire, et de la conservation de la mémoire lignagère liée à un espace désormais perdu. Ces stratégies d'implantation mobilisent un corps social, les confréries du Saint-Esprit, dont le recrutement est avant tout villageois. C'est pourquoi dans un second temps, il faudra étudier les parallèles entre les stratégies mémorielles des nobles et celles des simples villageois.

\section{Le Forez : un milieu montagnard franchissable}

2 Le Forez est une petite région couvrant moins de $4000 \mathrm{~km}^{2}$, qui correspond approximativement à l'actuel département de la Loire. Délimitée à l'ouest par les monts du Forez et à l'est par les monts du Lyonnais, la plaine du Forez est une haute plaine s'étendant du nord au sud sur une distance de quarante kilomètres et dont l'altitude moyenne est de 370 mètres $^{1}$. Le principal obstacle naturel est la Loire qui, bien que cinq ponts la franchissent, divise la plaine du Forez en deux, sur le plan humain, économique et même linguistique ${ }^{2}$. Les monts du Lyonnais sont quant à eux facilement franchissables, n'atteignant pas les mille mètres d'altitude et traversés par une série de routes $^{3}$ : la voie d'Aquitaine reliant Lyon à Clermont en passant par Feurs et la voie 
Lyonnaise allant jusqu'à Bordeaux et passant en Forez par Montbrison, cette seconde voie étant doublée par la voie Viennoise qui relie Vienne à Montbrison. Ces monts du Lyonnais, qui sont moins des montagnes que des plateaux et des collines découpés par de profonds vallons, deviennent cependant à la fin du xII ${ }^{\mathrm{e}}$ siècle une frontière politique.

Fig. 1. - Espace d'implantation des familles nobles étudiées.

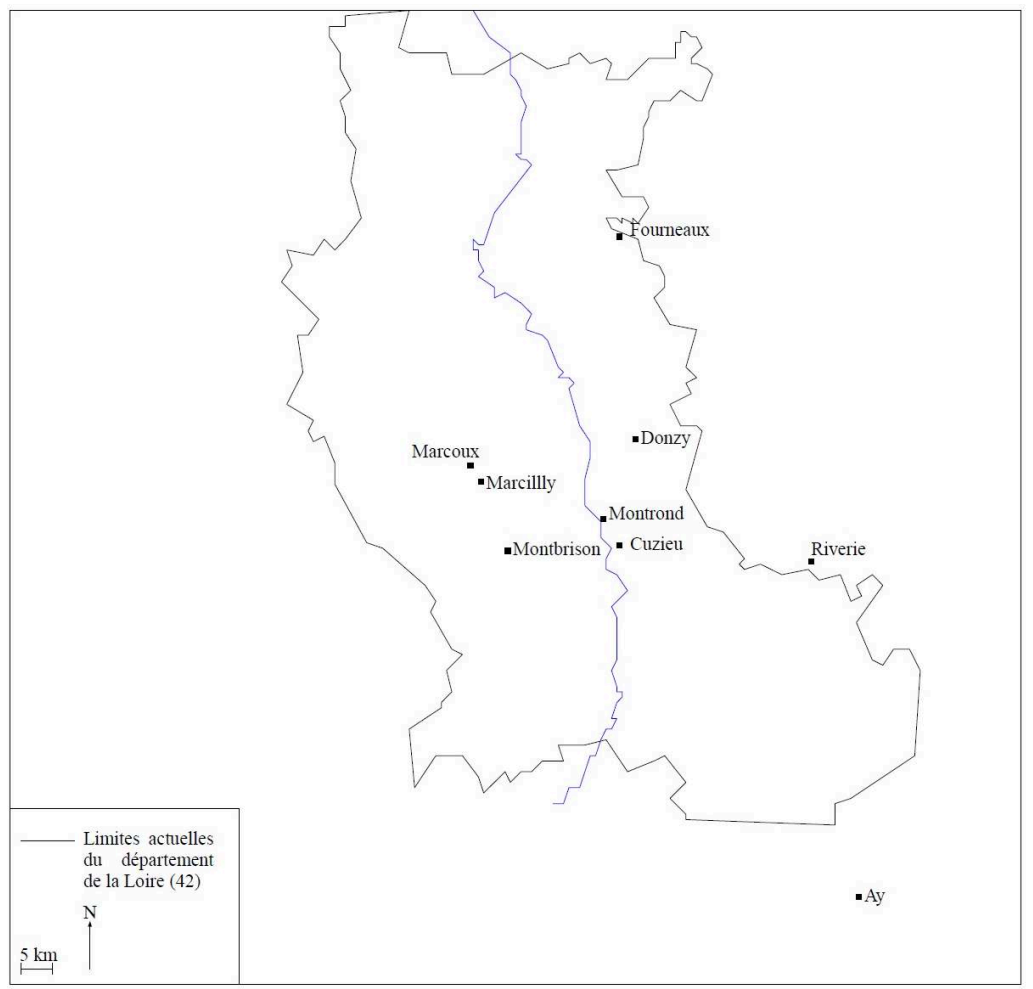

(c) Alexis Fontbonne.

\section{La naissance d'une frontière politique ${ }^{4}$}

Dès le $\mathrm{XI}^{\mathrm{e}}$ siècle, des conflits opposent les comtes de Lyon aux archevêques de la ville. Excommunié en 1076 par le synode de Latran, Artaud IV, premier à porter le titre de comte de Forez, doit rendre le droit de monnayage et la moitié des droits que payent les villes de Lyon et de Meximieux. Il reste cependant en possession de tout le Lyonnais, en plus du Forez et du Roannais, ainsi que de l'autre moitié des redevances de la ville de Lyon. Dans le cadre de ces tensions, Artaud et ses successeurs accordent au Forez une attention particulière, portant avec régularité le titre de comte de Forez et favorisant le développement de Montbrison où ils font construire un château, puis un hôpital.

En 1157, durant le gouvernement de Guy II - issu de la branche cadette et élevé à la cour de Louis VII - l'empereur Frédéric Barberousse reçoit l'hommage de l'archevêque de Lyon, Héracle de Montboisier et accorde à l'Église de Lyon une charte de privilèges très importants. Ce diplôme concède à l'archevêque le corps entier de la cité de Lyon et tous les droits régaliens dans l'étendue de l'archevêché à l'est de la Saône. Héracle, allié au comte de Mâcon assiège le château d'Iseron appartenant à Guy II ; l'attaque échoue et la ville de Lyon est prise par le comte de Forez. Le conflit s'éternise, se doublant de la rivalité entre l'empire et le royaume de France, puis de la querelle entre la papauté et 
Frédéric Barberousse. En 1167, l'archevêque Guichard de Pontigny, nommé par Alexandre III en accord avec Louis VII, conclut une transaction avec Guy II, restituant à celui-ci l'ensemble de ses privilèges. Le comte de Forez rend alors officiellement hommage à Louis VII et reçoit les droits royaux sur une série de places en Forez: Marcilly, Donzy, Cléppé, Saint-Priest, Lavieu et Saint-Romain.

L'accord de 1167, qui prévoyait que les droits sur la ville de Lyon seraient communs au comte et à l'Église de Lyon, ne tient cependant pas et est remplacé en 1173 par une transaction. Il s'agit d'un acte de vente, ratifié par le pape en 1174, par lequel Guy cède à l'archevêque et au chapitre de Lyon l'ensemble du Lyonnais et de ses droits sur la ville, en échange de compensations territoriales en Forez et en Roannais et de onze cents marcs d'argent. Bien que le Lyonnais n'ait pas été précédemment contesté, la transaction sanctionne la perte d'influence du comte sur ce territoire : les possessions de Guy II et de ses vassaux ne s'étendant plus que sur vingt-quatre paroisses sur cent quatre-vingt. L'échange ne s'est cependant pas fait facilement, les comtes contestant l'accord et portant, fait nouveau, le titre de comte de Lyon et de Forez jusqu'en 1202.

6 C'est donc au xiII ${ }^{\mathrm{e}}$ siècle que le pouvoir comtal s'installe pleinement en Forez, une installation qui sera longue : il faut attendre la première moitié du XIV siècle pour que la totalité des seigneurs foréziens reconnaissent l'autorité du comte. C'est dans ce contexte d'un pouvoir qui se recentre qu'il faut comprendre la migration des vassaux situés auparavant dans des terres désormais soumises à l'Église de Lyon. Ils constituent un soutien indispensable pour le comte face aux seigneurs du Forez réticents à prêter hommage.

\section{La circulation des vassaux : I'implantation forézienne des vassaux du comte}

7 Sur les deux cent quinze familles recensées par Édouard Perroy $^{5}$, cinq vont retenir notre attention, car elles permettent d'aborder les deux niveaux d'implantation du pouvoir comtal: implantation de vassaux du comte dans des fiefs foréziens et intégration de ces vassaux au sein des réseaux locaux de leurs fiefs. On peut ainsi remarquer que les vassaux du comte, issus de l'extérieur du Forez s'implantent dans des fiefs récemment acquis. C'est ainsi le cas des Aroud de Montrond, issus de Riverie en Lyonnais et qui suivent dans leur implantation, soit les seigneurs de Cuzieu, soit ceux d'Unias qui reçoivent leurs nouveaux fiefs entre la fin du XII ${ }^{e}$ siècle et le début du $\mathrm{XIII}^{\mathrm{e}}$ siècle $^{6}$. Ayant sans doute suivi le même parcours, on trouve Guillaume d'Ay, donzeau attaché aux Mays de Cuzieu, fief inféodé à Guy II dès 1190. Armand de Grandval est quant à lui probablement originaire du Beaujolais, à Fourneaux, où l'on trouve un autre Grandval et où sa famille est alliée $e^{7}$. Il est cependant seigneur de Marcilly en 1278, l'un des fiefs foréziens offerts par Louis VII à Guy II en 1167. Toujours issu du Beaujolais ${ }^{8}$ mais d'un rang moindre, on rencontre Guillaume, seigneur de Gouttelas en 1278, hameau dépendant de Rochefort, fief reçu par le comte lors de la transaction de $1173^{9}$. Si les origines de Guillaume Fabre, châtelain de Donzy en $1267^{10}$, ne nous sont pas connues, il est seigneur d'une des forteresses accordées un siècle plus tôt par Louis VII.

8 Dans l'étude de ces quelques cas, il est possible de comprendre la manière dont s'est faite la migration des nobles accompagnant le comte : ceux-ci s'implantent dans des 
fiefs qui ont été reçus récemment par Guy II, soit grâce aux dons de Louis VII en 1167, soit grâce aux compensations du traité de 1173. Ainsi, Guy II reconstitue-t-il dans un espace qui ne lui est pas acquis, comme l'atteste la lenteur des seigneurs locaux à lui rendre hommage, un réseau seigneurial sur lequel il peut s'appuyer, ceci sans entrer en conflit avec les seigneurs plus anciennement installés. La chronologie offerte par les sources étudiées ici permet de noter que le processus d'implantation est progressif : s'il commence à l'extrême fin du XII e siècle, il s'étend au cours du XIII siècle. Ainsi, les Aroud, qui arrivent au début du XIII ${ }^{\mathrm{e}}$ siècle à Montrond, sont déjà présents dans des actes montbrisonnais de la fin du XII ${ }^{e}$ siècle ${ }^{11}$. Il est nécessaire de revenir un instant sur le cas des deux familles issues du Beaujolais : les Grandval et les Gouttelas. En effet, le Beaujolais ne fait pas partie des territoires perdus par le comte lors de la transaction de 1173. Ainsi, plutôt que l'exil d'une noblesse dépossédée, il faut considérer les réimplantations étudiées comme une réorganisation du pouvoir, dont le centre est désormais la plaine du Forez.

Cependant, en plus de la reconstitution d'un réseau de pouvoir comtal recentré sur la plaine du Forez et la cité de Montbrison, il est nécessaire de comprendre comment se sont implantées ces familles. Si elles ont été choisies parmi celles qui ont effectuées une telle transplantation, c'est que toutes sont en relation avec une ou plusieurs confréries du Saint-Esprit. Ce n'est le cas d'aucune famille anciennement établie dans la plaine du Forez, bien qu'il existe un réseau de confréries particulièrement dense : on en connaît 124, soit presque une par paroisse. Les familles nobles du Forez et les confréries du Saint-Esprit étant assez bien connues grâce au dépouillement systématique des testaments du Forez effectué par Marguerite Gonon, il semble possible de donner un sens à une telle correspondance, au-delà du hasard de la conservation des sources. C'est donc aux confréries du Saint-Esprit, comme espace d'implantation sociale, qu'il faut à présent s'intéresser.

\section{Les confréries du Saint-Esprit : un espace d'intégration idéal ?}

10 La présence d'un réseau très dense de confréries du Saint-Esprit s'inscrit dans la vague de fondation d'institutions charitables diverses initiées par des laïcs à la fin du XII siècle : charité, hôpitaux, confréries. La référence au Saint-Esprit, présente dans une grande partie des fondations les plus anciennes de cette période, joue un rôle essentiel, car c'est par elle que le caractère laïc de l'initiative est validé. En effet, les théologiens et Innocent III effectuera le transfert entre leurs théories et la pratique institutionnelle - développent l'idée selon laquelle l'aumône n'est inspirée que si elle est le fait des laïcs et prend un caractère régulier, l'aumône des clercs et l'aumône exceptionnelle étant toutes deux des devoirs. De plus, dans un contexte de réfutation des possibilités d'une prédication laïque, l'inspiration laïque est réduite à cette seule œuvre d'aumône ${ }^{12}$.

11 Les confréries du Saint-Esprit que l'on rencontre en Forez et qui se diffusent au cours des $\mathrm{XIII}^{\mathrm{e}}$ et $\mathrm{XVI}^{\mathrm{e}}$ siècles sont des institutions charitables effectuant une aumône annuelle durant les jours de la fête de Pentecôte. À cette aumône s'ajoute un repas pris entre les membres, qui remplit aussi une fonction mémorielle. En effet, la demande la plus fréquente dans les testaments évoquant les confréries du Saint-Esprit est d'être tenu comme « confrère vif » au sein de la confrérie, c'est-à-dire voir sa place occupée par un pauvre dont on paye la présence en continuant à s'acquitter d'une cotisation ${ }^{13}$. La 
confrérie joue aussi le rôle d'une personne morale pouvant contrôler les dernières volontés du testateur, par exemple pour surveiller que des messes commandées soient bien dites par le prêtre rétribué pour cette action ${ }^{14}$.

12 Les confréries du Saint-Esprit perpétuent ainsi la mémoire et la volonté de ses membres après leur mort, tout en accomplissant une œuvre de salut, l'aumône. Rassemblant la partie la plus aisée de la communauté villageoise, elle remplit une fonction communautaire mais non pas égalitaire. La société villageoise est divisée entre les confrères dont la mémoire est transmise, les non-confrères et les pauvres qui sont effacés par les dons qui leur sont faits : le pauvre qui mange à la table des confrères est présent au nom d'un autre. La confrérie apparaissant avant tout comme un des acteurs constitutifs de la communauté villageoise, il est possible de s'interroger sur l'intérêt qu'elle représente pour des nobles dont l'envergure sociale dépasse celle du seul village. Si les nobles sont membres de confréries du Saint-Esprit, il faut cependant les appréhender comme des confrères particuliers.

\section{Être noble et confrère du Saint-Esprit : une stratégie d'implantation}

13 Avant d'aborder la position des nobles au sein des confréries du Saint-Esprit, il faut souligner une coïncidence qui peut expliquer pourquoi les nobles que nous étudions sont tous issus de lignages transplantés. En effet, les confréries du Saint-Esprit s'implantent et se diffusent en Forez en même temps que les seigneurs attachés au pouvoir comtal. Ainsi, alors que les familles anciennement établies possèdent leur propre réseau d'implantation au sein de la population de leurs fiefs, les familles «nouvelles» ont vu apparaître au moment où elles s'installaient un corps social remplissant une fonction communautaire et pouvant constituer un espace propice à des stratégies d'implantation au sein du tissu social villageois. Cette correspondance chronologique ne vaut en aucun cas causalité, mais elle a pu constituer, pour certaines familles, une occasion propice dont il s'est agi de profiter, ce de différentes manières.

En 1267, Guillaume Fabre, châtelain de Donzy, élit sa sépulture au cimetière de Salt-enDonzy et fonde son principal anniversaire à l'église Notre-Dame de Montbrison. Il lègue cependant, en plus, une quarte de seigle pour que les membres de la confrérie du SaintEsprit de Donzy le tiennent comme confrère après sa mort. Ce legs n'implique pas de prières particulières - contrairement à celui qui est fait à la confrérie de prêtres des Farges - et nous permet de voir qu'un noble, châtelain, ne dédaigne pas appartenir à une confrérie du Saint-Esprit ${ }^{15}$. Le testament de Guillaume d'Ay, en 1288, nous fournit une situation encore plus intéressante puisque celui-ci choisit d'élire sa sépulture dans le couvent des frères mineurs de Montbrison. Il souhaite cependant que ses héritiers le tiennent à perpétuité lui, son père et sa mère, comme confrères vifs en la confrérie du Saint-Esprit de Cuzieu ou d'Ay, comme ses héritiers préféreront ${ }^{16}$. La confrérie, en l'absence de sépulture, permet ainsi d'entretenir la mémoire locale du lignage. Le fait que la somme nécessaire pour être tenu confrère à perpétuité ne soit pas mentionnée peut de plus révéler une certaine familiarité avec les habitudes confraternelles; cette somme, qui correspond à une cotisation versée annuellement, étant aussi négligée par nombre de confrères de rang moindre. particulièrement complexe par Hugues Aroud de Montrond en 1274. Celui-ci, dont les 
parents sont passés de Riverie à Montrond, souhaite que ses héritiers le tiennent, lui, sa femme et sa mère comme confrères vifs en la confrérie du Saint-Esprit de Riverie, tandis que son père sera tenu confrère vif de la confrérie du Saint-Esprit de Montrond. Hugues étant seigneur de Montrond, son père enterré au cimetière des Farges, ces demandes d'intégration dans différentes confréries permettent de reproduire le tissu lignager en lui fournissant une signification dans la communauté locale. Chacun est ainsi tenu confrère dans l'espace où ses attaches sont les plus faibles: le souvenir d'Huges est maintenu dans le lieu qu'il a quitté mais où il conserve des intérêts, tandis que la mémoire de son père à Montrond permet de souligner la transplantation du lignage.

L'implantation de cette noblesse au sein des confréries permet de plus d'insérer ces dernières dans les réseaux de pouvoir comtaux. En 1278, Guillaume, seigneur de Gouttelas, Armand de Grandval, seigneur de Marcilly et Pierre, seigneur de Mayssimeu, reconnaissent, au nom de la confrérie du Saint-Esprit de Marcilly, devoir à la comtesse douairière Jeanne - le comte étant mort cette année - une rente d'un cartal de seigle pour le fournage de la confrérie, c'est-à-dire la cuisson du pain, probablement destiné à la fois aux distributions charitables et au repas de Pentecôte ${ }^{17}$. On ne connaît que deux degrés de la famille des seigneurs de Mayssimeu, Pierre et son père Zacharie. La présence de Pierre dans un acte concernant la gestion du blé peut s'expliquer par le fait qu'il contrôle un moulin situé aux confins du "ban de la rivière " de l'abbaye de Bonlieu $^{18}$, cours d'eau le plus proche de Marcilly. Dans le dialogue avec le pouvoir comtal, où une communauté villageoise ne peut prétendre au même poids que les représentants d'une cité marchande, la noblesse locale fait office d'intermédiaire. La double nouveauté de la diffusion des confréries et de l'implantation des familles nobles permet ainsi la constitution d'un nouveau réseau de pouvoir, allant du comte aux villageois en passant par ses anciens vassaux dans de nouveaux espaces. Ces familles nobles se rendent présentes en tant que lignage dans les communautés villageoises par le biais des pratiques mémorielles des confréries du Saint-Esprit. Appartenant à un lignage dont la mémoire est perpétuée par le corps qui perpétue la mémoire de communauté villageoise, intermédiaire entre les pouvoirs supérieurs et les non nobles, la «nouvelle» noblesse du Forez s'intègre donc non en imitant les familles plus anciennement installées mais en profitant de l'opportunité que constitue la multiplication des confréries du Saint-Esprit.

Cependant, la migration causée par la transaction de 1173 n'est pas la seule cause de mobilité et il s'agit à présent d'étudier comment le maillage mémoriel permis par les confréries entre différents villages au service d'une même famille dépasse les stratégies de la noblesse.

\section{Les lignages non-nobles : la memoria au village et entre villages}

18 L'ensemble des documents qui vont être étudiés ci-après sont postérieurs aux actes mentionnant des nobles foréziens. Il ne semble cependant pas possible d'en conclure que la noblesse a inventé certaines pratiques imitées ensuite par le reste de la population : le biais vient ici des sources, les nobles testant de manière plus précoce, la masse des testaments des populations des villages datant davantage du XIV ${ }^{e}$ siècle. 

un lieu. C'est ce que l'on observe à Souternon en 1348: un testateur lègue à sa sœur l'ensemble de ses biens, à charge pour elle de tenir leur père et leur mère comme confrères morts à perpétuité dans la confrérie du Saint-Esprit de Souternon. Léguant à sa sœur, il est possible que ce testateur n'ait pas de descendants ou d'autres parents proches et c'est peut-être la crainte de voir disparaître la mémoire familiale qui le conduit à donner un caractère impératif à sa demande, en utilisant pour cela l'intermédiaire confraternel: si sa sœur ne souhaite pas payer, alors les consuls pourront vendre les biens sur lesquels est assigné un cens d'un demenc de seigle et douze deniers ${ }^{19}$. L'existence d'un bien sur lequel est assigné exactement la somme nécessaire pour remplir une cotisation nous informe que le testateur devait probablement, dès son vivant, régler par ce biais le paiement dû à la confrérie. Durant sa vie, il incarne la mémoire familiale, mais après sa mort ces biais, revenant à sa sœur, risquent, par mariage, d'entrer dans une nouvelle famille, qui sera peut-être moins préoccupée par ce besoin de faire mémoire. Si nous observons dans un premier cas les stratégies destinées à se prémunir contre l'oubli, il existe des situations où, au contraire, le don a pour but d'ancrer une famille dans un espace et un temps beaucoup plus élargis. Ainsi, Julienne, femme de Zacharie de Chevrières effectue, en 1286, un legs aux confréries du Saint-Esprit de Chazelles, Chagons et Chevrière pour elle, ses parents, ses ascendants et ses successeurs ${ }^{20}$.

ci de la mémoire familiale dépasse donc le seul milieu nobiliaire et il est de même pour l'usage des confréries afin de reconstituer des liens distendus par les déplacements d'une population qu'il ne faut pas considérer comme repliée ou enclavée ${ }^{21}$.

21

En 1328, Étienne Geneytey impose différentes décisions à ceux qui bénéficient de ses legs. À son héritier, il impose de payer une assiette de confrère mort en la confrérie du Saint-Esprit de Grézolles pour le repos de l'âme de ses parents. Son cognat doit quant à lui le tenir comme confrère dans la confrérie du Saint-Esprit de Savigneu. Si son cognat ne s'exécute pas, les dons qui lui sont faits reviennent à l'héritier qui aura alors pour tâche de tenir Étienne, en plus de ses parents, pour confrère à Grézolles ${ }^{22}$. Les confréries du Saint-Esprit permettent ainsi de conserver la mémoire du testateur dans différents lieux: Grézolles est le lieu d'implantation de la famille d'Étienne, là où se trouvent son héritier et la tombe de ses parents, tandis que Savigneu est le lieu de résidence de son cognat. Le réseau des confréries permet ainsi de pallier le fait que l'espace du village n'englobe pas nécessairement l'espace d'une parenté, cela étant d'autant plus vrai si les liens matrimoniaux sont pris en compte. Ainsi, vers 1347, Alexie de Civa fait le choix d'être enterrée à Bussy, là où sont enterrés ses parents et elle demande à être tenue consœur de la confrérie du Saint-Esprit de Bussy ; elle donne de plus à son mari de quoi tenir la mère de celui-ci dans la confrérie du Saint-Esprit de Saint-Sulpice, aussi longtemps qu'il plaira à ce dernier ${ }^{23}$. Ici le réseau de dons et de demandes devient particulièrement complexe : si Alexie lie sa mémoire à celle de sa famille, elle entretient simultanément la mémoire de la famille à laquelle elle est liée par mariage dans le lieu d'implantation de celle-ci. La mobilité matrimoniale est en effet une forme de mobilité fréquente et le "retour " effectué par Alexie n'est pas unique : en 1395, une testatrice, dont le mari est enterré aux Salles demande à être tenue membre de la confrérie de Cervière, où elle élit sa sépulture ${ }^{24}$. Cette situation n'est cependant pas systématique, comme l'atteste le cas de Jeanne Tioleri qui, dans la 
décennie 1340, souhaite être tenue consœur dans la confrérie du Saint-Esprit de SaintCyr, village où son mari est enterré25. La confrérie est donc l'espace paradoxal du vécu communautaire de stratégies lignagères individuelles: les femmes peuvent agir différemment de leur mari, y compris lorsqu'elles ne sont pas veuves, c'est ainsi ce que fait Hugette, femme de Dion de la Revolleyrie qui lègue une maison à la confrérie du Saint-Esprit de Magneria pour en être tenue membre à perpétuité.

Dans un espace où les déplacements, sans être impossibles, sont rendus plus difficile par le milieu naturel et les frontières politiques, les confréries du Saint-Esprit permettent de maintenir des relations communautaires au-delà de la seule paroisse. Les croisements de parenté peuvent permettre la constitution d'espaces identitaires dépassant les déplacements quotidiens et aboutissent même dans certains cas à la constitution de communautés politiques, c'est ce que l'on observe dans un territoire où les contraintes naturelles sont bien plus fortes que dans le Forez, les Alpes.

\section{Un parallèle éclairant : les confréries des Alpes}

Pour comprendre le rôle politique que peuvent finir par remplir les confréries du SaintEsprit, il faut dans un premier temps souligner leur « apolitisme ». EEuvres charitables, les confréries placées sous la titulature de la troisième personne de La Trinité ne sont pas soupçonnées, contrairement à d'autres, de servir de couvertures à des conspirations contre les pouvoirs supérieurs.

Ainsi, en 1330, le Dauphin décide d'une enquête sur les confréries, suscitée par l'existence d'une confrérie jurée, dédiée à Sainte-Catherine, formée par des notables de Césanne et interdite aux nobles. Les notables se défendent de toute rébellion en affirmant s'être simplement réunis pour un banquet en plein air et discuter des statuts d'une association charitable ${ }^{26}$. À l'inverse, les confréries du Saint-Esprit ne sont pas inquiétées, au contraire, elles se multiplient au cours du xIV siècle remplissant souvent la fonction de fabriques, en plus de leurs attributions charitables ${ }^{27}$. Cette confiance dont bénéfice les confréries du Saint-Esprit auprès des pouvoirs supérieurs permet de comprendre pourquoi, plus que d'autres, elles servent de lieux d'implantation aux nobles du Forez. La bienveillance dont bénéficient les confréries ne se limite pas aux pouvoirs séculiers, comme l'atteste l'approbation accordée par l'évêque de Sion à la confrérie d'Anniviers en $1254^{28}$. Effectuant des distributions aux pauvres dès 1290 , cette confrérie possède un moulin et reçoit des redevances sur l'ensemble des alpages de la vallée dès la fin du XIII ${ }^{e}$ siècle. Elle institue ainsi un espace de vie commune sur le plan charitable et économique pour l'ensemble de la vallée, avec le soutien du siège épiscopal dont elle relève les redevances pour trois fiefs ${ }^{29}$. Comme en Forez, on note ici le croisement de réseaux horizontaux, les différents espaces de la vallée étant unis, et verticaux, cette unité se réalisant sous l'égide d'un corps social bénéficiant du soutien de l'évêque.

Un ultime aboutissement de cette capacité des confréries du Saint-Esprit à permettre la mise en relation de communautés au sein d'espaces enclavés se rencontre dans le Briançonnais. Une très forte densité de confréries du Saint-Esprit fait écho à un réseau complexe de groupements de communautés existant dès avant $1300^{30}$. Au cours du XIV ${ }^{\mathrm{e}}$ siècle, un processus de regroupement des communautés se met en œuvre: aux communautés de hameaux formant des ensembles solidaires dans les petites vallées secondaires du Queyras succède, dans un premier temps, une universitas rassemblant 
toute la communauté villageoise de la vallée. Puis, en 1343, le Dauphin Humbert II accorde aux représentants des différentes universitates la fondation d'une confédération des vallées briançonnaises. Chaque universitas se voit garantir une série de privilèges en échange de douze mille florins: l'élection des dirigeants hors de la présence d'un officier seigneurial, la maîtrise des forêts et des eaux, une limitation du contingent armé à fournir au prince, une protection des activités commerciales, des allègements de taxes et le remplacement du titre "d'hommes liges» du Dauphin par celui "d'hommes francs »31. Il est bien entendu que la présence immédiate du pouvoir comtal en Forez, le moindre enclavement des territoires et l'espace plus réduit du Forez empêchent de comparer terme à terme le cas des confréries du Saint-Esprit dans les Alpes et dans le Massif Central. Mais dans les deux cas, il est possible de voir comment l'existence d'un mouvement de confréries charitables légitimes et ayant une fonction mémorielle ouvre des possibilités pour tisser des liens lignagers et éventuellement politiques entre des espaces rendus distants par les contraintes du relief.

Si les montagnes du Forez ne sont pas un obstacle à la circulation, leur double nature d'obstacle naturel et de frontière politique en fait un élément de rupture de l'unité territoriale. Dans ces conditions, pour que la circulation soit possible, les voies de communication doivent se doubler de liens sociaux qui maintiennent en relation des territoires distincts. Qu'il s'agisse de la transplantation historique des vassaux du comte de Forez depuis leurs anciennes bases en Beaujolais et Lyonnais vers le nouveau centre du pouvoir comtal ou des déplacements à plus courte distance d'un village à un autre au gré d'une alliance matrimoniale ou de la diffusion d'une famille, les hommes du Forez ont dû inventer différents moyens pour nier la rupture de l'espace induite par les contraintes territoriale et politique. Pour cela, ils ont profité de la diffusion contemporaine des confréries du Saint-Esprit dont la double action, charitable et mémorielle, permet à la fois l'ancrage d'un lignage dans une communauté et la mise en relation de différents lieux auxquels est attaché un même lignage, qu'il soit noble ou non. Faire mémoire de ses parents dans le lieu où l'on s'installe alors que l'on entretient son propre souvenir dans celui que l'on a quitté, c'est l'un des moyens par lesquels la circulation des hommes ne se traduit pas par des déchirements, mais au contraire par une négation du temps et de l'espace, les deux paroisses se superposant l'une à l'autre dans l'univers de liens bâti par une même famille.

\section{BIBLIOGRAPHIE}

BAUTIER Robert Henri, « Recherches sur les routes de l'Europe médiévale. De Paris et des foires de Champagne à la Méditerranée par le Massif Central », Bulletin philologique et historique, Paris, 1960, t. 1, p. 99-143. 
CHOMEL Vincent, « À propos d'un livre récent : bourgs francs, communautés rurales et escartons en Dauphiné », Annales. E.S.C., 1956, nº 3, p. 347-360.

DUFOUR Jean, Dictionnaire topographique du Forez, Mâcon, Protat Frères, 1946.

FONTBONNE Alexis, « La Pentecôte des laïcs : une charité inspirée. Débats théologiques et appropriations laïques ", à paraître aux Presses Universitaires de Rennes dans les actes du colloque Pentecôtes médiévales.

GONON Marguerite, «La Loire, lien ou obstacle en Forez au Moyen Âge », Bulletin de la Diana, t. 34, 1966, p. 289-301.

GUICHARD Georges, PERROY Édouard (éd.), Chartes du Forez antérieures au XIV siècle, Mâcon, Protat Frères, 1933-1980.

JOURDAIN-ANNEQUIN Colette (dir.), Atlas culturel des Alpes occidental. De la Préhistoire à la fin du Moyen Âge, Paris, Picard, 2004.

LE GRIEL Alain, « Géologie et relief de la plaine du Forez », Plaines et milieux naturels de la plaine du Forez, Saint-Étienne, CEF, 1984.

PARAVY Pierrette, De la chrétienté à la réforme en Dauphiné, Rome, École Française de Rome, 1993.

PERROY Édouard, Les familles nobles du Forez au XIII siècle, essai de filiation, Montbrison, CEF, 1976.

POISSON Jean-Michel, «Quelques aspects de la circulation des produits et des hommes en Forez à la fin du Moyen Âge à partir des données archéologiques ", Les libertés au Moyen Âge, Montbrison, 1987, p. 85-94.

VIANIN Alexis, « La confrérie du Saint-Esprit d'Anniviers », Annales Valaisonnes, Sion, 1954, p. 122.

\section{NOTES}

1. A. Le Griel, « Géologie et relief de la plaine du Forez », p. 139.

2. M. Gonon, « La Loire, lien ou obstacle en Forez au Moyen Âge », p. 289-301.

3. R. H. Bautier, « Recherches sur les routes de l'Europe médiévale. De Paris et des foires de Champagne à la Méditerranée par le Massif Central », p. 99-143.

4. Pour l'histoire du comté de Forez, cf. J.E. Dufour, Dictionnaire topographique du Forez, p. XVII-XXVI.

5. E. Perroy, Les familles nobles du Forez au XIII siècle, essai de filiation.

6. Ibid., p. 73-74.

7. Ibid., p. 368.

8. Ibid., p. 367-368.

9. J.E. Dufour, Dictionnaire topographique du Forez, p. XXI.

10. G. Guichard, E. Perroy (éd.), Chartes du Forez antérieures au XIve siècle, t. 22, charte 1459.

11. E. Perroy, Les familles nobles du Forez au XIII ${ }^{e}$ siècle, essai de filiation, p. 72.

12. Sur cette question, nous nous permettons de renvoyer à A. Fontbonne, «La Pentecôte des laïcs: une charité inspirée. Débats théologiques et appropriations laïques ». 
13. C'est par exemple le cas de Guillaume d'Ay pour lui, son père et sa mère en 1288

(G. Guichard, E. Perroy (éd.), Chartes du Forez antérieures au XIV siècle, t. 8, charte 798).

14. La première mention d'une telle exigence se rencontre à Montbrison en 1316 (Archives Départementales de la Loire, B 1852 98-100).

15. G. Guichard, E. Perroy (éd.), Chartes du Forez antérieures au XIV siècle, t. 22, charte 1459.

16. Ibid., t. 6, charte 798.

17. Ibid., t. 2, charte 206.

18. E. Perroy, Les familles nobles du Forez au XIII siècle, essai de filiation, p. 541.

19. Archives Départementales de la Loire (désormais Arch. Dép. de la Loire) B 1858115.

20. G. Guichard, E. Perroy (éd.), Chartes du Forez antérieures au XIVe siècle, t. 5, charte 711.

21. J.-M. Poisson, "Quelques aspects de la circulation des produits et des hommes en Forez à la fin du Moyen Âge à partir des données archéologiques », p. 85-94.

22. Arch. Dép. de la Loire, B 1855, 49.

23. Arch. Dép. de la Loire, B 185892.

24. Arch. Dép. de la Loire, B 1876208.

25. Arch. Dép. de la Loire, B 18591.

26. V. Chomel, «À propos d'un livre récent: bourgs francs, communautés rurales et escartons en Dauphiné », p. 358.

27. P. Paravy, De la chrétienté à la réforme en Dauphiné, p. 495-496.

28. A. Vianin, « La confrérie du Saint-Esprit d'Anniviers », p. 122.

29. Ibid., p. 130.

30. P. Paravy, De la chrétienté à la réforme en Dauphiné, p. 501.

31. C. Jourdain-Annequin (dir.), Atlas culturel des Alpes occidental. De la Préhistoire à la fin du Moyen Âge, p. 268.

\section{RÉSUMÉS}

Suite à un échange réalisé en 1173 entre le comte et l'archevêque de Lyon, les nobles proches du comte et situés en lyonnais doivent migrer pour s'implanter dans le nouveau cœur du pouvoir comtal, la plaine du Forez. Les monts du lyonnais constituent alors une frontière naturelle et politique pour ses familles, qui vont tenter d'en diminuer l'importance. En effet, cette circulation nobiliaire n'est pas une rupture et les familles nobles développent un ensemble de stratégies visant à entretenir leur mémoire lignagère à la fois dans leur nouvel espace d'implantation et dans leur ancienne zone d'influence. Ces stratégies, qui profitent du développement contemporain des confréries charitables du Saint-Esprit ne sont cependant pas l'apanage des nobles. Il est ainsi possible d'étudier la manière dont la circulation des familles dans des espaces enclavés s'accompagne de célébrations mémorielles en plusieurs sites, aboutissant à la constitution d'un sentiment communautaire dont l'étendue dépasse largement la seule paroisse. 
AUTEUR

ALEXIS FONTBONNE

Professeur agrégé, collège Condorcet-Puy Guillaume 
Aux Temps modernes 


\title{
Le bois de construction des Alpes du sud : une ressource mise en œuvre localement et exportée
}

\author{
Lisa Shindo
}

1 Cet article, qui s'appuie sur des données récentes issues d'un travail de thèse interdisciplinaire ${ }^{1}$, propose de détailler les diverses utilisations du bois de construction, mais également ses déplacements, depuis la montagne vers la plaine.

2 Le cadre de cette étude va du bassin versant de la Haute Durance à la Basse Provence. La Durance prend sa source dans le Briançonnais, traverse les Alpes-de-HauteProvence, passe à une vingtaine de kilomètres au nord d'Aix et se jette dans le Rhône au niveau d'Avignon. Trois zones ont retenu notre attention. La première, la plus au nord, la Haute Durance, correspond au Briançonnais (dans les Hautes-Alpes), un massif montagneux où les sites étudiés sont, en moyenne, à une altitude de $1000 \mathrm{~m}$. La deuxième zone, la région de Digne-les-Bains (dans les Alpes-de-Haute-Provence), présente des sites à une altitude moyenne de 800 - $900 \mathrm{~m}$, c'est la Moyenne Durance. Enfin, la troisième zone considérée, le Pays d'Aix ou Basse Provence, comprend Aix-enProvence et ses alentours, à peu près à $400 \mathrm{~m}$ d'altitude (fig. 1). 
Fig. 1. - Carte de la zone étudiée.

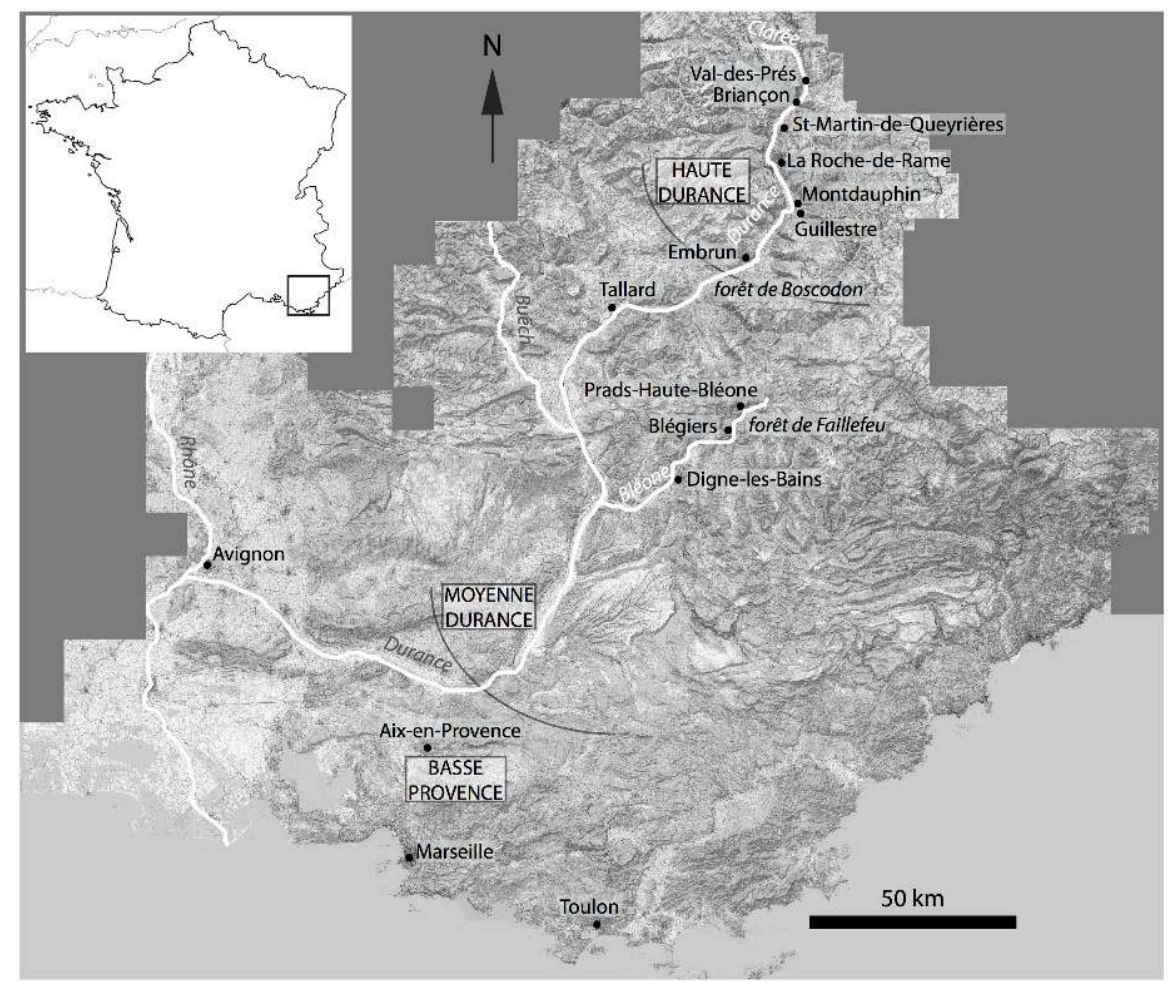

(c) L. Shindo, fond de carte : IGN scan 25.

3 Le bois de construction a été étudié au moyen de la dendrochronologie, discipline analysant les anneaux de croissance des arbres, les cernes. Elle permet de dater les séries de cernes, au moyen de leur synchronisation ${ }^{2}$. La dendrochronologie apporte des informations sur les types d'arbres mis en œuvre par les populations humaines (âges au moment de l'abattage, conditions de croissance), mais livre également les dates de construction des bâtiments quand ceux-ci comportent des pièces de bois.

\section{Utilisation locale du bois de construction}

Les usages du bois dans les Alpes du sud sont variés. Plusieurs travaux ont déjà traité cette question ${ }^{3}$ et nous allons ici nous concentrer sur le bois destiné à la construction locale. L'exploitation des forêts liée aux besoins locaux en bois de construction est de deux types. Le premier concerne l'utilisation de ce matériau par les populations locales, pour leurs propres besoins. Le deuxième, d'ampleur, est lié aux besoins militaires.

\section{Utilisation du bois par les montagnards pour leurs constructions locales}

\section{Les sources textuelles}

5 Nous n'avons trouvé que peu de mentions des prélèvements de bois destinés à la construction locale. Pour la période médiévale, il semblerait qu'il s'agisse de droits d'usages, non écrits. Il est tout de même possible d'en trouver des allusions, comme dans l'arrêt du Conseil Delphinal du 16 avril $1401^{4}$. Dans celui-ci, il est indiqué que la 
communauté de Val-des-Prés (Haute Durance) a le droit de faire son "bocheyrage " dans le bois des Chevalets. Cependant, un doute subsiste puisque dans cet arrêt, il n'est pas précisé si le bois coupé est destiné à la construction ou non. Un deuxième exemple se trouve dans les registres de comptes de la commune de Prads-Haute-Bléone (Moyenne Durance). Il y est fait mention, en 1660, de planches de bois portées par un habitant à la cabane d'alpage du Mourreau ${ }^{5}$, sans doute pour une réparation. La provenance de ces planches est inconnue, même si l'on peut fortement supposer qu'elles sont issues des riches forêts locales. À l'inverse, le 12 mai 1837, la commune de Blégiers (Moyenne Durance) « demande l'autorisation d'abattre 16 arbres dans la forêt communale pour réparer les bâtiments ${ }^{6}$. Ici, la provenance des bois est connue mais la nature des réparations et la localisation des bâtiments ne sont pas indiquées.

Les sources textuelles dressent un bilan incomplet de l'utilisation locale des bois de construction. C'est pour combler ces lacunes que leur étude dendrochronologique a été réalisée.

\section{La dendrochronologie}

$7 \quad$ Notre analyse s'appuie sur l'étude de plusieurs centaines de pièces de bois, en Haute et en Moyenne Durance, depuis la vallée de la Clarée jusqu'à celle de la Bléone ${ }^{7}$. Ces pièces de bois proviennent d'habitats (fermes et granges), dont certains restaurés, des pressoirs à vin, des bois de mine, des moulins et des édifices religieux.

Dans ces constructions locales, l'essence principalement mise en œuvre est le mélèze (Larix decidua Mill.), mais le pin sylvestre (Pinus sylvestris L.) et le sapin (Abies alba Mill.) sont aussi très présents, tandis que le pin cembro rarement (Pinus cembra L.). Quelques pièces en feuillus ont été identifiées en Moyenne Durance: chêne, hêtre, saule et peuplier. La moyenne des âges cambiaux (l'âge des arbres au moment de leur abattage) est supérieure à 100 ans pour les essences résineuses et leur diamètre moyen est de $22,5 \mathrm{~cm}$.

9 Bien que certains éléments architecturaux soient majoritairement réalisés avec une essence particulière (fermes des charpentes en mélèze, leviers de pressoirs à vin en pin sylvestre, etc.), il apparaît que le choix de l'essence est aussi lié à la ressource locale disponible.

10 Les pièces datées par la dendrochronologie renseignent sur les phases d'abattage et de construction dans la vallée de la Durance. Cinq grandes phases de construction, correspondant à l'essentiel des abattages, ont été identifiées ${ }^{8}$ : fin $\mathrm{XII}^{\mathrm{e}}$ siècle et début $\mathrm{XIII}^{\mathrm{e}}$ siècle, fin $\mathrm{XV}^{\mathrm{e}}$ et première moitié $\mathrm{du} \mathrm{xVI}^{\mathrm{e}}$ siècle, première moitié $\mathrm{XVII}^{\mathrm{e}}$ siècle,

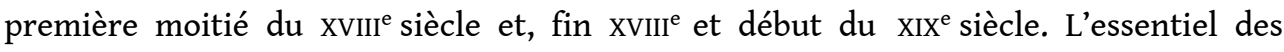
abattages est concentré dans ces cinq grandes phases. On observe cependant des abattages continus, $\mathrm{du} \mathrm{x}^{\mathrm{e}}$ au $\mathrm{xx}^{\mathrm{e}}$ siècle (exception faite de la seconde moitié du $\mathrm{xIV}^{\mathrm{e}}$ siècle, cf. infra), ce qui témoigne d'une activité d'entretien, de réparation, de transformation permanente du bâti, variant avec les fluctuations démographiques, les vicissitudes politiques, économiques et sanitaires. La deuxième moitié du XIve siècle fait figure d'exception puisqu'aucun des arbres analysés n'aurait été abattu à cette époque. Ce hiatus pourrait trouver son origine dans le contexte troublé de l'époque (épisodes de guerre, de famine et d'épidémies ${ }^{9}$ ), qui a vu le nombre de nouvelles constructions diminuer ; les populations locales ont, en outre, peut-être remployé des pièces de bois anciennes. Une telle hypothèse demande à être vérifiée par les sources textuelles. Et, de 
nouvelles investigations sur les constructions situées dans l'étage subalpin, hors vallée de la Clarée déjà bien étudiée par J.-L. Édouard ${ }^{10}$, sont à envisager car ce sont elles qui ont livré les pièces de bois les plus anciennes.

\section{Utilisation par les militaires pour les fortifications locales}

11 En raison de la position frontalière du Briançonnais avec la Savoie (qui s'étend du nord de Lyon jusqu'à Nice), les constructions militaires et l'entretien des troupes qui séjournent dans le Briançonnais exercent un lourd tribut sur les forêts locales, dès le $\mathrm{XVII}^{\mathrm{e}}$ siècle. Par exemple, en 1728, les habitants de La Roche-de-Rame déclarent :

"Qu'en l'année 1727 et 1728, ils ont fourni 800 palissades de pins pour Briançon », mais ce n'est pas tout !: « que l'on a encore pris cette année dans les bois obscurs, en pièces de sapin pour les bâtiments et fortifications de Briançon. "

Pour le moment, nous n'avons réalisé aucune analyse dendrochronologique dans un bâtiment à vocation militaire et ne pouvons donc pas préciser les caractéristiques des bois qui y étaient mis en œuvre. Il faut tout de même préciser que l'impact des installations militaires sur les forêts locales est important puisqu'en plus des bois de constructions, ces sites étaient de grands consommateurs de bois de chauffage. Ainsi, en 1728, les habitants de La Roche-de-Rame se plaignent d'avoir eu à fournir une forte quantité de bois de chauffage pour la forteresse pour la forteresse de Montdauphin ${ }^{11}$.

\section{Exportation du bois de construction}

13 Une partie des pièces de bois de Haute et Moyenne Durance était destinée à l'exportation vers l'aval, vers les zones où existait une forte demande en bois de construction. En effet, leur vente assurait un revenu aux propriétaires des forêts ${ }^{12}$. Plusieurs travaux ont déjà montré l'existence de liens commerciaux entre la Haute et la Moyenne Durance avec sa basse vallée. Par exemple, certains marchands de bois présents à Aix-en-Provence à la fin de l'époque médiévale sont originaires de Tallard ou du Bôchaine ${ }^{13}$ (Haute Durance). De même, en 1423-24, la reine Yolande, comtesse de Provence, autorise les Marseillais à faire venir les bois de la forêt de Boscodon (HauteProvence) pendant un $\mathrm{an}^{14}$. Ou encore, après le siège de leur ville en 1524, les Cordeliers de Marseille font venir un radeau de bois depuis le Dauphiné afin de procéder aux réparations de leur couvent ${ }^{15}$. Il a été établi qu'au XVIII siècle, ce sont les personnes travaillant dans la construction qui ont été les plus demandeuses de coupes de bois $(15,7 \%)^{16}$. Nous supposons qu'il en a toujours été ainsi au cours du temps même si nous n'avons pas de preuves pour toutes les époques. En effet, les sources textuelles conservent rarement la trace du trajet complet du bois, depuis sa forêt d'origine jusqu'à sa mise en œuvre finale.

\section{Restitution des étapes de l'exportation du bois}

\section{Autorisation de coupe et rédaction des actes chez le notaire}

La commercialisation du bois commence par l'autorisation de coupe. Les contrats commerciaux passés chez les notaires sont nombreux. La description des actes est précise et il est très souvent fait mention d'un délai à tenir pour la réalisation de la commande. Les exemples qui suivent portent principalement sur les forêts appartenant 
à des établissements religieux, puisque la forte organisation de ces derniers favorise l'enregistrement et la conservation de tous les actes les concernant.

Les prix faits ${ }^{17}$ enregistrés chez les notaires nous renseignent sur les acheteurs de bois destinés à l'exportation, ayant l'autorisation de coupe des propriétaires des forêts. Ces marchands de bois ne procèdent pas eux-mêmes à la coupe, ils engagent des "prifachiers» (terme qualifiant une personne chargée de réaliser une tâche pour un prix convenu d'avance. Ici, il s'agit de bûcherons). Par exemple, le 27 mai 1598, le sieur de Sauze, qui a déjà obtenu l'autorisation du propriétaire de la forêt de Faillefeu (le grand prieur de Cluny, seigneur de Faillefeu, aujourd'hui sur la commune de PradsHaute-Bléone dans le département des Alpes-de-Haute-Provence) commande la coupe de deux radeaux de 52 pans de bois chacun. Ce n'est pas lui qui va effectuer cette coupe, mais trois hommes originaires de Blégiers, avec qui il passe ce marché ${ }^{18}$. Nous n'avons, jusqu'à présent, pas rencontré de mentions de coupes et de ventes de bois réalisées par une même personne.

Toutes les autorisations de coupes n'impliquent pas la rédaction d'un prix fait chez le notaire, notamment celles relevant du droit d'usage. Cependant, nous supposons que dans le cas de vente de bois à des étrangers, le recours à un notaire devait être systématique.

\section{De la coupe à la sortie de la forêt}

Plusieurs études ont déjà été réalisées sur l'organisation du travail sylvestre ${ }^{19}$. Nous allons plutôt nous intéresser à ce qu'il se passe une fois les arbres abattus. Lorsque les arbres ont été coupés, un contrôle peut être réalisé par le propriétaire («[...] voir, visiter et mesurer le bois $\left.[. ..] »^{20}\right)$. Puis, les grumes sont sorties de la forêt. Un nouvel intervenant est parfois sollicité pour exécuter cette tâche, comme c'est le cas en 1586 où deux personnes se sont engagées à «[...] trayner et charrier le boys de failhefeu jusques a la riviere de bleaune, teste en eau [...] $»^{21}$. Au XvI ${ }^{\mathrm{e}}$ siècle, les radeliers marseillais sous-traitent le transport des grumes, de la forêt de Boscodon à la Durance $^{22}$.

\section{Flottage et/ou transport routier}

Une fois les grumes au bord du cours d'eau, de nouveaux prifachiers peuvent intervenir pour la construction et la conduite des radeaux de bois jusqu'à leur destination. Ce type de transport nautique, plus rapide que par voie terrestre, a déjà fait l'objet de plusieurs études $^{23}$. Les comptes des péages installés sur la Durance indiquent que, dès le XIII ${ }^{\mathrm{e}}$ siècle au moins, des pièces de bois en provenance des Alpes et à destination de la Basse Provence y circulent ${ }^{24}$. Ainsi, au début du $\mathrm{XV}^{\mathrm{e}}$ siècle, pas moins de 20 péages étaient établis entre Les Crottes (près d'Embrun) et Caumont (près d'Avignon) ${ }^{25}$. Ce nombre élevé de péages indique que les profits réalisés étaient considérables et laisse penser que le trafic sur la Durance était élevé.

19 En parallèle du flottage, certaines pièces de bois sont transportées par la route. Cet acheminement a l'avantage de pouvoir se pratiquer toute l'année, contrairement au flottage qui se fait en général à la fonte des neiges ${ }^{26}$, hors des périodes de crue des fleuves et rivières. Cependant, le transport routier se révèle plus coûteux (il peut être jusqu'à quatre fois plus élevé2 ${ }^{27}$ que le flottage) et il a donc moins été pratiqué. Suivant leur mode d'acheminement, par flottage ou par voie terrestre, les pièces de bois sont 
travaillées afin d'y faire passer des systèmes de fixation (corde, tige, etc.) et il est assez fréquent de retrouver ces traces dans les charpentes ${ }^{28}$.

\section{Les besoins de la Marine}

20 C'est sous Richelieu que la Marine royale prend son ampleur à Toulon. Donc, à partir du XVII ${ }^{\mathrm{e}}$ siècle, c'est une grosse consommatrice de bois, s'approvisionnant depuis les forêts du littoral jusqu'à celles de Seyne (Moyenne Durance). Entre 1708 et 1789, l'Arsenal de Toulon a construit 143 navires dont trois barques exigeant chacune « cinquante chênes et soixante pins blancs $»^{29}$. La Marine fait réaliser des inventaires sur les bois de Provence, jusqu'au Dauphiné au nord : celui d'Habert de Montmort (dès 1682) et celui de Chabert de L'Isle (1723). Ces enquêtes recensent les bois pouvant servir à la construction de navires. Entre 1689 et 1731, ce ne sont pas moins de 13 millions d'arbres qui sont listés, sur plusieurs centaines de localités. En effet, il a été plus logique de recenser les arbres un par un (des individus) que des superficies en raison de la spécificité des paysages provençaux. Les procès-verbaux de ces visites comportent également des informations sur la nature et l'âge des bois, le nombre et la qualité des pièces qui pourront en être tirées, le nom des propriétaires et enfin, leur localisation et leur éloignement des chemins et rivières (pour leur transport). Plus d'une dizaine de documents ont ainsi été dépouillés par G. Pichard et leurs données ont fait l'objet d'un traitement statistique ${ }^{30}$.

21 Ces enquêtes de la Marine sont plus exhaustives pour la Moyenne que pour la Haute Durance. En effet, si la présence des enquêteurs est signalée dans les archives de Guillestre dès $1642^{31}$, à St-Martin-de-Queyrières, les bois coupés pour la Marine ne sont pas récupérés et pourrissent sur place suite à « la difficulté de les extraire $»^{32}$. De fait, dans un mémoire de 1740 adressé à l'administration royale, les communautés briançonnaises rappellent que leurs forêts sont inaccessibles et «remplies de précipices $\Perp^{33}$. Les terrains escarpés et l'éloignement du Briançonnais aux chantiers navals méditerranéens ont certainement découragé la Marine d'y prélever trop d'arbres.

\section{Les bois importés en Basse Provence et leurs marques}

Depuis 2013, le Centre Camille Jullian (UMR CNRS 7299) a procédé à l'étude d'une dizaine de sites à Aix-en-Provence et aux alentours, entre 150 et $300 \mathrm{~m}$ d'altitude. Il s'agit principalement d'hôtels particuliers et d'édifices religieux, tels que l'église de la Madeleine, l'hôtel de Caumont, la bastide du Jas de Bouffan ou le domaine du Grand Saint-Jean par exemple ${ }^{34}$. Les pièces de bois étudiées sont majoritairement en sapins (pouvant atteindre $1 \mathrm{~m}$ de circonférence et $13 \mathrm{~m}$ de longueur) mais quelques pins type sylvestres et mélèzes ont également été identifiés en très faible quantité. Ces essences résineuses se développent aux étages montagnard et subalpin, c'est-à-dire entre 800 et $2200 \mathrm{~m}$ d'altitude ${ }^{35}$. En Basse Provence, dans le pays d'Aix, la végétation est de type méditerranéen et il est difficile de trouver des arbres avec de longs troncs rectilignes, permettant de réaliser des pièces de longue portée dans la construction. C'est pour cela qu'à partir $\mathrm{du} \mathrm{Xv}^{\mathrm{e}}$ siècle au moins le bois était importé depuis l'amont, depuis la Moyenne et la Haute Durance, où ce type d'arbres est abondant ${ }^{36}$. 
Lors de ces études dans les bâtiments aixois, nous avons identifié de nombreuses marques apposées sur les poutres et celles-ci ont retenu notre attention. Les marques laissées par les systèmes de fixation lors du transport des pièces de bois (par flottage ou par voie terrestre) sont assez facilement identifiables ${ }^{37}$. Les autres marques, composées de lignes et de motifs géométriques (fig. 2), ont pu être faites en forêt avant le transport, pendant le transport, par le marchand, par l'acheteur, par les charpentiers ou alors, une fois la poutre mise en place. Elles ont été réalisées après équarrissage des grumes, à la gouge, aux ciseaux à bois ou à l'aide d'un poinçon. S'il s'agit de marques liées au commerce et au travail du bois, nous ne sommes pas parvenus à comprendre leur signification. Les textes font souvent mention de ces marques réalisées par les différents intervenants du commerce du bois, comme dans cet acte de 1607 qui mentionne «[...] la marque dudict capitaine Pascal qu est un E [...]» (le capitaine Pascal était marchand de la ville d'Aix-en-Provence) ${ }^{38}$.

Fig. 2. - Quelques marques identifiées en Basse Provence, dans le pays d'Aix : bastide du Jas de Bouffan, hôtel de Caumont et bastide du Seuil.
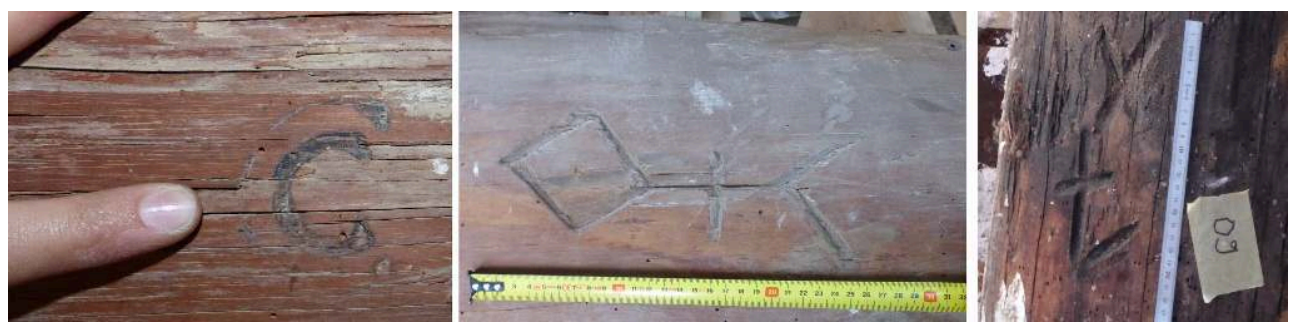

(c) Clichés Lisa Shindo.

À notre connaissance, il n'existe aucune étude publiée portant sur l'identification des marques de propriétaires de forêt, de bûcherons, de marchand et de charpentiers dans le sud-est de la France. La réalisation d'une telle étude, indispensable pour mieux appréhender les échanges commerciaux entre la montagne et la plaine, nécessitera la collaboration des divers acteurs du patrimoine et la mise en place d'une base de données commune.

\section{Conclusions et perspectives}

L'utilisation du bois de construction dans le bassin de la Durance est variée : utilisation locale par les populations et par les militaires en Moyenne et Haute Durance, exportation vers l'aval, en partie pour les besoins de la Marine, et en Basse Provence, importation pour répondre à la forte demande en bois de construction.

Des sources historiques témoignent de ces échanges de bois entre la montagne et la plaine, mais, dans l'état actuel des connaissances, il n'a jamais été possible de retracer un trajet complet du bois exporté, depuis la forêt source jusqu'au bâtiment où il a été mis en œuvre.

Pour résoudre cette problématique, deux axes de recherche sont en cours de développement. Le premier concerne l'étude des marques apposées sur les pièces de bois, en enrichissant notre base de données régionale («Marques pièces de bois PACA »). Cela implique également de continuer à travailler avec les historiens, pour identifier les nombreux intervenants du commerce du bois. La dendro-provenance est 
le second axe de recherche, il s'agit d'une application de la dendrochronologie permettant de déterminer la provenance des bois d'œuvre par l'étude de leur série de cernes $^{39}$. En plus de retrouver les forêts sources, la dendro-provenance permet d'obtenir des informations sur l'approvisionnement en bois, son transport, les routes commerciales et l'intensité du commerce du bois.

\section{BIBLIOGRAPHIE}

AMOURIC Henri, «Pratiques et usages de la forêt provençale au Moyen Âge », dans Servei d'Archeologia d'Adorra (dir.), La vida medieval a les dues vessants del Pirineu, I i II : 1r curs d'arqueologia d'Andorra del 26 de setembre al 2 d'octubre de 1988, 2r curs d'arqueologia d'Andorra del 12 al 23 de setembre de 1989, Andorra govern, 1991, p. 77-89.

BARATIER Édouard, La démographie provençale du XIII au XVI siècle, avec chiffres de comparaison pour le XVIII ${ }^{e}$, Paris, S.E.V.P.E.N, 1961.

BARRUol Guy, LONCHAMbon Catherine, fURESTIER Denis, MIRAMONT Cécile (dir.), La Durance de long en large. Bacs et radeaux dans l'histoire d'une rivière capricieuse, Forcalquier, Les Alpes de lumière (149), 2005.

BAUME Marie-Paule, La Bléone et Faillefeu, Toulon, Éditions Sira, 2011.

BERNARDI Philippe, " Fourniture et utilisation du bois d'œuvre à Aix-en-Provence à la fin du Moyen Âge ", dans Servei d'Archeologia d'Adorra (dir.), La vida medieval a les dues vessants del Pirineu, I i II : 1r curs d'arqueologia d'Andorra del 26 de setembre al 2 d'octubre de 1988, 2r curs d'arqueologia d'Andorra del 12 al 23 de setembre de 1989, Andorra govern, 1991, p. 91-98. BERNARDI Philippe, «L'exploitation des forêts », dans BERNARDI Philippe (dir.), Forêts alpines et charpente de Méditerranée, L'Argentière-La Bessée, Éditions du Fournel, 2007a, p. 47-55.

BERNARDI Philippe, « Le commerce du bois ", dans BERNARDI Philippe (dir.), Forêts alpines et charpente de Méditerranée, L'Argentière-La Bessée, Éditions du Fournel, 2007b, p. 79-88.

BILLIOUD Jacques, « Les bois des Hautes-Alpes en Provence », Bulletin de la société d'étude des HautesAlpes, $\mathrm{n}^{\circ}$ 52, 1960, p. 106-112.

BOUTICOURT Émilien, Charpentes méridionales. Construire autrement : le Midi rhodanien à la fin du Moyen Âge, Arles, Honoré Clair, 2016.

BOYER Jean, Le commerce des bois de charpente et menuiserie à Aix-en-Provence auX XVe, XVI ${ }^{e}, X_{I I}{ }^{e}$ siècles, actes du $108^{\mathrm{e}}$ Congrès national des Sociétés savantes, Grenoble, 1983, p. 121-138.

BRES Robert, « La forêt de Boscodon dans l'histoire de l'abbaye. Exploitation et commerce du bois du Moyen Âge au XVIII ${ }^{\mathrm{e}}$ siècle ", Cahiers de Boscodon, 3, 1985, p. 82-87.

BURRI Sylvain, «Vivre de l'inculte, vivre dans l'inculte en Basse Provence centrale à la fin du Moyen Âge : Histoire, archéologie et ethnoarchéologie d'un mode de vie itinérant ", thèse de doctorat en histoire, Aix-en-Provence, Aix-Marseille université, 2012. 
CHENARD Gaël, GALVIN-DEMOZ Monique, VALLE DE LORO Daniela (dir.), Auprès de mon arbre... La forêt dans les Hautes-Alpes d'y il a longtemps à nos jours, Dossier thématique des archives départementales des Hautes-Alpes, Gap, Agence culturelle du conseil Général, 2012.

DEVÈzE Michel, La Vie de la forêt française au XVI ${ }^{e}$ siècle, Paris, S.E.V.P.E.N., 1961, 2 vol.

DOUGLAS Andrew Ellicott, « Crossdating in dendrochronology », Journal of forestry, n 39, 1941, p. 852-831.

DURAND Aline, Les paysages médiévaux du Languedoc (XI ${ }^{e}$-XII ${ }^{e}$ siècles), Toulouse, Presses universitaires du Mirail (Tempus médiéval), 1998.

ÉDOUARD Jean-Louis, «Longue chronologie de cernes du mélèze et occupation humaine depuis plus de mille ans dans la vallée de la Clarée (Briançonnais, Alpes françaises) », dans TzoRTzIs Stéphan, DELESTRE Xavier (dir.), Archéologie de la montagne européenne, actes de la table ronde internationale de Gap, 29 septembre- $\mathrm{1}^{\mathrm{er}}$ octobre 2008, Bibliothèque d'archéologie méditerranéenne et africaine, $\mathrm{n}^{\circ} 4$, Paris, Errance, 2010, p. 325-333.

FALQUE-VERT Henri, Les hommes et la montagne en Dauphiné au XIII siècle, Grenoble, Presses Universitaires, 1997.

GADOUD Marie, "Les forêts du Haut-Dauphine à la fin du XVII ${ }^{\mathrm{e}}$ siècle et de nos jours ", Recueil des travaux de l'institut de géographie alpine, vol. 5, nº 1, 1917, p. 1-113.

HANECA Kristof, WAZNY Tomasz, VAN ACKER Joris, BEECKMAN Hans, « Provenancing Baltic timber from art historical objects: success and limitations ", Journal of Archaeological Sciences, $n^{\circ} 32,2005$,

p. 261-271.

LAMBERT Georges-Noël, « La dendrochronologie, mémoire de l'arbre », dans FERDIÈRE Alain (dir.), La datation en laboratoire, Paris, Éditions Errance (Collection « Archéologiques ») 2005, p. 19-75.

LE ROY LADURIE Emmanuel, Histoire humaine et comparée du climat. t. 1, Canicules et glaciers XIII ${ }^{e}-X_{\text {XIII }}^{e}$ siècle, Paris, Fayard, 2004.

LEROY Paul-Marie, Mémoire sur les travaux qui ont rapport à l'exploitation de la mâture dans les Pyrénées, Oloron-Sainte-Marie, Monhélios, 2003.

MILLE Pierre, «L'usage du bois vert au Moyen Âge : de la contrainte technique à l'exploitation organisée des forêts », dans COLARDELLE Michel (dir.), L'homme et la nature au Moyen Âge : paléoenvironnement des sociétés occidentales, actes $\mathrm{du} \mathrm{V}^{\mathrm{e}}$ Congrès international d'archéologie médiévale, Grenoble, 6-9 octobre 1993, Paris, Éditions Errance, 1996, p. 166-170.

NICOLAS Nathalie, «Guerre et insécurité : le coût de la mise en défense des châteaux du HautDauphinois (1360-1400) », thèse de doctorat en histoire, Aix-en-Provence, Université AixMarseille, 2012, 2 vol.

OZENDA Paul, La végétation de la chaîne alpine dans l'espace montagnard européen, Paris, Masson, 1985. PEYRIAT Pierre-André, « Problèmes forestiers en Provence d'après les archives de la Chambre des eaux et forêt d'Aix », Revue Provence historique, t. 15, fasc. 62, 1965, p. 229-244.

PICHARD Georges, « Arbres et forêts des Alpes à l'époque des premiers inventaires statistiques (Haut-Dauphiné - Haute-Provence, 1689-1732) », dans Économies et sociétés des pays de montagne, actes du $108^{\mathrm{e}}$ congrès national des sociétés savantes, Grenoble, 1983, Section d'histoire moderne et contemporaine, $\mathrm{n}^{\circ} 1,1984$, p. 11-34.

PICHARD Georges, « Espace et nature en Provence. L'environnement rural 1540-1789 », thèse de doctorat en histoire, Aix-en-Provence, Université de Provence Aix-Marseille I, 1999, 3 vol. 
PY Vanessa, « Mine, bois et forêt dans les Alpes du sud au Moyen Âge, Approches archéologiques, bioarchéologique et historique ", thèse de doctorat en archéologie, Aix-en-Provence, Université Aix-Marseille I, 2009, 3 vol.

SCLAFERT Thérèse, Cultures en Haute-Provence : déboisements et pâturages au Moyen Âge, Paris, S.E.V.P.E.N., 1959.

SCHWEINGRUBER Fritz Hans, Tree rings. Basics and Applications of dendrochronology, Dordrecht, De Reidel Publishing Company, 1988.

SHINDO Lisa, « Bois de construction et ressources forestières dans les Alpes du sud au II ${ }^{\mathrm{e}}$ millénaire : dendrochrono-écologie et archéologie », thèse de doctorat en archéologie, Aix-enProvence, Aix-Marseille Université, 2016.

SHINDO Lisa, LABBAS Vincent, ÉDOUARD Jean-Louis et GUIBAL Frédéric, « La construction en mélèze dans les Alpes du Sud depuis le $\mathrm{x}^{\mathrm{e}}$ siècle : une nouvelle lecture dendrochronologique de l'occupation humaine en montagne et des ressources forestières, données et méthodologies inédites ", dans ArcheoSciences, revue d'archéométrie, nº 42-2, 2018, p. 63-75.

SHINDO Lisa, CLAUDE Sandrine, « Buildings and wood trade in Aix-en-Provence (South of France) during modern period », dans Dendrochronologia, Elsevier, 2019, n 54, p. 29-36.

VACHALDE Christophe, «L'art de cuire la pierre en France méditerranéenne à la fin du Moyen Âge, approche interdisciplinaire d'un artisanat méconnu : la chaufournerie », thèse de doctorat en archéologie, Aix-en-Provence, Université Aix-Marseille, 2013, 3 vol.

VIVIER Nadine, Le Briançonnais rural aux XVIII et XIX siècles, Paris, L'Harmattan, 1992.

WAZNY Tomasz, « Historical timber trade and its implications on dendrochronological dating ", dans BARTHOLIN Thomas, BERGLUND Bjorn, ECKSTEIN Dieter, scHWEINGRUBER Fritz Hans (Eds.), Tree Rings and Environment, Proceedings of the International Dendrochronological Symposium, Ystad, South Sweden, 3-9 September 1990, Lundqua Report, $n^{\circ}$ 34, 1992, p. 331-333.

\section{NOTES}

1. L. Shindo, Bois de construction et ressources forestières dans les Alpes du sud au II millénaire : dendrochrono-écologie et archéologie.

2. Quelques ouvrages de référence : A. E. Douglas, Crossdating in dendrochronology, F. H. Schweingruber, Tree rings. Basics and Applications of dendrochronology, G.-N. Lambert, La dendrochronologie, mémoire de l'arbre.

3. H. Amouric, Pratiques et usages de la forêt provençale au Moyen Âge, P. Bernardi, Le commerce du bois, S. Burri, Vivre de l'inculte, vivre dans l'inculte en Basse Provence centrale à la fin du Moyen Âge: Histoire, archéologie et ethnoarchéologie d'un mode de vie itinérant, G. Chenard, M. Galvin-Demoz, D. Valle de Loro, Auprès de mon arbre... La forêt dans les Hautes-Alpes d'y il a longtemps à nos jours, A. Durant Les paysages médiévaux du Languedoc (XI ${ }^{e}$-XII ${ }^{e}$ siècles), N. Nicolas, Guerre et insécurité: le coût de la mise en défense des châteaux du Haut-Dauphinois (1360-1400), V. Py, Mine, bois et forêt dans les Alpes du sud au Moyen Âge, Approches archéologiques, bioarchéologique et historique, $\mathrm{C}$. Vaschalde, L'art de cuire la pierre en France méditerranéenne à la fin du Moyen Âge, Approche interdisciplinaire d'un artisanat méconnu : la chaufournerie. 
4. Archives départementales des Hautes-Alpes, 3E 7315 FF11. Le document consulté, écrit sur papier, semble être une transcription, postérieure au xvIII ${ }^{\mathrm{e}}$ siècle.

5. Archives départementales des Alpes-de-Haute-Provence, E dep 155/4. Merci à Madame M.-P. Baume pour sa transcription du texte.

6. Archives départementales des Alpes-de-Haute-Provence, 7M235.

7. L. Shindo, Bois de construction et ressources forestières dans les Alpes du sud au II millénaire : dendrochrono-écologie et archéologie.

8. L. Shindo, V. Labbas, J.-L. Édouard et F. Guibal, « La construction en mélèze dans les Alpes du Sud depuis le $\mathrm{x}^{\mathrm{e}}$ siècle: une nouvelle lecture dendrochronologique de l'occupation humaine en montagne et des ressources forestières, données et méthodologies inédites ».

9. E. Baratier, La démographie provençale du XIII au XVI siècle, avec chiffres de comparaison pour le XVIII', H. Falque-Vert, Les hommes et la montagne en Dauphiné au XIII siècle, E. Le Roy Ladurie, Histoire humaine et comparée du climat, t. 1, Canicules et glaciers XIII ${ }^{e}$-XVIII ${ }^{e}$ siècle.

10. J.-L. Édouard, Longue chronologie de cernes du mélèze et occupation humaine depuis plus de mille ans dans la vallée de la Clarée (Briançonnais, Alpes françaises).

11. Archives départementales des Hautes-Alpes, C109, fo 243.

12. N. Vivier, Le Briançonnais rural aux XVIII et XIX ${ }^{e}$ siècles, p. 40.

13. P. Bernardi, Fourniture et utilisation du bois d'œuvre à Aix-en-Provence à la fin du Moyen Âge, p. 94.

14. Archives communales de Marseille, parchemin, AA28, cité par R. Brès, La forêt de Boscodon dans l'histoire de l'abbaye. Exploitation et commerce du bois du Moyen Âge au XVIII siècle, p. 84.

15. M. Devèze, La Vie de la forêt française au XVI siècle, t. 2, p. 43.

16. G. Pichard, Espace et nature en Provence. L'environnement rural 1540-1789, p. 467.

17. Les prix faits sont des contrats passés entre un commanditaire et un exécutant, pour une tâche dont le prix est fixé à l'avance.

18. M.-P. Baume, La Bléone et Faillefeu, p. 65 (Archives départementales des Alpes-deHaute-Provence, Me Costelier, 2E16425, $\mathrm{f}^{\circ}$ 46).

19. P. Mille, L'usage du bois vert au Moyen Âge: de la contrainte technique à l'exploitation organisée des forêts, V. Py, Mine, bois et forêt dans les Alpes du sud au moyen âge, Approches archéologiques, bioarchéologique et historique, S. Burri, Vivre de l'inculte, vivre dans l'inculte en Basse Provence centrale à la fin du Moyen Âge : Histoire, archéologie et ethnoarchéologie d'un mode de vie itinérant.

20. M.-P. Baume, La Bléone et Faillefeu, p. 38 (Archives départementales des Alpes-deHaute-Provence, Me Estrayer, 2E4763, $\left.\mathrm{f}^{\circ} 71\left(\mathrm{v}^{\circ}\right)\right)$.

21. Ibid., p. 47 (Archives départementale des Alpes-de-Haute-Provence, Me Michel, 2E4147, fo 395( (vo)-397).

22. R. Brès, La forêt de Boscodon dans l'histoire de l'abbaye. Exploitation et commerce du bois du Moyen Âge au XVIII siècle, p. 84.

23. Voir par exemple P.-M. Leroy, Mémoire sur les travaux qui ont rapport à l'exploitation de la mâture dans les Pyrénées, G. Barruol, C.Lonchambon, D. Furestier, C. Miramont, La 
Durance de long en large. Bacs et radeaux dans l'histoire d'une rivière capricieuse ou P. Bernardi, Le commerce du bois.

24. T. Sclafert, Cultures en Haute-Provence: déboisements et pâturages au Moyen Âge, P. Bernardi, Fourniture et utilisation du bois d'œuvre à Aix-en-Provence à la fin du Moyen Âge, L'exploitation des forêts, et Le commerce du bois. Le flottage de bois sur la Durance est attesté depuis la fin du XII siècle, du moins pour les pièces originaires des forêts de l'abbaye de Boscodon (cité par J. Billioud, Les bois des Hautes-Alpes en Provence, p. 106).

25. J. Billioud, Les bois des Hautes-Alpes en Provence, p. 107.

26. P.-M. Leroy, Mémoire sur les travaux qui ont rapport à l'exploitation de la mâture dans les Pyrénées, p. 75.

27. P. Bernardi, Le commerce du bois, p. 82.

28. E. Bouticourt, Charpentes méridionales. Construire autrement : le Midi rhodanien à la fin du Moyen Âge.

29. P.-A. Peyriat, Problèmes forestiers en Provence d'après les archives de la Chambre des eaux et forêt d'Aix, p. 52

30. G. Pichard, Espace et nature en Provence. L'environnement rural 1540-1789 et Arbres et forêts des Alpes à l'époque des premiers inventaires statistiques (Haut-Dauphiné - HauteProvence, 1689-1732).

31. P. Bernardi, L'exploitation des forêts, p. 50.

32. M. Gadoud, Les forêts du Haut-Dauphine à la fin du XVII siècle et de nos jours, p. 5.

33. P. Bernardi, L'exploitation des forêts, p. 52.

34. L. Shindo, S. Claude, "Buildings and wood trade in Aix-en-Provence (South of France) during modern period".

35. P. Ozenda, La végétation de la chaîne alpine dans l'espace montagnard européen, p. 20.

36. M.-P. Baume, La Bléone et Faillefeu, P. Bernardi, Le commerce du bois. J. Boyer, Le commerce des bois de charpente et menuiserie à Aix-en-Provence aux $\mathrm{XV}^{e}, \mathrm{XVI}^{e}, \mathrm{XVII}{ }^{e}$ siècles.

37. E. Bouticourt, Charpentes méridionales. Construire autrement : le Midi rhodanien à la fin du Moyen Âge.

38. M.-P. Baume, La Bléone et Faillefeu, p. 85 (Archives départementales des Alpes-deHaute-Provence, Me Estrayer Barthélemy, 2E4758, fo 132( $\left.\mathrm{v}^{\circ}\right)$ ).

39. T. Wazny, Historical timber trade and its implications on dendrochronological dating, K. Haneca, T. Wazny, J. Van Acker, H. Beeckman, Provenancing Baltic timber from art historical objects: success and limitations.

\section{RÉSUMÉS}

Cette étude sur le bois de construction dans les Alpes du sud s'appuie sur des données récentes issues d'un travail de thèse interdisciplinaire. Le bassin versant de la Durance et la Basse Provence, principalement aux $\mathrm{XVII}^{\mathrm{e}}$ et $\mathrm{XVIII}^{\mathrm{e}}$ siècles, servent de cadre à cette étude. Au cours de cette période, le bois a été employé localement par les montagnards, mais également par les 
militaires dans le cadre des fortifications briançonnaises. La Marine, grosse consommatrice de bois de construction a procédé à plusieurs inventaires des arbres des Alpes du sud et est à l'origine de forts prélèvements dans les forêts de cette région. Les populations civiles ne sont pas en reste puisque les bois de Haute et Moyenne Durance ont été achetés par des marchands et transportés vers les zones situées en aval. La destination de ce bois d'œuvre exporté peut être illustrée par le cas de la ville d'Aix-en-Provence où de nombreuses poutres portent des marques, témoins des échanges entre la montagne et la plaine.

\section{AUTEUR}

\section{LISA SHINDO}

Dendrochronologue, chercheuse associée au Centre Camille Jullian (UMR CNRS 7299), MMSH 


\title{
Le contrôle du faîte des Vosges : aspects politiques et économiques à l'aube des Temps modernes
}

\author{
Jean-Marie Yante
}

1 À l'aube des Temps modernes, le contrôle de la chaîne des Vosges, séparant le duché de Lorraine à l'ouest et l'Alsace à l'est, cette dernière émiettée en un grand nombre d'entités politiques, est l'objet de convoitises des principales forces en place (dynastes lorrains, Habsbourg, Ribeaupierre, souverains bourguignons). La raison en est principalement d'ordre économique: des voies importantes du trafic international, notamment entre les Pays-Bas et l'Italie, empruntent les cols vosgiens et le massif recèle d'importants gîtes métallifères. Par la mise en œuvre conjointe de documents diplomatiques, comptables et figurés ainsi que d'acquis récents de l'archéologie, singulièrement de l'archéologie minière, le présent propos est de scruter l'un et l'autre aspect.

\section{Le franchissement routier du massif vosgien}

2 La montagne vosgienne n'est pas impénétrable et l'obstacle qu'elle constitue est franchi dès la plus haute Antiquité. À l'époque romaine, la traversée peut, semble-t-il, s'effectuer à cinq endroits (fig. $1 \mathrm{~A})^{1}$. Deux d'entre eux sont clairement attestés : le col de Saverne assure le passage de la route Metz-Strasbourg et celui du Donon permet à la voie de Langres de rejoindre Strasbourg. Trois autres franchissements s'avèrent probables mais, pour l'heure, non rigoureusement établis : le col de Saales (solution alternative pour la voie Langres-Strasbourg), celui du Bonhomme (favorisant la communication entre la vallée de la Meurthe et les régions du Haut-Rhin) et celui de Bussang (s'inscrivant dans une liaison secondaire entre Remiremont et Cernay)2. Certains tronçons pavés menant aux deux premiers rappellent l'architecture romaine, mais ne suffisent pas à affirmer l'antiquité des chemins ${ }^{3}$. Une dizaine de points de traversée du massif sont connus aux derniers siècles du Moyen Âge ou à l'aube des Temps modernes (fig. 1 B) ${ }^{4}$. 
Fig. 1. - Franchissements routiers du Massif vosgien.

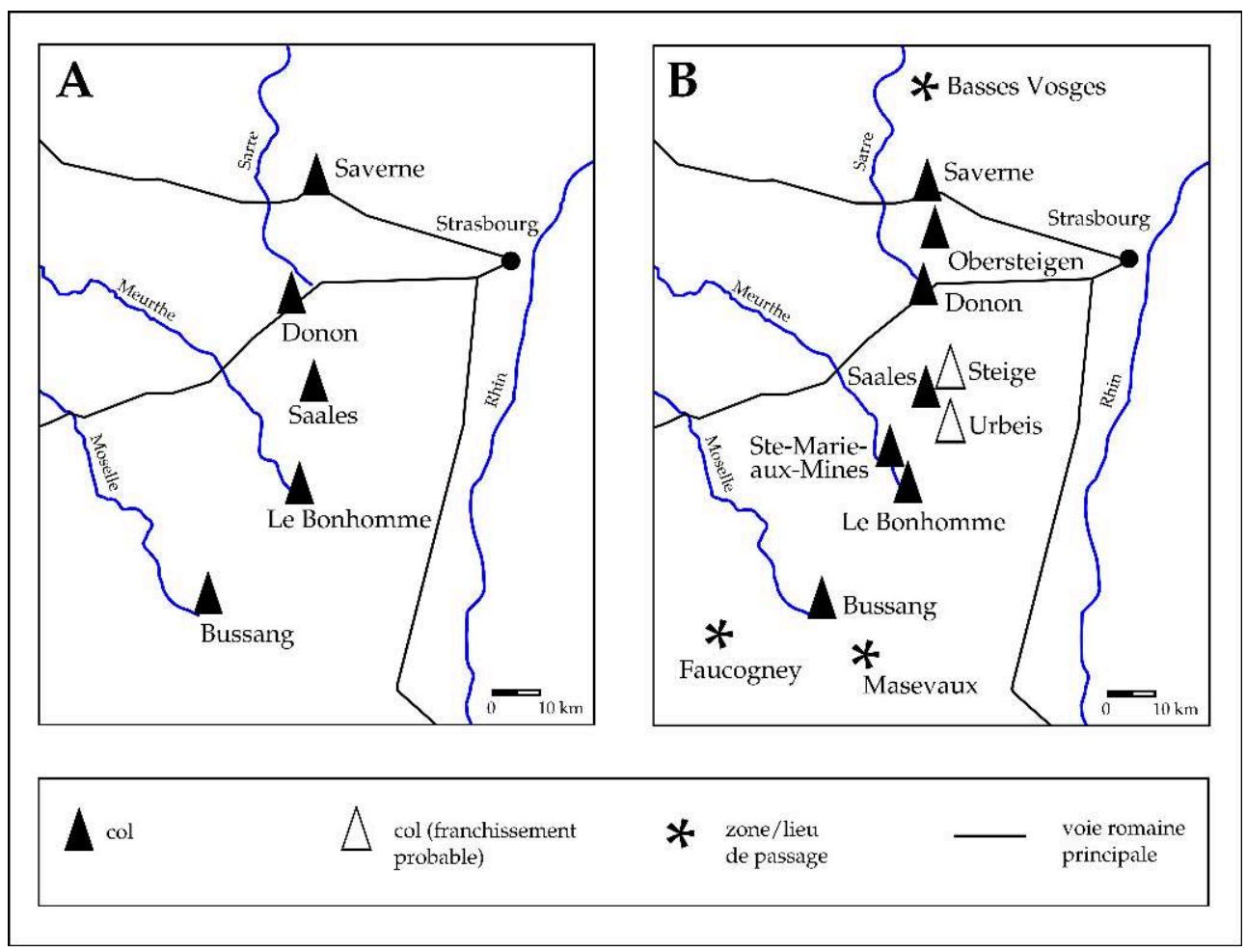

A. Époque romaine - B. Bas Moyen Âge.

(c) J.-M. Yante.

3 La route du col de Saverne reste fréquentée et connaît des aménagements au $\mathrm{XVI}^{\mathrm{e}}$ siècle ${ }^{5}$. Certains voituriers évitent le passage par Saverne et, au départ de Wasselonne, empruntent une route vers Dabo puis Sarrebourg. À Obersteigen, au pied du col menant à Dabo, s'est constitué un ordre religieux, les fratres hospitalis in Steiga, qui y ont érigé une maison d'accueil pour les voyageurs, attestée en $1220^{6}$.

- Au départ de Sarrebourg, le col du Donon demeure un lieu de franchissement du massif ${ }^{7}$.

-L'ascension de ce col est évitée par des transporteurs qui, en provenance d'Alsace, remontent la vallée de la Bruche, via Schirmeck, et se dirigent vers le col de Saales. En 1467, des marchands de Lübeck et de Göttingen y sont dévalisés par un brigand barricadé dans le château de La Roche ${ }^{8}$.

- Se branchant sur cette route, des voies transiteraient par les cols secondaires d'Urbeis et de Steige, et assureraient la liaison avec le Val de Villé puis Sélestat dans la plaine d'Alsace ${ }^{9}$.

- Au col dominant Sainte-Marie-aux-Mines, un itinéraire atteint également le faîte des Vosges. Au pied de celui-ci, côté lorrain, un péage, dit du beffroi, est perçu à Wisembach en $1290^{10}$.

- La fréquentation médiévale du col du Bonhomme est attestée par l'existence, en 1315, d'un hôpital Saint-Nicolas dans le village homonyme, sur le versant alsacien, et par celle, vingthuit ans plus tard, du pedagium de Bonohomine in valle sancti Deodati ${ }^{11}$.

- Alors que le franchissement du col de Bussang par une voie antique reste parfois discuté, en revanche, l'importance de ce passage aux derniers siècles du Moyen Âge est bien établie. L'ouverture du Saint-Gothard, aux alentours de 1220, confère une importance considérable à la route de Neufchâteau à Bâle ${ }^{12}$. En 1332, le duc Ferry IV de Lorraine accorde sa protection aux marchands de Metz gagnant la Lombardie via Nancy et le col de Bussang ${ }^{13}$. Le péage 
lorrain de l'Estraye (ou Lestraye), proche du col, est mentionné à plusieurs reprises aux XIII ${ }^{\mathrm{e}}$ et XIV siècles $^{14}$.

Des itinéraires évitent le franchissement du massif vosgien en empruntant des voies au nord ou au sud de celui-ci.

- La route reliant le cœur des Pays-Bas à l'Italie, via le massif ardennais, franchit la Moselle aux environs de Remich ou de Sierck, atteint la Sarre et, via Vaudrevange (Wallerfangen), Saint-Jean ou Sarrebruck, Sarreguemines, Rimling et Ingwiller, se dirige vers Strasbourg. Les préludes de la guerre de Cent Ans et l'établissement de nouveaux péages en France détournent certains courants de circulation et confèrent une importance considérable à cet itinéraire. $\mathrm{Au} \mathrm{XIV}{ }^{\mathrm{e}}$ siècle et à l'aube du Xv ${ }^{\mathrm{e}}$, sa fréquentation est le fait d'Italiens. Ceux-ci s'y font plus rares à la fin du XV $\mathrm{Xv}^{\mathrm{e}}$ siècle et au XVI ${ }^{\mathrm{e} 15}$.

- Des convois contournent également le massif par le sud, au départ de Remiremont ou du Thillot, et passent par Faucogney ou les environs. Des marchands ou transporteurs préfèrent en effet gagner l'Italie par Besançon, Pontarlier et le Grand-Saint-Bernard. Ils n'échappent pas à toute imposition, car Marie de Blois, duchesse de Lorraine, autorise en 1348 l'établissement au Thillot d'un péage à tenir en fief du duché16.

5 Le début du $\mathrm{XvI}^{\mathrm{e}}$ siècle voit également, au sud du massif, l'ouverture d'un chemin reliant, au départ de Masevaux, les Pays Antérieurs, plus particulièrement la vallée de la Doller, au duché de Lorraine. Soucieux de désenclaver la ville, dont la draperie jouit d'une notable réputation ${ }^{17}$, et d'en favoriser le commerce, Maximilien de Habsbourg autorise la création d'une voie nouvelle par le Gresson, d'où l'on peut descendre vers Saint-Maurice-sur-Moselle (en aval de Bussang) puis atteindre Le Thillot. Afin d'assurer à la communauté les moyens d'entretenir cette infrastructure, l'empereur lui concède, en 1510 , le droit d'y percevoir un péage sur les véhicules et les animaux ${ }^{18}$. Il convient enfin de relever, à la suite de Francis Rapp, qu'un « chevelu de sentiers plus ou moins praticables » existe à côté des voies principales ${ }^{19}$.

6 Pour l'heure, le repérage des péages, dès lors des autorités contrôlant le franchissement du massif, reste à poursuivre: l'évêque de Strasbourg à Saverne, passage historique, le duc de Lorraine au sud, au pied du col de Sainte-Marie-aux-Mines et de celui du Bonhomme, ainsi qu'au Thillot et à Bussang. Les conduits et péages ne font pas disparaître toute insécurité sur les itinéraires. Ainsi, en 1515, le duc Antoine de Lorraine fait donner l'assaut au château de Windstein servant de repère à des Raubritter ${ }^{20}$.

7 Les autorités déploient quelque effort pour améliorer la viabilité des chemins. En 1524, l'évêque de Strasbourg, Guillaume III de Honstein, fait aménager une nouvelle route au col de Saverne et estime l'ouvrage suffisamment exceptionnel pour faire graver son nom et la date sur une pierre encastrée dans la falaise ${ }^{21}$. Des aménagements routiers sont pareillement attestés au seuil du $\mathrm{XVI}^{\mathrm{e}}$ siècle à proximité plus ou moins immédiate du col de Bussang ${ }^{22}$. Les voies à ornières d'Urbès, au pied de celui-ci (côté alsacien) ${ }^{23}$, et de Malmerspach, à la sortie de Saint-Amarin en direction de Thann ${ }^{24}$, pourraient en être les témoins, même si on leur attribue fréquemment une origine romaine. À la fin du XVI $I^{e}$ siècle et à l'aube du XVII , des travaux sur cette voie mobilisent les ressources et le personnel des mines du Thillot ${ }^{25}$. 


\section{L'enjeu des gîtes métallifères}

8 À la fin du Moyen Âge, l'Europe occidentale connaît une pénurie de métaux précieux qui favorise une reprise de l'activité minière et métallurgique dans les pays germaniques et leurs marges. Cette recrudescence se prolonge jusqu'au milieu du Xvi siècle, grande époque des mines et de la métallurgie dans les Vosges, d'une véritable ruée vers l'argent ${ }^{26}$.

9 L'étude de l'exploitation des filons vosgiens impose de considérer la région dans son unité physique et humaine, par-delà le morcellement politique et administratif. En effet, les mines se situent le plus souvent près de la ligne des crêtes (auf der First), d'où des problèmes de délimitation dans le Val de Lièpvre, où la famille de Ribeaupierre possède des fiefs des côtés lorrain et alsacien. Des difficultés analogues surgissent au sud des Vosges, entre la Haute Alsace et la Bourgogne, entre la Lorraine et la Franche Comté ${ }^{27}$.

10 Les données techniques et commerciales de l'économie minière tendent à faire prévaloir des conditions communes. Les hommes d'affaires, notamment bâlois, qui animent les exploitations ont fréquemment des intérêts dans plusieurs bassins. Et il existe une unité corporative dans le massif : utilisation des mêmes systèmes de mesure, en dépit de l'existence d'étalons locaux, des mêmes techniques et des mêmes outils ${ }^{28}$. Deux exceptionnels documents iconographiques attestent l'effervescence et les acquis techniques dans les premières décennies du $\mathrm{xvI}^{\mathrm{e}}$ siècle: le Graduel de Saint-Dié (vers 1504-1514) et surtout les vingt-cinq planches du manuscrit d'Heinrich Gross (1530) qui, par des dessins à la plume rehaussés de couleurs, décrit en détail l'activité de la mine Saint-Nicolas à La Croix-aux-Mines ${ }^{29}$. L'activité minière du massif vosgien ${ }^{30}$ se répartit entre trois bassins : Val de Saint-Dié, Val de Lièpvre et Vosges méridionales (fig. 2 A) ${ }^{31}$. 
Fig. 2. - Les districts miniers vosgiens.

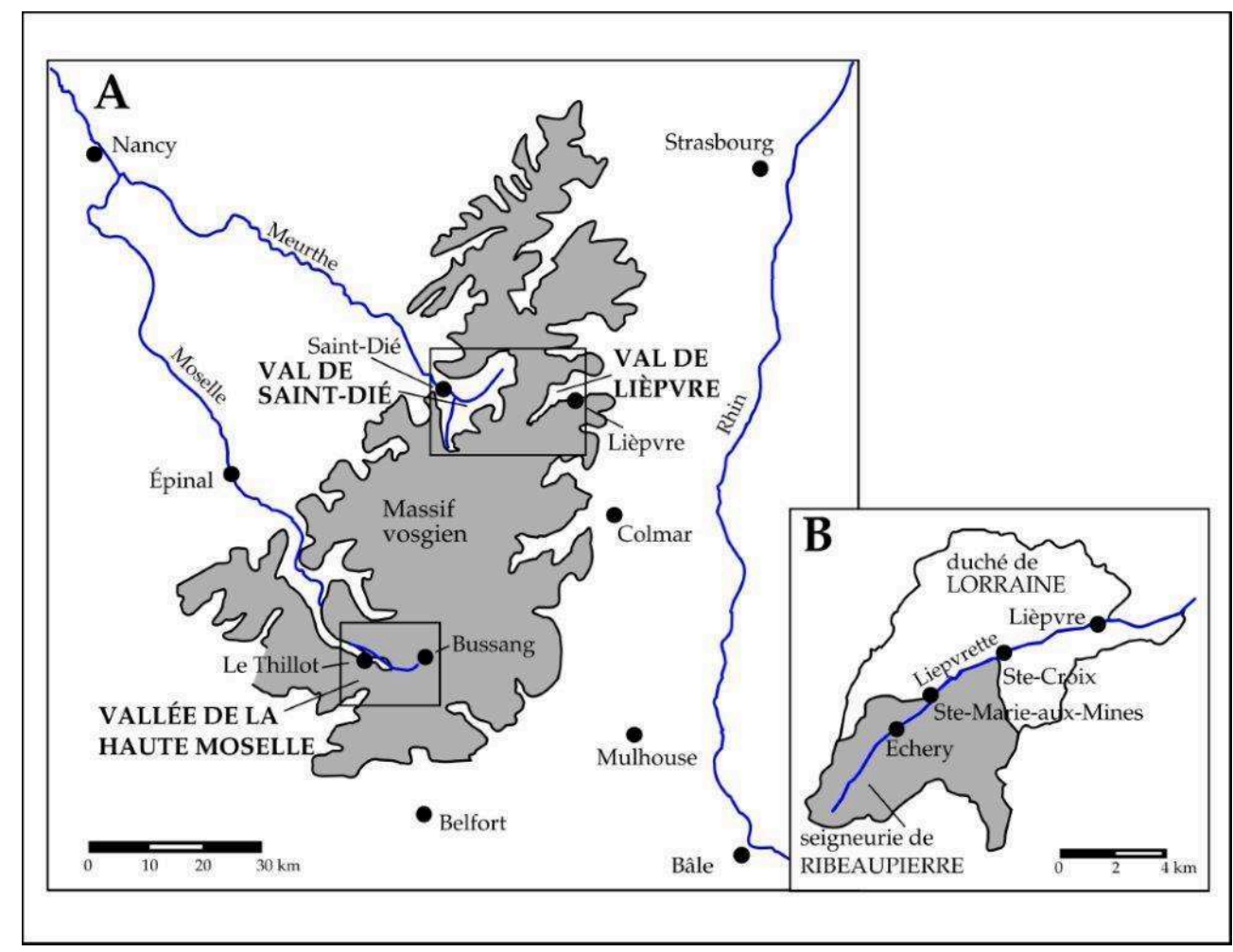

A. Carte générale - B. Limites territoriales du Val de Lièpvre.

(c) J.-M. Yante

\section{Le Val de Saint-Dié}

11 Le duc de Lorraine, seul maître des lieux dans le Val de Saint-Dié (ou de Galilée), à l'est de Saint-Dié, promulgue en 1250, 1317 et 1378 des ordonnances relatives à l'exploitation minière. Il faut toutefois attendre la fin des troubles causés par les hostilités avec la Bourgogne, qui s'achèvent à Nancy en 1477, pour assister à une recrudescence de l'extraction. En 1486, le duc René II dispose que tous ceux «qui vouldroient labourer, besongner et sercher mynières en nostre pays, [...] faire le puissent sans difficulté ». L'apogée des mines du Val de Saint-Dié s'étend sur deux décennies. Réellement entamée en 1518, la production culmine en 1523 avec la livraison de $1563 \mathrm{~kg}$ à la Monnaie de Nancy, et décline dès $1538^{32}$. Parmi les treize mines existant encore en 1608 , cinq seulement demeurent actives ${ }^{33}$.

\section{Le Val de Lièpvre}

Le Val de Lièpvre est coupé en deux : les mines méridionales relèvent de la seigneurie de Ribeaupierre, vassale des Habsbourg, les mines septentrionales appartiennent au duché de Lorraine (fig. 2 B) ${ }^{34}$. Des fouilles archéologiques révèlent que d'aucunes y seraient exploitées dès les $\mathrm{X}^{\mathrm{e}}$-XIII ${ }^{\mathrm{e}}$ siècles à l'Altenberg (Sainte-Marie-aux-Mines) ${ }^{35}$. Les travaux miniers acquièrent une réelle ampleur au début $d u \mathrm{XVI}^{\mathrm{e}}$ siècle. Deux mines sont mentionnées en 1512 et les exploitations se multiplient rapidement après la Guerre des Paysans $(1525)^{36}$. 
13 Depuis un traité du 9 décembre 1399, mettant fin à des querelles territoriales consécutives à l'extinction en 1381 de la famille locale d'Echery, la Lièpvrette et la Liverselle font office de frontière entre le duché de Lorraine et la seigneurie de Ribeaupierre. Mais le traité de partage omet de décrire avec précision les limites des bans et des juridictions. L'enjeu des mines d'argent au début du Xvi siècle ravive le conflit. Celui-ci devient aigu en 1516. De nouveaux pourparlers débouchent sur la signature d'un accord en 1518 et d'un autre en 1526 entre Antoine de Lorraine et Maximin de Ribeaupierre. La production d'argent (et subsidiairement celle fort négligeable de cuivre et de plomb) est rigoureusement répartie entre le duc de Lorraine et l'archiduc d'Autriche, suzerain des Ribeaupierre. Il en va de même des frais d'exploitation et de fonte des minerais. Le litige ne cesse pas pour autant. Il est encore en suspens en $1570^{37}$. On doit à ce conflit de territorialité la première carte du Val de Lièpvre, qui représente de part et d'autre de la Lièpvrette les territoires des deux souverainetés avec leurs villages, leurs châteaux, les entrées de mines, les cours d'eau et les chemins. Ce document, dressé pour le dossier des Ribeaupierre et conservé aujourd'hui à Innsbruck, livre une image déformée du Val : les terres des Ribeaupierre sont considérablement réduites au profit de celles du duché de Lorraine dont l'extension est exagérée ${ }^{38}$. L'édition française (1552) de la Cosmographie de Sébastien Munster consacre plusieurs pages à la description des mines du Val de Lièpvre, côté de la seigneurie de Ribeaupierre, description réalisée avec la collaboration du juge du pays, Haubinsack. L'ouvrage livre pareillement une ébauche cartographique ${ }^{39}$.

L'essor de l'exploitation minière dans la première moitié du XVI ${ }^{e}$ siècle provoque une forte immigration de mineurs et ouvriers allemands qui, adeptes de la Réforme, se fixent dans les villages du côté de Ribeaupierre, le duc Antoine expulsant de Lorraine les calvinistes qui s'établissent à Sainte-Marie-aux-Mines. La coupure linguistique et religieuse ne fait qu'exacerber la querelle territoriale ${ }^{40}$.

Les comptes du receveur de Saint-Dié puis ceux du Val de Lièpvre permettent de dénombrer 276 travaux effectués dans les différents vallons entre 1512 et 1628, date d'arrêt de l'exploitation. Sur ces travaux, 252 (soit $91 \%$ ) s'avèrent stériles et sont rapidement abandonnés ${ }^{41}$.

16 Il faut attendre 1529 pour voir les recherches se développer de façon spectaculaire, avec quatre-vingt-huit nouvelles fouilles et la reprise de vingt-cinq ouvrages antérieurs. C'est donc au total 113 travaux qui sont labourés durant cette année. Par contre, trois vallons seulement font l'objet de prospections entre 1530 et 1547. On observe une forte relance de la recherche minière au milieu $\mathrm{du} \mathrm{xvI}^{\mathrm{e}}$ siècle du fait de la découverte et de la mise en exploitation des riches filons argentifères de SaintPierremont qui, dès 1554, atteignent leur maximum de production avec une livraison exceptionnelle de $1885 \mathrm{~kg}$ d'argent fin. Trente-neuf nouvelles mines sont mises en chantier en l'espace de dix ans (de 1548 à 1557). De 1551 à 1574, la production totale d'argent des mines lorraines du Val de Lièpvre s'élève à $29237,376 \mathrm{~kg}$, soit une moyenne annuelle de $1218,224 \mathrm{~kg}$. Près de $90 \%$ proviennent du secteur de SaintPierremont ${ }^{42}$.

17 Une relance de la recherche est patente en 1571-1572. Un dernier sursaut intervient en 1583. À la fin du siècle, le champ d'investigation est épuisé. Les principales mines sont abandonnées les unes après les autres ${ }^{43}$. En outre, la conjoncture mondiale, après avoir favorisé l'expansion depuis la fin du xve siècle, la freine singulièrement à dater de 1560 . Les trésors d'argent de l'Amérique et de nouveaux procédés techniques, comme 
l'amalgame, atteignent peu à peu toute l'Europe. L'argent devient plus commun et par là même sa production s'avère moins rentable ${ }^{44}$.

En raison de la faible teneur du minerai vosgien, il est indispensable de l'affiner sur place ou à proximité. Dès le xvi ${ }^{\mathrm{e}}$ siècle, les cuveaux de minerai en provenance du Val de Lièpvre sont portés, au-delà du col de Sainte-Marie, à la fonderie de Wisembach, un transfert difficile et onéreux. Une fonderie est mentionnée ultérieurement à La Croixaux-Mines et une autre « au dessous » de Sainte-Croix-aux-Mines ${ }^{45}$. Des investigations récentes révèlent la multiplication de ces établissements dans le massif vosgien et, du fait de l'approvisionnement en combustible, leur relatif éloignement des lieux d'extraction ${ }^{46}$.

19 Aux moments conjoncturellement difficiles, les ducs de Lorraine et les archiducs d'Autriche soutiennent de multiples façons les entreprises : participations financières à la restauration de travaux anciens, agrandissement des concessions, relèvement des prix d'achat des métaux (essentiellement de l'argent par les Monnaies), concentration de plusieurs ouvrages afin d'obtenir un meilleur rendement à moindre coût, exemption de dîme ${ }^{47}$.

\section{Les Vosges méridionales}

20 À la périphérie plus ou moins immédiate du Ballon d'Alsace, les mines les plus anciennes seraient celles de Masevaux, dont l'exploitation est attestée à la fin du XIV siècle $^{48}$. À Plancher-les-Mines, dans la principauté ecclésiastique de Lure, la première mention est de 1458. Deux ans plus tard, soucieux d'étendre ses possessions, Philippe le Bon prétend que Lure se trouve en Bourgogne. Son fils, Charles le Téméraire, donne l'ordre en 1470 de «porter sa main » sur les mines de Plancher. Il argue que ces mines sont situées soit dans le comté de Bourgogne, soit dans celui de Ferrette ; à la différence de son père, Charles cumule en effet les deux titres. Mais la garde de l'abbaye de Lure appartient bien à la Maison d'Autriche et reste au XvI siècle à la branche allemande de celle-ci ${ }^{49}$.

21 Une hausse de la demande de cuivre (présent dans des minerais composites) favorise à partir de 1550 l'exploitation des mines de Bussang et du Thillot (Lorraine) situées sur le versant nord-est du massif de la Tête du Midi et dont les filons se poursuivent sur le versant sud-ouest, à Château-Lambert, territoire des souverains bourguignons. Un rapport de 1561 signale une mine de cuivre au Thillot et huit autres «nouvellement trouvées " près de Bussang, paraissant promettre une production de cuivre ${ }^{50}$. Décidée par le duc de Lorraine en septembre de l'année précédente, la fonderie établie près de Saint-Maurice-sur-Moselle commence à fonctionner. La plupart des ouvrages entamés autour de Bussang sont toutefois rapidement abandonnés. Montaigne évoque la mine d'argent qu'il y visite en 1580, mais la production ne semble pas répondre aux espoirs des prospecteurs locaux ${ }^{51}$. Il en va tout différemment des mines d'argent de Giromagny ou du Rosemont, au sud du Ballon d'Alsace, en territoire habsbourgeois. Malgré une conjoncture internationale difficile, celles-ci connaissent leur âge d'or dans la seconde moitié du XVI ${ }^{\mathrm{e}}$ siècle (production annuelle maximum de 2 tonnes en 1569-1571), avant un déclin dans le premier tiers du XvII ${ }^{\mathrm{e}}$ siècle ${ }^{52}$.

L'expansion de la production régionale de cuivre débute vers 1585 et dure une vingtaine d'années. De 1590 à 1599, Le Thillot livre en moyenne annuelle 400 cents (soit 190 à 200 quintaux métriques) et, de 1600 à 1609, environ 1165 cents (de 550 à 575 
quintaux). Les galeries s'enfoncent dans la montagne au point de rencontrer celles de Château-Lambert, d'où des incidents en 1603 et 1607. En 1603, la Chambre des Comptes de Lorraine prescrit de noyer immédiatement quelques ouvrages, parce que «les Bourguignons s'en approchent fort ». Quatre ans plus tard, deux mineurs du Thillot qui effectuent une reconnaissance près de la frontière, sont accueillis à coups d'arquebuses par ceux de l'autre côté ${ }^{53}$. La quantité de minerai extraite diminue dès 1605 . Des redressements passagers (1620-1621 et 1627-1629) constituent des incitations à persévérer, malgré la détérioration continue des conditions de production. La hausse du prix du cuivre, générale en Europe, offre à l'entreprise vosgienne un parapluie que ferme le renversement de la tendance internationale à partir de $1625^{54}$.

En 1632, faute d'amodiateur, la décision est prise d'arrêter les travaux à la mine comtoise de Château-Lambert, mais elle est rapportée l'année suivante du fait de la misère des ouvriers qui seraient licenciés et de graves pertes pour les installations ${ }^{55}$.

En se focalisant sur l'exploitation minière lorraine, force est de constater que les phases de production des différents districts se succèdent du début du XvI ${ }^{\mathrm{e}}$ siècle à 1630 . Alors qu'une ferme politique ducale soutient la recherche et la production du métal blanc qui s'épuise inexorablement dans le Val de Saint-Dié (ou de Galilée), le Val de Lièpvre entame son essor. Lui succédera l'exploitation du cuivre dans les Vosges méridionales ${ }^{56}$.

Le contrôle du trafic routier, nettement à la hausse au seuil et dans la première moitié $\mathrm{du} \mathrm{XVI}^{\mathrm{e}}$ siècle, retient pareillement l'attention des autorités détentrices de droits plus ou moins étendus sur le faite des Vosges. L'absence ou la perte de séries comptables, ou une mise en œuvre non encore réalisée de documents se prêtant à un traitement statistique, privent la recherche de précieux indicateurs conjoncturels. Il s'avère dès lors impératif de poursuivre les investigations, d'étoffer la carte des péages routiers du piémont vosgien, tant du côté lorrain qu'alsacien, et de scruter, dans les sources judiciaires notamment, tout indice d'une fréquentation régionale et/ou internationale des divers itinéraires.

\section{BIBLIOGRAPHIE}

ADAM Alphonse, Die drei Zaberner Steigen. Eine topographisch-historische Studie, Saverne, Gilliot, 1896. AMMANN Hektor, «La place de l'Alsace dans l'industrie textile du Moyen Âge », dans La bourgeoisie alsacienne. Études d'histoire sociale, Strasbourg et Paris, Éditions F.-X. Le Roux, 1954, p. 71-102.

L'archéologie des mines et de la métallurgie. Panorama des sites vosgiens, Strasbourg, Fédération Patrimoine Minier (Pierres et Terre, 34), 1990.

L'art et les mines dans les Vosges (Pierres et Terre, 25-26), 1982. 
BAILLY-MAîTRE Marie-Christine et BENOIT Paul, « Les mines d'argent dans la France médiévale », dans L'argent au Moyen Âge. XXVIII ${ }^{\mathrm{e}}$ Congrès de la S.H.M.E.S. (Clermont-Ferrand, 30 mai- $1^{\mathrm{er}}$ juin 1997), Paris, Publications de la Sorbonne, 1998, p. 17-45.

BRUN Aimé, « 1510 : une route à péage au Gresson », Société d'histoire de la vallée de Masevaux, Bulletin $n^{\circ}$ 9, 1999, p. 5-7.

CABOURDIN Guy, « Les ducs de Lorraine et l'exploitation des mines d'argent, 1480-1635 », Annales de l’Est, $5^{\mathrm{e}}$ sér., vol. XXI, 1969, p. 91-119.

CABOURDIN Guy, « Les ducs de Lorraine et la monnaie (1480-1635) », Annales de l'Est, $5^{\mathrm{e}}$ sér., vol. XXVII, 1975, p. 3-44.

CLOPPET Christian, Le système routier gallo-romain entre Rhône, Loire et Rhin. Tracés, structure, monuments, Lille, Diffusion Septentrion, 2003, 3 vol.

CORBIAU Marie-Hélène et YANTE Jean-Marie, « Héritage romain et créations médiévales. À propos d'itinéraires luxembourgeois et lorrains », dans EL GAMMAL Jean et JALABERT Laurent (dir.), Héritages. Universités d'hiver de Saint-Mihiel 2012 (Annales de l'Est, $7^{\mathrm{e}}$ sér., vol. LXIII, 2013, $\mathrm{n}^{\circ}$ spécial), 2014, p. 36-51.

DAVID Marie-Hélène et DAVID Laurent, « Le monastère d'Obersteigen. Éléments de l'histoire », dans Guide de l'église et de l'ancien monastère d'Obersteigen, Saverne, Société d'Histoire et d'Archéologie de Saverne et environs (Guide nº 3), 1991, p. 1-3.

DECOMBIS Vincent, «Les indices de passage à l'époque gallo-romaine en Haute-Moselle », dans Rотніот Jean-Paul, HUSSON Jean-Pierre et HEILI Pierre (éds), Le Thillot. Les mines et le textile. 2000 ans d'histoire en Haute-Moselle. Actes des Journées d'Études Vosgiennes, 27, 28 et 29 octobre 2007, Société d'Émulation des Vosges et Société d'Histoire de Remiremont et de sa région, 2008, p. 61-72. DE CRAECKER-DUSSART Christiane, « Le conduit entre la Meuse, la Moselle, la Sarre et le Rhin (à propos d'un acte de 1355) », Bulletin de la Commission royale d'Histoire, vol. CXLI, 1975, p. 349-382. DE CRAECKER-DUSSART Christiane, « Une grande route transversale lotharingienne au Moyen Âge », dans Tonlieux, foires et marchés avant 1300 en Lotharingie, actes des 4 es Journées Lotharingiennes, Luxembourg (Publications de la Section historique de l'Institut grand-ducal de Luxembourg, vol. CIV), 1988, p. 85-102.

DE PANGE Jean, Catalogue des actes de Ferry III, duc de Lorraine (1251-1303), Paris, H. Champion, 1930. DEROISY Armand, « Les routes terrestres des laines anglaises vers la Lombardie », Revue du Nord, vol. XXv, 1939, p. 40-60.

DIRWIMMER Christian, HIHN Hubert et SIFFER Jean-Louis, « Histoire des voies de communication dans le Val de Villé », Annuaire de la Société d'histoire du Val de Villé, vol. XxVII, 2002, p. 25-132.

DUBLED Henri, « Les chanoines d'Obersteigen », dans Du château de Birkenwald aux rochers du Schneeberg. À l'occasion du $4^{\text {ème }}$ centenaire du Château de Birkenwald, Saverne, Société d'Histoire et d'Archéologie de Saverne et environs (Cahier 40, IV), 1962, p. 21-26.

EHLINGER Gilbert et ROSENBLATT François, « La voie romaine de la Haute-Vallée de la Thur. Le tronçon d'Urbès ", Annuaire de la Société d'histoire des régions de Thann-Guebwiller, vol. XVI, 1985-1987, p. 15-16.

FINOT Jules, Les sires de Faucogney, vicomtes de Vesoul. Notice et documents, Paris, H. Champion, 1886. 
FLOTTÉ Pascal et FUCHS Matthieu, Carte archéologique de la Gaule. Le Bas-Rhin, 67/1, Paris, Académie des Inscriptions et Belles-Lettres, 2000.

FLUCK Pierre, Sainte-Marie-aux-Mines ou les mines du rêve. Une monographie des mines d'argent, Soultz, Les Éditions du Patrimoine Minier, 2000.

FLUCK Pierre et FLORSCH Nicolas, «L'archéologie du feu : les fonderies d'argent du Bonhomme », Bulletin de la Société d'histoire du canton de Lapoutroie-Val d'Orbey, vol. xv, 1996, p. 9-28, et vol. XVI, 1997, p. 13-27.

FRAY Jean-Luc, « Hospices et hôpitaux médiévaux en pays de moyenne montagne, de la Lotharingie à la France centrale », dans PAULY Michel avec la coll. de UHRMACHER Martin et PETTIAU Hérold (éds), Institutions de l'assistance sociale en Lotharingie médiévale. Einrichtungen der sozialen Sicherung im mittelalterlichen Lotharingien, actes des $13^{\text {es }}$ Journées Lotharingiennes. 12-15 octobre 2004. Université du Luxembourg, Luxembourg (Publications de la Section historique de l'Institut grand-ducal de Luxembourg, vol. CXXI ; Publications du CLUDEM, 19), 2008, p. 181-196.

GRANDEMANGE Jacques, Les mines d'argent du duché de Lorraine au XVI e siècle. Histoire et archéologie du Val de Lièpvre (Haut-Rhin), Paris, Éditions de la Maison des Sciences de l'Homme (Documents d'archéologie française, 30), 1991.

HAMM Gilles, Carte archéologique de la Gaule. La Meurthe-et-Moselle, 54, Paris, Académie des Inscriptions et Belles-Lettres, 2004.

HEITZ Henri, La côte et le col de Saverne, Saverne, Société d'Histoire et d'Archéologie de Saverne et environs (Cahier 187a), 1999.

HERRMANN Hans-Walter, « Die flandrisch-lampartische Strabe zwischen Strabburg und Sierck. Geschichte einer mittelalterlichen Neuanlage », dans BURGARD Friedhelm et HAVERKAMP Alfred (éds), Auf den Römerstraben ins Mittelalter. Beiträge zur Verkehrsgeschichte zwischen Maas und Rhein von der Spätantike bis ins 19. Jahrhundert, Mayence, Verlag Philipp von Zabern (Trierer Historische Forschungen, 30), 1997, p. 447-469.

HIRSCHFELL Georges et HIHN Hubert, «La circulation dans l'avant-vallée », Annuaire de la Société d'histoire du Val de Villé, vol. XXVII, 2002, p. 133-142.

JEANNIN Pierre, « Note sur l'abbaye de Lure au XVI ${ }^{\mathrm{e}}$ siècle. Aspects économiques et sociaux de la géographie historique ", dans actes $d u{ }^{2} 2^{e}$ Congrès national des Sociétés savantes tenu à Strasbourg et Colmar (Bulletin philologique et historique (jusqu'à 1610) du Comité des travaux historiques et scientifiques. Année 1967), 1969, vol. II, p. 483-525.

JEANNIN Pierre, «Conjoncture et production du cuivre dans les Vosges méridionales à la fin du XVI ${ }^{\mathrm{e}}$ et au début du XVII ${ }^{e}$ siècle ", dans Conjoncture économique, structures sociales. Hommage à Ernest Labrousse, Paris et La Haye, Mouton (École pratique des Hautes Études-Sorbonne. $\mathrm{VI}^{\mathrm{e}}$ section : Sciences économiques et sociales. Civilisations et sociétés, 47), 1974, p. 121-138.

JEANNIN Pierre, "Le cuivre dans l'économie minière et métallurgique des régions vosgiennes ", dans KELLENBENZ Hermann (édit.), Schwerpunkte der Kupferproduktion und des Kupferhandels in Europa 1500-1650, Cologne et Vienne, Böhlau Verlag (Kölner Kolloquien zur internationalen Sozial- und Wirtschaftsgeschichte, 3), 1977, p. 56-77.

LEVAlloIs Henri, « Catalogue des actes de Raoul, duc de Lorraine (1329-1346) », thèse, Paris, École des Chartes, 1902. [Un exemplaire en est conservé à la Bibliothèque municipale de Nancy, ms. $2116(1185)]$.

LIEBELIN François, Mines et mineurs du Rosemont, 2 e éd., Soultz, Éditions du Patrimoine Minier, 2015. 
MATTAUER Raymond, «Contribution à l'étude des anciennes mines et forges de la vallée de la Doller ", Annuaire de la Société d'histoire des régions de Thann-Guebwiller, 1953-1954, p. 115-128.

MENGUS Nicolas, « Un repaire de seigneurs-brigands : le château de La Roche », dans Châteaux forts d'Alsace. Histoire-Archéologie-Architecture, Saverne, Centre de Recherches Archéologiques Médiévales de Saverne, vol. v, 2001, p. 39-64.

MICHLER Matthieu, Carte archéologique de la Gaule. Les Vosges, 88, Paris, Académie des Inscriptions et Belles-Lettres, 2004.

PIERRE Francis, " Les recherches en archéologie minière dans le sud des Vosges lorraines ", Le Pays lorrain, vol. LXX, 1989, p. 233-242.

RACINE Pierre, « D'Italie aux Pays-Bas : les routes lorraines (1280-1350) », dans Les Pays de l'EntreDeux au Moyen Âge. Questions d'histoire des territoires d'Empire entre Meuse, Rhône et Rhin, actes du 113 ème Congrès national des Sociétés savantes (Strasbourg, 1988). Section d'histoire médiévale et de philologie, Paris, Comité national des travaux historiques et scientifiques, 1990, p. 209-224.

RACINE Pierre, « Des routes romaines aux routes médiévales : l'exemple de Neufchâteau », dans BURGARD Friedhelm et HAVERKAMP Alfred (éds), Auf den Römerstraben ins Mittelalter. Beiträge zur Verkehrsgeschichte zwischen Maas und Rhein von der Spätantike bis ins 19. Jahrhundert, Mayence, Verlag Philipp von Zabern (Trierer Historische Forschungen, 30), 1997, p. 297-317.

RAPP Francis, « Le Val de Bruche. Quelques directions de recherches », Revue d'Alsace, vol. XCVII, 1958, p. 21-35.

RAPP Francis, « Routes et voies de communication à travers les Vosges du XII ${ }^{\mathrm{e}}$ au début du XVI ${ }^{\mathrm{e}}$ siècle », dans Les Pays de l'Entre-Deux au Moyen Âge. Questions d'histoire des territoires d'Empire entre

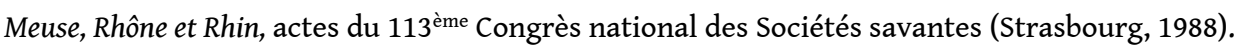
Section d'histoire médiévale et de philologie, Paris, Comité national des travaux historiques et scientifiques, 1990, p. 195-207. Article reproduit dans Annuaire de la Société d'histoire du Val de Villé, vol. XXVII, 2002, p. 15-24.

RAPP Francis, « La Lorraine et l'Alsace à l'aube de la Réforme », dans ROTH François (dir.), Lorraine et Alsace, mille ans d'histoire (Annales de l'Est, 6e sér., vol. LVI, 2006, nº spécial), 2007, p. 93-104.

SCHNEIDER Jean, La ville de Metz aux XIII et XIV siècles, Nancy, Georges Thomas, 1950.

WILSDORF Christian, " Dans la vallée de la Thur aux XIII ${ }^{e}$ et XIVe siècles : la transformation d'un paysage par la route ", dans actes du $92^{e}$ Congrès national des Sociétés savantes (Bulletin philologique et historique (jusqu'à 1610) du Comité des travaux historiques et scientifiques. Année 1967), 1969, vol. I, p. 303-330.

YANTE Jean-Marie, Le Luxembourg mosellan. Productions et échanges commerciaux. 1200-1560, Bruxelles, Académie royale de Belgique (Mémoire de la Classe des Lettres, coll. in-8º $3^{\text {e }}$ sér., t. XIII), 1996.

YANTE Jean-Marie, « Réseau routier et circulation dans le pays de Luxembourg-Chiny. Moyen Âge - Début des Temps modernes ", dans BURGARD Friedhelm et HAVERKAMP Alfred (éds), Auf den Römerstraßen ins Mittelalter. Beiträge zur Verkehrsgeschichte zwischen Maas und Rhein von der Spätantike bis ins 19. Jahrhundert, Mayence, Verlag Philipp von Zabern (Trierer Historische Forschungen, 30), 1997, p. 501-543.

YANTE Jean-Marie, « Voirie romaine et itinéraires médiévaux : le cas de la Lorraine centrale », Mémoires de l'Académie Nationale de Metz, sér. VII, vol. XXIX, 2017, p. 107-127. 
ZELLER Gaston, « Une ancienne voie de trafic international à travers la Sarre », Annales de l'Est, $4^{\mathrm{e}}$

sér., vol. II, 1934, p. 291-304.

ZUNDEL Anne, « Les routes en Haute-Alsace à la fin du Moyen Âge », dans Positions des thèses soutenues par les élèves de la promotion 1960 pour obtenir le diplôme d'archiviste paléographe, Paris, École des Chartes, 1960, p. 107-114.

\section{NOTES}

1. M.-H. Corbiau et J.-M. Yante, «Héritage romain et créations médiévales. À propos d'itinéraires luxembourgeois et lorrains », p. 44-46.

2. Des vestiges archéologiques ponctuent le parcours et tendent à en confirmer l'antiquité (v. Decombis, «Les indices de passage à l'époque gallo-romaine en HauteMoselle », p. 61-72). La voie est parfois associée à une artère reliant Metz à Bâle.

3. Chr. Cloppet, Le système routier gallo-romain entre Rhône, Loire et Rhin. Tracés, structure, monuments, p. 682-686.

4. M.-H. Corbiau et J.-M. Yante, «Héritage romain et créations médiévales. À propos d'itinéraires luxembourgeois et lorrains », p. 46-51.

5. A. Adam, Die drei Zaberner Steigen. Eine topographisch-historische Studie, p. 18 ; H. Heitz, La côte et le col de Saverne, p. 22-23.

6. H. Dubled, «Les chanoines d'Obersteigen », p. 21-26 ; M.-H. et L. David, « Le monastère d'Obersteigen. Éléments de l'histoire ", p. 1-2.

7. On a attribué une origine romaine au tronçon pavé de quelque 400 mètres, creusé de profondes ornières, qui a été dégagé en 1965 dans la forêt domaniale du Donon, à proximité du col de la "Roule Bacon» (P. Flotté et M. Fuchs, Carte archéologique de la Gaule. Le Bas-Rhin, 67/1, p. 300 ; G. Hamm, Carte archéologique de la Gaule. La Meurthe-etMoselle, 54, p. 326 ; M. Michler, Carte archéologique de la Gaule. Les Vosges, 88, p. 280). En fait, il pourrait s'agir d'une réalisation médiévale en lien avec le transport du sel du Saulnois, liaison connue sous la dénomination de "chemin d'Allemagne». Sur l'ancienne « route du sel »: Chr. Dirwimmer, H. Hihn et J.-L. Siffer, « Histoire des voies de communication dans le Val de Villé », p. 27-34.

8. F. Rapp, «Le Val de Bruche. Quelques directions de recherches », p. 28 ; N. Mengus, « Un repaire de seigneurs-brigands : le château de La Roche », p. 44.

9. Au péage de Châtenois se rejoignent la route en provenance du Val de Villé et celle arrivant de Sainte-Marie-aux-Mines. Voir le croquis du début du $\mathrm{XVI}^{\mathrm{e}}$ siècle conservé à Innsbruck et reproduit dans G. Hirschfell et H. Hihn, «La circulation dans l'avant-vallée », p. 139.

10. J. de Pange, Catalogue des actes de Ferry III, duc de Lorraine (1251-1303), p. 181, nº 932.

11. H. Levallois, «Catalogue des actes de Raoul, duc de Lorraine (1329-1346) », p. 125, $\mathrm{n}^{\circ}$ 348 ; J.-L. Fray, «Hospices et hôpitaux médiévaux en pays de moyenne montagne, de la Lotharingie à la France centrale », p. 183-184.

12. Chr. Wilsdorf, «Dans la vallée de la Thur aux XIII ${ }^{\mathrm{e}}$ et XIV ${ }^{\mathrm{e}}$ siècles : la transformation d'un paysage par la route », p. 303-330 ; F. Rapp, «Routes et voies de communication à travers les Vosges du XII ${ }^{\mathrm{e}}$ au début du XVI siècle », p. 196 ; P. Racine, «D’Italie aux Pays- 
Bas : les routes lorraines (1280-1350)», p. 212-215; Id., «Des routes romaines aux routes médiévales : l'exemple de Neufchâteau ", p. 297-317.

13. J. Schneider, La ville de Metz aux XIII' et XIV siècles, p. 188.

14. J.-M. Yante, "Voirie romaine et itinéraires médiévaux: le cas de la Lorraine centrale », p. 123 (tableau, $9^{\circ}$ ).

15. Voir notamment G. Zeller, «Une ancienne voie de trafic international à travers la Sarre », p. 291-304 ; A. Deroisy, "Les routes terrestres des laines anglaises vers la Lombardie», p. 40-60; Chr. de Craecker-Dussart, "Le conduit entre la Meuse, la Moselle, la Sarre et le Rhin (à propos d'un acte de 1355) », p. 349-382 ; Id., "Une grande route transversale lotharingienne au Moyen Âge ", p. 85-102 ; J-M. Yante, Le Luxembourg mosellan. Productions et échanges commerciaux. 1200-1560, p. 198-204; Id., « Réseau routier et circulation dans le pays de Luxembourg-Chiny (Moyen Âge-début des Temps modernes) », p. 509-512; H.-W. Herrmann, « Die flandrisch-lampartische Strabe zwischen Strabburg und Sierck. Geschichte einer mittelalterlichen Neuanlage », p. 447-469.

16. H. Levallois, Catalogue des actes de Raoul, duc de Lorraine (1329-1346), p. 131, $\mathrm{n}^{\circ} 366$ (à la date de 1343) ; J. Finot, Les sires de Faucogney, vicomtes de Vesoul. Notice et documents, p. 162 ; J. Schneider, La ville de Metz aux XIII et XIV siècles, p. 22-23.

17. H. Ammann, «La place de l'Alsace dans l'industrie textile du Moyen Âge », p. 91 et 101-102.

18. A. Brun, « 1510 : une route à péage au Gresson », p. 5-7.

19. F. Rapp, «Routes et voies de communication à travers les Vosges du XII au début du $\mathrm{XVI}^{\mathrm{e}}$ siècle », p. 206.

20. F. Rapp, « La Lorraine et l'Alsace à l'aube de la Réforme », p. 94.

21. Supra, note 5 .

22. A. Zundel, «Les routes en Haute-Alsace à la fin du Moyen Âge », p. 114.

23. G. Ehlinger et F. Rosenblatt, «La voie romaine de la Haute-Vallée de la Thur. Le tronçon d'Urbès ", p. 15-16 ; M. Zehner, Carte archéologique de la Gaule. Le Haut-Rhin, 68, p. 301.

24. Chr. Wilsdorf, «Dans la vallée de la Thur aux XIII et XIV siècles : la transformation d'un paysage par la route », p. 305-308 ; M. Zehner, Carte archéologique de la Gaule. Le Haut-Rhin, 68, p. 301.

25. P. Jeannin, «Conjoncture et production du cuivre dans les Vosges méridionales à la fin du XVI et au début du XVII siècle », p. 137, note 4.

26. M.-Chr. Baîlly-Maître et P. Benoit, «Les mines d'argent de la France médiévale ", p. 17-45 (pour le massif vosgien, p. 31 et 43-44).

27. $P$. Jeannin, «Le cuivre dans l'économie minière et métallurgique des régions vosgiennes ", p. 56-57.

28. Ibid., p. 57; Fr. Pierre, «Les recherches en archéologie minière dans le sud des Vosges lorraines », p. 235.

29. L'art et les mines dans les Vosges, spécialement p. 54-64 ; P. Fluck, Sainte-Marie-auxMines ou les mines du rêve. Une monographie des mines d'argent, p. 110-111.

30. Sur l'apport essentiel de l'archéologie minière à la redécouverte des réseaux vosgiens, dont les galeries du $\mathrm{XVI}^{\mathrm{e}}$ siècle taillées à la pointerolle, voir notamment 
L'archéologie des mines et de la métallurgie. Panorama des sites vosgiens; Fr. Pierre, "Les recherches en archéologie minière dans le sud des Vosges lorraines ", p. 233-242; P. Fluck, Sainte-Marie-aux-Mines ou les mines du rêve. Une monographie des mines d'argent.

31. D'après J. Grandemange, Les mines d'argent du duché de Lorraine au XVI ${ }^{e}$ siècle. Histoire et archéologie du Val de Lièpvre (Haut-Rhin), p. 12, fig. 1.

32. Ibid., p. 13 et 56 (note 6).

33. G. Cabourdin, «Les ducs de Lorraine et l'exploitation des mines d'argent, 1480-1635 », p. 115-116.

34. D'après J. Grandemange, Les mines d'argent du duché de Lorraine au XVI siècle. Histoire et archéologie du Val de Lièpvre (Haut-Rhin), p. 14, fig. 2.

35. Ibid., p. 56, note 7 .

36. Ibid., p. 13.

37. P. Jeannin, «Le cuivre dans l'économie minière et métallurgique des régions vosgiennes ", p. 59 ; J. Grandemange, Les mines d'argent du duché de Lorraine au XVI siècle. Histoire et archéologie du Val de Lièpvre (Haut-Rhin), p. 13-14 et 16.

38. G. Hirschfell et H. Hihn, «La circulation dans l'avant-vallée », p. 139.

39. J. Grandemange, Les mines d'argent du duché de Lorraine au XvI siècle. Histoire et archéologie du Val de Lièpvre (Haut-Rhin), p. 11.

40. Ibid., p. 16.

41. Ibid., p. 25.

42. Ibid., p. 25, 27, 29, 34 et 40.

43. Ibid., p. 34.

44. G. Cabourdin, «Les ducs de Lorraine et l'exploitation des mines d'argent, 1480-1635», p. 106.

45. Ibid., p. 101-102.

46. P. Fluck et N.Florsch, "L'archéologie du feu: les fonderies d'argent du Bonhomme »; P. Fluck, Sainte-Marie-aux-Mines ou les mines du rêve. Une monographie des mines d'argent, p. 187-193.

47. G. Cabourdin, «Les ducs de Lorraine et l'exploitation des mines d'argent, 1480-1635 », p. 109-113 ; Id., " Les ducs de Lorraine et la monnaie (1480-1635) », p. 18.

48. Mention d'une charte de 1387 relative aux mines (R. Mattauer, "Contribution à l'étude des anciennes mines et forges de la vallée de la Doller », p. 116).

49. P. Jeannin, « Note sur l'abbaye de Lure au $\mathrm{xVI}^{\mathrm{e}}$ siècle. Aspects économiques et sociaux de la géographie historique », p. 485 et 498.

50. P. Jeannin, «Conjoncture et production du cuivre dans les Vosges méridionales à la fin du XVI et au début du XVII e siècle », p. 122.

51. P. Jeannin, «Le cuivre dans l'économie minière et métallurgique des régions vosgiennes ", p. 67.

52. Fr. Liebelin, Mines et mineurs du Rosemont, p. 18, 47-48 et 257.

53. P. Jeannin, «Conjoncture et production du cuivre dans les Vosges méridionales à la fin du XVI ${ }^{e}$ et au début du XVII siècle », p. 124 et $128-129$; Id., « Le cuivre dans l'économie minière et métallurgique des régions vosgiennes », p. 57. 
54. P. Jeannin, «Conjoncture et production du cuivre dans les Vosges méridionales à la fin du XVI ${ }^{\mathrm{e}}$ et au début du XVII ${ }^{\mathrm{e}}$ siècle ", p. 129 et 134-135.

55. Ibid., p. 138 ; P. Jeannin, «Le cuivre dans l'économie minière et métallurgique des régions vosgiennes », p. 71.

56. J. Grandemange, Les mines d'argent du duché de Lorraine au XVI siècle. Histoire et archéologie du Val de Lièpvre (Haut-Rhin), p. 13.

\section{RÉSUMÉS}

À l'aube des Temps modernes, le contrôle de la chaîne des Vosges, séparant le duché de Lorraine à l'ouest et l'Alsace à l'est, est l'objet de convoitises des principales forces en présence (dynastes lorrains, Habsbourg, Ribeaupierre, souverains bourguignons). La raison en est principalement d'ordre économique : des voies importantes du trafic international, notamment entre l'Italie et les Pays-Bas, empruntent les cols vosgiens et le massif recèle d'importants gîtes métallifères. La mise en œuvre conjointe de documents diplomatiques, comptables et figurés et d'acquis récents de l'archéologie minière apporte un éclairage synthétique et si possible chronologique de l'évolution des réseaux routiers et de leur fréquentation d'une part, de l'exploitation des filons d'argent (Val de Saint-Dié et Val de Lièpvre) ou de cuivre (Vosges méridionales) d'autre part.

\section{AUTEUR}

\section{JEAN-MARIE YANTE}

Professeur émérite de l'université catholique de Louvain 


\title{
Marchands du Dauphiné à Bayonne et dans sa région au milieu du XVII siècle
}

\author{
Francis Brumont
}

1 Les migrations montagnardes ont fait l'objet de nombreuses études, donnant l'image de montagnes surpeuplées et misérables, envoyant dans les plaines voisines ou plus lointaines, des hordes de travailleurs, plus ou moins spécialisés, dont les envois d'argent permettent à leurs compatriotes restés au pays de survivre. Cette vision a été magistralement développée et pour ainsi dire figée pour quelques décennies par Fernand Braudel dès la première édition de la Méditerranée (1949) :

« La montagne est bien cela, écrit-il : une fabrique d'hommes à l'usage d'autrui. ${ }^{1}$

Cependant, cette vision stéréotypée et assez peu nuancée, a été battue en brèche depuis une cinquantaine d'années, notamment en inversant le point de vue braudélien, c'està-dire en partant de la montagne elle-même et non point de ce que l'on en voyait depuis la plaine ${ }^{2}$. Ces espaces sont apparus alors comme beaucoup moins uniformes et beaucoup moins misérables qu'avait pu faire croire une lecture rapide de Braudel qui çà et là avait apporté quelques nuances à son modèle ${ }^{3}$.

Cette révision historiographique s'est appuyée notamment sur les travaux de Laurence Fontaine sur les marchands du Dauphiné : elle a montré que loin d'être une émigration de la misère, il s'agissait d'une activité fortement organisée à partir des lieux de départ, l'Oisans dans ce cas précis, s'appuyant sur des réseaux familiaux et brassant des capitaux non négligeables ${ }^{4}$. La montagne n'est plus alors vue comme un espace pauvre, ni la migration comme une fatalité, mais plutôt comme un espace dynamique et producteur de richesses ${ }^{5}$. Et c'est dans un de ses premiers travaux que Laurence Fontaine signale incidemment, qu'ayant feuilleté quelques registres de notaires bayonnais, elle avait repéré une vingtaine d'actes concernant "ses » Dauphinois ${ }^{6}$. Un examen plus approfondi et pour ainsi dire exhaustif des registres des trois notaires les plus actifs à Bayonne dans le deuxième tiers du XVII siècle, Pierre de Harran (1613-1665), Jean Reboul (1632-1676) et Mathieu Jusan (1655-1672), auxquels il faudrait 
ajouter quelques liasses de notaires de Dax et de Mont-de-Marsan, m'a permis d'en repérer plus de 250 , qui sont la source unique de cette étude ${ }^{7}$.

4 Ce qui caractérise ces Dauphinois, c'est, d'une part, que ce sont des marchands dont nous devons étudier l'activité, et, d'autre part, des immigrés qui ont gardé des relations avec leur village d'origine et qui se sont aussi intégrés dans leur nouveau lieu de résidence, car la plupart demeurent de nombreuses années à Bayonne et dans ses environs, sans que nous ayons connaissance de retours durables au pays.

\section{Installation}

5 Les marchands forains sont nombreux à Bayonne, mais la plupart ne font qu'y passer allant en Espagne ou en revenant; d'autres s'y rendent régulièrement, étant habitués des foires franches qui s'y déroulent plusieurs fois par an. Ils proviennent essentiellement du Massif Central et de ses confins, l'Auvergne, le Limousin, le Gévaudan, le Lyonnais ou le Forez, et si nous connaissons assez souvent leur ville d'origine (Marvejols ${ }^{8}$, Thiers...) nous n'en savons guère plus sur ces marchands itinérants. Au contraire, les Dauphinois s'installent, et font des séjours de longue durée.

6 Les notaires bayonnais n'avaient qu'une connaissance approximative de la géographie alpine et se contentaient bien souvent de mentionner que le contractant était un marchand du Daufiné, Ils auraient pu apporter un peu plus de précision, car la plupart de ces migrants étaient originaires d'une seule région, l'Oisans. Quelques-uns viennent du chef-lieu du mandement d'Oisans, Bourg d'Oisans, comme Jacques Barruel ${ }^{9}$ ou Pierre Lantelme et Pierre Barthélemy ${ }^{10}$. Mais ils ne semblent pas avoir joué un grand rôle, certains d'entre eux étant simplement de passage. Ceux qui occupent le devant de la scène et que nous retrouverons tout au long de ces pages étaient nés dans de petits villages montagnards. Certains d'entre eux, cependant, comme les frères Claude et Silvestre Ravel, indiquèrent comme origine Bourg d'Oisans lorsqu'ils arrivèrent à Bayonne $^{11}$, mais ils provenaient en fait d'Allemond, où ils avaient conservé quelques biens $^{12}$. Non loin de là, et un peu plus haut dans la vallée, voici les Durif, qui sont de Vaujany ${ }^{13}$ comme Barthélemy Doz ${ }^{14}$, et les frères Claret, d'Oz ${ }^{15}$. Au sud-est de la capitale, voilà un autre groupe de villages fournisseurs de migrants: Vénosc, berceau des Rouard, Les Gauchoirs d'où est originaire Étienne Orcel, et plus à l'est, en remontant la vallée de la Romanche, Mont-de-Lans, patrie d'Étienne Magne (ou Magnon) et de ses deux frères ${ }^{16}$ et, tout près de là, Freney, d'où sont sortis Jacques et Claude Vinatier ${ }^{17}$. Encore plus haut, en remontant cette même vallée, en direction du Lautaret, Le Chazelet, d'où vient Félix Picq ${ }^{18}$ et La Grave, patrie de Louis Mathon ${ }^{19}$. Un petit nombre d'entre eux, installés, peut-être momentanément, à Mont-de-Marsan, étaient venus d'encore plus loin, du Monêtier au nord de Briançon pour deux d'entre eux ${ }^{20}$, un village d'où partiront tant de colporteurs de livres et de libraires au siècle suivant ${ }^{21}$. D'autres proviennent du Queyras, de Château-Queyras exactement, dans la haute vallée de la Durance pour les trois frères Gondret, « contreporteurs ", c'est-à-dire colporteurs ${ }^{22}$. Et enfin, d'autres encore arrivent de l'Italie actuelle, de Pragélas (Pragelato), au nord de Sestrière ${ }^{23}$ ou de Château-Dauphin, (Casteldelfino) dans la Val Varaita, un peu plus au $\operatorname{sud}^{24}$.

7 Les plus anciennes installations datent sans doute des premières années du XVII siècle ; en 1617, les frères Jean et Pierre Rouard, résidant à Dax, récupèrent des créances plus anciennes (1614 et 1615$)^{25}$; ils ne sont pas alors qualifiés de marchands du Dauphiné, et 
jamais par la suite, bien qu'ils soient toujours associés avec des marchands de cette origine, comme nous le verrons : il faudra attendre 1666, alors que Pierre et Jean sont décédés, pour que nous soit dévoilé leur lieu de naissance, Vénosc ${ }^{26}$. Il est possible qu'ils aient été précédés dans la région par Pierre Rol, marchand bayonnais, jamais cité comme Dauphinois, mais qui est en relation avec eux ${ }^{27}$ et qui a comme serviteur Barthélemy Doz, de Vaujany ${ }^{28}$, et prend comme apprenti, en 1656, Félix Picq, du Mazelet $^{29}$. Il est en tout cas tout à fait intégré dans le milieu marchand bayonnais et est nommé jurat en $1658^{30}$ et échevin en $1666^{31}$.

8 À partir de 1640 environ, et surtout dans les années 1650, les mentions de marchands du Dauphiné se multiplient : Pierre Vinatier en 1632, les Ravel en 1642, les Consul et les Rochette en 1656 et les Durif, qui joueront un grand rôle dans les années 1660, en 1657. Il semble que l'on ait affaire à un courant continu de nouveaux arrivants, sans que les anciens quittent les lieux, même si certains changent de résidence, sans toutefois revenir au pays. Il est assez intéressant de noter que ces migrants n'arrivent pas seuls : il s'agit le plus souvent de frères, deux (les Ravel, les Durif) ou trois (les Magne, les Gondret). Avec les Rochette, nous avons apparemment affaire à un véritable clan familial, dont il nous est difficile de démêler les liens de parenté : Étienne et Jean Rochette figurent, en 1656, avec d'autres notables (Rol, Rouard, Consul) parmi ceux qui engagent un procès contre des exactions que subissent les marchands en Quercy ${ }^{32}$; Jean avait deux frères Jacques et Pierre ${ }^{33}$ mais nous ne savons pas s'ils sont arrivés ensemble. Enfin, en 1671, sont présentés les héritiers de feu Jean Rochette: Étienne, Jacques, Pierre et Jean, dont certains font sans doute partie de la deuxième génération ${ }^{34}$. Parfois, il semble bien que les fratries aient été séparées, volontairement ou non : si Jean Chazal demeure à Bayonne, Claude Chazal réside à Bilbao ${ }^{35}$. Jean Coing commerce en Béarn tandis que Claude Coing est installé à Villeneuve-de-Marsan ${ }^{36}$; un Pierre Doz est momentanément à Madrid où il réside chez Pierre Dufau, à la «Porte du Soleil» (Puerta del Sol) ${ }^{37}$.

9 Au total, nous pouvons compter dans cet extrême sud-ouest de la France, dans les années 1640-70, une cinquantaine d'individus provenant du Dauphiné, originaires de l'Oisans essentiellement, répartis dans plusieurs villes et quelques autres installés en Espagne.

Il faut reconnaître d'emblée qu'il n'est pas toujours facile de savoir où chacun de nos marchands a fixé sa résidence. Certes, quelques-uns d'entre eux font preuve d'une stabilité à toute épreuve : à peine arrivés, les frères Ravel se sont installés au BourgSaint-Esprit, sur la rive droite de l'Adour, là même où les Juifs venus d'Espagne et du Portugal un siècle auparavant, avaient été assignés à résidence. En 1654, Claude Ravel y avait acheté un terrain pour bâtir sa maison ${ }^{38}$ et son neveu, prénommé aussi Claude, fit de même en 1662, en acquérant du chanoine Pierre Goubert, un terrain contigu au " cimetière des Portugais " $^{39}$. Dans cette même localité, vivent également Jacques et Damian Consul et Jean Guyot, leur associé ${ }^{40}$. D'autres sont installés à Bayonne : c'est le cas des Durif, Rochette, Jean Chazal ; certains sont en location, mais d'autres achètent ou font bâtir. Peu avant de se marier, en 1666, Jean Chazal avait acquis une maison rue de la Poissonnerie, d'une valeur de 4000 livres qu'il apporta à son épouse, Françoise David $^{41}$. Quant à Pierre Argentier, c'est dans la même rue, au lieu-dit «nogués ", qu'il fait bâtir la même année ${ }^{42}$. D'autres, enfin, vivent dans de petites villes, plus ou moins loin de Bayonne: nous avons déjà cité Dax, résidence des Rouard et des Vinatier, et Mont-de-Marsan. On pourrait y ajouter Villeneuve de Marsan, où vivent Jacques Didier 
et Claude Coing ${ }^{43}$, Saint-Jean de Luz avec les frères Claret ${ }^{44}$, le Béarn et, bien entendu, l'Espagne : Bilbao ${ }^{45}$, Logroño ${ }^{46}$ ou Valladolid ${ }^{47}$.

11 Il est aussi difficile de préciser leur résidence parce que beaucoup sont amenés, pour les besoins de la compagnie, à se déplacer, parfois assez loin ; c'est ce qui a poussé Jean Guyot à faire son testament, et ce d'autant plus que, protestant («bon et fidèle chrestien et catholique de la religion prétendue réformée ») il ne veut pas être enterré n'importe où :

« Comme il est obligé d'aller et venir à raison du négoce qu'il faict en compagnie et consorce des sieurs Consul, il luy peult survenir quelque accident et peut estre la mort mesme... $\wedge^{48}$

D'autres, ou les mêmes, peuvent résider quelque temps hors de la région; témoin Étienne Orcel, qui avait sans doute vécu à Lyon avant de venir à Dax : en 1666, il est qualifié de «bourgeois et marchand de Lyon » dans un acte ${ }^{49}$ alors qu'il n'y réside qu'épisodiquement: en 1660, 1664, 1665; certains marchands de Bayonne utilisent d'ailleurs sa connaissance du milieu lyonnais pour lui confier le placement de leurs fils en apprentissage chez des négociants de cette ville ${ }^{50}$. Les Durif ont également vécu à Lyon avant de se fixer à Bayonne : en janvier 1656, Pierre Durif y avait contracté une dette de 2100 livres, en compagnie de son beau-père, en faveur de Ferriol Eymar, marchand d'Oisans ${ }^{51}$. Le 23 avril 1557, les deux, beau-père et gendre, sont à Dax où ils fondent une société 52 et en 1559 encore, Jean Durif est qualifié de marchand de Lyon, résidant à Bayonne ${ }^{53}$. Cela expliquerait la facilité avec laquelle, ils se sont insérés dans le milieu marchand de notre ville. Il n'y a là rien d'étonnant, Lyon étant souvent le premier point d'ancrage des Dauphinois, avant qu'ils ne puissent se lancer dans des aventures plus lointaines ${ }^{54}$.

13 Il faut également envisager ces déplacements comme faisant partie d'une histoire familiale, sur plusieurs générations : une première installation à Lyon est dans l'ordre des choses, vu la proximité de cette ville, capitale du commerce de gros, avec le Dauphiné. Un exemple: Pierre Rouard achetait des marchandises à Monsieur d'Argentier, de Lyon ${ }^{55}$; or, en 1660, Pierre Argentier, fils de Jean, est associé de Pierre Rouard ${ }^{56}$ et, un peu plus tard encore (1663), arrive un autre Jean Argentier, peut-être frère de Pierre, qui s'installe à Saint-Jean de Luz ${ }^{57}$. Laurent Rouard était «bourgeois et marchand » de Lyon avant de venir à Bayonne, peu avant la mort de Pierre ${ }^{58}$ de même qu'Étienne Orcel et les Durif avaient résidé dans cette cité où toutes facilités leur étaient offertes pour trafiquer toutes sortes de marchandises. Ils pouvaient ensuite, de leur propre chef, ou suivant une stratégie familiale prédéfinie, s'installer plus loin où, forcément, à cause de la distance et de l'autorité que leur donnaient l'âge et leur réussite antérieure, ils pouvaient s'émanciper.

Les stratégies matrimoniales sont un bon reflet des moyens utilisés par ces familles pour nouer des alliances profitables à leurs affaires et contrôler les membres établis au loin ; il était traditionnel qu'une partie des migrants soient mariés au village où leurs femmes demeuraient et où ils revenaient régulièrement ${ }^{59}$. Cela semble être le cas des frères Vinatier, du Freney en Oisans : à l'annonce de leur décès, survenu à peu de temps d'intervalle, au début des années 1660, leurs épouses respectives se font octroyer la tutelle de leurs enfants et envoient un de leurs frères à Bayonne pour régler la succession et recevoir ce qui revient aux enfants ${ }^{60}$. Mais leur associé, P. Rouard était sans doute marié à Dax où ses enfants s'établirent et prospérèrent, de même que Pierre Argentier comme nous le verrons plus bas. Chez les Durif, on se marie aussi au pays : 
Jean a été marié par son père en 1661, avec une demoiselle de Vaujany, Marguerite Collomb, l'acte ayant été passé devant un notaire de Bourg d'Oisans ${ }^{61}$. Pierre, quant à lui, s'était sans doute marié beaucoup plus tôt (il marie sa propre fille en 1664$)^{62}$, avec Ennemonde, fille de Geoffrey Peyre, originaire d'Oz, établi plus tard à Dax ${ }^{63}$. Le beaupère et le gendre feront des affaires ensemble et c'est à Durif que Peyre, accablé par les dettes, finit par vendre tous les biens qu'il avait à $\mathrm{Oz}$ (« bastimens, terres, predz, boys, montaignes, meubles de maison et de labourage ou bestiaux »), moyennant 5600 livres et la possibilité pour lui et sa femme, née Philis Basset, de vivre dans la maison ${ }^{64}$.

Ces unions servaient à conforter les alliances entre familles et à développer les activités professionnelles, car les dots et les apports des maris étaient bien souvent versés dans les capitaux des sociétés. Quand Jean Durif se marie, il reçoit de son père Laurent, marchand de Vaujany, une somme coquette, 8000 livres tournois, qu'il peut prendre, soit en liquide, soit en recevant la moitié d'une métairie à Vaujany; il choisit le liquide que son frère Pierre avance et place aussitôt dans la société qu'ils ont en commun tandis que Pierre reçoit procuration pour vendre la métairie ${ }^{65}$. Et quand Pierre marie, en 1664, sa fille Apolline avec Fabian Faure, de Dax, fils de Jean, bourgeois et marchand de cette ville, ce qui est remarquable, c'est l'apport du futur à la société nouvellement constituée à l'occasion entre les Durif et Fabian Faure ${ }^{66}$. Pierre Durif avait donné 5000 livres à sa fille, dont 4000 devaient entrer dans le capital de la nouvelle société qui devait être créée le $1^{\mathrm{er}}$ janvier 1665 ; quant à Jean Faure, il donnait à son fils 42000 livres, dont 30000 la veille des noces et 12000 après sa mort. Pierre devait loger et entretenir sa fille et son gendre à Bayonne pendant la durée de la compagnie (6 ans). Les sommes considérables promises par Faure n'étaient pas de l'argent liquide, mais des biens immeubles (moulin, métairies, maison) et des créances qu'il n'avait pas encore remises à Pierre Durif deux ans après, si bien que le contrat fut rompu moyennant quelques dédommagements à Pierre, Fabian Faure restant néanmoins intégré à la compagnie ${ }^{67}$. Notons que Jean Faure, père de Fabian, était associé en affaires, de façon semble-t-il informelle, avec Geoffrey Peyre, beau-père de Pierre Durif $^{68}$.

Et quand l'amour s'en mêle, il faut bien s'adapter à ce schéma, comme en témoigne la triste histoire des amours de Pierre Argentier et de demoiselle Marie d'Andoings, fille de noble Anthonin d'Andoings, capitaine de la tour Saint-Esprit et de Marie Delalande, demoiselle, issue d'une famille de marchands et d'officiers royaux ${ }^{69}$. Pierre avait recherché Marie en mariage et la demoiselle sa mère " $y$ avoit donné les mains ", en croyant que le père accorderait son consentement. On dresse le contrat le 11 octobre 1662 , le mariage est consommé «à l'insceu du père » qui porte plainte au Parlement si bien qu'Argentier fait évoquer l'affaire au Conseil du Roi, ce qui témoigne de l'ampleur du réseau constitué par ces Dauphinois. Comme de coutume dans ces cas-là, des amis s'interposent et on négocie " pour remettre toute l'affaire dans les voyes de l'honneur et de la justice ». Le gendre et le beau-père discutent ensemble et un nouveau contrat est dressé : les « époux » devront « se réépouser à toutes heures licites », Marie apporte tous ses droits à l'héritage et Argentier la somme de 25000 livres, une somme qui dut contribuer à panser les blessures d'amour-propre d'Anthonin, d'autant que le beaupère de sa fille, Jean Argentier, était comme lui, officier royal, lieutenant en la châtellenie du mandement d'Oisans. Heureuse fin, toute provisoire, hélas, puisque le 26 novembre 1664, Marie, infirme et paralysée, dictait son testament : elle était mère 
d'une petite fille, née le 24 août, dont la marraine était sa mère et le parrain son beaupère $e^{70}$.

\section{Des compagnies familiales}

On l'aura compris, à la lecture des lignes qui précèdent, c'est en famille que les marchands dauphinois émigrés dans la région bayonnaise s'organisaient, des sociétés familiales qui, en conséquence, étaient tributaires des aléas de la démographie. Voilà les Ravel, un cas très simple : Claude et Silvestre, frères, ont fondé une société le 6 avril $1642^{71}$; les comptes sont rendus régulièrement et quand Sylvestre meurt en 1655 ou début 1656, son fils Michel le remplace ${ }^{72}$ et un peu plus tard, son frère Claude les rejoint. C'est Claude oncle qui a clairement la direction des affaires, ses neveux, surtout Claude ne semblant pas avoir la fibre des affaires. En 1661, ils ne sont plus associés à leur oncle, mais celui-ci les prend à son service, moyennant salaire et l'obligation de les entretenir, même Claude qui est marié ${ }^{73}$. Deux ans et demi après, Claude manifeste le désir de quitter la société, car il veut choisir un autre négoce ${ }^{74}$; il s'associe alors avec Barthélemy Doz, un sujet aussi instable que lui, et avec "une autre personne ", non nommée, mais qui s'avère être Pierre Durif, chargé de les contrôler et de mettre un peu d'ordre dans leurs affaires ${ }^{75}$. Pour la suite, passons sur les détails; Doz s'installe plus ou moins à Bilbao et fait la navette en France et Espagne ; Ravel s'associe de nouveau avec P. Durif, début $1666^{76}$, mais, à notre grande surprise, nous le retrouvons, un an et demi plus tard, capitaine de la frégate "l'espérance", armée en guerre, qui a pris deux barques chargées de marchandises appartenant à des Espagnols dont il demande qu'elles soient déclarées de bonne prise ${ }^{77}$. Ce fils de montagnard était devenu un vrai Bayonnais!

18 Les Durif, Pierre et Jean, présentent un cas assez semblable de société fondée sur deux frères, avec la différence que leur association, sans doute née durant leur séjour à Lyon, semble indéfectible, même s'ils créent continuellement des associations provisoires à côté de la compagnie fraternelle. Ainsi, dès 1657, nous l'avons dit, Pierre fonde une société avec son beau-père, Geoffrey Peyre, qui durera jusqu'en $1662^{78}$. En même temps, en 1661-62, ils font des affaires avec les Rochette, mais la dissolution de la compagnie qu'ils avaient ensemble se termine par un procès, les désaccords provenant du fait que des dettes des autres compagnies des intéressés étaient versées au passif de la compagnie commune :

«Des articles importans qui charge [sic] lad. societté des sommes considérables

lesquelles ne regardent que le fait particulier desd. Rochette. ${\aleph^{79}}^{79}$

Il se peut que cette compagnie soit la même que celle qui avait été fondée par écrit privé entre les Rochette, Thomas Martin leur associé et $P$. Durif et qui est dissoute à son terme le 19 mars 1663, Durif recevant 1800 livres de la part des Rochette ${ }^{80}$. Toujours à la même époque (juin 1661), ils étaient associés avec Barthélemy Doz, leur compatriote de Vaujany, association qui ne dura que deux ans et demi et fut dissoute par la volonté des Durif, malgré l'opposition de Doz qui leur devait plus de 2500 livres $^{81}$. Par la suite, les Durif formeront une nouvelle société avec leur ancien commis, Jacques Barruel, natif du Bourg d'Oisans, et épisodiquement de nouveau avec les Rochette et Doz, puis Claude Ravel le jeune, cette dernière société ayant bénéficié des 8000 livres de la dot de Pierre Durif ${ }^{82}$; en 1664, comme nous l'avons vu, ils incorporeront à la compagnie le gendre de Pierre, Fabian Faure. Ne quittons pas les Durif sans évoquer le cas 
divertissant d'un de leurs neveux, Alexis, fils de M. Me Claude Durif, conseiller du roi en l'élection de Grenoble, qui a été envoyé à Bayonne pour les seconder, mais ce qu'il désire, c'est entreprendre un voyage en mer $^{83}$. Il s'engage avec un capitaine partant pour les Antilles, hésite au dernier moment si bien que les gardes de M. d'Artagnan, gouverneur de la ville, doivent l'embarquer de force; en fait, il n'ira que jusqu'à La Rochelle et repartira vers Vaujany, en passant par Cahors où son oncle lui fait remettre de l'argent. Cette petite aventure avortée coûtera tout de même 583 livres à son père. On a l'impression, dans le cas des deux frères, où Pierre semble occuper la première place, d'avoir affaire à des marchands contrôlant, au moins en partie, les autres marchands du Dauphiné installés à Bayonne ou au Bourg Saint-Esprit.

Notre dernier exemple concernera des personnages que nous avons déjà maintes fois rencontrés, les Rouard, de Dax, et leurs associés fidèles. Nous ne savons pas grandchose de Pierre Rouard et des Vinatier avant 1648 si ce n'est, comme nous le verrons, qu'ils ont été impliqués dans des trafics plus ou moins licites. Le 2 décembre 1648, par écrit privé, formalisé devant notaire un an après, une société a été formée entre Pierre et Laurent Rouard, Claude et Jacques Vinatier et Jean leur père (demeuré en Oisans) et Étienne Orcel ${ }^{84}$. Sont donc associés des marchands résidant à Dax, à Lyon et en Dauphiné (Freney), tous originaires de l'Oisans. Fondée à l'origine pour 4 ans, la compagnie perdurera avec cette même configuration jusqu'au décès de Claude Vinatier, en 1660. Cette année-là, la compagnie accueille un autre associé, Pierre Argentier, puis Jean Chazal, d'abord commis résident à Bayonne, et neveu de Pierre Rouard; en octobre 1662, Chazal fonde une première société avec son cousin Jean Rouard, qui sera dissoute au bout de huit ou neuf mois, dissolution suivie d'un procès entre les cousins ${ }^{85}$. Cela n'empêchera pas Chazal d'entrer dans la compagnie principale qu'il représente à Bayonne, d'abord seul puis en compagnie de P. Argentier. Nous avons ici à une compagnie solide, bénéficiant de la longévité de ses dirigeants et des liens étroits qu'ils ont su tisser avec Lyon.

21 Parmi ces marchands bien installés, un individu dénote un peu, que nous avons déjà rencontré à maintes reprises, c'est Barthélemy Doz, originaire de Vaujany. Il est d'abord commis chez Pierre Rol, puis fit partie de diverses compagnies : le 15 octobre 1660, il s'engage verbalement avec les trois frères Magne, de Mont-de-Lans, « au traficq et négosse de la marchandise que faisoient lesdictz Maignons », mais cette compagnie, à laquelle il avait pu apporter plus de 6000 livres, est dissoute six mois après, le 15 avril 1661, en présence de Pierre Durif ${ }^{86}$. Peu de temps après, le $1^{\text {er }}$ juin 1661 , il entre dans la compagnie de ce dernier ${ }^{87}$, puis s'engage, en 1664 au plus tard, nous l'avons dit, avec Claude Ravel le jeune ${ }^{88}$. Il doit s'agir alors de la compagnie formée en mars 1664 entre les deux et une troisième personne (qui, nous le savons, est Pierre Durif, lequel n'apparaît pas dans l'intitulé de la société, «Ravel, Doz et compagnie»). Certaines clauses de ses statuts manifestent une certaine méfiance, sans doute à l'égard de Doz: d'abord, que les décisions importantes seront prises d'un commun accord, et ensuite, que les associés :

«N'entendoient traffiquer autres marchandises que celles qui estoient de leur commune connaissance et que les autres marchands de leur profession comme sont les sieurs Argentier et Orcel, Durif et Rochette et autres semblables ont accoutumé de faire conduire tant en la présant ville qu'en Espaigne. $»^{89}$

Pas d'aventure donc, mais Doz joue les électrons libres, commerce pour son propre compte, «fait en tout et partout le maitre absollu » et persiste dans "son humeur entreprenante». La compagnie sera donc dissoute, Ravel et Doz continueront seuls, 
sous la tutelle de Durif, avec qui ils sont en procès et, par la suite, nous l'avons dit, Doz fera la navette entre Bayonne et Bilbao. Un marchand donc qui ne veut pas entrer dans un moule préétabli, mais qui continue quand même à négocier et, peut-être à prendre plus de risques que ses compatriotes. Ce modèle de compagnie est bien conforme au modèle général décrit par Laurence Fontaine :

"Ces réseaux de parenté s'organisent en des compagnies familiales très souples, nouées et dénouées au gré des nécessités du commerce, de la mort, de

l'enrichissement ou de l'appauvrissement des uns et des autres. $»^{90}$

Ces pratiques ne leur sont évidemment pas spécifiques et bien d'autres marchands migrants font de même: on pourra en juger par le seul exemple des marchands auvergnats ou alpins (dont quelques Dauphinois) installés dans les hautes vallées ariégeoises (ou ne faisant qu'y passer) ${ }^{91}$.

\section{Un négoce bien réglé et profitable}

Trafiquer comme " les marchands de la profession », les marchands dauphinois, cela va sans dire, qu'est-ce que cela signifie ? Un autre texte parle de « marchandz négocient et coustumiers à faire venir des marchandises de Lion, Tolose, Montauban, Limoges et autres semblables endroitz en ceste ville $\aleph^{92}$. Parmi ces marchands, dont ce texte donne une liste, outre des Bayonnais de souche, figurent nos vieilles connaissances, Rouard, Rol, Consul, Martin, Rochette et autres. Ce sont donc des marchands "grossiers", comme l'on disait, c'est-à-dire des marchands en gros ; mais nous n'avons que peu de données sur les marchandises dont il s'agit, car ces détails apparaissaient dans les livres de comptes qui ne nous sont pas parvenus. Il nous faut donc nous contenter de quelques notations éparses, notamment quand un litige se produit. Voici donc, en vrac, des dentelles d'or et d'argent venues de Lyon ${ }^{93}$, des cartes à jouer, d'un honorable marchand de Thiers dont la marque a été usurpée ${ }^{94}$, des futaines et des aiguilles, chargées sur un navire ${ }^{95}, 300$ douzaines de gants de chevreau couleur verte avec 3 petites fleurs de soie au-dessus de la main achetées par les Durif à un gantier de Lyon ${ }^{96}$, des toiles, sans doute du Maine, achetées à Bordeaux ${ }^{97}$, des futaines de Montpellier ${ }^{98}$; il faudrait sans doute y ajouter des razes et des cadis de Montauban, car les marchands de cette ville, notamment les Roumagnacq, sont très présents à Bayonne et souvent bénéficiaires de lettres de change tirées en leur faveur ${ }^{99}$. Il y a sans doute aussi de nombreux autres produits, notamment de la mercerie, mais nous ne pouvons apporter plus de précision.

Quels sont les destinataires de ces produits ? Il y a d'abord les ventes au détail dans les boutiques que possèdent nos marchands eux-mêmes, comme celle que Claude Ravel loue au Bourg Saint-Esprit, sous l'hôpital des pauvres ${ }^{100}$. D'autres louent une maison dans les rues commerçantes de Bayonne où il est certain que le rez-de-chaussée est occupé par une boutique: c'est le cas de la compagnie Consul, Guyot et Gauthié, qui louent « aux cinq cantons ", en plein centre-ville ${ }^{101}$; dès 1649 , les Rouard avaient loué rue de la Salie, une maison qui s'était écroulée quatre ans plus tard, si bien qu'ils s'installèrent, toujours en location, non loin de là, rue du Port Neuf ${ }^{102}$. Ils peuvent également vendre à des merciers ou autres détaillants comme les tailleurs Johannis de Chibau et Pierre Duhart, de Saint-Jean de Luz qui doivent un millier de livres à Rouart et compagnie ${ }^{103}$ ou cette société formée de trois marchands d'Auvergne et du Dauphiné qui agissent en Béarn et qui, ayant fait faillite, se sont réfugiés à Saint-Sébastien ${ }^{104}$. Un 
certain nombre de ces marchands, isolés ou en compagnie, ont des comptes courants chez nos Dauphinois et règlent leur dû régulièrement: il s'agit donc d'une clientèle fidèle et sûre. Notons que parmi ces clients les « Portugais » du Bourg-Saint-Esprit sont parmi les plus assidus : un certain nombre d'entre eux fait faillite au milieu des années 1660 et, comme il faut négocier pour leur donner des délais de paiement et réduire leurs dettes, le notaire liste consciencieusement les créanciers parmi lesquels figurent toujours trois ou quatre compagnies de Dauphinois ${ }^{105}$.

On voit aussi passer des colporteurs, ayant leur propre société ou achetant leur mercerie à Bayonne : Louis Mathon, marchand de Lagrave, en Dauphiné, doit aux frères Magne 365 livres pour des marchandises délivrées en plusieurs fois plus 195 livres le jour de l'acte ; il est possible d'ailleurs que ledit Mathon soit fixé dans la région, puisque c'est son beau-frère, vivant en Chalosse, qui règle cette dette ${ }^{106}$. Quant aux frères Gondret, « contreporteurs » de Château-Queyras, deux d'entre eux, en compagnie d'un troisième colporteur, Pierre Gertous, de Casteldelfino, sont au service d'un autre Dauphinois, Étienne Vergés, moyennant un salaire qui varie de 50 livres par an pour Geoffrey Gondret, le plus jeune, à 140 livres pour Philippe, le plus expérimenté sans doute, qui était déjà au service de Vergés depuis deux ans ${ }^{107}$. Voici encore la compagnie, à capitaux minimes, de Philip Marqueret, de Mont-de-Lans, Silvestre Cret, d'Oz et son beau-frère Pierre $\mathrm{Col}$, qui résidaient à Mont-de-Marsan ; comme ce dernier était décédé à Saint-Céré en Quercy en revenant de Thiers où il était allé faire quelques "emplettes", on apprend qu'il avait apporté 94 livres 7 sous au cabal de la société, somme dont sa mère était l'héritière ${ }^{108}$.

Les clients espagnols de nos marchands sont souvent d'une autre envergure; les Dauphinois traitent de préférence avec leurs compatriotes ou, en leur absence, avec d'autres marchands français, souvent béarnais, si du moins l'on en juge par leur patronyme. Ainsi, P. Barthélemy, du Bourg d'Oisans, installé à Valladolid est en relation avec les Magne qui lui envoient des marchandises ${ }^{109}$, avec les Durif qui lui prêtent de l'argent ${ }^{110}$ et est associé avec un marchand de Mont-de-Marsan ${ }^{111}$. À Bilbao, se trouve Jean Chesnau, commis de J. Rouard, qui, en 1663, a en magasin des marchandises d'une valeur de 10000 livres environ ${ }^{112}$ et François Mallet qui doit plus de 14000 livres aux Durif pour des marchandises qu'ils lui ont envoyées ${ }^{113}$. Inutile de continuer : l'Espagne est une destination importante, peut-être primordiale pour les marchands dauphinois (et pas seulement pour eux évidemment) qui s'y fournissent essentiellement en laine et en draps de Ségovie.

Les marchands dauphinois ne s'adonnent guère qu'au commerce; ils pratiquent très peu le prêt à la grosse, le placement favori des marchands bayonnais, et même épisodiquement, de certains «Portugais» du Bourg-Saint-Esprit; seuls les Rouard tentent l'aventure à deux ou trois reprises comme en 1661 où ils envoient " aux Indes " environ 20000 livres de marchandises (essentiellement des futaines) sur le Saint-Jean Baptiste, de Saint-Sébastien, dont était maître Pascual de Atocha avec l'intérêt à $40 \%{ }^{114}$. Pierre s'était aussi distingué, au début de sa carrière dans une activité délictueuse : en compagnie d'un marchand de Limoges, Pierre Tisseron et d'un flamand de Bayonne, Richard Van Barnavel, ils tentèrent de passer au nez et à la barbe des employés de la Monnaie de Bayonne, un certain nombre de réaux qu'ils auraient dû envoyer à ladite Monnaie pour qu'ils y soient fondus et refrappés ensuite, mais ils estimaient que le prix qu'on leur en donnait était trop inférieur à leur valeur sur le marché ${ }^{115}$. Cela se passait en 1631: les contrevenants avaient fait un arrangement à l'amiable avec l'un des 
maîtres de la Monnaie, arrangement qui fut contesté par les autres administrateurs de l'institution, mais, finalement, ils purent recouvrer leurs biens en plaidant devant le Parlement. Quelques mois après, le 3 mars 1632, des mulets appartenant à Pierre Tisseron et à Pierre Vinatier, marchands « limozins ", furent arrêtés près de Dax : on y trouva 750 écus cachés au milieu des marchandises. Après recours au Parlement, puis au Conseil Privé, les contrevenants purent récupérer leur avoir, une dizaine d'années après ${ }^{116}$.

Faute de livres de comptes, nous ne pouvons qu'évaluer grossièrement, au hasard de la conservation des sources, les résultats des entreprises commerciales des Dauphinois. Les redditions périodiques des comptes, devant notaire, de la société formée par les Ravel frères nous permet de voir l'évolution des capitaux engagés dans une compagnie d'envergure moyenne. Elle avait été fondée en 1642 avec un capital de 4000 livres partagé entre les deux frères ${ }^{117}$; en 1649 , le cabal (marchandises, créances, argent liquide) s'élève à 8400 livres $^{118}$ et en 1656, après la mort de Silvestre, à la même somme (8 300 livres) $)^{119}$; la progression reprend avec la nouvelle organisation entre Claude et ses neveux : 9800 livres en 1658 et 10100 livres en $1661^{120}$. Entre ces deux dernières dates, le bénéfice aurait atteint $32 \%$ du cabal de départ, ce qui montre bien qu'une partie de ces bénéfices n'était pas reversée intégralement et était utilisée pour acheter des biens immobiliers (maisons) ou placée dans d'autres associations. Ces chiffres ne sont donc pas tout à fait comparables, mais montrent néanmoins une évolution positive des activités de la compagnie.

Avec les Rouard, nous sommes dans un autre monde: pour évaluer les capitaux manipulés par cette compagnie, nous n'avons que le partage fait à la mort des frères Vinatier pour donner à leurs enfants, représentés par leur mère, ce qui leur revenait. On peut supposer que les calculs furent longs et difficiles, d'autant plus que de nouveaux associés (Argentier, Chazal) étaient arrivés entre-temps ${ }^{121}$. Toujours est-il que les héritiers des défunts eurent droit à 135483 livres 8 sous d'un côté, plus 25 556,50 livres de l'autre (sans que l'on puisse bien déceler ce qui différencie ces deux sommes), soit en tout 158000 livres, une somme énorme, alors que les Vinatier (en comptant le père qui avait contribué à la création de la compagnie) ne représentaient que la moitié des associés. Il est probable que les Ravel sont plus représentatifs de la moyenne des marchands dauphinois, mais l'exemple des Rouard montre qu'en une génération on peut connaître un succès considérable, ouvrant la porte à d'autres horizons : M. Me Michel de Rouard, fils de Pierre, est alors, au début des années 1660, conseiller au Parlement de Bordeaux après l'avoir été au présidial de Dax.

Ce qui frappe dans l'organisation commerciale des Dauphinois, c'est leur souci de rester entre soi : les sociétés fonctionnent d'abord entre parents, souvent très proches (frères, beau-père et gendre) et voisins. On remarquera, par exemple, que les associés de la compagnie Rouard viennent de trois villages contigus au sud de Bourg d'Oisans (Les Gauchoirs, Vénosc, Freney) et que les Durif fréquentent plutôt leurs voisins de Vaujany ou d'Oz. Il y a quand même une exception, c'est la compagnie formée par Jacques et Damian Consul (de Bourg d'Oisans), Jean Guyot (de La Souchère en Casteldelfino) et Antoine Gautié (du Puy-en-Velay), ce qui ne l'empêchera pas de perdurer de nombreuses années. En outre, dans cette composition et décomposition permanente 
des associations, malgré les difficultés qui se produisent à la clôture des comptes et engendrent souvent des procès ou des arbitrages, les anciens associés ne se fâchent pas pour autant et continuent à faire des affaires ensemble, sans doute parce qu'on est en famille et entre voisins justement. Il faudrait pouvoir évaluer le rôle joué par les parents restés au pays, participant parfois directement dans ces sociétés, ou indirectement par l'apport d'argent (dots), mais nous ne savons rien de leur influence dans la conduite des affaires, de même que nous ne connaissons pas la fréquence des voyages faits en Oisans par nos marchands. On ne peut que soupçonner aussi le rôle des Dauphinois de Lyon qui fournissent des marchandises et des fonds. Il est quand même clair que ce qui a joué dans la réussite de nos marchands, c'est aussi le fait qu'ils provenaient de familles aisées, notables dans leur village, au minimum marchands, qui pouvaient leur procurer des alliances utiles.

Le comportement des marchands dauphinois diffère sur quelques points de celui des marchands bayonnais ou dacquois: ils n'achètent pas de biens immobiliers et, notamment pas de terre, ou du moins en faible quantité ; ils ne pratiquent pas le prêt à la petite semaine, de petites sommes ou de denrées ; ils dédaignent les prêts maritimes, à la grosse aventure, si prisés par les marchands bayonnais et n'affrètent pas de navires : leur commerce est un commerce terrestre, les longs déplacements ne leur font pas peur. Dirons-nous qu'ils adoptent un comportement d'immigrés ? Les réponses sont sans doute individuelles: certains, comme Pierre Rouard ou Pierre Rol (s'il est Dauphinois) ne font jamais mention de leur origine et sont tout à fait installés, sans esprit de retour sans doute; d'autres, comme Pierre Durif qui n'oublie jamais de faire marquer par le notaire qu'il est marchand de Vaujany et ne fait que résider à Bayonne, où il vit en location, mais agrandit son patrimoine dans ses montagnes natales qu'il a quittées sans doute depuis ses années de jeunesse en rachetant une moitié de métairie à son frère Jean et en acquérant le patrimoine de son beau-père à $\mathrm{Oz}$, d'autres donc, ont peut-être l'intention de retourner au pays pour y couler une vieillesse heureuse.

\section{BIBLIOGRAPHIE}

ALBERA Dionigi, CORTI Paola, « Migrations montagnardes dans l'espace méditerranéen. Esquisse d'une analyse comparative ", Mélanges de l'École française de Rome. Italie et Méditerranée, tome 112, $\mathrm{n}^{\circ} 1,2000$, p. 359-384.

BRAUDEL Fernand, La Méditerranée et le monde méditerranéen à l'époque de Philippe II, 4 éd., Paris, Armand Colin, 1979, 2 vol.

FONTAINE Laurence, Le voyage et la mémoire. Colporteurs de l'Oisans au XIXe siècle, Lyon, Presses Universitaires, 1984.

FONTAINE Laurence, Histoire du colportage en Europe (XV-XIXe siècles), Paris, Albin Michel, 1993.

FONTAINE Laurence, « Espaces, usages et dynamiques de la dette dans les hautes vallées dauphinoises (XVII ${ }^{\mathrm{e}}-\mathrm{XVIII}{ }^{\mathrm{e}}$ siècles) ", Annales. Histoire, Sciences Sociales. $49^{\mathrm{e}}$ année, $\mathrm{n}^{\circ} 6,1994$, p. $1375-1391$. 
FONTAINE Laurence, « Subir et utiliser les institutions : les réseaux de migrants dans l'Europe moderne », Revue du Nord, tome 76, n 307, 1994, p. 811-821.

POUJADE Patrice, Une société marchande. Le commerce et ses acteurs dans les Pyrénées modernes, Toulouse, Presses Universitaires du Mirail, 2008.

\section{NOTES}

1. F. Braudel, La Méditerranée et le monde méditerranéen à l'époque de Philippe II, p. 46.

2. D. Albera, P. Corti, « Migrations montagnardes dans l'espace méditerranéen. Esquisse d'une analyse comparative », p. 359-384.

3. Ibid., p. 360-362.

4. L. Fontaine, «Espaces, usages et dynamiques de la dette dans les hautes vallées dauphinoises (XVII ${ }^{\mathrm{e}}$-XVIII ${ }^{\mathrm{e}}$ siècles) », p. 1375-1391.

5. L. Fontaine, Histoire du colportage en Europe (XV-XIX siècles) ; «Subir et utiliser les institutions : les réseaux de migrants dans l'Europe moderne », p. 811-821; D. Albera, P. Corti, « Migrations montagnardes », p. 368-376.

6. L. Fontaine, Le voyage et la mémoire. Colporteurs de l'Oisans au XIXe siècle, p. 21-22.

7. Archives Départementales de Pyrénées-Atlantiques, 3 E 3577-3662 (P. de Harran), 3 E 4347-4408, (J. Reboul) et 3 E 4052-4068 (M. Jusan) ; ces registres étant en ligne sur le site des Archives, je me contenterai dorénavant de citer la cote du registre et le numéro de la vue.

8. 3 E $3631, n^{\circ} 261$ (8-III-1644).

9. 3 E $4395, n^{\circ} 596$ (25-II-1665).

10. 3 E 4400, nº 585 (6-IV-1666).

11. 3 E 3631, $\mathrm{n}^{\circ} 424$ (10-II-1644).

12. 3 E $3654, \mathrm{n}^{\circ} 137$ (20-V-1658) et 122 (3-VI-1658).

13. 3 E 4392, $\mathrm{n}^{\circ} 478$ (20-V-1664).

14. 3 E 4382, no 729 (15-IV-1661).

15. 3 E 9676, nº 296 (14-IX-1663).

16. 3 E 4382, no 729 (15-IV-1661).

17. 3 E 4401, nº 240 (17-III-1666).

18. 3 E 4374, $\mathrm{n}^{\circ} 1003$ (11-XII-1658).

19. 3 E 4061, no 1051 (19-III-1664).

20. Archives Départementales des Landes, (Arch. Dép. Landes dorénavant) 3 E 4/32, nº 78 (27-VI-1673).

21. L. Fontaine, Histoire du colportage en Europe, p. 69-94.

22. Arch. Dép. Landes, 3 E 4/20, $n^{\circ} 117,164,165,186$ et 187 (mai-octobre 1659).

23. 3 E 3638, $n^{\circ} 40$ (18-III-1650) et 3 E 4401, n 739 (6-VII-1666).

24. Arch. Dép. Landes, 3 E 4/20 186 (27-X-1559) ; il s'agit de Pierre Gertous, un Bernard Gertous, du même lieu est signalé en Pays de Foix, un peu plus tard (P. Poujade, Une société marchande..., p. 213). 
25. 3 E 3581, $\mathrm{n}^{\circ} 532$ et 535 (17-II-1617).

26. 3 E 4401, $n^{\circ} 240$ (17-III-1666).

27. 3 E 3641, nº 585 (12-IV-1649).

28. 3 E $4374, n^{\circ} 231$ (9-IX-1658).

29. 3 E 4374, nº 1003 (11-XII-1658), acte d'entrée en apprentissage du 17-III-1656.

30. 3 E $4374, \mathrm{n}^{\circ} 231$ (9-IX-1658).

31. 3 E 4401, nº 275 (27-VIII-1666).

32. 3 E 4052, nº 621 (10-IV-1656).

33. 3 E $4388, n^{\circ} 480$ (19-III-1663).

34. 3 E 4403, $n^{\circ}$ 307, (18-VIII-1671).

35. 3 E 4060, nº 1298 (27-IX-1663).

36. 3 E 4380, $n^{\circ} 561$ (13-XI-1660) et 3 E 4383, nº 483 (14-VIII-1661).

37. 3 E 4400, n 315, (16-VI-1666).

38. 3 E 4372, nº 229 (15-III-1657).

39. 3 E 4386, nº 576 (12-V-1662).

40. 3 E 4398, $n^{\circ} 901$ (2-X-1665).

41. 3 E 4062, $\mathrm{n}^{\circ} 857$ (9-VII-1666).

42. 3 E 4063, $\mathrm{n}^{\circ} 325$ (6-III-1666).

43. 3 E 4383, $\mathrm{n}^{\circ} 483$ (14-VIII-1661).

44. 3 E 9676, nº 296 (14-IX-1663).

45. 3 E 4060, nº 1297 (27-IX-1663).

46. 3 E 4395, $\mathrm{n}^{\circ} 1258$ (28-II-1665).

47. 3 E 4064, nº 409 (11-III-1666).

48. 3 E 4401, $\mathrm{n}^{\circ} 739$ (6-VII-1666).

49. 3 E 4063, nº 998 (14-VIII-1666).

50. 3 E 4395, $n^{\circ} 950$ (14-III-1665) et 4396, $n^{\circ} 440$ (18-V-1665).

51. Arch. Dép. Landes, 3 E 56/7 (26-V-1664).

52. Arch. Dép. Landes, 3 E 56/5 (19-VI-1662).

53. 3 E 4377, $\mathrm{n}^{\circ} 300$ (26-XI-1659).

54. L. Fontaine, Histoire du colportage en Europe..., p. 27.

55. Arch. Dép. Landes, 3 E 4/16, nº 35 (17-VII-1647).

56. 3 Е 3660, 323 (30-I-1660).

57. 3 E 3661, no 159 (30-IX-1664).

58. Laurent est mentionné pour la première fois en 1660 ( $3 \mathrm{E} 4378, \mathrm{n}^{\circ}$ 1, 29-II-1660).

59. L. Fontaine, Histoire du colportage en Europe..., p. 24.

60. 3 E 4401, nº 240 (17-III-1666).

61. 3 E 4399, nº 311 (27-I-1666).

62. 3 E $4400, n^{\circ} 572(6-I V-1666)$.

63. Arch. Dép. Landes, 3 E 56/5 (19-VI-1662).

64. Arch. Dép. Landes, 3 E 56/6 (20-IX-1663). 
65. 3 E 4399, n 311 (27-I-1666).

66. Arch. Dép. Landes, 3 E 56/7 (26-V-1664).

67. 3 E 4400, n 572 (6-IV-1666).

68. Arch. Dép. Landes, 3 E 56/7 (15-IX-1665).

69. 3 E 4390, n 750 (24-XI-1663).

70. 3 E 4393, nº 311 (26-IX-1664).

71. 3 E 3631, nº424 (6-II-1644).

72. 3 E 3651, no 198 (24-III-1656).

73. 3 E 4384, $\mathrm{n}^{\circ} 118$ (15-XII-1661).

74. 3 E 3661, nº 486 (23-IV-1664).

75. 3 E 4395, nº 218 (3-II-1665).

76. 3 E 4399, $\mathrm{n}^{\circ} 311$ (27-I-1666).

77. 3 E 4403, n 21 (15-VIII-1667).

78. Arch. Dép. Landes, 3 E 56/5 (19-VI-1662).

79. 3 E 4387, $n^{\circ} 123$ (20-XI-1662).

80. 3 E 4388, nº 480 (19-III-1663).

81. 3 E 4395, nº 225 (2-II-1665).

82. 3 E 4395, nº 225 (2-II-1665).

83. 3 E 4397, no 160 (12-IX-1665).

84. 3 E 4401, nº 240 (17-III-1666).

85. 3 E 4393,nº 923 (30-VII-1664).

86. 3 E 4382, $\mathrm{n}^{\circ} 729$ (15-IV-1661).

87. 3 E 4388, nº 560 (12-III-1663), 3 E 4395, nº 225 (2-II-1665).

88. 3 E 4393, nº 561 (2-IX-1664).

89. 3 E $4395, n^{\circ} 218$ (3-III-1665).

90. L. Fontaine, Histoire du colportage en Europe..., p. 28.

91. P. Poujade, Une société marchande..., p. 209-218.

92. 3 E 4052, nº 621 (10-IV-1656).

93. 3 E $4388, \mathrm{n}^{\circ} 560$ (12-III-1663).

94. 3 E 4379, $\mathrm{n}^{\circ} 122$ (18-VIII-1660).

95. 3 E 4383, nº 350 (23-VIII-1661).

96. 3 E 4396, nº 883 (17-IV-1665).

97. 3 E 4400, nº 803 (21-V-1666).

98. 3 E 4401, $\mathrm{n}^{\circ} 383$ (17-VIII-1666).

99. 3 E 4397, nº 239 (1-IX-1665).

100. 3 E 4381, no 739 (11-II-1661).

101. 3 E 4060, nº 952 (16-XI-1663).

102. 3 E 4386, nº 1185 (13-VIII-1662).

103. 3 E 4060, no 1208 (23-X-1663).

104. 3 E 4380, nº 561 (13-XI-1660). 
105. Exemples : Domingo Luis d'Almeida (3 E 4390, $\mathrm{n}^{\circ} 220,20-\mathrm{VIII}-1663$ ), Louis Alvarez (3 E 4391, nº 887, 19-III-1664), Antoine Rodz Pachecou (3 E 4398, nº 89, 24-XII-1665).

106. 3 E 4061, no 1051 (19-III-1664).

107. Arch. Dép. Landes, 3 E 4/20, nº 117, 164, 165, 186 et 187 (mai-octobre 1659).

108. Arch. Dép. Landes, 3 E 4/52, nº 26 (5-II-1670).

109. 3 E 4064, no 409 (11-III-1666).

110. 3 E 4406, $\mathrm{n}^{\circ} 598$ (6-IV-1666).

111. 3 E 4394, nº 461 (17-XI-1664).

112. 3 E 4060, nº 1524 (12-VII-1663).

113. 3 E 4391, nº 901 (18-III-1664).

114. 3 E 4383, nº 350 (23-VIII-1661).

115. 3 E 4347, no 193, 196, 258, 261, 266 (avril-juin 1632).

116. 3 E 4356, no 471 (14-V-1640).

117. 3 E 3631, no 424 (6-II-1644).

118. 3 E 3637, nº 551 (16-IX-1649).

119. 3 E 3651, no 198 (24-III-1656).

120. 3 E 3654, $\mathrm{n}^{\circ} 128$ (20-V-1658) et $\mathrm{n}^{\circ} 124$ (10-I-1662).

121. 3 E 4401, nº 240 (17-III-1666).

\section{RÉSUMÉS}

$\mathrm{Au}$ milieu du XVII ${ }^{\mathrm{e}}$ siècle, une importante colonie de marchands dauphinois, originaires pour la plupart de l'Oisans, est installée à Bayonne et dans sa région. Même si l'on peut recenser quelques colporteurs, la plupart sont des marchands en gros, regroupés en compagnies familiales et/ou associés avec d'autres Dauphinois, qui traitent avec des détaillants dans la région ou en Espagne, se cantonnant généralement à ces activités commerciales. La plupart ont gardé de solides relations avec le pays natal d'où viennent leurs épouses ainsi qu'avec Lyon où sont installés nombre de leurs compatriotes et d'où provient une bonne partie de leur marchandise.

\section{AUTEUR}

\section{FRANCIS BRUMONT}

Professeur des universités (retraité), Université de Toulouse - Jean-Jaurès 


\title{
Mobilité et ancrage local : les enjeux des confréries à Turin au XVIII ${ }^{\mathrm{e}}$ siècle
}

\author{
Nicoletta Rolla
}

1 Dans la première moitié du XVIII ${ }^{\mathrm{e}}$ siècle, Turin, capitale du royaume des États de Savoie, connut un important processus de transformation urbaine. L'ouverture de plusieurs chantiers dans la capitale et sur le territoire constituait une opportunité d'emploi et d'investissement pour les entrepreneurs, maîtres et travailleurs du bâtiment. Ils provenaient surtout de l'arc alpin, et notamment de la région des lacs de Lugano et de Côme, ainsi que des Alpes nord-occidentales autour de la ville de Biella, où ils retournaient périodiquement. L'histoire des chantiers du bâtiment en Piémont est strictement liée à l'histoire des migrations alpines, saisonnières ou de longue durée. Centre de négociation des commandes publiques, Turin était l'épicentre d'un mouvement migratoire plus ample qui touchait les différents sites piémontais. Cet article porte sur cette circulation et sur les dynamiques et les instruments qui l'ont rendue possible.

2 L'historiographie désormais vaste sur les migrations alpines a souvent insisté sur l'importance des chaînes migratoires et de la solidarité de groupe. Les études sur les familles d'artistes et leurs communautés, par exemple, ont contribué à montrer le rôle des liens familiaux, capables d'orienter et de déterminer la réussite des expériences migratoires ${ }^{1}$. La reproduction du voisinage, de ses logiques et de ses liens sociaux, dans les pays d'arrivée a souvent été présentée comme la clé du succès des parcours d'installation en ville de ces immigrés ${ }^{2}$. Dans les villes italiennes, l'existence de confréries réunissant leurs membres sur la base de l'origine géographique a contribué à amplifier l'importance de la solidarité de groupe dans les parcours d'insertion urbaine ${ }^{3}$.

Le cas turinois semble répéter un modèle d'immigration amplement étudié par l'historiographie, basé sur l'exploitation des chaînes migratoires et du réseau familial. À Turin comme ailleurs, certaines familles d'artistes avaient consolidé leur présence pendant plusieurs générations. Les confréries garantissaient à une population affectée par une forte mobilité, un ancrage local, selon une dynamique dominée par la force de la solidarité du groupe d'origine. Les mêmes acteurs accentuaient, dans leurs discours, l'importance de l'appartenance à une même « nation ${ }^{4}$ et se représentaient eux-mêmes 
comme groupes cohérents et solidaires, réunis autour des confréries « nationales », qui se distinguaient des autres groupes de migrants, parfois de façon conflictuelle.

4 Mais dans les mêmes années, de fortes tensions perturbaient la vie des confréries, ce qui pose plusieurs questions sur la force de leur cohésion. Cet article vise à comprendre les dynamiques internes de ces institutions au-delà des représentations données par leurs membres et d'une tradition historiographique qui les a considérées comme l'expression d'une "solidarité des origines $»^{5}$. La cohésion du groupe, qui a été souvent indiquée comme un facteur crucial du succès des expériences migratoires, est ici assumée en tant qu'hypothèse à vérifier. En effet, comme cela a été vérifié dans d'autres contextes, les migrants provenant d'un même village ne connaissent pas nécessairement un sentiment d'identité commune ${ }^{6}$ qui se consolide seulement après plusieurs générations ${ }^{7}$.

5 Après avoir reconstruit les trajectoires de la circulation des travailleurs et des entrepreneurs du bâtiment des villages alpins vers les chantiers piémontais via Turin, cet article porte sur le rôle des liens communautaires dans les parcours professionnels de ces travailleurs spécialisés. L'analyse des activités des confréries permet de mieux contextualiser l'efficacité de la solidarité de groupe et de montrer le processus complexe et conflictuel de construction de l'appartenance à la "nation »- suisse, milanaise, biellese -, et de définition des communautés des immigrés. Cette analyse se focalise sur les chantiers publics ouverts à Turin et dans le Piémont entre 1713 et 1742, quand les souverains investirent massivement dans les constructions en laissant une documentation abondante. Pour comprendre le contexte dans lequel agirent les entrepreneurs, les maîtres et les travailleurs du bâtiment, il faut commencer par décrire cette période de croissance exceptionnelle.

\section{La ville s'agrandit}

Durant les années de paix entre la signature du Traité d'Utrecht (1713) et l'entrée du Royaume de Sardaigne dans la Guerre de Succession d'Autriche (1742), Turin connut un moment de grand développement architectural et urbanistique ${ }^{8}$. La fin de la Guerre de Succession d'Espagne qui avait touché directement le territoire piémontais et la ville de Turin, ouvrit une nouvelle phase de croissance démographique à laquelle contribua largement l'arrivée d'immigrés du territoire piémontais et des États voisins ${ }^{9}$. La pression démographique et la perspective d'une fructueuse spéculation immobilière donnèrent l'élan aux travaux du troisième agrandissement de la ville, avec la réalisation, à partir de 1719, de dix-huit nouveaux îlots dans le secteur occidental. Le troisième agrandissement de Turin incluait aussi les nouveaux quartiers militaires qui devaient compléter le système défensif de la ville. Enfin, l'acquisition du titre royal par les Savoie relança la réalisation d'un programme à la fois urbanistique et politique qui devait élever Turin au rang de capitale royale. La tâche fut confiée au Sicilien Filippo Juvarra, "Premier Architecte Civil» à partir de $1714^{10}$. On lui doit, entre autres, les projets du Palais Madama, des églises de saint Philippe Neri et du Carmine, le projet de requalification et d'alignement de la rue Dora Grossa dans les quartiers médiévaux ${ }^{11}$ à Turin et, aux environs de la capitale, l'achèvement de la « couronne de délices » - les résidences royales de Mirafiori, Stupinigi, Rivoli et Venaria - et le projet de la Basilique de Superga. 
7 Les efforts financiers de la couronne concernaient aussi le territoire, et notamment les chantiers militaires du Piémont. La période de paix donna l'occasion de terminer la construction et de réparer les bâtiments militaires endommagés pendant les années de guerre : au lendemain de la paix d'Utrecht de nombreux chantiers furent ouverts dans les forteresses du Piémont, notamment celles d'Exiles, de la Brunetta, de Fenestrelle et de Demonte.

8 La gestion des commandes pour la construction des bâtiments civils et militaires royaux était confiée au bureau de l'Azienda generale fabbriche e fortificazioni, installé à Turin, qui assignait les travaux et souscrivait les contrats avec les entreprises. Les entreprises adjudicataires étaient choisies après la publication des avis, les tiletti, à Turin et dans toutes les localités concernées par les chantiers. L'analyse des contrats publics permet de connaître le profil des entrepreneurs impliqués dans ces commandes publiques. Parmi les 465 maîtres dont nous connaissons la provenance, seuls $15 \%$ se déclarèrent turinois. Les autres étaient originaires d'une dizaine de communautés de la région de Biella (25\%), de l'État de Milan (20\%), des vallées piémontaises - Val Sesia, Val de Suse, Vallée de Lanzo - (11 \%) et du Lac de Lugano (8\%). On constate la tendance des entrepreneurs à fixer leur résidence dans la capitale. Même quand les travaux concernaient des chantiers ouverts dans le Piémont, $93 \%$ des entrepreneurs obtenant des commandes résidaient à Turin. L'importance d'habiter à Turin de façon stable s'explique par la proximité avec le centre du pouvoir, mais pas seulement. Nous allons maintenant essayer de comprendre quels étaient les avantages à résider dans la capitale.

\section{L'importance d'habiter Turin}

9 Pour beaucoup d'entrepreneurs, Turin était la première étape d'un voyage qui les conduisait sur les différents chantiers du Piémont. Ceux qui avaient acquis une certaine spécialisation dans les bâtiments militaires, se déplaçaient dans les forteresses de Demonte, Brunetta, Exilles et Fenestrelle dans les Préalpes occidentales, ou d'Alessandria, Valenza, Casale dans la plaine du Pô selon les opportunités de travail et le calendrier des chantiers. Parfois, ils arrivaient à gérer plusieurs sites simultanément, malgré la distance qui les séparait.

10 Cette circulation s'appuyait avant tout sur la collaboration d'autres entrepreneurs et sur la capacité à mobiliser des alliances professionnelles solides. L'analyse des contrats publics permet de reconstruire les réseaux professionnels des contremaîtres et des entrepreneurs afin d'évaluer l'ampleur de leur rayon d'action dans le Piémont ${ }^{12}$. En souscrivant un contrat avec l'Azienda generale, les entrepreneurs se déclaraient, dans le même temps, débiteurs du fisc pour l'avance reçue sur le coût total des travaux et pour les éventuels retards ou dommages causés. Chaque contrat était l'occasion de constituer une alliance professionnelle entre entrepreneurs, qui s'associaient afin de partager les coûts et les risques de l'entreprise, et leurs garants qui fournissaient la couverture financière. En analysant la composition des consortiums adjudicataires, on constate une tendance générale à construire des alliances professionnelles qui dépassent les limites de la communauté des compatriotes : $70 \%$ des sociétés étaient en fait constituées de membres de différentes origines géographiques. Ces données permettent de relativiser une interprétation historiographique qui a insisté sur l'importance des liens professionnels à l'intérieur de la communauté d'origine. 
11 Ces réseaux professionnels dessinaient le rayon d'action des entrepreneurs dans le Piémont. Le cas des entrepreneurs Carlo Andrea et Agostino Menafoglio, originaires de Marzio dans l'État de Milan, est exemplaire. Grâce à leurs compétences et à leur réseau professionnel, ils arrivèrent à imposer leur présence et à obtenir un nombre significatif de commandes publiques. Spécialisé dans les démolitions et les travaux de maçonnerie dans les chantiers militaires, Carlo Andrea travailla, entre 1712 et 1716, pour le compte de l'Azienda generale sur dix-sept chantiers dispersés dans tout le Piémont, auxquels s'ajoutaient sept commandes gérées par son oncle, Agostino. En 1711-12, ils travaillaient en même temps aux forteresses de la Brunetta, d'Exilles, de Demonte, de Casale, de Mortara, de Verrua, d'Asti, d'Ivrea et de Turin, considérablement éloignés les uns des autres. Les dix-sept sociétés dont Carlo Andrea faisait partie, impliquaient 35 entrepreneurs et contremaîtres, de différentes origines et résidant à Turin. L'appui financier du négociant et prêteur à intérêt milanais Giuseppe Maria Galimberti, résidant à Turin, fut sûrement crucial pour le succès de l'entreprise Menafoglio. Il se présenta comme garant pour bien dix contrats signés par les Menafoglio. En plus, Galimberti était lié aux représentants de la plus haute noblesse piémontaise, comme Hercule Roero de Cortanze, gouverneur et vice-roi du Piémont, qui figure parmi ses débiteurs ${ }^{13}$.

L'élargissement du réseau de relations en dehors du groupe de Milanais résidant à Turin se produit très tôt, à l'occasion du second contrat signé par les Menafoglio en janvier 1712, quand ils obtinrent la commande pour différents travaux dans le fort d'Exilles. À cette occasion débute l'association avec la famille biellese des Pistone, résidente à Turin, qui apporte en dot un précieux réseau de relation avec les autres entrepreneurs du Biellese, très actifs sur les chantiers piémontais. Parmi ces derniers, Gio Henrico Zo, maitre forgeron et prêteur à intérêt originaire de Biella, qui entre 1713 et 1720 s'adjugea quinze contrats publics à Turin et dans le Piémont.

Leur succès était fondé sur la capacité à construire un réseau professionnel large, qui dépassait les limites de la communauté d'origine. La constitution de consortiums comportait différents avantages, de la division des risques et des coûts d'entreprise à la capacité de suivre différents chantiers en même temps, en passant par la possibilité d'élargir ses propres alliances professionnelles et, de cette façon, l'éventail des opportunités de travail.

Dans ce processus, Turin jouait un rôle central. Entrepreneurs et contremaîtres avaient des occasions de se rencontrer sur les chantiers piémontais, mais la majeure partie d'entre eux résidait dans la capitale. Dans les parcours de ces entrepreneurs, Turin était devenu une étape incontournable en tant que lieu de sociabilité, centre financier et siège du pouvoir politique. Elle était le lieu de négociation des commandes publiques de tout le Piémont et le centre des affaires des entrepreneurs et des contremaîtres actifs dans les chantiers piémontais. C'est à Turin que se joue la partie pour s'adjuger les commandes publiques, pour construire un réseau professionnel et obtenir les garanties nécessaires à les réaliser. Et c'est à Turin que ces maitres et entrepreneurs créent leurs organisations professionnelles pour défendre leurs intérêts.

\section{Les associations des métiers du bâtiment}

15 À Turin, le phénomène corporatif connaît une chronologie très différente de celle des autres villes italiennes et européennes ${ }^{14}$. Malgré les tentatives des souverains pour 
encourager leur institution, les corporations restèrent longtemps absentes du panorama politique et économique de la ville. Les premières associations de métier naquirent dans les années 1730, quand ailleurs elles commençaient à perdre vigueur. Dans ce contexte, les professions du bâtiment furent pionnières dans la création d'organisations de métier, sous forme notamment de confréries.

16 La compagnie de sainte Anne des architectes et des maîtres maçons fut instituée dans les années 1620. Réservée aux Luganais et aux Milanais, cette confrérie réunissait ses membres selon des critères à la fois professionnels et « nationale ». L'institution de la compagnie de sainte Anne paraît strictement liée à la défense des intérêts des Suisses résidant dans les territoires des ducs de Savoie. En vertu d'une alliance militaire signée en 1512 entre le duc Charles III de Savoie et les cantons suisses - limitée ensuite aux cantons catholiques - les Luganais jouissaient d'une série de privilèges et d'exemptions fiscales ${ }^{15}$. Les privilèges et les exemptions accordés aux Suisses furent renouvelés, à la demande des intéressés, tout au long du xviII siècle et restèrent valables au moins jusqu'en 1739. Dans le processus de négociation avec les autorités piémontaises, la compagnie de sainte Anne se présenta toujours en tant que contrepartie légitime à représenter les intérêts des Suisses résidant dans les États des ducs de Savoie, abstraction faite de leur profession ${ }^{16}$. Pour jouir des privilèges les Suisses résidant en Piémont étaient obligés d'obtenir des syndics de la confrérie une attestation de leur origine suisse ${ }^{17}$, en fournissant des preuves et des témoins ${ }^{18}$.

17 La dévotion à sainte Anne était partagée par une autre confrérie turinoise, celle qui réunissait les maîtres charpentiers originaires de Graglia, Muzzano e Pollone, trois villages proches de la ville de Biella, dans les Alpes piémontaises. Les premières informations sur son existence n'apparaissent qu'une centaine d'années après l'institution de la compagnie des maîtres maçons luganais et milanais. À partir de 1710 et pour les vingt années suivantes, les registres des congrégations de la confrérie nous informent exclusivement sur son activité dévotionnelle et sur la collecte de fonds pour les célébrations de la fête de sainte Anne ${ }^{19}$. Dans la même période, les mandats de paiement en faveur des maîtres tombés en disgrâce témoignent de l'activité d'assistance de la confrérie ${ }^{20}$. En 1733, la confrérie assuma le titre et les fonctions de corporation des maîtres charpentiers, en perdant le caractère " national ».

18 Dans les dernières décennies, les études sur les confréries ont montré l'éventail de fonctions remplies par ces institutions hétérogènes, au-delà des aspects religieux. À côté de la dévotion pour les saints protecteurs, les confréries fournissaient assistance à leurs membres et à leurs familles, représentaient des espaces de sociabilité autonomes, donnaient prestige et pouvoir à leurs administrateurs et - quand il s'agissait de confréries nationales - pourvoyaient à la protection et à la médiation linguistique et culturelle des nouveaux immigrés ${ }^{21}$. La reconstruction des activités des confréries turinoises est utile pour en comprendre le rôle crucial dans les stratégies des entrepreneurs, maîtres et travailleurs du bâtiment.

\section{Sacré et profane}

19 À Turin, le bilan de deux confréries dédiées à sainte Anne montre leurs principaux terrains d'intervention. Une partie importante des efforts financiers était dévolue au culte de la sainte protectrice, à la construction et l'entretien de la chapelle, et aux aides économiques aux maîtres en difficulté et à leurs familles (généralement de 5 lires) ${ }^{22}$. 
Parmi les noms des bénéficiaires, certains se répètent, signal de l'existence de rapports de clientèle entre bienfaiteurs et assistés, fréquents dans les institutions d'assistance de la ville ${ }^{23}$. Les confréries représentaient une ressource importante dans les moments d'inactivité, soutenant financièrement les travailleurs entre deux emplois.

L'assistance aux maîtres maçons dans les moments d'inactivité se transformait souvent en soutien à leur retour au pays, sous la forme de versement d'une petite contribution aux frais du voyage ${ }^{24}$. Cette demande arrivait à la compagnie des maîtres maçons luganais et milanais de la part de qui par « malchance, tombé d'une fabrique à Turin »" pour " infirmité vacillante » ${ }^{26}$, ou pour être " en état de ne pas pouvoir gagner sa vie ni avoir quelqu'un pour le secourir $\|^{27}$, se trouvant "en état très misérable dû à une longue maladie ${ }^{28}$, demandait à la compagnie une aide économique pour pouvoir se « retirer au mieux qu'il puisse vers la patrie où il a quelques parents $»^{29}$. À travers son activité charitable, les confréries exerçaient un contrôle social qui permettait de connaître la situation économique et les conditions de santé de ses membres : quand les syndics ou les conseillers de la compagnie n'étaient pas «bien informés $»^{30}$ de la condition de leurs compatriotes, des témoins étaient appelés pour confirmer l'état nécessiteux des requérants. Ce modèle d'assistance favorisait aussi les entrepreneurs et les contremaîtres qui, grâce à l'activité des confréries, dont ils présidaient les conseils, pouvaient maintenir un équilibre social au sein d'une main-d'œuvre qu'il leur fallait souple et ponctuellement disponible dans un contexte de forte variabilité de l'offre d'emploi.

21 L'activité des confréries ne se limitait pas à la dévotion et à l'assistance. Alimentées par les donations et les aumônes des confrères, leurs caisses étaient souvent dotées d'un patrimoine important qui permettait certaines formes d'investissement. La compagnie des maîtres maçons, par exemple, fit construire un bâtiment, connu sous le nom de Casa di Sant'Anna (maison de sainte Anne), et acheta deux appartements qui généraient des revenus locatif ${ }^{31}$. Le patrimoine de la compagnie était aussi employé dans l'activité de prêts à intérêt, concédés principalement, mais non exclusivement aux confrères et destinés à des investissements lucratifs, y compris dans la construction.

Les confréries étaient donc actives dans des domaines cruciaux, comme l'assistance et le crédit, généralement peu accessibles aux immigrés. À Turin, le système d'assistance, qui venait d'être reformé en 1717, garantissait l'accès aux hôpitaux de la ville seulement aux Turinois et aux résidents depuis au moins trois ans. En outre, parmi les pauvres qui remplissaient les critères d'admission à l'hôpital, une hiérarchie se dessinait favorisant les "pauvres honteux $\|^{32}$ et ceux qui étaient capables d'activer un circuit de protection garantissant un accès préférentiel ${ }^{33}$. L'insertion dans un réseau de relations locales était indispensable aussi pour obtenir le crédit nécessaire pour participer à l'économie de la ville. Les études sur les marchés urbains d'Ancien Régime ont montré les dynamiques d'accès au crédit, souvent basées sur la réputation et sur les rapports de confiance ${ }^{34}$.

23 Les confréries organisaient donc leur activité autour d'exigences spécifiques de leurs membres, liées à des moments particuliers de leur parcours, marqués par la maladie, l'inactivité, les exigences financières et le retour au pays d'origine. En ce sens, les confréries semblaient l'expression de groupes qui s'organisaient autour de besoins ponctuels et circonstanciels, liés à la mobilité. La défense de leurs intérêts et privilèges, l'accès à l'assistance et aux circuits du crédit, les investissements immobiliers, passaient souvent par les confréries. Elles garantissaient un ancrage local à des 
individus concernés par une forte mobilité. À travers leur participation aux confréries, les acteurs définissaient et affirmaient leur appartenance à la ville. Mais pour se dire membre d'une confrérie et jouir de cet instrument d'enracinement, l'origine géographique n'était pas un critère suffisant. Des dynamiques plus complexes concourraient à définir l'appartenance à une «nation ». Les observer de plus près nous permet d'évaluer et de mieux contextualiser l'importance des communautés d'origine dans les parcours de ces migrants.

\section{La « nation »}

Concrètement, dans le récit des protagonistes, la confrérie coïncidait avec la congrégation de ses membres : elle s'identifiait par l'action de se rassembler, de se réunir autour d'un lieu, l'autel, une fois par an. La congrégation définissait les limites de la communauté - composée de ceux qui participaient à la cérémonie - et sa hiérarchie, à travers l'élection du conseil et un rituel organisé autour de la distribution des repas et de la carità (une sorte de fougasse) de la part du priore aux participants. En outre, à travers leur contribution à la collecte des aumônes, les participants légitimaient leur appartenance à la communauté. Ce moment révélait au reste de la congrégation la répartition des charges au sein de la confrérie qui, au-delà de la célébration de la fête, n'avait pas d'autre occasion de se réunir.

La valeur « dynamique, fondatrice et créative » de la cérémonie, pendant laquelle « des capacités juridiques étaient affirmées [...] et attribuées à des protagonistes spécifiques » ${ }^{35}$ n'était pas ignorée par les acteurs impliqués, ce qui explique les conflits qui éclataient à ces occasions. En 1740, par exemple, deux maîtres maçons, Giovanni Antonio Pezzi et Galeazzo Pagano, originaires de Valsolda (État de Milan), déclarèrent leur intention de célébrer la fête de sainte Anne dans une autre église, suscitant la réaction du conseil qui interdit la cérémonie ${ }^{36}$, car cette initiative aurait causé un grave préjudice à la confrérie et ôté la dévotion à sa chapelle ${ }^{37}$. Les raisons concrètes de l'opposition du conseil apparurent au cours de la controverse soulevée devant le Tribunal du Sénat quand le procureur de la confrérie rappela que le jour de la fête «l'université pour satisfaire ses nécessités fait sortir le bacile et les bussole pour la collecte des aumônes ${ }^{38}$ : au cœur de la controverse, se trouvaient la collecte et la gestion des ressources destinées à financer les activités de la confrérie, instruments de gestion et soutien de la mobilité professionnelle et géographique des membres ${ }^{39}$.

Giovanni Antonio Pezzi et Galeazzo Pagano, les protagonistes de cet épisode, étaient des entrepreneurs très connus et actifs sur les chantiers piémontais. Leurs actes d'insubordination renvoient à une conflictualité aux sommets de la hiérarchie de la compagnie pour le contrôle de ses ressources financières. Au sein des confréries émergent d'autres conflits, verticaux, qui opposaient maîtres et salariés. L'évolution que subit la célébration de la fête de sainte Anne de la confrérie des maîtres-maçons luganais et milanais est significative. Jusqu'à la fin des années 1660, le rituel prévoyait la distribution de la carità et le repas pour toute la collectivité, bien que le repas des officiels et des contremaîtres et celui des garçons représente des moments distincts de la fête. Le repas offert aux garçons - terme qui à Turin définissait les travailleurs salariés non qualifiés - véhiculait la représentation des rapports hiérarchiques de subordination des salariés aux maîtres. Dans les rapports de travail, le pain, du reste, constituait une part du salaire dû aux travailleurs, parfois l'unique compensation 
versée durant la période d'engagement ${ }^{40}$. En 1667, le repas offert aux garçons fut supprimé «pour lever de nombreux abus » ${ }^{41}$ évoquant l'existence de tensions dans la confrérie.

Les confréries n'étaient ainsi pas nécessairement l'expression d'une communauté unie et d'une «solidarité des origines » spontanée. L'existence de ressources financières qui permettaient aux syndics et conseillers d'intervenir dans des domaines stratégiques pour la vie des migrants, alimentait la rivalité, ce qui explique les tensions qui traversaient les confréries. La cohésion interne de ces communautés était donc continuellement remise en question et l'appartenance à la "nation" n'était pas spontanée mais demandait la participation active à la vie de la confrérie et l'acceptation de ses hiérarchies internes.

La circulation des artistes des Lacs en Piémont avait son épicentre dans la capitale. La quasi-totalité des entrepreneurs, bien qu'actifs sur les chantiers éparpillés dans tout le Piémont, résidait à Turin, centre financier et politique de l'État. La proximité de l' Azienda generale représentait sûrement une condition favorable, mais l'importance de résider dans la capitale s'explique aussi par la nécessité de repérer les ressources financières et les associés essentiels pour gérer les commandes publiques. C'est donc à Turin que les entrepreneurs se dotèrent des instruments pour défendre leurs intérêts, à travers, par exemple, des organisations formelles, telles que les confréries qui leur permettaient de développer leurs activités, de consolider leur prestige et de contrôler la mobilité de la main-d'œuvre. Instituées pour fournir assistance et médiation culturelle aux nouveaux arrivés, les confréries élargirent leur champ d'action dans des domaines cruciaux. L'activité de crédit à intérêt fournissait aux entrepreneurs les ressources financières nécessaires à l'accomplissement de leur contrat. L'activité d'assistance représentait une ressource pour les travailleurs dans les moments d'inactivité liés au rythme des chantiers, aux accidents et aux maladies. Dans le même temps, elle fournissait aux entrepreneurs - qui se trouvaient à la tête des confréries un formidable instrument de contrôle social sur une main-d'œuvre qu'il lui fallait toujours disponible et souple, dans un contexte de forte variabilité de l'offre d'emploi.

L'historiographie a généralement vu dans ces institutions l'expression de la défense des intérêts des groupes qui se définissaient à partir d'une origine géographique commune. Sur cette cohésion, mûrie tout au long des chaînes migratoires et à travers le réseau familial, se fondait le succès surprenant des artistes des Lacs. Mais l'observation du contexte piémontais montre l'importance d'élargir les alliances professionnelles audelà des limites des communautés d'origine et de construire un réseau social capable de déterminer le succès. Dans le même temps, l'observation des dynamiques internes aux confréries montre une réalité complexe. Autour des confréries se définissait une communauté qui ne coïncidait pas forcément avec celle des compatriotes. Loin d'être l'expression de la cohésion des communautés qui reproduisaient les solidarités et les rapports de voisinage mûris dans les pays d'origine, les confréries et leurs autels étaient des lieux fortement contestés où une nouvelle communauté et de nouveaux équilibres sociaux se définissaient. On assiste à un processus de construction ou de reconfiguration - parfois conflictuelle - de l'appartenance aux « nations» qui donnait 
accès aux ressources locales (marchés du travail, privilèges, assistance, etc.) et qui permettait la construction de liens stables avec la ville.

\section{BIBLIOGRAPHIE}

AGo Renata, Economia barocca. Mercato e istituzioni nella Roma del Seicento, Roma, Donzelli, 1998.

AGULHON Maurice, La sociabilité méridionale. Confréries et Associations dans la vie collective en Provence orientale à la fin du XVIII siècle, t. 1, Aix-en-Provence, Publications des Annales de la faculté des lettres, 1966.

BALANI Donatella, « Sviluppo demografico e trasformazioni sociali nel Settecento », dans RICUPERATI Giuseppe (dir.), Storia di Torino, vol. V, Dalla città razionale alla crisi dello Stato d'Antico Regime (1730-1798), Torino, Einaudi, 2002, p. 625-688.

BIANCHI Stefania, « La patria altrove. Quartieri, confraternite e corporazioni per salvaguardare l'identità (Ticino e città d'Italia, secoli XVI-XVIII) », dans STUDER Brigitte, ARNI Caroline, LEIMGRUBER Walter, MATHIEU Jon, TISSOT Laurent, Die Schweiz anderswo - La Suisse ailleurs, Schweizerisches Jahrbuch für Wirtschafts - und Sozialgeschichte/Annuaire suisse d'histoire économique et sociale, 29 (2015), p. 67-82.

BLACK Christopher et GRAVESTOCK Pamela (dir.), Early Modern Confraternities in Europe and Americas. International and Interdisciplinary Perspectives, Aldershot-Burlingot, Ashgate, 2006.

CANEPARI Eleonora, « Mestiere e spazio urbano nella costruzione dei legami sociali degli immigrati a Roma in età moderna », dans ARRU Angiolina, RAMELLA Franco (dir.), L'Italia delle migrazioni interne. Donne, uomini e mobilità in età moderna e contemporanea, Roma, Donzelli, 2003, p. 33-76.

CAVALlo Sandra, « Assistenza femminile e tutela dell'onore nella Torino del XVIII secolo », dans Annali della Fondazione Luigi Einaudi, XIV (1980), p. 127-155.

CAVALLO Sandra, « Strategie politiche e familiari intorno al baliatico. Il monopolio dei bambini abbandonati nel Canavese tra Sei e Settecento », dans Quaderni Storici, 53 (1983), p. 391-420.

CAVALLO Sandra, « Charity, power and patronage in eighteenth century in italian hospital: the case of Turin ", dans GRANSHAW Lindsay, PORTER Roy (dir.), The hospital in history, London, Routledge, 1989, p. 93-122.

CERUTTI Simona, La Ville et les métiers : naissance d'un langage corporatif. Turin, XVII ${ }^{e}$-XVIII ${ }^{e}$ siècle, Paris, Éditions de l'École des hautes études en sciences sociales, 1990.

CERUTTI Simona, « Travail, mobilité et légitimité. Suppliques au roi dans une société d'Ancien Régime (Turin, XVIII ${ }^{\mathrm{e}}$ siècle) », Annales HSS, 3, 2010, p. 571-611.

CALABI Daniela et LANARo Paola (dir.), La città italiana e i luoghi degli stranieri (XIV-XVIII secolo), RomaBari, Laterza, 1998.

CASTIGLIONI Pietro, Relazione generale con una introduzione storica sopra i censimenti delle popolazioni italiane dai tempi antichi sino all'anno 1860, Torino, Stamperia Reale, 1862.

COMOLI MANDRACCI Vera, Torino, Roma-Bari, Laterza, 1983. 
FONTAINE Laurence, « Solidarités familiales et logiques migratoires en pays de montagne à l'époque moderne », Annales ESC, 6, 1990, p. 1433-1450.

FONTAINE Laurence, « Migration and work in the Alps (17th-18th centuries). Family strategies, kinship and clientelism », History of the Family, vol. 3, issue 3, 1998, p. 351-369.

GARRIOCH David, MICHAEL Sonenscher, « Compagnonnages, Confraternities and Associations of Journeymen in Eighteenth Century Paris », European History Quarterly, 16 (1986), p. 25-45.

GARRIOCH David, «Les confréries religieuses, espace d'autonomie laïque à Paris au XVIII e siècle », dans CROQ Laurence, GARRIOCH David (dir.), La religion vécue. Les laïcs dans l'Europe moderne, Rennes, Presses universitaires de Rennes, 2013, p. 143-163.

MARTINI Manuela, Bâtiment en famille. Migrations et petite entreprise en banlieue parisienne au $X^{e}$ siècle, Paris, CNRS éditions, 2016.

MULDREW Craig, The Economy of Obligation. Culture of Credit and Social Relations in Early Modern England, New York, Saint Martin's press, Basingstoke, MacMillan press, 1998.

LEVI Giovanni, Centro e periferia Centro e periferia di uno stato assoluto : tre saggi su Piemonte e Liguria in età moderna, Torino, Rosenberg \& Sellier, 1985.

LORENZETTI Luigi, « Razionalità, cooperazione, conflitti : gli emigranti delle Alpi italiane (1600-1850) », dans ARRU Angiolina, CAGLIOTTI Daniela Luigia, RAMELLA Franco (dir.), Donne e uomini migranti. Storie e geografie tra breve e lunga distanza, Roma, Donzelli, 2008, p. 181-209.

LORENZETTI Luigi, HEAD-KÖNIG Anne-Lise (dir.), « Les migrations de retour », Histoire des Alpes, 14, 2009.

NELLI Humbert S., From Immigrants to Ethnics: the Italian Americans, Oxford-New York, Oxford University Press, 1983.

OLMo Carlo, « Une architecture imparfaite. La reconstruction de la via Dora Grossa à Turin (1736-1776) », Annales. Économies, Sociétés, Civilisations, 46, 3, 1991, p. 651-666.

ORELLI Chiara, « I migranti nelle città d'Italia » dans CESCHI Raffaello (dir.), Storia della Svizzera italiana dal Cinquecento al Settecento, Bellinzona, Casagrande, 2000, p. 257-288.

PANAYI Panikos, German Immigrants in Britain during the 19th century, 1815-1914, Oxford, Berg Publishers, 1995.

RICCI Giovanni, « Naissance du pauvre honteux : entre l'histoire des idées et l'histoire sociale », Annales. Économies, Sociétés, Civilisations, 38, 1, 1983. p. 158-177.

RICCI Giovanni, « Povertà, vergogna e povertà vergognosa », Società e Storia, 5 (1979), p. 305-337.

RICCI Giovanni, Povertà, vergogna, superbia : $i$ declassati fra medioevo e età moderna, Bologna, Mulino, 1996.

ROCCIA Rosanna, «Testimonianze di una solidarietà d'origine », dans COMOLI MANDRACCI Vera (éd.), Luganesium artistarum universitas. L'archivio e i luoghi della compagnia di Sant'Anna tra Lugano $e$ Torino, Lugano, Casagrande, 1992, p. 97-123.

Rolla Nicoletta, La piazza e il palazzo. I mercati e il vicariato di Torino nel Settecento, Pisa, Plus edizioni, 2010.

ROLLA Nicoletta, « Credito al consumo e giustizia a Torino nella prima metà del Settecento ", Società e Storia, 136, 2012, p. 299-329. 
SCHNYDER Marco, « “Partire a guadagnarsi il pane”. I 'Ticinesi’ nei mestieri di Torino a fine Settecento », Arte e Storia, 52, 2011, p. 336-341.

SEVERIN Dante, Per la storia della emigrazione artistica della Svizzera italiana. Privilegi Sabaudi agli architetti e mastri da muro luganesi (XVII sec.), Bellinzona, Arturo Gabironi, 1933.

STUDER Brigitte, ARNI Caroline, LEIMGRUBER Walter, MATHIEU Jon, TISSOT Laurent, « Die Schweiz anderswo - La Suisse ailleurs », dans « Schweizerisches Jahrbuch für Wirtschafts- und Sozialgeschichte - Annuaire suisse d'histoire économique et sociale », band 29, 2015.

TORRE Angelo, Il consumo di devozioni. Religione e comunità nelle campagne di Ancien Régime, Venezia, Marsilio, 1995.

TORRE Angelo, « Il bosco della Rama : rituali e forme del possesso nel Monferrato casalese », dans AMBROSOLI Mauro, BIANCO Furio, Comunità e questioni di confini in Italia settentrionale (XVI-XIX sec.), Milano, Angeli, 2007, p. 60-71.

TORRE Angelo, Luoghi. La produzione di località in età moderna e contemporanea, Roma, Donzelli, 2011.

\section{NOTES}

1. L. Fontaine, "Solidarités familiales et logiques migratoires en pays de montagne à l'époque moderne ", p.1433-1450; L. Fontaine, "Migration and work in the Alps (17th-18th Centuries). Family strategies, kinship and clientelism», p.351-369. M. Martini, Bâtiment en famille. Migrations et petite entreprise en banlieue parisienne au $\mathrm{XX}^{e}$ siècle.

2. D. Calabi, P. Lanaro, La città italiana e $i$ luoghi degli stranieri (XIV-XVIII secolo); M. Schnyder, " "Partire a guadagnarsi il pane”. I "Ticinesi” nei mestieri di Torino a fine Settecento », p. 336-341.

3. C. Orelli, I migranti nelle città d'Italia.

4. «Nazione». Les citations traduites dans le texte apparaissent en intégralité, en version originale, dans les notes.

5. L'expression est de R. Roccia, Testimonianze di una solidarietà d'origine, p. 97-123.

6. P. Panayi, German Immigrants in Britain during the 19th Century.

7. H.S. Nelli, From Immigrants to Ethnics: the Italian Americans.

8. V. Comoli Mandracci, Torino.

9. G. Levi, Centro e periferia, p. 39. Selon Pietro Castiglioni, la population de Turin passa de 49175 habitants en 1720 à 58832 en 1740, dans P. Castiglioni, Relazione generale con una introduzione storica sopra $i$ censimenti delle popolazioni italiane dai tempi antichi sino all'anno 1860, p. 240; Cf. aussi D. Balani, Sviluppo demografico e trasformazioni sociali nel Settecento, p. 625-688.

10. «Primo Architetto Civile ", Archivio di Stato di Torino (dorénavant ASTo), Camera dei Conti, Piemonte, art. 689, Patenti Controllo Finanze, (1713-1717), m. 214, f. 88.

11. C. Olmo, Une architecture imparfaite. La reconstruction de la via Dora Grossa à Turin (1736-1776), p. 651-666. 
12. ASTo, revisiero della guerra, azienda fabbriche e fortificazioni, contratti, passim. Dans la présentation des résultats, je tiens à remercier Pascal Cristofoli du Centre de recherches historiques de l'EHESS de Paris pour son aide précieuse.

13. ASTo, S.R., Insinuazione di Torino, L. 6, 1713, c. 453.

14. S. Cerutti, La Ville et les métiers. Naissance d'un langage corporatif. Turin, XVII ${ }^{e}$-XVIII ${ }^{e}$ siècle.

15. D. Severin, Per la storia della emigrazione artistica della Svizzera italiana. Privilegi Sabaudi agli architetti e mastri da muro luganesi (XVII sec.).

16. ASTo, Materie politiche, Negoziazioni con gli svizzeri, m 5, fasc. 13, Atti vertenti avanti la Camera de Conti; Ivi, m. 8, fasc. 5, Memoria delle rispettive obbligazioni portate dai tratti di Lega tra il Duca di Savoia e li Svizzeri; Ivi, fasc. 16, Supplica de Luganesi per ottenere da S.M. la conferma delle esenzioni e privilegi (1733); Ivi, m. 9, fasc. 6, Suppliche dell'università degli architetti.

17. Ibid.

18. Archivio della Compagnia di Sant'Anna dei luganesi a Torino (dorénavant ACSALT), Ufficiali e Soci, III, Testimoniali di attestazione giudiciale (1703-1747).

19. ASTo, Corte, Archivio Mastri da Bosco o di Grosseria, m. 1, Ordinati (1710-1733), passim.

20. Ivi, m. 1 , sch. 18 e 19.

21. M. Agulhon, La sociabilité méridionale. Confréries et Associations dans la vie collective en Provence orientale à la fin du XVIII siècle; C. Black, P. Gravestock (éds.), Early Modern Confraternities in Europe and Amercas. International and Interdisciplinary Perspectives; D. Garrioch, M. Sonenscher, Compagnonnages, Confraternities and Associations of Journeymen in Eighteenth Century, Paris, p. 25-45 ; D. Garrioch, Les confréries religieuses, espace d'autonomie laïque à Paris au XVIII 'eiècle, p. 143-163 ; A. Torre, Il consumo di devozioni. Religione e comunità nelle campagne di Ancien Régime.

22. ACSALT, Ordinati e verbali, II, 1, passim.

23. S. Cavallo, Assistenza femminile e tutela dell'onore nella Torino del XVIII secolo, p. 127-155, Ead., Strategie politiche e familiari intorno al baliatico. Il monopolio dei bambini abbandonati nel Canavese tra Sei e Settecento, p. 391-420; Ead., Charity, power and patronage in eighteenth century in italian hospital: the case of Turin, p. 93-122.

24. Sur les migrations de retour, voir L. Lorenzetti, A.-L. Head-König (éds), Les migrations de retour.

25. « disgrazia cascato d'una fabrica in Turino », ACSALT, Attività Assistenziali, Sussidi, 1 (1713-49), f. 17.

26. « infermità vacilante », Ivi, f. 21.

27. " essersi alquanti giorni fato male à una gamba in statto di non poter si guadagnarsi il vivere ne aver chi lo possi socorere ", Ivi, f. 23.

28. « miserabilissimo stato stante la sua lunga malatia », Ivi, f. 29.

29. " retirare al meglio che potrà verso la patria in ove ha qualche parente ", Ivi, f. 17.

30. «benissimo informati ».

31. ACSALT, Contabilità e patrimonio, Casa di Sant'Anna, fasc. 59-67.

32. G. Ricci, Naissance du pauvre honteux : entre l'histoire des idées et l'histoire sociale, p. 158. Id., Povertà, vergogna e povertà vergognosa; Id., Povertà, vergogna, superbia: i declassati fra medioevo e età moderna. 
33. S. Cavallo, Conceptions of Poverty, p. 170.

34. A. Renata, Economia barocca. Mercato e istituzioni nella Roma del Seicento; C. Muldrew, The Economy of Obligation. Culture of Credit and Social Relations in Early Modern England; N. Rolla, La piazza e il palazzo. I mercati e il vicariato di Torino nel Settecento; N. Rolla, « Credito al consumo e giustizia a Torino nella prima metà del Settecento », p. 299-329.

35. "dinamico, fondativo e creativo ", "vi si affermano capacità giuridiche [...] e le si attribuiscono a protagonisti specifici », A. Torre, Il bosco della Rama : rituali e forme del possesso nel Monferrato casalese, p. 61.

36. ACSALT, Ordinati e verbali, Libro II (1713-1788), f. 35.

37. ACSALT, Liti, 10, 1_(1bis) r.

38. «La medema università per li bisogni d'essa fa esponer li bacile e bussole per la raccolta delle elemosine ", Ibid., $14 \mathrm{v}$.

39. S. Cerutti, Travail, mobilité et légitimité. Suppliques au roi dans une société d'Ancien Régime (Turin, XVIII siècle), p. 571-611.

40. Les registres des ordonnances civiles du tribunal du Vicariat de Turin conservent de nombreuses traces des comptes ouverts par les employeurs dans les boulangeries pour les repas des travailleurs : ASTo, S.R., Vicariato, Atti e ordinanze civili.

41. ACSALT, Ordinati e verbali, Libro I (1636-1713), c. 102r.

\section{RÉSUMÉS}

Durant les années de paix entre le Traité d'Utrecht (1713) et la Guerre de Succession d'Autriche (1742), l'ouverture de plusieurs chantiers à Turin et dans le Piémont constituait une opportunité d'investissement pour les entrepreneurs du bâtiment provenant des Alpes nord-occidentales. Centre de négociation des commandes publiques, Turin était l'épicentre d'une circulation plus vaste vers les différents chantiers piémontais. Dans ce contexte, l'activité des confréries était cruciale dans le processus d'installation en ville. À Turin, on connaît l'existence de deux confréries «nationales » des maîtres maçons de Lugano et de Milan, et des maîtres charpentiers de Graglia et Muzzano. Cet article porte sur le rôle de ces confréries dans la mobilité des migrants. Il vise à montrer le processus complexe et conflictuel de construction de l'appartenance à la « nation » - suisse, milanaise, biellese - et de définition des communautés des immigrés.

\section{AUTEUR}

NICOLETTA ROLLA

Gerda Henkel Stiftung Fellow, LaDéHis-CRH, EHESS, Paris 


\title{
Des Alpes à Saint-Domingue : les commerçants du Haut-Dauphiné et les colonies caribéennes au XVIII siècle
}

\author{
Boris Deschanel
}

Le concept de circulations a connu une large diffusion dans l'historiographie, depuis les années 1980. L'histoire des économies européennes préindustrielles s'est, en particulier, appropriée la notion, aussi bien pour l'appliquer à l'échange de biens marchands qu'aux déplacements des hommes. Dans ce dernier cas, le terme s'est progressivement et partiellement substitué à l'idée de migration, qui dominait jusque-là la littérature. Comme le remarquait Laurence Fontaine, ces évolutions lexicales s'inscrivent dans un ensemble de changements, qui ont concerné à la fois la géographie, l'histoire et l'anthropologie, et qui ont conduit à renouveler les modèles interprétatifs mobilisés afin d'analyser les mouvements de populations à travers l'espace, aussi bien dans des contextes industriels que préindustriels ${ }^{1}$. D'un point de vue strictement historiographique, le concept de circulations s'est construit à partir de trois idées clefs. En premier lieu, l'histoire des phénomènes circulatoires tend à critiquer une vision trop passive et mécaniste des migrations, en insistant au contraire sur les initiatives prises par les acteurs en vue d'organiser (à l'avance ou non) leurs déplacements. En second lieu, l'histoire des circulations s'est aussi constituée en réaction au modèle "répulsion-attraction » qui avait longtemps prévalu dans la littérature: de ce point de vue, les mouvements des individus ne résultent pas exclusivement de la misère, ou plus exactement d'un différentiel de richesse et de développement économique. En troisième lieu enfin, l'idée de circulations permet d'insister sur la réversibilité du déplacement, sur le maintien de liens entre le territoire d'origine et le territoire de départ, éventuellement sur des formes saisonnières de migrations. Initialement, l'adoption de ce cadre interprétatif cherchait surtout à rompre avec une conception très surplombante des migrations, qui tendait à dépeindre les individus engagés dans ces déplacements comme des êtres passifs, mus par des 
logiques économiques ou socio-économiques extérieures. De ce point de vue, le concept de circulations a logiquement nourri la réflexion d'historiens qui s'intéressaient en priorité aux déplacements de groupes dominés: colporteurs, ouvriers, travailleurs saisonniers... En revanche, les enquêtes consacrées à des groupes dominants, à l'instar de la bourgeoisie commerciale du $\mathrm{XVIII}^{\mathrm{e}}$ siècle, ont insisté avec beaucoup plus de précocité sur les stratégies individuelles des acteurs, dans une perspective beaucoup plus compréhensive. Dans le cas des Alpes dauphinoises, par exemple, des monographies et des biographies du $\mathrm{XIX}^{\mathrm{e}}$ siècle s'attachaient déjà à décrire les expéditions organisées par les négociants issus de la notabilité locale, qui s'orientèrent aussi bien vers l'Europe méridionale (Espagne, Italie) qu'en direction des espaces coloniaux (Antilles, Amérique continentale). Ces voyages lointains, bien documentés grâce à la conservation de quelques archives familiales et entrepreneuriales, sont souvent présentés comme la manifestation d'un capitalisme aventureux et audacieux, qui participe à ce titre des mythologies entretenues par les familles bourgeoises. Dans cette perspective, les circulations sont donc vues comme un outil de prospection, entre les mains d'un groupe professionnel bien constitué (les milieux marchands et négociants). La question que nous souhaiterions poser vise à rompre avec cette conception: il ne s'agit pas d'analyser l'instrumentalisation des phénomènes circulatoires par les gens d'affaires, mais plutôt l'impact de ces phénomènes circulatoires sur l'organisation structurelle du commerce. Bien sûr, le problème est récurrent, dans le cadre des études liées aux diasporas marchandes. En l'occurrence, il s'agit toutefois de l'appliquer à une situation bien distincte, dans la mesure où nous nous pencherons sur les circulations océaniques de négociants originaires d'une même région - le Haut-Dauphiné - qui ne se reconnaissaient pourtant pas dans une même communauté (culturelle, linguistique ou religieuse). Notre objectif sera ainsi de comprendre en quoi les circulations marchandes contribuent à façonner un groupe social, dans le contexte d'Ancien Régime. Il s'agit ainsi de s'intéresser à la manière dont elles modifient à la fois l'image et les positions sociales des agents, dans les localités des Alpes dauphinoises dont ils étaient originaires.

\section{Les milieux commerçants dans le Haut-Dauphiné}

2 Il importe, au préalable, de s'interroger sur la définition de notre objet: comment identifier le groupe, mais aussi le terrain d'étude qui sera le nôtre ? La délimitation du Haut-Dauphiné est plus délicate qu'il n'y paraît. L'opposition entre Haut et BasDauphiné relève en effet de l'usage, non d'une démarcation administrative et officielle². Sous l'Ancien Régime, cette distinction permet en réalité de différencier le Dauphiné des plaines et des basses vallées du Dauphiné plus montagneux, dans les massifs alpins et pré-alpins. En retenant cette ébauche de définition, on peut donc considérer que le Haut-Dauphiné englobe l'ensemble du département actuel des Hautes-Alpes, auquel il faut ajouter la partie méridionale de l'Isère et la portion orientale de la Drôme. Les reliefs des «terres froides » étant, quant à eux, traditionnellement rejetés à l'extérieur de cette aire spatiale. De ce point de vue, le Haut-Dauphiné se compose de massifs plus ou moins élevés, où les contraintes inhérentes à la pente et au climat sont inégalement marquées, mais il englobe en outre des vallées (Durance, Buëch). Il s'agit en somme d'un espace caractérisé avant tout par la proximité de la montagne, structuré autour de quelques axes de circulation (souvent situés dans les vallées et au niveau des cols) et de 
localités hiérarchisées. Grossièrement, la région est dominée par de petites villes relativement bien desservies (Briançon, Embrun, Gap), ainsi que par un réseau de bourgs intermédiaires, comme Serres, Guillestre, Saint-Bonnet, Mens ${ }^{3} \ldots$ Ces communautés servaient d'interfaces entre les circuits extérieurs et des villages ou hameaux moins peuplés ou plus reculés.

3 Les sous-régions du Haut-Dauphiné semblent relativement indépendantes les unes par rapport aux autres, notamment d'un point de vue économique. Les évolutions des prix, au cours $d u \mathrm{XVIII}^{\mathrm{e}}$ siècle, ne traduisent pas une intégration très poussée des divers marchés locaux. Le Briançonnais était plutôt tourné vers l'Italie et Grenoble. Plus au sud, l'Embrunais et le Queyras semblent moins dynamiques d'un point de vue commercial : les entrepreneurs locaux étaient surtout absorbés par des échanges courts et de petits trafics transfrontaliers. Les zones méridionales, pour leur part, s'orientaient davantage vers la Haute-Provence et Marseille : c'était surtout le cas de la vallée du Buëch, des Baronnies, dans une moindre mesure du Gapençais. Le Diois se trouvait quant à lui tiraillé entre les influences méridionales, lyonnaises et les réseaux d'affaires protestants. Le reste de la région était sous l'influence des villes locales - à l'image du Champsaur, très dépendant de $\mathrm{Gap}^{4}$ - ou de la capitale dauphinoise, Grenoble ${ }^{5}$.

4 Les individus liés au commerce et installés dans la région s'inscrivaient donc dans des contextes extrêmement variés, plus ou moins favorables au développement des firmes. Ce qui explique aussi, par ailleurs, la grande diversité des acteurs, de leurs spécialisations et de leurs niveaux de richesse. Pour tenter d'étudier la démographie des milieux marchands, il est donc crucial de ne pas se cantonner à une définition trop rigide, mais d'opter au contraire pour une approche large, permettant de saisir l'ensemble des agents impliqués, indépendamment des variations dans les appellations locales. En l'occurrence, les milieux commerçants rassemblent non seulement des «marchands » ou des « négociants» déclarés, mais aussi des colporteurs, regrattiers, commerçants spécialisés (épiciers, merciers, etc.). Derrière cette apparente hétérogénéité, il faut tout de même souligner que certains termes, apparemment bien spécifiques, présentent dans la région une signification très large : " négociants » et « marchands » recouvrent en particulier des activités des plus variées.

5 Si l'on s'en tient à cette définition très souple, quel était le poids des milieux commerçants dans la région? Sous l'Ancien Régime, l'évaluation est plus difficile, car elle doit s'appuyer sur les divers rôles fiscaux des communautés. René Favier a montré que le pourcentage de commerçants oscillait entre $5 \%$ à $10 \%$ dans les principales localités (villes et bourgs) ${ }^{6}$. Pour les villages et les hameaux, les pourcentages étaient moins élevés, souvent inférieurs à $2 \%$. Après la Révolution, le constat est à peu près identique. Dans les Hautes-Alpes, les commerçants représentaient environ $5 \%$ des individus recensés sur les rôles de l'emprunt forcé de l'an IV (1795) 7 . Quelques décennies plus tard, le rapport au roi du comte de Chabrol (1830) permet de déduire que 2,5\% des habitants du département étaient assujettis à la patente ${ }^{8}$. Enfin, en 1847, Pilot de Thorey évaluait à environ 3,7\% la part de la «classe commerçante » dans la population des cantons isérois du Haut-Dauphiné9. Ainsi, la proportion globale se maintint entre $2 \%$ et $4 \%$. Mais ces pourcentages augmentaient dans les municipalités les plus peuplées. De surcroît, les commerçants étaient sur-représentés dans les strates les plus fortunées de la société : on recense environ $10 \%$ de gens d'affaires parmi les 
membres du collège électoral de 1829 - alors que le cens favorisait plutôt les propriétaires de biens fonciers et immobiliers.

6 En somme, les commerçants tendaient à apparaître comme un groupe très minoritaire (pendant toute la période considérée), plutôt implanté dans les bourgs et les petites villes de la région, et plutôt riche dans l'ensemble - quand bien même des disparités indéniables existaient en son sein. Entre les négociants de Briançon et les colporteurs des villages de montagne, entre les banquiers de Gap et les petits boutiquiers des bourgades voisines, s'étendait un fossé à la fois social et financier. Tous ces acteurs, en dépit de leurs multiples particularités, présentaient toutefois le point commun de s'insérer, directement ou indirectement, dans des circuits d'échanges plus vastes.

\section{Circulations montagnardes, circulations atlantiques}

7 Les milieux commerçants du Haut-Dauphiné assuraient pour partie un travail de redistribution locale des marchandises. De ce point de vue, ils contribuaient à la circulation intra-régionale et inter-régionale des biens de consommation, et se positionnaient par conséquent comme des intermédiaires de première importance. L'intégration des Alpes dauphinoises aux réseaux marchands s'effectuait selon plusieurs voies distinctes. Comme nous l'avons signalé, une partie de la région était alimentée par Marseille et la Provence (les Baronnies, la vallée du Buëch, dans une moindre mesure le Gapençais, l'Embrunais, le Briançonnais). Les régions frontalières, autour de Briançon et du Queyras, avaient pu se tourner occasionnellement vers les marchés et les fournisseurs italiens, mais les réglementations douanières imposées par les États sardes entravaient les échanges directs. Enfin, il faut relever l'influence de Grenoble et le rayonnement plus lointain de Lyon. La correspondance de la famille Pinet, installée à Gap, démontre par exemple l'existence de liens réguliers avec ces deux dernières places ${ }^{10}$. Sans doute s'agit-il d'un exemple particulier, mais les Pinet occupaient une telle place dans les milieux d'affaires haut-dauphinois que leurs orientations géographiques avaient aussi une influence plus générale sur la banque et le commerce locaux.

Négociants, marchands, mais aussi boutiquiers ou colporteurs contribuaient ainsi à tisser un ensemble d'interconnexions, entre ces espaces extérieurs, plus ou moins distants, et les centres de consommation du Haut-Dauphiné. Bien sûr, l'intérêt économique de ces marchés alpins pouvait sembler limité, sinon dérisoire. En dépit des apparences - et de la réputation miséreuse de la région, colportée par les rapports d'intendance puis par les mémoires de préfets et d'érudits -, les Alpes dauphinoises présentaient aussi des perspectives de profits, liées pour l'essentiel aux contrats militaires. L'approvisionnement des troupes cantonnées dans les montagnes, en nourriture, en armes, en matériel de tout genre, avait ainsi contribué à enrichir plusieurs familles, à l'image des Pinet à Gap, des Barrillon à Serres, des Ithier qui leur étaient apparentés ${ }^{11}$... En retour, le Haut-Dauphiné exportait peu sa propre production intérieure, sauf (rares) exceptions. Des ateliers installés dans le Briançonnais, le pays du Buëch ou les Baronnies produisaient certes quelques objets manufacturés (bijoux, chapeaux, étoffes.... ${ }^{12}$, mais sans générer d'exportations massives. Aussi, pour une partie de la bourgeoisie commerciale locale, l'essentiel résidait moins dans la maitrise des flux régionaux et des marchés locaux, que dans la capacité à ouvrir leurs horizons, en direction des circuits extérieurs (italiens, lyonnais, provençaux, grenoblois...). Ce qui 
impliquait non seulement des circulations marchandes, mais aussi humaines. Est-ce à dire que les acteurs qui se tournaient vers l'extérieur étaient aussi ceux qui n'étaient pas parvenus à s'imposer régionalement? Le constat est en réalité plus nuancé. Quel que soit le type de commerce considéré - du négoce au colportage - de nombreux acteurs du Haut-Dauphiné étaient en fait absorbés (en partie au moins) par des transactions lointaines. Or, ces individus jouissaient fréquemment d'un statut influent dans leurs communautés d'origine. Les Barrillon, les Pinet, les principales familles du Briançonnais (comme les Borel, les Bompard, les Caire, les Prat) ou de la vallée du Buëch (les Ruelle, les Chauvet, etc.) disposaient à la fois de solides assises locales et de relations avec des places extérieures.

9 Les archives privées viennent largement étayer ce constat. Une partie de la documentation démontre l'existence de relations très régulières et importantes entre certains négociants du Haut-Dauphiné et des places extérieures : la correspondance et la comptabilité de la maison Pinet font état de liens avec Lyon. Les papiers personnels d'Abel, à Antonaves (Hautes-Alpes) ${ }^{13}$, le fonds Chauvet et Lafaye ${ }^{14}$ - deux commerçants venus de Ribiers et d'Orpierre (Hautes-Alpes), témoignent tous de l'implantation de Haut-Dauphinois à Marseille. Quant aux archives Borel ${ }^{15}$ - qui regroupent aussi des papiers concernant les principales familles marchandes du Briançonnais -, elles révèlent des séjours prolongés à Turin. Le corpus ainsi obtenu, à partir de recherches dans les séries privées des archives départementales des trois départements dauphinois (Hautes-Alpes, Drôme, Isère) ainsi que dans des territoires "périphériques" (Lyon, Marseille, Turin), rappelle qu'une partie de ces milieux d'affaires montagnards s'orienta aussi vers des marchés et des horizons plus lointains, en s'impliquant dans le commerce maritime. C'est en particulier le cas des Dauphinois installés à Marseille, bien sûr. Auxquels s'ajoutent quelques cas plus particuliers : originaire de Menglon, dans le Diois (Drôme), Jacques Dusseigneur s'installa par exemple à Gênes à la fin du XVIII ${ }^{e}$ siècle, en s'appuyant vraisemblablement sur des liens avec les protestants de Genève $^{16}$. Quant à la famille Barrillon, à Serres (Hautes-Alpes), elle était alliée aux Pinchinat de Barcelonnette (Alpes-de-Haute-Provence), dont une branche s'était implantée à Bayonne - où fut donc envoyé le jeune Jean Joseph François Alexandre Barrillon, pour s'initier aux affaires. Parmi ces négociants, plusieurs individus se signalent par des déplacements plus ou moins prolongés dans les espaces coloniaux, et tout particulièrement à Saint-Domingue.

10 Il est certes difficile d'établir un recensement précis des acteurs concernés. Les passeports fournissent une source importante, mais tardive. Des traces existent dans les archives paroissiales des colonies, mais qui ne permettent guère de saisir des séjours temporaires. Il est aussi possible de travailler à partir de plans cadastraux, afin d'identifier les possessions de certains Dauphinois, mais cela n'est valable que pour les propriétaires. De même, les dédommagements des colons de Saint-Domingue ne fournissent pas des renseignements exhaustifs et tendent à se focaliser sur les détenteurs d'habitations. La seule possibilité est donc de croiser les données issues de trois sources principales : les noms figurant dans les passeports post-révolutionnaires ; les renseignements contenus dans les archives familiales; enfin, les biographies et les dictionnaires biographiques $\mathrm{du} \mathrm{xIX}^{\mathrm{e}}$ siècle, complétés par une exploitation plus ponctuelle des archives coloniales (paroissiales ou administratives).

11 L'étude des passeports donne une première idée, même déformée, de l'importance des possessions coloniales pour les milieux d'affaires du Haut-Dauphiné. Pour les territoires 
dauphinois, nous conservons plusieurs séries, datées de la période 1800-1805. L'époque n'est certes plus celle de "l'âge d'or" du premier empire colonial: la révolution haïtienne et la guerre avec le Royaume-Uni avaient mis à mal le système esclavagiste, les circulations marchandes entre la Caraïbe et la France, et par voie de conséquence la prospérité des firmes métropolitaines. Pourtant, les brefs espoirs d'un retour à la paix en 1802-1803 suffisent à ranimer, chez certains Dauphinois, l'illusion d'une réimplantation à Saint-Domingue et d'une relance du négoce océanique traditionnel. La part des passeports vers les Antilles (françaises ou espagnoles) reste ainsi non négligeable ( $8 \%$ de la documentation). Et ces passeports sont très majoritairement accordés à des hommes d'affaires ou à leurs familles, déjà actifs dans le commerce atlantique avant $1793^{17}$. Tous ces efforts consentis afin de remettre le pied dans les îles témoignent indirectement de l'importance des échanges coloniaux pour une partie de la bourgeoisie négociante des Alpes dauphinoises.

Les fonds familiaux et les archives d'entreprise confirment du reste le constat. Pour le Haut-Dauphiné, quelques grands ensembles documentaires doivent être signalés. Citons en premier lieu les archives Chauvet et Lafaye, qui concernent en réalité plusieurs familles de la vallée du Buëch et des environs impliquées dans le trafic avec Saint-Domingue : outre les Chauvet et les Lafaye, citons le cas des Ruelle, Allégret, Hugues, Payan, Barrillon ou Philippon, tous évoqués avec plus ou moins de détails dans la correspondance et la comptabilité. Le fonds Saffroy contient quant à lui des éléments abondants à propos de la famille Tanc, dont quelques membres se tournent vers la Martinique entre la fin du XVIII et le début du XIX ${ }^{e}$ siècle. Notons également l'existence de fonds familiaux (archives de la famille Ruelle, de la famille Bompard), qui n'ont pas été déposés dans des services publics, et donc l'accès s'avère par conséquent parfois difficile. À cela s'ajoute une série d'informations recueillies dans la bibliographie de l'époque contemporaine, à des fins scientifiques ou mémorielles. Ces sources peuvent aussi être confrontées aux données dont nous disposons à propos du reste du Dauphiné, en particulier à travers les archives des Dolle et des Raby, et l'étude qu'en a tirée Pierre Léon dans les années 1960.

Tous les documents disponibles tendent donc à confirmer l'ancrage solide des milieux commerçants du Dauphiné, et singulièrement du Haut-Dauphiné, dans les espaces antillais. En découlent des circulations marchandes et humaines à travers l'Atlantique, dont il est néanmoins malaisé de déterminer avec précision les origines. Deux hypothèses clefs peuvent être mentionnées, qui ne sont d'ailleurs pas incompatibles entre elles. La première est directement issue des travaux de Pierre Léon: il s'agit d'insister sur le rôle de la fréquentation des foires de Beaucaire, qui auraient suscité chez les négociants du Dauphiné et du Haut-Dauphiné un intérêt pour le commerce colonial, sous l'influence de partenaires étrangers (espagnols principalement). La seconde hypothèse tient plutôt aux informations extraites des archives d'acteurs implantés dans le département actuel des Hautes-Alpes : compte tenu de l'attraction qu'exerçait Marseille sur les Alpes méridionales, il n'est pas exclu que l'installation d'entrepreneurs haut-dauphinois dans le port provençal ait contribué, à terme, à les engager à se tourner vers le commerce maritime et caribéen. On peut aussi se demander si les circulations militaires n'ont pas favorisé ces mouvements. Rappelons que, dans le Haut-Dauphiné, les familles de négociants étaient souvent liées au personnel militaire local. Et que la présence de soldats dans les possessions coloniales était également forte. La correspondance des Duplantier (originaires de Voiron) en Louisiane, dans les années 1770 , illustre bien ce processus ${ }^{18}$, qui nous semble 
potentiellement valable pour certains acteurs venus du Haut-Dauphiné. Nous savons par exemple qu'une partie des affaires de Barrillon - dans les Alpes comme dans les Îles - était liée à des transactions avec l'administration militaire. Pour certains négociants, ces aspects ont donc pu revêtir une certaine influence.

Quoi qu'il en soit, vers la fin des années 1780 , l'implication de la bourgeoisie d'affaires du Haut-Dauphiné dans le commerce colonial est donc avérée. Elle se concentre notamment vers Saint-Domingue et s'apparente bien à un ensemble de circulations, $y$ compris en cas d'installation prolongée. La plupart du temps, l'installation dans les îles est en effet perçue comme provisoire. Elle s'effectue d'ailleurs en priorité dans les ports ou à proximité des ports (fig. 1). Elle s'accompagne parfois de l'achat de propriétés, surtout dans la Plaine du Nord. C'est par exemple le cas de Barrillon, qui acquiert une habitation au Pilate, à une soixantaine de kilomètres du Cap-Français, et en prend la tête jusqu'à la révolution haïtienne. Reste que même dans cette configuration, les relations avec la métropole et le Haut-Dauphiné perduraient. Barrillon revint en France avant la Révolution, puis repartit à Saint-Domingue en 1791, avant de devoir fuir face aux soulèvements des esclaves du Nord.

Fig. 1. - Répartition des commerçants du Haut-Dauphiné à Saint-Domingue (1770-1793).

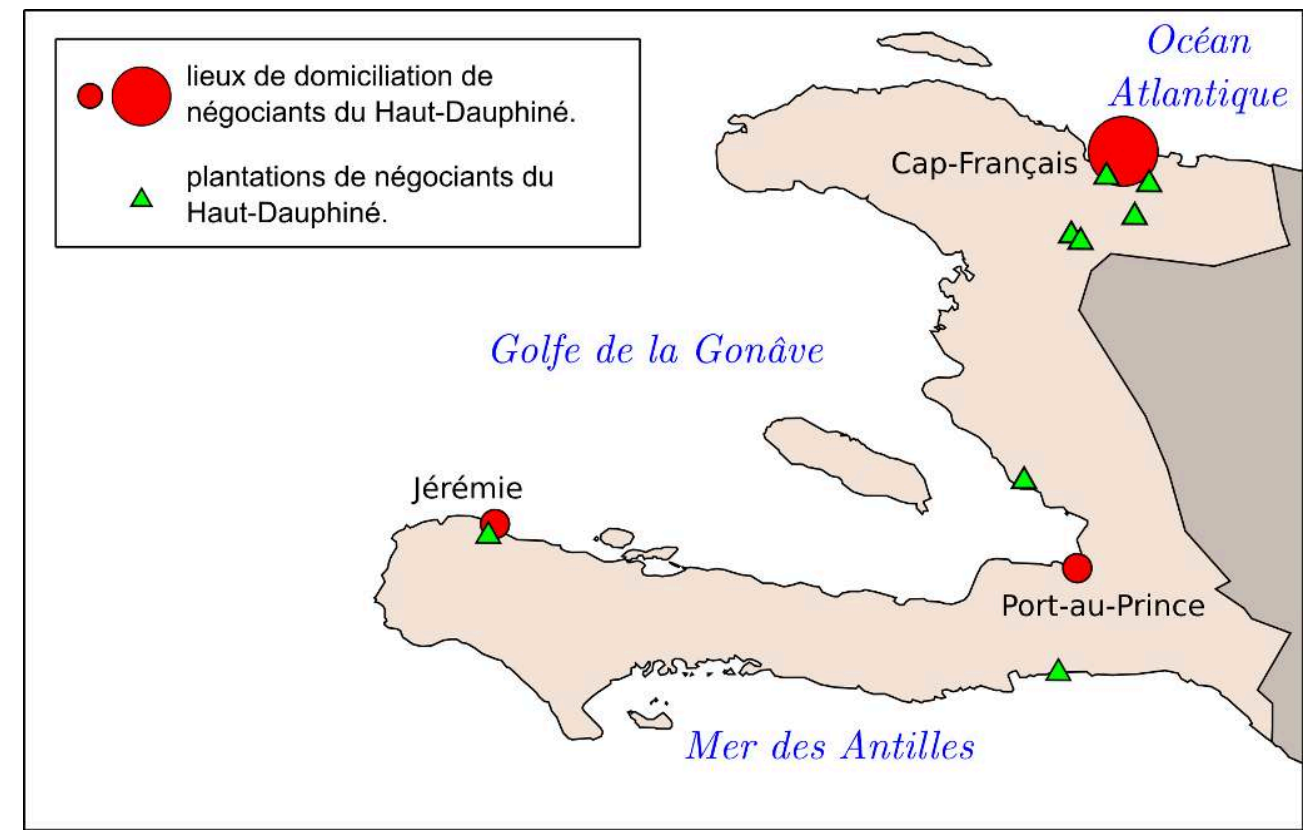

(C) B. Deschanel.

Parallèlement, tous les négociants identifiés conservaient d'ailleurs des liens avec le Haut-Dauphiné, indépendamment de la durée de leur séjour de l'autre côté de l'Océan. En règle générale, une branche de la famille restait dans les Alpes: Barrillon pouvait par exemple compter sur la présence de son père à Serre et de ses cousins à Veynes, les Ithier. Les parents, frères, sœurs et oncles de Chauvet ou de Lafaye étaient eux aussi restés à Orpierre, Ribiers à la Faurie, près du Buëch. De la même manière, une partie des Ruelle ou des Tanc était installée dans les communautés montagnardes, cependant que quelques membres de ces familles étaient allés tenter leur chance dans les colonies.

Reste donc à saisir comment ces circulations maritimes s'articulaient aux circulations montagnardes? La question est délicate, car il faut alors distinguer deux types 
d'échanges. D'un point de vue strictement commercial (c'est-à-dire sur le plan de la circulation des marchandises entre les Antilles et l'Europe), les liens semblent plutôt distants. Certes, il est difficile de proposer une évaluation statistique globale. L'exploitation de la comptabilité des sociétés Chauvet montre cependant que la firme n'alimentait que de manière extrêmement marginale le Haut-Dauphiné en produits coloniaux (celui-ci représentait moins de $1 \%$ des flux de crédit mentionnés dans le grand livre de 1785-1788). D'un point de vue humain, en revanche, les interconnexions perdurent bel et bien. Environ $5 \%$ des lettres rédigées étaient ainsi destinées à des partenaires installés dans les Alpes dauphinoises ; la proportion s'élève à environ $9 \% \mathrm{si}$ l'on tient également compte des individus installés en dehors du Haut-Dauphiné, mais originaires de la région. Cette approche quantitative présente assez rapidement des limites, toutefois, car elle conduit à agglomérer des missives dont le contenu et les objectifs n'étaient pas nécessairement homogènes.

\section{Un groupe social multi-situé ?}

En définitive, les circuits montagnards et coloniaux n'étaient donc pas étroitement imbriqués. Plus exactement, une différenciation économique assez marquée apparaît même à travers les quelques sources comptables dont nous disposons. En revanche, les mouvements des négociants entre l'Europe occidentale et l'aire caribéenne étaient quant à eux fortement conditionnés par des circulations montagnardes et locales. Les échanges et les alliances qui se manifestaient dans les communautés du Haut-Dauphiné favorisaient en effet l'intégration des acteurs au sein d'un même ensemble social et professionnel et, par-là même, à l'intérieur de circuits commerciaux plus vastes et plus lointains. Cela remet en question l'image de circulations « emboîtées », c'est-à-dire de circuits courts, englobés dans des circuits régionaux, inter-régionaux, internationaux, qui en détermineraient le fonctionnement. En réalité, tout se passe plutôt comme si les négociants du Haut-Dauphiné prenaient appui sur un capital relationnel bien localisé (l'ensemble des liens sociaux établis dans leurs communautés d'origine) pour s'assurer ensuite des conditions d'installation satisfaisantes dans les Antilles, ainsi que pour renforcer la stabilité de leurs maisons de commerce respectives. Dans les faits, les échanges de biens marchands s'effectuaient selon les principaux axes de l'époque : les Haut-Dauphinois expédiaient les denrées coloniales vers les ports de l'Atlantique (Bordeaux, Nantes) et vers Marseille, où elles étaient ensuite revendues ou acheminées en direction des grands centres de consommation et de redistribution - à Lyon, par exemple. De même, les entrepreneurs s'approvisionnaient en produits manufacturés européens sur les principales places de commerce ou dans les fabriques du BasDauphiné - autour de Grenoble, de Voiron, dans la vallée du Rhône. Sans surprise, les mouvements des marchandises s'effectuaient pour la plupart à l'écart des massifs alpins - à quelques exceptions près ${ }^{19}$.

En somme, l'organisation des acteurs, de part et d'autre de l'Atlantique, s'inscrivait dans des circuits marchands très différenciés, mais qui s'articulaient essentiellement l'un à l'autre à travers un tissu de relations familiales ou amicales. Dans cette perspective, l'observation des pratiques des négociants du Haut-Dauphiné à un niveau très local (que ce soit dans les espaces alpins ou antillais) donne finalement accès à des phénomènes beaucoup plus vastes, liés au négoce atlantique et méditerranéen. C'est dans ce sens que l'on peut qualifier les milieux négociants en question de multi-situés : 
l'analyse des trajectoires des gens d'affaires permet non seulement d'éclairer la question des relations et des circulations montagnardes, mais aussi d'aborder le problème de l'engagement des agents dans les échanges maritimes. Encore faut-il comprendre ce qui structure cette organisation multi-située, c'est-à-dire l'ensemble de liens entre les individus et les familles de négociants qui, à travers l'Océan, conféraient au groupe sa cohérence sociale.

19 L'étude plus approfondie de quelques négociants du Haut-Dauphiné apporte de multiples éclaircissements à ce propos. Trois familles, déjà évoquées, peuvent être retenues: les Chauvet, les Ruelle, les Tanc. Dans le premier cas, nous avons surtout affaire à un négociant, issu d'une lignée de propriétaires, qui se lance dans le commerce au Cap-Français, entre 1785 et 1789. Dans les deux autres cas, les affaires marchandes se doublent d'investissements fonciers (acquisitions d'habitations), à Saint-Domingue et à la Martinique - mais dans des circonstances assez dissemblables.

Pour Chauvet, le passage dans les Antilles est surtout l'occasion de réaliser des opérations profitables rapidement et de construire un ensemble de liens avec des entrepreneurs dominguois. Liens qu'il met ensuite à contribution, une fois rentré en métropole, à Marseille où il s'installe dans les années 1790. Dans les Îles et à Marseille, Chauvet continue d'entretenir des relations épistolaires avec d'autres notables. Il assume même un rôle d'intermédiaire entre une partie de la bourgeoisie marchande alpine et grenobloise (comme les Perier, les Ruelle, les Allégret...) et le monde colonial. C'est par exemple Chauvet qui, dans les années 1790, oriente l'un des fils Ruelle, qui souhaitait se consacrer au commerce avec les colonies, malgré une conjoncture peu favorable. C'est lui qui, à la fin des années 1780, fournit à Claude Perier des informations sur des habitations que le négociant grenoblois souhaitait acheter. C'est lui enfin qui renseigne ses amis et ses parents sur l'attitude de certains acteurs hautdauphinois installés de fraîche date dans les Îles - rendant possible au passage une forme de contrôle social à distance, malgré l'éloignement géographique.

21 Le parcours de Chauvet, toutefois, est avant tout celui d'un négociant. Les Ruelle offrent quant à eux un aperçu sensiblement différent, puisque la famille finit par acquérir des terres et s'intègre davantage, de ce fait, à la société coloniale de SaintDomingue $^{20}$. Mais comme les Dolle et les Raby, les Ruelle ne rompent pas pour autant avec leur région d'origine : la famille est encore très présente à Serres, où elle compte parmi les principaux notables de la fin de l'Ancien Régime au début du xix siècle. L'organisation collective des Ruelle est similaire à celle que nous venons d'évoquer à propos de Chauvet : maintien des liens avec la métropole; relations suivies avec des partenaires issus du Haut-Dauphiné mais installés à Marseille et dans la Caraïbe ; exploitation de ces relations locales au service de stratégies marchandes de plus grande ampleur enfin. La famille est néanmoins beaucoup plus attachée aux Îles : en témoigne le fait que la révolution haïtienne ne précipite pas son départ (contrairement au cas de Barrillon, par exemple), mais qu'elle la pousse plutôt à s'exiler à Cuba. C'est là, à Matanzas, que les Ruelle tentent d'ailleurs de perpétuer leurs affaires jusqu'au milieu du XIXe siècle. Il n'empêche : quand la crise du café cubain éclate, François Ruelle prend la décision de revenir dans les Hautes-Alpes, où il s'éteint quelques années plus tard.

22 La conservation de ces liens semble constituer un enjeu particulièrement important. C'est ce que montre, par contraste, la correspondance adressée à un certain Marcel Tanc, natif de Tallard - l'oncle de Xavier Tanc, connu pour ses textes abolitionnistes ${ }^{21}$. Marcel était déjà présent en Martinique au début des années 1790, vraisemblablement 
depuis quelques années. À la fois négociant et propriétaire, il s'y adonne sans doute à un commerce colonial des plus classiques. Toutefois, et au contraire des Chauvet ou des Ruelle, les relations qu'il entretient avec le reste de la famille, restée dans les Alpes, sont une source de reproches plus ou moins voilés mais récurrents. Ses neveux, ses cousins déplorent son silence, regrettent son absence et l'exhortent parfois à revenir parmi eux. En creux, ces plaintes laissent entrevoir une dimension caractéristique de ces circulations : en quittant les Alpes pour gagner la Caraïbe, les acteurs n'étaient pas censés renoncer à leur univers d'origine. Bien plus: d'une certaine façon, les circulations maritimes apparaissent comme étroitement orientées vers l'univers montagnard. Rien d'étonnant, alors, à ce que le refus d'un Marcel Tanc de rentrer au pays natal soit perçu comme une transgression.

En traversant l'Océan, les négociants du Haut-Dauphiné s'émancipaient moins du jeu des relations et des stratégies familiales qu'ils ne le consolidaient. Un rapide recensement des négociants ayant séjourné dans les Antilles l'illustre assez bien. Chauvet regagne la métropole avant les révolutions française et haïtienne et la fortune acquise dans les îles permet in fine à sa famille de devenir l'une des plus riches du département des Hautes-Alpes, dans la première moitié du XIX ${ }^{e}$ siècle. Les Ruelle rentrent plus tardivement, eux aussi avec les capitaux acquis grâce à leurs plantations dominguoises et, surtout, cubaines. Barrillon, après avoir fui la révolution haïtienne, devient un des banquiers parisiens les plus influents, tout en restant (indirectement) très présent dans le Haut-Dauphiné, via ses divers parents. La famille détenait d'ailleurs une belle propriété, à l'écart du bourg de Serres - les Barrillons - qui symbolisait assez bien son influence locale. Enfin, la famille de Lafaye - qui mourut à Saint-Domingue comptait encore parmi la notabilité protestante d'Orpierre sous la Restauration et la monarchie de Juillet.

De ce point de vue, l'étude du terrain dauphinois suggère - dans la lignée de nombreuses monographies - que la notion de «stratégie familiale» semble particulièrement adaptée à une analyse des circulations entre les espaces montagnards et atlantiques. Ce sont précisément ces stratégies qui contribuent également à façonner un groupe professionnel et social, autour de pratiques et de comportements communs. Derrière les liens familiaux, c'est en effet un ensemble de solidarités financières, de contrôles, d'échanges d'informations qui se profile : autant d'éléments indispensables à la bonne marche des affaires et des entreprises. Sans minimiser nullement les difficultés inhérentes aux voyages et aux installations dans la Caraïbe, cette orientation d'une partie des négociants dauphinois ne doit donc en aucun cas être interprétée comme une rupture avec le milieu d'origine. Les circulations étudiées relevaient rarement d'initiatives individuelles et aventureuses : elles s'inscrivaient plutôt dans le cadre de pratiques mûrement réfléchies - comparables à celles que dépeignait Laurence Fontaine à propos des colporteurs de l'Oisans, du reste. En accomplissant de tels déplacements, les négociants participaient en effet à un effort d'enrichissement collectif, qui rejaillissait à terme sur l'ensemble du groupe familial. De ce point de vue, les circulations entre les Alpes méridionales et les Antilles peuvent être envisagées comme des processus qui contribuaient à asseoir la puissance socio-économique de quelques familles. Celles-ci n'étaient généralement pas exclusivement versées dans le négoce : elles se composaient aussi de propriétaires, de fabricants, de notaires. C'est-à- 
dire de roturiers relativement aisés, qui assumaient sur place d'importantes intermédiations financières ou marchandes, et qui tentaient notamment de reconduire leur domination sociale à travers leurs relations dans les colonies. Ce faisant, les circulations maritimes contribuèrent aussi à fédérer ces notables autour d'une expérience commune et spécifique. Ce d'autant que les récits postérieurs ne manquent pas, pour magnifier de tels séjours. Il s'ensuit le développement d'une véritable mythologie entrepreneuriale, certes bien localisée, cantonnée à quelques lignages, mais qui témoigne aussi du rôle social et symbolique de ces voyages, par-delà les profits économiques générés. En somme, ces mouvements de va-et-vient entre la montagne et les îles qui ont surtout marqué la seconde moitié du xvIII siècle ont contribué à consolider plus durablement, et à plusieurs égards, la position relative de cette petite bourgeoisie, au sein des formations sociales alpines.

\section{BIBLIOGRAPHIE}

FONTAINE Laurence, Pouvoirs, identités et migrations dans les hautes vallées des Alpes occidentales (XVII XVIII siècle), Grenoble, PUG, 2003, p. 217-224.

ROBINET M., Dictionnaire universel, Londres, 1780, vol. 15, p. 151.

FAVIER René, Les villes du Dauphiné aux XVII et XVIII siècles, Grenoble, PUG, 1995.

DESCHANEL Boris, Négoce, espaces et politique. Les recompositions socio-économiques du commerce dauphinois dans la Révolution, thèse de doctorat en histoire, Paris, Paris I - Panthéon-Sorbonne, 2015.

CHABROL de CROUZOT Christophe de, Rapport au roi sur l'administration des finances, Paris, Imprimerie royale, 1830 .

PILOT de THOREY Jean-Joseph-Antoine, Statistique du département de l'Isère, Grenoble, Allier, 1847.

BURGAUD-GONSET Hélène, Les Ruelle : chroniques familiales, [s.l.n.d.], 1991.

\section{NOTES}

1. L. Fontaine, Pouvoirs, identités et migrations dans les hautes vallées des Alpes occidentales (XVII - XVIII $e^{e}$ siècle), p. 217-224.

2. Voir par exemple M. Robinet, Dictionnaire universel, Londres, 1780, vol. 15, p. 151.

3. À cet égard, cf. la typologie proposée par R. Favier, Les villes du Dauphiné aux XVII et $\mathrm{XVIII}{ }^{e}$ siècles.

4. Comme le met par exemple en évidence une étude des créances de la famille Pinet (arch. dép. Isère, 14 J 26), laquelle assurait un rôle plus ou moins informel de banquier dans la région. 
5. Des précisions sur cette configuration géographique générale figurent dans la thèse de doctorat sur lequel ce texte s'appuie en partie (Boris Deschanel, Négoce, espaces et politique. Les recompositions socio-économiques du commerce dauphinois dans la Révolution, p. 150-187).

6. R. Favier, op. cit., p. 254 et 287-288.

7. Arch. dép. Hautes-Alpes, L 526-527.

8. Chr. De Chabrol de Crouzot, Rapport au roi sur l'administration des finances, Paris, Imprimerie royale, 1830. Sur la question des patentes et des patentables, voir notamment le tableau présenté p. 25-26.

9. J.-J.-A. Pilot de Thorey, Statistique du département de l'Isère, Grenoble, Allier, 1847.

10. Arch. dép. Isère, $14 \mathrm{~J}$ 5-9.

11. Arch. dép. Hautes-Alpes, $15 \mathrm{~J}$ (et en particulier 15 J 1-7).

12. Pour un état des manufactures sous l'Ancien Régime, dans une partie du HautDauphiné, on se reporta notamment aux arch. dép. Hautes-Alpes, C 26.

13. Arch. dép. Hautes-Alpes, $38 \mathrm{~J} 12-13$.

14. Arch. Chambre de commerce et d'industrie de Marseille-Provence, L 19/62/01-12.

15. Arch. dép. Hautes-Alpes, F 3484.

16. LSE Library, Dusseigneur and Wollaston (1784-1800).

17. Arch. dép. Hautes-Alpes, L 324-326 ; arch. nat., $\mathrm{F}^{7}$ 3537, 3541.

18. Les Duplantier exerçaient le commerce, tout en entretenant d'étroites relations avec les autorités militaires. Voir LSU Libraries, Special Collections : Armand Duplantier Family Letters : correspondance (1777-1859).

19. De manière assez marginale, quelques fabriques haut-dauphinoises trouvaient des débouchés à Marseille et dans les colonies. En retour, les familles des négociants implantés dans les Îles pouvaient occasionnellement se fournir en produits de l'agriculture antillaise, mais ces opérations demeurent anecdotiques.

20. Voir H. Burgaud-Gonset, Les Ruelle : chroniques familiales, [s.l.n.d.], 1991.

21. Arch. dép. Hautes-Alpes, 77 J (non classé).

\section{RÉSUMÉS}

Si les migrations des petits commerçants alpins ont été largement abordées par l'historiographie, les mobilités des marchands ou négociants plus fortunés ont été plus délaissées, en dehors des monographies d'entreprises ou des études familiales. Pourtant, de nombreuses lignées de notables du Haut-Dauphiné se sont tournées vers les échanges coloniaux au cours du XVIII ${ }^{\mathrm{e}}$ siècle. L'implication des acteurs s'est traduite aussi bien par l'installation de marchands alpins dans les Antilles que par le maintien de liens épistolaires et commerciaux entre les Alpes dauphinoises et la Caraïbe. Cette communication tentera d'analyser les mécanismes liés à ces circulations, à partir de la comparaison de plusieurs fonds d'archives privées. Il s'agira ainsi de se demander dans quelle mesure et de quelle façon l'insertion des entrepreneurs haut-dauphinois au sein de 
communautés montagnardes a pu influencer leurs pratiques et leurs stratégies dans le cadre du négoce maritime et colonial.

\section{AUTEUR}

\section{BORIS DESCHANEL}

Maître de conférences en histoire, Université d'Avignon et des Pays du Vaucluse 


\title{
Le pasteur Oberlin au Ban de la
} Roche (1740-1826) : un homme des Lumières pionnier de l'économie de montagne

\author{
Marie-Noële Denis
}

1 Le pasteur Oberlin (fig. 1) a exercé son ministère pendant 60 ans dans les huit paroisses du fief du Ban de la Roche, l'une des régions les plus déshéritées des Vosges décrite ainsi :

«Le pays présente un aspect sévère et sauvage... Pendant de longs mois d'hiver des vents violents balayent la contrée ensevelie sous la neige ; en été, des trombes d'eau et des orages terribles déchirent les gorges des montagnes, dévastent les vallées; en toute saison, des brouillards persistants... Point de cultures, point d'industrie, point de commerce. Une centaine de familles éparses dans l'isolement et l'abandon le plus complet... » ${ }^{1}$ 
Fig. 1. - Portrait d'Oberlin.

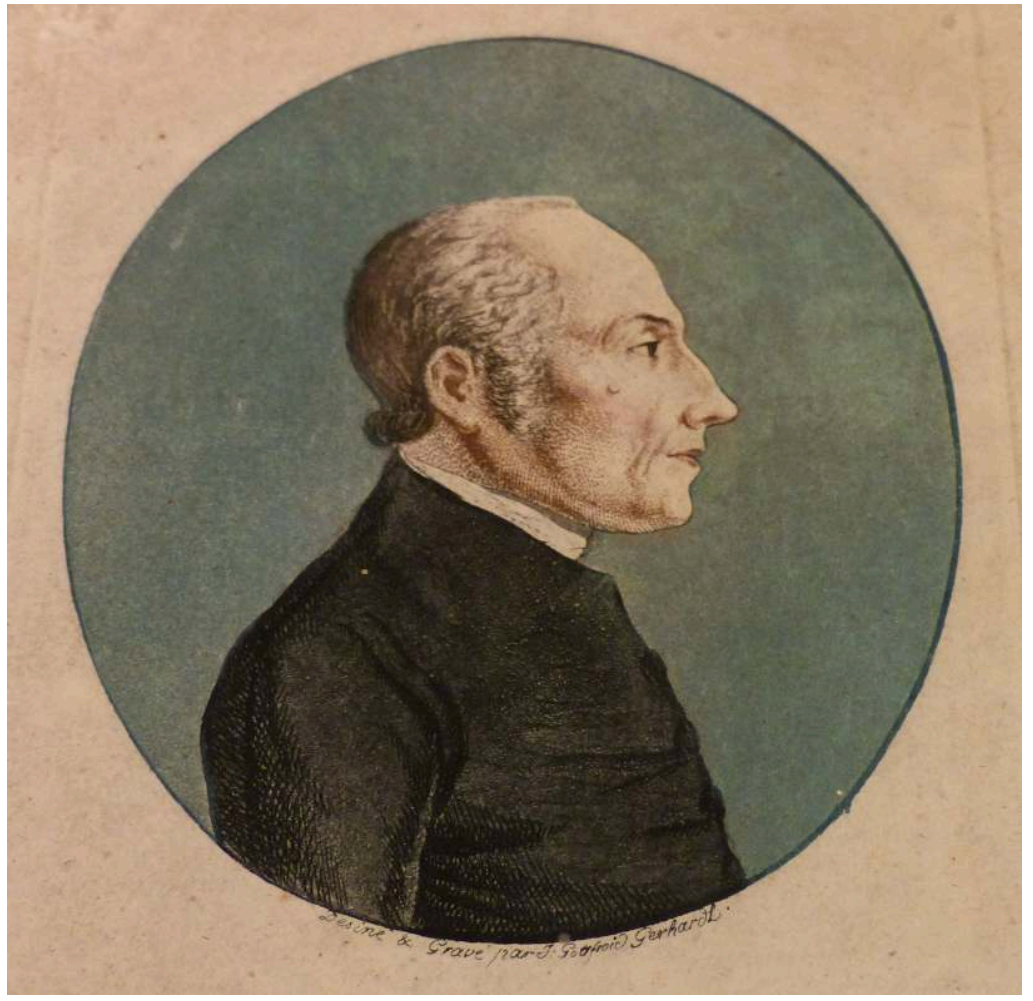

Ce portrait rappelle l'austérité du personnage en même temps, par le costume, ses fonctions ecclésiastiques. Ce profil est à rapprocher des nombreuses silhouettes physiognomoniques réalisées au presbytère. Gravure de J. Gottfried Gehrardt.

(c) Musée Oberlin, crédit photographie : Élisabeth Manouvrier.

2 C'est dans ce cadre austère que Jean Frédéric Oberlin s'emploiera à expérimenter et développer une économie de montagne fondée à la fois sur le développement d'une agriculture spécifique, de l'industrie et de l'instruction, pour améliorer les conditions de vie de ses paroissiens.

\section{Le Ban de la Roche}

3 Lorsqu'en 1767 Voyer d'Argenson, seigneur du Ban de la Roche, confie à Jean Frédéric Oberlin la charge de la paroisse de Waldersbach (Bas-Rhin) celle-ci se compose de cinq villages: Fouday, Solbach, Bellefosse, Belmont, Walddersbach et de trois hameaux: Trouchy, Penbois et La Hutte. La population présente la double particularité d'être de confession luthérienne et de langue romane dans un environnement catholique et de langue germanique.

\section{Les conditions naturelles}

Le Ban de la Roche est un pays de moyenne montagne dont les altitudes s'élèvent de 340 à 1100 mètres. Le relief se compose de croupes en gradins qui s'étagent de la vallée de la Bruche à la ligne des crêtes. Dans les zones les plus plates, les sols sont peu fertiles et lessivés par les pluies et les surfaces cultivables très réduites. Les pentes les plus abruptes sont couvertes de forêts. Le climat montagnard est rude, exposé aux vents 
d'ouest, les pluies abondantes (1 200 à $1500 \mathrm{~mm}$ d'eau par an), de même que l'enneigement, variable selon les années. Les récoltes sont à la merci du moindre incident climatique (fig. 2).

Fig. 2. - Le paysage du Ban de la Roche au XIXe siècle.

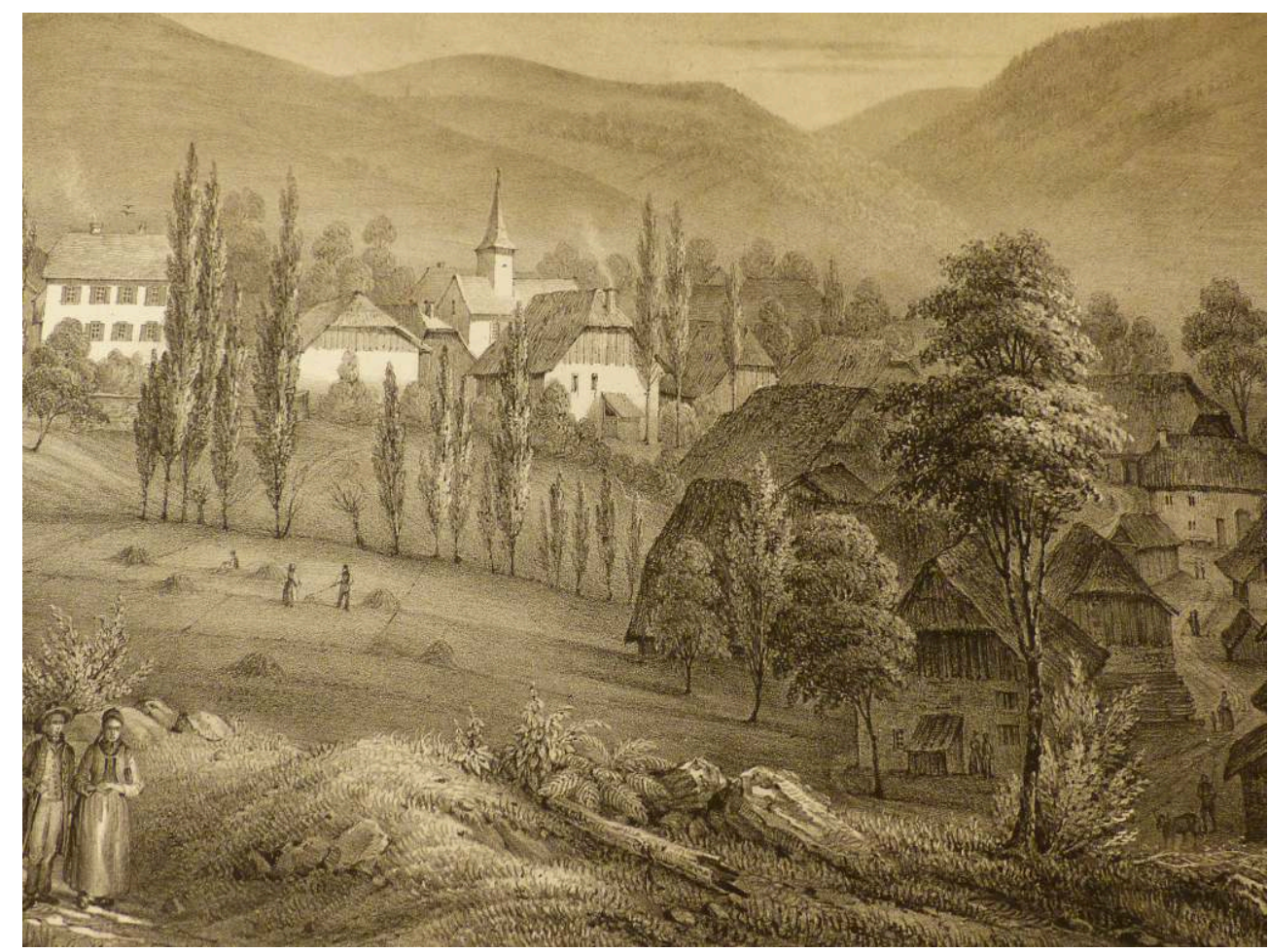

Paysage de moyenne montagne, de prairies et de forêts. Le presbytère se trouve à l'extrême gauche et le temple au centre du village. On remarque au premier plan les maisons couvertes en chaume.

(c) Musée Oberlin, Lithographie de Th. Muller. 1837. Crédit photographie : Élisabeth Manouvrier.

\section{La situation économique}

«L'agriculture du Ban de la Roche est une agriculture marginale... Elle est incapable de nourrir à elle seule la population. C'est uniquement un complément de ressources s'ajoutant à d'autres activités $»^{2}$

5 Cette autre activité est essentiellement constituée par la métallurgie du fer qui s'est développée à Rothau (Bas-Rhin). Les mines sont nombreuses au XVII ${ }^{e}$ siècle. Waldersbach possède son propre haut-fourneau. Après la guerre de Trente Ans (1618-1648) les forges de Rothau, associées à celles de Framont, ne furent remises en fonction qu'en 1724. Pendant la période révolutionnaire leur propriétaire, Louis Champy, y installa deux forges avec hauts fourneaux, martinets, et des "casernes » pour loger les ouvriers. La population augmenta rapidement ; 391 habitants en 1720, 802 en 1730, 2175 en 1777, 2490 en 1789. Mais il y a peu de relations et d'échanges entre ces nouvelles populations industrielles venues d'ailleurs, pour moitié catholiques, et les autochtones, que la production agricole locale ne suffit pas à nourrir. Néanmoins, une nouvelle ressource agricole, mieux adaptée aux conditions climatiques, va permettre en partie de faire face. Il s'agit de la pomme de terre, culture des terres pauvres, qui s'est répandue dans les pays germaniques, dont l'Alsace, dès le milieu du Xvir e siècle. 


\section{Le pasteur Oberlin et son univers}

6 Le pasteur Oberlin, qui s'installe à Waldersbach en 1767, succède au pasteur Stuber, déjà engagé dans le développement du Ban de la Roche. Il a été l'élève du Gymnase à Strasbourg, puis de la faculté de théologie. Son père, professeur de langues anciennes à ce même gymnase, était le premier intellectuel d'une lignée de boulangers, entré par son mariage dans une famille de pasteurs et de professeurs d'université. Jean Frédéric Oberlin, doué pour les langues, parlera l'allemand avec ses parents et le français avec ses enfants. Après quelques années de préceptorat, il choisit de s'installer au Ban de la Roche (fig. 3, 4).

Fig. 3. - Vue générale du temple depuis une des fenêtres du presbytère.

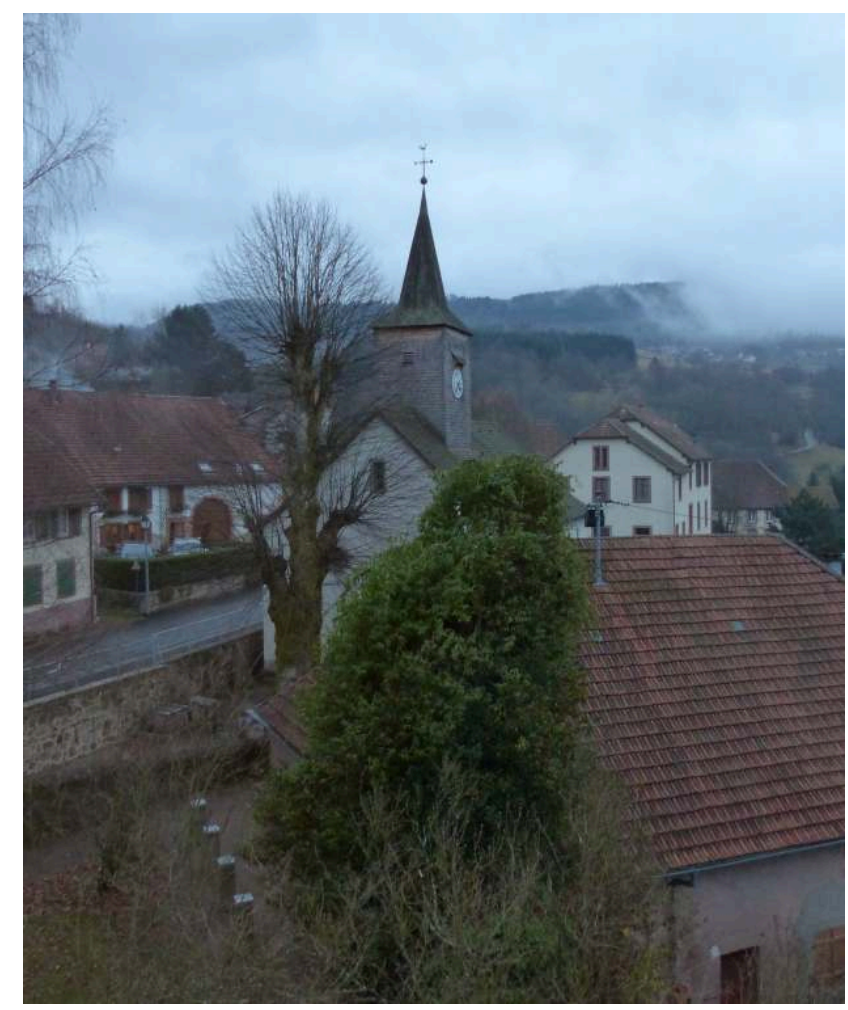

Au loin on aperçoit la montagne brumeuse et couverte de forêts.

(c) Musée Oberlin, crédit photographie : Élisabeth Manouvrier. 
Fig. 4. - Le temple la nuit.

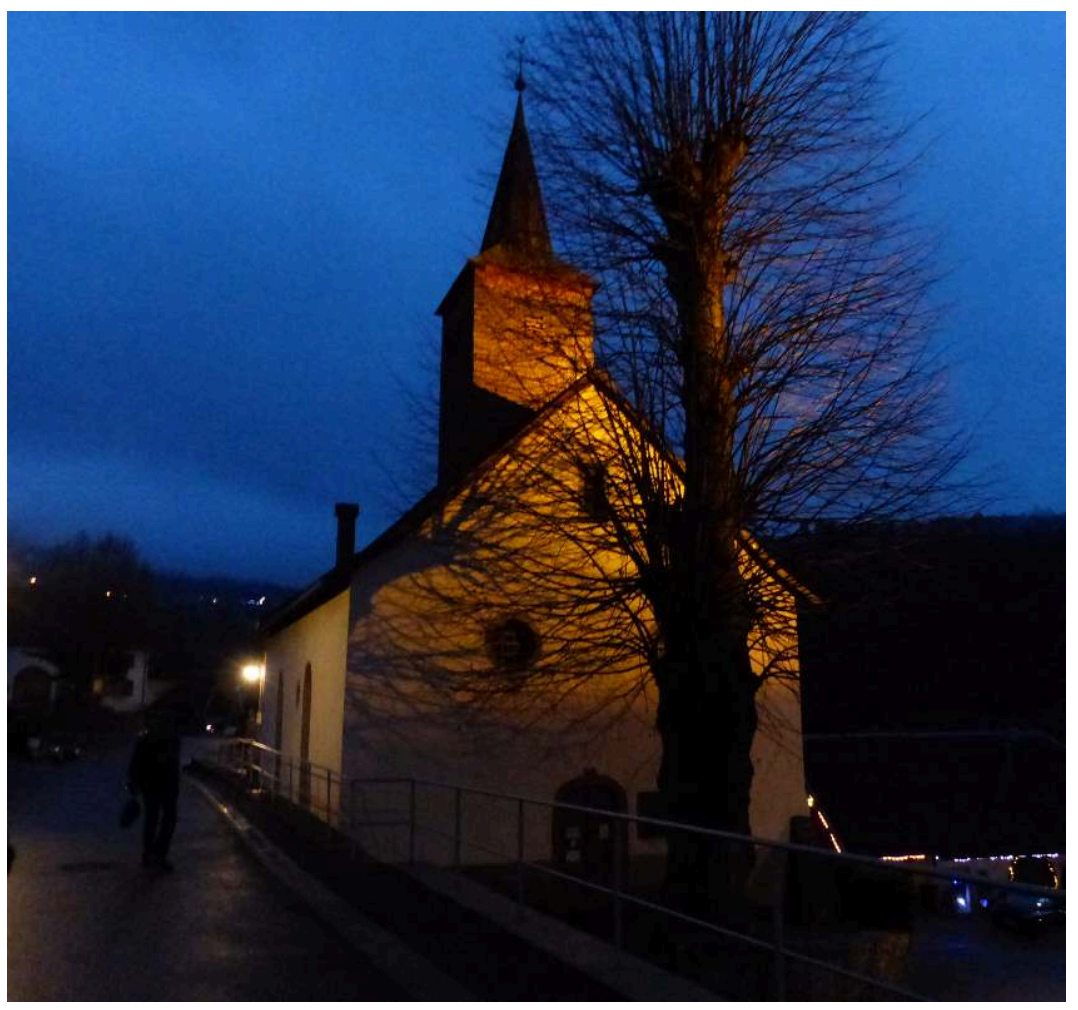

(c) Musée Oberlin, crédit photographie : Élisabeth Manouvrier.

7 Cet isolement géographique, où il vécut pendant 59 ans, n'en fait pas pour autant un homme seul. Il lit beaucoup et correspond avec ses pairs dans toute l'Europe. Il est en relation épistolaire avec le mouvement piétiste des Frères Moraves, et la baronne de Krudener sera plusieurs fois l'hôte du presbytère de Waldersbach. L'un de ses gendres ira prendre un poste de pasteur en Russie et son fils Henri Gottfried sera précepteur à Riga. De ce fait, Oberlin échange des messages avec le tsar et, lors de l'invasion de 1814, le presbytère sera placé sous la sauvegarde de ce souverain. Il est aussi en correspondance avec Lavater, dont il apprécie les élucubrations scientifiques, de même que le phrénologue Gall (fig. 5). 
Fig. 5. - Le presbytère de Waldersbach.

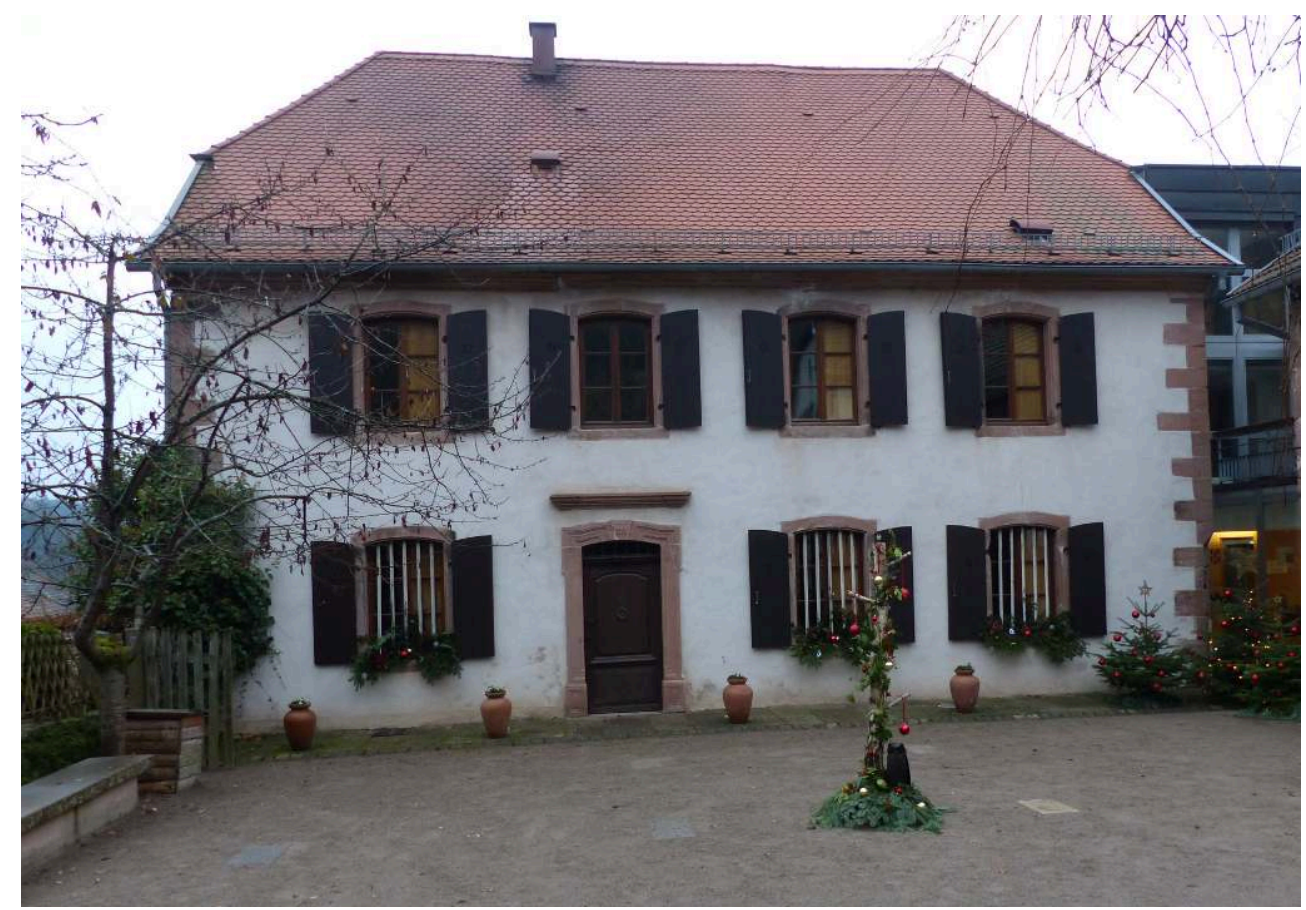

Construit par le baron de Dietrich pour loger le pasteur et sa famille, c'est une construction typique des logements d'hommes d'Église au xvIII siècle. On en remarque la sobriété, la symétrie des ouvertures, mais aussi la richesse des encadrements de la porte et des fenêtres en grès rose, à linteaux arrondis. Ce bâtiment abrite aujourd'hui le Musée Oberlin.

(c) Musée Oberlin, crédit photographie : Élisabeth Manouvrier.

Paradoxalement, et parallèlement à ses relations avec les courants mystiques, il adhère aux idées de l'Europe des Lumières. Il est en parfait accord avec l'abbé Grégoire sur l'esprit républicain et les droits de l'homme. Il le rencontrera et les deux personnages entretiendront une correspondance suivie. Grâce à l'abbé Grégoire et à François de Neufchâteau, l'activité économique et sociale du pasteur sera reconnue par deux distinctions honorifiques : la médaille d'or de la société royale d'agriculture en 1818 et la légion d'honneur en 1819. Il adhère aux théories des physiocrates et possède dans sa bibliothèque plusieurs manuels d'agriculture. Il connaît les "Éléments d'agriculture " de Duhamel de Monceau (1762), le "Socrate rustique» du Suisse Hirzel ${ }^{3}$. Ces deux auteurs se rattachent au mouvement physiocratique pour lequel seule l'agriculture est productrice de richesse et sa primauté absolue doit être posée comme programme politique. Duhamel de Monceau prône, outre la culture du blé, celle des fourrages artificiels et des nouveaux tubercules et racines telles que les pommes de terre, les raves et les navets. Hirzel dans son livre, traduit en français en 1764, envisage avant tout un projet de société rurale dans le cadre d'un idéal social moralisateur.

9 Il sera aussi en relation, dans la lignée de l'Émile de J.-J. Rousseau qu'il a lu et annoté, avec les pédagogues novateurs de son temps. Il possède le Manuel élémentaire ou recueil méthodique des connaissances nécessaires à l'instruction de la jeunesse de Basedow de Dessau. Il visitera les pédagogues de la vallée du Rhin : Jean Georges Stuber, son prédécesseur, le pasteur Schlosser à l'Institut d'Éducation d'Emmendingen, l'académie militaire de Pfeffel à Colmar. Il connaît aussi l'œuvre de Pestalozzi. 


\section{La révolution agricole au Ban de la Roche}

10 L'effort du pasteur Oberlin dans le domaine des progrès agricoles, inspirés par les physiocrates et les agronomes de son époque, se porta en premier lieu sur l'amélioration des rendements des cultures existantes par l'augmentation des engrais. Dès 1775 , il rédige un avis au public où il préconise trois moyens d'augmenter le fumier, dont la construction de coffres à fumier et de fosses à purin, et il offre une récompense de 9 livres à ceux qui exécuteront ses directives.

11 Le deuxième point important est l'amélioration des pâturages. Dans les zones humides, ils doivent être suffisamment drainés et les prés de fauche améliorés et développés pour permettre la stabulation pendant l'hiver. On doit augmenter aussi le fourrage par la création de prairies artificielles. Oberlin choisit pour cela le trèfle de Hollande qui réussira parfaitement au Ban de la Roche. Si les bêtes peuvent être nourries à l'étable, la vaine pâture doit disparaitre et les pâturages devenir des champs cultivables.

12 Le pasteur Oberlin préconise de nouvelles cultures: le lin, la pomme de terre déjà connue, mais dont il fait venir de nouvelles semences de Riga destinées à améliorer la productivité, la betterave fourragère, le trèfle. Pour remédier à l'érosion des sols et à la déforestation massive due à l'industrie métallurgique, il recommande de planter des arbres : des fruitiers pour l'alimentation, mais aussi des arbres destinés à reconstituer la forêt.

13 En 1782, il crée une caisse d'emprunt doublée d'une caisse d'amortissement qui devait aider les emprunteurs à se dégager progressivement de leurs dettes. Ceux-ci sont soigneusement sélectionnés pour leur moralité et leur conduite exemplaire. Il encourage ses paroissiens à s'assurer contre les incendies, fréquents et catastrophiques de fait de la proximité des maisons et de leur couverture en chaume. Au-delà des physiocrates, il propose non seulement un projet agricole, mais un idéal social issu d'un ordre moral voulu par Dieu.

\section{Développement de l'industrie}

14 Pour assurer un complément de ressources à ses paroissiens, le pasteur Oberlin s'est aussi préoccupé de développer une industrie locale. Au début du XIX ${ }^{e}$ siècle, l'activité minière et métallurgique perd de l'ampleur, le tissage artisanal à domicile est en train de disparaitre. Il invite alors la famille Legrand, père et fils, à venir installer au Ban de la Roche une véritable industrie textile. Jean-Luc Legrand, né à Bâle, juriste, pédagogue (collaborateur de Pestalozzi), commerçant et industriel, exploitant un brevet pour tisser la bourre de soie, choisit de créer une rubanerie et inaugure avec Oberlin une collaboration exemplaire. Son fils Daniel poursuivra son œuvre et prendra part à l'élaboration d'une législation internationale du travail, en particulier pour les enfants.

\section{Un modèle architectural}

L'architecture traditionnelle du Ban de la Roche s'apparente à la maison vosgienne, ferme monobloc où bêtes et gens vivent sous le même toit. Les maisons sont construites en moellons de grès, avec pignon souvent en colombage. Les encadrements de portes et de fenêtres sont en grès taillé, particulièrement remarquables par le portail en plein 
cintre de la grange. La pente des toits est importante et ceux-ci sont, la plupart du temps, couverts en chaume.

La disposition intérieure sépare nettement les hommes des animaux et la maison comporte deux systèmes de circulation, l'un à l'intérieur pour l'hiver qui fait communiquer l'habitation, la grange et l'étable, et l'autre à l'extérieur pour la belle saison, par l'« usoir ». Le logement proprement dit comporte, en façade, une entrée, la pièce commune, et éventuellement une chambre, et sur l'arrière, la cuisine et une autre pièce annexe, souvent utilisée comme atelier de tissage. L'aménagement des combles en pièces d'habitation est rare. Les maisons sont pauvres, exiguës, correspondant à de très petites exploitations à l'usage d'ouvriers-paysans.

Le pasteur Oberlin va s'employer à améliorer cet habitat. Il va charger le maître d'école de Bellefosse de découvrir des couches de grès de bonne qualité pour éliminer le bois et édifier des constructions moins humides. Des carrières furent ainsi ouvertes à Colroyla-Roche, Plaine et Champenay. Et à la fin du XviII ${ }^{e}$ siècle, avec le peu d'aisance qui s'est installé dans les villages, le grès remplace peu à peu le bois.

Pour des raisons d'économie et de confort thermique, il encourage la construction de maisons doubles où deux habitations sont disposées symétriquement, de part et d'autre d'une grange commune, ou dos à dos (fig. 6). Il encourage l'amélioration de l'hygiène et du confort par des plafonds plus élevés, des ouvertures plus larges. En place des cheminées ouvertes, il préconise, par l'exemple, un système de chauffage de type alsacien, plus efficace, qui comporte, dans la salle commune, un gros poêle (fig. 7) alimenté par le foyer de la cuisine. Enfin il favorise parmi la population, par l'octroi de bourses, l'apprentissage des métiers du bâtiment.

Fig. 6. - Une ferme double selon un des plans recommandés par le pasteur Oberlin.

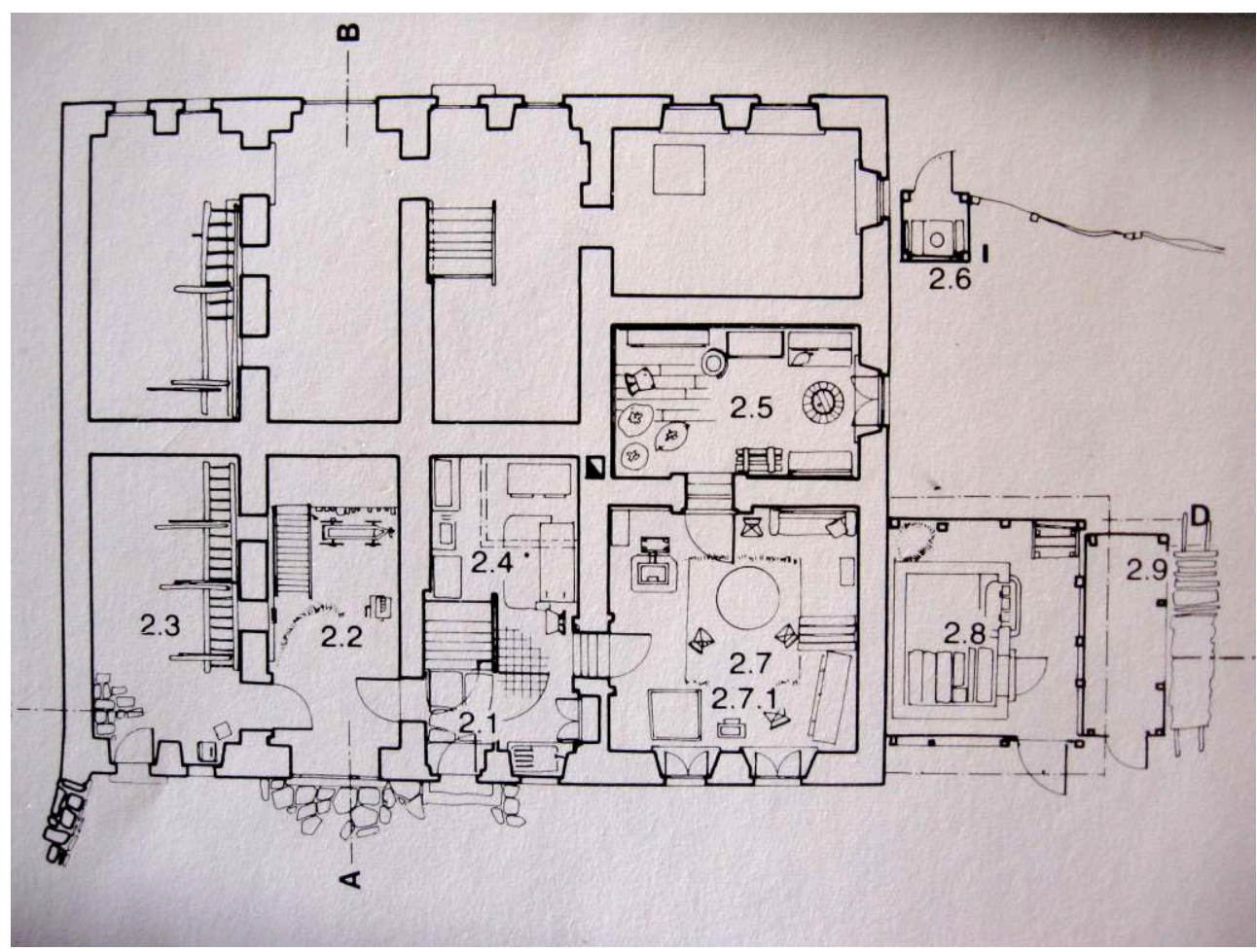

La symétrie est quasi parfaite mais l'une des fermes est maintenant inoccupée.

(c) Musée Oberlin, crédit photographie : Élisabeth Manouvrier. 
Fig. 7. - Le poêle en fonte, dit « pyramide ", à tambours emboîtés.

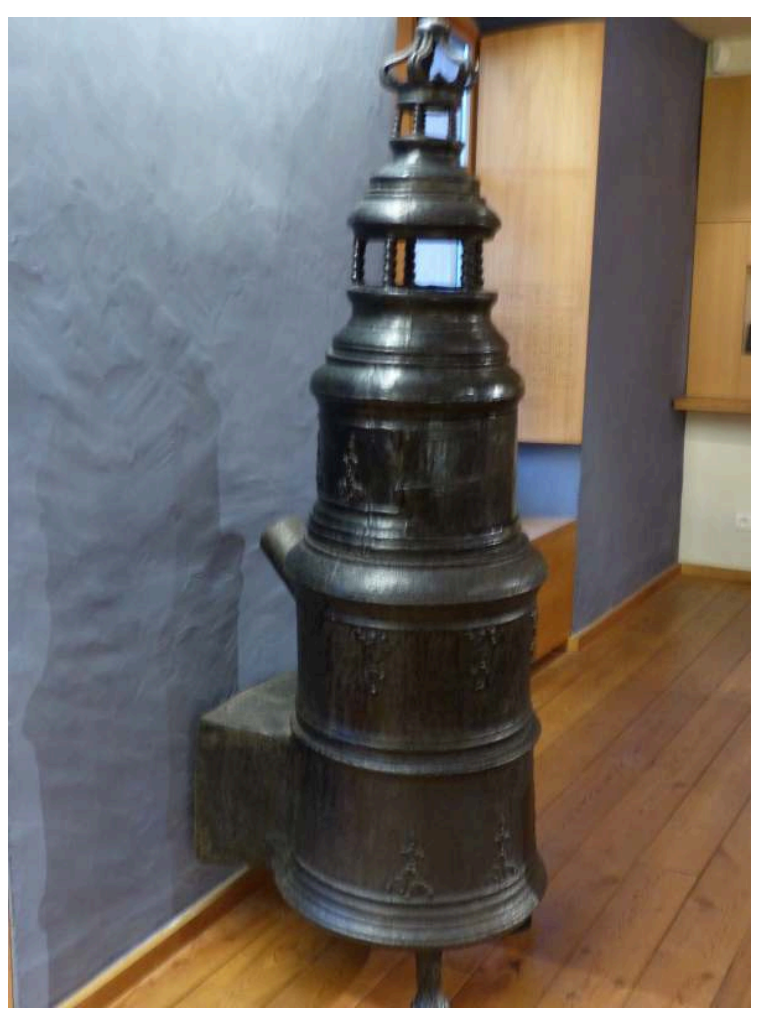

Le poêle en fonte chauffait la salle commune du presbytère, était recommandé par le pasteur en remplacement des cheminées traditionnellement utilisées dans la région.

(c) Musée Oberlin, crédit photographie : Élisabeth Manouvrier.

\section{L'instruction}

19 Mais le pasteur Oberlin, en homme éclairé de son siècle, pense que le progrès au Ban de la Roche ne sera possible que si la population possède la maitrise des nouveaux savoirs. Il va donc poursuivre et amplifier l'œuvre pédagogique de son prédécesseur, J. G. Stuber. Pour lui, l'instruction commence tôt et doit se prolonger tout au long de la vie. Il fera construire une école dans chaque village ${ }^{4}$, instruire des maitres. Il est considéré comme l'initiateur en France des écoles maternelles avec ce qu'il appelait « les poêles à tricoter » destinés aux plus jeunes et dirigés par les « conductrices de la petite enfance». Pour les adultes, il organisera des conférences et créera une bibliothèque de prêt de plus de 100 volumes.

Le matériel pédagogique qu'il a lui-même confectionné, réparti actuellement entre le Musée Oberlin de Waldersbach et le Musée Alsacien de Strasbourg, est impressionnant : plaques de lanterne magique, cartes de géographie du Ban de la Roche, de la France, de l'Europe, cartes à jouer supports de leçons de vocabulaire d'animaux et de plantes, modèles réduits de machines mécaniques (tours, bocards), instruments scientifiques (microscope, kaléidoscope, lanternes magiques). Il porte un intérêt tout particulier à la botanique, et a lui-même composé un vaste herbier (fig. 8) où il s'applique à déterminer les propriétés alimentaires et thérapeutiques des plantes locales, dont certaines sont 
déjà bien connues des habitants. Ce savoir pratique est intégré à l'enseignement dès le plus jeune âge, lors de promenades pour les plus petits.

Fig. 8. - Planche de l'herbier d'Oberlin. Fin du XVIII' siècle.

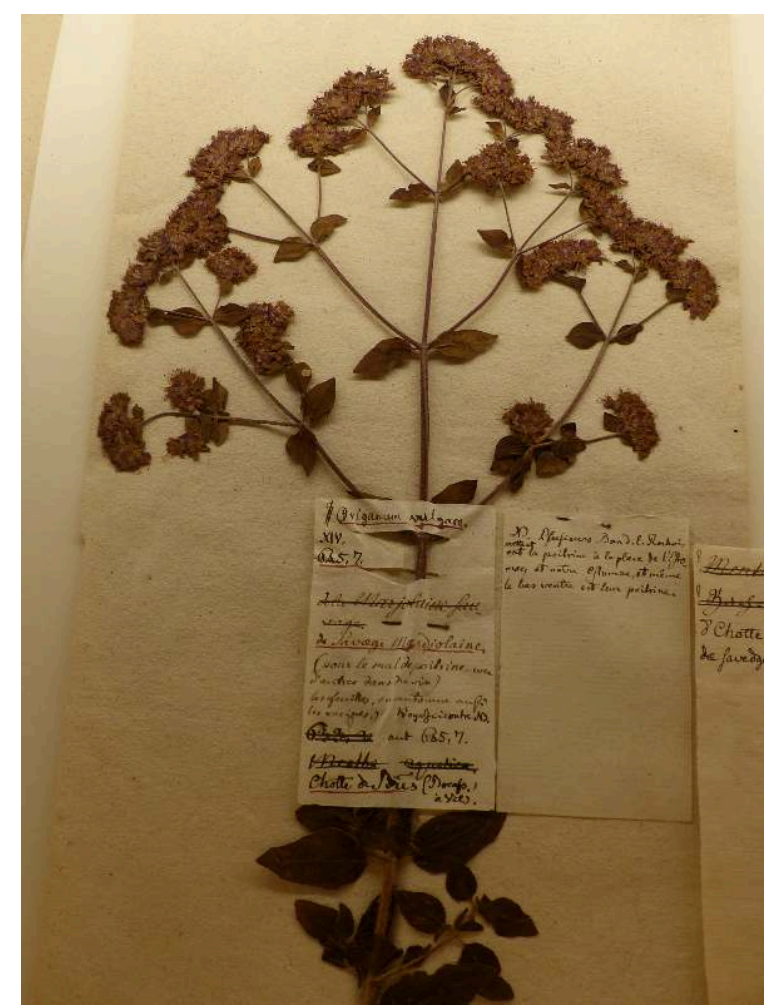

Le nom de la plante est inscrit en latin, en français et en patois local. Ses propriétés curatives sont aussi précisées.

(c) Musée Oberlin, crédit photographie : Élisabeth Manouvrier.

Les grands principes de cette pédagogie nouvelle tiennent compte du rythme de développement de l'enfant, de l'importance des sens dans l'apprentissage (Il s'agit de toucher, sentir, manipuler avant de nommer) et du besoin de produire pour mieux comprendre. Oberlin se soucie de former ainsi un homme utile à la société.

Jean Frédéric Oberlin est devenu une figure légendaire, connu jusqu'au Japon et aux États-Unis pour son œuvre philanthropique, sociale et pédagogique. Homme des Lumières, il s'est essayé, dans le petit univers du Ban de la Roche, à développer, dans un esprit à la fois mystique et pragmatique, une économie de montagne fondée sur une agriculture novatrice, inspirée des physiocrates, complétée par une industrie moderne, alors naissante. Son souvenir reste bien vivant, relayé par la création à Waldersbach d'un musée dont la réputation dépasse nos frontières. Néanmoins, les conditions naturelles peu favorables dans un site de montagne particulièrement rude, n'ont pas abouti à la prospérité agricole espérée. Ce n'est que grâce au développement de l'industrie textile, dans la deuxième moitié du xixe siècle, que la population du Ban de la Roche a pu survivre sur place, cette phase de relative prospérité économique étant maintenant terminée. 


\section{BIBLIOGRAPHIE}

DENIS Marie-Noële et ERKER Alain, « Les jouets d'Oberlin », dans SCHNEIDER Malou et GEILER MarieJeanne (dir.), Jean Frédéric Oberlin. Le divin ordre du monde 1740-1826, Strasbourg, éd. du Rhin, 1991, p. 101-113.

DENIS Marie-Noële et GROSHENS Marie-Claude, L'architecture rurale française, vol. Alsace, Paris, Berger-Levrault, 1979.

Encyclopédie d'Alsace, article « Oberlin », Strasbourg, Publitotal, 1984, vol. 9, p. 5608-5609.

GROSHENS Marie-Claude et BALD Gilbert, « Habitat et habiter au ban de la Roche », Revue des Sciences Sociales de la France de l'Est, nº 9, 1980, p. 246-263.

HERTZOG Jean-François, Description du Ban de la Roche, Strasbourg, F. G. Berger-Levrault, An VI de la République Française.

MAEYENS Claude, « Le Ban de la Roche. L'évolution géographique d'une cellule de moyenne montagne du XVIII siècle à nos jours ", thèse de géographie $3^{\mathrm{e}}$ cycle, université de Strasbourg, 1975.

PETER Roland, « Le pasteur Oberlin et l'abbé Grégoire », Bulletin de la Société d'Histoire du Protestantisme Français. CXXVII, 1981.

SCHNEIDER Malou et GEILER Marie-Jeanne (dir.), Jean Frédéric Oberlin. Le divin ordre du monde 1740-1826, Strasbourg, éd. du Rhin, 1991.

\section{NOTES}

1. G. Dumoulin, Oberlin. Cité par M. Schneider et M. J. Geiler, Le pasteur Oberlin, le divin ordre du monde.

2. Cl. Maeyens, «Le Ban de la Roche. L'évolution géographique d'une cellule de moyenne montagne $d u$ XVIII $^{\mathrm{e}}$ siècle à nos jours ", thèse de géographie $3^{\text {ème }}$ cycle, université de Strasbourg, 1975, pp. 35-43.

3. Ces deux volumes, annotés par lui, existent dans sa bibliothèque.

4. À Waldersbach en 1770, Bellefosse en 1773, Belmont en 1779.

\section{RÉSUMÉS}

Le pasteur Oberlin a exercé son ministère pendant 60 ans dans les huit paroisses des Vosges qui constituent le fief du Ban de la Roche. Ami de l'abbé Grégoire, connu de François de Neufchâteau, en correspondance avec les esprits éclairés de l'époque, à la fois pragmatique et mystique, il est connu surtout pour ses innovations en matière d'enseignement. Il a mené aussi une action civilisatrice dans cette région déshéritée de montagne. Il s'est attaché à développer l'agriculture 
en encourageant l'extension des terres labourables, la culture de plantes nouvelles (pomme de terre et trèfle), en développant l'élevage. Il encouragea la plantation d'arbres fruitiers et d'espèces destinées à régénérer la forêt. Il innova en créant une société d'agriculture et une caisse d'épargne. En complément de cette agriculture peu productive, il s'est employé à attirer dans la vallée des industriels du textile. Il se soucia aussi d'améliorer l'habitat par la recherche de matériaux solides et sains, la transformation du plan des maisons, du système de chauffage, la multiplication des ouvertures, la formation d'artisans spécialisés. Enfin son œuvre pédagogique, qui débute dès la maternelle, offrit à ses paroissiens, par des méthodes novatrices, avec les outils pour maîtriser leur environnement, une ouverture sur le monde.

\section{AUTEUR}

\section{MARIE-NOËLE DENIS}

Chercheur CNRS retraitée 


\title{
Histoire de la migration marchande de la Vallée de Barcelonnette : une première esquisse
}

\author{
Laurent Surmely
}

\footnotetext{
Lorsque l'on évoque l'émigration dans la Vallée de Barcelonnette $^{1}$ (fig. 1), immanquablement, c'est la spectaculaire et originale migration des Barcelonnettes au Mexique qui vient à l'esprit. Cependant les nombreuses données recueillies et rassemblées par l'association historique Sabença de la Valéia, par les érudits locaux des siècles précédents et par le musée de Barcelonnette indiquent que, dès le XvII siècle au moins, le commerce était pratiqué par les habitants de cette vallée dans différentes régions de France et quelques pays limitrophes.
} 
Fig. 1. - La Vallée de Barcelonnette (1718-1790).

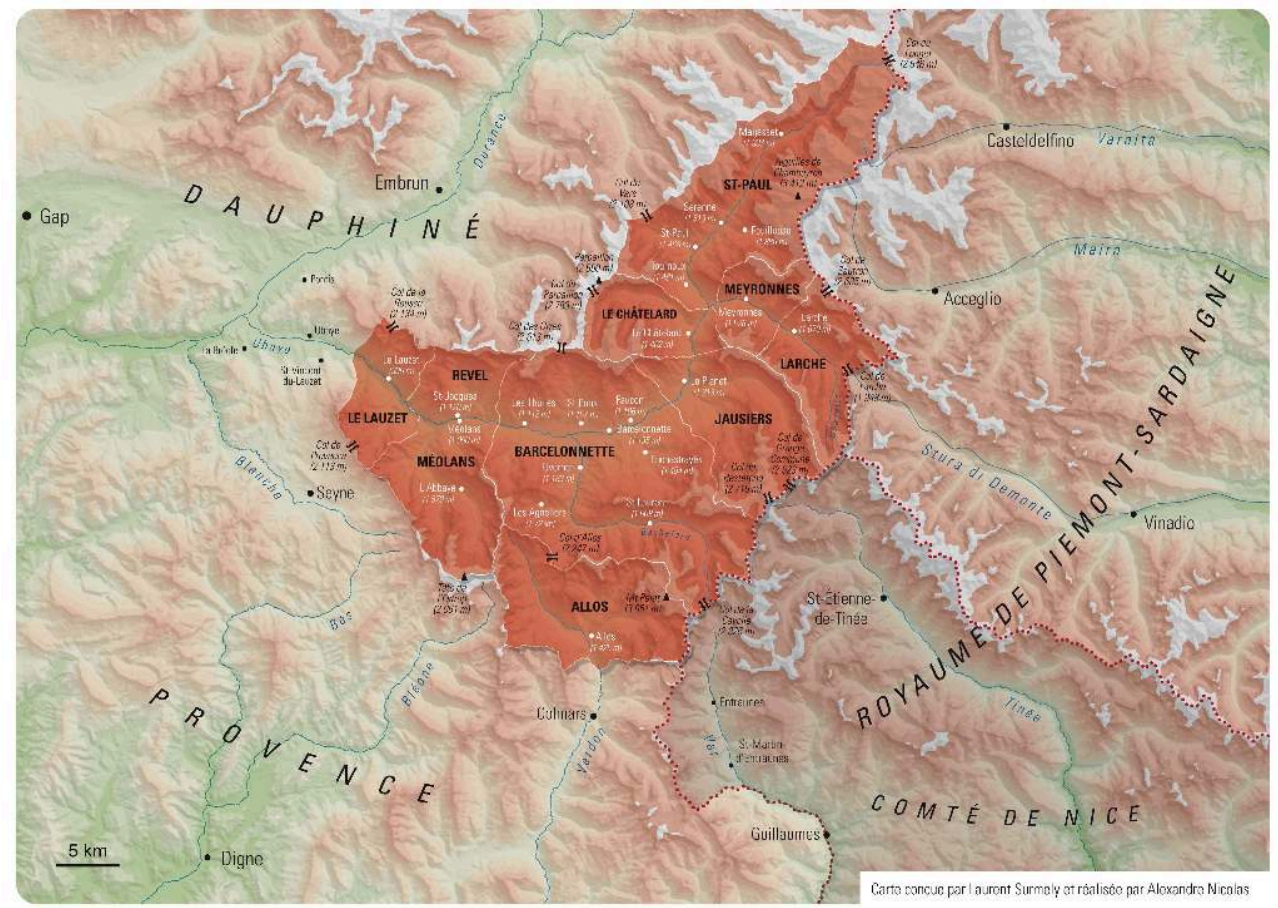

(c) Laurent Surmely et Alexandre Nicolas.

2 Depuis le début des années 2000, nous avons entrepris toute une série de recherches visant à comprendre l'émigration saisonnière de cette vallée pour les deux derniers siècles de l'Ancien Régime en essayant de reconstituer les réseaux migrants. Trois études y ont été particulièrement consacrées. Une première, inédite, menée à partir des archives judiciaires produites par les deux tribunaux ayant pour ressort la Vallée dans son ensemble ${ }^{2}$, nous a permis de comprendre dans ses grandes lignes les réseaux marchands de la période 1752-1791 à l'échelle du territoire. Grâce à une deuxième, qui sera bientôt partiellement publiée ${ }^{3}$, effectuée grâce à l'exploitation des archives judiciaires et notariales de la communauté d'habitants de Jausiers entre 1610 et $1730^{4}$, nous avons pu reconstituer les réseaux migrants à une échelle plus restreinte. Une troisième, elle aussi inédite, qui synthétise à la fois des données issues des listes des registres du tirage au sort (1817-1860) et les registres de passeport pour l'extérieur (1833-1860) ${ }^{6}$ nous a donné la possibilité d'évaluer la situation des réseaux migrants dans leurs grandes lignes et d'identifier quelques évolutions durant la première moitié $\mathrm{du} \mathrm{XIX}^{\mathrm{e}}$ siècle. L'ensemble de ces travaux, ainsi que la synthèse des données éparses connues, complétés par une étude rapide réalisée dans les registres de l'insinuation de Barcelonnette entre 1611 et $1634^{7}$ et par une autre dans les archives notariales de Jausiers entre 1730 et 1820 , nous permettent aujourd'hui d'esquisser une première histoire des réseaux marchands de la Vallée de Barcelonnette.

\section{L'âge du " grand commerce » (XVe-début du XVII siècle)}

En raison du faible nombre de données disponibles, cette période et ses bornes ont été déterminées essentiellement par rapport à nos connaissances des réseaux marchands suivants et aux quelques informations rassemblées sur ces siècles qui clôturent le 
Moyen Âge et couvrent une bonne partie de l'époque moderne. Si le début de la chronologie est vague et approximatif, la fin est mieux établie. À Jausiers, l'analyse des archives indique que la période, qui s'étend d'au moins 1610 jusqu'aux années 1640, constitue un temps de transition et de mutation pour son réseau marchand. Ce découpage arbitraire ne recouvre donc aucune réalité historique mais permet d'établir l'ancienneté des réseaux marchands et quelques-unes des caractéristiques que nous retrouverons tout au long de leur histoire. Nous l'avons dénommé l'âge du «grand commerce » car, contrairement aux âges suivants, le réseau marchand valéian semble géographiquement plus étendu et moins spécialisé que ses successeurs.

4 Actuellement, les premiers marchands valéians ${ }^{8}$ identifiés sont Marcellin Guiramand de Barcelonne et, peut-être, Pierre Textoris, installés à Aix-en-Provence. En 1405, ils s'associent avec Pierre Barre marchand drapier de Marseille. Dans cette société ce dernier fournit deux tiers du capital et se charge de garantir l'approvisionnement en marchandises provenant des différentes foires du royaume de France qu'il fréquente. Leur société est spécialisée dans le commerce de draps qu'elle diffuse dans la cité via une boutique acquise avant 1411. Durant la première moitié du xve siècle, Marcellin et Pierre Textoris poursuivent leur activité avec d'autres associés constituant plusieurs sociétés successives. Au même moment, une autre compagnie marchande drapière valéiane possédant une boutique exerce son activité à Aix. Il s'agit de la société associant Jacques Guiramand et un marchand de Pertuis9.

5 Il est impossible de dire, avec ces deux seuls exemples, si un réseau marchand valéian existe dès le $\mathrm{xv}^{\mathrm{e}}$ siècle. Cependant les caractères originaux qui transparaissent à travers l'histoire de ces deux boutiques (sociétés ou compagnies marchandes valéianes groupant de deux à quatre associés se livrant à l'importation de marchandises textiles revendues dans leur région d'implantation grâce à des boutiques situées en ville) et que l'on retrouvera, à quelques exceptions près, dans quasiment tous les réseaux suivants jusqu'au $\mathrm{xx}^{\mathrm{e}}$ siècle, plaident en faveur de l'existence de réseaux marchands valéians actifs dès le dernier siècle du Moyen Âge.

6 Dans la première moitié du XviI ${ }^{e}$ siècle, l'échantillon de 75 marchands, collecté dans les registres de l'insinuation de Barcelonne, nous met en présence d'un réseau marchand qui s'étend de la Toscane à l'Espagne avec cependant une assez forte concentration d'individus en Provence et dans la basse vallée du Rhône (fig. 2). Même si nous ne connaissons pas les logiques qui ont présidé à une telle configuration, il est intéressant de noter que ce réseau semble utiliser les voies commerciales traversant les Alpes qu'empruntent certaines marchandises, notamment textiles ${ }^{10}$. 
Fig. 2. - Villes fréquentées par les marchands de Barcelonnette (1610-1634).

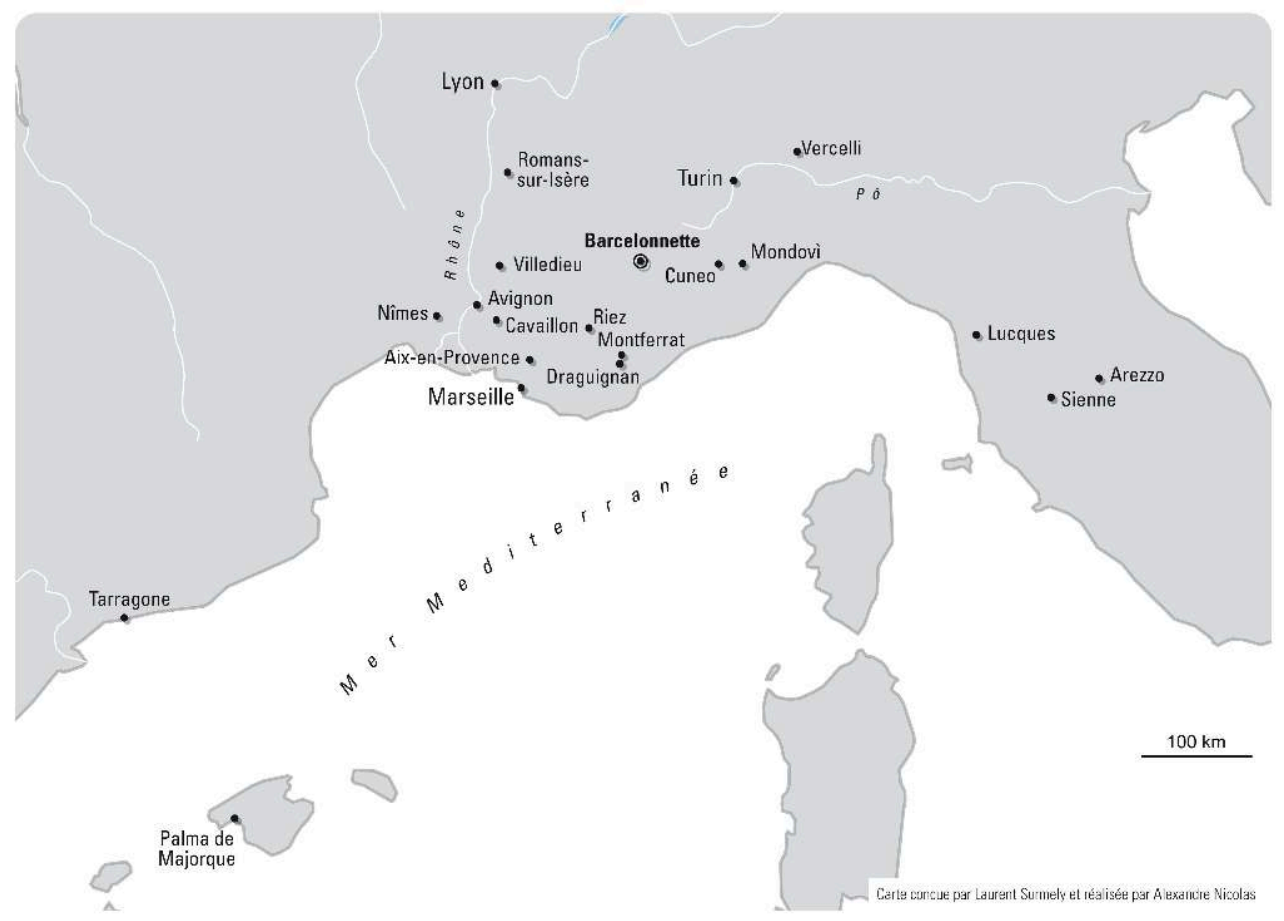

(c) Laurent Surmely et Alexandre Nicolas. D'après les registres de l'insinuation de Barcelonnette.

7 Même si le type de commerce pratiqué n'est connu que pour une minorité d'entre eux, les marchands repérés dans l'insinuation sont des commerçants qui exercent le grand commerce et sont spécialisés dans les tissus, essentiellement les draps, à l'exemple de Pierre Gastinel. Ce natif de la paroisse de Saint-Pons est installé à Palma de Majorque où il possède une boutique de tissus depuis 1608 environ ${ }^{11}$. Ce marchand s'intéresse également à ce qui fait la richesse de l'île : l'huile, le blé, qu'il exporte. Cette propension à investir ses capitaux dans les secteurs assurant la richesse des régions où l'on est installé est aussi une caractéristique très forte des réseaux marchands valéians des siècles suivants, du moins pour les commerçants les plus importants. Pierre appartient sans l'ombre d'un doute à un réseau marchand valéian, il est en affaire avec ses cousins Pierre Bruet de Barcelonne et Glaud Lion installé à Marseille. Entre 1616 et 1632, il prend en apprentissage ${ }^{12}$ au moins cinq jeunes gens de sa vallée d'origine. Il existe également une autre boutique tenue par un valéian qui vend des tissus à Palma de Majorque : celle de Jean Graugnard ${ }^{13}$.

8 Les échantillons collectés de marchands au début du XVII siècle tant à Barcelonne qu'à Jausiers semblent indiquer que les réseaux marchands ne comprennent pas que des commerçants effectuant le grand commerce mais aussi de plus petits se livrant à un commerce beaucoup plus modeste, pratiquant peut-être le colportage. C'est ce que semblent indiquer, même si nous n'en avons pas la preuve formelle, à la fois la forte concentration des marchands valéians dans une zone géographique assez limitée (basse vallée du Rhône et Provence) et les implantations repérées dans de toutes petites villes, voire des villages. 


\section{Lâge des réseaux marchands en Piémont et dans les États génois (début XVII siècle-années 1740)}

9 À Jausiers (communauté d'habitants comprenant 335 maisons en 1702) ${ }^{14}$, les échantillons de marchands ou supposés tels, indiquent que les 40 premières années du $\mathrm{XVII}^{\mathrm{e}}$ siècle marquent la fin d'une période de mutation de son réseau marchand. Cohabitent ainsi des marchands fréquentant la Provence, la basse vallée du Rhône (fig. 3), la Toscane, et d'autres, toujours plus nombreux au fil des années, la plaine piémontaise. Passé les années 1650, seule cette dernière destination avec, dans une moindre mesure, la côte génoise, à partir des années 1660, sont fréquentées et sillonnées par les commerçants jausiérois. L'impression, non vérifiée faute de connaissances sur la période précédente, est que ce redéploiement du réseau s'accompagne d'une spectaculaire montée des effectifs. Sur la période 1615-1730, l'échantillon de marchands constitué compte 612 individus commerçant en Piémont et 28 dans les états génois (fig. 4). De toute évidence se produit à Jausiers, bien que plus précocement et suivant des modalités et une chronologie différentes, un phénomène que Laurence Fontaine avait décrit et appelé le « repli sur l'espace régional » ${ }^{15}$.

Fig. 3. - Villes françaises fréquentées par les marchands de Jausiers (vers 1615-1655).

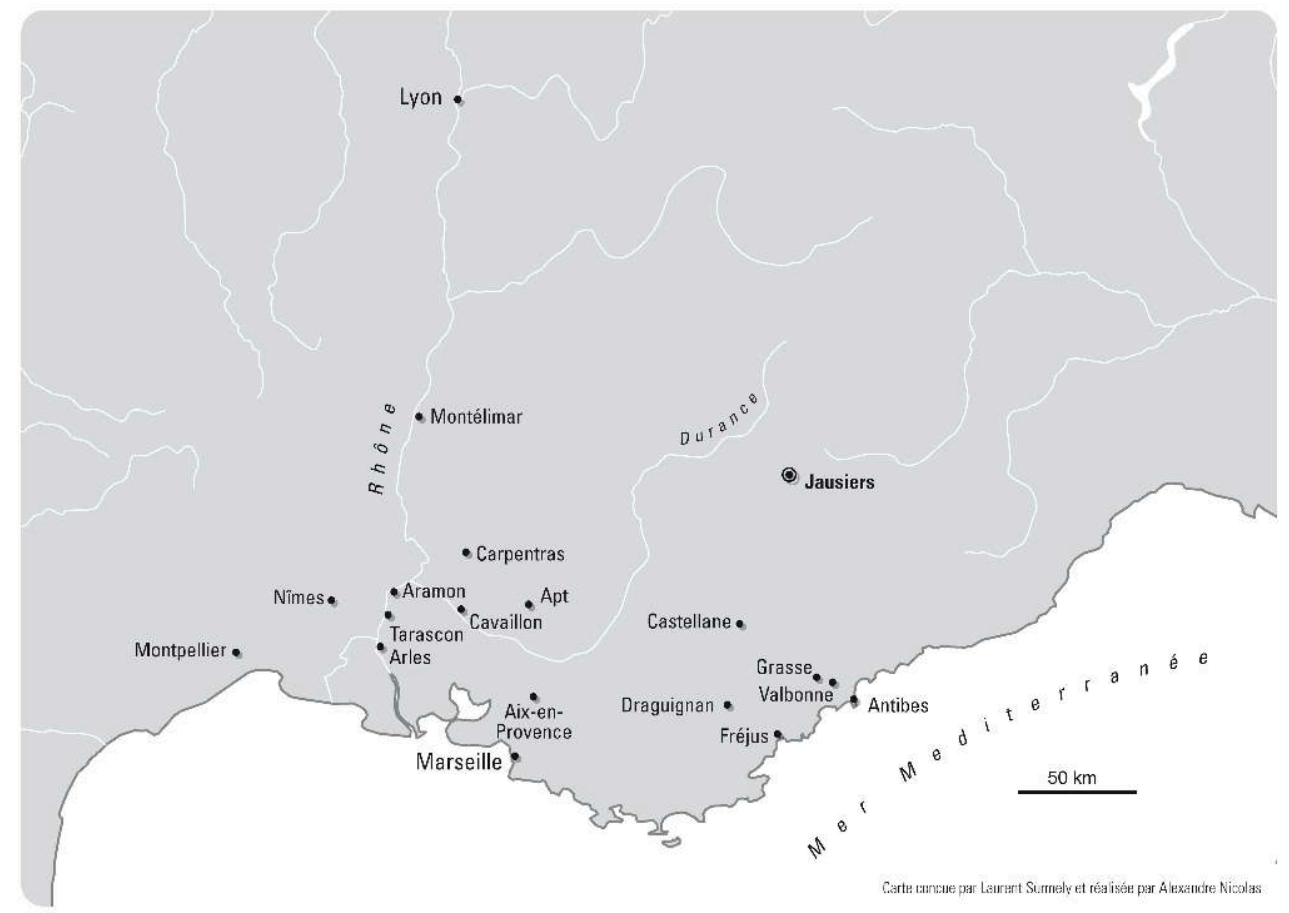

(c) Laurent Surmely et Alexandre Nicolas. D'après les archives notariales et judiciaires locales. 
Fig. 4. - Villes piémontaises et génoises fréquentées par les marchands de Jausiers (vers 1615-1730).

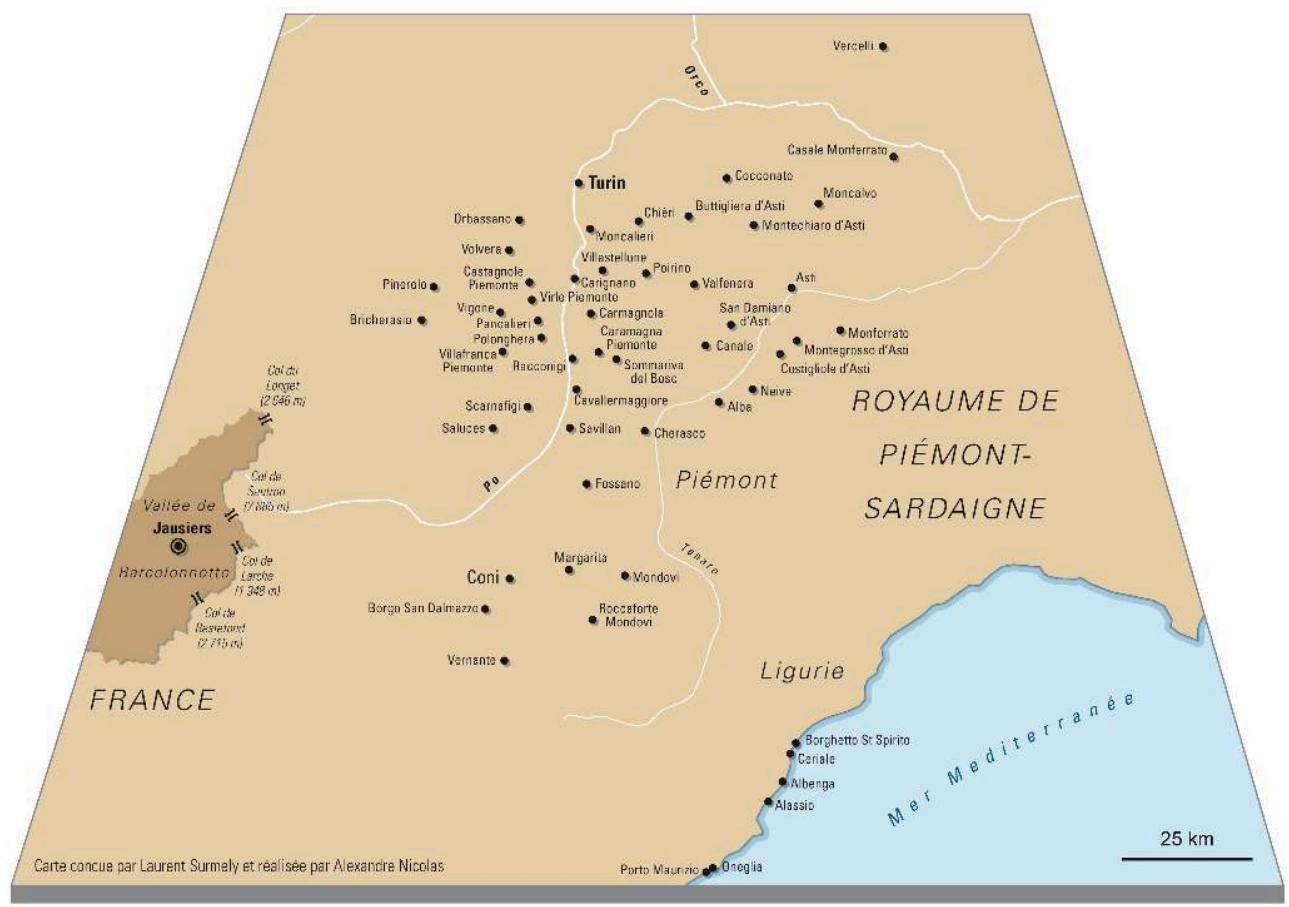

(c) Laurent Surmely et Alexandre Nicolas. D'après les archives notariales et judiciaires locales.

Ce nouveau réseau se compose de marchands associés, comme à l'âge précédent, au sein de sociétés établies pour des durées variant de quatre à dix ans, dont chaque membre apporte une partie du capital (en numéraire mais aussi en marchandises). Ces compagnies marchandes, dont les associés ont souvent des liens de parenté plus ou moins éloignés, se livrent à un commerce transalpin. Elles importent en Piémont et sur la côte génoise, grâce à de véritables caravanes muletières qu'ils affrètent, des marchandises textiles (draps, toiles très majoritairement) et un peu de merceries provenant d'une grande partie du royaume de France. Si quelques marchands font le déplacement jusqu'en Bourgogne ou en Languedoc pour leurs achats, la très grande majorité des compagnies marchandes s'approvisionnent à Lyon, alors le deuxième marché textile du royaume où, souvent, un des associés demeure une partie de l'année afin de gérer les achats. Ces sociétés importent aussi une production régionale de draps de laine bon marché, cadis et surtout cordeillats, fabriqués majoritairement dans la Vallée du Verdon (draps dits « de Colmars ») mais aussi dans la Vallée de Barcelonnette. Les marchandises sont réceptionnées et stockées dans les boutiques appartenant à la société. Celles-ci sont installées dans les trois principales villes de la plaine piémontaise: Torino, Casale-Montferrato et, dans une moindre mesure, Cuneo. Dans leur boutique, les compagnies marchandes vendent les marchandises importées, en gros, à d'autres marchands de la ville ou des villes voisines et, au détail, à une clientèle urbaine. Ils approvisionnent aussi, exception faite des draps de Colmars et de la Vallée de Barcelonnette, leurs nombreux compatriotes merciers ${ }^{16}$.

11 Ces derniers représentent l'essentiel de l'effectif. Ils pratiquent le métier de marchand de manière saisonnière, généralement d'octobre à avril. Leur commerce se limite à visiter au cours de leur tournée, plusieurs fois dans l'hiver, une clientèle rurale, résidant dans une dizaine de villages (fig. 5), à qui ils vendent généralement à crédit. 
Leur assortiment de marchandises, transporté par un mulet ou directement à dos d'homme pour les plus modestes, se compose de draps de Colmars et/ou de la Vallée de Barcelonnette qu'ils ont acquis avant leur départ et de draps, de toiles, d'autres marchandises textiles et de merceries achetés dans les boutiques de leurs compatriotes chez qui ils se rendent plusieurs fois dans l'hiver afin de se réapprovisionner. Ce réseau marchand comprend également des marchands-boutiquiers. Ce sont d'anciens merciers ou de jeunes marchands qui ont ouvert des boutiques destinées à écouler le même type de marchandises que leurs congénères mais dans des villes plus modestes que celles où sont installés les magasins des compagnies marchandes, ou dans de gros bourgs. Sur la période étudiée, ce sont 32 villes et bourgs du Piémont et de la côte génoise qui ont compté au moins une boutique tenue par des Jausiérois.

Fig. 5. - La zone de colportage de Jean-Pierre Teissier en Piémont (hiver 1687-1688).

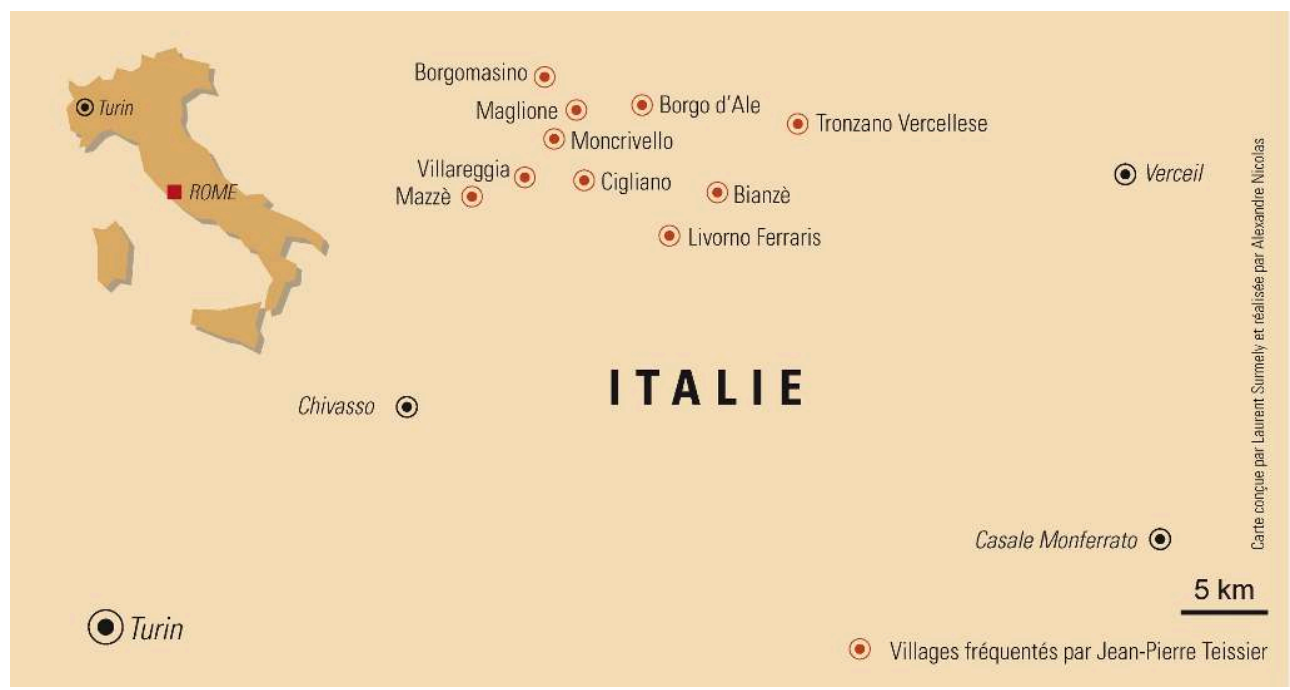

(c) Laurent Surmely et Alexandre Nicolas. D'après son inventaire après décès (2 E 19496, fol. 80 à 97).

En l'état actuel de nos recherches, il apparaît que le réseau marchand, qui a identifié et exploite déjà, avec l'importation de draps de Colmars, un marché porteur pour des draps de laine destinés à une clientèle modeste, a permis la naissance et le développement d'une industrie drapière dans la Vallée. Beaucoup d'indices recueillis dans les archives durant les années 1610-1620 indiquent l'émergence de cette industrie: de nouveaux foulons à drap sont construits à Saint-Paul et à Jausiers notamment ${ }^{17}$. Les foulonniers qui prennent à rente ces nouveaux établissements sont des spécialistes qui viennent de l'extérieur de la Vallée ${ }^{18}$. Un certain nombre de tisserands originaires du Haut-Verdon s'installent à Jausiers et Barcelonnette où se fonde une confrérie Saint-Blaise ${ }^{19}$ composée en partie de d'individus originaires de cette vallée voisine. Des contrats d'apprentissage passés par des tisserands de Colmars sont repérés dans les registres de l'insinuation de Barcelonne jusqu'au début des années 1620. De mêmes normes de fabrication indiquent également que la création/ transformation d'un artisanat domestique en industrie s'est faite grâce à un transfert de savoir-faire du Haut-Verdon vers la Vallée de Barcelonnette. À la fin du XvII siècle, la Vallée exporterait aux alentours de 5000 pièces de draps cordeillats ${ }^{20}$.

Les fortunes acquises par les marchands dans le commerce s'investissent dans l'industrie de la soie qui fait la fortune du Piémont ${ }^{21}$. Idéalement placées sur la route 
commerciale entre Turin et Lyon, premier centre européen de production de tissus de soie, les principales compagnies marchandes jausiéroises s'intéressent dans la deuxième moitié $d u \mathrm{XVII}^{\mathrm{e}}$ siècle à ce commerce. Dans les années 1680 , certains marchands deviennent propriétaires de moulins à soie en Piémont et d'autres réunis autour de la famille Laugier, construisent à partir de 1681 deux moulins à soie dans la Vallée, à Jausiers et à Uvernet. Enfin, en vrais professionnels de la vente à crédit ou pour faciliter les transactions financières des compagnies marchandes auxquelles ils appartiennent, certains marchands se lancent dans le commerce de l'argent en devenant marchands-banquiers en Piémont ou à Lyon.

\section{L'âge du colportage (années 1740-première moitié du $\mathrm{XIX}$ siècle)}

Le réseau marchand de Jausiers subit, à partir des années 1730, de profondes transformations. Sans que nous en connaissions tous les tenants et les aboutissants, il apparaît que ce sont les multiples conséquences induites par le rattachement de la Vallée de Barcelonnette à la France en 1713 qui en soient à l'origine ${ }^{22}$. L'augmentation importante des droits de douane portant sur les marchandises françaises entrant en Piémont et sur la soie piémontaise importée en France sape, pour l'essentiel, les principaux ressorts du commerce jausiérois. Les marchands et merciers prenant la route du Piémont se font de plus en plus rares surtout à partir des années 1760 jusqu'à disparaître quasiment complètement dans les années $1790^{23}$. Si la destination génoise se maintient sans grands changements, de nouvelles aires commerciales apparaissent progressivement: la Provence, Lyon, la Bourgogne et de manière marginale la Flandre. Ces nouveaux réseaux marchands se composent exclusivement d'individus appelés marchands-colporteurs ou marchands-forains (en Bourgogne). Les compagnies marchandes ne sont pas à la tête de ces réseaux, leurs anciens membres sont devenus marchands, industriels ou rentiers majoritairement en Piémont ou à Lyon ou dans la Vallée. Les colporteurs, à la fin du siècle, sont à présent minoritaires à Jausiers. Une très grande partie des enfants de merciers se sont transformés, pour la période hivernale, en porteurs de curiosité c'est-à-dire en montreurs de marmottes, en porteurs de lanterne magique, en joueurs de vielle ou d'orgue. À partir des années $1760 / 1770$, le réseau dominant dans cette communauté d'habitants n'est plus un réseau marchand.

L'évolution constatée à Jausiers, du moins en ce qui concerne le déclin puis la fin du réseau marchand piémontais et l'émergence de nouvelles aires commerciales, se retrouve dans l'échantillon de 386 marchands rassemblé pour la seconde moitié du XVIII siècle. Même si nous manquons de données, les archives utilisées semblent indiquer que pour une majorité de paroisses, des marchands fréquentaient le Piémont jusqu'au début des années 1760. Enclenché apparemment aussi au cours des années 1730 , un mouvement de reconversion touche la plupart d'entre elles. Le petit réseau à destination de la côte génoise se maintient sans grands changements. Les réseaux marchands des hameaux de la partie supérieure du vallon du Bachelard (paroisse de Fours) et de la paroisse de Maurin continuent à rester spécialisés dans le commerce en Piémont, ils n'importent plus de marchandises françaises, du moins légalement, et se réduisent à la seule dimension colporteuse. Ceux des autres paroisses diminuent et changent de destination comme à Jausiers pour laisser la place à d'autres spécialités 
migrantes ou se reconvertissent complètement dans de nouvelles aires commerciales déjà identifiées à Jausiers : Provence, Bourgogne-France-Comté, Flandre orientale-Sudest des Pays-Bas et, nouveauté, la ville de Lyon (fig.6) où les valéians pratiquent un colportage non plus en zone rurale mais en zone urbaine, un ensemble de rues ou un quartier remplaçant la dizaine de villages visités chaque hiver ${ }^{24}$.

Fig. 6. - Villes fréquentées par les colporteurs de la Vallée de Barcelonnette (1752-1791).

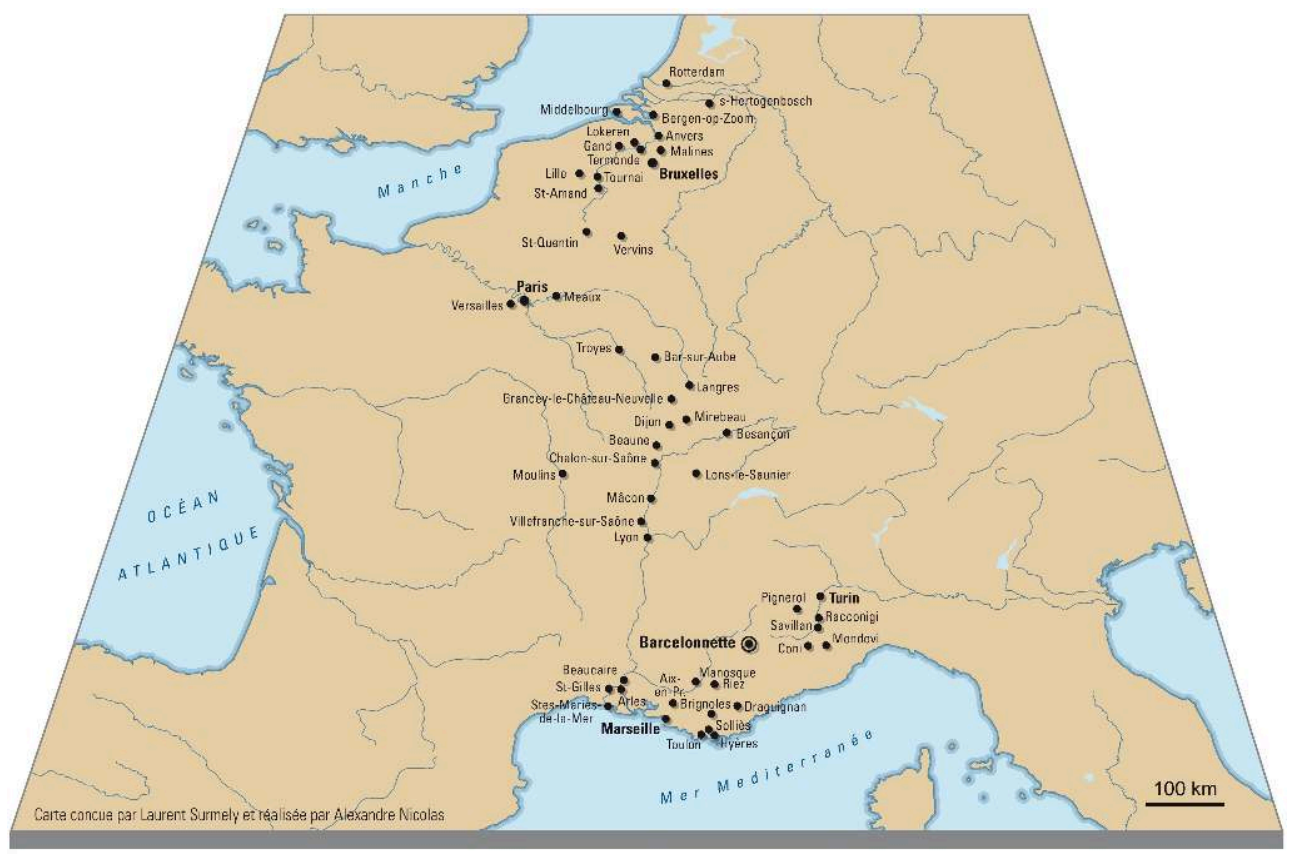

(c) Laurent Surmely et Alexandre Nicolas. D'après les archives des tribunaux de la judicature et de la préfecture de Barcelonnette.

Ces réseaux colporteurs demeurent spécialisés dans la vente de marchandises textiles complétées de mercerie. Ils reposent avant tout sur la diffusion de produits importés dans les campagnes de la nouvelle aire commerciale comme en Piémont (fig. 7). Dans les Flandres, les colporteurs vendent des marchandises provenant d'Angleterre, de France, d'Allemagne, de Suisse et du sud de la Belgique actuelle. Alors qu'apparemment dès le départ, le réseau piémontais maîtrisait ses approvisionnements via les compagnies marchandes, ce n'est pas le cas pour ces nouveaux réseaux lors de leur création. Les colporteurs se fournissent, au début, auprès de marchands locaux installés dans les plus grandes villes. C'est seulement dans un deuxième temps, que d'anciens colporteurs enrichis s'associent afin de créer des boutiques et devenir importateursfournisseurs reformant des réseaux complets allant du grossiste-importateur au colporteur en passant par le marchand-boutiquier. Cette évolution est surtout vraie pour les réseaux bourguignon, lyonnais et peut-être provençal et semble inachevée dans les Flandres. Ces réseaux diffusent également, sauf dans les Flandres, des draps de Colmars et de la Vallée de Barcelonnette, mais en bien moindre quantité que du temps du plein développement de l'âge précédent. D'une manière générale ces nouveaux réseaux, comme nous l'avons constaté à Jausiers, ne réussissent pas quantitativement à absorber tous les anciens merciers et ne trouvent également pas de débouchés assez larges pour la production drapière régionale. 
Fig. 7. - La zone de colportage de Barnabé Léautaud dans les Flandres (hiver 1829/1830).

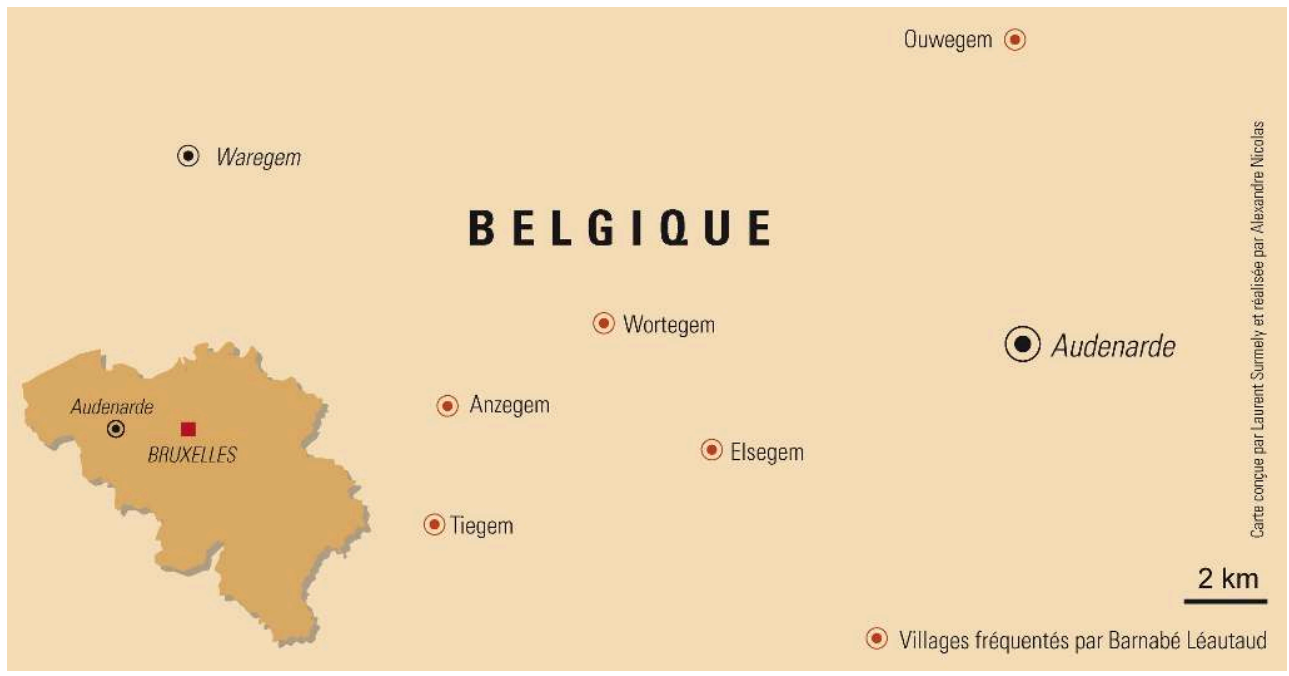

(c) Laurent Surmely et Alexandre Nicolas. D'après son livre des mémoires de ses affaires conservé au musée de Barcelonnette.

L'industrie drapière locale entame ainsi à partir des années 1730 un long déclin qui se terminera par sa disparition complète dans la première moitié $d u$ xix ${ }^{e}$ siècle malgré des tentatives de modernisation, de montée en gamme, voire de reconversion dans d'autres productions comme le coton ${ }^{25}$. Son principal débouché dans la seconde moitié du XVIII ${ }^{\mathrm{e}}$ siècle demeure le Piémont malgré, en 1760 , l'interdiction d'importation des draps français prise par le royaume de Piémont-Sardaigne. Finalement, le moyen le plus efficace que les valéians ont trouvé pour maintenir au moins en partie l'activité de leur industrie drapière jusqu'à la Révolution fut la contrebande. Victimes collatérales également des politiques protectionnistes du royaume de France et du Royaume de Piémont-Sardaigne, les moulins à soie de la Vallée connaissent de premières difficultés un peu avant les années 1750. Ces moulins, après une longue agonie, disparaissent eux aussi, à la veille de la Révolution pour celui d'Uvernet et au début du XIX ${ }^{e}$ siècle pour celui de Jausiers ${ }^{26}$.

\section{Lâge des Amériques (années 1840-xxe siècle)}

18 À partir des années 1820, de nouveaux changements sont perceptibles dans les réseaux migrants de la commune de Jausiers (qui a succédé à l'ancienne communauté d'habitants dans les mêmes limites en 1790). Même si les chiffres sont modestes, les registres du tirage au sort reflètent assez fidèlement les évolutions constatées à travers l'ensemble des archives utilisées. Ils permettent de constater l'émergence puis le développement d'une migration importante d'ouvriers en soie vers Lyon (tabl. 1). Ce phénomène marque une rupture dans l'histoire des réseaux migrants de cette commune, car ce n'est plus un mouvement massif saisonnier mais quasiment annuel. Il semblerait que l'on soit en présence des prémices de l'exode rural qui, progressivement tout au long du xix ${ }^{e}$ siècle, prive la Vallée d'une partie importante de sa population. Ces registres permettent également de noter que la migration des porteurs de curiosité décline puis disparaît et que s'initie et se développe, de manière quasi simultanée, une migration marchande vers la Louisiane et le Mexique (à partir des années 1830), ce que 
confirment les registres de passeports pour l'extérieur (tabl.2). Ces mouvements deviennent réellement massifs dans la seconde moitié des années 1840 au moment où l'émigration des ouvriers en soie s'éteint progressivement. Jausiers devient le foyer principal de ces nouveaux réseaux et redevient une commune où la marchandise domine ${ }^{27}$. Bien qu'il soit impossible d'y mesurer une quelconque évolution des réseaux colporteurs, vu la modestie des jeunes hommes concernés, le recoupement de données collectées dans les communes où les réseaux marchands dominaient montre que les réseaux vers les Flandres, la Bourgogne, Lyon, la Provence et peut-être la république génoise demeurent actifs jusqu'à la fin des années 1840, alors que le Piémont a complètement disparu dès la fin des années 1810. Passé 1850, seuls se maintiennent le réseau flamand (jusque peut-être dans les années 1870-1880) et dans une moindre mesure le réseau bourguignon.

Tabl. 1. - Les Migrations à Jausiers (1816-1860).

\begin{tabular}{|c|c|c|c|c|c|c|c|c|c|c|}
\hline Métiers/destinations & 1816 & 1821 & 1826 & 1831 & 1836 & 1841 & 1846 & 1851 & 1856 & Totaux \\
\hline $\begin{array}{c}\text { Marchands des réseaux } \\
\text { traditionnels } \\
\text { (Bourgogne, Lyon ...) }\end{array}$ & 9 & 6 & 6 & 4 & 6 & 2 & 2 & 5 & 2 & 42 \\
\hline Porteurs de curiosité & 1 & 4 & 5 & 4 & 1 & 4 & & & & 1960 \\
\hline Ouvriers en soie & & 1 & 11 & 18 & 33 & 29 & 8 & 4 & 2 & 106 \\
\hline Louisiane & & & & 2 & 2 & 2 & 1 & 1 & 3 & 11 \\
\hline Mexique & & & & & & 2 & 15 & 23 & 23 & 63 \\
\hline
\end{tabular}

D'après les listes des registres du tirage au sort.

Tabl. 2. - L'émigration vers les Amériques à Jausiers (1833-1860).

\begin{tabular}{|c|c|c|c|c|c|c|c|c|c|c|c|c|}
\hline & 1833 & 1838 & 1839 & 1840 & 1841 & 1842 & 1843 & 1844 & 1845 & 1846 & 1847 & 1848 \\
\hline Louisiane & & & 1 & 1 & 1 & & 4 & 1 & & 2 & 1 & \\
\hline Mexique & 4 & 1 & & 3 & 2 & 2 & 3 & & 7 & 2 & 4 & 17 \\
\hline Totaux & 4 & 1 & 1 & 4 & 3 & 2 & 7 & 1 & 7 & 4 & 5 & 17 \\
\hline
\end{tabular}

\begin{tabular}{|c|c|c|c|c|c|c|c|c|c|c|c|c|c|}
\hline & 1849 & 1850 & 1851 & 1852 & 1853 & 1854 & 1855 & 1856 & 1857 & 1858 & 1859 & 1860 & Totaux \\
\hline Louisiane & & & & & 3 & 2 & 1 & 1 & 2 & & & 1 & 21 \\
\hline Mexique & 17 & 12 & 10 & 9 & 8 & 23 & 14 & 4 & 7 & 3 & 6 & 3 & 161 \\
\hline $\begin{array}{c}\text { Amérique } \\
\text { du Sud }\end{array}$ & & 2 & & & & & & & & 2 & & & 4 \\
\hline $\begin{array}{c}\text { San } \\
\text { Francisco }\end{array}$ & & 2 & & & & & & & & & & 1 & 3 \\
\hline Totaux & 17 & 16 & 10 & 9 & 11 & 25 & 15 & 5 & 9 & 5 & 6 & 5 & 189 \\
\hline
\end{tabular}

D’après les passeports pour l'extérieur.

Si d'une manière générale, nous n'avons pu décrire les évolutions du début du XIX siècle que dans leurs grandes lignes et de manière très approximative pour les réseaux migrants précédents étant donné la modestie des échantillons rassemblés et l'absence d'études, la situation est tout autre pour l'émigration vers la Louisiane et le Mexique grâce à une bibliographie assez fournie et à des archives qui mesurent mieux les pratiques migratoires qu'auparavant ${ }^{28}$. Le réseau louisianais se met en place à partir des 
années 1830, connaît son apogée dans les années 1860-1880 puis disparait progressivement ${ }^{29}$. Quantitativement parlant, c'est un réseau modeste mobilisant moins de 200 individus et se déployant pour l'essentiel dans quelques paroisses le long des rives du Mississippi entre la Nouvelle Orléans et le nord de la ville de Bâton Rouge (fig. 8). Les valéians, originaires principalement de Jausiers et des communes voisines de la Condamine-Châtelard et de Faucon, vendent dans les plantations qui s'échelonnent le long du fleuve, tout ce dont les ouvriers et employés ont besoin: textiles et merceries, mais aussi des outils et de la nourriture. Ce sont des colporteurs qui transportent leurs marchandises sur des charrettes attelées. Ils visitent leurs clients plusieurs fois par an et exercent ce métier toute l'année. On constate une évolution, même si certaines questions comme les approvisionnements ont très peu été étudiées, similaire à celle des réseaux colporteurs. À partir des années 1840, les premières boutiques apparaissent et se multiplient. Il semblerait que progressivement le réseau maitrise ses approvisionnements et se fait importateur de marchandises, ce dont paraît témoigner l'histoire du magasin des frères Jaubert de la Nouvelle Orléans. Puis, comme du temps des réseaux marchands piémontais, les capitaux accumulés par certains s'investissent dans les secteurs économiques qui font la richesse de leur région d'implantation: achat de plantations et de sucreries, participation à la fondation de banques.

Fig. 8. - Paroisses louisianaises fréquentées par les marchands de la Vallée de Barcelonnette.

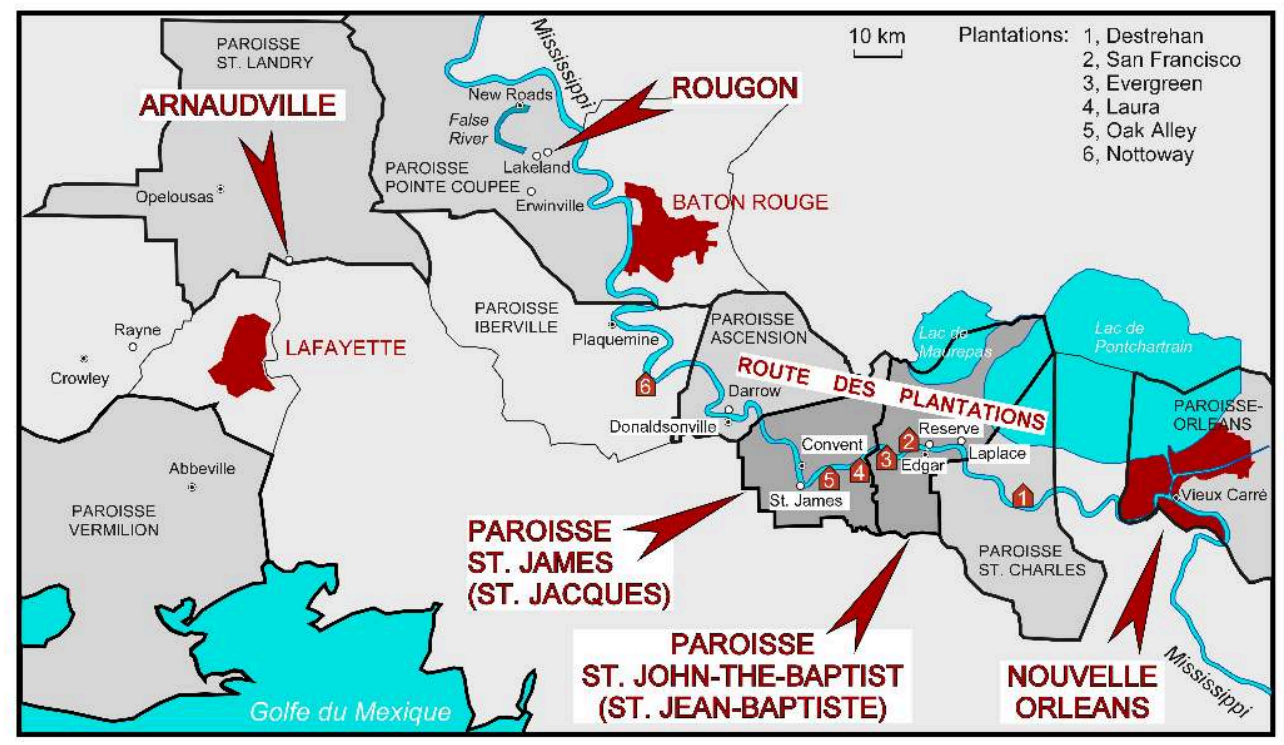

Conception : Jean-Claude Hippolithe-Piolle @

20 Le schéma de développement est différent pour le réseau marchand mexicain ${ }^{30}$. Il repose d'emblée sur l'implantation de boutiques, dénommées cajones de ropa, spécialisées dans la vente de marchandises textiles. La première à Mexico, la capitale du pays, est fondée en 1827 par un marchand jausiérois, Dominique Arnaud qui appartient à une dynastie de marchands-industriels dont les affaires se trouvent à Jausiers mais aussi à Lyon ${ }^{31}$. Et effectivement parmi la première génération de boutiques à se mettre en place dans ce pays d'Amérique centrale apparaît l'affaire de la famille Gassier qui possède déjà une banque à Barcelonnette ${ }^{32}$. Nous retrouvons ensuite le même cas de figure qu'en Piémont deux siècles plus tôt: l'implantation et les premiers 
développements de ce réseau marchand se font à l'initiative et sous l'impulsion des plus importants marchands qui attirent ensuite dans leur sillage leurs nombreux compatriotes. Ceux-ci ne sont plus des colporteurs qui développent leur commerce dans les campagnes et s'approvisionnent dans les magasins de leurs compatriotes, mais des employés qui vont être embauchés directement afin d'être vendeurs dans l'établissement ou, pour quelques-uns, voyageurs de commerce sillonnant ainsi une partie du pays au profit de leurs patrons. Un certain nombre d'entre eux réussissent, après quelques années de travail, à s'associer à d'autres valéians, et, avec l'appui de leurs anciens patrons, à développer leur propre affaire.

21 Les affaires des Barcelonnettes au Mexique s'organisent, jusqu'à la fin du XIX siècle, de la même manière qu'en Piémont. Elles regroupent des marchands associés qui apportent chacun une partie du capital et concluent des contrats de société pour des durées allant de 4 à 8 ans en général. Ces marchands-associés diffusent dans leur magasin des marchandises textiles d'importation qui proviennent pour beaucoup d'Europe mais aussi, très certainement, des États-Unis. Progressivement, à partir des années 1870 , le réseau maîtrise ses approvisionnements via les plus importants commerces et se fait, même, importateur de marchandises dans le pays.

Le réseau se développe de manière exponentielle à partir de la fin des années 1840 . En 1864, les 45 magasins recensés (dont 19 à Mexico) emploient près de 400 Barcelonnettes comme vendeurs ${ }^{33}$. En 1890, on compte 110 maisons de commerce valéianes dont certaines se transforment en grands magasins comme à Paris ou à Londres ${ }^{34}$. L'apogée du réseau est atteint à la veille de la révolution mexicaine de 1910. Des jeunes partiront vers ce pays jusqu'au début des années 1950. Comme en Piémont, à Lyon ou en Louisiane, les capitaux accumulés s'investissent dans l'industrie, surtout textile, la banque, voire dans le secteur agricole dans certaines provinces.

Cette première esquisse de l'histoire marchande de la Vallée de Barcelonnette, quoique très incomplète et très imparfaite, a permis pour la première fois d'établir une filiation étroite entre différentes migrations qu'aujourd'hui nous pouvons qualifier de marchandes. Le spectaculaire mouvement des Barcelonnettes au Mexique, par exemple, ne peut plus être présenté comme un épiphénomène sorti de nulle part, sans véritables liens avec le passé, si ce n'est l'habitude qu'avaient les valéians de voyager depuis au moins le xvII ${ }^{\mathrm{e}}$ siècle. Bien au contraire, il s'inscrit dans une très longue histoire dont il est le dernier épisode. Cette synthèse brise également l'idée selon laquelle les migrations alpines auraient été immuables, à l'image de leurs économies et sociétés, du Moyen Âge au début de l'époque contemporaine. Les différents réseaux marchands, à rebours de ces interprétations, ont fait preuve tout au long de leur histoire de capacités importantes de souplesse et d'adaptation face à des environnements changeants.

24 Cette esquisse met aussi en lumière le rôle fondamental des élites locales ${ }^{35}$ dans la création et l'organisation de ces réseaux. Longtemps oubliés et pourtant omniprésents dans les archives à tel point qu'il est plus facile de les repérer et de les étudier que les colporteurs, qui eux demeurent largement invisibles, les marchands propriétaires d'une boutique se livrant au "grand commerce " sont présents dans tous les réseaux (même de manière indirecte dans le cas des réseaux que nous avons qualifié de colporteurs). Ce n'est certainement pas un hasard si ces réseaux se sont développés 
dans des régions fréquentées par ces marchands dans les décennies qui précèdent leur naissance, ou si Jacques Arnaud, membre de la dynastie Laugier-Arnaud, à l'origine du réseau mexicain, s'est installé près de 25 ans auparavant dans une paroisse louisianaise proche de celles exploitées commercialement par les valéians.

Cette synthèse établit aussi que pour certaines vallées alpines, les marchands ont pu avoir un véritable rôle dans le développement économique local. Jusqu'à présent, on pensait plutôt que les réseaux colporteurs s'étaient développés à partir et grâce à l'industrie drapière locale. Les valéians se seraient lancés dans le commerce de marchandises textiles en allant vendre leur production à l'extérieur. Cette courte histoire démontre que les réseaux marchands valéians se sont développés sans lien avec une quelconque industrie locale jusqu'au début du XviI ${ }^{\mathrm{e}}$ siècle. Bien au contraire, ce sont eux qui sont à l'origine de l'implantation de l'industrie drapière et de l'industrie du moulinage de la soie dans cette vallée.

\section{BIBLIOGRAPHIE}

ARNAUD François, Les Barcelonnettes au Mexique. Extrait des documents et notions historiques sur la vallée de Barcelonnette, Digne, imprimerie Chaspoul, Constans et Barbaroux, 1891.

AUVARO-ANTIQ Raymonde, L'émigration des Barcelonnettes au Mexique, Nice, Éditions Serre, 1992.

CosTE Pierre, «Jacques Arnaud, ses frères, ses descendants », dans Les Barcelonnettes au Mexique, 4 ème édition, Barcelonnette, Sabença de la Valéia, 2004, p. 100-112.

COULET Noël, Aix en Provence, espace et relations d'une capitale (milieu XIVe siècle-milieu XVe siècle), Aixen-Provence, Publications-diffusion université de Provence, 1988, 2 vol.

D'ANGLADE Jean-Louis, Un grand patron barcelonnette au Mexique, Joseph Ollivier, 2 ème édition, Barcelonnette, Jean-Louis d'Anglade/Sabença de la Valéia, 2011.

FONTAINE Laurence, Histoire du colportage en Europe $\mathrm{XV}^{e}$-XIX ${ }^{e}$ siècle, Paris, Albin Michel (coll. L'évolution de l'humanité), 1993.

FONTAINE Laurence, Pouvoirs, identités et migrations dans les hautes vallées des Alpes occidentales (XVII XVII siècle), Grenoble, PUG (coll. La pierre et l'écrit), 2003.

GouY Patrice, Pérégrinations des « Barcelonnettes » au Mexique, Grenoble, Presses Universitaires de Grenoble, 1980.

HYPPOLITE-PIOLLE Jean-Claude, De l'Ubaye aux rives du Mississippi, les Barcelonnettes commerçantsplanteurs de Louisiane, Barcelonnette, Sabença de la Valéia, 2006.

SURMELY Laurent, "Le traité d'Utrecht et ses conséquences en Ubaye ", dans Histoire d'une frontière. $150^{\circ}$ anniversaire de l'annexion du Comté de Nice à la France, actes du colloque de Puget-Théniers 9-11 octobre 2009, Puget-Rostang, Roudoule écomusée en terre gavotte-Amont-ADTRB, 2010, p. 82-107. 
SURMELY Laurent, Le réseau marchand de Jausiers (vers 1620-vers 1730) : préfiguration du mouvement migratoire vers le Mexique?, Barcelonnette, Sabença de la Valéia, à paraître en 2020.

\section{NOTES}

1. La Vallée de Barcelonne (1232-1713), puis de Barcelonnette, est une entité politique et administrative regroupant, jusqu'en 1789, huit communautés d'habitants (SaintPaul, Larche, Meyronnes, le Châtelard, Jausiers, Barcelonnette, Méolans, Revel et le Lauzet) situées dans la moyenne et la haute Ubaye et une communauté (Allos) située dans la Vallée du Haut-Verdon. De 1388 à 1718, les communautés d'Entraunes et de Saint-Martin d'Entraunes dans le Haut-Var lui furent rattachées administrativement tout comme les communautés de la Vallée Stura di Demonte durant une partie des $\mathrm{Xv}^{\mathrm{e}}$ et $\mathrm{XVI}^{\mathrm{e}}$ siècles (dates exactes inconnues). Attachée au Comté de Provence jusqu'en 1388, la vallée passe sous domination savoyarde jusqu'au traité d'Utrecht (1713), année de son rattachement définitif à la France. À partir de 1790, la Vallée de Barcelonnette forme, avec le rattachement des 4 communes de la basse Ubaye (Saint-Vincent du Lauzet, la Bréole, Ubaye et Pontis) le district puis en 1800 l'arrondissement de Barcelonnette.

2. Archives départementales des Alpes-De-Haute-Provence, B 411 à B 591, étiquettes du tribunal de la judicature; B 381 à B 385, étiquettes du tribunal de la préfecture ; B 2792 et B 2 793, registres des défauts du greffe du tribunal de la préfecture ; B 408, B 409 et B 410, étiquettes couvrant la période septembre 1752-avril 1753 ; B 612-B 615, procédures civiles du tribunal de la judicature, B 616-B 617 requêtes et informations du même tribunal, B 2 807, B 2812 et B 2 833, procédures civiles du tribunal de la préfecture.

3. L. Surmely, Le réseau marchand de Jausiers (vers 1620-vers 1730): préfiguration du mouvement migratoire vers le Mexique?.

4. Archives départementales des Alpes-De-Haute-Provence, $2 \mathrm{E} 19416$ à $2 \mathrm{E} 19614$, 2E 1594 à $2 \mathrm{E} 1607,2 \mathrm{E} 19691$ et 19692, B 2952 à B 2957. Ces registres représentent la totalité des archives notariales et judiciaires de la communauté d'habitants puis commune de Jausiers de la période 1615-1820.

5. Archives départementales des Alpes-De-Haute-Provence, 1R 127 à 1R 171.

6. Archives départementales des Alpes-De-Haute-Provence, $4 \mathrm{M} 77$.

7. Archives départementales des Alpes-De-Haute-Provence, B 44 à B 128.

8. Nom que se sont donnés jusqu'au XIx siècle les habitants de la Vallée de Barcelonne/ Barcelonnette en référence à son appellation locale Valéia (la Vallée en français).

9. N. Coulet, Aix en Provence, espace et relations d'une capitale (milieu XIV siècle-milieu XV siècle), p. 300-301.

10. Le rapprochement a été fait, pour les réseaux marchands alpins, par L. Fontaine, Histoire du colportage en Europe XVe-XIXe siècle, p. 19-21.

11. Joaquim Ma BOVER, Immigrants als concessos 1600-1650, http://www.onomastica.cat/ sites/onomastica.cat/files/10_bover.PDF consulté le 29/04/2019.

12. Archives départementales des Alpes-De-Haute-Provence, registres de l'insinuation de Barcelonnette, B 69, fol 13, B 84, fol. 481, B 96, fol. 761, B 119, fol. 27 et B 122, fol. 701.

13. Joaquim Ma BOVER, ibid. 
14. Recensement de maisons établi à partir du cadastre de Jausiers (Archives départementales des Bouches-du-Rhône, B 1014).

15. L. Fontaine, Histoire du colportage en Europe Xve-XIXe siècle, p. 51-55.

16. La structuration de ce réseau est typique des réseaux marchands alpins du XVII siècle, voir L. Fontaine, Histoire du colportage en Europe XVe-XIX siècle, p. 23-35.

17. Archives départementales des Alpes-De-Haute-Provence, B 636, fol. 223, acte d'obligation du 2 mai 1617 mentionnant la construction d'un "parayre " (H. Barnier, Images d'archives: les moulins de Saint-Paul et le forestage de Parrouard de 1575 au cadastre napoléonien 1813-1841) pour celui de Saint-Paul et 2E 19416, fol. 181, prix-fait pour la construction de deux paroirs à battre les draps, pour celui dit du pont couvert de Jausiers, $1^{\text {er }}$ juillet 1618.

18. Celui du pont couvert est pris à rente par Louis Silve de Seyne en 1619 (Archives départementales des Alpes-De-Haute-Provence, B 83, fol. 509). En 1644, celui de SaintPaul est encore pris à rente Marc Baudin feu Marc de Guillaumes (Archives départementales des Alpes-De-Haute-Provence, B 656, fol. 29).

19. Archives départementales des Alpes-De-Haute-Provence, B 87, fol. 85, acte de fondation de la confrérie Saint-Blaise de Barcelonne, 3 février 1620.

20. Archives départementales des Alpes-Maritimes, «cità e contado di Nizza », mazzo 15, mémoires de monsieur Pascalis prieur de Molanès, official de Barcelonnette, 1689.

21. Le duché de Savoie grâce à la maîtrise et à l'avance technique acquise dans ce type de production, devient, à partir du XVI $I^{\mathrm{e}}$ et surtout du XVII ${ }^{\mathrm{e}}$ siècle, le premier producteur européen de soie grège et de soie filée.

22. La Vallée de Barcelonnette n'est pas la seule à être touchée par les conséquences produites par le traité d'Utrecht. Voir L. Fontaine, Pouvoirs, identités et migrations dans les hautes vallées des Alpes occidentales (XVII'-XVIII siècles), p. 214.

23. L. Surmely, Le traité d'Utrecht et ses conséquences en Ubaye, p. 102-105.

24. Cette transformation des réseaux marchands en réseaux colporteurs n'est pas propre à la Vallée de Barcelonnette. Elle est constatée dans d'autres vallées alpines voir L. Fontaine, Histoire du colportage en Europe XV ${ }^{e}-\mathrm{XIX}{ }^{e}$ siècle, p. 58-60.

25. L. Surmely, Le traité d'Utrecht et ses conséquences en Ubaye, p. 105.

26. L. Surmely, ibid., p. 105.

27. Les registres de passeports pour l'extérieur de la période 1833-1860 recensent 293 passeports délivrés pour le Mexique dont 161 pour les seuls Jausiérois.

28. Le changement de nature de l'émigration, qui de saisonnière devient de longue durée ou définitive, et les destinations lointaines, qui nécessitent la prise obligatoire de passeports, expliquent en grande partie cette situation.

29. Cette description du réseau louisianais a été faire à partir des recherches de J.C. Hyppolite-Piolle, De l'Ubaye aux rives du Mississippi, les Barcelonnettes commerçantsplanteurs de Louisiane.

30. Les principales caractéristiques du réseau mexicain ont été établies à partir des ouvrages suivants: F. Arnaud, "Les Barcelonnettes au Mexique»; R. Auvaro-Antiq, L'émigration des Barcelonnettes au Mexique; P. Gouy, Pérégrinations des «Barcelonnettes » au Mexique.

31. P. Coste, « Jacques Arnaud, ses frères, ses descendants », p. 100-112. 
32. J.-L. D’Anglade, Un grand patron barcelonnette au Mexique, Joseph Ollivier, p. 63-64.

33. F. Arnaud, ibid., p. 31-33.

34. F. Arnaud, ibid., p. 46-52.

35. L. Fontaine, Pouvoirs, identités et migrations dans les hautes vallées des Alpes occidentales (XVII ${ }^{e}$-XVIII ${ }^{e}$ siècles), p. 210.

\section{RÉSUMÉS}

Une série de recherches sur l'émigration saisonnière, nous permet aujourd'hui d'esquisser une première histoire sur cinq siècles de l'émigration marchande de la Vallée de Barcelonnette. Quatre «âges" ont pu être définis. À l'âge du "grand commerce » ( $x v^{\mathrm{e}}$-début du XVII ${ }^{\mathrm{e}}$ siècle), succède un âge de "repli sur l'espace régional " au début du XvII ${ }^{\mathrm{e}}$ siècle où les marchands se spécialisent dans la diffusion de textiles en Piémont et dans la république génoise. Les années qui suivent le rattachement de la Vallée de Barcelonnette à la France voient l'avènement de l'âge du «colportage» (années 1740-première moitié du XIX siècle) durant lequel les valéians commercent en Provence, en Bourgogne, en Flandre et les rues de la ville de Lyon. Les nouvelles conditions économiques ne permettant plus le développement de ces réseaux marchands en Europe, ceux-ci s'exportent et se déploient en Louisiane et au Mexique, au cours de l'âge des «Amériques » (années 1840-XXe siècle).

\section{AUTEUR}

\section{LAURENT SURMELY}

Responsable commercial, président de Sabença de la Valéia/connaissance de la Vallée de Barcelonnette 


\title{
Des Pyrénées à la Sierra Maestra : aux origines du modèle caféier cubain, Casamajor et les Béarnais dans l'Oriente
}

\author{
Jacques de Cauna
}

Je remercie tout particulièrement mes collègues Paul Estrade, Michèle Guicharnaud-Tollis, Jean Lamore, Bernard Lavallé, Agnès Renault et le regretté Alain Yacou, ainsi que les personnes qui ont eu l'amabilité de m'ouvrir leurs archives familiales: Mmes Marie-José Delrieu, Geneviève Fabre de Caumale et Pierre son époux, MM. Paul de Casamajor, Dominique Patte de Dufourcq, Sidney Emery et le regretté Pierre de Lestapis.

1 Loin des grands échafaudages conceptuels et des contraintes méthodologiques, le grand fleuve de la connaissance historique est souvent alimenté par les petites rivières de la sérendipité, les surprises du vécu et de la proximité. Telle fut ma rencontre avec Prudent de Casamajor. Plus connu à Cuba sous le nom de Prudencio Casamayor, il fut l'homme clé de la présence française, et surtout béarnaise, dans l'Oriente cubain. Né à Sauveterre-de-Béarn, il venait de l'ouest de l'île voisine d'Haïti, l'ancienne colonie française de Saint-Domingue où sa famille fut l'une des plus prolifiques et des plus célèbres de la Reine des Antilles dont les Pyrénéens, Basques, Béarnais et Gascons, extrêmement nombreux, représentaient près de la moitié des colons blancs ${ }^{1}$.

\section{Les Casamajor, une vieille famille béarnaise aux Îles}

L'histoire de l'actuelle république d'Haïti a retenu particulièrement le nom de l'un d'eux, Messire Jean-Pierre de Casamajor de Charritte, chevalier de l'Ordre royal et militaire de Saint-Louis, l'un des plus grands gouverneurs de la partie française de Saint-Domingue (mais aussi de l'île oubliée de Sainte-Croix et de celle de la Martinique). Après une brillante carrière navale, il fut l'auteur de la plus importante réforme administrative connue par la colonie et s'était signalé dans le nord de l'île comme l'un 
des plus importants propriétaires fonciers, à l'origine de la fondation, avec le Béarnais Ducasse, de la grande ville et capitale économique du Cap-Français, le Paris des Antilles, aujourd'hui Cap-Haïtien.

Les armoriaux nous disent que " la famille de Casamajor - qui portait Écartelé, aux 1 et 4 de gueules au lévrier rampant d'argent accolé du même; aux 2 et 3 d'azur à une tour d'argent maçonnée, ouverte et percée de sable - était originaire de Rivehaute, près de Navarrenx, en Béarn, où se trouvait la maison de son nom ». Et qu'« anoblie en 1583, elle s'était divisée au début du XVII ${ }^{e}$ siècle en trois branches principales connues sous les noms de Gestas, Charritte et Jasses ", toutes issues de Guicharnaud, notaire à Navarrenx et secrétaire d'Henri II, roi de Navarre, puis d'Henri III, futur Henri IV de France, qui l'avait anobli, dit-on, pour ses bons et loyaux services. Mais il n'est pas toujours facile de distinguer parmi les nombreux Casamajor des îles. On trouvait ainsi à Saint-Domingue, dans le Nord, un Louis-Gabriel de Casamajor, chevalier de Saint-Louis, major du Port-de-Paix, à côté d'un Pierre Casamajor, huissier audiencier de l'Amirauté du Cap, son frère, ou des demoiselles Casamajor, filles d'un chirurgien dotées d'une pension, dans la même ville. Et surtout, dans le Sud, un David Casamajor, autre frère, notaire royal en la sénéchaussée de Saint-Louis, originaire de Navarrenx et habitant à Aquin où il décéda en 1770 à 90 ans, auteur d'une très prolifique postérité.

4 Tous ces personnages appartiennent à la branche de Casamajor-Sallabert, également présente en Martinique et en Guadeloupe, propriétaire à Sauveterre-de-Béarn lors de la réformation du terrier royal en 1676 des terres appelées Lasgoates en la personne de «Jean de Casemajor-Salabert [sic]» et du « sieur Casemajor, juge ». On en trouve des représentants présents à Sauveterre le 9 juin 1675 au contrat de mariage de «Jeanne de Casemaior [sic, pour Casamajor], de la ville de Sauveterre, fille de feu sieur de Casemaior [Pierre] et de feue damoiselle Estrugue de Bégué ", avec "Me Samuel de Blair, d'Orthez, receveur des consignations au Parlement de Navarre » à Pau. La dite "damoiselle de Casemaior, future épouse, assistée de M. Me Pierre de Casemaior, conseiller du roy et lieutenant-général au siège de Sauveterre, son frère, damoiselle Catherine de Casemaior, sa sœur, M. de Colomme, conseiller du roy au parlement de Navarre, Me Jean de Bégué, conseiller du roy, assesseur au sénéchal de Navarre, noble Jacques de Saint-Melion, sr [seigneur] de Moliède, noble Charles de Casemaior, abbé [laïque] d'Orion, Me Gédéon de Nolivos, avocat en la cour, Me Jean de Casemaior, $\mathrm{s}^{\mathrm{r}} \mathrm{de}$ Salebert, et Me Jean d'olivier, sr d'Arrosere, premier jurat de Sauveterre, ses parents ». Un acte qui confirme bien la parenté des Casamajor de Sauveterre (et de la branche landaise et antillaise de Salabert) avec ceux des trois branches les plus connues, de Gestas, de Charritte et de Jasses, puisque les Casamajor d'Orion appartenaient à la branche de la maison de Jasses à Labastide-Villefranche. Ainsi d'ailleurs que la parenté qui les unit à la famille du gouverneur de la Guadeloupe puis de Saint-Domingue, Pierre-Gédéon de Nolivos ${ }^{2}$, petit-fils du personnage cité dans l'acte, introducteur du café à Saint-Domingue sur son habitation de Léogane en 1726. On note d'autre part que l'enregistrement des titres de noblesse de la famille de Casamajor de Salabert auprès du Conseil souverain de l'île de la Guadeloupe le 2 mai 1768 indique clairement: " originaires de Sauveterre de Béarn, passés dans les Landes et à la Guadeloupe, filiation 1491 ». Les divers Casamajor présents à Saint-Domingue représentent donc bien en fait les principales branches de la grande maison noble béarnaise de Casamajor, alliée notamment aux Navailles-Méritein, aux Espalungue, barons d'Arros, et aux Béarn, dont la souche est à Sauveterre et Rivehaute près de Navarrenx et qui forma les 
nombreuses branches de Casamajor de Charritte, de Gestas, de Rivière, de Jasses, d'Orion, de Montgaston, de Sallabert, de Treslay, de Disse, d'Usquein...

Celui du Sud, le notaire David (de) Casamajor, était propriétaire de la grande sucrerie Casamajor ou Gaye (ce dernier nom venant d'une famille d'Arthez-de-Béarn, originaire de Malaussane, curieusement, celle de mon beau-frère). Cette habitation était à Aquin, c'est-à-dire, ce qui n'est plus aujourd'hui que le Vieux-Bourg d'Aquin, à l'entrée duquel existe encore un carrefour du nom de Barrière-Gaye, du nom du premier propriétaire, souvenir du portail d'entrée de l'ancienne sucrerie dont ne subsiste qu'un pan de mur (fig. 1). David de Casamajor possédait en outre une autre habitation dans le quartier montagneux de l'Asile, entre Saint-Louis et Jérémie, qu'il avait tenté d'établir en sucrerie mais sur laquelle « cette culture n'avait pas mieux réussi que celle de l'indigo et du cotonnier ", nous dit l'historiographe de Saint-Domingue Moreau de Saint-Méry qui nous apprend par ailleurs que le notaire fut l'auteur d'une nombreuse descendance légitime mais aussi «naturelle ", ce qui revient à dire à l'époque « de couleur " ${ }^{3}$. On en trouve de nombreuses traces dans les quelques registres paroissiaux de Saint-Thomas d'Aquin qui subsistent de 1731 à 1775 . Dans ce dernier, on relève, par exemple, sur ses neuf pages, trois baptêmes d'enfants mulâtres au nom de Casamajor, parfois même transcrit dans une prononciation béarnaise Casemajou: Pierre, ML (Mulâtre Libre), le 8 juin, au quartier de l'Azile, fils naturel de Pierre Casamajor et de Françoise, dite Visse, mulâtresse ; François-Jacques Cassamajor [sic] ; le 6 juillet, né le 24 janvier à la Colline à Mangon, fils légitime de Jacques Cassamajor [Cassamajou sur un autre acte] et de MarieHenriette Boisdenier, mulâtres ; et enfin Jean-Baptiste, mulâtre, fils légitime de Charles Casamajor et d'Anne Bineau, parrain Joseph Casamajor [Casemajour sur un autre acte].

Fig. 1. - Plan d'une partie de la plaine et des hauteurs d'Aquin (XVIII' siècle).

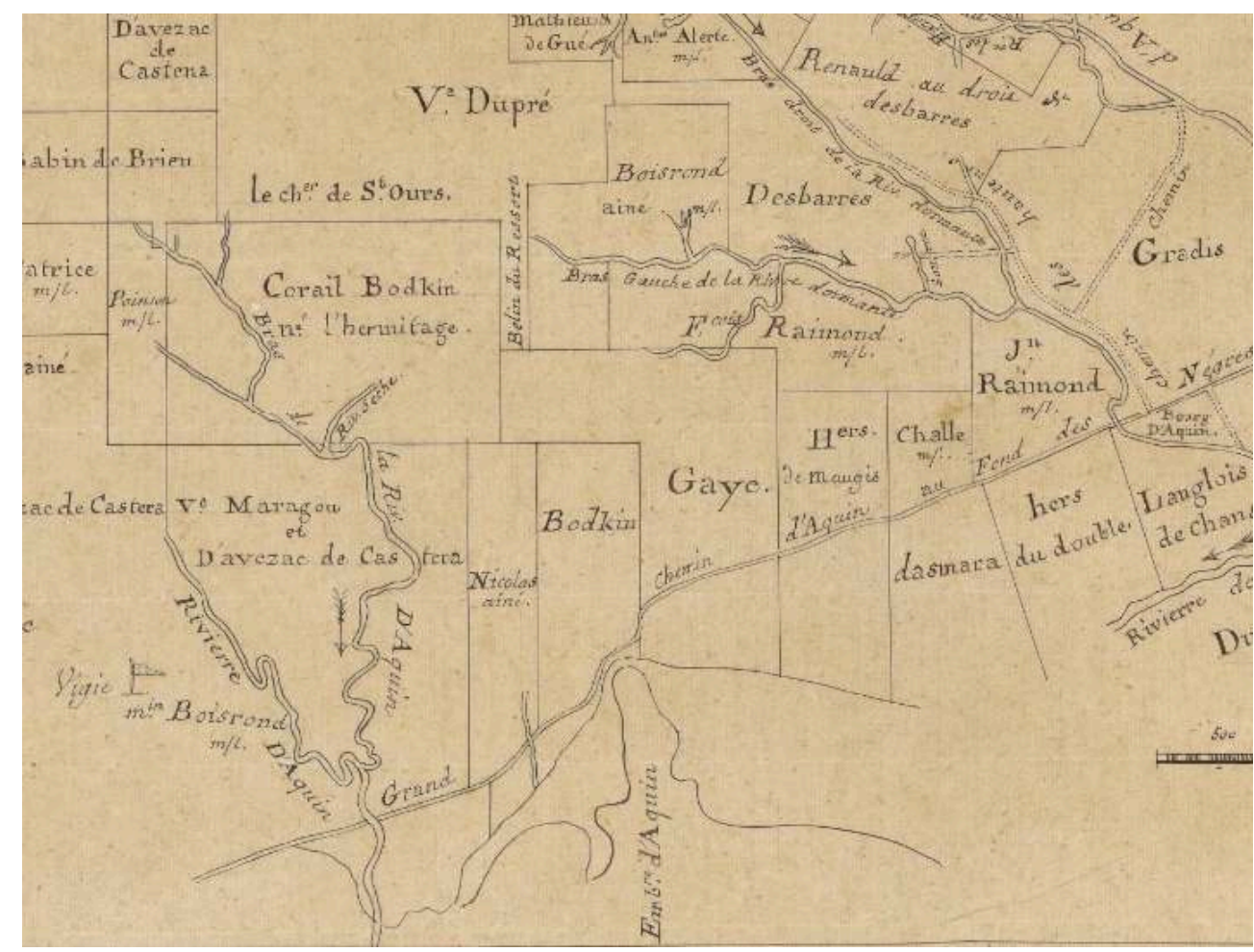

BNF, Département des Cartes et Plans, n 100, cartographe inconnu. 
6 C'est donc de lui sans doute, David Casamajor, que descendait ce M. Casamajor membre très distingué de cette élite de couleur dont quelques notables subsistent difficilement jusque dans les campagnes les plus reculées du pays-en-dehors (la province rurale) d'Haïti - qui avait tenu à venir du lointain quartier montagneux de l'Asile, dans le sud d'Haïti, à plusieurs heures de route et de piste, pour me rencontrer à Port-auPrince dans les derniers jours de ma présence en Haïti. Ayant eu vent de mon départ définitif au terme d'une quinzaine d'années, il tenait à tirer au clair auprès de moi les origines de sa famille, qu'il pensait espagnoles jusqu'à ce que lui fût révélée l'existence des Casamajor béarnais.

7 J'étais loin alors de penser à l'époque qu'une de ces bonnes fortunes que la vie nous réserve allait me mettre en présence quelques années plus tard, à mon retour dans ma ville natale, du représentant actuel des Casamajor «restés au pays » dans la grande maison familiale (ce qui, compte tenu de la signification du nom, est quasiment pléonastique) de Sauveterre, M. Paul de Casamajor. Plus aléatoire encore était le fait qu'il ait pu s'intéresser de près aux origines et à l'histoire de sa famille, devenant ainsi, comme cela est souvent le cas dans les maisons anciennes, celui que tous considèrent comme l'historiographe et généalogiste officiellement en charge de la mémoire familiale ${ }^{4}$.

\section{De Prudent de Casamajor à Prudencio Casamayor : Cuba, le café, les Béarnais}

8 Si l'on excepte le gouverneur de Charritte, que sa brillante carrière navale, sa fortune et ses hautes fonctions appelaient à la plus grande notoriété, le plus célèbre de tous les Casamajor antillais, à Cuba tout au moins, reste sans nul doute Pierre-Prudent de Casamajor, qui y est connu sous le nom de Prudencio Casamayor et a été l'homme clé de la présence française, et surtout béarnaise, dans l'Oriente, autour de Santiago de Cuba et de Guantanamo. Aucun nom à Cuba ne fut aussi honoré et respecté que celui de Prudencio Casamayor, nous dit un voyageur français peu après sa mort. Il était venu de l'île voisine d'Haïti parmi le flot de réfugiés qui fuyaient les troubles révolutionnaires et l'insurrection des esclaves. Il y eut en effet à cette époque, dans les dernières années de l'Ancien Régime et à l'orée du XIXe siècle, autour de Santiago de Cuba et dans les environs immédiats, pendant près d'un demi-siècle, plus de vingt mille créoles français de Saint-Domingue, dont la moitié de noirs et gens de couleur, renforcés par des allersretours continuels de La Nouvelle Orléans, puis par un arrière-courant d'arrivées de compatriotes gascons, et surtout béarnais, embarqués à Bordeaux ${ }^{5}$. Ils y créèrent notamment plus de cent cinquante cafetales (caféteries) françaises qui laissèrent une marque indélébile sur cette partie du pays, quadruplant notamment la production de café et doublant le commerce maritime, avec notamment d'importantes activités corsaires dont les fameux frères Pierre et Jean Laffite et leurs parents Dominique You et Renato Beluche furent les plus célèbres représentants ${ }^{6}$.

9 Prudencio Casamayor, ou plutôt Prudent de Casamajor, ancien gérant de sucreries dominguoises, avait réussi par son activité à devenir l'un des négociants les plus en vue de la place de Santiago et, en quelque sorte, l'agent général, l'homme d'affaires, le conseiller et même le banquier de cette petite colonie de réfugiés dont bon nombre lui étaient apparentés. Après s'être livré à des activités maritimes de commerce (jusqu'à 
Philadelphie) et de course puis avoir servi le gouvernement local comme interprète, il avait débuté dans la spéculation en achetant dans les hauteurs de la Sierra Maestra promises plus tard à une certaine célébrité, des terres en friches que l'on pouvait croire incultes mais qu'il fit prospérer en les revendant ou louant par petits lots de 100 carreaux pour le cafép. Il avait aussi réactivé l'exploitation des mines de cuivre d'El Cobre (fig. 2) et créé tout un réseau de routes. À sa mort le 18 mars 1842 sous le nom de Prudencio Casamayor, il faisait figure de patriarche révéré et richissime, laissant une descendance naturelle d'au moins six enfants de couleur qui se poursuit aujourd'hui aux États-Unis (fig. 3). Sa carrière et son action à Cuba sont aujourd'hui bien connues par les sources cubaines.

Fig. 2. - La Caridad d'El Cobre, église de la ville du cuivre réactivée par Casamajor.

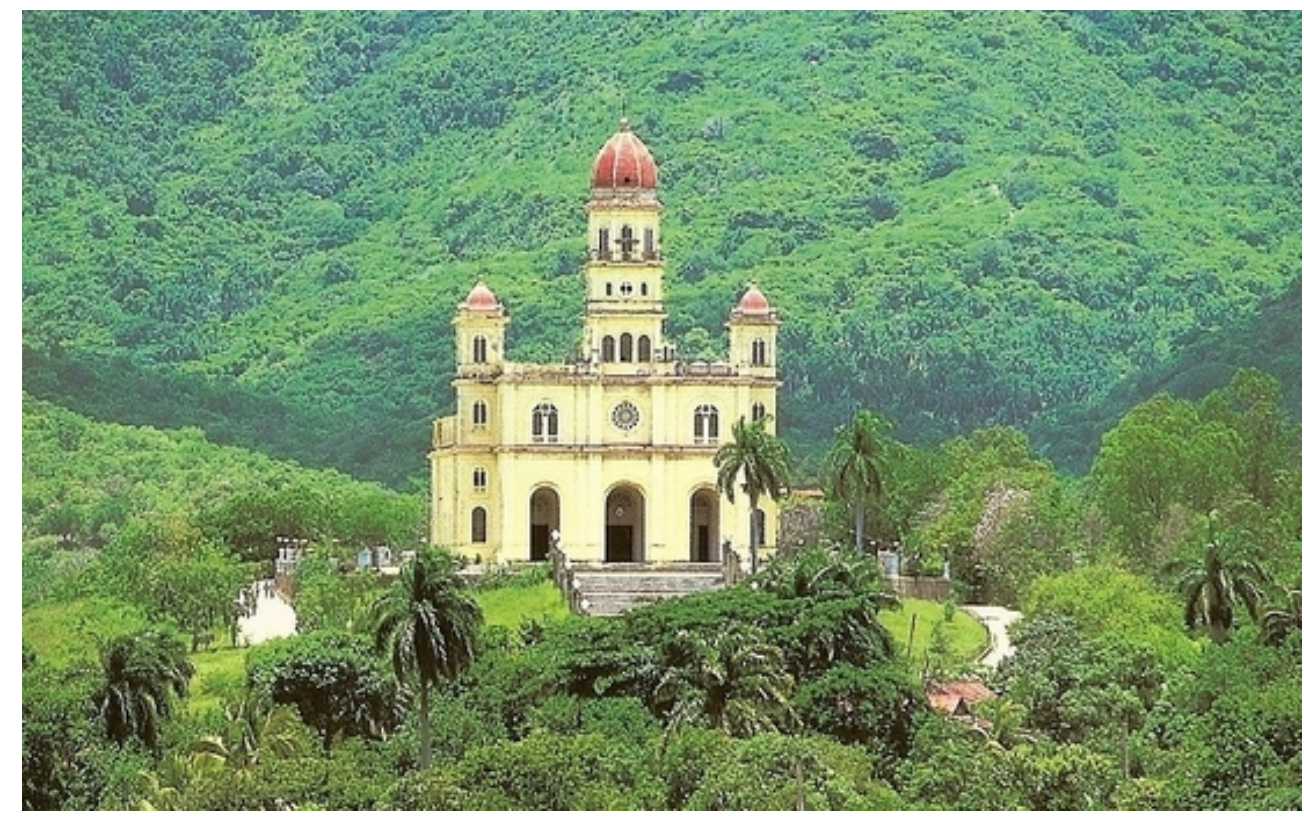

(C) Jacques de Cauna. 
Fig. 3. - Justine de Casamajor, épouse Lay (1814-1870), fille de Prudent de Casamajor et de la quarteronne d'origine créole bordelaise Madeleine Brun.

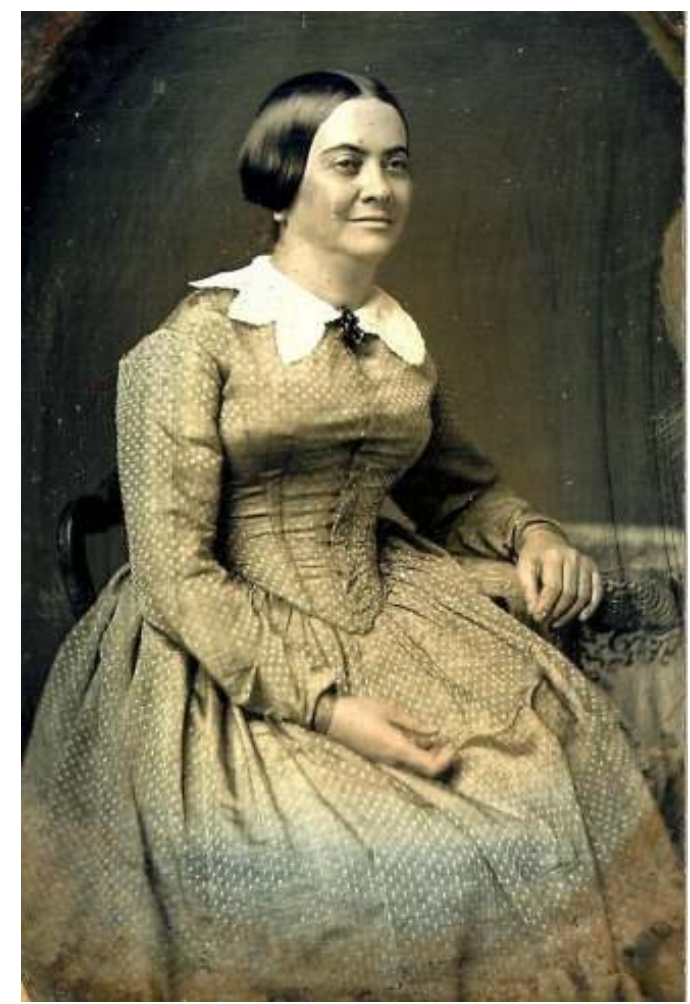

(C) Jacques de Cauna.

10 Mais le personnage lui-même restait cependant mal connu, y compris dans sa région d'origine où l'on sait peu de choses de ses racines béarnaises. Gabriel Debien - qui ne connaissait que son nom espagnol - se demandait même s'il ne s'appelait pas Prudent Grandmaison. L'historien cubain Juan Perez de La Riva le dit né à Sauveterre-de-Béarn le 18 juin $1763^{8}$. C'est ce que dit aussi Prudencio Casamayor lui-même dans son testament de 1842 où il précise qu'il est :

« Natural de Salvatierra en la provincia de Bearn en Francia et vesino de esta ciudad de Santiago de Cuba, hijo legitimo de Don Juan Casamayor y de Juana de Fourcade Casamayor, el primero de mi propia naturaleza y la segunda de Osserain, Francia. $»^{9}$

11 Perez de La Riva ajoute qu'il connaissait l'espagnol depuis son enfance à cause de sa mère mais on ne voit pas pourquoi, le nom de Forcade (ou Fourcade) étant bien béarnais et non espagnol. Il le dit aussi issu d'une famille de petite noblesse de robe, mais sans autres précisions ni indications de sources.

12 La mise en ligne récente d'une bonne partie des registres paroissiaux béarnais (1728-1898 seulement) permet aujourd'hui de faire clairement le point sur le profond enracinement de Prudent dans la vieille noblesse béarnaise :

«Le dix-huit juin mil sept cent soixante trois est né un fils légitime de Jean de Casamajor, escuyer [souligné par moi], conseiller du roy lieutenant général du sénéchal de cette ville, et de dame [id.] Jeanne de Forcade Casamajor, son épouse. $»^{10}$

13 La noblesse du père, qualifié d'« écuyer » est donc bien réelle. Il en est de même pour « demoiselle [id.] Jeanne de Casamajor, sœur du père », qui présente l'enfant avec « Maître Pierre Lafont, avocat en parlement et cousin germain du père ». Le qualificatif de "dame ", appliqué à la mère paraît plus aléatoire dans la mesure où son propre père, 
"Mr Pierre de Forcade, parrain », est dit «négociant de St-Jean-Pied-de-Port », alors que la marraine « dame Jeanne de Majendie Habas, de Labastide », est bien de la famille des Majendie de la maison noble de Habas à Labastide-Villefranche ${ }^{11}$. L'un de ces Magendie, Pierre, épousera d'ailleurs peu après, le 16 février 1765 à Sauveterre, Jeanne de Nolivos, fille de Paul de Nolivos et de Jeanne-Marie de Casamajor Salabert.

Quant à « Me Pierre de Lafont, avocat en la cour ", la douzième page du registre nous apprend qu'il est effectivement cousin germain de Jean de Casamajor, père de Prudent, depuis son mariage le 28 novembre 1738 avec la sœur de ce dernier, "demoiselle Marie-Jeanne de Casemajor-Salebert [sic], en présence des sieurs de Casemajor, juge [Jean], de Nolivos, de Lafont, cousins germains du dit de Lafont... qui ont signé » avec l'officiant, "Casamajor prêtre». Cet acte inédit nous confirme donc bien l'appartenance des Casamajor de Sauveterre dont Prudent est issu, à la branche de Sallabert présente en Guadeloupe. La page suivante affiche en vis-à-vis l'acte de naissance le 17 septembre 1739 de «Pierre de Lafont, fils à Me Pierre de Lafont, avocat en la cour, et à demoiselle Marie de Casemajor-Salebert, conjoints ", présenté le lendemain au baptême par Me Pierre de Casemajor-Salebert, son grand-père du côté maternel [qui est aussi celui de Prudent], et demoiselle Jeanne de Casemajor, sa grandmère du côté paternel [grande tante de Prudent, autre alliance antérieure avec un Lafont] ».

La correspondance familiale inédite de la famille noble des comtes de Casamajor de Gestas, établie dans l'Artibonite à Saint-Domingue en la personne du comte JeanCharles-Amant-Constant de Casamajor de Gestas et de Rivière, héritier de la plantation de sa mère à la Petite-Rivière de l'Artibonite et de trois maisons à Saint-Marc, dans l'ouest de la colonie ${ }^{12}$, laisse ainsi entrevoir par ailleurs que Prudent pourrait aussi être plus particulièrement proche $\mathrm{du}$ rameau des Casamajor-Treslay dont un membre, Jacques de Casamajor, seigneur du Treslay de Dognen, avait épousé Suzanne de Magendie-Sendos, fille de Jean de Magendie marié en 1711 avec Catherine de BéarnSendos, dame d'Iratze et Sillègue et héritière de Saint-Dos, maison issue des BéarnSalies ${ }^{13}$.

16 Une autre lettre inédite, datée du 4 février 1820 à San Yago de Cube, adressée "à Monsieur de Bellegarde, à Bellegarde, par Oche, département du Jerse [Auch, département du Gers] » et portant la signature «P. Casamajor » accompagnée de points maçonniques, montre qu'il s'occupait à cette date des intérêts à Cuba du frère survivant de Louis de Bellegarde, co-fondateur avec lui de la hacienda Santa-Catalina qui est à l'origine du premier village français dans la baie de l'actuelle base américaine de Guantanamo ${ }^{14}$. On y apprend que pour faire face aux frais de la succession, Prudent de Casamajor avait dû vendre :

« Une partie des terres [il y avait en tout 17500 hectares] aux sieurs d'Aslon [sic, pour le vicomte d'Alzon qui avait commandé sous l'occupation anglaise de SaintDomingue le corps colonial de York] et Jean Faure, anciens propriétaires à Port-auPrince et à la Rivière-Froide, créanciers de la succession. $»^{15}$

17 Louis de Bellegarde, en réalité Louis-Joseph Laforgue, chevalier de Bellegarde, personnage fédérateur très important mais mal connu de cette émigration, appartenait à l'ancienne famille gasconne de Laforgue de Bellegarde à ne pas confondre avec celle des fameux capitaines de la maison de Saint-Lary de Bellegarde. Chef de la branche aînée, chevalier de Saint-Louis, il avait émigré en 1791 pour servir comme colonel chef 
d'état-major dans l'armée des Princes avant de se retirer en Guadeloupe après avoir servi comme lieutenant au régiment du Cap.

D'autres pièces émanant des archives de Saint-Domingue nous éclairent aussi quelque peu sur les activités, mal connues, de Prudent de Casamajor dans la colonie française où il était arrivé jeune, à 22 ans, en 1785, avant son passage à Cuba en 1797. On le trouve d'abord sur la grande sucrerie de Lugé [ayant appartenu aux Fleuriau] à Montrouis, au débouché de l'Artibonite, où il fait son apprentissage de la plantation comme tout nouvel arrivant ${ }^{16}$. Son nom apparaît en effet pour la première fois dans une correspondance du 21 octobre 1788 postérieure à la mort du propriétaire, le célèbre et fantasque baron périgourdin Jean Pasquet de Lugé. L'exécuteur testamentaire du baron, un Béarnais dénommé J.-B. Lacombe, écrit à Madame de Lugé, vivant en France et dont il est le procureur-général, que le précédent gérant, M. Béhu-Lacaze, béarnais aussi sans aucun doute, ayant quitté la plantation pour une place plus lucrative, avait été remplacé en août par «M. de Casamajor» qui, certes, n'avait pas la même expérience mais était «fort laborieux, intelligent, honnête et prévenant » - qualités reconnues généralement aux Béarnais dans la colonie où il venait sans doute tout juste d'arriver. On le retrouve lors de l'inventaire après décès du baron qui est établi le 11 novembre 1788 " en présence du sieur Pierre-Prudent Casamajor, économe-gérant de l'habitation et gardien des scellés apposés le 4 de ce mois ». En décembre, à peine deux mois après son arrivée, ses appointements, primitivement fixés à 5000 livres, sont doublés, à charge pour lui de nourrir l'économe, le chirurgien (tous deux blancs) et le personnel (noir) de l'hôpital, preuve certaine de la confiance que l'on plaçait en lui après notamment les améliorations apportées à l'état de santé de l'atelier. Il restera cependant moins de deux ans dans ce poste, l'héritier de la plantation, le vicomte Walsh de Serrant ayant décidé lors de sa venue dans l'île de lui retirer sa charge le 15 août 1790 pour la confier à l'un de ses protégés, le jeune Gast, qui ne fit pas l'affaire et qu'il dut remplacer moins de huit mois plus tard par un certain Dutoya, autre Béarnais à coup sûr ${ }^{17}$.

Prudent de Casamajor exerça ensuite de 1792 à 1795 les fonctions de gérant essentiellement sur une caféterie du plateau de Rochelois au centre de la presqu'île du Sud. On le trouve en effet qualifié en novembre 1792 de "Prudent de Casamajor, habitant du Rochelois » au moment où il prend la succession du gérant de Vézien qui a été "obligé d'abandonner devant l'insurrection générale des ateliers de la plaine » la grande sucrerie Nolivos au Cul-de-Sac déjà gravement endommagée et dont 54 des 178 esclaves étaient à l'hôpital à la suite des troubles ${ }^{18}$. Il fallait, on s'en doute, un certain courage pour se lancer dans une entreprise aussi hasardeuse et il est probable qu'il ne put tenir très longtemps car, après une nouvelle insurrection des esclaves du Cul-deSac menés par Mamzelle au début de l'année 1793 et la prise de Port-au-Prince le $1^{\mathrm{er}}$ juin 1794 par les Anglais et les émigrés royalistes, il n'est plus sur l'habitation en novembre 1796 lorsqu'elle est donnée à ferme à un négociant anglais, le sieur Forbes. Il avait dû se retirer assez rapidement au Rochelois, quartier montagneux isolé et plus tranquille, où il avait accepté dès 1792 de gérer la grande caféterie béarnaise Sillègue à l'Anse-à-Veau, moyennant un sixième des revenus. Pierre de Sillègue, dit «l'Américain ", possédait là près de 600 hectares de terres et une centaine d'esclaves. On retrouvera ensuite son fils Jean de Sillègue dans le sillage de Prudent de Casamajor à Cuba, en compagnie du neveu de ce dernier, Joseph Dufourcq, qui est dit « d'Orthez » et qui est plus précisément Joseph de Dufourcq, d'Arthez-de-Béarn, dont le père Gratian-Grégoire 
de Dufourcq, seigneur de Lescun de Larreule, avait épousé Marie-Jeanne-Justine de Casamajor, sœur de Prudent ${ }^{19}$.

C'est dans ce quartier d'altitude du Rochelois, vaste plateau culminant à mille mètres, idéal pour les caféiers, que Prudent de Casamajor dut se familiariser avec le monde bien spécifique du café ${ }^{20}$ qu'il fera prospérer à Cuba «à la méthode française ». C'est à coup sûr par ses connexions béarnaises, et plus précisément par ses alliances familiales dans la région de Sauveterre, qu'il a obtenu ces deux postes qui n'étaient pas sans dangers. Un cousin germain de Pierre-Gédéon de Nolivos, propriétaire de la sucrerie du Cul-deSac, Paul de Nolivos, écuyer, seigneur de Lourenties, avait en effet épousé Jeanne-Marie de Casamajor-Salabert, sœur de Jean de Casamajor, écuyer, conseiller du Roi et son lieutenant-général de justice à Sauveterre en 1765, le père de Prudent. Or, ces Casamajor, comme les Nolivos et les Casamajor-Treslay, étaient proches parents par alliance des Sillègue de la région de Sauveterre, bien connus par le célèbre personnage du mousquetaire Athos d'Alexandre Dumas, dans la réalité Armand de Sillègue d'Athos d'Autevielle.

Selon les historiens cubains, Prudent de Casamajor aurait été également propriétaire jusqu'en 1793 d'une caféière dans les hauteurs du district de Jérémie, autre front pionnier caféier, où il avait fondé une maison de commerce à l'Anse-d'Hainault avec son frère, Paul, et l'appui des Républicains avant de partir pour les États-Unis, à Philadelphie, d'où il établit une ligne commerciale avec Baracoa avant de s'installer définitivement à Santiago en $1797^{21}$. On comprend que ces activités maritimes aient pu favoriser un départ précoce au moment des troubles, ou plutôt un non-retour que l'on pouvait supposer temporaire mais qui s'installe dans la durée en raison de la dégradation progressive de la situation dominguoise. Ce départ de l'Anse-d'Hainault s'était fait en compagnie donc de son frère Paul, mais aussi de son parent Jean de Sillègue, de son neveu Jean-Joseph de Dufourcq et de leurs serviteurs.

\section{L'aventure cubaine des cousins Dufourcq et ses étonnantes destinées familiales}

On trouve ainsi dans les premières années du xix siècle à Cuba aux côtés de Prudent, les Dufourcq, en compagnie de leurs proches parents et alliés béarnais de Casamajor, de Sillègue, de Lestapis, de Majendie, Daudinot (d'Arthez)..., la plupart réfugiés de SaintDomingue, auxquels on peut ajouter son beau-frère, le créole bordelais Jean Despaigne et son ami gascon de Labastide d'Armagnac, José Delisle. Très proche de Prudent de Casamajor, chez qui il fait adresser ses lettres à Santiago au début de son aventure cubaine, franc-maçon comme lui et son exécuteur testamentaire désigné avec son parent Jean de Sillègue, José Delisle se maintint après la grande vague d'expulsions anti-napoléonienne de 1809 et devint l'une des quatre grandes fortunes de caféières françaises de l'Oriente cubain, avec Casamajor, son gérant Despaigne, qui lui était associé dans la fondation de Santa-Catalina et le cousin germain béarnais, lui aussi naturalisé, Don José Dufourcq qui, d'ailleurs, à son retour à Paris, prendra en charge l'éducation du demi-frère de Jose-Maria de Heredia, autre proche parent, le jeune JoséGustave de Heredia $^{22}$. Il suffit d'ouvrir une lettre de Cuba dans les archives du château de Caumale acquis par Delisle (fig. 4) à son retour, pour voir ces noms apparaître à coup sûr : c'est une véritable famille créole gasconne élargie qui s'est reconstituée sur place 
et qui agrège les nouveaux venus, parents ou proches, constituant le noyau dur de la présence « béarnaise » dans l'Oriente autour du promoteur historique.

Fig. 4. - Le château de Caumale à Escalans, acheté par Joseph-Bernard (José) Delisle en 1828, revendu en 1870 par les héritiers de son fils Juan-José (Gustave) Delisle, né à Santiago de Cuba en 1805.

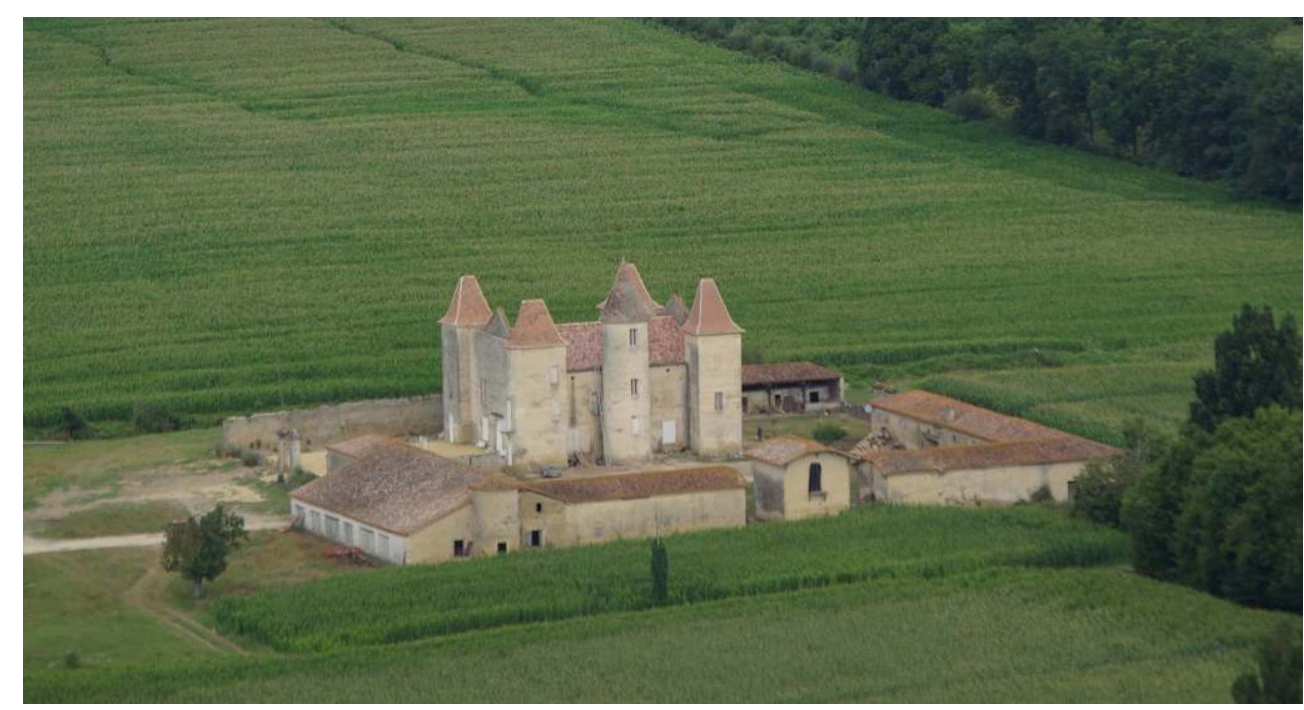

(C) Jacques de Cauna.

L'origine de l'incroyable aventure des Dufourcq d'Arthez aux Amériques est dans le mariage de Gratian-Grégoire de Dufourcq de Membrède, fils de Pierre Dufourcq, seigneur de Lescun de Larreule et de Jeanne-Scholastique de Membrède, avec MarieJeanne-Justine de Casamajor (fig. 5) qu'il avait épousée le 11 février 1783 à Sauveterrede-Béarn où ils reposent tous les deux, bien qu'ayant vécu longtemps dans la maison d'Arthez où il était né le 12 mars 1756 (fig. 6) ${ }^{23}$. Justine, son épouse, née le 12 juillet 1759 à Sauveterre-de-Béarn où elle décéda aussi en 1850, était fille de noble Jean de Casamajor, juge et lieutenant-général au siège de Sauveterre, et de Jeanne-Justine de Forcade-Biays (ou Forcade d'Osserain, elle-même fille de Jean de Forcade, d'Osserain, et de Marie de Jourdel, de Labastide-Villefranche), et, par conséquent sœur de Prudent de Casamajor, élément déterminant pour l'évolution des destinées familiales des Dufourcq. 
Fig. 5. - Justine Jeanne-Marie, dite Jeanne-Justine, de Casamajor, sœur de Prudent et épouse de Gratian-Grégoire de Dufourcq de Membrède, seigneur de Lescun de Larreule, née le 12 juillet 1759 à Sauveterre, mariée le 11 février 1783, mère de Jean-Joseph Dufourcq marié à Santiago en 1839 à Euphémie Girard, tante de José-Maria de Heredia.

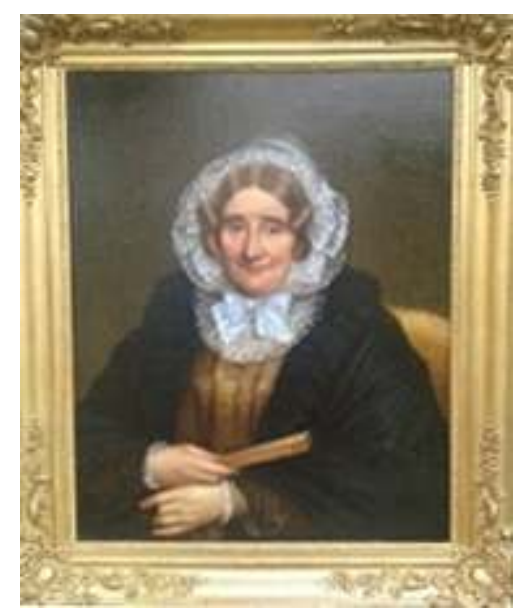

(C) Jacques de Cauna.

Fig. 6. - Arthez-de-Béarn. La Maison Dufourcq, état actuel vu de l'arrière (côté rempart).

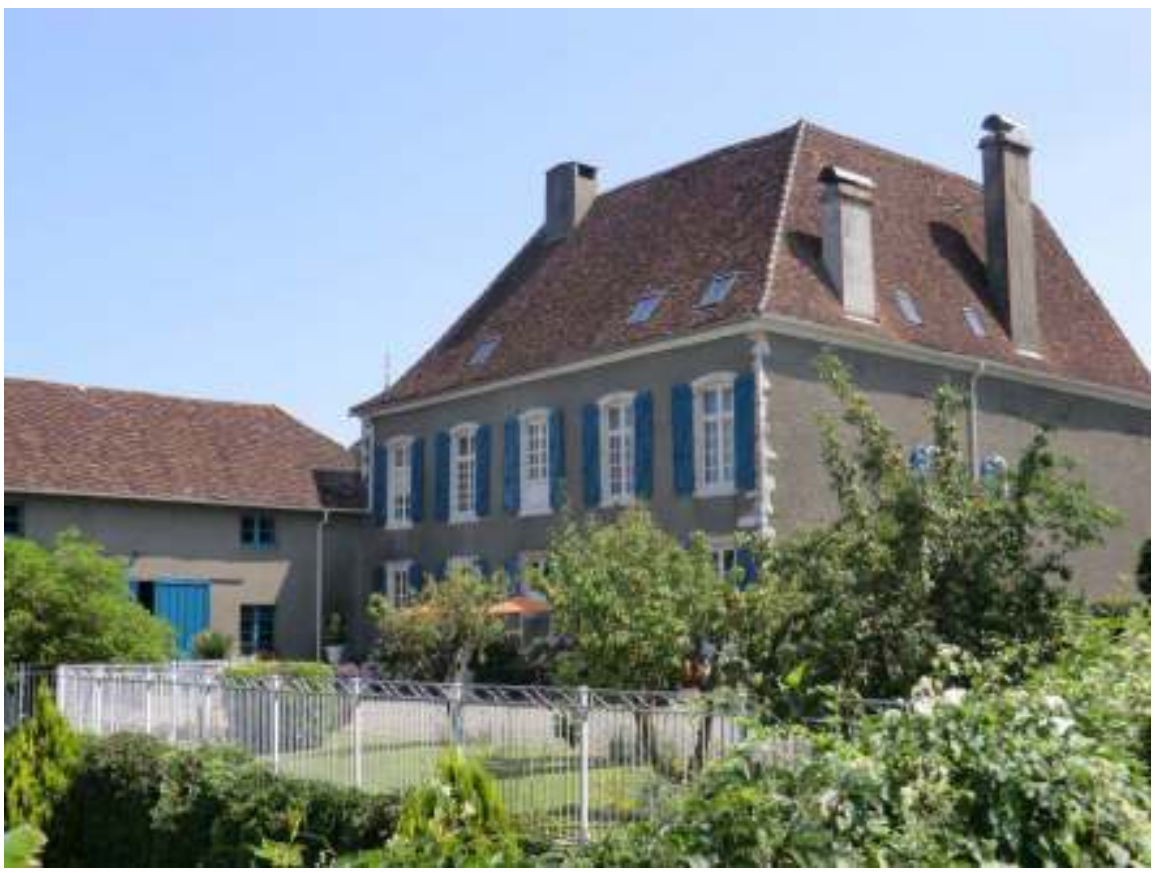

(c) Jacques de Cauna.

En effet, des douze enfants du couple, tous nés et baptisés à Arthez-de-Béarn, cinq partirent pour les îles pendant que les autres restaient dans la maison familiale d'Arthez. Le premier en date, l'aîné, Jean de Dufourcq, né le 11 novembre 1783, s'embarqua comme pilotin, fit l'expédition de Saint-Domingue en 1802 et eut de Françoise Ginesta Félix et Louis-Michel de Dufourcq, lequel se maria à Cuba, à Sans Luis del Caney le 4 février 1852 avec Louise-Thérèse Daudinot (alias d'Audinot), d'une famille de réfugiés de Saint-Domingue elle aussi originaire d'Arthez et parente des Lestapis de Mont. 
ensuite Jean-Joseph de Dufourcq, «négociant », né le 10 mars 1791, qui partit de Bordeaux le 3 décembre 1825, âgé de 34 ans, « pour affaires de commerce » à Santiago en compagnie de son cadet Pierre-Paul, alias Paulin, 32 ans, qui y décédera, tout comme le suivant Henri, benjamin de la lignée, né en 1799 et parti en 1826. Pierre-Gustave, né en 1796, reçut beaucoup plus tard, le 6 novembre 1857, un "passeport à l'étranger " pour prendre la relève et tenter d'assurer la survie de l'exploitation des biens cubains à une époque où s'est amorcé le déplacement de la prospérité du café vers le sucre qui affiche une production pour la première fois supérieure à celle du café en 1846, avec 148000 tonnes, pour atteindre 600000 tonnes en 1867 et faire de Cuba le premier exportateur mondial au xx ${ }^{e}$ siècle. En seulement vingt ans, de 1841 à 1862, l'effectif des ateliers d'esclaves des plantations de café cubaines est ainsi passé de 115000 esclaves à seulement $26000^{24}$.

La vie de Jean-Joseph est un véritable roman. Devenu José Dufourcq à Cuba, bel homme vétéran médaillé de la Bérézina, il se lança en 1824 dans le commerce d'Amérique avec son cousin germain Lucien Casamajor, fils de Prudent et de Madeleine Brun, à Philadelphie puis à Santiago où il épousa le 30 janvier 1839 Louise-Sophie, dite Euphémie, Girard, native de La Nouvelle Orléans où son père, fils du fameux notaire de Jérémie filleul de la Pompadour, s'était réfugié avant de fonder la caféière Monti-Bello dans la Sierra Maestra. Sa sœur, Sophie Girard, avait épousé à Jérémie en 1787 le Nantais né à Bazas, Jean-Baptiste Sallefranque, décédé en 1818 à La Amistad.

Par son mariage José Dufourcq devint parent des deux autres sœurs Girard, Louise et Helmina-Jeanne-Louise, et de leurs époux respectifs, Domingo de Heredia, le père du fameux poète parnassien, et le Béarnais Eugène de Ribeaux, d'Orthez, apparenté aux Lestapis, de Mont, banquiers à Bordeaux. Si bien que les trois beaux-frères s'associèrent pour l'achat d'une cafetal [caféière], comme le firent à cette époque bon nombre de Béarnais réfugiés de Saint-Domingue ou attirés directement de leur province vers ce nouvel Eldorado où ils savaient pouvoir trouver le soutien actif d'une large communauté de "pays». Ils baptisèrent leur acquisition du nom hautement symbolique de La Fraternidad (fig. 7) qui rappelle à la fois leurs liens familiaux, leur amitié et leur implication maçonnique dans la loge locale de L'Humanité. Preuve de leur ferme volonté d'œuvrer ensemble, ils avaient acquis en même temps en 1835 les cafetales La Candelaria et La Simpatia avec 153 esclaves en tout qui restèrent dans l'indivision. 
Fig. 7. - Cafetal La Fraternidad, aux trois beaux-frères : Eugène de Ribeaux (d'Orthez), ép. d'Helmina Girard, José Dufourcq (d'Arthez-de-Béarn), ép. d'Euphémie Girard, et Domingo de Heredia, ép. de Louise Girard et père de José-Maria.

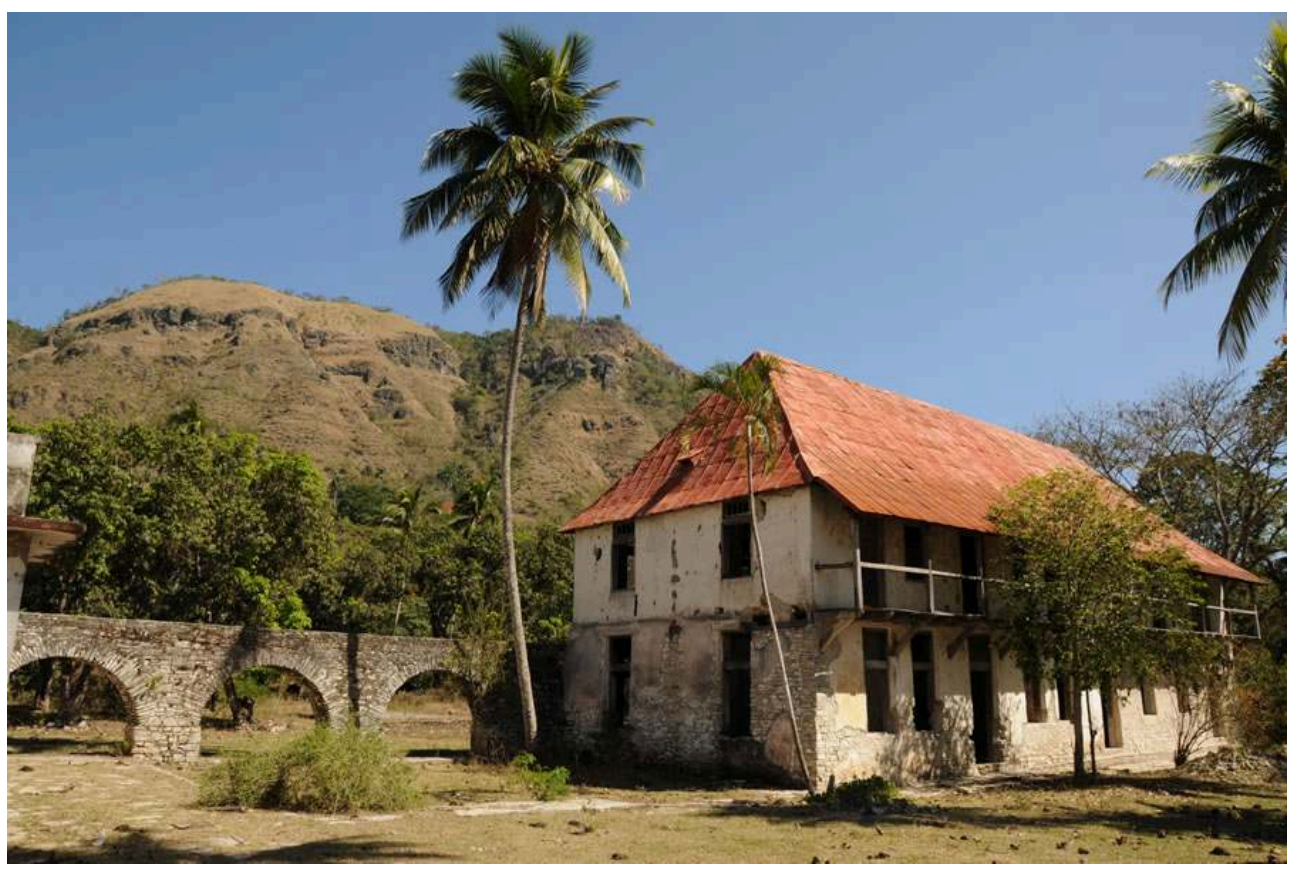

(C) Jacques de Cauna.

À son retour de Cuba en 1839, âgé de 48 ans, fortune faite, Joseph, qui résidait à Pau, 9 rue du collège, acheta un domaine agricole et ses dépendances à Mont où ses cousins de Lestapis devaient faire édifier plus tard leur château (fig. 8). Il y décéda le 8 mars 1874 après un dernier voyage en 1842 laissant sept enfants dont la descendance, illustrée par de brillantes personnalités d'hommes d'affaires et inventeurs, tant aux États-Unis avec Edward-Léonce Dufourcq qu'en France avec une alliance au célèbre baron Bich, appartient encore aujourd'hui à la noblesse subsistante. 
Fig. 8. - Le château de Mont construit par Henry de Lestapis en 1855, fils de l'armateur bordelais Adrien-Pierre, frère du banquier financier de Casamajor et marié à la créole d'origine basque mexicaine Manuela de Garay.

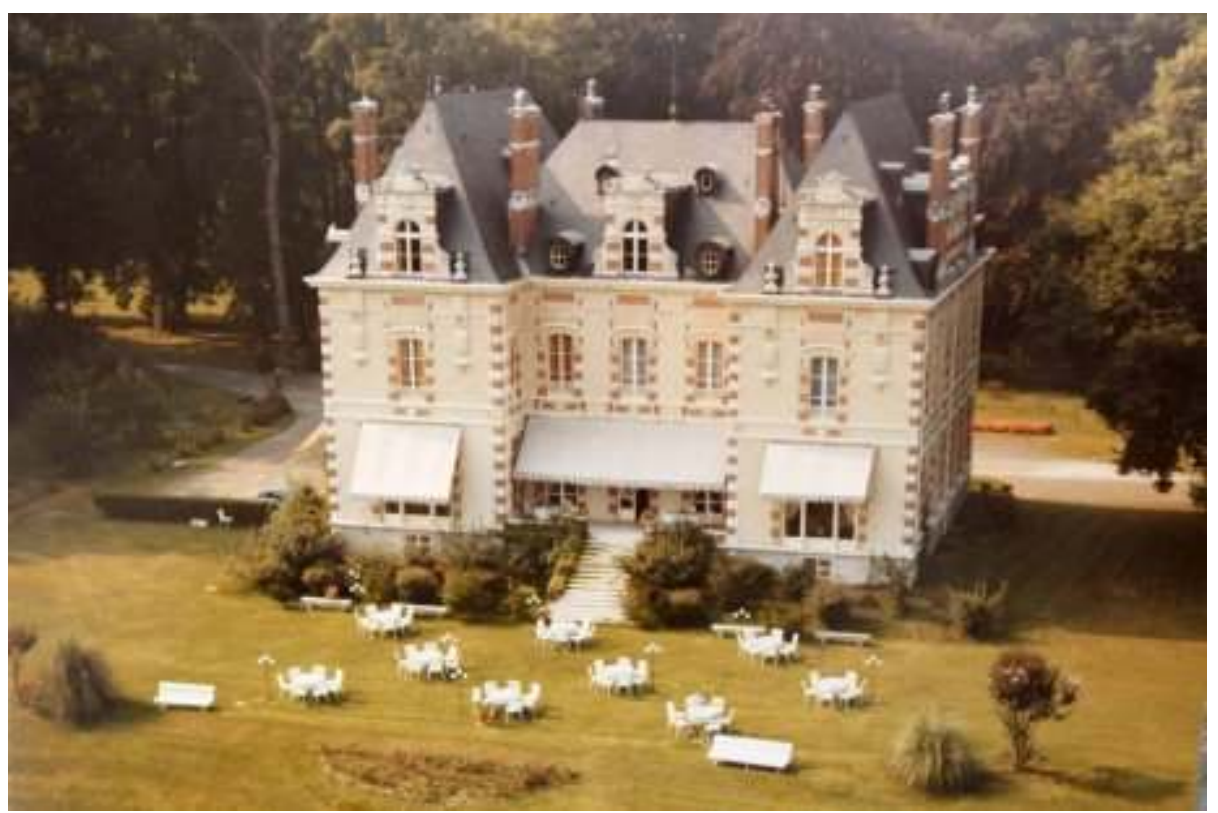

(c) Jacques de Cauna.

Quant aux demoiselles de Heredia, filles du poète et de son épouse Louise-Marie Despaigne (elle-même fille de Juan-José-Léoncio Despaigne et d'Isabelle Dutocq) (fig. 9) et cousines des Casamajor et des Dufourcq, elles se marièrent toutes à Paris avec des poètes et écrivains: Marie-Louise Antoinette, dite Maricote de Heredia (Paris 1875-1963), épousa le poète Henri de Régnier et devint ainsi la poétesse Marie de Régnier, alias Gérard d'Houville en littérature, auteur, entre autres du très beau poème «Les dames créoles» (fig. 10). Et ses sœurs, Héléna Élisabeth Caridad (1871-1953) et Louise, dite Loulouse (1878-1930), épousèrent respectivement, la première les écrivains Maurice Maindron et René Doumic en secondes noces, et la seconde les écrivains Pierre Louys puis Auguste Gilbert de Voisins, ami du précédent, petit-fils de la célèbre ballerine d'origine italienne La Taglioni, née en Suède, et arrière-petit-fils d'une créole de Saint-Domingue. Il n'y eut aucune postérité des trois sœurs, sauf un fils de Marie qu'elle avait eu en réalité avec son beau-frère Pierre Louys et qui mourut sans enfants. 
Fig. 9. - Louise Despaigne, épouse de José-Maria de Heredia.

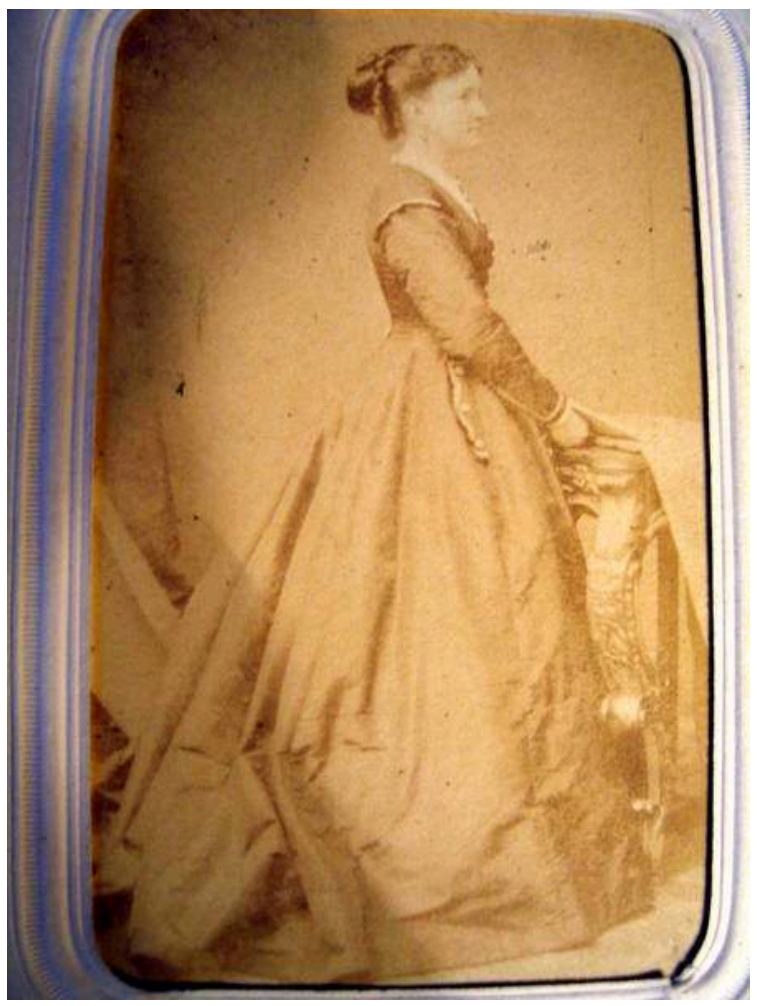

(c) M.-J. Delrieu.

Fig. 10. - Marie de Heredia de Régnier (1875-1963), fille de José-Maria de Heredia et de LouiseMarie Despaigne.

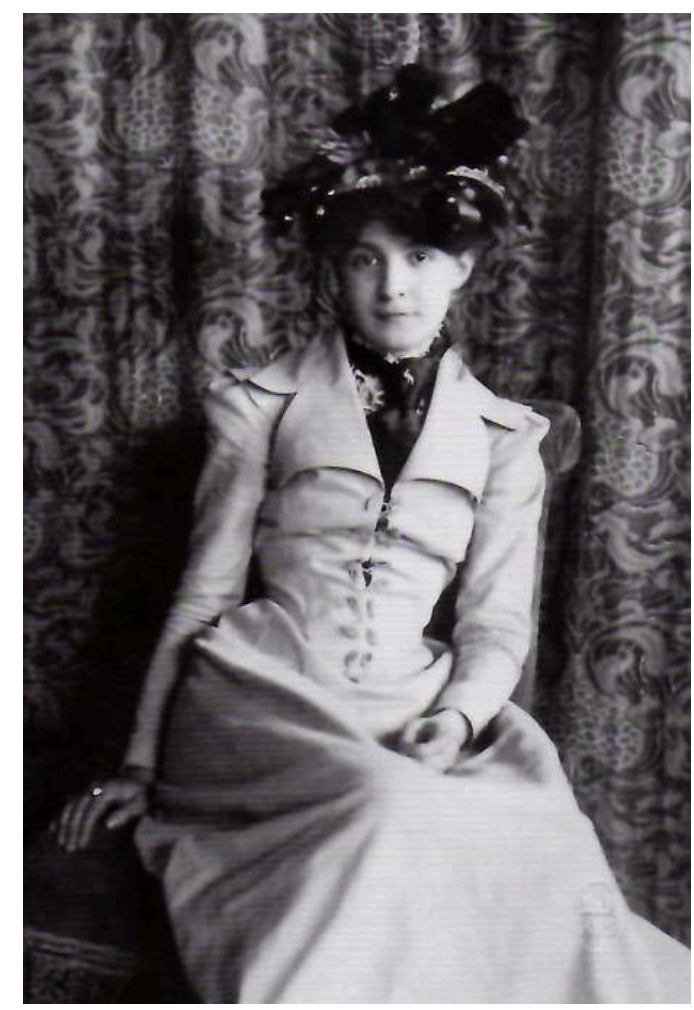

(c) M.-J. Delrieu. 
Entre mémoire perdue (la maison Dufourcq à Arthez, le château de Mont, à l'abandon) et mémoire retrouvée (le château de Caumale restauré, la famille de Casamajor, la caféière $L a$ Fraternidad au patrimoine mondial de l'Unesco), l'histoire des Béarnais de Cuba offre encore de vastes champs d'investigations pluridisciplinaires pour la recherche.

\section{BIBLIOGRAPHIE}

CASAMAJOR Paul de, Un précurseur sauveterrien : Prudent de Casamajor, Béarn, Saint-Domigue, Cuba, $\mathrm{XVIII}^{e}$-XIX ${ }^{e}$ siècles, préface J. de Cauna, Sauveterre-de-Béarn, 2009.

CAUNA Jacques de, « La maison Dufourcq à Arthez, les seigneurs de Lescun, Corisande d'Andoins et Cuba ", Revue de Pau et du Béarn, $\mathrm{n}^{\circ}$ 42, 2015, p. 59-77.

CAUNA Jacques de, «Une autre Espagne : les Aquitains de Saint-Domingue en quête de refuge à Santo-Domingo et Cuba (1791-1810) », Revue de Pau et du Béarn, n 34, 2007, p. 61-84.

Cauna Jacques de, Cadets de Gascogne. La Maison de Marsan de Cauna, Capbreton, Bordeaux, Princi Negue, 2000-2004, 4 t., t. IV.

CAUNA Jacques de, L'Eldorado des Aquitains, Gascons, Basques et Béarnais aux Îles d'Amérique, Biarritz, Atlantica, 1998.

CAUNA Jacques de, Au temps des isles à sucre. Histoire d'une plantation de Saint-Domingue au XVIII ${ }^{e}$ siècle, Paris, Karthala, 1987.

CAUNA Jacques de, «L'habitation d'un Béarnais à Saint-Domingue, la sucrerie Nolivos à la Croixdes-Bouquets (1774-1796) », Revue de Pau et du Béarn, $\mathrm{n}^{\circ}$ 12, 1984, p. 213-232.

DEBIEN Gabriel, « Les colons de Saint-Domingue réfugiés à Cuba (1793-1815) », Revista de Indias, $\mathrm{n}^{\circ}$ 55-56, mai-juin 1954, p. 559-605, 12-36.

GUICHARNAUD-TOLLIS Michèle, « Une contribution à l'histoire de Cuba : le bulletin de la Société de Géographie de Paris (1822-1855) », Jean LAMORE, Cuba et la France, actes du colloque de Bordeaux (décembre 1982), CIEC, Pessac, P. U. de Bordeaux, 1982, p. 87-125.

OROzCo Maria Elena, «Le Béarnais P. Casamayor et les Aquitains à Santiago de Cuba, première moitié du XIXe siècle ", Bernard LAVALLÉ (dir.), L'émigration aquitaine en Amérique latine au XIX ${ }^{e}$ siècle, Maison des Pays ibériques, Bordeaux, 1995, p. 45-74.

PEREZ DE LA RIVA Juan, El barracon y otros ensayos, La Habana, Ed. Ciencias Sociales, 1975.

PORTUONDO ZUÑIGA Olga, Los colones franceses y el fomento cafetalero, Les Français dans l'Orient cubain, coll. int. Santiago, avr. 1991, MPI, Pessac, 1993.

REIBLE Marcel, La Sucrerie Lugé à Saint-Domingue, Poitiers, Imp. Oudin, 1976.

ROSEMOND de BEAUVAllon Jean-Baptiste, L'T̂le de Cuba, Paris, Dauvin et Fontaine, 1844. 


\section{NOTES}

1. Sur tout ce qui suit, voir J. de Cauna, L'Eldorado des Aquitains, Gascons, Basques et Béarnais aux Îles d'Amérique, et la salle L'Eldorado des Aquitains de l'exposition permanente Bordeaux au xVIII siècle, le commerce atlantique et l'esclavage au Musée d'Aquitaine, Bordeaux (catalogue bilingue français anglais par F. Hubert, C. Block et J. de Cauna).

2. J. de Cauna, "L'habitation d'un Béarnais à Saint-Domingue, la sucrerie Nolivos à la Croix-des-Bouquets (1774-1796)».

3. J. de Cauna, L'Eldorado des Aquitains, Gascons, Basques et Béarnais aux Îles d'Amérique, p. 181.

4. P. de Casamajor, Un précurseur sauveterrien [...].

5. En 1810, il y avait 192 caféières dans l'Oriente, dont 176 appartenant à des Français. En 1843, les Français y avaient encore 179 caféières (Arch. diplo., Correspondance consulaire, La Havane, État des propriétés rurales appartenant à des Français dans l'île de Cuba, 1843).

6. J. de Cauna, «Une autre Espagne: les Aquitains de Saint-Domingue en quête de refuge à Santo-Domingo et Cuba (1791-1810) », p. 61-84.

7. G. Debien, Les colons de Saint-Domingue réfugiés à Cuba (1793-1815), et J. de Cauna, L'Eldorado des Aquitains, Gascons, Basques et Béarnais aux Îles d'Amérique, p. 452-453. Voir aussi le Plan des divers terrains achetés par Don Prudencio Casamayor pour les consacrer à la culture du café, les établir selon les divisions données, les vendre et faciliter l'ouverture des chemins et l'approvisionnement en nègres des acheteurs, Guantanamo, 1817.

8. J. Perez de La Riva, El barracon y otros ensayos, p. 377.

9. Arch. Hist. de Santiago de Cuba, Protocolos de la Escribana de la Real Hacienda 388, $\mathrm{n}^{\circ}$ 1842.

10. A. D. $64,5 \mathrm{Mi} 513-1$, p. $174 / 1716$.

11. C'est par les Majendie que se renforce la parenté de Prudent de Casamajor avec les Nolivos, Habas, Sillègue, les seigneurs de Cassaber et les Bertier. Jeanne, sœur de son père Jean, avait épousé Jérémie-Joseph de Magendie dont elle eut Pierre, marié en 1765 à Jeanne de Nolivos, et Jeanne-Marie, mariée à Jean-André de Habas.

12. Fonds J. de Cauna. Lettres des 28 juillet 1771, de Saint-Marc, et 18 août 1779, de l'Artibonite, dans lesquelles il est question de M. Casamajor, habitant Bordeaux, et de Mme Jean de Casamajor de Gestas (Françoise-Félicité de Rivière). Voir aussi J. de Cauna, L'Eldorado des Aquitains, Gascons, Basques et Béarnais aux Îles d'Amérique, et l'État dit de l'Indemnité de Saint-Domingue, tome VI, 1832.

13. J. de Cauna, Cadets de Gascogne. La Maison de Marsan de Cauna, IV, 68.

14. J. Perez de La Riva, El barracon y otros ensayos, p. 377.

15. Fonds J. de Cauna. Original.

16. J. de Cauna, L'Eldorado des Aquitains, Gascons, Basques et Béarnais aux Îles d'Amérique, et pour une description de l'habitation de Lugé, Au temps des isles à sucre, p. 27-28 et planche 24 h.t., photo des vestiges.

17. M. Reible, La sucrerie Lugé, 1973, p. 52, 66. 
18. J. de Cauna, «L'habitation d'un Béarnais à Saint-Domingue, la sucrerie Nolivos à la Croix-des-Bouquets (1774-1796)», p. 222.

19. Archives privées aimablement communiquées par M. Pierre de Lestapis, cousin des Casamajor, Nolivos et Sillègue, d'après Arnaud de Lestapis, Un coin de Béarn autrefois. On trouve à Arthez-de-Béarn, sur la grille du portail d'entrée de la maison des seigneurs de Lescun de Larreule - voisine de celle des Gaye et souvent confondue avec le château de Corisande d'Andoins, l'égérie d'Henri IV, Diane, seigneuresse d'Arthez et Lescun, vicomtesse de Louvigny, fille de Paul d'Andoins et de Marguerite de Cauna - un monogramme aux initiales de Gratian-Grégoire Dufourcq de Membrède, père de JeanJoseph.

20. À Saint-Domingue, le café colonial était cultivé à découvert sur des plantations en quinconce, situées entre 300 et $1000 \mathrm{~m}$ d'altitude. Voir P.-J. Laborie, The coffee planter of Saint Domingo, 1798, jamais traduit en français.

21. O. Portuondo Zuñiga, Los colones franceses y el fomento cafetalero, Les Français dans l'Orient cubain, p. 118.

22. BN, Ms 5678, archives de la maison de Heredia, communiquées par Mme Marie-José Delrieu. Lettre de J. Delisle à Domingo de Heredia, 4 mai 1832: «Le temps et l'éloignement n'ont rien enlevé de l'amitié que vous m'aviez inspirée... et votre mariage avec une jeune personne [Luisa Girard] pour laquelle ma famille a toujours conservé les sentiments les plus affectueux... Les cinq collèges principaux de Paris sont Henry IV, Louis le Grand et Stanislas, (avec internes), Charlemagne et Saint Louis (externes seulement)... ». Domingo de Heredia, qui était à Pau en 1835, avait épousé Genobeba Yvonnet au Potosi à Cuba en 1817, avec l'Arthézien André Daudinot pour témoin, dont un fils épousera une Dufourcq.

23. Pour plus de détails, voir J. de Cauna, «La maison Dufourcq à Arthez, les seigneurs de Lescun, Corisande d'Andoins et Cuba », p. 59-77.

24. M. Guicharnaud-Tollis, «Une contribution à l'histoire de Cuba: le bulletin de la Société de Géographie de Paris (1822-1855) », p. 87-125.

\section{RÉSUMÉS}

L'insurrection des esclaves de Saint-Domingue (Haïti) provoqua l'exil dans les îles voisines de nombreux Gascons et Béarnais, principal groupe régional de l'ancienne colonie antillaise. Dans la partie orientale de Cuba, le courant d'émigration antillaise des Béarnais, initié par de grands chefs fondateurs, soutenu par de puissants réseaux et alimenté par la tradition, persévéra durant toute la première moitié du XIX ${ }^{e}$ siècle. Un Sauveterrien, Prudent de Casamajor, ancien gérant de sucreries devenu négociant, fut par son activité l'agent général, l'homme d'affaires, le conseiller et même le banquier de cette petite colonie de réfugiés dont bon nombre lui étaient apparentés. Il débuta dans la spéculation en achetant à bas prix dans les hauteurs de Santiago des terres en friches difficiles d'accès que l'on pouvait croire incultes mais qu'il fit prospérer en les cédant à des compatriotes par petits lots pour l'installation de caféières (cafetales) et en les reliant par un réseau de routes dont la principale est toujours connue sous le nom de Camino frances. Méconnu 
en Béarn, il est un personnage majeur de l'histoire cubaine et ses cousins Dufourcq sont parents du poète José-Maria de Heredia.

\section{AUTEUR}

JACQUES DE CAUNA

Docteur d'État (Sorbonne), professeur honoraire ITEM, université de Pau, CIRESC CNRS/EHESS, chaire d'Haïti à Bordeaux 
AuX $\mathrm{XIX}^{\mathrm{e}}$ et $\mathrm{XX} \mathrm{X}^{\mathrm{e}}$ siècles 


\title{
Les circulations de bois dans le Vercors-nord au XIX ${ }^{\mathrm{e}}$ siècle : l'histoire d'une dépossession?
}

\author{
Gilles Della-Vedova
}

1 Étudier les circulations de bois entre les montagnes et les espaces périphériques au XIX siècle consiste à chercher à comprendre comment le processus industriel a modifié durablement le rapport des sociétés humaines avec la forêt. Cette période est ponctuée de deux moments majeurs: 1827, avec le Code forestier, dont la mise en place se déroule durant la monarchie de Juillet, et la seconde décennie du Second Empire avec, en 1860, la loi sur le reboisement, complétée quatre ans plus tard par celle sur le regazonnement ${ }^{1}$.

2 Ce n'est donc pas par hasard si le xix siècle a été choisi par l'historiographie pyrénéenne pour étudier les résistances des sociétés locales aux changements à l'œuvre ${ }^{2}$. C'est avec une volonté comparatiste que le refus est interrogé ici avec l'expression de "dépossession ", c'est-à-dire de captation des ressources ligneuses qui circulent. Il s'agit donc d'examiner l'intégration des "hauts pays " à la société industrielle dont les modalités modernes de contrôles s'exercent jusque dans les forêts de montagnes via l'action de l'administration forestière. Bernard Kalaora et Antoine Savoye enquêtent à leur manière sur ce sujet dans La forêt pacifiée $e^{3}$. La " pacification " n'a pas résulté seulement d'une approche intellectuelle par l'élite forestière puisque l'école de Nancy est longtemps restée imperméable aux propositions de Le Play ${ }^{4}$. Elle serait le fruit d'une négociation plus compréhensive faite par le bas, c'est-à-dire par les agents forestiers en contact avec les sociétés locales.

3 C'est la raison pour laquelle le support de l'étude se situe en Dauphiné mais à l'échelle micro, au sein du massif du Vercors. En effet, le canton de Villard-de-Lans, nommé le pays des Quatre montagnes au XIX ${ }^{e}$ siècle, en forme sa pointe septentrionale. Il se caractérise par l'importance des forêts. L'augmentation de la population grenobloise, qui passe de 45000 habitants en 1872 à 77438 en 1911, et de ses communes 
environnantes dans le contexte de la deuxième industrialisation alimente la demande accrue de bois. De surcroît, les circulations se font à d'autres échelles.

Le récit du réagencement forestier peut se mener en trois temps, d'abord en constatant que les circulations de bois sont héritées du passé, ensuite en comprenant que les applications du Code forestier de 1827 entravent les circulations et un certain mode de développement montagnard; enfin en saisissant que, dès le début du Second Empire, des accommodements se mettent en place.

\section{Des circulations héritées}

5 Parmi les poncifs trainés par les montagnes, leur enclavement et leur manque d'intégration par des circulations difficiles sont un lieu commun. Dans ce tableau misérabiliste, le XIX $x^{e}$ siècle serait, enfin, le temps de l'ouverture du fait de l'essor des routes et des travaux publics engagés à cet effet. Cette vision, vision d'en bas, vision venue des villes et de la société industrielle qui cherche à légitimer son action, est fortement à nuancer quand elle se situe sous l'angle des sociétés locales. Le XIX ${ }^{\mathrm{e}}$ siècle est à replacer dans une chronologie bien plus ample et les circulations des bois en fournissent un exemple de choix.

\section{Un XIX siècle forestier}

6 Dès l'époque moderne, les transports des ressources ligneuses sont une activité de la plus haute importance. Dans le massif, ils font vivre des familles entières. Les unes sont les "gens du bois $"^{5}$. Les charbonniers en sont des figures communes ${ }^{6}$. Voici par exemple Pierre Gauthier qui exerce cette activité de pauvres et qui décède en 1859. Son fils Benjamin (né en 1841) est bûcheron et le fils aîné de ce dernier fait la même activité que son père. La transformation des arbres en charbon devient moins nécessaire avec la construction des routes, mais la survie de la famille passe toujours par l'exploitation et la circulation des bois. Un suivi prosopographique d'individus qui ont, dans un acte d'état civil entre 1835 et 1875, une profession liée au travail du bois montre une grande cohérence professionnelle. Couper des arbres, débiter des grumes, transporter les produits fabriqués s'inscrit dans un grand nombre de combinaisons, chez un même individu en fonction de la saison mais aussi réparties entre les différents hommes au sein d'une même maison. Les circulations du bois sont donc héritées parce qu'elles s'inscrivent dans un mode de développement local ainsi qu'en attestait la Réformation des bois du Dauphiné au XvIII ${ }^{\mathrm{e}}$ siècle :

«Les plus grandes parties des habitants de cette communauté [Villard-de-Lans] se faisant marchand de bois traitent avec le plus offrant pour leur livrer du bois de sapin... $»^{7}$

7 De surcroît, le transport de bois participe d'une ancienne intégration des forêts du massif qui font l'objet d'exploitation à d'autres échelles. L'une est régionale. En effet, dans les années qui suivent l'ordonnance de Colbert de 1669, l'intendant du Dauphiné se plaint de l'état déplorable des forêts "à cause des forges du Dauphiné, des manufactures d'acier, d'ancres, de lames et d'épée et de toute autre espèce $»^{8}$. Ceci se prolonge durant la période révolutionnaire lorsque l'auteur d'un rapport écrivait que «Les bois de Valchevrières, Corrançon, et Arbouillis [Herbouilly] mis en coupes réglées 
fourniront environ 10000 charges de charbon par an " pour alimenter les forges de canons de Saint-Servais situées au bord de l'Isère ${ }^{9}$. Il y a un usage protoindustriel.

8 L'autre échelle concerne la partie méridionale du royaume. Toujours à la fin du XVII siècle, l'intendant du Dauphiné cité défendait aux communautés d'Autrans, de Lans, de Méaudre et de Villard-de-Lans d'exploiter ou de couper des arbres avant qu'ils ne soient visités afin de distinguer lesquels seraient bons pour la marine ${ }^{10}$. L'interdiction est renouvelée au début du xvIII ${ }^{e}$ siècle, ce qui prouve peut-être qu'elle n'est guère suivie $^{11}$. Au sein du massif, les grumes passent par de multiples «pas » où ils sont jetés en contrebas pour poursuivre leur voyage. Arrivés au bord de l'Isère, ils composent des convois qui descendent la rivière, puis le Rhône, et sont transportés en direction de la foire de Beaucaire. La toponymie actuelle le long de l'Isère garde le nom de plusieurs lieux nommés "ports» qui étaient des lieux de transbordement. Ces flux se poursuivent durant la première moitié $\mathrm{du}$ xIX $\mathrm{X}^{\mathrm{e}}$ siècle puisqu'en 1834 le préfet demande une liste de commerçants amenés à composer les tribunaux de commerce et que deux "marchands de bois de Marine $" y$ figurent ${ }^{12}$.

9 Les circulations du bois constituent donc un héritage pour des usages diversifiés, à des échelles emboîtées et elles sont partagées par un grand nombre d'acteurs. Dans ce temps long, malgré des velléités, l'État est demeuré faible.

\section{L'État peine à contrôler les bois et les circulations}

D'abord, l'encadrement est structurellement insuffisant malgré les mesures de l'ordonnance de 1669. La législation révolutionnaire, dans ses premières années, va dans une direction opposée à celle de l'Ancien Régime et rapproche la prise de décision des espaces concernés. Dès le Consulat, Bonaparte tente de revenir en arrière et la Restauration lui emboîte le pas mais le maillage reste très faible sur le terrain. Une archive de 1813 note qu'il y a un garde à Autrans, Lans et Méaudre mais aucun à Villard-de-Lans ${ }^{13}$. Cette absence continue à être notée sept ans plus tard ${ }^{14}$.

11 Ensuite, au ras du sol, la qualité du recrutement fait défaut. Les gardes forestiers, pas toujours clairement différenciés des gardes champêtres, sont souvent natifs de la commune. Cela représente un avantage pour identifier des délinquants comme dans le cas du garde Rolland qui manqua d'être tué pour cela en $1833^{15}$. Mais c'est un inconvénient, car les traitements très faibles versés par les municipalités les rendent sensibles à la concussion et, plus largement, à l'influence des notabilités locales.

Enfin, l'État peine à contrôler les circulations de bois car les agents forestiers sont hostiles à la plupart des prélèvements. Comme le montre Martine Chalvet, ils s'estiment les descendants de Colbert et de la raison d'État ainsi que les héritiers d'un temps long qui remonte à l'Ancien Régime. Ils s'opposent donc aux temps nouveaux du libéralisme et à l'individualisme de la société industrielle. Par conséquent, ils se heurtent tout à la fois aux usages communs des sociétés de montagne et aux intérêts des marchands qui veulent prendre le train de l'intégration économique et de l'âge industriel. 


\section{La filière bois contrôlée par une oligarchie locale}

13 Elle entend bien profiter des opportunités nouvelles. Les hiérarchies sociales s'expliquent pour une large part par leurs capacités à exploiter et à exporter les ressources ligneuses.

Il s'agit d'un trait de l'Ancien Régime comme le montrent les sources d'enrichissement de la famille des Esbrard de la Vallonne ${ }^{16}$. Elle s'installe en co-résidence à Grenoble et dans les montagnes de Lans d'où elle tire une partie de ses revenus. En effet, à la fin du $\mathrm{XVIII}^{\mathrm{e}}$ siècle, elle possède une scie hydraulique dont les planches découpées descendent à dos de mulet à Sassenage. Elle est représentée sur le plateau de Villard-de-Lans par la famille Jullien qui possède également une scie hydraulique et qui se livre au même type de commerce.

La famille Jullien s'enrichit durant la période révolutionnaire et profite des circulations de bois. Jean Gabriel Jullien décède en 1805 et possède une fortune d'un peu plus de 70000 francs $^{17}$. Son fils, également notaire et maire de la commune, laisse une succession à peine inférieure à 150000 francs trente ans plus tard ${ }^{18}$.

Ces familles tissent des liens entre elles de manière à contrôler le marché forestier. Par exemple, quand Jean Baptiste Gabriel Joseph Jullien décède, Pierre Jourdan est l'un des deux témoins à signer l'acte de décès. De même, Benoît Bertrand (1775-1851) épouse une sœur de Jean Baptiste Gabriel Joseph Jullien. Domicilié à Autrans, il est propriétaire de 315 hectares entre cette commune et celle voisine de Méaudre; le capital foncier dépasse 100000 francs lors de son décès. Les produits sont évacués par Sassenage où son frère Alexandre est notaire. L'un de ses enfants, Félix Eusèbe Eugène, devient notaire à Villard-de-Lans à la mort de l'oncle Jullien. De manière très symbolique, il vit au «château Bernard» qui n'est autre que l'ancienne maison Jullien, laquelle avait remplacé l'ancienne maison des Esbrard de la Vallonne.

17 Ainsi, l'exploitation et les circulations de bois sont au cœur des stratégies d'un grand nombre d'acteurs locaux. Les uns appartiennent aux meilleures familles qui exercent toutes les possibilités offertes par la notabilité pour être incontournable. Agents de l'État, ils doivent seconder l'administration forestière. Grands propriétaires, ils ne peuvent accepter de voir scier la branche sur laquelle leur fortune s'est étendue. De surcroît, ils contribuent à faire vivre de nombreuses familles pluriactives qui cherchent à se développer en tant que bûcherons, scieurs ou voituriers de manière légale ou non. C'est ce système en équilibre qui se trouve remis en question à la suite du Code forestier de 1827.

\section{Des circulations entravées}

18 Le Code forestier est voté en 1827 mais ses effets mettent une dizaine d'années pour apparaître dans le canton de Villard-de-Lans. Les années 1840 coïncident avec l'optimum démographique qui, conjugué à la crise économique de la monarchie de Juillet entraînent l'explosion révolutionnaire et forestière de 1848. Toutefois, malgré cet événement, les mouvements de fonds en vue d'un contrôle des circulations de bois demeurent sous le Second Empire. 


\section{Un nouveau contrôle sur les bois et leur circulation}

19 Les sociétés locales perçoivent de manière particulièrement brutale certaines dispositions du Code forestier. Par exemple, selon l'article 177, ses procès-verbaux étaient considérés comme des preuves pour des délits inférieurs à cent francs et un barème très détaillé graduait une échelle des peines, doublées en cas de récidive de mois d'un an ou si les délits se déroulent de nuit (articles 200 et 201), qui pouvaient conduire à la prison. L'article 90 précisait que seule l'administration forestière décidait quels étaient les terrains communaux à soumettre au régime forestier. En excluant fermement le petit bétail et, de manière à peine moins stricte, le gros bétail, le système pastoral est perturbé. Ceci se déroule au moment où l'élevage bovin prenait de plus en plus d'importance dans le canton. La dépossession est perçue comme totale, surtout par rapport à la période révolutionnaire antérieure. Guizot prolonge cette répression durant les années 1840.

Le deuxième dispositif consiste à recruter des gardes forestiers qui ne soient plus issus du microcosme local. Progressivement, des étrangers arrivent. Par exemple, en 1845, le conservateur soutient la candidature de Belle, natif du département voisin de la Drôme, « car le conseil municipal d'Autrans [...] avec raison avait reconnu la nécessité d'avoir pour garde un étranger $\aleph^{19}$. De surcroît, l'administration tente d'appliquer la loi du 19 floréal an XI (29 avril 1803) qui cherche à intégrer d'anciens militaires en tant que gardes forestiers. Par exemple, Pierre Antoine Meyzin, âge de 31 ans et ancien militaire au $12^{\mathrm{e}}$ régiment d'artillerie est mentionné en 1851.

21 La dernière mesure, symbole de la tyrannie exercée par l'administration forestière, est le marteau chargé de frapper les bois qui circulent. C'est un objet anciennement importé par l'administration forestière pour empêcher la contrebande. Le Code forestier devient l'occasion de l'agiter à nouveau pour chercher à superviser les transports. C'est explicitement pour cette raison qu'un maire d'Autrans, qui était arrivé à cette responsabilité pour s'opposer à l'emprise des deux frères riches en bois, adresse une demande à l'administration supérieure afin que le garde champêtre puisse en détenir un ${ }^{20}$. Cet instrument est explicitement brandi par le procureur général au garde des Sceaux, trois ans plus tard, pour expliquer l'origine de l'émeute forestière qui secoue cette même commune en avril $1848^{21}$. L'ensemble de ces mesures entraîne la remise en cause d'une grande partie de la société locale.

\section{Lutte des masses/lutte des classes}

En explorant les archives judiciaires, l'historiographie s'est livrée à des statistiques relatives à la délinquance forestière. Celle-ci est colossale et Jean-François Soulet multiplie les chiffres impressionnants ${ }^{22}$. Il reprend une estimation communément admise qui veut que, pour une affaire poursuivie, trois autres demeurent inconnues; les approches quantitativistes ont donc leurs limites.

Une autre source utilisée, celle des dossiers communaux conservés par l'administration forestière, fournit une approche complémentaire à celle de la justice pour étudier les délinquants ${ }^{23}$. Elle montre qu'il s'agit de membres de la même famille dans la moitié des cas recensés lorsque le délit est clairement réalisé en groupe, que les hommes constituent plus de $93 \%$ des 128 affaires et que les espaces reculés et les plus proches de la forêt sont les plus propices aux délits. Si les prélèvements peuvent s'expliquer 
pour des questions de survie, d'autres correspondent à une délinquance "spéculative " ${ }^{24}$. En effet, le 8 septembre 1855, le conservateur adressait au préfet une liste de 26 délinquants forestiers pour lesquels le conseil municipal d'Autrans demandait une remise des amendes. L'agent forestier distinguait les «insolvables » des "solvables ", les derniers étant " très solvables ${ }^{25}$. Les deux dernières catégories représentent $38 \%$ des cas. Louis Durand-Poudret (vers 1801-1868) est « solvable ». Il vient d'une famille de très petits propriétaires et possède 2,1 hectares en 1834 . Il se procure des revenus par la pluriactivité, car il est cordonnier au moins en 1834 et en 1843. La solvabilité apparaît également lors de la donation entre vifs que Louis Durand-Poudret et Catherine Gamond réalisent en 1868: les quatorze parcelles fournissent un revenu annuel de 282 francs ce qui signifie un capital de l'ordre de 5600 francs. À cela, il faut ajouter les biens mobiliers composés essentiellement d'outils pour l'exploitation, de quatre vaches et deux génisses, les animaux étant estimés 1000 francs pour un total de 1195 francs (mais il y a 1800 francs de dettes) ${ }^{26}$. Jean-Louis Brunel est quant à lui « très solvable ». Né en 1809, il est l'aîné d'un homme qui détenait un capital mobilier supérieur à 4600 francs lors de son décès ${ }^{27}$. Son beau-père est un petit propriétaire de 5,2 hectares en 1834 mais lié au négoce. À Autrans, le mariage de Jean-Louis Brunet en 1838 se déroule une semaine après celui de sa sœur cadette avec un cabaretier, profession très en lien avec le transport. Lors de son décès en 1888, la fortune mobilière monte à 1346 francs $^{28}$. Par les deux branches de la famille, Jean-Louis Brunet est rattaché à des entités dont le développement repose sur les circulations marchandes. La délinquance pourrait s'agencer aux activités d'autres parents, afin d'assurer l'enrichissement de tous ses membres dans une optique de développement et pas - ou pas seulement - de survie.

24 Ainsi, il semble excessif de voir dans la répression par l'administration forestière une lutte des classes. Par contre, par le nombre d'affaires, il y a bien une lutte des masses puisque toute la société locale se trouve inquiétée. La lutte de l'administration forestière, après avoir éclairci le taillis de la petite délinquance, cherche à abattre les pièces maîtresses.

\section{Des notables qui vacillent}

Le portrait de Claude Vincent-Martin est emblématique de la force et de la durée de la lutte que l'administration forestière entreprend contre les piliers de l'ancien mode de développement. Il est lié au monde du négoce, dont celui du bois, par la famille de sa première épouse. Quant à la seconde, originaire de Lans, le choix pourrait s'expliquer par le fait que son père est domicilié sur l'autre versant d'une forêt particulièrement exploitée, probablement le long d'un axe d'évacuation du bois. De plus, le garde champêtre Romagnier signe l'acte de mariage, ce qui pourrait signifier qu'il est un allié de Claude Vincent-Martin. Ce pluriactif "propriétaire, marchand de bois et de fromages [qui] exerce principalement la profession d'aubergiste $»^{29}$ est un délinquant d'habitude. En mai 1843, quelques mois après la délimitation des bois communaux de Méaudre, un procès-verbal lui est adressé pour l'établissement d'un chantier à façonner le bois qui "est établi à 140 mètres de la forêt communale dans un cabaret " lui appartement ${ }^{30}$. Les affaires s'enchaînent: prélèvement de quatre résineux, treize épicéas et cinq fagots en septembre 1843, constat du recel de 51 résineux le 20 juin et $1^{\mathrm{er}}$ juillet 1846, 21 résineux les 26 juin et 2 juillet de la même année, sept hêtres et deux fagots les 10 et 16 novembre 1846 encore et ainsi de suite... À la faveur de la Révolution 
de 1848, il devient maire de la commune et reste en place durant toute la Deuxième République. Il a donc le verbe haut face aux représentants de l'administration forestière. Il les insulte en février 1850 et en août 1853. En 1852, il refuse de les accompagner pour constater des délits forestiers. Claude Vincent-Martin transporte également les arbres. L'audience qui se déroule devant la troisième chambre à Grenoble le 25 août 1854 montre qu'en juin 1853 des agents forestiers ont fait le constat à Engins que 50 résineux se trouvaient dans la voiture de François Ravaux, mais que les arbres étaient marqués du marteau de Claude Vincent-Martin. Le procès apprend que ce dernier possède des «magasins " à Sassenage, c'est-à-dire des entrepôts ${ }^{31}$. Claude Vincent-Martin démissionne de la mairie en 1853, réintègre le conseil municipal douze ans plus tard. À l'occasion de la proclamation de la République en 1870, il préside la commission municipale mais ne parvient pas par la suite à revenir diriger l'assemblée communale. L'administration forestière a finalement gagné le bras de fer qui l'opposait à cet homme depuis près de 30 ans et au mode de développement qu'il animait. Toutefois, l'idée de victoire, grâce au Code forestier, est trompeuse. En effet, les circulations de bois sont négociées à partir des premières années du Second Empire.

\section{Des circulations de bois négociées}

Elles bénéficient d'un contexte favorable. Il y a une moindre pression démographique puisque de 1851 à 1876 la population cantonale baisse de $14 \%$. De surcroît, l'état des forêts s'améliore rapidement. Une visite du garde général dans les bois d'Autrans en 1859 l'amène à constater que :

«La franche moitié de la clairière s'est reboisée depuis le cadastre et que le surplus

s'améliorait et même promptement. $\|^{32}$

Ces éléments entraînent un accommodement de la part de l'administration forestière.

\section{L'accommodement}

Les facteurs de ce changement d'attitude sont triples. À l'échelle nationale, les autorités impériales sont plus conciliantes et une révision du régime forestier, dans un sens plus respectueux de l'intérêt communal, se déroule en 1853 en Isère. De surcroît, le décret impérial du 24 juin 1858 établit une nouvelle répartition des compétences entre ce qui relève des communes et ce qui appartient à l'administration forestière. Enfin, la loi du 18 juin 1859 autorise les agents de l'administration forestière à transiger avant un jugement définitif sur les poursuites des délits et contraventions en matière forestière commis dans les bois soumis au régime forestier.

Toutefois, les préjugés ont la vie dure sous la plume et gênent l'accommodement : en 1870 encore, le conservateur dénonce la population de Méaudre et sa pratique « de ce que en temps révolutionnaire, on appelait le brigandage dans les bois $"^{33}$. Mais la nouveauté est que certaines circulations de bois délictueux peuvent être consenties par une appréciation personnelle de la situation des délinquants. En 1854, le conservateur propose de baisser l'amende de Jean David, pourtant «très solvable », car ce n'est pas un délinquant d'habitude. En 1858, c'est au tour du garde général de plaider en faveur du journalier Benoît Ronin; le mois suivant, il réclame cette fois l'indulgence pour Bonnet qui a enlevé six résineux. La situation personnelle, la mise en contexte et l'exposé des logiques qui conduisent les délinquants à faire circuler des bois sont, avant 
la diffusion des conceptions de Le Play, déjà pris en compte par des éléments d'échelons inférieurs de l'administration forestière.

L'accommodement dépasse les simples situations individuelles pour envisager le développement des villages. Durant les années de conflit, aux coupes ordinaires, d'autres dites "extraordinaires » avaient pour utilité d'éponger les amendes que les communes devaient à l'administration, 11688,66 francs dans le cas d'Autrans pour celles entre 1843 et 1851 . Les archives montrent des inflexions puisque les fonctionnaires forestiers passent d'un contrôle des circulations pour assurer le développement des forêts à l'autorisation du commerce des bois en vue de l'essor des communes. Durant les années 1860, alors que le nombre d'habitants fléchit, l'administration forestière autorise la quantité de stères de bois à prélever dans les coupes ordinaires. Cet appui peut conduire à des situations paradoxales. À Méaudre, le garde général prend la défense d'un marchand de bois auprès du préfet :

«Dans le canton Chabert (Henri) est le seul marchand de bois qui maintienne le prix des bois à une valeur convenable [...]. N'est-il donc pas de l'intérêt de la commune à ménager un homme sans lequel c'est l'avis de tout le monde, les coupes ne se vendraient qu'à vil prix ? $»^{34}$

Par conséquent, les années du Second Empire sont décisives. La fermeté des années 1840 se modifie dès le milieu de la décennie suivante par la recherche de la compréhension de la logique d'acteurs modestes ${ }^{35}$. Faut-il privilégier une lecture qui insiste sur la fermeté attendue de la répression ou qui met l'accent sur le changement de perception d'une partie de l'administration forestière ? La dernière période est donc celle d'une intégration renforcée des circulations de bois à l'économie globale.

\section{Le développement du maillage routier}

Les routes sont le vecteur de deux légendes, l'une noire qui explique l'exode rural par leur essor, l'autre rose qui fait remonter le désenclavement à leur construction. La période à partir des années 1860 voit dans le Vercors la mise en réseau entre trois types de tracés.

Il y a d'abord les grandes artères. La plus importante était la route qui, partant de Villard-de-Lans, descendait jusqu'à Sassenage et qui « est avant tout la grande route du bois $»^{36}$. C'est également vers l'ouest que les routes exportent des bois vers la basse vallée de l'Isère. Celle des Grands Goulets, celle des gorges de la Bourne qui est inaugurée en 1872 après plus de dix ans de travaux, puis celle de Combe-Laval, entérinent une exploitation intensive des forêts à la fin du XIX ${ }^{e}$ siècle.

Les circulations de bois sont facilitées par des routes secondaires qui composent un réseau. Dans le canton de Villard-de-Lans, l'une d'elles joint le plateau à Grenoble en passant par Saint-Nizier en 1875. Une autre relie Méaudre à Villard-de-Lans par les gorges de Méaudret, permettant ainsi le branchement sur les gorges de la Bourne. Les travaux se déroulent au début des années 1880 et se poursuivent au cours de la même décennie par une route entre Méaudre et Autrans.

Enfin, les vidanges des cantons forestiers sont rendues possibles par un chevelu de sentiers qui se dessine à partir du dernier quart du XIX ${ }^{e}$ siècle. Par exemple, en 1872, le garde général suggère d'améliorer les chemins de Nave, du Violet, du Navelets et des Grands Clots à Autrans ${ }^{37}$. L'administration forestière multiplie les rapports pour 
souligner l'intérêt des nouveaux tracés et élargir ceux qui existent. Georges Jorré calcule une " densité routière " qui place le Vercors en tête des massifs régionaux ${ }^{38}$.

Le maillage routier renforce l'intégration des espaces forestiers, car il met en relation une offre en bois de plus en plus importante, suite à la transformation d'une partie des taillis en futaies, et une demande accrue par la croissance urbaine et par les multiples usages industriels.

\section{Temps nouveaux}

Globalement, le massif du Vercors, au prisme du canton de Villard-de-Lans, correspond aux inflexions de Martine Chalvet pour qui une nouvelle page de l'histoire des forêts est inaugurée à partir des années $1860^{39}$. Dans le canton, cette période nouvelle se déroule dans un contexte de baisse de la pression démographique d'environ $18 \%$ entre 1876 et 1911. Ce facteur expliquerait que les condamnations à l'encontre des particuliers se font plus rares dans les dossiers conservés par l'administration forestière.

38 À l'échelle communale, malgré des frictions résiduelles entre les municipalités et les agents forestiers, l'entente est cordiale à la fin du xix siècle. Tout notable qui se respecte exploite également des ressources ligneuses. Par conséquent, il n'y a aucune surprise à voir les communes investir dans les routes. En 1891, Villard-de-Lans n'hésite pas à emprunter 10000 francs à la caisse des chemins vicinaux pour financer ses travaux. Dans un contexte de baisse des prix, la commune cherche à résorber sa dette en multipliant les demandes d'emprunts garantis sur ses forêts. Elle est cependant contrainte de quémander à nouveau de nouvelles coupes auprès de l'administration forestière. Les tensions se poursuivent donc entre la municipalité et l'administration forestière mais elles ne prennent pas les mêmes formes qu'à l'époque de VincentMartin. Les agents forestiers sont devenus des alliés par l'accent mis sur les futaies, par le fait de privilégier les résineux à la croissance plus rapide et par l'aide technique qu'ils apportent avec les agents des Ponts et Chaussées pour améliorer les circulations.

L'élément nouveau qui semble prendre plus d'importance est l'apparition de nouveaux défis pour les circulations de bois. Par exemple, les travaux entrepris en 1912 sur le Chemin de grande communication $\mathrm{n}^{\circ} 2$, entre Villard-de-Lans et Pont-en-Royans, jettent une lumière sur ces questions. Les routes sont défoncées du fait d'une inadéquation grandissante entre les matériaux utilisés pour les construire et le poids des chargements. En effet, pour réduire les coûts de transport, "les Entrepreneurs [donnent] la charge maxima à leurs voitures qui pèsent quelquefois 5000 à 6000 kilogrammes $»^{40}$. Quand il s'agit de faire payer les travaux de réfection de la chaussée, les communes situées en contrebas du plateau dans le Royans estiment qu'elles ont déjà suffisamment contribué, afin d'aider les scieries qu'elles abritent et vers lesquelles les matières brutes sont plus nombreuses à circuler. Les circulations plus aisées grâce aux routes expliquent que la transformation sous la forme de charbon ait été abandonnée. Si des scieries se maintiennent, la concurrence semble plus rude avec leurs homologues d'en bas qui peuvent remonter plus haut et descendre encore plus de simples grumes afin de les débiter. La circulation par camions après la guerre ne fait qu'amplifier les nouvelles logiques du développement.

La quantité de sources disponibles, et notamment les fonds de l'administration forestière et ceux des Ponts et Chaussées, montre combien les circulations du bois charpentent toute réflexion sur le développement des montagnes. Les documents 
permettent des approches quantitatives où l'effet réducteur des catégories est à pondérer avec une prosopographie des acteurs des sociétés rurales.

41 Les agents forestiers inférieurs, c'est-à-dire les gardes forestiers et les gardes généraux, sont essentiels pour comprendre ce qui se joue. En effet, ils permettent de nuancer la vision de Jean-François Soulet opposant deux mondes. Si cette situation est peut-être acceptable dans les Pyrénées, l'exemple du Vercors est sensiblement différent car ils paraissent être des synapses. Leur attitude empirique de compréhension des réalités locales précéderait les analyses de Le Play qui remet les hommes dans les bois. Les populations locales ne se réduisent pas à une galerie de portraits. Une subtile hiérarchie et des réseaux sont présents. Ils sont animés par des considérations tout à la fois économiques, familiales, de tradition mais également de politique locale. Les agents forestiers seraient les rouages qui savent identifier les vrais délinquants pour les déraciner. Si le curé a charge d'âme, ils se sentent les trésoriers des communes et doivent amener les bonnes pratiques du développement. Dans cet objectif, les circulations, hier menaces sont devenues des atouts.

Plus nombreuses en quantité comme en qualité, elles résultent d'un jardinage d'une partie des massifs au début $\mathrm{du} \mathrm{xx}^{\mathrm{e}}$ siècle et contribuent à charpenter l'image d'une ruralité heureuse. Ainsi, Ardouin-Dumazet note dans sa description du canton que :

"Sur la route, des chars portant des troncs de sapin sont conduits par des voituriers enfouis sous de grandes limousines et dont le sauvage aspect s'harmonise bien à celui du paysage. $»^{41}$

Les circulations des touristes, qui commencent à grimper par les routes, vont faire des forêts des éléments paysagers recherchés.

\section{BIBLIOGRAPHIE}

Anonyme, « Une grande famille du Val de Lans : Les Esbrard de la Vallonne », Jadis au pays des Quatre montagnes. Les cahiers du Peuil, $\mathrm{n}^{\circ} 2,1995$, p. 15-31.

ARDOUIN-DUMAZET Victor-Eugène, Voyage en France, $9^{e}$ série. Graisivaudan et Oisans, Paris/Nancy, Berger-Levrault éditeur, 1911.

CHALVET Martine, Une histoire de la forêt, Paris, Le Seuil, 2011.

CHEVALLIER Pierre, COUAILHAC Marie-José, L'administration des Eaux et Forêts dans le département de l'Isère au XIX siècle, Grenoble, Centre de recherche d'histoire économique, sociale et institutionnelle, 1983.

DELLA-VEDOVA Gilles, « Les agents auxiliaires du contrôle spatial des montagnes : les gardes champêtres/forestiers dans le canton de Villard-de-Lans (deuxième tiers du XIX ${ }^{\mathrm{e}}$ siècle) ", dans LIGNEREUX Aurélien (dir.), Polices et montagnes (XVIII ${ }^{e}-\mathrm{XXI}^{e}$ siècles). Journées d'études 21 au 22 mai 2015, Grenoble, Presses universitaires de Grenoble, 2016, p. 175-189.

HANUS Philippe, «Je suis né charbonnier dans le Vercors » : petite histoire des hommes dans la forêt, Lans, Maison du Parc, 2000. 
JOLAS Tina, zONABEND Françoise, « Gens du finage, gens du bois », dans JOLAS Tina, PINGAUD MarieClaude, VERDIER Yvonne et ZONABEND Françoise, Une campagne voisine : Minot, un village bourguignon, Paris, Éd. de la Maison des sciences de l'homme, 1990, p. 37-63.

JORRE Georges, «L'établissement des routes dans le massif du Vercors », Revue de géographie alpine, $\mathrm{n}^{\circ}$ 9-2, 1921, p. 229-284.

KALAORA Bernard, SAVOYE Antoine, La forêt pacifiée : les forestiers de l'École de Le Play, experts des sociétés pastorales, Paris, l'Harmattan, 1986.

MOURRAL D. «Les forêts du canton de Villard-de-Lans (massif du Vercors) », Revue de géographie alpine, $\mathrm{n}^{\circ} 15-1,1927, \mathrm{p} .133-143$.

PUYO Jean-Yves, « Enseignement forestier et sciences sociales : "le grand nulle part"

(1824-1914) », Les Études sociales, 2001, n 134, p. 7-22.

REY M., Un intendant en province à la fin du XVII ${ }^{e}$ siècle. Essai sur l'administration de Bouchu, intendant de justice, police et finances en Dauphiné et des armées de sa majesté en Italie 1686-1706, Grenoble, imprimerie F. Allier père et fils, 1896.

SOULET Jean-François, Les Pyrénées au XIXe siècle, Bordeaux, Éditions Sud Ouest, 2004.

\section{NOTES}

1. M. Chalvet, Une histoire de la forêt.

2. J.-F. Soulet, Les Pyrénées au XIX ${ }^{e}$ siècle.

3. B. Kalaora, A. Savoye, La forêt pacifiée: les forestiers de l'École de Le Play, experts des sociétés pastorales.

4. J.-Y. Puyo, «Enseignement forestier et sciences sociales: "grand nulle part" (1824-1914)», p. 7-22.

5. T. Jolas, F. Zonabend « Gens du finage, gens du bois », p. 37.

6. P. Hanus, "Je suis né charbonnier dans le Vercors" : petite histoire des hommes dans la forêt.

7. Archives départementales de l'Isère, II C. 956, « Réformation des eaux et forêts, en exécution des lettres-patentes du 14 novembre 1724. Procès-verbaux des commissaires des bois du Dauphiné. Élection de Grenoble ", tome 8, Villard-de-Lans, 1725-1728, fol. $2211 \mathrm{v}$.

8. P. Chevallier, M.-J. Couailhac, L'administration des Eaux et Forêts dans le département de l'Isère au XIX ${ }^{e}$ siècle, p. 101 (qui reprennent M. Rey Un intendant en province à la fin du XVII siècle. Essai sur l'administration de Bouchu, intendant de justice, police et finances en Dauphiné et des armées de sa majesté en Italie 1686-1706).

9. Archives départementales de l'Isère, L463, «Rapport sur les ouvrages à faire pour rétablir l'ancienne fonderie de canons située à Saint-Gervais sur la rive gauche de l'Isère au-dessous de Grenoble ", messidor an II, fol. 5.

10. D. Mourral, « Les forêts du canton de Villard-de-Lans (massif du Vercors) », p. 138.

11. Archives départementales de l'Isère, II C. 956, Ibid., fol. 2 205r.

12. Archives municipales de Villard-de-Lans, carton sans référence, « Divers » (il s'agit de la réponse à une demande du préfet du 23 février 1834 pour dresser la liste des commerçants amenés à composer les tribunaux de commerce). 
13. Archives départementales de l'Isère, $6 \mathrm{P} 4 / 1$, «État de traitement des gardes de toutes classes chargés de la surveillance des bois communaux de la sous-inspection de Vizille ».

14. Archives départementales de l'Isère, $6 \mathrm{P} 4 / 1$, «Lettre du directeur de l'enregistrement des domaines et des forêts au préfet de l'Isère le 2 février 1820 ».

15. G. Della-Vedova, «Les agents auxiliaires du contrôle spatial des montagnes: les gardes champêtres/forestiers dans le canton de Villard-de-Lans (deuxième tiers du XIX siècle) ».

16. Anonyme, « Une grande famille du Val de Lans : Les Esbrard de la Vallonne ».

17. Archives départementales de l'Isère, 3Q38/204 et 3Q38/141.

18. Archives départementales de l'Isère, $3 Q 38 / 206$ et 3Q38/145.

19. Archives départementales de l'Isère, $6 \mathrm{P} 8 / 19$, extrait du courrier du conservateur des forêts au préfet le 18 février 1845 .

20. Archives départementales de l'Isère, 2U291, "Affaires politiques. Rapports semestriels sur la situation morale, politique et judiciaire adressés au garde des Sceaux », 1848-1854 (sans date).

21. Archives départementales de l'Isère, 2U291, "Affaires politiques. Rapports semestriels sur la situation morale, politique et judiciaire adressés au garde des Sceaux », 1848-1854 (sans date [printemps 1848]).

22. J.-F. Soulet, Ibid., p. 644-663.

23. Les archives de l'administration forestière concentrent plusieurs dizaines de cas qui peuvent être enquêtés et ils permettent de saisir le «regard sur» que les fonctionnaires portent sur les délinquants. 128 affaires ont été retrouvées entre 1837 et 1868 pour la commune d'Autrans. Elles contiennent 142 noms avec des doublons certains. 54 recherches biographiques ont été entreprises.

24. J.-F. Soulet, Ibid. p. 651.

25. Archives départementales de l'Isère, $6 \mathrm{P} 8 / 19$, lettre du conservateur des forêts au préfet le 8 septembre 1855 .

26. Archives départementales de l'Isère, 3E20 991, « Donation entre vifs chez le notaire Jourdan à Villard-de-Lans », le 29 février 1868, acte n 44.

27. Archives départementales de l'Isère, 3Q38/206.

28. Archives départementales de l'Isère, 3Q38/209.

29. Archives départementales de l'Isère, 15M88. Extrait de la notice rédigée par le maire, le $1^{\text {er }}$ novembre 1858.

30. Archives départementales de l'Isère, $2 \mathrm{U} 1$ 13, "Dossiers d'appels correctionnels concernant les délits forestiers. Arrondissement judiciaire de Grenoble 1853-1859. Procès-verbaux rapportés contre le sieur Martin (Claude), cabaretier et marchand de bois à Méaudre » (sans date [après 1855]).

31. Archives départementales de l'Isère, $2 \mathrm{U} 1$ 131, «Dossiers d'appels correctionnels concernant les délits forestiers. Arrondissement judiciaire de Grenoble 1853-1859", procès-verbal du 23 juin 1853 et audience du 25 août 1854 .

32. Archives départementales de l'Isère, $6 \mathrm{P} 8 / 19$, extrait du rapport du garde général le 26 février 1862. 
33. Archives départementales de l'Isère, $20225 / 8$, extrait de la lettre du conservateur au préfet le 14 juillet 1870 (c'est l'auteur qui souligne).

34. Archives départementales de l'Isère, 20225/8, extrait du procès-verbal de reconnaissance du garde général le 25 novembre 1868.

35. La situation de l'ancienne section forestière de Corrençon, qui se détache de Villard-de-Lans pour devenir une commune à part entière, demanderait à être investiguée plus précisément. En effet, les bois soustraits de Villard-de-Lans sont répartis entre les différents habitants devenus indépendants et les communaux sont très faibles.

36. G. Jorre, «L'établissement des routes dans le massif du Vercors », p. 239.

37. Archives départementales de l'Isère, $6 \mathrm{P} 8 / 20$, lettre du conservateur au préfet le 29 mars 1872.

38. G. Jorre, Ibid., p. 281.

39. M. Chalvet, Ibid., p. 192.

40. Archives départementales de l'Isère, 7 096W6. Extrait du rapport de l'agent-voyer cantonal le 24 décembre 1896.

41. V.-E. Ardoin-Dumazet, Voyage en France, $9^{e}$ série. Graisivaudan et Oisans, p. 306.

\section{RÉSUMÉS}

$\mathrm{Au} \mathrm{XIX}{ }^{\mathrm{e}}$ siècle, dans le Vercors septentrional (Isère), les ressources forestières sont l'objet de circulations qui se font à plusieurs échelles. Durant le siècle, la constitution d'un réseau à partir des chemins de grande communication et des sentiers forestiers explique l'importance de l'exportation des bois pour permettre le développement. C'est la raison pour laquelle l'application du Code forestier est l'objet d'analyses menées à partir des dossiers des Eaux et forêts, de ceux de l'administration communale, de l'état civil et du cadastre. En complément d'une approche par les organisations, avec la circulation des idées de Le Play (Kalaora et Savoye), une autre, localisée, montre que l'on passe des bois de la discorde à ceux de la concorde. La prise en compte par les agents forestiers des situations locales des délinquants fait que les foudres de l'administration passent des " petits » à la répression contre ceux qui font de la circulation des bois le fondement de leur notabilité.

\section{AUTEUR}

\section{GILLES DELLA-VEDOVA}

Professeur en CPGE, lycée du Parc (Lyon), chercheur associé au Laboratoire d'études rurales (université Lumière-Lyon II) 


\title{
Le développement en co-
} construction par les migrations familiales (canton de Villard-deLans $\mathrm{XIX}^{\mathrm{e}}-\mathrm{XX}^{\mathrm{e}}$ siècle)

\author{
Gilles Della-Vedova
}

1 En 1851, Scipion Geymond, un homme natif de Villard-de-Lans, une commune de montagne située au nord du massif du Vercors (Isère) se déclarait dans un courrier :

«Heureux de vous annoncer qu'un de mes bons amis dont la femme et la sœur dirigent un atelier de broderie assez considérable veut bien se charger des quatre petites dont vous me parlez. C'est une honnête maison où ces enfants apprendront un bon état et elles n'auront sous les yeux que de bons exemples [...] »

Il précise plus loin qu'il a :

«[...] appris par Monsieur Sappey que le fils de Monsieur André Allard habitant Lyon [...] voudra bien se charger de recevoir par votre invitation les enfants par la voiture de Grenoble à Lyon qui lui-même les conduira dans le bateau à vapeur et le chemin de fer qui se rendra à Paris $[. ..] »^{1}$

3 L'extrait présente l'intérêt d'esquisser un trajet qui part du haut pays montagnard en direction des régions de faible altitude; il correspond à l'image emblématique des «pauvres gens $\|^{2}$ à la recherche de meilleures conditions d'existence. En outre, il donne l'impression que cette émigration est facilitée par les modes de transports modernes: bateau à vapeur et chemin de fer accélèrent les circulations et éloignent toujours plus rapidement les migrants. Enfin, le document comporte une dimension genrée puisque des hommes s'entendent entre eux pour diriger et décider des directions empruntées par des femmes. L'auteur garde des attaches à son pays natal et il connaît des intermédiaires qui conduiront les enfants à Paris. L'interconnaissance nous rappelle qu'hier comme aujourd'hui, la migration s'effectue à l'aide de jalons, de balises, de bouées voire un maillage social qui a pour vocation à servir de filet de sécurité.

Tout compte fait, l'extrait évoque une situation qui se rattache à ce qui a longtemps été nommé l'«exode rural». Il concernait principalement des "pauvres gens» qui 
quittaient massivement leur région de naissance pour aller s'entasser dans les villes, perdre leur santé dans les manufactures, ruiner leurs familles au cabaret et la débauche et se pervertir l'esprit en écoutant les démagogues socialistes. Le mouvement était particulièrement accentué dans les montagnes.

5 Le thème des migrations a été étudié à l'échelle nationale en particulier par Paul-André Rosental qui en montre toute la diversités. Dans les Alpes, il a fait depuis longtemps l'objet d'enquêtes fouillées par les géographes Jules Blache puis Germaine Veyret ${ }^{4}$. Plus récemment, des historiens se sont emparés du sujet, notamment Laurence Fontaine ${ }^{5}$ puis Anne-Marie Granet-Abisset. Cette dernière poursuit son travail avec Luigi Lorenzetti autour des « migrations de retour $»^{6}$.

6 La réflexion proposée ici se fait à l'échelle micro du canton, lequel est organisé autour d'un plateau divisé en deux petites vallées longitudinales qui sont à une hauteur d'environ 1000 mètres. Le choix de ce terrain d'étude se justifie d'une part par sa proximité avec Grenoble qui connaît un essor démographique surtout à partir de la deuxième étape de l'âge industriel à la fin du siècle. D'autre part, le choix de ce petit périmètre de cinq communes s'explique par la méthode qui repose sur la saisie de l'intégralité des actes d'état civil durant près de 70 ans. Un recoupement des informations permet de composer une base individu afin de fournir les éléments à une prosopographie des acteurs.

7 La période qui va du milieu du XIX siècle à la fin des années 1930 permet de comprendre que derrière le terme de "migration », ceux de "déplacement » et de "mobilité » sont préférables car ils donnent moins l'idée d'une coupure. Il s'agira également de s'intéresser aux retours possibles et aux significations qui peuvent être données. Il faut aller plus loin afin de souligner qu'à côté des émigrations, les montagnes peuvent être des lieux d'immigration c'est-à-dire où l'on s'installe, sans pour autant que cela soit définitif.

\section{Le départ des « pauvres gens »?}

8 L'émigration serait d'abord une question économique puisqu'elle concernerait les plus humbles. L'accroissement démographique, en particulier dans les campagnes qui est à son optimum au milieu du $\mathrm{xIX}^{\mathrm{e}}$ siècle, et la machine à diviser la propriété que constituerait le Code civil conjugueraient leurs effets pour expulser de nombreux sans terres qui trouveraient à s'employer d'abord dans les villes en voie d'industrialisation. L'analyse dense de la situation dans le canton de Villard-de-Lans au cours de la seconde moitié du XIX siècle montre la complexité du processus.

\section{Des départs difficiles à mesurer}

Les recensements quinquennaux montrent que la population du canton croît jusqu'en 1851. Depuis le début des années 1820 , la hausse était de l'ordre de $15 \%$; après 1851 , elle fléchit quelque peu puis de manière plus nette. Puis, de 1876 à 1931, la baisse est de l'ordre d'un cinquième avant de connaitre une reprise à partir des années 1930. Il n'y a donc ni vidange ni exode, car les valeurs demeurent limitées par rapport à d'autres montagnes voisines, les densités demeurent plus élevées que dans des secteurs 
d'altitude voisins parce qu'il y a moins de raisons de partir malgré la proximité grenobloise.

Une autre approche consiste à étudier les migrations à l'aide des registres des mariages. Il s'agit de connaitre la part des époux extérieurs à la commune où se déroulent les noces. L'endogamie est massive dans le canton puisque la part des époux qui sont de la même localité que leurs femmes est en moyenne de $68 \%$ des cas entre 1835 à 1844 à $59 \%$ entre 1865 et 1874 . L'idée de départ des épouses, surtout des jeunes femmes, est fortement remise en cause. Les coups de sonde portée dans la période suivante montrent que la part des conjoints natifs de Villard-de-Lans continue à s'abaisser : $54 \%$ à partir de l'échantillon des épouses nées dans le canton en 1875.

11 Dans ce lent mouvement, les frontières sont perméables et invisibles. Des mouvements de fonds continuent à orienter les départs dans certains espaces au détriment d'autres. Ce sont les 77 mariages qui se déroulent dans le canton entre 1835 et 1844 pour lesquels l'époux n'est pas originaire du canton qui sont étudiés. Ils proviennent de communes qui se situent en dehors du canton mais au sein du massif. Des territoires de vie internes au Vercors franchissent les limites administratives cantonales et départementales. Le deuxième espace est composé d'un arc de cercle de localités dont les communaux s'accrochent aux pentes du massif. Il débute au sud, aux portes du Trièves, se prolonge le long du Drac et s'égrène ensuite le long d'un chapelet de lieux en bordure de l'Isère. Cette zone illustre que les frontières dites naturelles sont franchies. Les arêtes du Moucherotte et les blanches parois verticales ne sont pas des handicaps. La montagne n'est donc pas un isolat, elle est à intégrer avec son piémont pour former une même unité. Durant les décennies suivantes, les tendances ne se métamorphosent pas radicalement. L'échantillon des mariages à partir des individus nés en 1875 montre que les conjoints se recrutent dans la plaine proche de Grenoble. La route des gorges de la Bourne n'évacue pas les jeunes gens de manière aussi efficace que les bois exportés. Les aires migratoires ne sont pas bouleversées par l'ouverture de nouveaux axes de transport ce qui montre par conséquent des logiques choisies.

\section{Des destinations bien différentes}

Sur les 77 mariages qui, entre 1835 et 1844, concernent un époux qui n'est pas originaire du canton de Villard-de-Lans, 42 chefs de famille de l'épouse ont pu être identifiés avec certitude et les portraits biographiques dessinés. Dans 19 cas (45,3\%), le beau-père de l'époux a en 1834 une très petite propriété inférieure à quatre hectares alors que la très petite propriété représente $57 \%$ des cotes d'après la matrice cadastrale. La petite propriété, entre quatre et dix hectares correspond à dix situations $(23,8 \%)$ soit à peu près la part des cotes. La moyenne propriété, entre dix et 30 hectares, correspond à douze cas $(28,5 \%)$, soit quelques points ne plus que le pourcentage des cotes en 1834. Ce ne sont donc pas des jeunes femmes qui, poussées par la misère, partent le long des chemins mais des filles qui participent de stratégies familiales plus complexes.

13 L'importance de la petite propriété se lit également par l'étude des familles qui, au milieu du XIX ${ }^{\mathrm{e}}$ siècle, quittent Autrans et Méaudre, deux des communes du canton pour se rendre en Algérie ${ }^{7}$. Il ne faut pas imaginer que les plus misérables s'en vont. En effet, les demandeurs doivent justifier d'un avoir de mille francs. Sur l'ensemble des biographies retracées dans le cas de Méaudre, les sans terres sont absents dans la 
mesure où aucun très petit propriétaire inférieur à un hectare n'a été repéré. On trouve des petits propriétaires comme Henri Pascal dit Ronzat. Né en 1807, il possède deux hectares; un demi-hectare, en indivision entre son frère et lui complète les biens fonciers. Il assure ses moyens d'existence par le travail du bois en tant que menuisier.

D'autres individus relèvent de la moyenne propriété comme Jean Roland, un aîné qui se retrouve après le décès de sa mère en 1835 à la tête de 11,4 hectares. Son beau-frère est également un moyen propriétaire avec 19 hectares à Méaudre en 1835. Dans son cas, l'impression qui se dégage est celle d'un véritable investissement. Il s'agit de s'établir et, grâce au capital de départ, d'investir de manière capitaliste dans les opportunités foncières que l'Algérie recèle.

caractéristique est celle de la permanence de certains liens car des voyages de retour se déduisent. Par exemple, Henri Pascal-Ronzat déclare la naissance de son fils Adrien à Méaudre en 1854. De son côté, Joseph Blanc-Brude (v. 1799-1882) est revenu avec femme et enfants à Méaudre. Né vers 1799, Joseph Blanc-Brude est, durant les années 1830 et 1840, un petit cultivateur qui exploite 5,3 hectares en 1835. En Algérie, ils vivent de manière très précaire. Peut-être devant le décès de certains autres colons, il décide de rembarquer rapidement. En 1854, son fils Adrien naît à Méaudre et le père est retourné dans son hameau d'origine.

16 Les types de départs, qu'ils soient proches ou lointains, partagent donc des caractéristiques communes. Au cœur d'elles, il importe de ne pas avoir une approche par individu mais de suivre des logiques de groupes.

\section{Des mobilités qui s'inscrivent dans des logiques sociales}

17 Les unes inscrivent les mobilités comme un phénomène de génération. La pyramide des âges de Méaudre en 1881 sert d'illustration. La quantification par tranche d'âge et en fonction du sexe montre que les tranches d'âge entre 15 et 25 sont resserrées. La société est bien ouverte, car les jeunes disparaissent temporairement avant de revenir ce que les effectifs prouvent à nouveau. Jeunes filles et jeunes hommes peuvent servir en tant que domestiques agricoles dans des exploitations situées en dehors de Méaudre. Il s'agit d'un temps d'apprentissage qui sert à accumuler un capital. Celui-ci peut être pécuniaire avec les dots que les jeunes filles cherchent à se constituer mais peut-être aussi un capital d'apprentissage pour des compétences qui peuvent ensuite être reprises au village natal. La quantité plus importante de jeunes hommes absents est aussi liée au service militaire. La tranche d'âge jusqu'à 25 ans correspond à un temps d'attente du mariage suivi de l'installation dans une exploitation.

La dimension familiale s'avère donc capitale pour comprendre les logiques migratoires. En effet, les départs ne sont qu'un segment d'une trajectoire du glissement qui s'opère dans certaines familles et qui partent en direction de la ville. Le processus peut s'étaler sur plusieurs générations. Par exemple, la famille Bellier est repérée dans le Vercors central à la fin du XVIII siècle. À la génération suivante, en 1831, un garçon passe un contrat de mariage à Villard-de-Lans avec une fille originaire de Lans. Deux filles de ce couple poursuivent leur trajectoire dans la septentrionale du massif dont la vue plonge sur Grenoble. Le contrat de mariage de l'une d'elles est signé en contrebas des pentes du Vercors, à Sassenage. Au début du xxe siècle, un des enfants est installé à proximité de la vallée du Drac. 
19 D'autres configurations montrent que la génération des parents anticipe les circulations opérées par les enfants. C'est, par exemple, le cas d'Eugène Mure-Ravaud (1826-1889) qui est indiqué tantôt négociant, voiturier ou commerçant. Il est clairement en lien avec Grenoble comme son mariage en 1859 avait pu l'illustrer puisqu'un des témoins y vivait comme cordonnier. Une de ses filles épouse un employé de commerce de Grenoble en 1885. L'année suivante, une autre fille se marie dans cette ville avec un fabricant d'huile. Le décès de leur père peut être considéré comme un facteur qui accélère le glissement vers la vallée. En 1914 Louis, le benjamin, se marie à son tour à Grenoble. Dans le cas de cette famille, à côté du facteur répulsif que peut constituer le décès d'Eugène, il y a des facteurs attractifs qui expliquent que les enfants se rendent à Grenoble : ils en connaissent des membres et les aînés favorisent l'arrivée des cadets.

20 Les migrations sont indubitablement un phénomène complexe dont les facteurs push et pull en direction de la ville résultent d'une combinaison de facteurs ne se réduisant pas à une ou deux catégories. L'âge des individus, leur position dans la famille, la taille de la propriété et la présence ou pas d'activités qui s'inscrivent dans la pluriactivité forment un ensemble. De plus, le phénomène peut s'étirer sur plusieurs générations. L'idée d'un mouvement qui concernerait les plus pauvres, ceux «en trop» est incapable d'expliquer le processus. Le foisonnement des situations rencontrées a permis de voir que l'idée de départ ne traduit pas non plus la réalité des situations. Des liens se tissent entre la montagne et la ville et ils sont constitutifs de la création de territoires de mobilités.

\section{Tisser le lien entre la montagne et la ville}

21 Le départ du canton de Villard-de-Lans n'empêche pas d'y revenir. C'est l'un des intérêts d'une approche individuelle de constater, en l'absence momentanée de toute quantification du phénomène, que mille signes indiquent que la montagne et la ville, reliées par les circulations forment les deux faces d'une même pièce, celle du développement.

\section{La montagne, espace de ressources}

Le canton de Villard-de-Lans fait figure d'espace de ressources. Des hommes vont y chercher leurs épouses. Par exemple, dans les registres des mariages du canton entre 1835 et 1874, 37 individus sont indiqués domiciliés à Grenoble et 24 n'en sont pas natifs. En fait, treize sont originaires du canton de Villard-de-Lans. Sauf exception, le couple ne s'y installe pas ce qu'il ne signifie pas qu'il perd ses attaches. En effet, des jeunes femmes s'en retournent accoucher, au moins pour le premier enfant, auprès de leurs familles.

23 D'autres confient leur progéniture à leur famille ou à des proches. Par exemple, dans les années 1880, Joseph Laurent-Dray et Victorine Eymaron prennent des enfants en nourrice dans une logique pluriactive à Villard-de-Lans. Mais en 1892, la mère devenue trop âgée transfère à sa fille Marie Lucie, née en 1868, la tâche de nourricière. Les réseaux de placement mériteraient d'être mieux connus et peut-être faut-il faire des liens avec Jean-Louis, un autre enfant du couple, qui vit à Grenoble. Est-ce par ce dernier que des allers et retours d'enfants se tissent? 
dernier exemple montre que les ressources économiques structurent une partie des relations entre la montagne et la ville. La complémentarité est source de développement. Dans le canton de Villard-de-Lans, au XIX ${ }^{e}$ siècle, les deux ressources principales sont le bois ainsi que l'élevage puisqu'une race bovine reconnue par l'État est l'objet d'une promotion importante. En 1875, est créée une station d'élevage qui rassemble des cultivateurs du canton et des personnes extérieures dont bouchers grenoblois. Certains sont des natifs du canton comme c'est le cas de Laurencin Magdelain. Il est né le 6 juin 1846 de Pierre et Françoise Ravix. Si l'étendue de la propriété de son père reste inconnue, son grand-père Antoine devait en posséder environ 16,5 hectares lors de la confection du cadastre en 1834. L'élevage fournit de la viande sur le marché grenoblois mais également des produits laitiers. Cette fois, c'est avec Autrans que les attachent se font. En effet, en 1896, Louis François Roux-Dauphiné, négociant comme son père, crée en mai 1896 avec son frère Jules Adrien Clovis qui est devenu négociant également à Grenoble une société en "pour la fabrication et le commerce de beurres et de fromages, le commerce des huiles, cafés et poivres, articles d'épicerie ou autre ${ }^{8}$. La liste des produits permet de comprendre que les uns descendent tandis que les autres montent ce qui assure l'importance de Louis François Roux-Dauphiné : il devient maire de la commune en 1900. Ces quelques exemples montrent que sur plus d'un demi-siècle, les relations entre la ville et la montagne ne se distendent pas. Au contraire, les changements qui interviennent au sein de l'une et de l'autre forment de nouvelles conditions favorables au maintien des liens.

Espace de ressources, le canton de Villard-de-Lans fait la ville de Grenoble dans la mesure où il lui envoie son bois, ses bovins, ses produits laitiers et la main-d'œuvre qui travaille dans la ville. En 1926, à la fin de la période, Joseph Jouanny compte 882 personnes natives du canton à Grenoble c'est-à-dire le canton le plus fortement présent par le nombre de ses ressortissants ${ }^{9}$. Cependant, les liens apparaissent également par un attachement au pays natal.

\section{L'attachement au pays natal}

26 Les archives le laissent voir de deux manières. D'une part, il y a un maintien qui apparaît par la propriété de terres. En se limitant à nouveau aux propriétaires domiciliés à Grenoble entre la matrice du cadastre napoléonien et celle du cadastre rénové à la veille de la Première Guerre mondiale, la part passe de $2,1 \%$ des cotes localisées pour la première date à $5,6 \%$ à la seconde. Les noms correspondent à ceux que l'on retrouve dans les listes nominatives de recensement. Nombreux sont les employés, les domestiques, mais plus encore les commerçants ou les artisans: menuisiers, garçons de magasin, cordonniers, maçons, gantières.

D'autre part, le désir de reformer une sociabilité à la fois d'entraide mais également dans une volonté de développement amène à formaliser les liens entre immigrés du Vercors à Grenoble. En 1903, les statuts de la Société de secours mutuels de retraite des enfants de Villard-de-Lans voyaient le jour. Quatre ans plus tard, elle était présidée par l'un des migrants les plus notables du canton, Marius Repellin. En 1936, l'Union fraternelle du Villard-de-Lans fusionnait avec la Société de retraite des enfants du Villardde-Lans ${ }^{10}$. Son président était André Isnard dont le père était gantier à Villard-de-Lans. Cet exemple montre à quel point la ganterie entreprise dans le cadre du domestic system est également un trait d'union entre ville et montagne. Instituteur lors de son service 
militaire en 1917, André Isnard vit déjà à Grenoble et devient par la suite chef comptable. Il est intéressant de noter qu'en 1917, il vit 11 rue Charrel, c'est-à-dire exactement la même adresse que le secrétaire de l'Union fraternelle en 1936. Cet indice laisserait penser que le tissage des liens entre la montagne et Grenoble pourrait passer par des points d'attache rapprochés ou semblables à l'intérieur de celle-ci. Enfin, il faut prendre ne compte les mouvements de retour.

\section{Remonter de la ville à la montagne} (a) Marie Laurent-Dray, quittée précédemment quand elle suppléait sa mère pour nourrir au sein de jeunes enfants venus de Grenoble. En 1911, Alphonse est menuisier et il se rend dans cette ville où il devient mécanicien en 1914. Il l'est toujours en 1924 quand il monte une société de mécanique. Deux ans plus tard, il est de retour dans son hameau situé dans la partie de Villard-de-Lans où l'essor touristique pour la bonne société est en train de se développer. Ainsi, la montagne peut devenir un terrain de (re) conquête pour des migrants.

\section{La montagne, lieu d'arrivées}

31 Vercors des mille chemins, comme l'écrivent Philippe Hanus et Laure Teuilières, vers qui convergent des étrangers en temps de guerre ${ }^{11}$. En effet, le canton est aussi une terre d'immigrations pour des individus qui oscillent entre la ville et la montagne.

\section{Un espace d'investissement pour des notabilités en formation}

Premièrement, des notables issus de la ville cherchent à s'implanter en montagne. La ganterie s'est amplifiée, dans le cadre du domestic system, à partir de l'arrivée de Jean 
Antoine Masson qui vient de Grenoble et qui est arrivé vers 1836. La lettre que le maire fait parvenir au contrôleur intermédiaire - peut-être de l'octroi de Grenoble - précise qu'«il n'est pas maître gantier, il est seulement commissionnaire des gantiers de Grenoble pour la distribution aux particuliers $»^{12}$. Si Jean-Antoine part avec ses enfants, l'aîné, Alexandre, reste à Villard-de-Lans et organise un réseau autour de lui. Celui-ci rassemble sa belle-famille, des habitants du bourg centre de Villard-de-Lans où il vit. Alexandre Masson, présent comme témoins sur plusieurs actes d'état civil d'individus qui sont gantiers. À la génération suivante, Alexandre a trois garçons dont Jean Alexandre Jules (1854-ap. 1936). Cet homme se retrouve à la tête de la commune de Villard-de-Lans de part et d'autre de la Première Guerre mondiale.

L'histoire se poursuit au $\mathrm{xx}^{\mathrm{e}}$ siècle. Une autre famille non originaire du canton tenta d'exercer son influence sur le Vercors nord. Daniel Huillier est un enfant de la route des gorges de la Bourne, ouverte en 1872 et objet d'engouement touristique des plus importants à la fin du xix ${ }^{e}$ siècle. Né en 1870 à Pont-en-Royans de parents cultivateurs, il n'a que 23 ans quand il s'installe à Villard-de-Lans en tant que conducteur de voitures. Il a pour cousin un maître d'hôtel réputé de Pont-en-Royans. Se perçoit donc une famille qui cherche à s'implanter aux deux extrémités de la nouvelle route. Quand il se remarie en 1902, Daniel Huillier est devenu entrepreneur de voitures. Son frère, cultivateur près de Pont-en-Royans en 1893, vient prêter main-forte comme conducteur de voitures. C'est après la Grande Guerre que l'entreprise familiale s'impose définitivement dans le canton en plusieurs étapes. Il se modernise, car en 1923 il passe aux véhicules moteurs pour assurer les deux voyages entre Villard-de-Lans et Pont-enRoyans. La rapidité des cars de Daniel Huillier fait qu'il concurrence très clairement le tramway au début des années 1930 . Ses enfants sont de jeunes conducteurs. C'est le cas de Victor (né en 1903) qui officierait dès 1921. Cinq ans plus tard, il est rejoint par ses autres frères, Émile (né en 1899), Georges (né en 1907) et Paul (né en 1909).

Ainsi, la montagne ne se réduit pas à l'émigration, elle est aussi un espace d'immigration pour des cas peu nombreux mais qui sont devenus des acteurs de premier plan du développement local.

\section{Immigrés d'avant-hier et d'hier}

Les analyses envisagent le développement qu'à partir des villes. À ces trajectoires ascendantes ou descendantes, il faut adjoindre les circulations humaines horizontales, c'est-à-dire entre régions d'altitude. Les uns associent des massifs proches. Il y a ceux qui sont originaires de Chartreuse. Par exemple, le 7 février 1853, Georges Jacques Depierre, un scieur de long natif de la commune forestière de Saint-Christophe-entredeux-Guiers, épouse une fille d'Autrans et s'installe durablement dans cette commune.

Ces relations, ténues mais réelles, sont réactivées durant l'entre deux-guerres avec l'installation de fromagers venus de montagnes plus lointaines. Les uns sont liés à l'implantation de la Laiterie briançonnaise, une entreprise fromagère du négociant et industriel Jules Gravier. À Lans, celui-ci confie l'exploitation à venue de Jules Janin (1882-1952) né à Jarsy dans la Savoie fromagère qui a dû se rendre dans les HautesAlpes car son épouse, Suzanne Meissimilly est d'Arvieux et leurs enfants naissent au Freney-d'Oisans et à Guillestre. De surcroit, une main-d'œuvre originaire de Suisse, des Hautes-Alpes complète les effectifs ${ }^{13}$. 
larc alpin, outre France. Il y a des Suisses mais surtout les Italiens qui vont s'investir dans deux branches du développement du canton, l'un traditionnel avec l'exploitation forestière, l'autre moderne avec l'essor des grands hôtels à partir des années 1930. Une centaine de noms a été retrouvée et des recherches se sont déroulées en particulier avec les dossiers d'identité des étrangers en Isère ${ }^{14}$. Ces documents attestent de la capacité à circuler, à disparaitre pour mieux réapparaître à Villard-de-Lans ou juste à côté. Des filières migratoires existent et les régions principales de départ correspondent à un large arc de cercle, le long de la bordure du massif alpin et passant dans la région du lac de Garde. Ce sont des espaces montagnards plutôt appauvris d'où, en France, une place dans les métiers de la domesticité. La présence de ces étrangers est liée à celle de leurs compatriotes. Par exemple, en 1931, le Splendid Hôtel de Villard-deLans avait parmi son personnel Lina Scramoncin. Cette jeune "femme de chambre", était née en 1905, à Sologna, un petit village situé dans la province de Vicense, au débouché du Monte Grappa, le long de la rivière Cismon. Elle y travaillait avec Yolande Scramoncin, « argentière » dans le même hôtel, elle-aussi née à Sologna en 1911. Cinq ans plus tard, Marguerite Todesco, "ménagère » née en 1909 officiait à l'Hôtel Terminus tandis que Louis Tomasi, né en 1907 également à Sologna, était " chauffeur " pour l'Hôtel Edelweiss, selon la liste nominative de recensement.

Ces dernières biographies pondèrent l'image d'un développement qui serait uniquement organisé par la ville pour montrer qu'il peut également se faire par des échanges entre les espaces montagnards. Ceux-ci ne sont pas vidés et desséchés par les départs. Il y a au contraire des arrivées qui inaugurent les dynamiques inversées des Trente Glorieuses quand les fonds de vallées humides entrèrent dans l'abandon et que les territoires d'altitude brillèrent au chaud soleil réfléchi sur la neige.

L'approche du phénomène migratoire par la prosopographie a permis de ne pas essentialiser, de ne pas réduire et du même coup de légitimer le choix de termes préférables comme ceux de circulations ou de mobilités. La méthode n'enlève pas les grandes tendances mais elle les nuance. En particulier, l'image du départ des plus pauvres est réductrice. Les biographies abordent les individus mais, surtout, elles fournissent les éléments de contextualisation qui sont explicatifs. Les phénomènes de génération, de position par rapport à la composition des familles doivent attirer l'attention. De même, l'espace d'arrivée n'est pas un saut dans l'inconnu mais l'activation de relais et de réseaux. Les déplacements sont aussi liés à des séquences de vie qui se situent dans des temporalités diverses.

41 Des tendances lourdes s'observent et elles persévèrent longtemps. Les échanges humains entre massifs continuent et la création de nouvelles routes ne modifie pas de manière radicale les directions empruntées par ceux qui s'en vont. De même, des mouvements lents de sortie des montagnes, parfois sur plusieurs générations, sont également observables. 

voulues et pas des espaces subis. L'exemple de Villard-de-Lans envisage que, dès l'entre-deux-guerres, certains territoires de montagnes reprennent des habitants. Le lien avec le système touristique est à souligner afin d'envisager, à nouveaux frais, les circulations entre les villes et les montagnes.

\section{BIBLIOGRAPHIE}

BLACHE Jules, Le massif de la Grande-Chartreuse et du Vercors. Étude géographique, Grenoble, Éditions Didier et Richard, 1931, 2 vol.

FONTAINE Laurence, Le voyage et la mémoire: colporteurs de l'Oisans au XIX siècle, Lyon, Presses universitaires de Lyon, 1984.

GRANET-ABISSET Anne-Marie, La route réinventée. Les migrations des Queyrassins aux XIXe et XXe siècles, Grenoble, Presses universitaires de Grenoble, 1994.

GUESLIN André, Gens pauvres, pauvres gens dans la France du XIX siècle, Paris, Aubier, 1998.

HANUS Philippe, TEULIÈRES Laure (dir.), Vercors des mille chemins. Figures de l'étranger en temps de guerre, Rochechinard, CPIE-Vercors/un comptoir d'édition, 2013.

LORENZETTI Luigi, GRANET-ABISSET Anne-Marie, « Les migrations de retour. Jalons d'un chapitre méconnu de l'histoire alpine ", Histoire des Alpes, $n^{\circ} 14,2009$, p. 13-24.

JOUANNY Joseph, Les origines de la population dans l'agglomération grenobloise, Grenoble, imprimerie Allier père et fils/Didier et Richard, 1931.

MURE-RAVAUD Georgette, SALON Marianne, «Le calvaire des familles autranaises parties en Algérie en 1851 », Jadis au pays des Quatre montagnes. Les cahiers du Peuil, n 3, 1997, p. 80-91.

MURE-RAVAUD Georgette, SALON Marianne, «La grande aventure algérienne », Jadis au pays des Quatre montagnes. Les cahiers du Peuil, 2000, $\mathrm{n}^{\circ} 4$, p. 79-80.

ROSENTAL Paul-André, Les sentiers invisibles : espaces, familles et migrations dans la France du XIX ${ }^{e}$ siècle, Paris, Éditions de l'École des hautes études en sciences sociales, 1999.

VEYRET-VERNER Germaine, VINCENT Paulette, « Étude démographique du haut Dauphiné septentrional », Revue de géographie alpine, n 34-3, 1946, p. 333-354.

\section{NOTES}

1. Archives municipales de Villard-de-Lans, carton sans référence, pochette « Monsieur Gémond secours aux orphelins », lettre de Gé[y]mond au maire (?) de Villard-de-Lans le 19 octobre 1851.

2. A. Gueslin, Gens pauvres, pauvres gens dans la France du XIX siècle. 
3. P.-A. Rosental, Les sentiers invisibles : espaces, familles et migrations dans la France $d u$ XIX siècle.

4. J. Blache, Le massif de la Grande-Chartreuse et du Vercors. Étude géographique, et

G. Veyret-Verner, P. Vincent, «Étude démographique du haut Dauphiné septentrional ».

5. L. Fontaine, Le voyage et la mémoire : colporteurs de l'Oisans au XIXe siècle, et A.-M. GranetAbisset, La route réinventée. Les migrations des Queyrassins aux XIXe et XXe siècles.

6. L. Lorenzetti, A.-M. Granet-Abisset, « Les migrations de retour. Jalons d'un chapitre méconnu de l'histoire alpine ».

7. Le corpus a été établi à partir des noms indiqués par G. Mure-Ravaud, M. Salon, «La grande aventure algérienne » et G. Mure-Ravaud, M. Salon, «Le calvaire des familles autranaises parties en Algérie en $1851 »$. Il comporte donc une vingtaine de chefs de famille qui partent à la fin de la Deuxième République.

8. Archives départementales de l'Isère, 11U427, Roux-Dauphiné Frères, fabrication et commerce de beurre et fromages, commerce des huiles, cafés et épices, 30 mai 1896

9. J. Jouanny, Les origines de la population dans l'agglomération grenobloise.

10. Archives départementales de l'Isère, 2828 W69, Statuts de la Société des enfants de Villard-de-Lans, approuvés le 5 octobre 1903.

11. P. Hanus, L. Teulières (dir.), Vercors des mille chemins. Figures de l'étranger en temps de guerre.

12. Archives municipales Villard-de-Lans, carton sans référence "Divers", pochette «Lot 4 serrurerie ». Extrait de la réponse à une demande du « commissionnaire » au maire de Villard-de-Lans le 16 novembre 1838.

13. En 1931, la famille Janin est complétée par Alfred Aegerter (né en 1886) et de JeanBaptiste Mathieu qui viennent de Suisse. Jean Chancel (né en 1911) est de Villard-SaintPancrasse ce qui laisse entendre que Gravier fait venir du personnel.

14. Archives départementales de l'Isère, 2973/1-385. Index alphabétique des dossiers d'identité des étrangers résidant dans le département de l'Isère durant les années 1930-1950.

\section{RÉSUMÉS}

Réservoirs de populations prolifiques, les montagnes sont perçues comment alimentant des migrations descendantes selon une trajectoire rectiligne. Une étude menée à partir des actes de l'état civil et des recensements dans un canton de montagne proche de la ville permet de préciser, nuancer et contester cette lecture. Préciser puisqu'il est possible d'identifier celles et ceux qui descendent. Les clés de compréhension passent par la composition des familles en montagne et celles déjà installées en ville. Nuancer car les circulations connaissent des étapes et des temporalités à repérer. Le creeping est à revoir et les circulations sont à apprécier en fonction des activités exercées. Il faut enfin contester la descente par les migrations de retour. À côté des migrations vers le bas, le développement repose sur d'autres situations qui partent des bas pays 
vers les régions d'altitude mais également des circulations entre les massifs montagnards à différentes échelles.

\section{AUTEUR}

\section{GILLES DELLA-VEDOVA}

Professeur en CPGE, lycée du Parc (Lyon), chercheur associé au Laboratoire d'études rurales

(université Lumière-Lyon II) 


\title{
La mobilité des Savoyards aux portes de la Maurienne (1860-1914)
}

\author{
Jean-Marc Villermet
}

\section{Une ouverture sur le monde}

1 La Savoie a conservé de son histoire séculaire et de sa position frontalière à la jonction de trois pays, France, Italie et Suisse, des particularismes locaux dans des domaines variés. Si la circulation des hommes a toujours existé, elle se renforça et s'accéléra avec l'apparition de nouveaux moyens de communication, terrestres et maritimes, lors des révolutions industrielles successives, puis aériens, surtout après la Seconde Guerre mondiale. En quoi les portes de la Maurienne furent-elles impactées par le phénomène migratoire à partir du milieu du xIX siècle ? Comment mesurer scientifiquement la mobilité des habitants de cet espace montagnard au $\mathrm{XIX}^{\mathrm{e}}$ et $\mathrm{au} \mathrm{xx}^{\mathrm{e}}$ siècles? Quelles trajectoires ont-ils suivi ? Pourquoi ont-ils privilégié une direction plus qu'une autre? Quelles furent les conséquences de ces déplacements pour le territoire? Dominé par les massifs du Grand Arc et de la Lauzière, au cœur d'un triangle reliant les villes de Chambéry, Albertville et Saint-Jean-de-Maurienne, ce territoire est a priori géographiquement enclavé, sans liaison directe par voie terrestre avec la vallée voisine, la Tarentaise. Malgré tout, des relations ont eu lieu entre les deux vallées, particulièrement dans une dimension internationale. Comment se sont-elles mises en place? Quels furent les effets de cette situation sur le fonctionnement de la société locale?

2 Afin d'apprécier la mobilité des familles sur les pentes des massifs du Grand Arc et de la Lauzière (fig. 1), une étude fut menée à partir des registres de matricules déposés aux archives départementales de la Savoie ${ }^{1}$. Femmes et enfants étant, hélas, souvent absents des archives à l'échelle locale, il a été néanmoins possible d'envisager parfois leur mobilité par le biais du mariage, en étudiant notamment une cohorte de 977 hommes domiciliés dans le canton d'Aiguebelle. Ils sont tous âgés de 20 ans entre 1860, année du rattachement de la Savoie à la France, et la fin du XIX ${ }^{e}$ siècle, lorsque débute la Belle Époque ${ }^{2}$, synonyme de progrès sociaux, économiques, techniques voire politiques, 
et qui se prolongent jusqu'à la Première Guerre mondiale. La période retenue coïncide avec l'installation du chemin de fer dans la traversée de la Maurienne : le train arriva en gare d'Aiguebelle en 1856. Le suivi de la mobilité de cette cohorte masculine est rendu possible jusqu'à l'âge de 40 ans puisque la plupart des dossiers de soldats font mention de leurs lieux d'habitation dans le cadre du suivi de leur mobilisation. L'étude de ces 977 dossiers a consisté à repérer, dans un premier temps, le lieu de l'affectation des hommes, lors de la conscription, puis les localités où ils résidèrent par la suite. Plus de $95 \%$ de la population étudiée était, à l'origine, native des portes de la Maurienne : les 977 hommes dont le parcours fut analysé sont tous nés entre 1840 et 1874, les plus jeunes ayant eu 40 ans avant le $1^{\mathrm{er}}$ janvier 1915. Au-delà de cet âge, les registres ne fournissent plus d'information.

Fig. 1. - Plan de l'espace Grand Arc - Bellachat - Lauzière : la ligne de crêtes sépare les vallées de la Maurienne et de la Tarentaise.

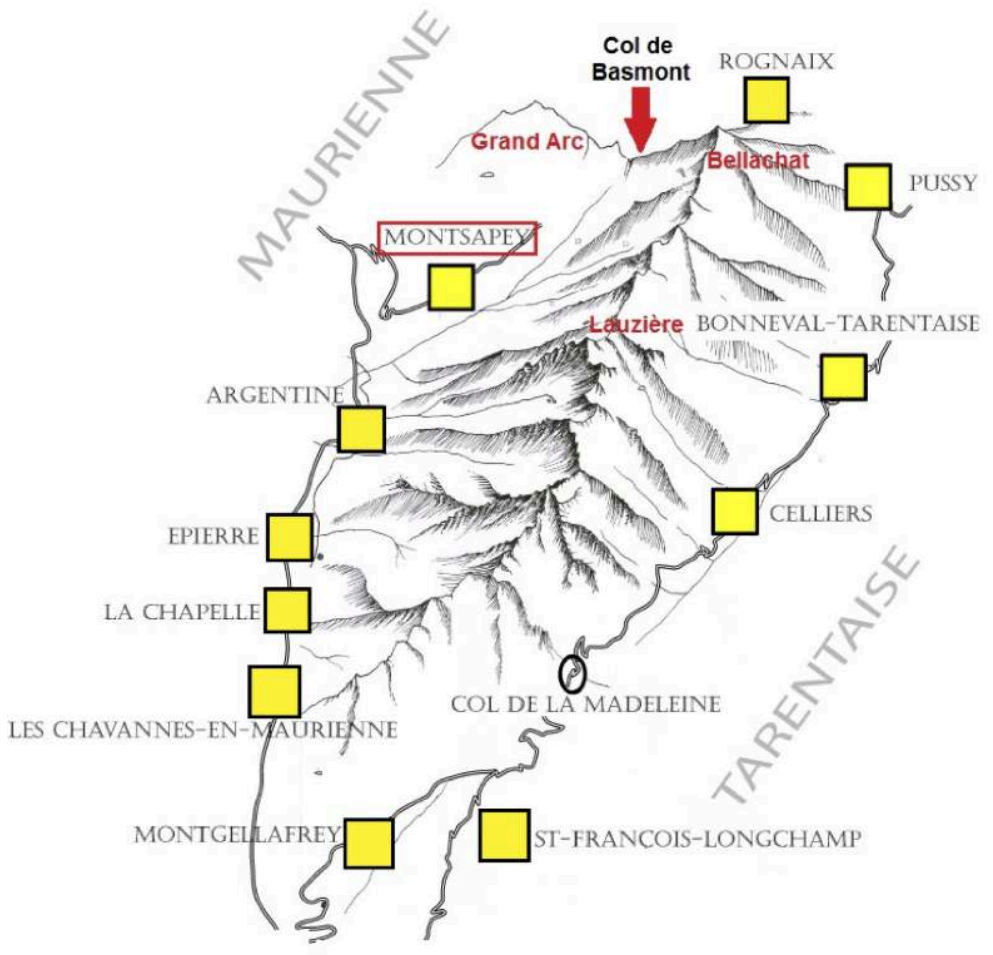

(c) DAO : Jean-Marc Villermet. Fonds de carte : Syndicat Mixte de la Lauzière (collectivité locale).

Les résultats chiffrés de cette étude sont scientifiquement exploitables en raison de l'étendue de la population concernée, dans l'espace et dans le temps, bien qu'ils ne couvrent pas la totalité des hommes résidant sur le territoire puisque les registres de matricules ne font apparaître que les noms des individus tirés au sort durant cette période ${ }^{3}$. Cette étude ne permet donc pas d'enregistrer de manière exhaustive les mobilités masculines puisque, au cours du demi-siècle envisagé, un certain nombre d'individus échappèrent à la conscription. Bien que n'étant pas référencés dans les archives militaires, et s'il demeure difficile d'appréhender le phénomène, un certain nombre de ces hommes non repérés par l'Armée se déplacèrent tout de même et voyagèrent parfois vers des contrées lointaines, sans qu'il soit possible de connaitre avec exactitude leur destination (fig. 2). 
Fig. 2. - Population masculine étudiée aux portes de la Maurienne (977 individus nés entre 1840 et 1874).

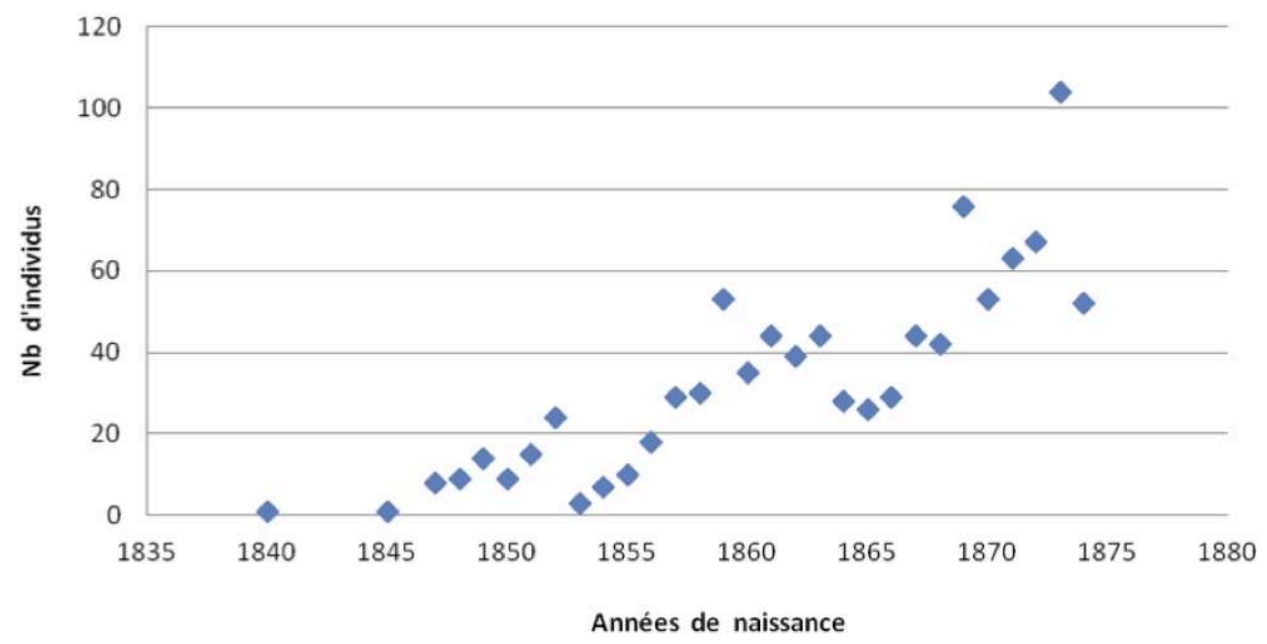

(C) Jean-Marc Villermet. D’après les registres de matricules (Arch. Dép. Savoie).

4 Les sources consultées permettent d'établir des échelles de mobilité en distinguant l'étendue des relations entre la Basse-Maurienne et le reste du département de la Savoie d'une part, entre les localités montagnardes du canton d'Aiguebelle inscrites dans l'espace alpin et le reste de la France d'autre part. Il s'agit aussi d'identifier la proportion de séjours voire d'installations à l'étranger afin d'évaluer l'étendue des relations transfrontalières à l'entrée de la Maurienne, mais aussi l'importance des échanges dans l'empire colonial français et avec des pays plus lointains.

5 Au total, les 977 individus étudiés, tous originaires des portes de la Maurienne, ont effectué au moins 3612 déplacements (déménagements?), temporaires ou définitifs, entre 1860 et 1915. Il est fort possible qu'ils se soient davantage déplacés encore puisque l'Armée n'assurait des relevés d'information qu'à des moments précis correspondant à une période de mobilisation. Les données sur les registres de matricules montrent qu'en moyenne un homme a changé 3,6 fois de lieu d'habitation durant les vingt années de son existence correspondant à une période de "maturité ", entre 20 et 40 ans : le rapprochement entre les registres de matricules et ceux des recensements communaux de population permet d'établir que les Mauriennais voyageurs, en âge de fonder et faire croître une famille, contribuèrent souvent à la mobilité de femmes et enfants ; même si cette dimension demeure difficile à quantifier d'une manière générale ${ }^{4}$.

Quelle fut la part de la mobilité justifiée par des considérations économiques sur un territoire montagnard réputé difficile ${ }^{5}$ et la part d'une mobilité davantage orientée sur une forme de "volontarisme » et un goût pour l'aventure ? Les motifs de cette mobilité et les comportements furent différents selon l'âge, la structure familiale ou encore l'évolution des ressources économiques, difficilement repérables ${ }^{6}$, en dehors des changements intervenus à propos de l'étendue des parcelles indiquée sur des registres de recensements communaux. Les plus jeunes, dans les familles non liées au travail de la terre, déménagèrent plus souvent, pour des motifs allant du désir d'autonomie, lorsque les individus avaient une vingtaine d'années, ils s'engagèrent par exemple durablement dans l'Armée, à la recherche d'une meilleure qualité de vie pour les plus 
âgés, comme en témoignent les travaux de Christian Villermet publiés en $2000^{7}$. Aux portes de la Maurienne, en un demi-siècle (1860 à 1915), la mobilité de proximité fut dominante puisqu'un peu moins de la moitié des hommes étudiés $(43,89 \%)$ n'ont pas quitté leur canton ou leur département à l'occasion de ces changements de résidence. À l'opposé, près de $1 / 5^{\mathrm{e}}$ de la population masculine envisagée $(19,21 \%)$ connut un dépaysement plus significatif en s'installant dans les grandes villes françaises.

7 Les raisons principales qui poussèrent les trentenaires à déménager plusieurs fois furent probablement différentes de celles des très jeunes individus quittant le service militaire. L'ambition de changer de lieu ou de statut professionnel motiva un certain nombre d'entre eux. Les individus de la fin $d u x x^{e}$ siècle et du début $d u x^{e}$ siècles trouvèrent-ils une certaine stabilité professionnelle? Les archives consultées ne permettent pas d'avoir des certitudes à ce sujet. Dans l'hypothèse d'une stabilité, les hommes recherchèrent-ils davantage un logement plus grand, à la suite de la naissance d'enfants par exemple, un phénomène parfois repérable sur les registres de recensements communaux? Cette explication pourrait justifier la mobilité des trentenaires voire des quadragénaires quittant la terre, comme l'attestent quelques cas dans les registres nominatifs de population au sein des archives communales. Bien qu'il ne s'agisse pas de l'objet principal de cette recherche, une étude sociologique plus fine comparant les fiches nominatives des registres de matricules et les informations contenues dans les registres paroissiaux ou communaux - sur les territoires d'accueil permettrait sans doute d'aller plus loin dans l'analyse mais les sources demeurent pour l'heure fragmentaires.

8 Il est également permis de s'interroger sur des aspects matériels et économiques motivant un départ, comme la possibilité de modifier la surface et la qualité des logements occupés à l'occasion d'une migration: un territoire offre-t-il davantage d'opportunités qu'un autre pour se loger et rayonner ? Concernant les jeunes en âge de fonder une famille, quelles furent les opportunités offertes pour louer, construire ou agrandir une habitation à la fin du XIXe siècle et au cours du $\mathrm{Xx}^{\mathrm{e}}$ siècle? À propos des chantiers de construction, la question est posée au regard de l'évolution du cadastre aux portes de la Maurienne ${ }^{8}$ : il apparaît que les constructions nouvelles furent modestes au cours de la période étudiée; la plupart des habitations étant souvent présentes au cours de la première moitié du xix siècle. De quels moyens les jeunes bénéficièrent-ils pour s'installer ailleurs que sur leur terre natale? L'étendue territoriale impactée par le bâti souligne que les familles, installées parfois depuis plusieurs générations, avaient déjà péniblement construit des bâtiments sur des terres d'altitude reculées et qu'il était sans doute difficile d'envisager des constructions nouvelles à la fin du XIX et au début du $\mathrm{Xx}^{\mathrm{e}}$ siècle.

9 Dans le cas d'individus ayant poursuivi des études, les mobilités liées à des raisons professionnelles représentèrent un peu moins de $15 \%$ de l'ensemble de la population : elles furent plus nombreuses en fond de vallée que sur les territoires d'altitude aux portes de la Maurienne. Le dynamisme du territoire pourrait aussi être mesuré à travers l'évaluation du nombre de déménagements souhaités et en étudiant l'importance de la mobilité contrainte, mais il se trouve que les sources n'offrent pas d'éclairage particulier sur cet aspect. Constatons simplement que les jeunes hommes n'étaient logés au départ que de façon provisoire, chez leurs parents, dans la famille élargie ou chez des connaissances pour les plus humbles'. 
généralement, l'Église et l'Armée offrirent des opportunités aux jeunes originaires des portes de la Maurienne pour rayonner à travers l'empire français, sur les terres coloniales : 8,58\% des déplacements à l'étranger furent réalisés en Afrique du Nord, en Algérie essentiellement, et 5,38 \% d'entre eux concernèrent l'Indochine. Ces chiffres méritent toutefois d'être manipulés avec précaution dans la mesure où les registres de matricules font aussi parfois mention de l'Afrique sans autre précision (3,36\% des déplacements sont ainsi désignés). Il s'agit peut-être de contrées non francophones sur le continent, mais cela est peu probable en raison de la barrière de la langue à cette époque. D'une manière générale, quelques cas particuliers mis à part, les grands sites usiniers de la vallée de la Maurienne ont peu attiré la population des pentes de l'espace Grand Arc - Lauzière davantage au contact de la Combe de Savoie et de territoires plus éloignés ${ }^{10}$.

\section{Des destinations très variées}

11 Spatialement, au sein de la cohorte étudiée aux portes de la Maurienne, plus de la moitié des déplacements $(56,11 \%)$ furent effectués en dehors de la Savoie, au sein de l'Hexagone et dans les territoires français d'Outre-mer : 30,9\% des changements de résidences se déroulèrent en direction de départements limitrophes ou sur un territoire très proche, principalement dans l'Ain, en Haute-Savoie, en Isère et dans le Rhône.

La mobilité concerna particulièrement la région de Lyon (13,6 \%) mais aussi Paris ${ }^{11}$ et la proche périphérie de la capitale $(9,11 \%)$ ou encore les Bouches-du-Rhône (3,86 \%), dans la région de Marseille notamment, les trois grandes villes étant reliées par le P.L.M.. Lorsque la confrontation des registres de matricules avec les registres communaux permet de suivre le parcours de quelques chefs de famille au départ du territoire de Montsapey, il apparaît qu'à la fin du $\mathrm{XIX}^{\mathrm{e}}$ et au début du $\mathrm{xx}^{\mathrm{e}}$ siècles la migration des jeunes hommes était souvent quasi définitive même si les migrations saisonnières, qui existaient depuis plusieurs siècles déjà ${ }^{12}$, se perpétuèrent tout au long de la période entre 1860 et 1914.

Souvent employés dans des fermes, les cultivateurs de Montsapey et des communes environnantes se déplacèrent avec régularité entre les portes de la Maurienne (printemps-été) et les rives de la mer Méditerranée (automne-hiver) à Arles, Marseille, Cannes ou encore Tarascon. Autre particularité des portes de la Maurienne, un certain nombre de mineurs ${ }^{13}$ se déplacèrent au rythme des chantiers proposés à Saint-Georgesd'Hurtières et à La Motte-d'Aveillans, près de Grenoble, à Romanèche-Thorins, en Saône-et-Loire, à Sourcieux-les-Mines et à Sain-Bel dans le département du Rhône.

La population masculine rayonna inégalement sur le territoire national. L'essentiel des déplacements se déroula sur un espace couvrant les départements compris à l'intérieur d'un arc de cercle joignant la zone située entre la Picardie au nord et les Pyrénées orientales au sud, le Massif central à l'ouest et la frontière italo-suisse à l'est. Néanmoins, à l'échelle de l'Hexagone, la plupart des autres régions françaises ont été concernées par le phénomène migratoire au départ du territoire de la BasseMaurienne, entre la fin du xix siècle et la Première Guerre mondiale. Au cours du demi-siècle étudié, les habitants de Montsapey et des communes riveraines ont irrigué le territoire national par leur mobilité, sauf dans trois directions : le nord-est, le cœur $\mathrm{du}$ Massif central proprement dit, et la région du sud-ouest, Bassin aquitain et 
Pyrénées. L'étude statistique démontre qu'en dehors de trois zones, globalement, le territoire national fut bien irrigué par des réseaux qui se mirent en place au fil des décennies (fig. 3).

Fig. 3. - Principales zones de déplacements dans les départements français de la population masculine, au départ de Montsapey et des communes riveraines en Basse-Maurienne, entre 1860 et 1915 .

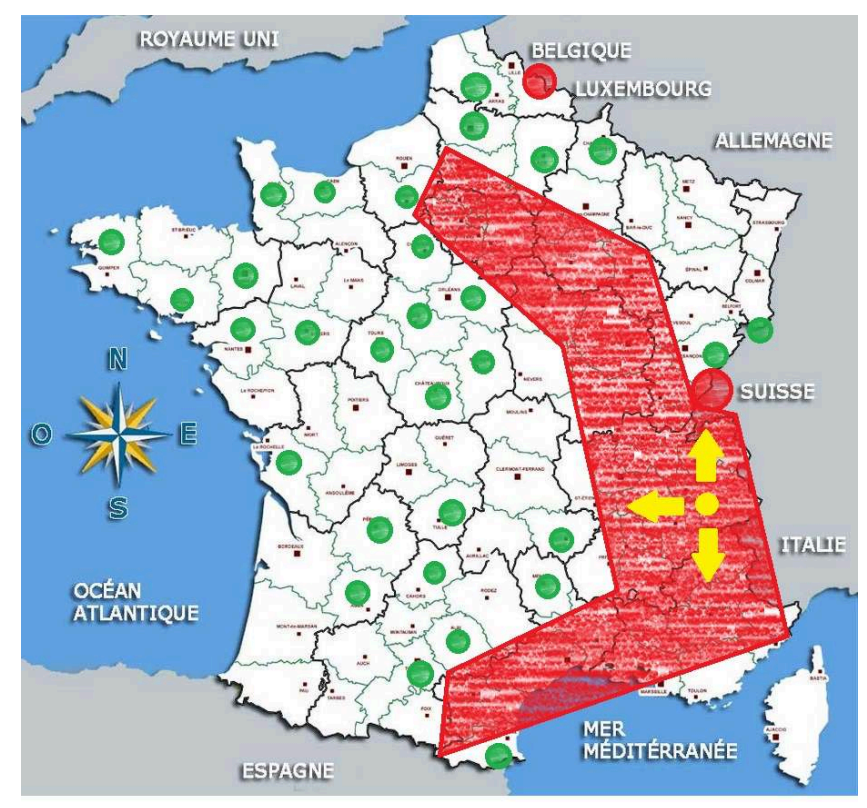

Fréquentation régulière

Zone de départ

Fréquentation ponctuelle

(c) Jean-Marc Villermet. Carte réalisée à partir des registres de matricules de 1860 à 1894 - Arch. Dép. Savoie. matricules recensent également la profession exercée par chacun des individus mobilisés sous les drapeaux. À l'échelle d'une cohorte de près d'un millier d'individus, il est possible de repérer avec une certaine précision le fonctionnement économique et social du territoire. S'il n'est pas surprenant que la grande majorité des hommes soient liés à la terre (68\%), presque tous les cultivateurs étaient propriétaires ou issus d'une famille de propriétaires $(92,3 \%)$ comme le montrent les recensements communaux de population, ce qui signifie concrètement qu'après leur départ, soit temporaire, soit définitif, le territoire a progressivement souffert de bras manquants sur les terres d'altitude qui ne furent pas nécessairement remplacés.

Le phénomène de mobilité débuta assez tôt à la fin du XIX $x^{e}$ siècle et s'accéléra par la suite. Néanmoins, la déprise rurale ne fut pas immédiatement palpable, malgré une baisse du nombre d'habitants recensés. En effet, en diverses circonstances, et notamment entre les deux guerres mondiales, le départ des hommes dont les familles étaient ancrées sur le territoire montagnard depuis plusieurs générations fut compensé par une arrivée massive et temporaire de migrants italiens aux portes de la Maurienne. Le phénomène dura au moins pendant une décennie: les archives communales de 
Montsapey permettent de quantifier a minima les mouvements migratoires dans l'espace transfrontalier.

17 Les statistiques concernant la répartition des émigrants par catégories socioprofessionnelles soulignent que les départs ne furent pas uniquement liés à des considérations économiques. Si le territoire s'est progressivement vidé de sa population, cela est aussi en partie lié au degré de qualification des hommes. Près de $70 \%$ des migrations concernèrent des individus liés de près ou de loin à la paysannerie qui obtenaient des rendements et des revenus modestes, aussi bien en fond de vallée qu'en montagne : beaucoup de Mauriennais quittèrent leur région d'origine pour cause de pauvreté et de morcellement des propriétés, comme l'a montré Pierre Judet ${ }^{14}$. Cependant, les artisans formés sur le terrain, avec souvent un haut degré de qualification furent particulièrement recherchés. Par exemple, les métiers de bouche furent valorisés : une partie de la population des portes de la Maurienne, engagée sous les drapeaux dans un premier temps, alimenta par la suite des filières et des réseaux, non seulement en France mais en Europe et même au-delà des océans.

\section{Constitution progressive de réseau}

18 Les cuisiniers, garçons de cafés et d'hôtellerie-restauration exercèrent souvent à Lyon ou Paris, pour débuter, avant de se rendre à l'étranger, en Suisse, en Grande-Bretagne, voire aux États-Unis. Dès le rattachement de la Savoie à la France, un cuisinier né à Aiguebelle circula parmi les grands restaurants de son temps, et s'installa en alternance à Genève et à Londres durant une vingtaine d'années avant de gagner l'État de Rhode Island et la ville de Providence sur la côte est des États-Unis. À son retour en Europe, à la fin du XIXe siècle, il rejoignit les rives du lac Léman, Coppet, dans le canton de Vaud, et Genève, avant de s'installer au Grand Hôtel de Bruxelles ${ }^{15}$. La plupart des autres cuisiniers des portes de Maurienne exercèrent leur profession dans les grandes villes françaises, essentiellement à Paris, Lyon, Marseille et Nice tout en revenant régulièrement dans les Alpes du Nord, notamment dans les villes thermales, Aix-lesBains, Divonne-les-Bains ou encore Allevard.

Dans le même esprit, confiseurs et pâtissiers formés aux portes de la Maurienne déployèrent leurs talents dans les grands hôtels européens de la Belle Époque au cœur de l'espace transfrontalier. Ainsi, après avoir fréquenté Grenoble au temps de la conscription, l'un d'entre eux fut installé professionnellement à l'Hôtel de San Remo, en Ligurie, au tournant du siècle, puis transféré à l'Hôtel Beau Rivage de Genève, avant de gagner la Méditerranée à Hyères. En alternance, il exerça ensuite en Suisse, à Nice, Lucerne, Londres, Versailles, Maison-Laffitte... et revint en Maurienne peu avant la Première Guerre mondiale. Le plus souvent, les spécialistes des métiers de bouche étaient engagés pour une saison, un ou deux ans tout au plus. Quant aux boulangers des portes de la Maurienne, la plupart d'entre eux, une vingtaine au total dans l'étude réalisée à partir des registres de matricules, gagnèrent les terres lointaines, sans doute engagés durablement par l'Armée. Beaucoup sillonnèrent mers et océans pour ravitailler les soldats en Cochinchine (dès 1883), puis sur l'île de Formose (1884-1885) et au Tonkin (1885-1886).

Les translations entre les portes de la Maurienne et le reste du territoire national furent facilitées grâce au concours de professionnels engagés dans les métiers liés au transport. L'étude porte sur une cinquantaine d'entre eux. Au départ, tous étaient 
domiciliés sur les flancs opposés de l'Arc. Propriétaires le plus souvent d'une carriole, tractée par des chevaux pour les plus riches d'entre eux, ils vivaient essentiellement de la location ou du transport de marchandises et contribuèrent à mettre en relation différents territoires de la Savoie, mais aussi des espaces plus lointains en France. Les lieux de domiciliation de ces Mauriennais suivirent en général les grands axes de circulation. Si quelques-uns d'entre eux s'établirent dans la région parisienne ou dans le sud de la France, la plupart des voituriers évoluèrent entre le Rhône et les Alpes, ce qui leur permit de conserver des contacts avec leur milieu d'origine.

Concernant les emplois dans les transports ferroviaires, l'étude menée à partir des registres de matricules souligne que les premiers employés originaires des portes de la Maurienne au sein de la compagnie du P.L.M. sont nés à Montsapey et à Saint-Georgesd'Hurtières en 1847. Cependant, au cours des décennies suivantes et jusqu'à la Première Guerre mondiale, un véritable réseau se structura entre la rive gauche de l'Arc et la région lyonnaise si bien que Les Hurtières fournirent plus des trois-quarts de la maind'œuvre de l'entrée de la vallée employée par la Compagnie P.L.M. alors en pleine expansion. Nombre d'entre eux s'installèrent à Oullins, à partir du début des années 1880 où ils résidaient (fig. 4) ${ }^{16}$. Néanmoins, certains choisirent de rejoindre la même entreprise "à l'étranger ", dans les colonies, notamment à Constantine, en Algérie (1888), et en Suisse (de 1898 à 1914). Globalement, les jeunes hommes originaires des portes de la Maurienne s'installèrent le long du réseau ferré, en Savoie et dans les départements limitrophes. Quelques employés de la compagnie P.L.M., nés au pied du Grand Arc et de la Lauzière, décidèrent aussi de s'établir à Paris tout en travaillant parfois dans la vallée de la Maurienne, à Modane par exemple ${ }^{17}$.

Fig. 4. - Cités ouvrières de la compagnie P.L.M. à Oullins où se constitua une communauté originaire des portes de la Maurienne dès la fin du XIXe siècle.

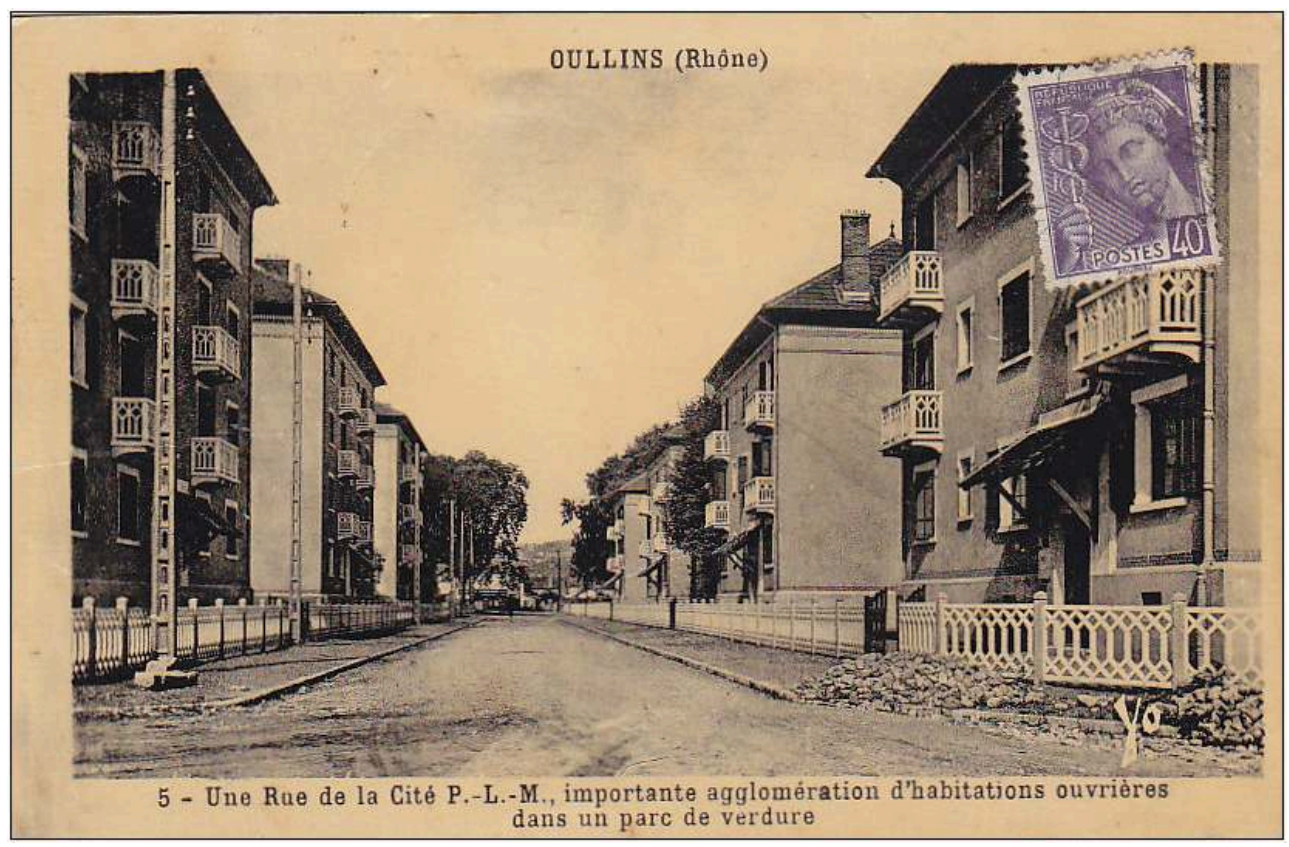

(c) Droits Réservés.

Quelques habitants des portes de la Maurienne se firent également embaucher par d'autres compagnies comme le Chemin de fer du Nord (en 1883 et 1884), mais aussi 
dans des villes à l'intérieur desquelles le réseau ferré prospéra. Plusieurs Mauriennais trouvèrent du travail au sein de la Compagnie de Tramway du Loir-et-Cher, à Blois (1900), de la Compagnie de Chemin de fer du Midi (1901), de la Compagnie de Tramway de Marseille (1899 et 1900) ou encore auprès de la Compagnie des Chemins de fer de Fourvière et de l'Ouest lyonnais (1900 à 1903).

L'enquête menée à partir des registres de matricules permet d'identifier des translations de Mauriennais vers les principales villes françaises pour des raisons éducatives. Quelques habitants de Montsapey, d'Aiguebelle et des environs voyagèrent dans le but de parfaire leurs études: plusieurs d'entre eux menèrent des carrières professionnelles sans retour en Savoie. Les archives font mention de différents parcours vers des écoles normales, écoles de pharmacie, écoles vétérinaires ou encore vers l'École Polytechnique à Paris : par exemple, admis au concours de l'établissement de la rue Descartes, en1891, Louis-Joseph Piot, domicilié sur les pentes du Grand Arc obtint " une bourse avec trousseau ${ }^{18}$ et devint ingénieur au sein d'une compagnie ferroviaire privée. Ne retournant pas en Maurienne après ses études, il évolua au Service central des Chemins de Fer du Nord occupant différents postes à Cambrai, Béthune, Douai, Valencienne et Arras avant de rejoindre la SNCF après la nationalisation des chemins de fer ${ }^{19}$. Son fils, également polytechnicien ${ }^{20}$ ne revint pas davantage sur les terres de ses aïeux aux portes de la Maurienne.

Plusieurs autres jeunes, nés au pied du Grand Arc et de la Lauzière, intégrèrent la faculté de pharmacie de Paris (1893) et de Lyon (1894) en choisissant par la suite de poursuivre sur place leur vie professionnelle, sans retour en pays de Savoie. Dans un certain nombre de cas, dès le dernier quart du XIX siècle, la poursuite d'études, parfois conjuguée à la volonté d'embrasser une carrière militaire, constitua un mobile pour voyager, s'éloigner du berceau familial et de l'espace montagnard. Ainsi, Adolphe Pitton, né à Montsapey, intégra la Garde Républicaine à Paris, en 1883, avant de choisir une autre voie en s'expatriant aux États-Unis. D'autres jeunes Mauriennais, nés à Montsapey ou dans la périphérie proche, décidèrent de s'installer dans la capitale pour les mêmes raisons en faisant carrière dans l'infanterie ou la cavalerie : par exemple, un cultivateur né à Aiton, en 1869, fut formé à Paris avant d'être domicilié à Versailles. Lorsqu'ils revinrent dans les Alpes, les militaires de la Garde Républicaine firent carrière ailleurs qu'en Maurienne (promotions 1874 et 1875).

S'il est difficile de suivre dans le détail le parcours des 977 jeunes référencés sur les registres de matricules, faute de documents susceptibles d'apporter des précisions utiles, en revanche, les dossiers de plusieurs Mauriennais déposés aux Archives générales des frères maristes à Rome permettent de comprendre leur parcours éducatif dans une dimension transfrontalière. Bien que peu nombreux aux portes de la Maurienne, des hommes se déplacèrent aussi pour apprendre et se cultiver. Leurs réseaux se constituèrent très tôt en raison de la conjoncture géopolitique du moment, à la fin du XIX ${ }^{e}$ et au début du Xx ${ }^{e}$ siècles (fig. 5, 6, 7, 8 et tab. 1). 
Fig. 5 - Vue aérienne des portes de la Maurienne vers 1950.
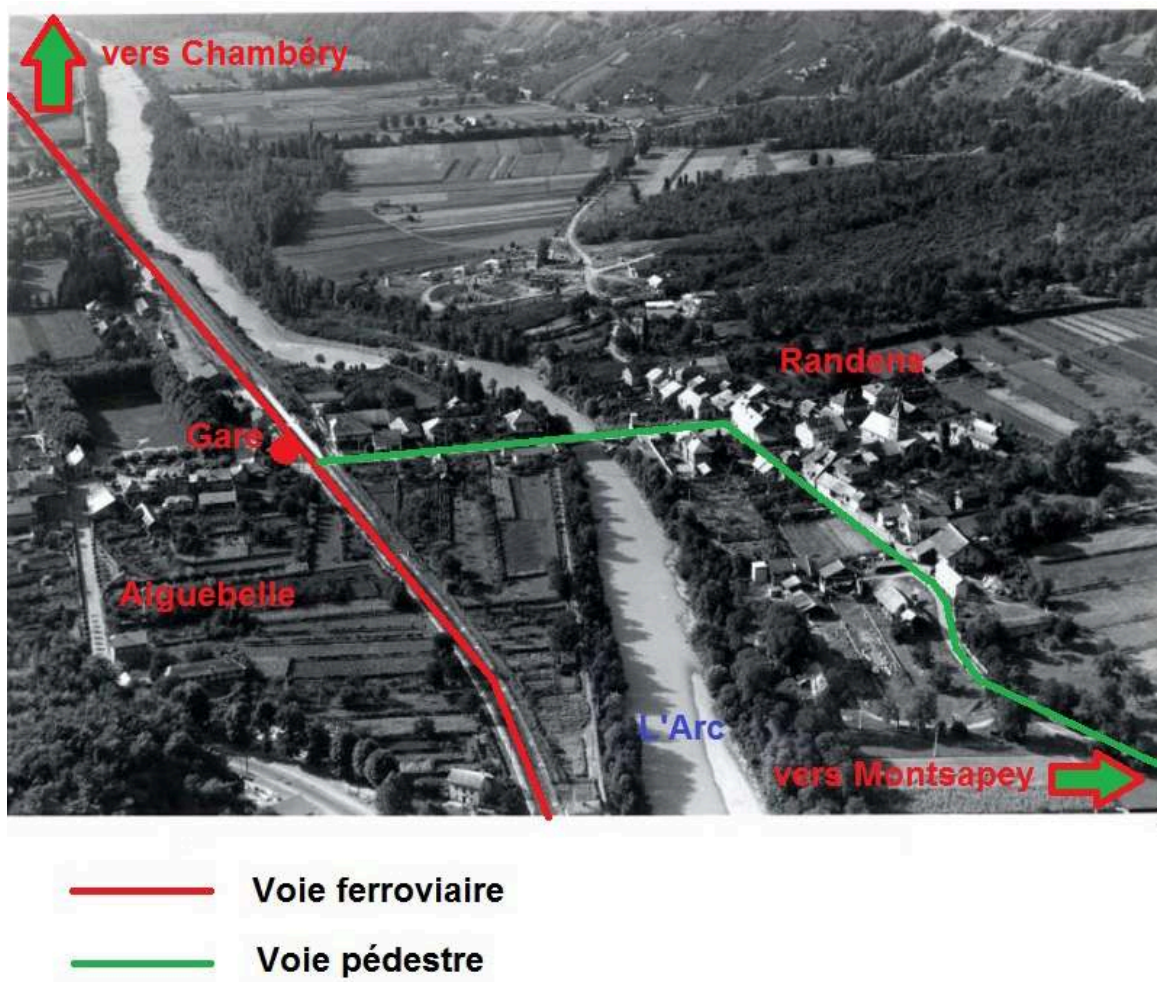

Schéma réalisé à partir d'une carte postale.

Aiguebelle et Randens, L'Arc, 1950, Photographie aérienne de Roger Henrard @ , Réf. 3Fi1 1-252, Arch. Dép. Savoie. 
Fig. 6. - Vue générale d'Aiguebelle et du Massif de La Lauzière.

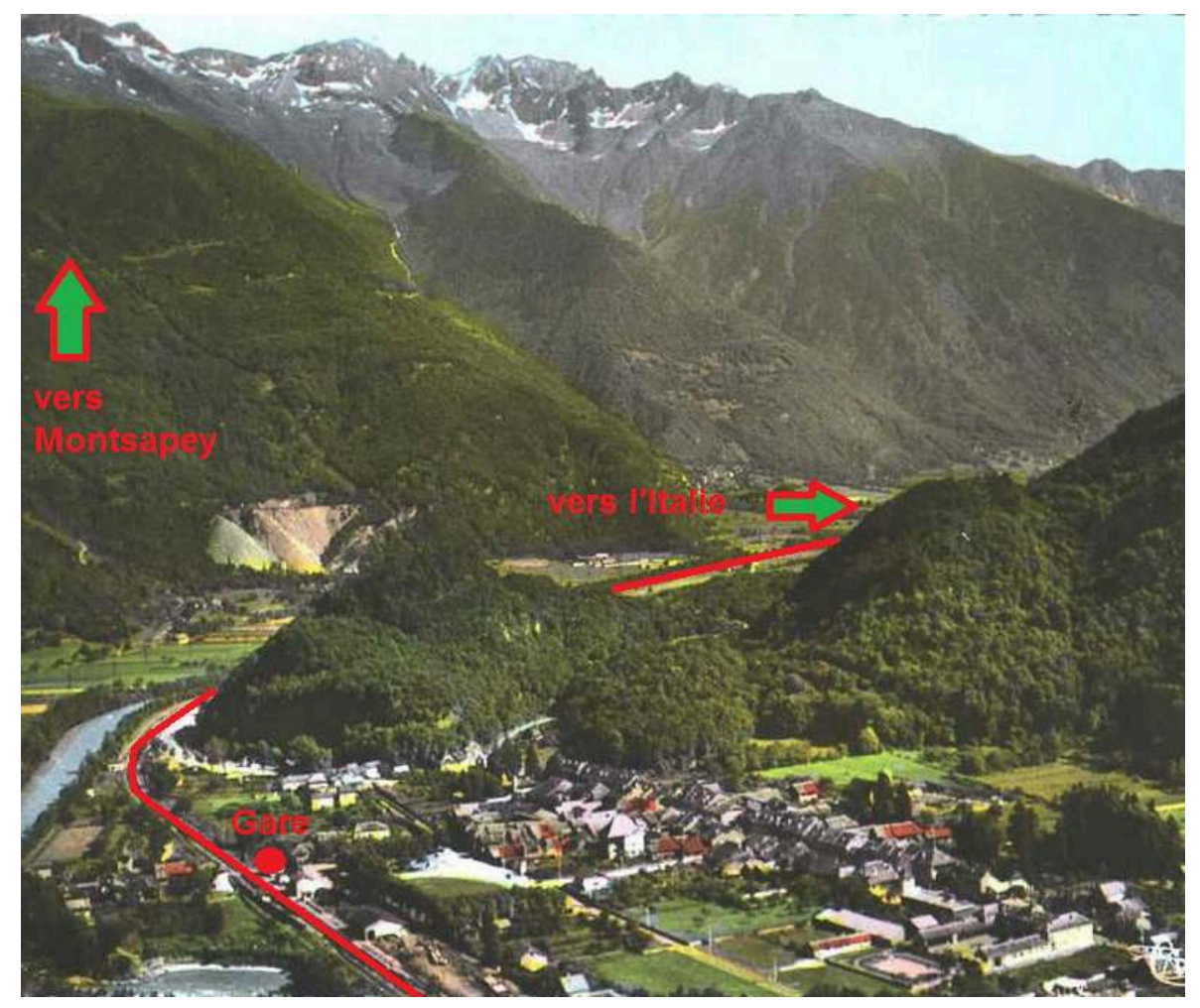

Schéma réalisé à partir d'une carte postale non datée ; milieu du xx siècle ? Le chantier du tunnel Isère-Arc (1948-1954) a déjà débuté (excavations visibles dans la montagne).

Aiguebelle - Vue générale aérienne de la Lauzière, Combier Imprimeur, Mâcon - Réf. 2Fi 3000, Arch. Dép. Savoie. 
Fig. 7. - La voie ferrée au pied du Grand Arc : passage à niveau en gare d'Aiguebelle au début du xxe siècle.

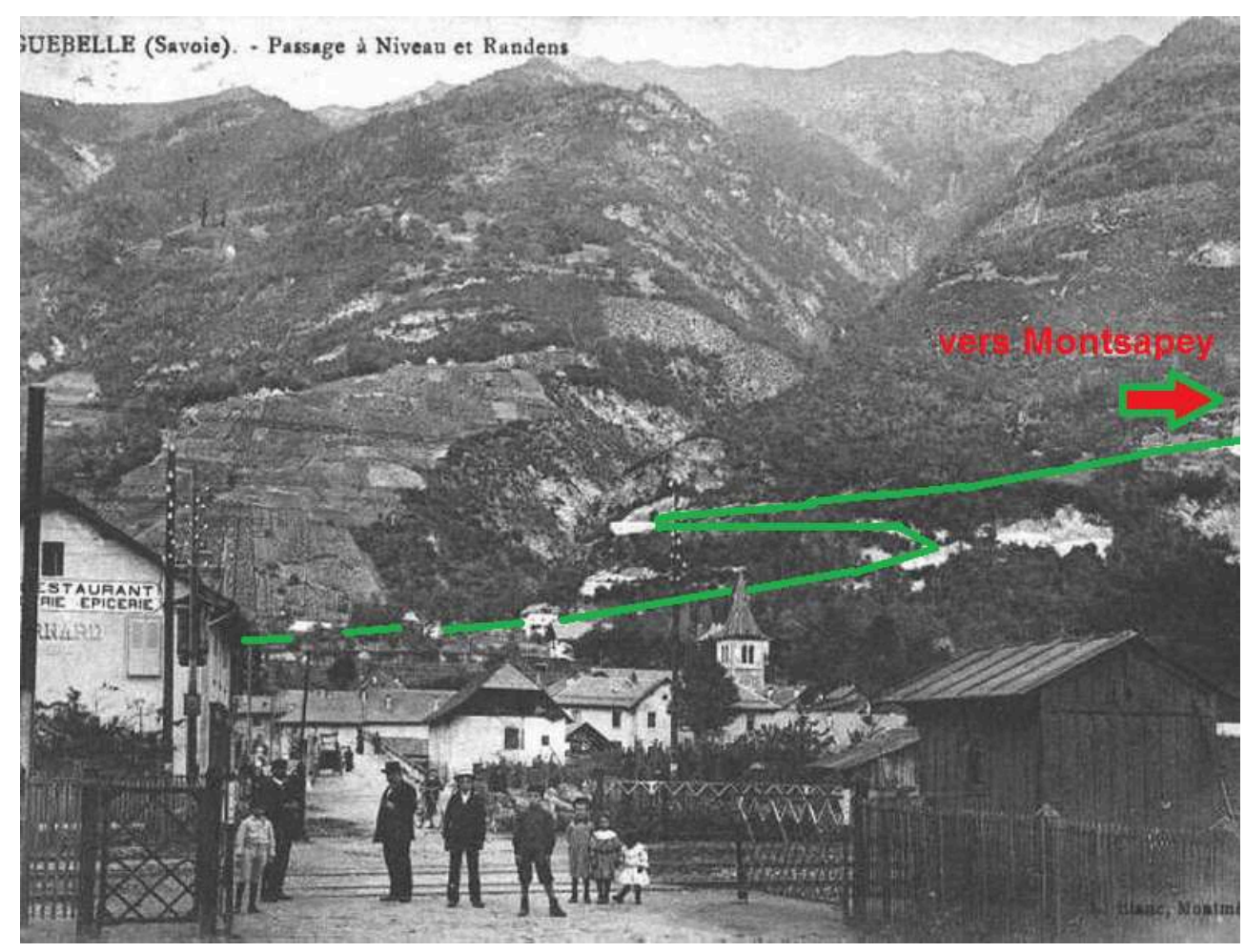

Cette photographie illustre aussi la mise en culture des terres, très haut en altitude, sur des pentes abruptes, pour nourrir une population nombreuse.

Aiguebelle, Passage à niveau, et Randens, Photographie de L. Blanc @ ( Montmélian, Réf. 2Fi 3012 Arch. Dép. Savoie.

\begin{tabular}{|l|l|}
\hline Afrique & 90 \\
\hline Amérique & 36 \\
\hline Asie & 35 \\
\hline Europe & 51 (hors France et hors Allemagne en 1914) \\
\hline Océanie & 1 \\
\hline
\end{tabular}

Tabl. 1. - Nombre de déplacements (temporaires ou définitifs) des jeunes originaires des portes de la Maurienne sur les cinq continents entre 1860 et 1915.

(c) Jean-Marc Villermet. D'après les registres de matricules, Arch. Dép. Savoie. 
Fig. 8 - Pays et colonies françaises (en rouge) fréquentés par 147 jeunes originaires des portes de la Maurienne entre 1860 et 1914.

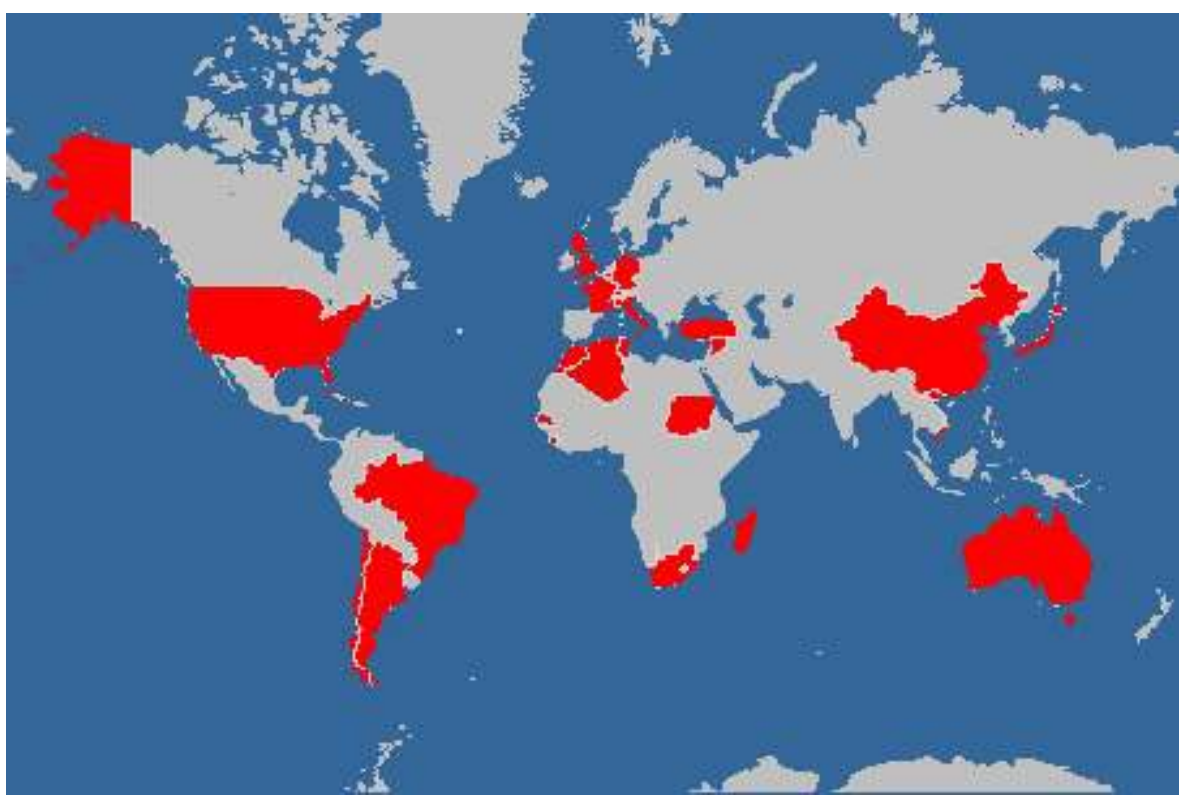

(c) Jean-Marc Villermet. D’après les registres de matricules, Arch. Dép. Savoie.

\section{BIBLIOGRAPHIE}

Actes de la $7^{\mathrm{e}}$ journée scientifique de l'AHICF, « Armées et chemins de fer en France », Vincennes, 19 octobre 1995, textes de conférences données de 1993 à 1995, Revue d'histoire des chemins de fer, $\mathrm{n}^{\circ} 15,1996,276 \mathrm{p}$.

Actes des deuxièmes rencontres de la commission « histoire sociale des transports par fer » de l'AHICF, « Origines sociales et géographiques des cheminots français », Paris, 4 avril 1999, Revue d'histoire des chemins de fer, $\mathrm{n}^{\circ} 22,2000,317 \mathrm{p}$.

AMSELLE Jean-Loup, « Métissage, branchement et triangulation des cultures », Revue germanique internationale, $\mathrm{n}^{\circ} 21,2004$, p. 41 à p. 51.

BERNE Laurence, Ouverture et fermeture de territoire par les réseaux de transports dans trois espaces montagnards (Bugey, Bauges et Maurienne), thèse en géographie dirigée par Jean Varlet, Chambéry, Université de Savoie, 2008, 373 p.

BERNIER Xavier, Traverser - Essai sur les figures spatiales d'un défi social, HDR en Géographie, Université Savoie Mont-Blanc, Chambéry, 2014.

BERNIER Xavier, « Les mobilités touristiques dans la verticalité des territoires de montagne : les différentes logiques spatiales d'accès aux stations touristiques d'altitude », dans WALTER François, DUC Gérard, PERROUX Olivier, SCHIEDT Hans-Ulrich, Histoire des transports et de la mobilité : entre concurrence modale et coordination (de 1918 à nos jours), Éditions Alphil, 2014, p. 383 à p. 397. 
BERNIER Xavier, 2007, Mountain roads as heritage objects : towards a typology of heritage status development processes, 11 th World Conference on Transport Research (11 ${ }^{\text {ème }}$ conférence mondiale sur la recherche dans les transports). June 24-28 2007, university of California, Ed.- Berkeley CA USA, $13 \mathrm{p}$.

BERTHIER-MC LAUGHLIN Cécile, Bourlingueuses : le voyage au féminin entre les deux guerres (1919-1939), thèse de doctorat en Littérature française sous la direction de Myriam BOUCHARENC, Université Paris X - Paris-Nanterre, 2010, 425 p.

BOGEY-REY Annick, «À pied, à cheval, en train, le rôle des moyens de transport dans le choix des décors et des mobiliers d'églises du XVIII ${ }^{\mathrm{e}}$ au XIX ${ }^{\mathrm{e}}$ siècle ", Échanges et voyages en Savoie, Coll. L'Histoire en Savoie, n 11-2006, Ed. S.S.H.A., 2006, et t. XXXVIII-XXXIX, S.H.A.M., 2004-2005, p. 360 .

BONIFACE Xavier, «L'aumônerie militaire française en guerre d'Algérie », Vingtième siècle, $\mathrm{n}^{\circ}$ 77, 2003, p. 47 à p. 57.

BROC Numa, «Les explorateurs français du XIX ${ }^{\mathrm{e}}$ siècle reconsidérés ", Revue française d'Histoire d'Outre-mer, vol. 69, n 256, 1982, p. 237 à p. 273

CARON François, Histoire des Chemins de fer en France, t. II : 1883-1937, Paris, Fayard, 2005, 1018 p. CHÂTELAIN Claude, Les Cousins - La fabuleuse odyssée de l'exil des Savoyards en Argentine, Montmélian, Éd. La Fontaine de Siloé, 1990, 342 p.

CHEVANDIER Christian, Cheminots en usine, les ouvriers des Ateliers d'Oullins au temps de la vapeur, Lyon, Presses universitaires de Lyon, 1993, $319 \mathrm{p}$.

CORNU Pierre, « Pour une archéologie sociale des sentiers migratoires. Retour historien sur la question de la mobilité spatiale dans la France rurale du XIX ${ }^{\mathrm{e}}$ siècle ", dans MAYAUD (J-L.) et LUTZ (R.), Histoire de l'Europe rurale contemporaine. Du village à l'État, Paris, Ed. Armand Colin, 2006, 405 p., p. 72 à p. 93.

COTTET-DUMOULIN Émilie, Franchir pour unir, équiper pour rattacher Les premiers chemins de fer en Savoie : intentions, usages, représentations (années 1830-années 1880), université de Savoie, thèse de doctorat sous la direction de Denis VARASCHIN, 2013, 697 p.

DE BAECQUE Antoine, La traversée des Alpes-Essai d'histoire marchée, Coll. Bibliothèque des Histoires, Paris, Gallimard, 2014, 432 p.

DEQUIER Daniel, Maurienne, la vallée de l'aluminium, Montmélian, Ed. La Fontaine de Siloé, 1992, 245 p.

DEVANNE Anne-Sophie, Marcheurs en montagne et expérience de l'espace, Une analyse de la construction du rapport à l'espace, à travers la pratique de la marche dans les Pyrénées, Institut National d'Agronomie Paris-Grignon, thèse de doctorat en Sciences de l'environnement, Engref, Paris, 348 p.

DUBIEF Pierre Jean, La Lettre de voyage, Rennes, Presses Universitaires de Rennes, 2007, 292 p.

FARCY Jean-Claude et FAURE Alain, La Mobilité d'une génération de français - Recherche sur les migrations et les déménagements vers et dans Paris à la fin du XIXe siècle, INED, Paris, 2003, 591 p. FORRAY François, Franchir les Alpes, Coll. L'Histoire en Savoie, Chambéry, Ed. S.S.H.A., nº 106-1992, $48 \mathrm{p}$. 
HACHEZ-LEROY Florence, « Chambéry première usine de transformation d'aluminium de Pechiney (1912-1947) ", dans Des barrages, des usines et des hommes, Études offertes au professeur Henri Morsel, Grenoble, Presses Universitaires de Grenoble, décembre 2002.

HEFFERNAN Michaël John, « Literacy and Geographical Mobility in Nineteenth Century Provincial France: Some Evidence from the Department of Ille-et-Vilaine », Local Population Studies, 1989, 42, p. 32 à p. 42 .

JOURDAIN Virginie, « L'hôtellerie bruxelloise1880-1940 - Acteurs, structures et logiques spatiales d'un secteur multiforme ", thèse de doctorat en Histoire, Art et Archéologie, sous la direction de Serge JAUMAIN et Laurent TISSOT, université Libre de Bruxelles - Faculté de Philosophie et lettres, université de Neuchâtel - Faculté de Lettres et Sciences humaines, 2012, 384 p.

JUDET Pierre, « Savoie 1860 - une société assez largement ouverte vers la France », dans MILBACH Sylvain, La Savoie terre ouverte - occupations, annexions, révolutions, Coll. L'Histoire en Savoie, Ed. S.S.H.A., $\mathrm{n}^{\circ}$ 20-2010.

LEJEUnE Dominique, La France de la Belle Époque, Paris, Armand Colin, 2011, 240 p.

LETONNELIER (G.), «L'émigration des Savoyards », Revue de Géographie alpine, vol. 8, n 4, 1920, p. 541 à p. 584.

MELDOLESI Tommaso, « Le chemin de fer entre $\mathrm{XIX}^{\mathrm{e}}$ et $\mathrm{XX}^{\mathrm{e}}$ siècle : manifestations de l'inquiétude se penchant vers la folie pendant le voyage en train et à la gare ", Conserveries mémorielles - Revue transdisciplinaire de jeunes chercheurs, Dossier : Mobilité, espace et temps. Quelle mémoire pour la réalité augmentée?, nº 17, 2015, Québec.

MIQUET François, «L'émigration des Savoyards originaires du Faucigny au XIX ${ }^{\mathrm{e}}$ siècle ", Revue Savoisienne, 1916, p. 248 à p. 251.

MOUSTIER Philippe et Laurent RIEUTORT, « Des trains de moutons pour se nourrir... Transhumance ferroviaire et alimentation à travers l'exemple provençal », dans Revue d'Histoire des chemins de fer, $\mathrm{n}^{\circ} 41$, p. 89 à p. 109.

PALLUEL-GUILLARD André, Impressions de voyage en Savoie ou comment les voyageurs ont vu la Savoie, Chambéry, Ed. SSHA, 1990, 56 p.

PoIsson Véronique, « Les grandes étapes de cent ans d'histoire migratoire entre la Chine et la France ", Hommes \& Migrations, n 1254, mars-avril 2005, p. 6 à p. 17.

PORTAZ Maud, Être cheminot à Chambéry au temps des grandes compagnies ferroviaires, Université de Savoie, Chambéry, Master 1 Histoire, 2009, 182 p.

PRUDHOMME Claude, La Stratégie missionnaire du Saint-Siège sous le pontificat de Léon XIII (1878-1903), thèse de doctorat, décembre 1989, 2 tomes, publiée à Rome, École Française de Rome, 1994, 621 p. ROSENTHAL Paul-André, « La migration des femmes (et des hommes) en France au XIXe siècle », Annales de démographie historique, 2004, 1 n 107, Belin, 256 p., p. 107 à p. 135.

SORREL Christian, « Savoyards de Paris », La Savoie et l'Europe 1860-2010. Dictionnaire historique de l'Annexion, Montmélian, Ed. La Fontaine de Siloé, 714 p.

STOSKOPF Nicolas et LAMARD Pierre, Transports, territoires et société, Coll. Histoire industrielle et société, Paris, Ed. Picard, 2011, 276 p.

SUTTON Kevin, «L'accélération comme invention perpétuelle des traversées alpines », Revue d'histoire des chemins de fer, Dossier « Vitesse ferroviaire, gestion du temps et construction des territoires ", n 42-43, 2012, p. 201 à p. 218. 
TOWNLEY (M.), L'émigration savoyarde en Argentine - 1884-1920, Mémoire d'Histoire, Université Paris IV Sorbonne, $165 \mathrm{p}$.

VANIA Béatriz M., «Viajantes europeus nas colônias italianas - European travellers in the Italian colonies » - Doutora em História das Américas pela universidade de Gênova, Itália, 1992, e PósDoutora pela universidade de Pádua, 2003, Italia - in Estudos Ibero-Americanos, PUCRS, vol. 38, novembre 2012, p. 281 à p. 293.

VARASCHIN Denis, Aux sources de l'histoire de l'annexion de la Savoie, Bruxelles, Ed. P.I.E. Peter Lang, $2009,265 \mathrm{p}$.

VENAYRE Sylvain, La Gloire de l'aventure. Genèse d'une mystique moderne. 1850-1940, Paris, Aubier, 2002, $352 \mathrm{p}$.

VICINI Mathieu, Une communauté cheminote au temps des compagnies : les employés de la gare internationale de Modane (1871-1936), université de Savoie, Chambéry, Master 1 Histoire, 2003, 240 p.

VILLERMET Christian, Un balcon en montagne - Aspects de la vie en altitude depuis le seizième siècle dans un village de Savoie, op. cit., deuxième partie : « Entre tradition et modernité (1792-1914) - Une agriculture qui progresse lentement », Saint Jean de Maurienne, Derrier, 2000, 248 p.

WOLKоWITSCH Maurice, «Les chemins de fer à la conquête des campagnes. L'aménagement du territoire par les réseaux dits secondaires en France, histoire et patrimoine, 1865-2001 ", actes du $9^{\text {e }}$ colloque de l'AHICF, Châteauroux, 6 au 8 septembre 2001, Revue d'histoire des chemins de fer, $\mathrm{n}^{\circ}$ 24-25, 2001, $447 \mathrm{p}$.

\section{NOTES}

1. Archives Départementales de la Savoie (Arch. Dép. Savoie): Série complète des registres de matricules entre 1860 et 1894 - canton d'Aiguebelle $1 \mathrm{R}$ - États signalétiques et des services : registres de matricules de recrutement militaire : Classes 1878 à 1892 : cote $1 \mathrm{R} 13-98$. Classes 1892 à 1909 : cote 1R 99-198. Classes 1910 à 1926 : cote 1R 199-297 (étude jusqu'à la cote 1R 199-225).

2. D. Lejeune, La France de la Belle Époque.

3. Bulletin des Lois de la République Française, Ed. Imprimerie nationale. Texte de référence : Année : 1872-07, BnF Gallica. Identifiant : ark:/12148/bpt6k210062f

4. P.-A. Rosental, « La migration des femmes (et des hommes) en France au XIX ${ }^{e}$ siècle ».

5. J.-Cl. Duclos, S. Gros et J.-F. Lyon-Caen, Habiter. Centre de Culture Scientifique, technique et industrielle, Eurêka Chambéry, Habiter la montagne, Espace montagne, Exposition permanente.

6. C. Villermet, Un balcon en montagne - Aspects de la vie en altitude depuis le seizième siècle dans un village de Savoie.

7. Idem.

8. Arch. Dép. Savoie - Étude comparative à propos du village de Montsapey. Cadastre napoléonien : plan cadastral. - Bonvillaret, Bourgneuf, Chamousset, Saint-Georges-d'Hurtières, Montgilbert, Montsapey, Saint-Pierre-de-Belleville, Randens. Cadastre Montsapey - 1911-1944. 3P 2130-2133 ; 3P 7467. Cadastre Montsapey rénové - 1911-1944. 1280W 206-207. 
9. Arch. Dép. Savoie - Registres communaux, Montsapey, Cote 1876-1936 (6M 2128-2139).

10. F. Hachez-Leroy, «Chambéry première usine de transformation d'aluminium de Pechiney (1912-1947)». "Xénius », magazine de la connaissance, enregistré le 27 octobre 2015 pour Arte. Invitée: Florence Hachez-Leroy, maître de conférences, institut universitaire de France, université d'Artois, membre du comité scientifique de L'Espace Alu à Saint-Michel-de-Maurienne. Diffusion : 27 janvier 2016. D. Dequier, Maurienne, la vallée de l'aluminium.

11. Chr. Sorrel, "Savoyards de Paris ", La Savoie et l'Europe 1860-2010. Dictionnaire historique de l'Annexion, p. 448 à p. 451.

12. D. Varaschin, Aux sources de l'histoire de l'annexion de la Savoie, p. 34. Musée de l'Histoire de l'immigration, «Économie et immigration: qu'est-ce que la migration saisonnière? ", Palais de la porte dorée, Paris.

13. Dossier « Mines et mineurs », L’Alpe, Grenoble, Ed. Glénat - Musée Dauphinois, $\mathrm{n}^{\circ} 74$, 2016, p. 6 à p. 57.

14. P. Judet, «Savoie 1860 - une société assez largement ouverte vers la France ».

15. V. Jourdain, L'hôtellerie bruxelloise 1880-1940 - Acteurs, structures et logiques spatiales d'un secteur multiforme.

16. Chr. Chevandier, Cheminots en usine, les ouvriers des Ateliers d'Oullins au temps de la vapeur.

17. M. Vicini, Une communauté cheminote au temps des compagnies : les employés de la gare internationale de Modane (1871-1936).

18. Courrier des Alpes, 6 octobre 1891, p. 3. Courrier des Alpes, 21 novembre 1891, p. 3.

19. Bibliothèque Centrale de l'École Polytechnique, Piot, Louis Joseph, X 1891, 1872-1959.

20. Bibliothèque Centrale de l'École Polytechnique, Piot, Jacques Antoine Joseph, X 1920, 1900-1929.

\section{RÉSUMÉS}

Cet article concerne le phénomène migratoire à l'échelle d'un village de montagne, en Savoie, et des communes alentour. Le territoire est a priori géographiquement enclavé. Malgré tout, des relations ont eu lieu entre les vallées. Comment se sont-elles mises en place? Quels furent les effets de cette situation sur le fonctionnement de la société locale? À partir des registres de matricules déposés aux archives départementales de la Savoie et des sources privées, une étude fut menée sur une cohorte de 977 hommes, représentant pratiquement autant de familles différentes. Mobiles sur le territoire national voire international, ils voyagèrent à l'étranger dans une dimension européenne et intercontinentale. Se déplacèrent-ils toujours seuls ou bien furentils accompagnés par des membres de leur famille, par des femmes et des enfants? 


\section{AUTEUR}

\section{JEAN-MARC VILLERMET}

Professeur d'Histoire-Géographie, docteur en Sciences Humaines, du Politique et du Territoire, associé au laboratoire LLSETI (Langages, Littératures, Sociétés, Études Transfrontalières et Internationales), université Savoie - Mont-Blanc 


\title{
Une race écartelée ? Les enjeux sociaux, économiques et politiques des bovins de Villard-de-Lans (Isère) du milieu du XIX ${ }^{\mathrm{e}}$ siècle à 1914
}

\author{
Gilles Della-Vedova
}

1 Lors de la séance de juillet 1864 au conseil général de l'Isère, le comte d'Agoult, grand notable du pourtour grenoblois, se proposait d'inventer une dénomination en faveur de la race bovine qui était en train d'être reconnue par les autorités du Second Empire. Il déclarait :

[qu'] « en présence de cet attachement aussi vif et aussi persistant à une race dont les éleveurs appréciaient instinctivement tout le mérite; en présence de ce dévouement si naturel, que nous appellerons pro bobus, qui est à nos yeux du véritable patriotisme, la défense généreuse de ses bœufs et de ses champs, on ne peut reconnaitre que de tels sentiments, si bien fondés, méritent une récompense : car c'est à ces dignes montagnards seuls que nous devons la conservation de cette race si précieuse dans toute sa pureté. $»^{1}$

2 L'intérêt de l'extrait est double, à commencer par son auteur. Le comte d'Agoult est dans la position surplombante du notable qui caractérise les sociétés de montagne. Il atteste de la circulation de la modernité, qu'il représente à travers l'emploi à deux reprises en quelques lignes du terme de "race» qu'il oppose aux habitants des montagnes, « dignes » mais se comportant « instinctivement ». De surcroît, la citation joue un jeu d'échelle entre petite et grande patrie et traduit la manière dont les montagnes s'agrègent à l'espace national. L'extrait correspond bien aux objectifs fixés : à travers une étude locale, il s'agit de percevoir l'intégration des campagnes dans un vaste ensemble de circulations économiques, sociales et culturelles, d'en identifier les acteurs et de comprendre les mécanismes du développement à partir du point de vue des sociétés rurales montagnardes.

Le terrain désigné par le comte d'Agoult a été retenu d'une part parce qu'il se situe en altitude. Le canton de Villard-de-Lans correspond à la pointe septentrionale du massif 
du Vercors. Il est organisé autour d'un plateau composé de deux petites vallées longitudinales qui sont à une hauteur d'environ 1000 mètres. Il s'agit donc d'un espace de moyenne montagne "à vache ", ainsi qu'elle est communément qualifiée, celle qui est rapidement expédiée car elle n'est ni tout à fait la vraie montagne, la haute, celle des exploits et des conquêtes, ni tout à fait celle des basses terres car l'altitude la rendrait irrémédiablement différente de celles-ci. D'autre part, le canton de Villard-deLans est distant de Grenoble d'une trentaine à une quarantaine de kilomètres. À partir des années 1880 , le chef-lieu de l'Isère connaît un essor démographique et industriel dans le contexte de la deuxième industrialisation, ce qui conduit à envisager l'élevage dans le cadre de la relation entre l'offre montagnarde en bovins et la demande en nourriture pour le marché urbain.

4 La race bovine de Villard-de-Lans se retrouve au cœur d'enjeux multiples qui permettent de comprendre les dynamiques du développement rural. À propos des acteurs, l'utilisation par l'historiographie de certaines archives fait passer au second plan les éleveurs. Le dépouillement d'autres sources et la méthode prosopographique les font apparaître et montrent que les circulations correspondent à une autre. Ceci peut être abordé de deux manières, d'une part en situant l'histoire de la race dans un jeu d'acteurs multiples, d'autre part en identifiant ces animaux comme des produits d'une société montagnarde en quête de circulations, enfin en dégageant la construction dynamique du développement rural.

\section{Une race au cœur d'un jeu d'acteurs multiples}

5 L'historiographie a depuis longtemps établi combien l'élevage concernait un grand nombre d'intervenants, les pouvoirs publics, des penseurs, comme les Physiocrates pour qui il est une nécessité, et bien d'autres auteurs qui mettent au point un discours surplombant. Ces écrits appartiennent à trois grands groupes d'acteurs.

\section{Des notables promoteurs?}

6 Il est communément admis de faire véritablement débuter l'histoire de la race au début des années 1860. En effet, le 17 novembre 1862, Félix Réal envoyait un mémoire adressé au ministre de l'Agriculture et du commerce afin de réclamer le regard bienveillant de l'administration sur ces animaux, demande accordée l'année suivante et confirmée en 1864. L'affaire est donc entendue : ce sont les notables - Réal en 1862, le comte d'Agoult deux ans plus tard dans l'extrait liminaire - qui ont eu un rôle décisif ${ }^{2}$.

7 Il est certain, premièrement, qu'émergent des figures primordiales. Félix Réal constitue la cheville ouvrière de la race. Sa position s'explique d'abord par sa richesse immobilière. Il vit à Grenoble, mais a des propriétés tout autour du chef-lieu départemental. Son influence est aussi le reflet de sa carrière. Fils de l'ancien conventionnel André Réal, il commence une carrière juridique à Grenoble en 1830 et il est élu député la même année. À Paris, il devient secrétaire général au ministère des Travaux publics, de l'Agriculture et du commerce avant d'intégrer le conseil d'État en 1837. Pour Philippe Vigier, il est le coryphée des conservateurs isérois durant les années $1840^{3}$.

8 Toutefois, plus que la figure du notable au singulier, il faut envisager l'existence d'un groupe social, dont des liens tissés entre eux dans des réseaux permettent aux bovins 
de Villard-de-Lans d'être reconnus par les autorités du Second Empire. C'est le cas de la commission des sept pèlerins qui se rendent dans la montagne autour du berceau de la race, les 8 et 9 octobre 1864 après leur désignation par le préfet, le mois précédent.

L'action de la commission est décisive à deux égards. D'une part, sa composition met en relief les notables qui représentent cinq des six membres désignés par le préfet. Leur origine géographique montre que les uns proviennent des régions de plaines situées en auréole en contrebas du Vercors nord, d'autres sont issus du territoire en question. Il s'agit bien de diffuser la race en la faisant adopter par les autorités voisines. D'autre part, le rapport, rédigé à l'occasion de la venue de la commission, contribue à une transformation de la représentation des montagnes. Ignorées quand les inspecteurs d'agriculture rédigent un tableau de l'agriculture en Isère en 1843, en vue de perfectionner l'agriculture en général dont l'élevage, vingt ans plus tard, les montagnes deviennent un centre qui rayonne, ce que l'on voit avec l'emploi du terme de "foyer » par les auteurs.

10 Par conséquent, les notables sont des acteurs essentiels parce qu'ils décernent la reconnaissance des bovins de Villard-de-Lans. Leur rôle s'articule avec celui des autorités administratives.

\section{Les autorités administratives}

11 Les représentants de l'État participent également à la politique de descente sur les masses de l'amélioration de l'espèce bovine. À nouveau, les animaux de Villard-de-Lans se sont retrouvés ballottés en fonction des fluctuations administratives des différents préfets.

Les considérations qui les animent peuvent être économiques en cherchant à améliorer la qualité du cheptel. Le préfet Pellenc, en place de 1832 à 1847, recherche cet objectif et opère de différentes manières. Il fait dresser un cahier des charges qui, jusqu'en 1837, confie au conseil général le soin de répartir chaque année. À partir de 1838 , ce sont uniquement des taureaux schwitz qui sont importés en Isère. Les grands propriétaires, clients, alliés ou proches des notables du Conseil général sont les premiers livrés. En 1840, Pellenc introduit trois changements : il met en place des vacheries qui comprennent plus d'un animal - environ cinq -, il continue à importer des mâles mais se tourne également vers les femelles, et il tente de réaliser un véritable maillage du département. À la fin de la monarchie de Juillet, de nouvelles inflexions se font jour. Le bétail de Suisse est rejeté en raison de son prix, du fait qu'en trop petit nombre il ne parvient pas à améliorer le cheptel et parce qu'il serait issu d'un milieu géographique finalement trop différent de celui en Isère. Il faut comprendre que les autorités sont à la recherche d'animaux d'un système agricole proche de celui qui existe en Isère où les bêtes servent également pour leur force de travail. C'est pourquoi, à partir de 1851, la race Salers a le vent en poupe, car elle est « élevée dans un pays de montagnes qui a beaucoup d'analogies avec le nôtre", écrit le préfet ChapuysMontlaville dans une circulaire ${ }^{4}$. Dans le même temps, le prix de la saillie baisse de moitié.

À côté de ces préoccupations économiques, les préfets ont également en tête des finalités politiques. En effet, la station d'élevage de la race bovine avait été fondée dans le canton de Villard-de-Lans en 1875. Cette initiative provenait du préfet André qui estimait que l'ardeur des cultivateurs s'était assoupie depuis 1864. Les milieux 
légitimistes s'intéressent de près à la jeune institution puisque la station est présidée par le marquis de Monteynard, issu d'une famille de "catholiques et monarchistes intransigeants", pour citer Pierre Barral ${ }^{5}$. Elle comprend quatre comtes et trois marquis. 18 ans plus tard, le concours spécial départemental de la race bovine de Villard-de-Lans est institué, dans le sillage des manifestations du centenaire de la proclamation de la République et de la républicanisation des campagnes afin de conquérir le suffrage paysan. Le préfet Edmond Robert se trouve chargé de la mise en œuvre des épreuves et si la race de Villard-de-Lans nous est si bien connue c'est parce que les fonds de la préfecture ont gardé des dossiers qui représentent aujourd'hui neuf cartons d'archives.

14 Ces documents permettent de voir que, grâce aux préfets, les vaches du canton font également les notables. En effet, siéger comme jury peut se révéler être un moyen de promotion et des notables s'appuient sur la croupe des bêtes pour se hisser à des postes de responsabilités. Le début de la carrière de Léon Perrier en fournir une illustration. En 1910, il est déjà conseiller général du canton de Bourg-d'Oisans et il tente de s'emparer du siège de député de la troisième circonscription de l'Isère. Cette même année, les services de la préfecture envoient tout spécialement un courrier au ministère de l'Agriculture afin d'obtenir son placement en tant que jury chargé du premier groupe des taureaux, c'est-à-dire à la place la plus stratégique dans le concours spécial. Son nom doit donc être diffusé, car il figure dans les catalogues des exposants, pour lesquels il faudrait cependant préciser à partir de quel moment ils sont diffusés au sein de la population. Les élections se déroulèrent trois semaines avant le concours spécial et Méaudre, la commune la plus engagée dans le perfectionnement des bovins, lui offre le score le plus élevé du canton, supérieur à la moyenne de l'arrondissement. Quatre ans plus tard, après avoir siégé quatre années dans le jury des taureaux, sur les cinq candidats, Léon Pérrier obtient la majorité absolue dans toutes les communes du canton et jusqu'à plus de $72 \%$ à Méaudre.

15 Ainsi, les bovins sont écartelés entre les différents courants politiques qui, dans un régime de suffrage universel masculin, tentent de capter l'électorat à leur profit. Toutefois, pour être crédibles, les notables ont besoin de l'aide scientifique amenée par des techniciens.

\section{Les velléités des techniciens}

16 Ces derniers, experts du thème de l'élevage recrutent dans différents milieux : en particulier chez les vétérinaires mais également, avec l'essor des services de l'État chargés des questions agricoles, parmi les professeurs d'agriculture. À nouveau, les bovins du canton se trouvent au croisement de plusieurs considérations. Les unes sont techniques. Elles voient au milieu du siècle un changement de paradigme. Au croisement des variétés qui favorisaient les circulations montagnardes avec l'importation de reproducteurs de Suisse ou dans le Massif central, l'apparition des races est contemporaine d'une recherche du perfectionnement animal par sélection. Cette transformation apparaît également dans le rapport de la commission qui se rend dans le canton de Villard-de-Lans en 1864. En effet, du 14 au 24 mai, vient de se dérouler le concours régional de Grenoble. À la suite de cet événement, l'inspecteur général de l'Agriculture Rendu rédige un rapport très défavorable aux animaux de Villard-de-Lans, notamment en leur déniant la notion de race. Par conséquent, la commission doit avoir connaissance de ce texte ou de sa teneur. Elle prend son temps 
pour argumenter et justifier, et utilise à ces fins l'expertise d'Eugène Tisserand (1816-1888) qui enseigne à l'école vétérinaire de Lyon, lequel a rédigé de nombreux ouvrages agricoles dont un sur l'élevage six ans plus tôt. C'est lui qui établit l'expertise scientifique que les notables ont à contresigner pour emporter l'adhésion de l'autorité administrative.

17 La présentation des trois types d'acteurs régulièrement convoqués par l'historiographie montre qu'il est réducteur d'opposer les agents de l'État et ses alliés face à ceux qui composent les sociétés locales. Cela revient, en effet, à oublier le rôle des notables qui ont un pied dans chaque milieu. De plus, il est préférable d'envisager des réseaux avec, par exemple, des effets de générations, plutôt que des groupes faussement homogènes. Cependant, cette perception a l'inconvénient d'abonder dans une conception du développement qui ne pourrait que descendre sur les masses rurales routinières. Tout compte fait, n'est-ce pas ce que, de manière paradoxale, le comte d'Agoult reconnaissait aux habitants du canton : c'est parce qu'ils ont été routiniers que, grâce à l'intervention de l'État, de ses notables et du nouveau savoir scientifique des techniciens que le handicap est devenu un atout. Cette interprétation n'est-elle pas hémiplégique?

\section{Une race venue d'en bas (socialement), c'est-à-dire d'en haut (géographiquement)}

18 Les animaux de Villard-de-Lans n'ont pas attendu l'onction de cette trinité pour faire l'objet de circulations avant l'âge industriel. Ils ne résultent pas de l'action d'un homme ou même d'un petit groupe. L'approche doit être collective et les sociétés rurales locales vont alors retrouver toute leur place dans la compréhension de l'évolution du développement, ce qui peut être tenté selon trois approches.

\section{La chronologie à reconsidérer}

Premièrement, il y a un enjeu chronologique. En retenant la date de 1864 comme repère donc comme référence dans l'histoire de la race, l'action des notables et des autorités parait plus importante que celle des cultivateurs. Elle met en avant l'initiative d'individus singuliers au détriment des collectifs et livre, par conséquent, une analyse conforme à la pensée agrarienne ${ }^{6}$.

Les recherches effectuées concordent avec celles de Philippe Grandcoing. Pour l'historien de la race limousine, en effet, la première moitié du XIX siècle doit être réévaluée, car à en pleine époque du modèle anglais de la durham, s'amorce :

«L'abandon de l'engraissement au profit de la production de jeunes animaux et par

la féminisation du cheptel. $»^{7}$

21 Le modèle promu par la société industrielle du bœuf gras ne saurait effacer une autre forme de connaissance, collective et populaire fondée autour d'autres critères. Avec Annie Antoine, il est préférable de dire que si :

«La question de la race ne se pose pas vraiment aux éleveurs », [cela ne veut pas

dire] « qu'ils ne différenciaient pas leurs animaux et qu'ils ne préfèrent pas telles caractéristiques à telles autres. $»^{8}$

Dans l'espace de moyenne montagne du Vercors nord, la situation semble assez proche de celles d'autres parties du territoire français. En effet, il est possible d'envisager des 
transformations. D'une part, elles sont quantitatives. Dans le territoire qui correspond aujourd'hui au massif du Vercors, Jules Blache relève des progrès dans la fonction pastorale entre les «montagnes de Lans » des territoires au sud de la rivière la Bourne en 1748. Ces derniers ne comprendraient que 200 bovins tandis que les premières monteraient à un effectif de 863. Le rapport homme/animal est d'un à quinze au sud de la Bourne à un à trois au nord de celle-ci. La statistique de 1809 montre une hausse de l'effectif puisque l'on passe à près de 2000 bovins soit un animal pour deux hommes. À la fin de la Deuxième République, le cheptel dépasse les 3500 têtes.

D'autre part, les transformations sont également qualitatives ce dont le rapport de 1864 porte témoignage. En effet, il ne dénombre que 130 bœufs dans le canton ce qui, comme dans le Limousin, prouve une féminisation du cheptel. Bien entendu, les vaches du lait dont les produits alimentent depuis longtemps les marchés. Le fromage dit «de Sassenage " tient son nom du lieu d'exportation et pas celui de sa production. La capacité laitière est liée avec la gestion des veaux qui sont enlevés très jeunes à la mère pour alimenter le marché en viande et pour profiter de la lactation. Les circulations en veaux sont très importantes dans l'économie locale et même à l'échelle départementale. En 1859, une pétition initiée probablement par la boucherie grenobloise et à laquelle une partie des cultivateurs du canton appose sa signature dénonce un maximum des prix fixé par l'administration municipale. Cela limite les exportations alors que les habitants ont «la facilité d'engraisser leurs bestiaux ${ }^{9}$. De plus, cela détourne les meilleures bêtes qui fournissent le marché lyonnais au détriment du chef-lieu du département. De surcroît, les femelles sont également utilisées pour leur force musculaire dans les travaux des champs, pour l'exploitation et les circulations des bois qui circulent des forêts vers la vallée de l'Isère.

Ainsi, il y a bien un enjeu autour de la chronologie, car 1864 masque une initiative collective qui, en amont, provient également des exploitants montagnards. Par conséquent, toute histoire des circulations bovines de montagnes ne peut se dispenser d'étudier les exploitants c'est-à-dire de procéder à une analyse économique et sociale.

\section{Une race portée par la petite exploitation}

Puisqu'avec Philippe Grandcoing, il convient de souligner «l'empirisme paysan », il est nécessaire d'aller à la rencontre de ces derniers ${ }^{10}$. Or, trop souvent, les petits exploitants sont un point aveugle de la recherche, même chez ce dernier.

Il faut bien reconnaître que l'aubaine extraordinaire du chercheur. C'est ainsi qu'il faut qualifier la cinquantaine de pages d'indications écrites par Louis Mure-Ravaud (vers 1777-1860) de la Restauration au début du Second Empire et qui reposent dans des archives privées. Il habite un hameau en hauteur du bourg centre de Villard-de-Lans et détient une propriété de 9,1 hectares lors de la confection de la matrice cadastrale en 1834. Le document l'identifie comme "voiturier ", alors qu'il est également cultivateur. Ses deux carnets montrent un homme inséré aux circulations montagnardes. Il fabrique et vend principalement des produits laitiers - fromages et beurre - ainsi que des veaux qu'il livre au marché dans la vallée proche. À l'évidence, ce sont ses déplacements qui le font vivre, à la fois pour ce qu'il exporte et pour ce qu'il importe, $\mathrm{du}$ sel mais également du trèfle. La mention de ces produits montre que le développement est bien lié au commerce des produits issus de l'élevage. Son cas, exceptionnel par l'archive conservée mais peut-être normal parce qu'il ressemblerait à 
de nombreux autres individus moins finement connus, nous conduit à avancer l'hypothèse que l'élaboration de la race bovine de Villard-de-Lans est portée par des hommes comme lui. En effet, ce sont tous ces cultivateurs qui, loin d'être immobiles, circulent incessamment en direction de la plaine, soit directement, soit indirectement grâce à un fils. Ils sont donc sensibles au renforcement de la demande en viande et en produits laitiers quand l'essor démographique devient plus prononcé. De surcroît, durant la première moitié du XIX siècle, des mutations dans la consommation des habitants se produisent puisque la part de la viande ovine et porcine baisse tandis que celle d'origine bovine croît.

La race de Villard-de-Lans ne résulte donc pas d'une injonction de la société globale au milieu du xIx ${ }^{e}$ siècle, mais de la perception locale, celle de simples cultivateurs ou guère mieux, au moins un demi-siècle plus tôt.

Les petites exploitations qu'ils dirigent sont dynamiques. Elles apparaissent lors de la confection des matrices cadastrales dans les premières années de la monarchie de Juillet. Si l'on considère que la très petite propriété va jusqu'à quatre hectares, que la petite lui succède jusqu'à dix hectares, avant que la moyenne prenne le relais jusqu'à 30 hectares, $57 \%$ des cotes relevaient de la première, 22,4 de la deuxième et $15,9 \%$ de la troisième; la grande propriété privée représentait moins de $5 \%$ des cotes. Près de 80 ans plus tard, la première catégorie s'est tassée mais elle représente encore la moitié des cotes. La part de la petite propriété reste constante tandis que la moyenne propriété s'accroît de $5 \%$, surtout dans la tranche inférieure. Ainsi, l'essor de la circulation de la race de Villard-de-Lans et de ses produits permet de maintenir la vitalité du canton qui se perçoit même dans une baisse démographique moins importante que dans d'autres secteurs des montagnes iséroises ou du massif du Vercors.

Toutefois, envisager uniquement la vache de Villard-de-Lans dans sa finalité économique reviendrait à trop suivre les rails de la seule rentabilité économiquement mesurable. Elle sert aussi de tremplin social et politique à l'échelle locale.

\section{Des vaches tremplins?}

30 Une expression latine médiévale qualifiait de vaccipotentes ceux dont la force sociale est associée aux vaches. Elle peut être reprise pour qualifier un groupe d'hommes parmi lesquels différentes trajectoires se dessinent.

Il y a ceux dont la possession de vaches et leur présentation au concours spécial participent à une petite notabilité locale. Élie Chabert (né en 1853) fait partie d'eux. Il est issu d'une puissante famille locale dont la fortune est d'abord liée à la circulation des bois et d'autres marchandises, dans les deux directions, entre le plateau et la vallée. Certains de ses membres se retrouvent à la tête de différentes municipalités du canton de la Restauration au Second Empire. C'est donc tout naturellement qu'Élie Chabert, propriétaire d'environ dix hectares, est élu à chaque reprise maire entre 1888 et 1904. Cette fonction le désigne comme délégué de Méaudre. Sa fonction de maire doit l'inciter à utiliser un de ses plus beaux prés comme terrain d'expérience pour des travaux de drainage, sous l'impulsion des services de l'État en vue d'améliorer la qualité des ressources fourragères. De même, il se doit d'être inscrit au concours spécial et pas seulement pour faire de la figuration. Il doit incarner l'excellence, d'où sa présence à sept reprises dans les palmarès sur 18 candidatures entre 1893 et 1903. Ainsi, les vaches 
sont l'un des attributs qu'il partage avec ses concitoyens mais qu'il doit porter haut et fort du fait de sa désignation par les nombreuses familles qui, comme cela a déjà été indiqué, font reposer leur développement sur les circulations de la race bovine de Villard-de-Lans.

Avec Zacharie Faure, les vaches servent de faire-valoir. Il est l'un des grands promoteurs de la race puisque son nom apparait comme participants dans différents concours régionaux éloignés de Grenoble ; il est même primé à l'Exposition universelle de Paris en 1889. Il est cependant atypique, car il relève de la tranche supérieure de la moyenne propriété : il possède autour de 26 hectares en 1896 et s'agrandirait encore de cinq hectares à la veille de la Grande Guerre. Mais être un grand propriétaire ne lui permet pas de diriger la mairie d'Autrans. En effet, l'étable de 25 animaux qu'il entretient ne fait pas le poids face à l'auberge de son concurrent Jean-Pierre Faure. Il échoue à plusieurs reprises pour administrer la commune. Le notable d'envergure nationale, l'opportuniste Durand Savoyat, dans sa conquête d'Autrans, cherche à s'appuyer sur l'élevage. Il s'était même inscrit la première année du concours spécial. Dans le même ordre d'idée, il s'appuie sur Zacharie Faure, républicain d'occasion, pour lui faire obtenir le Mérite agricole dès 1887, ce qui est chose faite en 1896. Sans dénier les mérites de cet éleveur primé à de nombreuses occasions lors du concours spécial, les $46 \%$ d'animaux récompensés sur 57 déclarations pourraient également s'expliquer, à mérites égaux, par la volonté de mettre en avant les vaches républicaines par rapport aux « bêtes réactionnaires et bien pensantes " ${ }^{11}$.

Enfin, d'autres figures montrent que l'excellence bovine permet de décrocher l'excellence électorale locale. C'est le cas d'Adrien Léon Barnier. Il est propriétaire de la même superficie qu'Élie Chabert et fait donc partie de la tranche supérieure de la petite propriété. Mais ses origines familiales paraissent plus obscures. Comme Zacharie Faure, il est également récompensé à l'échelle nationale puisqu'il obtient le premier prix au Concours général de Paris en 1892 pour le centenaire de la République. Il fait passer des réclames dans la presse agricole spécialisée du département afin de promouvoir la circulation de la race. Dans le prolongement de ses succès dans les concours, il affronte dans les urnes Élie Chabert, l'homme des forces sociales traditionnelles. Il parvient à entrer au conseil municipal en 1900, puis à l'emporter péniblement pour devenir maire de Méaudre en 1908. Durant ces années, sur 68 déclarations faites entre 1903 et 1911, 49 sont primées $(72 \%)$. Ainsi, les bovins servent à assurer une renommée auprès des petits cultivateurs comme lui, qui peut se transformer en succès dans les urnes.

La race de Villard-de-Lans est bien écartelée dans la mesure où la vision par en haut, par les notables et par les études zoologiques au milieu du XIX ${ }^{e}$ siècle, est à compléter par celle venue du bas de la société et qui lui est antérieure probablement d'un siècle. Les montagnards promeuvent les bovins pour la triple aptitude (travail, viande, lait) en vue d'assurer leur développement. Il s'agit de renforcer la renommée de leurs bêtes pour en faciliter le commerce et en écouler les produits tout en les utilisant dans le cadre de leurs petites propriétés et pour les autres activités du système sylvo-pastoral du nord du massif du Vercors. La finalité économique n'est pas la seule clef de lecture.

Toutefois, l'écartèlement décisif n'est-il pas celui du temps? En effet, tout le monde se retrouvait autour des animaux de Villard-de-Lans, car ils étaient le fruit d'un équilibre socio-économique et technique qui, par définition, est amené à se transformer. Plutôt que de parler de déclin, ne faut-il pas envisager un changement de configuration qui fait que l'accord qui s'était créé se délite progressivement? 
Après la reconnaissance de la race, trois périodes se sont succédé. La première est celle du temps de la récupération. Le rapport de 1864 entraîne la décision du conseil général d'acquérir des reproducteurs issus du canton pour les disperser dans le département. Les autorités profitent donc des efforts collectifs largement diffusés dans les populations locales. Avec la station d'élevage de 1875 puis les débuts du concours départemental, c'est le temps de la collaboration. Les animaux participent aux concours régionaux, ils bénéficient d'une manifestation qui leur est consacrée. Mais chacun des deux partenaires a son idée en tête. Pour les éleveurs, le concours est un moyen d'accroître la renommée, d'élargir les ventes d'animaux comme cela se déroulait jusqu'alors. Pour les autorités, la triple aptitude, bien que toujours revendiquée, s'estompe progressivement devant une spécialisation laitière qui est de plus en plus manifeste dans les rapports et les discours des autorités. L'âge industriel impose une autre logique, liée aux évolutions zootechniques, qui décerne les primes à partir de l'observation de points déterminés. Les animaux sont mesurés de manière mathématique avec des coefficients différents.

L'ensemble des catégories sont évaluées de la sorte à partir de 1907 et la note de l'animal est calculée à partir de la moyenne des différents jurys. C'est le début du temps du délitement qui s'explique par une double délégitimation des cultivateurs. La première est la rupture d'un consensus autour du jugé et des caractéristiques partagées par tous comme dans la méthode Guénon. En 1904, le professeur départemental d'agriculture Rouault avait expliqué que pour séparer la race du Mézenc de celle de Villard-de-Lans, la teinte du pelage est secondaire alors qu'il avait souligné par ailleurs que chez les exposants c'était une question déterminante. La deuxième délégitimation est donc le fait de passer d'un concours où le classement importait à un examen où le palmarès était par ordre alphabétique! Sur la courbe de l'évolution du nombre d'éleveurs, c'est à partir de 1907 que le nombre d'exposants domiciliés dans le canton décroche. Cette césure préfigure une période de maintien de la race avant que celle-ci ne perde les subventions du gouvernement en 1946 et entre en déclin durant les «Trente Glorieuses ».

Ainsi, étudier les circulations de montagnes à partir des sociétés rurales locales permet d'envisager le développement comme une tension toujours en équilibre entre des perspectives à des échelles emboîtées et pour des finalités croisées.

\section{BIBLIOGRAPHIE}

ANTOINE Annie, «L'élevage en France (XVII ${ }^{\mathrm{e}}$-XVIII ${ }^{\mathrm{e}}$ siècles) », dans Association des historiens modernistes des universités, La terre et les paysans. Productions et exploitations agricoles aux XVII et $\mathrm{XVIII}^{e}$ siècles en France et en Angleterre, Paris, Presses de l'université Paris-Sorbonne, 1999, p. 7-60. BARRAL Pierre, Le département de l'Isère sous la Troisième République, 1870-1940. Histoire sociale et politique, Paris, Librairie Armand Colin, 1962.

BARRAL Pierre, Les agrariens français de Méline à Pisani, Paris, Armand Colin, 1968. 
CHEVALLIER Denis (dir.), Le temps des villardes, une race bovine des montagnes, Lyon, Parc naturel du Vercors/La Manufacture, 1986.

GRANDCOING Philippe, «Comment naît une race ? La race bovine limousine dans la première moitié du XIX siècle ", dans Histoire et Société Rurales, nº 20, 2003, p. 121-146.

REYNAUD Florian, L'élevage bovin. De l'agronome au paysan (1700-1850), Rennes, Presses universitaires de Rennes, 2009.

VIGIER Philippe, La Seconde République dans la région alpine. Étude politique et sociale, Paris, Presses universitaires de France, 1963, 2 vol.

\section{NOTES}

1. Archives départementales de l'Isère, PER 1499/7, Sud-Est, $\mathrm{n}^{\circ} 19$, juillet 1864, Société d'agriculture et d'horticulture de l'arrondissement de Grenoble, «Race bovine du Villard de Lans ", p. 850.

2. Pour Denis Chevallier, qui écrit un ouvrage entièrement consacré à la "villarde ", " ce n'est qu'à ce moment-là [seconde moitié du XIX siècle] que l'on peut parler d'une véritable civilisation de la vache ». Voir D. Chevallier (dir.), Le temps des villardes, une race bovine des montagnes, p. 13.

3. P. Vigier, La Seconde République dans la région alpine. Étude politique et sociale.

4. Archives départementales de l'Isère, PER2 437/17, Recueil des actes administratifs de la préfecture et du département de l'Isère, $1851, \mathrm{n}^{\circ}$ 4, p. 36.

5. P. Barral, Le département de l'Isère sous la Troisième République, 1870-1940. Histoire sociale et politique, p. 489.

6. P. Barral, Les agrariens français de Méline à Pisani.

7. P. Grandcoing, « Comment naît une race ? La race bovine limousine dans la première moitié du XIX siècle », p 121.

8. A. Antoine, « L'élevage en France (xVII ${ }^{\mathrm{e}} \mathrm{XVIII}{ }^{\mathrm{e}}$ siècles) », p. 27.

9. Archives municipales de Grenoble, 3F20. Race bovine de Villard-de-Lans : Création et promotion de cette race 1859-1893.

10. P. Grandcoing, Ibid., p. 121.

11. Archives départementales de l'Isère, $29 \mathrm{M} 26$ « Zacharie Faure ». Extrait d'une lettre d'Émile Durand-Savoyat au préfet le 9 août 1887.

\section{RÉSUMÉS}

Dans la seconde moitié du XIX ${ }^{\mathrm{e}}$ siècle, la promotion de l'élevage passe par des races de montagnes destinées à se répandre dans les massifs et à alimenter les marchés urbains. Elles sont un enjeu de pouvoir de la part des agrariens que sont les notables républicains et les techniciens de 
l'agriculture qui cherchent à imposer les cadres de pensée de l'économie capitaliste de l'âge industriel. Dans le canton de Villard-de-Lans, la recherche de la spécialisation laitière se heurte aux logiques davantage diversifiées des cultivateurs qui veulent demeurer un centre et ne pas être réduits à une périphérie. Les relations avec la ville sont tempérées par celles avec d'autres espaces ruraux. À l'articulation des archives de la préfecture, du dépouillement d'une revue spécialisée et de l'utilisation d'une base de données fondée sur l'état civil, les recensements et les cadastres, il s'agira de mettre au jour ce que les circulations entraînent comme enjeux sociaux, économiques et politiques.

\section{AUTEUR}

\section{GILLES DELLA-VEDOVA}

Professeur en CPGE, lycée du Parc (Lyon), chercheur associé au Laboratoire d'études rurales (université Lumière-Lyon II) 
Aujourd'hui 


\title{
Encadrer la coutume migratoire : l'exemple de la transhumance pyrénéenne dans la première moitié du $\mathrm{XX}^{\mathrm{e}}$ siècle
}

\author{
Henri Pinoteau
}

1 Circulation montagnarde entre toutes, la transhumance est indissociable dans l'esprit général du paysage montagnard, même si elle n'a plus l'ampleur d'autrefois. Par commodité de langage, nous parlerons ici de «transhumance» pour tout type de circulation de troupeau, qu'elle se fasse au sein même d'une montagne ou entre une plaine et une montagne, sans distinction donc entre transhumance proprement dite et estivage. Pour une période très longue, la transhumance est difficile à quantifier de façon systématique. Elle se réglait alors par l'oral et des contrats privés ${ }^{1}$, et peu à peu par des contrats passés entre des entités plus vastes : entre communes, entre syndics, et bien sûr entre vallées. C'est le cas dans les Pyrénées avec les lies et passeries, les facerias, et autres cartas de pax. On en trouve aussi des traces dans l'activité judiciaire, car l'existence d'accords n'empêchait pas toujours les conflits, parfois très violents dans ces régions où l'élevage est un enjeu économique majeur². Pendant des siècles, les États n'intervinrent pour ainsi dire pas, en tout cas pas dans la gestion quotidienne ni même annuelle, et cet état de fait ne changea que très progressivement ${ }^{3}$. D'ailleurs, on ne trouve que peu d'éléments à ce sujet dans les archives de l'État avant la seconde moitié du XIX ${ }^{e}$ siècle. La commission des Pyrénées changea la donne avec les traités des limites de 1856 et 1858 . Les questions pastorales y étaient abordées, mais avant tout sous un angle frontalier.

De tout cela, on trouve des traces en archives départementales, dans les séries des Eaux et Forêts, des intendances, des administrations préfectorales, ou encore de la justice ; aux Archives nationales, en séries et sous-séries A, F/7, F/10, F/12, entre autres; les archives du ministère des Affaires étrangères sont également une source précieuse $\mathrm{e}^{4}$. 
On constate néanmoins que durant la première moitié $\mathrm{du} \mathrm{xx}^{\mathrm{e}}$ siècle, le pouvoir central s'est peu à peu approprié cette question. Nous nous proposons d'aborder cette forme de circulation du point de vue du ministère de l'Agriculture, pour y montrer l'ingérence progressive de l'État à partir de la fin du XIX ${ }^{e}$ siècle. Nous nous baserons pour cela sur un petit corpus tiré de la sous-série F/10 (Agriculture) des Archives nationales. Précisons d'emblée que les archives du ministère de l'Agriculture ont subi divers avatars au cours de la première moitié $\mathrm{du} \mathrm{xx}^{\mathrm{e}}$ siècle, ce qui rend la documentation disponible aujourd'hui probablement partielle et incomplète. Une dizaine d'articles cotés $\mathrm{F} / 10 / 5464$ à $\mathrm{F} / 10 / 5475$ permettent néanmoins d'avoir une idée de la façon dont le ministère de l'Agriculture a géré la transhumance à l'époque considérée, de préciser la connaissance qu'il en pouvait avoir, et les buts poursuivis par le gouvernement à cette époque, en nous concentrant sur la zone pyrénéenne. Se posent les questions de la réglementation d'une pratique coutumière, de la logistique mise en œuvre comme des influences politiques soulevées par ces enjeux agro-pastoraux. Nous finirons par un exemple d'incident diplomatique pastoral, en Navarre en 1921, qui concentre tous les problèmes que pouvait poser la transhumance transfrontalière.

\section{La progressive mise en place d'un encadrement juridique}

4 Après des siècles de relative indifférence, on constate à la fin du XIX ${ }^{\mathrm{e}}$ siècle et au début $\mathrm{du} \mathrm{xx}^{\mathrm{e}}$ la multiplication d'accords internationaux entre la France et les différents États frontaliers relatifs à la transhumance et aux conditions dans lesquelles elle doit s'exercer dans les zones frontalières. Il se trouve qu'environ $60 \%$ des frontières françaises sont montagnardes, donc bien souvent lieux de pacage que la frontière administrative ne partage pas en deux moitiés absolument étanches. La gestion des frontières, et en particulier des circulations internationales, doit comprendre celle de mouvements de bétail et la cohabitation en un même lieu de troupeaux de nationalité distincte, mouvements et cohabitation qui sont immémoriaux alors que les frontières internationales ont grandement évolué ${ }^{5}$.

\section{Légiférer et réglementer}

5 Ces accords internationaux prennent le nom de conventions ou d'arrangements. En France, ils sont publiés sous la forme de décrets qui livrent la teneur intégrale de ces conventions. Le décret lui-même est signé par le président de la République, sur proposition du président du Conseil, du ministre des Affaires étrangères, et du ministre de l'Agriculture. On retrouve donc là la double problématique internationale et pastorale. Parfois, certains accords mentionnent le nom des plénipotentiaires signataires au nom de leurs gouvernements respectifs. Ainsi, pour la convention du 31 mai 1929 entre la France et l'Italie, les représentants français sont M. Lesage, directeur de l'agriculture au ministère de l'Agriculture, et M. Leclainche, inspecteur général des écoles vétérinaires, chef des services vétérinaires au même ministère ; du côté italien, les représentants du roi sont $\mathrm{M}$. Bisanti, chef du service zooïatrique du ministère royal de l'Intérieur, et $\mathrm{M}$. Ballerini, conseiller commercial à l'ambassade d'Italie à Paris ${ }^{6}$. On constate en l'occurrence que du côté français, l'Agriculture prend le pas sur les Affaires étrangères. 
6 Le texte de ces accords règle les questions de transit de bétail sur pied ou abattu, et parfois des deux à la fois. Il met l'accent sur la sûreté sanitaire et confie aux vétérinaires la responsabilité de l'examen des animaux ou de la viande. Ces opérations de contrôle se font dans des bureaux de douane définis, et le bétail est soumis à un certificat de santé et d'origine. Certaines publications de décrets comprennent en annexe des modèles de certificat où l'on retrouve des données d'origine de l'animal commune, propriétaire -, de signalement et de renseignements sur l'expéditeur et le destinataire. Selon les lieux et les époques, le propriétaire peut avoir à fournir un état signalétique des animaux qu'il souhaite faire transhumer dans une zone transfrontalière, avec des indications aussi précises que l'espèce, le sexe, la race, la robe, l'âge voire le poids de chaque bête ${ }^{7}$. Rétrospectivement, il s'agit bien d'une question de traçabilité de la viande et du bétail. Les frontières peuvent leur être fermées à tout moment en cas de problème sanitaire dans une commune où paît un troupeau ou d'où provient la viande, ainsi que dans les communes limitrophes. Il est prévu des cas de dérogation exceptionnelle à une telle fermeture, dérogation octroyée par le préfet ou son homologue étranger. Il faut enfin noter que les retours dans le pays d'origine sont aussi contrôlés que les sorties : un certificat du maire de la commune où a pacagé un troupeau est nécessaire lors du passage de la frontière. Enfin, le ministre de l'Agriculture a la faculté de prendre des arrêtés pour interdire provisoirement, par dérogation aux accords internationaux en vigueur, le pacage et l'hivernage de telle espèce en provenance de tel pays ${ }^{8}$. Un autre arrêté ministériel y met fin quand la situation le permet.

7 On voit donc que, succédant à la coutume, se met en place un système de contrôle des mouvements internationaux à deux échelons : échelon ministériel pour les accords généraux avec des puissances étrangères ou des décisions de fermeture ponctuelle, et échelon préfectoral pour des questions plus locales et la gestion des bureaux de douanes.

\section{Pourquoi légiférer?}

8 Pourquoi mettre en place un tel encadrement de ces mouvements animaux ? La raison sanitaire est évidemment celle qui transparaît immédiatement dans chaque document. À une époque où la vaccination, malgré ses progrès, est loin d'être systématique, les risques épizootiques sont grands et fréquents; le principal moyen de lutte reste alors le contrôle soigneux des troupeaux et l'isolement des sujets atteints. Dans ce but, au ministère de l'Agriculture, la direction des services sanitaires et scientifiques et de la répression des fraudes tient à jour un bulletin sanitaire hebdomadaire, listant par maladie et par département le nombre d'animaux atteints, ce qui permet au ministère d'avoir une idée précise de la situation sanitaire française presque au jour le jour. On surveille ainsi les foyers de péripneumonie contagieuse, de dourine, de rage, de charbon symptomatique, de tuberculose ${ }^{9}$. Les accords internationaux citent également parmi d'autres la peste bovine, la morve, la fièvre aphteuse, la clavelée, ou encore la gale. La liste des épizooties est longue, et la fréquence des fermetures temporaires de frontière ainsi que les précautions prises pour tout animal passant une frontière, attestent du poids de la question vétérinaire dans la réglementation progressive des mouvements de transhumance. 
9 Sur ce dernier point, il est intéressant de noter que les documents officiels mentionnent textuellement des institutions aussi anciennes que les faceries. Ainsi cet accord fixant l'interprétation des traités de délimitation franco-espagnols pour les droits et privilèges des frontaliers, signé en 1899, qui mentionne dans son article 1 :

«Les frontaliers qui ont le droit d'aller faire pacager leurs troupeaux sur les territoires de l'État voisin, en vertu de contrat de facérie [sic], doivent se munir d'un acquit à caution $[. ..] »^{10}$

\section{De la logistique à la politique étrangère}

\section{Les dispositions à prendre sur le terrain}

Mettre en œuvre une telle politique de contrôle des mouvements de bétail suppose une certaine connaissance des particularismes locaux, dont les Pyrénées sont bien sûr représentatives. On trouve ainsi régulièrement dans les archives du ministère de l'Agriculture des cartes annotées qui tendent à montrer aux services centraux ce que les cartes administratives ne peuvent figurer. Tantôt cartes d'état-major, tantôt cartes levées à la main, elles permettent de figurer les zones de pacage transfrontalières, les itinéraires de bestiaux, ou encore les zones atteintes par une épizootie ou à vacciner. On en trouve ainsi pour des zones aussi complexes que la vallée des Aldudes, que certains troupeaux espagnols doivent traverser de part en part pour passer de Baztan à Valcarlos. Les Douanes ont ainsi délimité soigneusement l'itinéraire que doivent suivre les troupeaux espagnols, qui ne doivent pas s'en écarter et ne pas partager les mêmes points d'eau que des troupeaux français, pour éviter tout contact ${ }^{11}$. Cette même vallée est aussi limitrophe du Pays-Quint au statut international si particulier.

11 Les acteurs sur le terrain de ce contrôle des trafics sont les vétérinaires. Ceux-ci sont parfois des vétérinaires départementaux, éventuellement attachés à un bureau de douane donné ; si un bureau de douane n'a pas de service d'inspection vétérinaire, le ministère de l'Agriculture désigne un vétérinaire travaillant à son compte pour ce faire ${ }^{12}$. On trouve donc dans les dossiers du ministère un certain nombre de documents traitant la question du recrutement de ces indispensables agents. Des questions très concrètes se posent au ministère : qui doit payer le vétérinaire ? Est-ce l'État ou le propriétaire des bestiaux inspectés? Où doit se faire le contrôle quand le poste de douane est mal situé ou en mauvais état?

L'examen des dossiers montre que chaque situation est particulière et dépend du terrain; les avis du préfet et des Douanes sont alors primordiaux pour trancher. Les listes établies par les directions des services vétérinaires montrent qu'il n'y a pas un vétérinaire par poste de douane, mais que les vétérinaires se répartissent la frontière en fonction de leur lieu de résidence. Par ailleurs, il faut souligner que les visites se font à des dates prévues, ainsi que le stipulent les accords internationaux ${ }^{13}$, ce qui suppose que les propriétaires doivent se renseigner pour connaître les dates arrêtées par les préfets et publiées par voie d'affichage. Ces dates, assez peu nombreuses, font en sorte que les vétérinaires n'aient pas à se déplacer tous les jours, ce qui contraint les bergers à respecter un calendrier précis. Cela n'est pas sans poser problème en certains lieux où les bergers ont coutume de redescendre depuis bien longtemps leurs troupeaux à des dates très variables, comme le fait remarquer en 1927 M. Bouchet, président du syndicat du Pays de Soule ${ }^{14}$. 
13 Les vétérinaires mettent en œuvre les décisions ministérielles et préfectorales par des visites de troupeaux, des opérations de marquage ou tatouage ${ }^{15}$, de vaccination et parfois d'abattage lorsqu'il est ordonné en cas de maladie ${ }^{16}$. Ils permettent aussi de fournir des statistiques au ministère qui tient à connaître le nombre d'animaux transhumants par espèce et par département.

\section{Des réclamations à tous les niveaux}

14 Alors que le gouvernement français tente ainsi petit à petit de contrôler ces mouvements, avec un succès délicat à estimer avec la seule documentation du ministère, les mesures prises contrarient nécessairement les intérêts de certains propriétaires. On trouve ainsi un certain nombre de réclamations adressées à l'État, avec des origines variables. Certaines de ces demandes émanent par exemple de simples particuliers, parfois seuls et parfois en groupe : ainsi en 1945, ce groupe de vingt-cinq propriétaires espagnols de la frontière basque qui demande à la direction des douanes à Bayonne l'autorisation d'introduire leurs troupeaux sur des pacages français ${ }^{17}$. La demande est d'ailleurs appuyée par Jean Etcheverry-Aïnchart, député des Basses-Pyrénées à l'Assemblée nationale constituante, qui rappelle qu'il s'agit :

«De bergers espagnols de la vallée d'Aezkoa qui viennent en France avec leurs

troupeaux pour les pacages d'hiver, conformément à un usage immémorial. ${ }^{18}$

Le député insiste pour que leur demande soit acceptée sous peine de remettre en cause les traités internationaux de 1856 et $1858^{19}$. Il arrive également qu'un propriétaire étranger s'adresse directement au ministre de l'Agriculture pour une demande exceptionnelle. Dans ce cas, si le ministre donne son accord, il en prévient le préfet du département concerné et soumet la demande aux conditions habituelles de visite et de vaccination $^{20}$. D'autres demandes sont relayées par les conseils généraux, par exemple pour éviter des visites vétérinaires systématiques, ou pour être autorisés à rembourser une partie des frais vétérinaires sur leur budget ${ }^{21}$. Il est aussi arrivé que le ministère de l'Agriculture soit saisi par une instance aussi importante que le Syndic général des Vallées d'Andorre pour demander le pacage exceptionnel de bovins andorrans en France $^{22}$.

\section{Les influences de la politique étrangère}

Outre ces demandes relativement ponctuelles quant à leurs conséquences, il existe aussi des cas où la politique étrangère ou du moins des événements étrangers ont eu des retombées sur les questions pastorales. Ce fait est particulièrement net avec l'Espagne. En 1946, la frontière franco-espagnole avait été fermée, ce qui posait la question de la continuité ou non de la transhumance. Le ministère des Affaires étrangères, saisi par celui de l'Agriculture, lui répondit que cette fermeture n'entraînait pas pour autant l'interdiction pour les bergers espagnols de la région de Llívia de venir pacager en France, pourvu que ce fût réciproque ${ }^{23}$.

17 La guerre civile espagnole avait déjà eu des répercussions dans les années 1930. En 1936, les Andorrans, dont une bonne partie des ressources venait de la vente du bétail, avaient dû demander une permission exceptionnelle d'entrée de bovins en France pour les y écouler : 
« Vu les événements d'Espagne, la population andorrane est obligée de se ravitailler en France et une prompte solution de cette affaire permettrait à nos administrés d'obtenir des devises françaises, ce qui faciliterait d'autant leurs échanges avec le commerce français. $»^{24}$

18 La guerre civile perturba en effet quelque temps le bon déroulement des mouvements transhumants habituels; en mai 1937, les troubles intérieurs avaient ainsi conduit à la fermeture totale de la frontière, comme l'écrivait le directeur des services vétérinaires des Pyrénées-Orientales :

«Je suis sans nouvelles de Puigcerda, la frontière est complètement fermée, et d'après certains renseignements on s'attend à des événements graves, la ville est fortifiée par les anarchistes. $»^{25}$

19 Autre exemple de l'incidence de la politique dans le déroulement de la transhumance : en mars 1920, le ministre de l'Agriculture recevait une lettre de l'Association centrale pour l'Aménagement des montagnes dont voici la teneur :

«La dépréciation du change est l'origine de sérieux dangers pour l'industrie pastorale des Pyrénées, car elle favorise la transhumance des troupeaux espagnols qui ne contribuent nullement au ravitaillement de la France, mais qui dégradent considérablement ses pâturages. Beaucoup d'Espagnols ont déjà profité de la prime actuelle de la Pesetas sur le Franc pour louer des pâturages français en vue de l'estivage prochain, et pour obtenir que leurs troupeaux y soient admis à partir du 25 juin, tandis qu'ils n'y venaient ordinairement qu'à la fin de juillet ou au commencement d'août. $»^{26}$

20 Les cours monétaires ont donc favorisé les propriétaires espagnols qui ont loué des pâtures pour des durées inhabituellement longues, ce qui rend indisponible pendant autant de temps ces pâtures aux troupeaux français; cette situation n'était pas acceptable pour l'Association qui, depuis 1904, œuvrait pour la défense de ces terres montagnardes et leur saine mise en valeur ${ }^{27}$.

21 Ces quelques cas tendent à nous montrer une transhumance sujette aux aléas, tant de circonstances très locales que de facteurs politiques parfois inattendus, des pétitions particulières aux fluctuations monétaires en passant par les conflits civils. Loin d'être un phénomène immuable comme on pourrait l'imaginer trop facilement, la transhumance nous apparaît au contraire comme étroitement soumise aux conjonctures du moment.

\section{Bergers de Cize contre vétérinaires du Valcarlos : exemple d'un incident diplomatique pastoral}

Présentons à présent un exemple de conflit pastoral parmi d'autres dans cette région navarraise qui en est agitée depuis des siècles ${ }^{28}$, conflit qui nous montre l'État aux prises avec des enjeux locaux très forts sur lesquels vient buter la réglementation générale pensée par l'Agriculture et les Affaires étrangères.

\section{Une entrée délicate en Espagne}

Le début de l'affaire paraît pourtant presque anodin. À la fin du printemps de l'année 1921, des négociations franco-espagnoles étaient en cours, au plus haut niveau des deux États, pour l'ouverture de la frontière. Des troupeaux français du syndic de Cize attendaient au pied de Valcarlos que le passage en Espagne leur fût autorisé. Or, 
l'attente se prolongeait, car le préfet des Basses-Pyrénées avait fait suspendre l'opération de clavelisation des troupeaux destinés à transhumer en Espagne. L'administrateur des douanes de Valcarlos attendait donc une autorisation formelle de la sous-direction des Douanes à Madrid pour laisser entrer ces troupeaux non vaccinés, tandis que la sous-direction attendait elle-même un certificat de non-clavelisation signé par le préfet des Basses-Pyrénées. Le certificat tardant à arriver, les troupeaux français n'avaient plus d'herbage et ces quelques 8000 moutons étaient désormais en péril faute de nourriture : l'entrée dans les pacages espagnols devenait urgente et les bergers pressaient les douanes de Valcarlos de leur ouvrir le passage.

Ce responsable finit par recevoir le 6 juin un télégramme de Madrid lui faisant savoir que l'autorisation formelle lui parviendrait le lendemain - autorisation qui, pour l'anecdote, devait lui être donnée par son propre père, sous-directeur des Douanes à Madrid, qui s'en trouvait donc son supérieur hiérarchique. Or, l'administrateur de Valcarlos n'attendit pas cette autorisation officielle, et commença aussitôt à distribuer les acquis à caution aux bergers et à les laisser entrer sur les pâturages espagnols. Par ailleurs, l'autorisation espérée n'arriva jamais, le ministre espagnol ne souhaitant rien signer tant que le certificat français de non-clavelisation ne lui serait pas parvenu par la voie diplomatique la plus officielle ${ }^{29}$.

\section{L'apparition de l'épizootie : naissance d'un long contentieux}

Une fois les moutons entrés en Espagne, l'été sembla se dérouler normalement. Mais en septembre, pour une raison que nous ignorons, l'Espagne décida de procéder d'autorité à la clavelisation de ces troupeaux français, ce qui était contraire aux accords internationaux en vigueur à ce moment précis, comme nous le reverrons. Un vétérinaire navarrais de la vallée d'Aezcoa supervisa cette opération. Mais le véritable problème se déclara brusquement le mois suivant, lorsqu'en octobre, la clavelée fit son apparition dans ces troupeaux et y commença des ravages. Le bétail, fort atteint, fut rapatrié en France en novembre seulement, le même vétérinaire ne s'étant déplacé pour constater la maladie qu'un mois après son apparition ${ }^{30}$. L'administration préfectorale dressa des listes de victimes, pour dénombrer, commune par commune et propriétaire par propriétaire, le nombre de moutons morts de la maladie ${ }^{31}$. La situation s'aggrava encore puisque les moutons transhumants, revenant d'Espagne, contaminèrent les troupeaux restés en France. 644 moutons moururent en Espagne et 2445 en France $^{32}$, ce qui était catastrophique pour les propriétaires; ceux-ci réclamèrent que l'Espagne, responsable d'une mauvaise vaccination, forcée qui plus est, les remboursât de leurs pertes.

Or, la situation était encore plus compliquée qu'on pouvait l'imaginer, car les bergers français n'avaient pas déclaré tous les moutons à leur entrée en Espagne afin de ne pas acquitter de droits d'entrée jugés trop élevés; de même à la sortie, avec la complicité passive de l'administrateur des douanes de Valcarlos, une partie des pertes ne fut-elle pas déclarée par les bergers pour éviter de payer des droits a posteriori ${ }^{33}$ : ainsi, sur les 644 morts en Espagne, seuls 212 avaient été déclarés ${ }^{34}$. 


\section{Une impossible réparation}

27 Après enquête, il fut attesté que le vaccin utilisé par les Espagnols, fabriqué en Algérie, était défectueux. Tous les partis étaient donc en tort: les douanes de Valcarlos pour avoir ouvert la frontière avant un ordre formel, les vétérinaires espagnols pour avoir vacciné de force et causé la mort de centaines d'animaux, et les bergers français pour n'avoir pas déclaré toutes les entrées et donc fraudé. L'Espagne refusa de rembourser toutes les pertes, mais seulement celles des animaux ayant été déclarés à la douane : ce n'était qu'une fraction de toutes les pertes, et les propriétaires français ne pouvaient l'accepter.

Les deux partis campant sur leurs positions respectives, le problème s'enlisa plusieurs années, mobilisant les ministères de l'Agriculture et des Affaires étrangères, mais aussi les élus locaux et nationaux. D'un côté, l'Espagne n'acceptait de rembourser que les pertes déclarées à l'entrée, à raison de 100 pesetas par tête ${ }^{35}$, et de l'autre, les propriétaires exigeaient une réparation à hauteur des pertes réelles. Il était d'ailleurs avancé par le ministère des Affaires étrangères en 1925 que si les bergers français avaient effectivement fraudé la douane, les tarifs espagnols étaient abusifs depuis longtemps ${ }^{36}$. Enfin, pour compliquer encore l'affaire, la légalité de la vaccination de troupeaux français par des vétérinaires espagnols était contestée par la France: les Espagnols avaient agi en se basant sur un ordre royal du ministère de l'Agriculture espagnol, ordre contraire à un accord franco-espagnol signé deux jours avant mais pas encore publié et donc pas encore connu des fonctionnaires de l'Agriculture. L'ordre royal était donc devenu caduc mais avait été ignoré des vétérinaires espagnols ${ }^{37}$. L'Espagne se basait sur cet imbroglio législatif pour contester la culpabilité de ses vétérinaires.

29 La contestation française était portée notamment par Jean Ybarnegaray, député des Basses-Pyrénées. Celui-ci écrivait par exemple en avril 1922 au ministre de l'Agriculture une longue lettre défendant les intérêts de ses électeurs, lettre dont voici quelques extraits :

Nous ne saurions accepter la thèse du Gouvernement espagnol, reconnaissant sa part de responsabilité, mais n'émettant le principe d'indemnisation que pour les animaux qui ont succombé en Espagne. Ceux-ci, d'après la déclaration fort incomplète à la douane ne sont qu'au nombre de 212, alors que les pertes totales se montent au chiffre de 2445 .

La proposition du Gouvernement espagnol ne peut donc être retenue que comme une plaisanterie. Une mauvaise plaisanterie à ajouter à toutes celles que la France consent à tranquillement subir, depuis cinq ans, de la part de ce peuple qui a conservé de si grand passé un goût marqué par l'insolence [...].

Hélas, pendant qu'on délibère négligemment à Madrid, le malheur pèse lourdement sur nos pauvres bergers de Cize [...]. À la veille de retourner parmi eux - et de retrouver là-bas, dans mes montagnes basques, ces graves visages pleins de douleurs et de reproche, je m'adresse de nouveau à vous et sachant ce que peut un homme qui veut, je vous demande de vouloir que l'Espagne fasse, vis-à-vis de ces paysans qu'elle a ruinés - et dans le plus bref délai - le geste équitable qui convient. Veuillez vous en souvenir - pour des centaines de foyers bien [sic] qu'il s'agit d'une question de vie, et peut-être ont-ils droit à ce que cette angoisse imprévue leur soit épargnée, eux que la dernière guerre a tout particulièrement ravagés?

Je vous prie d'excuser, Monsieur le Ministre, cette lettre dont le ton vous paraîtra exceptionnel - et peut-être un peu ridicule, c'est le lot continuel de la souffrance de 
prêter au sourire - et je souffre profondément, pour ces paysans, mes amis, pour qui le troupeau est le rêve - et la vie. ${ }^{38}$ dont la France, se soient peu à peu saisis des questions de transhumance, pratique favorisant les contacts entre troupeaux de plusieurs nationalités, et donc potentiellement soumis à des réglementations différentes en matière de sécurité sanitaire. On constate une multiplication des acteurs jouant un rôle dans les circulations animales, des ministres aux vétérinaires départementaux. La transhumance pose des questions tant de droit que de logistique et de diplomatie, surtout lorsque d'inévitables incidents se produisent. Ces incidents sont d'ailleurs la preuve que les craintes vétérinaires du gouvernement étaient justifiées. d'épaisseur des dossiers ${ }^{39}$ reste un obstacle pour analyser davantage la connaissance et la gestion de la transhumance par le ministère de l'Agriculture. Il faudrait naturellement pour en avoir un tableau plus précis examiner les fonds conservés aux archives départementales, en particulier la correspondance des services vétérinaires départementaux avec l'administration centrale. Enfin, il pourrait être fructueux d'effectuer une comparaison avec la situation du côté espagnol.

Notons enfin que la délimitation de plus en plus ferme et stricte de frontières n'a jamais empêché le maintien des mouvements transhumants traditionnels et de leurs formes juridiques ancestrales : l'État ne les a jamais supprimées, si tant est qu'il ait jamais souhaité le faire. En ce sens, la frontière pyrénéenne pourrait être pensée comme un lieu de passage, certes contrôlé et encadré, bien plus qu'un lieu de fermeture.

\section{BIBLIOGRAPHIE}

ALLABERT Marigeorges et PAILHÈs Claudine (dir.), La frontière pyrénéenne : guide des sources d'archives des relations et espaces transfrontaliers pyrénéens (France-Andorre), Foix, Conseil général de l'Ariège, 2005. 
ARVIZU y GALARRAGA Fernando de, Le conflit des Aldudes : étude d'un problème frontalier en Pays basque (XVII ${ }^{e}$-XVIII ${ }^{e}$ siècles), thèse de doctorat en histoire du droit, Toulouse, université de Toulouse-I, 1990, 5 vol.

CAVAILLÈs Henri, La transhumance pyrénéenne et la circulation des troupeaux dans les plaines de Gascogne, thèse de doctorat ès lettres, Paris, A. Colin, 1931.

DESCOMBEs Paul, « La défense des montagnes », Revue des deux mondes, t. 39, juin 1907, p. 897-916.

LEFEBVRE Théodore, « La transhumance dans les Basses-Pyrénées ", Annales de géographie, vol. 37, $n^{\circ} 205,1928$, p. 35-60.

SOLDEVILA I TEMPORAL Xavier, « L'élevage ovin et la transhumance en Catalogne nord-occidentale (XIII ${ }^{\mathrm{e}}$-XIV ${ }^{\mathrm{e}}$ siècles) », dans Pierre-Yves LAFFONT (dir.), Transhumance et estivage en Occident des origines aux enjeux actuels, actes des $\mathrm{XXVI}^{\mathrm{e}}$ journées internationales d'histoire de l'Abbaye de Flaran (9 au 11 septembre 2004), Toulouse, Presses universitaires du Mirail, 2006, p. 110-118.

VIERS Georges, «Le Pays des Aldudes », Revue géographique des Pyrénées et du Sud-Ouest, vol. 22, n 4 , 1951, p. 260-284.

\section{NOTES}

1. Pour le versant catalan au Moyen Âge par exemple, voir notamment les sources notariées exploitées par X. Soldevila i Temporal : «L'élevage ovin et la transhumance en Catalogne nord-occidentale (XIII ${ }^{\mathrm{e}}$-XIV ${ }^{\mathrm{e}}$ siècles) », p. 110-118.

2. Sur l'organisation de la transhumance dans les Pyrénées-Atlantiques par exemple, voir T. Lefebvre, "La transhumance dans les Basses-Pyrénées », p. 40-41. Sur le droit pastoral pyrénéen et la montée de la puissance des communes face aux seigneuries, voir notamment $\mathrm{H}$. Cavaillès, La transhumance pyrénéenne et la circulation des troupeaux dans les plaines de Gascogne.

3. Le cas du Pays-Quint en constitue une exception emblématique, puisque la frontière fut tracée d'autorité en 1785 par le traité d'Elizondo préparé par le comte d'Ornano et le marquis de Caro : G. Viers, «Le Pays des Aldudes », p. 272-273.

4. Voir M. Allabert et $\mathrm{C}$. Pailhès (dir.), La frontière pyrénéenne : guide des sources d'archives des relations et espaces transfrontaliers pyrénéens.

5. Et encore les Pyrénées furent-elles une frontière moins mouvante que les Alpes.

6. Archives nationales, $F / 10 / 5464$, convention sanitaire vétérinaire signée à Paris, le 31 mai 1929, entre la France et l'Italie.

7. Par exemple : Archives nationales, F/10/5464, décret du 24 décembre 1913 publiant l'arrangement entre la France et la Belgique pour le pacage des animaux dans les zones frontières.

8. Par exemple : Archives nationales, $F / 10 / 5464$, copie du Journal officiel du 3 septembre 1911 publiant l'arrêté du ministère de l'Agriculture du 31 août 1911 interdisant momentanément le pacage et l'hivernage d'animaux en provenance d'Espagne ou d'Andorre. Ce n'est qu'en mars suivant que cette mesure sera levée : ibid., arrêté du ministère de l'Agriculture du 6 mars 1912.

9. Par exemple: Archives nationales, F/10/5464, bulletin sanitaire hebdomadaire du 4 mai au 10 mai 1913. 
10. Archives nationales, $\mathrm{F} / 10 / 5468$, accord signé à Bayonne le 4 mai 1899 par le service des épizooties de la préfecture des Basses-Pyrénées.

11. Archives nationales, $\mathrm{F} / 10 / 5467$, carte annotée de la vallée des Aldudes ( $1^{\text {re }}$ moitié du xx ${ }^{\mathrm{e}}$ siècle); ibid., arrêté préfectoral du 31 mars 1930 pris par le préfet des BassesPyrénées.

12. Par exemple, Archives nationales, $F / 10 / 5464$, décret du 24 décembre 1913 publiant l'arrangement entre la France et la Belgique pour le pacage des animaux dans les zones frontières.

13. Ibid.

14. Archives nationales, F/10/5467, lettre de M. Bouchet au préfet des Basses-Pyrénées, 24 avril 1927.

15. Archives nationales, $\mathrm{F} / 10 / 5467$, note du préfet des Pyrénées-Orientales au ministre de l'Agriculture, 2 juillet 1931.

16. Ainsi, Archives nationales, $F / 10 / 5468$, arrêté du ministère de l'Agriculture du 24 septembre 1914 ordonnant l'abattage de bovins de certains propriétaires dans les Pyrénées-Orientales.

17. Archives nationales, $F / 10 / 5464$, pétition de vingt-cinq particuliers au directeur des douanes à Bayonne, 1945.

18. Archives nationales, $\mathrm{F} / 10 / 5464$, lettre de Jean Etcheverry-Aïnchart à l'inspecteur général des services vétérinaires, 19 décembre 1945.

19. Ibid.

20. Par exemple: Archives nationales, $F / 10 / 5465$, note du ministre de l'Agriculture au préfet de l'Hérault au sujet de la rentrée en Andorre de 600 ovins appartenant à M. Joseph Puig, propriétaire andorran.

21. Archives nationales, $\mathrm{F} / 10 / 5465$, note du préfet de l'Ariège au ministre de l'Agriculture, relayant la demande du Conseil général de ce département, 4 juillet 1924.

22. Archives nationales, F/10/5465, lettre du Syndic général des Vallées d'Andorre au ministre de l'Agriculture, 12 août 1936.

23. Archives nationales, $\mathrm{F} / 10 / 5465$, note du ministre des Affaires étrangères au ministre de l'Agriculture, 11 mai 1946.

24. Archives nationales, F/10/5465, lettre du Syndic général des Vallées d'Andorre au ministre de l'Agriculture, 12 août 1936.

25. Archives nationales, $F / 10 / 5467$, lettre du directeur des services vétérinaires des Pyrénées-Orientales, 24 mai 1937.

26. Archives nationales, F/10/5465, lettre de l'Association centrale pour l'Aménagement des montagnes au ministre de l'Agriculture, 22 mars 1920. La concurrence espagnole par la monnaie était aussi un enjeu dans les PyrénéesAtlantiques: T. Lefebvre, « La transhumance dans les Basses-Pyrénées », p. 57.

27. P. Descombes, «La défense des montagnes », p. 907.

28. Voir par exemple pour la vallée voisine la thèse de F. de Arvizu y Galarraga, Le conflit des Aldudes : étude d'un problème frontalier en Pays basque (XVII -XVIII ${ }^{e}$ siècles). Voir aussi G. Viers, « Le Pays des Aldudes ».

29. Tous ces faits sont résumés dans: Archives nationales, F/10/5468, lettre de Jean Inchauspé, vice-syndic de Cize, à Louis Barthou, député des Basses-Pyrénées, ministre 
de la Guerre, 17 juin 1921. C'était de la part du ministre espagnol une garantie en cas d'épizootie, qui permettrait de rejeter la faute sur la France.

30. Archives nationales, $F / 10 / 5468$, note de l'inspecteur général Mesnard au ministre de l'Agriculture, 14 février 1923.

31. Nous avons ainsi un tableau précis des propriétaires du syndic de Cize ayant des troupeaux transhumants ou non, issus des communes de Aincille, Aincihe-Mongelos, Arnéguy, Çaro, Estérençuby, Gamarthe, Ispoure, Jaxu, Saint-Jean-le-Vieux, SaintMichel, Suhescun, et Uhart-Cize. Voir Archives nationales, F/10/5468, liste des pertes dues à la clavelée [1921].

32. Ibid.

33. Archives nationales, F/10/5468, note de l'inspecteur général Mesnard au ministre de l'Agriculture, 14 février 1923.

34. Archives nationales, $F / 10 / 5468$, note du ministère des Affaires étrangères au ministère de l'Agriculture, 4 septembre 1925.

35. Ibid.

36. Archives nationales, $\mathrm{F} / 10 / 5468$, note du président du Conseil au ministre de l'Agriculture, 29 janvier 1923. Voir aussi Archives nationales, F/10/5468, note de l'inspecteur général Mesnard au ministre de l'Agriculture, 14 février 1923 : l'accord franco-espagnol du 4 mai 1899 stipulait dans son article 2 la gratuité de la délivrance de ces acquis à caution, ce que respectait la France, alors que l'Espagne faisait payer 0,85 F. par tête.

37. Ibid.

38. Archives nationales, $\mathrm{F} / 10 / 5468$, lettre de Jean Ybarnegaray, député, au ministre de l'Agriculture, 8 avril 1922. Les passages soulignés ont été respectés.

39. 1,5 m. linéaire seulement pour cinquante ans d'activités et toutes les frontières terrestres métropolitaines.

\section{RÉSUMÉS}

La transhumance est sans doute une des plus anciennes formes de circulations montagnardes périodiques. Au-delà de la question pastorale, elle peut aussi s'envisager sous un angle administratif et international. Si la mise en œuvre de la circulation d'animaux domestiques dans un cadre montagnard frontalier fut longtemps une affaire locale basée sur la coutume, la situation évolue largement au début $\mathrm{du} \mathrm{xx}^{\mathrm{e}}$ siècle. Les archives de l'administration du ministère de l'Agriculture font en effet apparaître le besoin grandissant de l'État d'en connaître davantage, d'encadrer voire d'institutionnaliser ces pratiques, en codifiant l'usage de l'espace montagnard. Le but est avant tout d'éviter les épizooties. On propose donc de montrer comment l'État s'y est pris pour lutter contre ces fléaux que la transhumance ne pouvait qu'aggraver, par des mesures à la fois diplomatiques, administratives et sanitaires. 


\section{AUTEUR}

\section{HENRI PINOTEAU}

Archiviste paléographe, conservateur du patrimoine, chef du pôle Agriculture, Postes et Télécommunications aux Archives nationales. Direction des fonds, département de l'Environnement, de l'Aménagement du territoire et de l'Agriculture 


\title{
Les figues d'exportation en Kabylie (1930-1953) : réussite ou échec du colonisateur?
}

\author{
Isabelle Chiavassa
}

1 L'administration coloniale en Algérie, dès le XIX siècle, a essayé d'encourager l'agriculture par tous les moyens: crédit agricole, tests de culture au Jardin d'essai, pépinières, prêt de semences, subventions, irrigation, lutte contre les calamités comme les sauterelles...

2 Je traiterai ici de son rôle dans la circulation de l'innovation en contexte colonial, en Kabylie, à partir des années 1930. Cette région d'Algérie, montagneuse, comporte aussi des vallées et des plaines au rôle jugé essentiel ${ }^{1}$. La circulation des hommes et des idées était constante par la route menant à Alger et à Constantine. Le massif du Djurdjura luimême ne constituait pas un obstacle, grâce à plusieurs cols². Ce massif s'élève à 2308 mètres d'altitude, avec des stations de ski, et un glacier souterrain ${ }^{3}$. Ces montagnes n'ont jamais fait entrave au commerce. Le cas étudié ne se situe pas en haute montagne: les figuiers en Kabylie poussaient sur des pentes entre 300 et 600 mètres, voire jusqu'à 1200 mètres d'altitude ${ }^{4}$. La culture en terrasses n'est pas pratiquée en Kabylie ${ }^{5}$.

3 Cette innovation, c'est l'autorité coloniale qui l'a impulsée en menant une politique d'amélioration du séchage des figues. Quelle était l'idée? Rationaliser, gagner en productivité, éviter le gaspillage de figues abîmées, améliorer le sort des indigènes, ou exporter? On dispose aux Archives nationales d'outre-mer, à Aix-en-Provence, des rapports et correspondances des administrateurs de commune mixte et des souspréfets, dans les archives de la sous-préfecture de Tizi-Ouzou. Ils permettent de rechercher les traces d'une problématique de la résistance à l'innovation ou de l'adaptation à la modernité. Les communes mixtes étaient de vastes territoires ruraux, peuplés de très nombreux indigènes, et de rares Européens, et dirigés non par un maire élu, mais par un administrateur nommé par le gouvernement général de l'Algérie. Les agriculteurs concernés ici sont presque tous indigènes. 
Or, la situation antérieure à cette politique de séchage des figues est connue: la description de la Kabylie par Hanoteau et Letourneux, dès $1893^{6}$, montre que le séchage des figues se faisait au soleil sur des claies. La nuit, on superposait les claies et on les recouvrait de paillassons ou d'écorces de liège. La Kabylie à peine pacifiée après l'insurrection de 1871, il s'agit bien ici des traditions locales, mais déjà en 1893, les gros propriétaires de figuiers organisaient le séchage dans des bâtiments pour la nuit ${ }^{7}$. Cet ouvrage indique aussi la grande importance des figues dans l'alimentation des indigènes, on en comptait 28 variétés différentes.

\section{Initiative et étapes}

5 En 1930 est organisée une démonstration officielle de séchage lors de la semaine du figuier, à Sidi Aïch et à Bougie, en présence des élus et autorités, sous la présidence du préfet de Constantine. Le Kabyle est vu comme «bon laboureur mais mauvais industriel ", il faut - dit la brochure officielle imprimée du congrès - lui apprendre le séchage : les organisateurs font fonctionner une armoire à soufrer les figues, et une machine de stérilisation à vapeur venue de Marseille ${ }^{8}$.

6 Les acteurs de cette "semaine du figuier", se demandant comment décider les producteurs à modifier leurs méthodes traditionnelles, concluent qu'il faut un supplément de prix, une hausse du prix que l'exportateur doit payer au producteur. Toutefois c'est de la culture familiale, le séchage est un travail fait gratuitement par les femmes et les enfants ; désormais il faudra recruter de la main-d'œuvre payée, voilà la difficulté soulevée par la création d'ateliers; un ébouillantage et un soufrage ne peuvent être que collectifs.

7 L'initiative vient probablement du gouverneur général Jules Carde qui va créer l'Ofalac ${ }^{9}$, Office algérien d'action économique et touristique, mais surtout des Chemins de fer d'Algérie : en 1930, c'est le service commercial des Chemins de fer de l'État qui organise cette semaine du figuier. Ce service est inquiet de la régression des exportations, due à la concurrence des figues d'Orient et de Californie ${ }^{10}$. C'est également le contexte du centenaire de la conquête de l'Algérie.

8 Cette politique est portée ensuite par un conseiller agricole de l'arrondissement de TiziOuzou, André Heintz, qui publie une brochure en 1935. En Kabylie, explique cette brochure, on compte bien plus de figuiers que d'oliviers : 2950000 figuiers. Le séchage se fait au soleil, et la nuit ou en cas de pluie, par empilement dans l'habitation, car « il n'existe aucun séchoir digne de ce nom ». Heintz propose des améliorations pour lutter contre la concurrence en métropole des figues d'Asie mineure, de Grèce ou d'Italie : il faut agir sur les variétés, la greffe, les labours, les engrais, et surtout sur le séchage. La création de séchoirs coopératifs est indispensable avec un local, des claies empilables, une chaudière pour ébouillanter, une armoire à soufrer. "Des intérêts particuliers souffriront", dit-il: usuriers, courtiers, exportateurs, mais "beaucoup d'indigènes s'ouvrent aux idées coopératives » et à ce projet ${ }^{11}$.

9 Il s'agit de rendre exportable les figues en les séchant mieux, et non de favoriser l'indigène et sa consommation. L'effort portera sur quatre communes mixtes qui possèdent beaucoup de figuiers: Fort-National, le Haut-Sebaou, le Djurdjura et la Mizrana. 

1930, n'ont eu lieu que de timides initiatives, «peut-être avait-on omis d'intéresser la masse des fellahs »? Il veut « intéresser le fellah kabyle » (1937); après le congrès, qui s'est naturellement conclu par un bon banquet en $1930^{13}$, tout est resté lettre morte. Il faut un local et une aire à l'extérieur ; les producteurs doivent assister au tri, qui sera fait par un ouvrier du pays. Il convient de payer comptant les producteurs, et de prendre pour modèle les coopératives du tabac (Tabacoop) ${ }^{14}$.

11 Le premier essai en 1937 à Fort-National, essai de séchage et de stérilisation, a lieu au douar Iraten et va être étendu à d'autres douars. Ici dès 1938, "on a obtenu un rendement supérieur de $50 \%$ à celui que les indigènes réalisent avec leurs procédés archaïques $\aleph^{15}$. En 1939, l'administrateur de Fort-National doit avouer un été frais et pluvieux, une récolte déficitaire conjuguée à la mobilisation générale en septembre. Les deux ateliers de séchage ont donc très peu fonctionné. Il propose au gouverneur général de créer 7 nouveaux ateliers. En mai 1940, toujours aussi optimiste, il écrit au sous-préfet de Tizi-Ouzou sa volonté de finir d'installer ses trois ateliers, joignant un tableau chiffré très précis, le personnel, les salaires, les subventions, le matériel... Au gouvernement général, la commission du paysannat assure depuis Alger le suivi de ces progrès dans six communes mixtes, et propose des subventions; en $1941^{16}$ elle inscrit dans le discours officiel ces ateliers de séchage rationnel, les plus anciens étant apparus à Makouda et Tizi Rached (douars situés dans les communes mixtes de la Mizrana et Fort-National). Cette politique jugée importante par le gouvernement général a abouti maintenant à des campagnes annuelles de séchage, à des bilans de la coopérative rédigés par l'administrateur de commune mixte. Ce fonctionnaire s'est mué en véritable chef d'entreprise, le style de ses rapports est totalement celui d'un entrepreneur, ou du moins d'un chef de coopérative ${ }^{17}$.

L'administration prête du matériel et met à disposition un ingénieur des services agricoles $^{18}$. Un rapport rédigé en 1939 porte sur le marasme économique en Petite Kabylie $^{19}$. Il précise que les sécheries coopératives de figues n'ont pas donné tous leurs résultats, car il y a eu des frais d'installation, et "quelques administrateurs ont présenté des bilans trop optimistes ». Cette année 1939 est défavorable: outre des pluies, une récolte médiocre et le départ d'une partie du personnel mobilisé, les prix ont été modifiés ; à la Soummam, l'intendance de l'armée a acheté les figues à un prix très faible ${ }^{20}$. Le rendement serait meilleur si le matériel était plus important mais, dit ce rapport, le but de l'administration est tout autre :

«Il s'agit d'encourager par l'exemple les indigènes à monter à leur compte de petites entreprises, afin d'être à l'abri des prix d'achat très insuffisants offerts par les gros commerçants européens ou indigènes. »

On perçoit ici un aspect tout nouveau : il ne s'agit plus de sécher mieux les figues, de produire plus et mieux, mais de rendre l'indigène entrepreneur à son compte, c'est l'organisation et la mentalité que l'autorité coloniale envisage de transformer. Selon ce texte, un gros commerçant kabyle de Sidi Aïch vient de monter sa propre sécherie, et ce genre de sécherie risque de faire la loi sur le marché à la place des coopératives officielles. Par ailleurs, une pépinière de 50000 figuiers qui seront donnés aux fellahs est mise en place à Bougie. Ils les paieront bien plus tard, au bout de 4 ans, quand les arbres produiront ${ }^{21}$.

14 En 1944 est envisagée la réquisition des figues, car la Kabylie est le plus gros producteur de figues sèches d'Afrique du Nord, mais, objecte l'administration, on a déjà pris aux 
Kabyles par réquisition leur huile, leurs céréales et leur viande, en les rémunérant très faiblement ${ }^{22}$. Le gouverneur général standardise dès 1937, puis par des arrêtés successifs les figues sèches pour l'exportation : en 1946, elles sont classées en 4 qualités (de 8 grammes à 14 grammes), une norme de tolérance est fixée pour les figues fermentées ainsi qu'une qualité d'emballage ${ }^{23}$.

En 1950, l'administration lance des ateliers de séchage ambulants, après un nouveau congrès du figuier, tenu à Bougie en 1949. Ce sont des jeeps aménagées, qui procèdent à la désinsectisation et à la désinfection, dans la commune mixte d'Azeffoun par exemple. À Fort-National, l'autorité envisage de créer un atelier «chez X..., indigène jeune, ouvert, chevalier du Mérite agricole " l'emplacement favorable de ses terrains, très visibles à un carrefour, doit permettre de convaincre par l'exemple, et d'aboutir à une nouvelle coopérative ${ }^{24}$. La démonstration est donc essentielle pour cette circulation de l'innovation en montagne ${ }^{25}$.

16 J'observe en 1953 une exigence de qualité supérieure. À Fort-National, c'est une coopérative de production, la Fibrocoop, qui se charge de la récolte. Lors d'une tournée d'un agent du gouvernement général, les producteurs lui ont remis des suggestions pour une nouvelle organisation : un atelier fonctionne depuis 3 ans, «les produits ne peuvent s'imposer que s'ils ont une qualité supérieure et un prix de revient réduit », il faut un traitement rationnel. En effet, l'atelier collectif séparait les figues de chaque producteur, et ceux-ci négligeaient de les reprendre ; elles sont ensuite mal conservées, deux équipes et par conséquent deux chefs exécutent les travaux (équipe Ébouillantage - sulfurisation, équipe Manipulations); l'agréage, examen de la marchandise par l'acheteur, était superficiel, sans que le contrôleur puisse apercevoir et juger réellement les figues situées tout au fond, sous les autres. Il faut prévoir une seule équipe, du matériel, du pétrole, du gaz et du sel fournis au fur et à mesure, un enlèvement au fur et à mesure du séchage, réaliser le pesage et l'agréage lors du conditionnement. Un afflux de producteurs, qui adhéreront à la Fibrocoop, est attendu et permettra de réduire les frais. La coopérative, estime l'administration, doit payer aux producteurs ces figues traitées à un niveau plus élevé que la rémunération accordée par les exportateurs aux figues non traitées ${ }^{26}$.

\section{Longueurs et résistances}

17 À la Mizrana en 1938, la « méfiance normale du Kabyle » s'ajoute à l'existence d'un çoff (clan) hostile au caïd, et selon les rapports conservés dans les archives, «l'hostilité englobe toute l'administration " : les ateliers ont échoué dans un douar. Dans un autre douar de la Mizrana, les fellahs sont retombés dans leurs habitudes anciennes : le local est malpropre, il n'existe pas de précaution contre les insectes (le local n'étant pas fermé), les fellahs réduisent les doses de soufre, et la désinsectisation n'est pas faite ${ }^{27}$. À Dra-el-Mizan en 1939, l'autorité demande de ne pas créer d'ateliers en famille, car « le fellah fataliste et arriéré ne saurait tirer un bon parti du matériel moderne, il n'aurait pas compris la portée d'une organisation nouvelle». L'administrateur est satisfait de ses ateliers, mais en supprime un, car à cet endroit précis règne un état d'esprit fait d'indifférence et de malveillance ${ }^{28}$.

Un rapport soigné et relié sur Fort-National explique l'expérience, illustrée par des photographies. Le premier atelier à Tizi Rached a rencontré scepticisme et appréhension, et n'a vu venir que 64 fellahs sur 240. Pour vaincre ces résistances, 
l'autorité leur a demandé de désigner des représentants, tous indigènes : et c'est un complet succès, dit cet administrateur optimiste ${ }^{29}$.

En 1940, le sous-préfet se plaint au préfet: le gouvernement général a fixé un prix maximum au quintal, mais les producteurs les vendaient plus cher auparavant. Les Kabyles ont besoin de ce revenu, car les céréales sont presque introuvables, ils sont mécontents et «soupçonnent l'action de commerçants israélites »; par conséquent ils ne viennent pas à nos ateliers, dit le sous-préfet, et «nous perdrons le bénéfice des efforts de 4 ans $»^{30}$.

Dans le rapport de bilan 1942 à Fort-National, les producteurs sont peu enthousiastes car ils vont perdre le marché clandestin, lié à la Seconde Guerre mondiale ; s'y ajoutent des campagnes de dénigrement de ces ateliers, menées par des propriétaires, de mèche avec les industriels; "l'atelier ne touche que peu de la production du douar $»^{31}$. Le problème est bien le prix, certains préfèrent livrer une figue non traitée payée tout de suite : l'exportateur doit absolument donner une prime.

21 En 1951, l'administrateur du Djurdjura raconte son expérience d'atelier ambulant. Après un épisode de méfiance, les producteurs se sont présentés, mais des pluies diluviennes ont empêché le travail de séchage. Parmi les difficultés rencontrées, un tri sévère, car chacun apporte peu, et plusieurs variétés de figues; la plupart des petits fellahs n'ayant pas d'abri pour les claies et les couvrant avec des moyens de fortune, elles avaient pris l'humidité. Les producteurs satisfaits toutefois ont largement fait savoir leur sentiment aux autres. À la Mizrana, 22 producteurs ont fait traiter leurs figues, puis sont survenus de violents orages. L'administrateur en profite pour préciser qu'il faut des claies moins lourdes, un éclairage de nuit - autre que l'éclairage sommaire des phares des jeeps -, diminuer les temps morts. Il compte améliorer l'efficacité l'année suivante en organisant des causeries données par des moniteurs agricoles $^{32}$. Toujours en 1951 mais à Fort-National, les producteurs kabyles réclament un atelier fixe : ils craignent que la jeep ne soit pas assez présente. Mais :

« La vraie raison est la femme kabyle, c'est elle qui cueille et sèche les figues, et elle devrait intervenir à l'atelier mobile dans des conditions que ne prévoient pas les coutumes, alors si les coutumes kabyles sont en jeu, il ne fait pas de doute que tous nos raisonnements n'en viendront pas à bout. »

On peut créer un atelier qui travaillerait pour la coopérative, mais il faut des capitaux ; le plus délicat est l'agréage, examen de la marchandise par l'acheteur. Avant-guerre, l'agréage n'était pas fait avec soin; le producteur veut qu'il soit fait en sa présence, et en distinguant 3 catégories de figues. "On sortirait ainsi du stade de l'expérimentation auquel nous sommes après 13 ans d'essai $»^{33}$. Treize ans donc pour introduire cette innovation en montagne.

Enfin un rapport général sur la campagne de 1950 dans tout l'arrondissement de TiziOuzou évoque l'expérience de trois ateliers ambulants. L'un, à Fort-National, a joué un rôle de démonstration, l'autre a fonctionné à la Mizrana, et un dernier a circulé plus largement pour les indigènes dans les douars. Malheureusement, les conditionneurs refusent de monter leur prix ; pour économiser le coût du conditionneur, la coopérative procède elle-même à l'emballage. Fait révélateur, un agent technique du Paysannat « a obtenu la confiance générale par son esprit de persuasion, l'adresse et la souplesse de ses rapports avec les populations kabyles " : la question de la psychologie, des relations entre technicien venu d'Alger et fellahs est fondamentale ${ }^{34}$. La clef, le problème essentiel reste la mévente, le prix, les tarifs douaniers. 

arboriculture pendant la Seconde Guerre mondiale, à Fort-National ${ }^{35}$. Après un séchage le jour au soleil, il y a une mise à l'abri le soir ; la nuit, on garde le séchoir à figues (appelé gourbi) situé dans le champ. Des figues sont volées une nuit où personne ne surveille le gourbi. Par conséquent, aucun atelier collectif dans un bâtiment "en dur " n'existe dans ce douar. Ceci nous rappelle que ces expériences de séchage étaient très partielles et très locales. À Maillot en 1950, l'administration affirme un échec complet ${ }^{36}$. Et que conclut le sous-préfet Byr, dans la "monographie » (description générale) de son arrondissement de Tizi-Ouzou, en 1953 ? Il décrit toujours un séchage au soleil sur des claies de roseaux, et mentionne juste une industrie de la figue, « développée grâce à la pasteurisation et à d'importantes usines ", probablement d'emballage ${ }^{37}$. L'existence de bâtiments spécifiques permanents et bien équipés pour le séchage n'est toujours pas avérée.

L'origine de l'innovation se fonde sur l'administration coloniale, via trois institutions, les Chemins de fer de l'État, le Paysannat (service du gouvernement général ${ }^{38}$ ), et l'Ofalac. Ce dernier office crée en 1932 la marque déposée Algeria, pour l'apposer sur différents produits exportés, dont les figues sèches. Il s'agissait surtout d'exporter plus de figues et à un tarif plus élevé. Les idées circulent aussi en retour vers Alger, car les administrateurs de commune mixte procèdent à un important retour d'expérience, signalent les besoins, surtout financiers. L'administration agit pour l'exportation, mais admet que l'indigène doit y trouver son compte, en prix de vente à l'export et en autoconsommation. Le processus de mise en place d'un séchage industriel est lent et laborieux : au bout de vingt ans, il reste encore embryonnaire.

Je remarque quatre modalités intéressantes pour mieux faire circuler les techniques: des ateliers ambulants, avec des jeeps; un "indigène ouvert», qui va faire la propagande, la démonstration du progrès par l'exemple ; la formation des producteurs, grâce à des causeries prononcées par des moniteurs agricoles; et, pour obtenir la confiance des Kabyles, la diplomatie (exercée par les administrateurs de commune mixte et par les techniciens), essentielle pour cette circulation de l'innovation en montagne.

Dans Le déracinement, Pierre Bourdieu et Abdelmalek Sayad ont abordé les problématiques de progrès et de résistance dans l'agriculture, qui sont plus générales en Algérie vers 1950-1954. Les indigènes n'ignorent pas les nouveautés, la charrue, les tracteurs, les engrais, mais ne peuvent prendre de risques, n'ont pas les moyens techniques ni financiers; c'est une économie de survie permettant de nourrir leurs familles, mais pas d'investir ${ }^{39}$. Ces mêmes raisons expliquent probablement, pour les figues, le scepticisme des producteurs.

Sur la réussite de l'innovation dans cette agriculture de montagne, nous n'avons que la vision exprimée par l'autorité coloniale, la parole directe des paysans ne transparait pas. Ces documents témoignent en tout cas des modalités d'action de l'autorité en situation coloniale. Elle tente de convaincre par des expériences locales, exprime une représentation condescendante de l'indigène, affirme se heurter à la méfiance et au fatalisme. Les indigènes ont parfois, il est vrai, des stratégies d'évitement. La nouveauté a des conséquences en termes de commercialisation et d'évolution des prix ; c'est aussi 
un jeu de pouvoir entre autorité coloniale, conditionneurs, exportateurs, par conséquent entre acteurs politiques et acteurs économiques. Dans un livre récent, Samir Saul ${ }^{40}$ rappelle quela crise économique des années 1930 met à mal le "pacte colonial ", «ébranle l'ordre colonial », même sans compter les perturbations dues plus tard à la Seconde Guerre mondiale: les économies d'Afrique du Nord sont de type colonial, "basées sur l'agriculture, exportatrices de produits agricoles" mais en concurrence avec les produits de métropole. Il observe une "profonde inégalité entre minorité européenne (insérée dans une économie moderne) et fellahs concentrés dans une économie primitive ", de subsistance. Il conclut que l'Algérie vit bien une structure sociale de type colonial et que «l'extension de la misère donne une impulsion nouvelle au nationalisme».

Lors de ces tentatives du colonisateur pour imposer les techniques qu'il croit meilleures en montagne, le vocabulaire utilisé témoigne du regard porté : il convient d'« éduquer le producteur " (expression utilisée en 1930 ${ }^{41}$ ), alors même que les fellahs ont leurs propres habitudes de culture. En élargissant la vision à l'ensemble des colonies, on observe souvent cette croyance absolue dans le progrès, qui s'inscrit d'emblée dans le projet colonial : l'un des piliers du pouvoir colonial, avec le travail des indigènes, la santé et les écoles, est la mise en valeur imposée du territoire, comme l'écrit Marc Michel $^{42}$. Jean Fremigacci, autre historien des colonies, identifie, lui aussi ${ }^{43}$, ce "dogme » de la supériorité morale du colonisateur, supériorité censée entrainer les administrés dans la voie du progrès, et qui ne semblait guère souffrir de remise en question.

\section{BIBLIOGRAPHIE}

BERTHAULT Pierre, L'évolution et l'organisation de la paysannerie indigène en Algérie, Alençon, Imprimerie alençonnaise, 1938.

BOURDIEU Pierre et SAYAD Abdelmalek, Le déracinement : la crise de l'agriculture traditionnelle en Algérie, Paris, Éditions de Minuit, 1964.

DESPOIS Jean, «La culture en terrasses dans l'Afrique du Nord », Annales. Économies, Sociétés, Civilisations, vol. XI, $\mathrm{n}^{\circ} 1,1956$, p. 42-50.

HANOTEAu Adolphe et LetourneuX Aristide, La Kabylie et les coutumes kabyles, $2^{\mathrm{e}}$ éd., Paris, Bouchène, 2003, 3 vol.

FERAOUN Mouloud, Le fils du pauvre, Paris, Éditions du Seuil, 1954.

FREMIGACCI Jean, État, économie et société coloniale : Madagascar, Paris, Karthala, 2013.

LACOSTE Yves, Unité et diversité du Tiers-Monde. Des représentations planétaires aux stratégies sur le terrain, Paris, La découverte/Hérodote, 1984.

MAHÉ Alain, Histoire de la Grande-Kabylie, XIX ${ }^{e}-X X^{e}$ siècles : anthropologie historique du lien social dans les communautés villageoises, Alger, Bouchène, 2001. 
MICHEL Marc, Essai sur la colonisation positive : affrontements et accommodements en Afrique noire, Paris, Perrin, 2009.

SAUL Samir, Intérêts économiques français et décolonisation de l'Afrique du Nord : 1945-1962, Droz, Genève, 2016.

\section{NOTES}

1. Y. Lacoste, Unité et diversité du Tiers Monde. Des représentations planétaires aux stratégies sur le terrain, p. 470-539.

2. A. Mahé, Histoire de la Grande-Kabylie, $\mathrm{XIX}^{e}-\mathrm{XX}^{e}$ siècles : anthropologie historique du lien social dans les communautés villageoises, p. 17.

3. Les archives d'époque citent déjà le ski-club de Michelet et des touristes venus à Maillot pour le pratiquer.

4. 1200 mètres selon le sous-préfet de Tizi Ouzou (1953), Archives nationales d'outremer, fonds de la sous-préfecture de Tizi-Ouzou, FR ANOM 915/88, et selon le rapport de Laurette sur Maillot (1950), même service, fonds du gouvernement général, FR ANOM GGA 20 X 9.

5. Selon J. Despois, « La culture en terrasses dans l'Afrique du Nord», p. 43-45: la culture en terrasses n'est pas pratiquée, car sur les pentes, les figuiers servent à retenir le sol pour les céréales, l'araire tiré par deux bœufs a l'avantage de ne pas trop égratigner la terre, et cet attelage de deux bœufs serait peu maniable sur des terrasses.

6. A. Hanoteau et A. Letourneux, La Kabylie et les coutumes kabyles, p. 399-404.

7. Une fois sèches, elles sont conservées en jarres ou paniers ou dans des moules de bois, parfois dans des chambres hautes.

8. Archives nationales d'outre-mer, fonds de la sous-préfecture de Tizi-Ouzou, FR ANOM 915/6. Sidi Aïch était le chef-lieu de la commune mixte de la Soummam.

9. L'Algérie voyant sa position commerciale sur les marchés extérieurs se détériorer, un décret du 29 octobre 1931 crée l'Ofalac (Journal officiel de l'Algérie du 27 novembre 1931).

10. Lors du congrès du CTHS à Pau, l'un des présidents de séance a pu témoigner : les Chemins de fer de l'État étaient composés d'employés presque tous originaires de Sidi Aïch ; voilà qui explique pourquoi ces services ont favorisé la culture et l'exportation des figues.

11. Archives nationales d'outre-mer, fonds de la sous-préfecture de Tizi-Ouzou, FR ANOM 915/6.

12. Ibid.

13. Congrès organisé avec délégation officielle, excursion, concert...

14. Archives nationales d'outre-mer, fonds de la sous-préfecture de Tizi-Ouzou, FR ANOM 915/6.

15. P. Berthault, L'évolution et l'organisation de la paysannerie indigène en Algérie, p. 6.

16. Archives nationales d'outre-mer, fonds de la préfecture d'Alger, FR ANOM 91/4 I 74.

17. Archives nationales d'outre-mer, fonds de la sous-préfecture de Tizi-Ouzou, FR ANOM 915/6. 
18. Archives nationales d'outre-mer, fonds de la sous-préfecture de Tizi-Ouzou, FR ANOM 915/2.

19. On sait que la Kabylie a souffert de la pauvreté à cette époque (A. Mahé, Histoire de la Grande-Kabylie, XIX ${ }^{e}$-XXe siècles : anthropologie historique du lien social dans les communautés villageoises, p. 26-27).

20. Archives nationales, papiers Montagne, FRAN 19960480/4. L'intendance a demandé des figues noires plus nutritives au lieu des blanches commercialisées d'habitude, a fixé un prix plus haut que pour les blanches, mais ensuite, les a achetées à un prix très bas.

21. P. Berthault, L'évolution et l'organisation de la paysannerie indigène en Algérie, p. 4-5.

22. Archives nationales d'outre-mer, fonds de la sous-préfecture de Tizi-Ouzou, FR ANOM 915/2.

23. Ibid.

24. Ibid.

25. Le syndicat des conditionneurs de figues sèches se plaint en 1952 de l'apparition d'une coopérative de vente : les conditionneurs ont connu une suite de déboires, malgré la hausse du prix ; alors que cette coopérative créée en 1951 a obtenu, elle, une aide gratuite des pouvoirs publics, et ne vend pas les qualités inférieures de figues (qu'elle écoule chez les conditionneurs). Ce syndicat proteste contre cette situation (Archives nationales d'outre-mer, ibid.).

26. Archives nationales d'outre-mer, fonds de la sous-préfecture de Tizi-Ouzou, FR ANOM 915/90.

27. Archives nationales d'outre-mer, fonds de la sous-préfecture de Tizi-Ouzou, FR ANOM 915/6.

28. Ibid.

29. Ibid.

30. Ibid.

31. Ibid.

32. Archives nationales d'outre-mer, fonds de la sous-préfecture de Tizi-Ouzou, FR ANOM 915/8.

33. Ibid.

34. Ibid.

35. M. Feraoun, Le fils du pauvre, passim.

36. Rapport Laurette (CHEAM), Archives nationales d'outre-mer, fonds du gouvernement général, FR ANOM GGA 20 X 9.

37. Archives nationales d'outre-mer, fonds de la sous-préfecture de Tizi-Ouzou, FR ANOM 915/88.

38. Les efforts de ce service pendant les années 1930 sont soulignés par J. Berque, Le Maghreb entre deux guerres, p. 317.

39. P. Bourdieu et A. Sayad, Le déracinement : la crise de l'agriculture traditionnelle en Algérie, p. 19-20.

40. S. Saul, Intérêts économiques français et décolonisation de l'Afrique du Nord: 1945-1962, p. 24-26. 
41. Archives nationales d'outre-mer, fonds de la sous-préfecture de Tizi-Ouzou, FR ANOM 915/6.

42. M. Michel, Essai sur la colonisation positive : affrontements et accommodements en Afrique noire, p. 295.

43. Pour le cas de Madagascar du moins. J. Fremigacci, État, économie et société coloniale: Madagascar, p. 50.

\section{RÉSUMÉS}

L'émergence de l'innovation technique est constatée en Kabylie, dans l'Algérie française, massif montagneux marqué par une agriculture très modeste, inséré toutefois dans l'économie marchande. Les archives des communes mixtes et des sous-préfectures, aux Archives nationales d'outre-mer, témoignent de l'action du colonisateur: des conseillers agricoles tentent de promouvoir un nouveau mode de séchage des figues, la construction de hangars de séchage, des méthodes plus « industrielles ». Après des démonstrations organisées dès 1930, l'administration coloniale favorise l'installation d'ateliers. Elle constate un échec relatif vers 1953 ; les paysans ont parfois des réticences. L'innovation exige de convaincre les producteurs et de financer des coopératives. L'administration souhaite exporter plus de figues sèches en métropole. Dans ce discours colonial, l'espace montagnard est perçu comme espace de résistance au changement, mais les fellahs «s'ouvrent aux idées coopératives».

\section{AUTEUR}

\section{ISABELLE CHIAVASSA}

Conservateur en chef du patrimoine au ministère des Armées, chercheuse associée au Groupe de recherches en histoire (GRHIS, EA 3831, Université de Rouen) 


\title{
La montagne touristique française : une démographie en panne?
}

\author{
Christophe Gauchon
}

1 L'émigration des habitants des montagnes est un phénomène décrit maintes fois depuis bien longtemps, à tel point que l'on se demande parfois pourquoi des hommes sont-ils venus s'installer dans des milieux aussi répulsifs... La pauvreté chronique, l'hostilité des éléments, l'omniprésence des périls sont souvent mobilisés dans cette perception déterministe qui prend rarement en compte les motifs qui ont pu présider à la colonisation très ancienne des montagnes. Au cours $\mathrm{du} \mathrm{xx}^{\mathrm{e}}$ siècle, la question démographique a joué un rôle primordial dans les politiques publiques de la montagne. Deux citations complémentaires en témoignent bien :

«Après avoir joué un rôle capital aux origines du peuplement, il semble que les montagnes voient les hommes se détourner d'elles. »

2 Ainsi Jules Blache concluait-il son ouvrage L'Homme et la Montagne, paru en 1934. Il traduisait ainsi une réelle préoccupation de l'époque quant au dépeuplement des montagnes françaises, dans un mouvement d'exode rural amplifié par les difficultés de modernisation de l'agro-pastoralisme et aggravé par les pertes de la Première Guerre mondiale. Moins de trente ans après, Paul et Germaine Veyret proposaient un diagnostic beaucoup plus encourageant:

«Le ski transforme le destin de la montagne, il la délivre de la léthargie hivernale [...] il crée des emplois beaucoup plus nombreux [que l'alpinisme]. Il renverse l'antique courant d'émigration qui, comme l'eau, coulait du haut vers le bas, dépeuplant les montagnes; il y a maintenant une immigration ascendante vers les stations de ski. ${ }^{1}$

Cette citation n'est pas isolée, et le préfet Grimaud, à l'occasion du centenaire du rattachement de la Savoie à la France en 1960 s'était exprimé en des termes équivalents. Ils dénotent à la fois un grand optimisme quant aux évolutions en cours dans l'après-guerre, et assignent aussi un but impératif à la politique d'aménagement touristique: faire cesser l'exode, inverser les courbes migratoires, ramener de nouvelles populations en montagne. Ces citations illustrent un questionnement 
classique en géographie du tourisme, quant à l'effet peuplant, ou non, du tourisme en général. Beaucoup plus proche de nous, Philippe Duhamel n'écrit-il pas :

«Le tourisme est une activité peuplante. Il se développe (à l'exception des villes, grandes ou petites) en position littorale, ou dans les espaces montagnards, des espaces vides d'hommes et d'activités. Cela favorise donc, en général, la croissance de population, soit en évitant une émigration locale, soit en produisant la venue de migrants pour assurer le bon fonctionnement de la station ou de la région touristique, souvent dépourvues d'un nombre suffisant d'actifs. Aussi n'est-il pas rare de voir la courbe démographique d'une région se stabiliser ou s'inverser pour progresser avec son développement touristique. $»^{2}$

Dans un manuel classique paru en 1993, J.-M. Dewailly et E. Flament illustrent la « vertu peuplante $»^{3} \mathrm{du}$ tourisme par un graphique qui montre l'évolution de la population dans quatre communes de haute Tarentaise entre 1936 et 1990. Les deux courbes de Tignes et Val d'Isère, dont la population a été multipliée respectivement par 3 et par 8 , s'opposent aux courbes de Villaroger et Sainte-Foy-Tarentaise, deux communes voisines venues beaucoup plus tard au tourisme, dont la population a stagné et a même plutôt décru dans les trente ans qui ont suivi 1945. D'ailleurs, certaines stations d'altitude créées dans les années 1950-1970, comme Chamrousse, La Plagne ou Les Arcs, ont été dotées d'écoles primaires, ce qui signifie bien qu'elles avaient aussi comme objectif de fixer de nouvelles populations.

Depuis 2010, on observe un renouveau des études démographiques sur les Alpes, avec par exemple deux numéros de la Revue de Géographie alpine consacrés à cette question en 2011 : « Processus de migration dans les régions de montagne, et en particulier dans les Alpes» et en 2014 : «Nouveaux habitants, dynamiques de repeuplement en zone de montagne ». La tonalité générale, comme l'indiquent les titres de ces numéros, met en avant le regain d'attractivité des régions alpines même si la majorité de ces travaux s'appuient sur des exemples suisses et italiens plus que français ; les études récentes sur la démographie des montagnes françaises ont jusqu'ici plutôt porté sur les moyennes montagnes ${ }^{4}$.

6 De ces travaux récents, il ressort quatre grands types d'espaces montagnards dans les Alpes occidentales, au regard de leurs dynamiques démographiques :

- le vide marginalisé en voie de reconquête (les vallées liguriennes ou piémontaises, le Tyrol oriental5);

- les espaces urbains de montagne (par exemple Davos dans les Grisons);

- le report de la croissance urbaine sur les montagnes proches (le canton de Zurich');

- les espaces touristiques attractifs (par exemple Verbier en Valais ou Cortina dans les Dolomites ${ }^{7}$ ).

Or il semble que les régions de sports d'hiver des Alpes françaises, étudiées à travers leur solde migratoire récent, présentent un tableau quelque peu différent.

\section{Quelques préalables méthodologiques}

On connaît les limites du recensement tel qu'il est réalisé en France (indépendamment des changements du début des années 2000) : tout d'abord, les dynamiques migratoires sont saisies de façon plutôt grossière à travers le « solde migratoire apparent » (ce qui reste de l'évolution lorsque l'on a fait la part des naissances et des décès), sans mesure réelle des entrées et des sorties en l'absence de fichiers de population résidente par 
commune. D'autre part, il faut être prudent face au sous-recensement des résidents étrangers communautaires (Anglais par exemple à Chamonix ou en haute Tarentaise), sous-enregistrement qui peut être amplifié par la qualité très variable de formation des agents recenseurs, écueil sur lequel butent de nombreuses études fines. Il est difficile de savoir dans quelle mesure de tels biais sont constants, ou peuvent au contraire évoluer dans le temps et dans l'espace. Mais si ponctuellement tel ou tel résultat peut susciter le doute, les recensements continuent à avoir force de loi... Nous nous appuierons donc sur les six derniers recensements couvrant l'intervalle qui va de 1968 à 2014.

9 En théorie, l'étude des dynamiques migratoires ne peut pas s'arrêter au seul solde migratoire et devrait prendre en compte les entrées (taux d'immigration en \%) et les sorties (taux d'émigration en \%) appréhendées séparément; or, ces taux s'ils sont parfois disponibles à l'échelle des régions et des départements, ne peuvent être calculés au niveau des communes sur la seule base du "solde migratoire apparent ». Mais on sait que le même espace peut s'avérer à la fois très attractif et très répulsif (forts taux d'entrée et de sortie), ou peu répulsif et peu attractif (faibles taux d'entrée et de sortie). L'attractivité et la répulsivité, mesurées statistiquement, ne sont donc pas des caractères antinomiques, mais peuvent se combiner par toute une série d'arrangements. Ainsi, un solde négatif n'est pas incompatible avec une forte attractivité, et il faudra se garder de raccourcis trop hâtifs. Notre analyse ici s'arrêtera au seul niveau du solde, et ne peut préjuger de la réelle attractivité ou répulsivité, considérée chacune individuellement.

10 Chaque année, la revue Montagne leaders fait paraître le classement des 100 plus grandes entreprises d'exploitation des remontées mécaniques dans les montagnes françaises ${ }^{8}$. Le périmètre d'action de chacune de ces entreprises correspond peu ou prou à un domaine skiable. Le dernier classement en date, portant sur la saison 2015-2016, recense 17 stations en Haute-Savoie, 30 en Savoie et 10 en Isère, soit 57 stations dans les Alpes du Nord. Certaines s'étendent sur plusieurs communes, comme les Sept Laux qui chevauchent les trois communes des Adrets, Theys et la Ferrière; à l'opposé, la commune de Saint-Martin-de-Belleville est concernée par deux domaines skiables distincts quoique reliés, les Ménuires et Val Thorens, si bien que les 57 stations retenues concernent les territoires de 89 communes. Pour conserver la continuité des séries statistiques, la présente étude s'applique aux communes dans leurs limites au $1^{\mathrm{er}}$ janvier 2015, c'est-à-dire avant la constitution de «communes nouvelles»: par exemple nous conserverons Mont-de-Lans et de Vénosc, même si elles ont fusionné en une seule commune des Deux-Alpes à partir du $1^{\text {er }}$ janvier 2017. Au moment où nous avons finalisé les recherches documentaires, le site de l'INSEE n'affichait plus les séries historiques concernant Autrans (Isère), si bien que l'étude portera sur 88 communes. Enfin la dernière période intercensitaire correspond à 2009-2014 ou à 2008-2013 selon les communes.

11 Globalement, ces stations présentent un haut niveau d'activité économique, quel que soit le critère retenu: chiffres d'affaires (globalement 1,050 milliard d'euros en 2015-2016), nombre de remontées mécaniques et volumes d'investissement, nombre de journées-skieurs (35,8 millions sur la même saison), nombre de nuitées et taux de remplissage... Les 13 stations françaises les plus importantes se retrouvent dans l'échantillon, et leur part à l'échelle nationale ne cesse de s'accroître depuis trente ans, illustrant un fort mouvement de concentration dont profitent surtout les stations 
d'altitude de Tarentaise, du Faucigny et de l'Oisans, qui sont aussi moins touchées que les autres par les aléas nivologiques. De façon générale, ces stations ont donc largement atteint les objectifs économiques que leurs fondateurs leur avaient assignés.

Aucun tri complémentaire n'a été effectué dans cet échantillon, qui présente de ce fait une grande hétérogénéité : certaines stations sont proches de grandes agglomérations (Chamrousse par rapport à Grenoble) alors que d'autres sont situées dans de hautes vallées plus isolées (Bonneval-sur-Arc en Haute-Maurienne). Les volumes d'activité sont extrêmement variables parmi les stations de l'échantillon retenu: Gresse-enVercors ne comptabilise que 48000 journées-skieurs en 2015-2016 quand La Plagne en enregistre 2430000 , soit cinquante fois plus (et les chiffres d'affaires varient d'un rapport de 1 à 130)! Selon le découpage administratif, dans certains cas la commune et la station se superposent exactement (Tignes par exemple) alors qu'Aime ou Modane, chefs-lieux de canton, sont travaillées par d'autres dynamiques qui ne se résument pas à la présence respective de La Plagne et de Valfréjus. Certaines communes ont pu connaître au cours de la période récente d'importants changements socioéconomiques, comme Bourg-Saint-Maurice qui a perdu son bataillon de chasseurs alpins en 2012, ce qui a forcément des répercussions en termes migratoires mais sans rapport direct avec l'activité de la station des Arcs située sur la commune. Toutefois, nous avons conservé tel quel cet échantillon de 88 communes pour ne pas introduire de biais lié à un tri supplémentaire, et au-delà du traitement statistique, nous mobiliserons donc les exemples les plus variés pour vérifier si les tendances générales se vérifient dans les différents cas.

\section{Le constat}

13 Avec un demi-siècle de recul depuis la création des stations d'altitude, n'est-on pas amené à nuancer le constat de reprise démographique que célébraient Paul et Germaine Veyret? En effet, trois éléments apparaissent à l'examen des résultats des recensements de 2009 et de 2014. Des soldes migratoires majoritairement négatifs; sur les 88 communes de l'échantillon, 55 ont affiché un solde migratoire apparent négatif entre 2009 et 2014, soit $62,5 \%$, et cette proportion atteint les deux tiers parmi les 47 communes du département de la Savoie (fig. 1). Certains soldes sont très creusés sur cette période, comme celui de Valloire (-3,2\% par an) ou celui de Montricher-Albanne $(-3,4 \%$ par an). Les 10 plus grandes stations ( 7 en Savoie, 2 en Haute-Savoie et 1 en Isère) concernent 19 communes, parmi lesquelles 16 ont un solde migratoire apparent négatif $(85 \%)$ : cette tendance paraît donc d'autant plus forte que la spécialisation touristique est plus affirmée. 
Fig. 1. - La situation migratoire des communes-supports de stations dans les Alpes du nord.

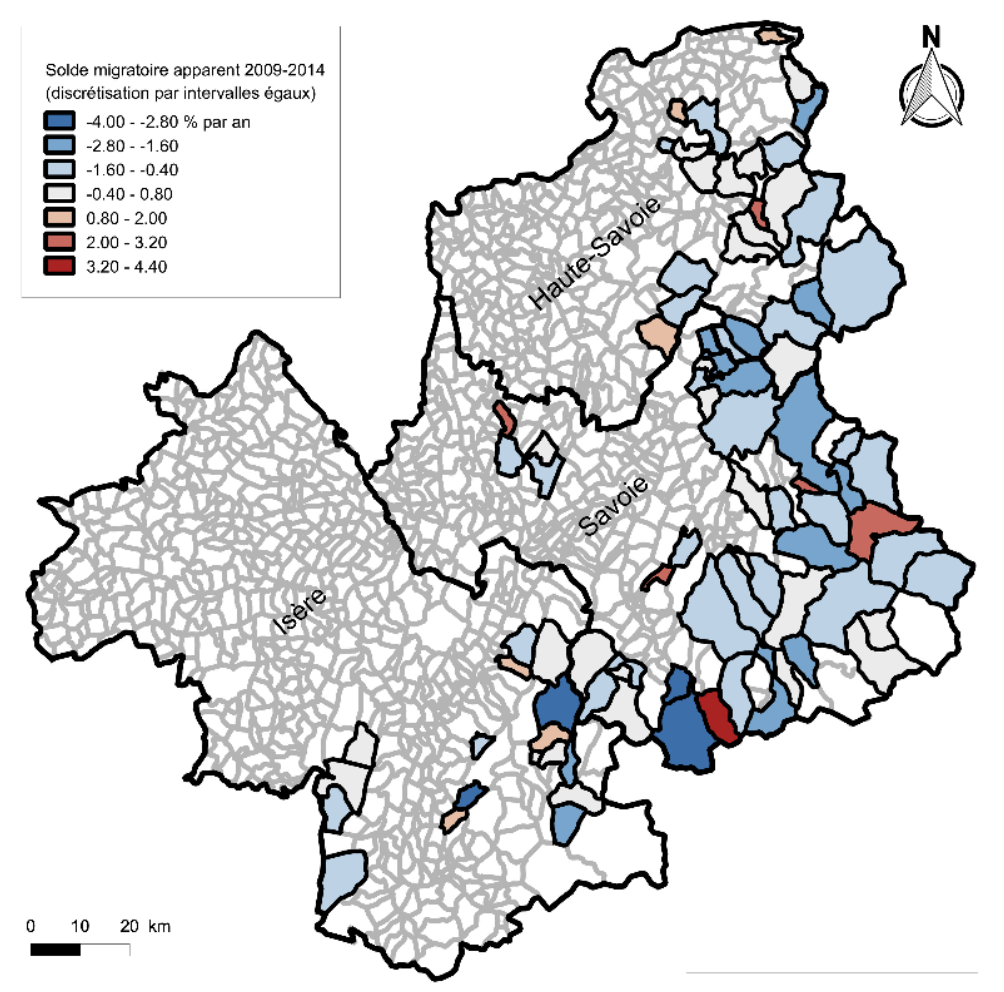

Données Recensements généraux de population, INSEE.

14 Cette tendance n'est pas nouvelle, mais elle s'est affirmée depuis les années 1990 : sur les six dernières périodes intercensitaires (1968-2014), 41 communes ont affiché au moins trois périodes avec un solde migratoire apparent négatif (soit $47 \%$, et même 53 \% pour les communes de Savoie) (fig. 2), même si des trajectoires différentes peuvent être identifiées (fig. 3). Tignes connaît une alternance de périodes négatives et positives, dont il est difficile d'extraire une tendance claire; Megève n'affiche que des soldes migratoires négatifs depuis 1968, et parmi les 19 communes supports des 10 plus grandes stations, 12 sont dans la situation d'avoir connu au moins trois périodes négatives. 
Fig. 2. - Une installation ancienne des soldes migratoires négatifs dans les communes-supports de stations des Alpes du nord.

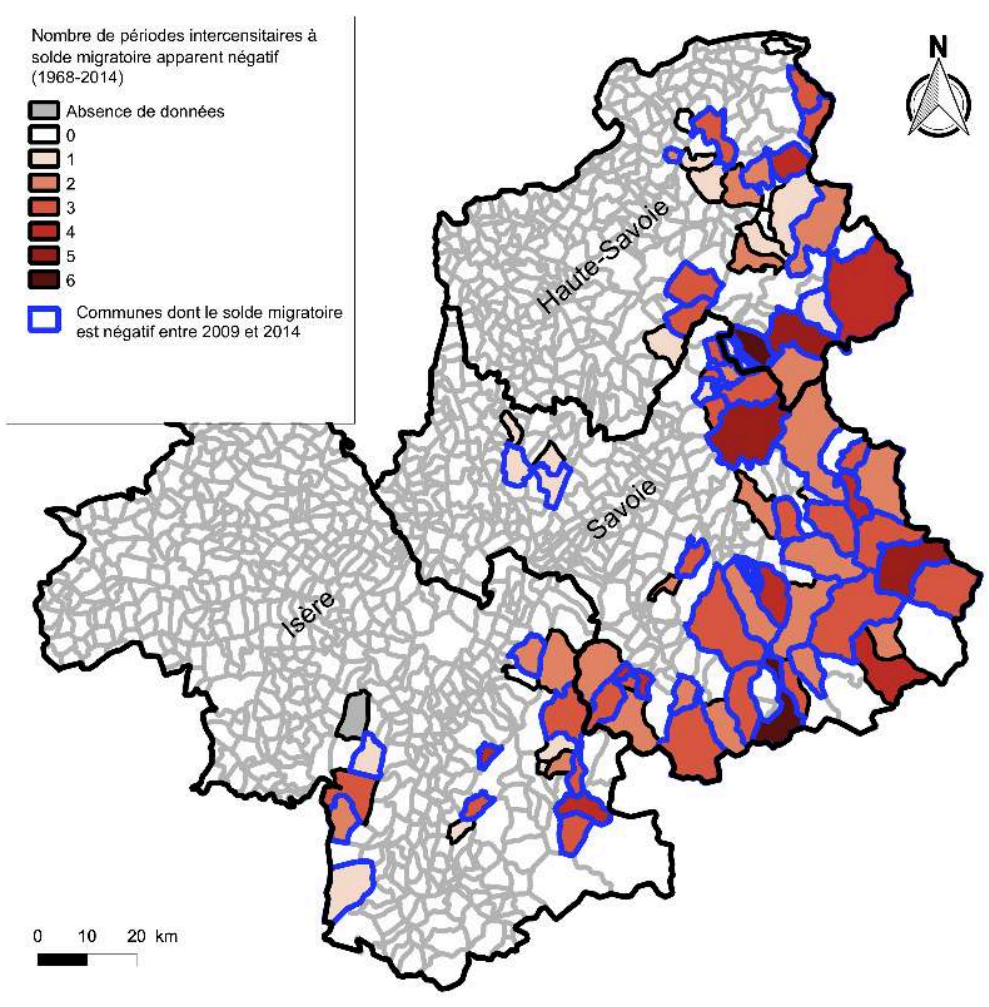

Données Recensements généraux de population, INSEE.

Fig. 3. - Diversité des trajectoires migratoire des communes-supports de stations des Alpes du nord (1968-2014).

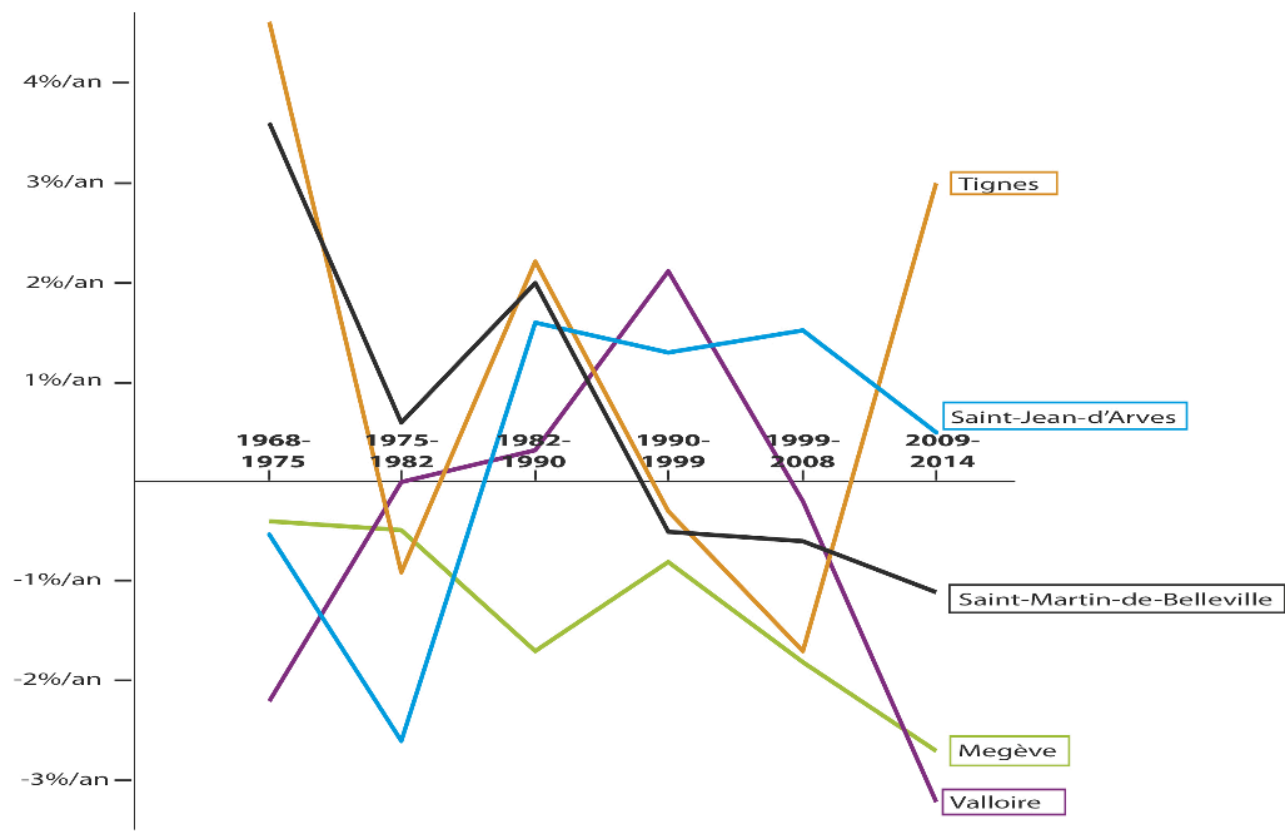

Données Recensements généraux de population, INSEE.

Une trajectoire type apparait, avec un solde migratoire négatif en 1968-1975 qui se retourne ensuite dans les années 1970-1990, avant de retrouver des valeurs négatives 
dans les années 2000-2010: Macôt-la-Plagne, Villaroger, Sainte-Foy-Tarentaise ou Montricher-Albanne, parmi d'autres, ont connu une telle évolution (fig.4). Cette trajectoire se retrouve logiquement sur la figure 5 qui montre la dégradation régulière des soldes migratoires apparents depuis 1975-1982, qui correspond à la période intercensitaire où le tourisme a le plus fonctionné comme activité peuplante. Précisons que ce ne sont pas nécessairement les mêmes communes qui présentaient un solde migratoire négatif en 1968-1975 et qui présentent ce caractère en 2009-2014.

Fig. 4. - Illustration de la notion de cycle migratoire des communes-supports de stations dans les Alpes du nord (1968-2014).

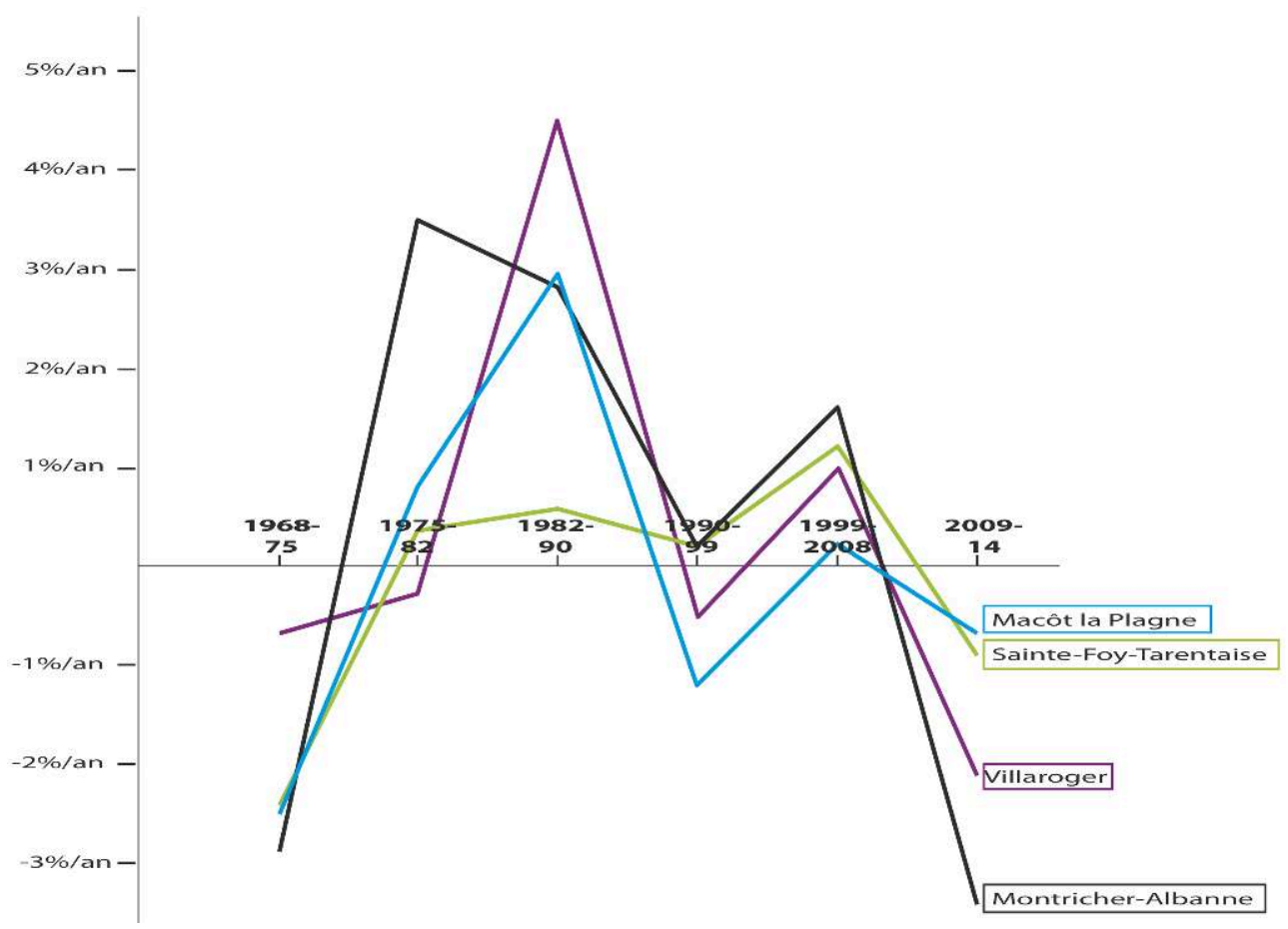

Données Recensements généraux de population, INSEE. 
Fig. 5. - Évolution des soldes migratoires entre 1968 et 2014 dans les communes-supports de stations des Alpes du nord.

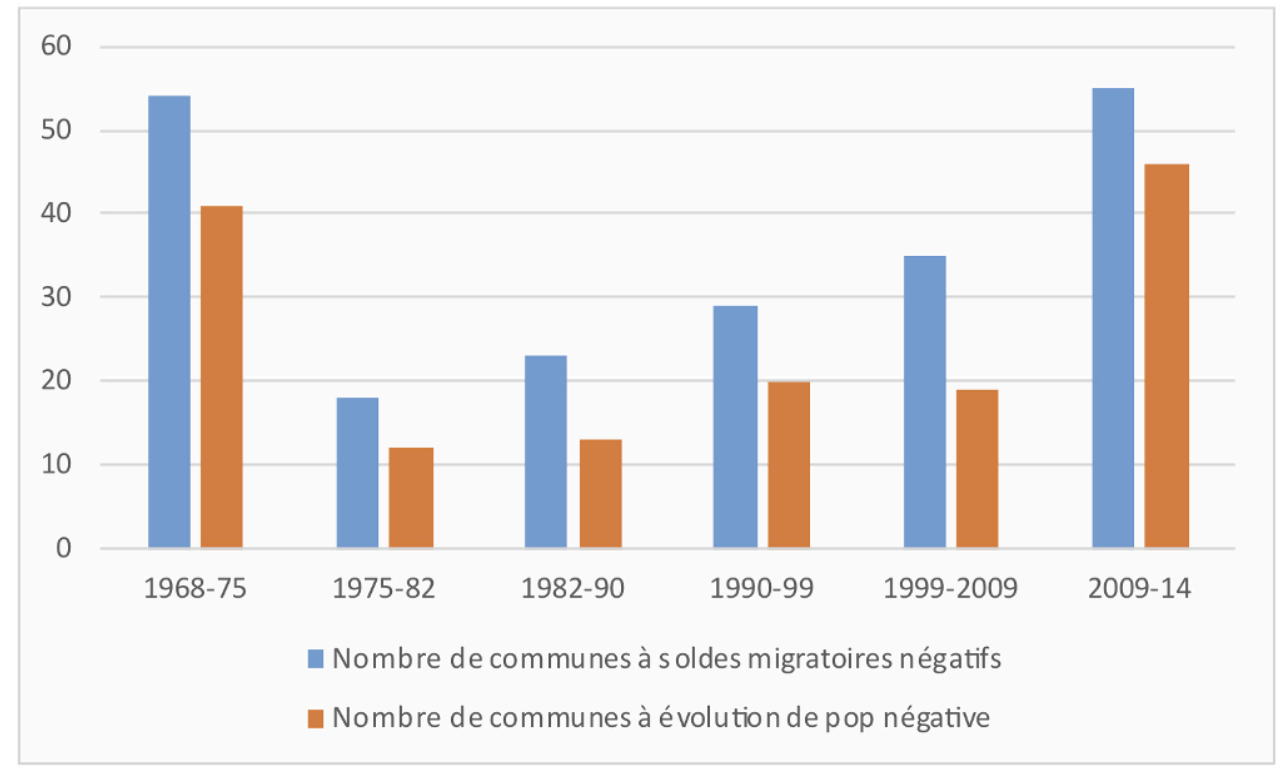

Données Recensements généraux de population, INSEE.

Dans une quarantaine de cas, les soldes migratoires négatifs sont une composante d'une baisse globale de la population (fig. 6). Dans des communes comme Mont-de-Lans ou les Allues, les soldes naturels positifs compensent les départs. Mais 46 communes sur 88 $(52,3 \%)$ voient leur population baisser entre 2009 et 2014, et là aussi la proportion est plus élevée pour les communes du département de la Savoie (57\%). Cela est somme toute logique pour des communes qui enregistrent des soldes migratoires négatifs depuis deux, trois ou quatre périodes intercensitaires. En effet, comme le montre la figure 5 , le mouvement migratoire et la croissance démographique des communes de l'échantillon ont connu une évolution parallèle depuis 1968. 
Fig. 6. - Situation démographique des 88 communes de l'échantillon (2009-2014, en \% par an).

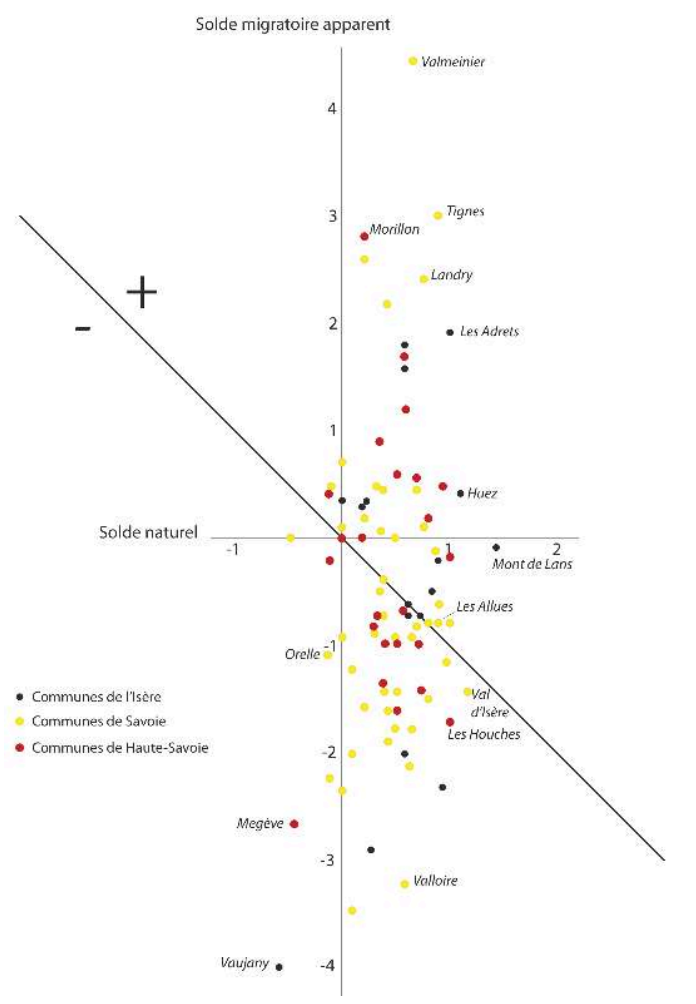

Données Recensements généraux de population, INSEE.

17 À cette tendance échappent surtout les communes en situation périurbaine ${ }^{9}$ comme Montcel au-dessus d'Aix-les-Bains, ou les communes de la vallée de l'Arve et du Giffre. Mais même pour ces communes-là, la situation est contrastée : Chamrousse a perdu près d'un quart de sa population depuis la création de la commune en 1986 (baisse de 607 à 473 habitants recensés).

On pourrait se poser la question d'un éventuel report de la dynamique démographique vers des communes voisines où la pression foncière est plus soutenable que dans les stations elles-mêmes. En effet, dans les années 1980 et 1990, on avait assisté à un mouvement d'installation de nouveaux habitants, venus des stations ou de l'extérieur, dans des communes proches (fond de vallée ou versant d'en face), mais ce mouvement s'est aujourd'hui estompé.

En Tarentaise, soit 43 communes constituant les quatre cantons de Moûtiers, Bozel, Aime et Bourg-Saint-Maurice, 15 communes voient leur population baisser entre 2006 et 2011. Entre 2003 et $2008^{10}$, le solde migratoire dans ces communes a été négatif pour toutes les tranches d'âge et pour toutes les CSP (sauf les employés et les artisans et commerçants) : il s'établit à $-4,6 \%$ sur ces cinq années, et à $-3,9 \%$ si l'on ne tient compte que de la population active. Ces données couvrent une période antérieure à la disparition du bataillon de Chasseurs alpins à Bourg-Saint-Maurice. Et plus largement, l'arrondissement d'Albertville (Tarentaise + Beaufortain + haute Combe de Savoie) enregistre un solde migratoire de $-0,1 \%$ par an entre 2008-2013. de Chamonix, Saint-Gervais et Sallanches : là aussi, et pour la même période 2003-2008, 
le solde migratoire a été négatif pour toutes les tranches d'âge et pour toutes les CSP (sauf les cadres et professions intellectuelles supérieures).

21 Cette tendance se vérifie donc pour les communes-supports de stations et pour les communes situées à proximité ; mais elle se vérifie aussi sur des espaces plus larges au sein duquel s'inscrivent ces espaces touristiques. Jusqu'aux années 2000, la Maurienne était seule à afficher un solde migratoire négatif, et cette dynamique était couramment mise sur le compte de la difficile gestion de la désindustrialisation, commencée voilà un demi-siècle et qui menace toujours de se poursuivre. Mais sur la période 2008-2013, les trois arrondissements de Saint-Jean-de-Maurienne, Albertville et Bonneville, dans lesquels se trouvent les principales stations d'altitude, affichent tous trois des soldes migratoires négatifs (respectivement $-0,6 \%,-0,1 \%$ et $-0,1 \%$ par an) et sont seuls dans ce cas par rapport au reste des départements savoyards ; la dynamique métropolitaine autour de Genève, Annecy et Chambéry reste beaucoup plus déterminante que la dynamique touristique, même avec le niveau d'activité et de spécialisation qu'on lui connait.

Et cette tendance transcende les types de stations, souvent décrits en termes de générations : stations villages comme Val d'Isère, stations de deuxième (Chamrousse), de troisième (Méribel pour la commune des Allues) ou de quatrième génération (Les Avanchers-Valmorel). Elle vaut aussi pour les stations plus familiales comme Aussois ou pour les stations à la clientèle plus aisée comme La Clusaz, et ce quel que soit le volume d'activités de la station, même si les plus grosses sont plus massivement concernées.

\section{Explications et implications}

Quatre pistes d'explications au moins peuvent être avancées. L'explication la plus classique, celle qui est la plus souvent invoquée, invoque la rareté du foncier et les prix de l'immobilier. La phrase revient comme une rengaine : « les jeunes ne peuvent plus se loger », et elle correspond bien souvent à la réalité. Si les communes se préoccupent souvent du logement des saisonniers, il leur est plus difficile de faciliter l'installation de nouveaux habitants à des prix préférentiels sans alimenter encore la spéculation. Mais cette explication parait encore trop restrictive, car on a vu que presque toutes les classes d'âge et CSP sont concernées.

Le peu d'opportunités d'emplois, car l'économie des sports d'hiver est très spécialisée, très peu diversifiée, et dans ce secteur aussi, les investissements s'accompagnent de réduction du personnel. Les sociétés d'exploitation de remontées mécaniques, qui constituent souvent le premier employeur de la commune, employaient pour la saison 2015-2016, 1828 personnes de façon permanente, c'est-à-dire $14 \%$ de moins qu'en 2009-2010; dans le même temps, et même s'ils ne sont pas directement impliqués dans les flux migratoires, les emplois saisonniers ont baissé de $18 \%$ (fig. 7). Cette évolution à la baisse est en partie indépendante du volume d'activités, mesuré en nombre de journées-skieurs; elle s'explique par des gains de productivité réalisés à l'occasion du remplacement de remontées mécaniques anciennes, et bien sûr elle ne concourt pas à offrir des perspectives professionnelles durables pour tous les employés, et encore moins à en attirer de nouveaux. 
Fig. 7. - Évolution du nombre d'emplois des entreprises de remontées mécaniques dans les 57 stations de l'échantillon (2009-2016).

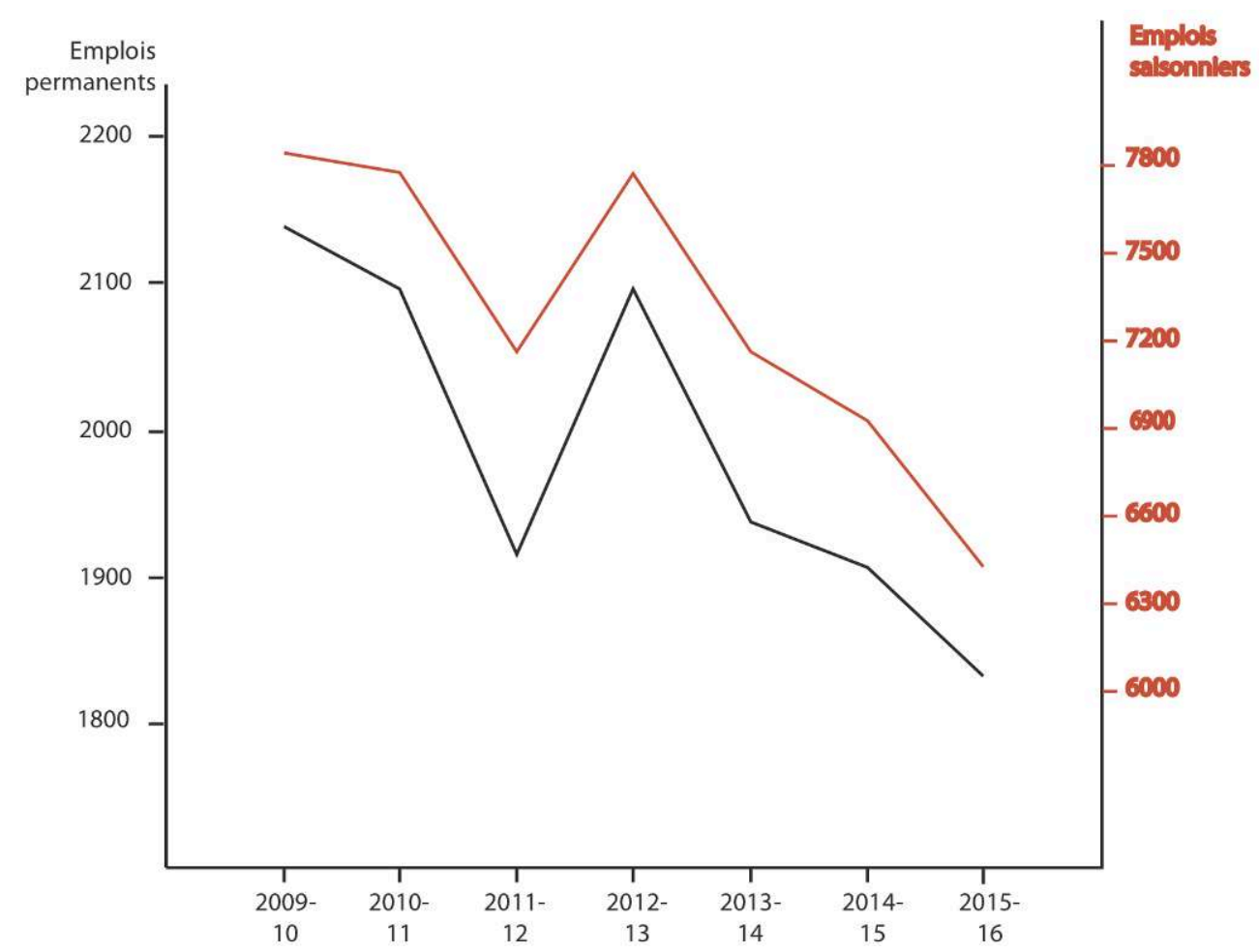

D'après Montagne Leaders, n² 257, septembre-octobre 2016. socioprofessionnelles des familles installées en stations et les types d'emplois proposés. La première génération d'entrepreneurs, commerciaux ou employés dans les stations de sports d'hiver était souvent composée de personnes à faibles niveaux de formation, issues de milieux dont le patrimoine était essentiellement foncier; le grand succès économique des stations de sports d'hiver s'est traduit par autant de réussites individuelles. À la génération suivante, les enfants, ou parfois les petits-enfants ont eu la possibilité de suivre des études supérieures, ce qui les a amenés à quitter les stations pour les villes universitaires environnantes ou plus éloignées. Mais le niveau de qualification acquis ne correspondait plus alors à l'offre d'emploi dans les territoires touristiques. L'activité touristique, si elle est peuplante, a ceci de caractéristique qu'elle produit surtout des emplois à faible niveau de qualification ${ }^{12}$. Dès lors, il est plus difficile pour ces enfants d'acteurs du tourisme d'envisager leur installation professionnelle dans le périmètre à neige, ce que montrent bien Ferrario et Price pour la vallée du Comelico dans les Dolomites :

«Pour certains, le Comelico n'a d'ailleurs pas besoin de diplômés: que fais-tu encore là? Tu vas devoir partir à un moment? $»^{13}$

Il est tentant de rapprocher cette trajectoire socio-professionnelle de celle qui a pu alimenter l'exode rural lorsque ces montagnes étaient essentiellement agro-pastorales.

Enfin, on observe peu de migrations d'agrément, telles que plusieurs auteurs ont pu les décrire dans les stations du littoral ou dans des régions plus rurales de moyenne montagne. Les stations d'altitude ont été conçues et construites dans une optique fonctionnaliste; on a parlé d'usines à ski. C'est dire qu'elles ne présentent pas 
nécessairement les aménités recherchées pour une installation permanente: les intersaisons sont longues et ne ressemblent pas toujours aux images présentées sur les catalogues des voyagistes, pendant plusieurs mois les stations prennent l'allure de grands chantiers de travaux publics où les habitants n'ont guère leur place, et le ski est rarement une pratique quotidienne contrairement à la promenade sur la plage ou au travail au jardin par exemple. La vie dans une station d'altitude présente un certain nombre de surcoûts (chauffage, automobile et frais afférents, équipement de la personne), et n'offre pas aux retraités les avantages d'une résidence plus économique que celle que l'on a laissée en ville.

28 C'est là que les remarques méthodologiques préalables prennent tout leur sens car de fait, il est vrai que de nouveaux habitants viennent s'installer dans ces communes, mais on en compte moins que de départs. La recherche actuelle insiste beaucoup sur l'attractivité de ces communes, et s'interroge beaucoup sur les motivations des nouveaux venus, sur leur façon d'habiter la montagne... Cela relève aussi d'un biais méthodologique, car il est plus facile d'identifier les nouveaux arrivants et de les interroger lorsqu'ils sont présents ${ }^{14}$ que d'aller rechercher des gens qui ont quitté ces communes, avec une traçabilité faible. Déduire des seuls soldes migratoires négatifs que la montagne a perdu son attractivité serait une grave erreur; mais dans une proportion croissante de communes supports de stations, cette attractivité ne suffit plus à compenser les départs.

Alors que les trois départements des Alpes du nord voient leur population augmenter tout au long de la période 1968-2014, avec des soldes migratoires et naturels positifs, et que les projections pour les décennies à venir laissent entrevoir une poursuite de cette augmentation ${ }^{15}$, les communes-supports de stations ont divergé de cette évolution régionale. Dans ces trois départements, le tourisme a constitué et continue à constituer un moteur économique indéniable, mais ses effets démographiques sont aujourd'hui beaucoup plus difficiles à apprécier: au minimum, de ces données issues du recensement, il faut admettre que les effets démographiques sont spatialement dissociés des " périmètres à neige » et de l'accueil des touristes eux-mêmes.

Or, on observe de la part des responsables des territoires une certaine cécité face à ces évolutions démographiques, et cette cécité obère la prise de conscience. Par exemple, dans la typologie des communes de montagne produite par la DATAR en $2011^{16}$, les communes des massifs de Savoie apparaissent très majoritairement dans la catégorie " la haute et moyenne montagne résidentielle et touristique ", mais sans que l'on puisse faire la part entre ce qui relève du "résidentiel » et du "touristique », comme si ces deux volets étaient nécessairement reliés ou trop difficiles à distinguer l'un de l'autre. Pour les auteurs de cette étude, cette catégorie concerne des "espaces d'altitude attractifs et jeunes à faible chômage [...] connaissant une forte attractivité migratoire. Leur situation socio-économique favorable repose sur la prédominance des activités résidentielles et touristiques en fort développement soutenant la croissance de l'emploi, incluant les grandes stations de sports d'hiver $\aleph^{17}$. Ce diagnostic optimiste est assez éloigné de la réalité telle qu'elle émane des recensements.

D'autres auteurs pratiquent plutôt l'euphémisation, car il paraît encore difficile d'admettre que la plus grande région de sports d'hiver au monde ne serait plus attractive en termes démographiques: ainsi, à propos de la Tarentaise, «le renouvellement de la population repose essentiellement sur l'excédent du solde naturel », ou bien "Albertville gagne de plus en plus d'habitants ${ }^{18}$, sans jamais dire 
clairement que le solde migratoire de la Tarentaise dans son ensemble est négatif (cf. supra). On peut s'étonner que de tels documents, qu'ils émanent de l'Insee ou de la Datar, ne soient pas plus explicites sur les questions abordées...

32 Le CDDRA Tarentaise est un peu plus lucide, lorsqu'il souligne que « le territoire fait face à un déficit des 18-25 ans, qui s'explique par le départ des jeunes adultes pour des raisons de formation ou d'émigration professionnelle $»^{19}$; on a vu que, dans les faits, ce comportement ne concerne pas cette seule classe d'âge. Le milieu associatif est plus enclin à voir la situation en face et à ne pas minimiser les problèmes. L'association Euromontana a profité des VIII ème assises européennes de la montagne qui se sont tenues en octobre 2012 à Chambéry pour alerter sur les difficultés que rencontrent les jeunes lorsqu'ils veulent s'installer et vivre en montagne, et pour proposer un certain nombre de mesures visant à renforcer l'attractivité des montagnes. Mais, là encore, la question ne concerne pas seulement les «nouvelles générations».

Cette difficulté des communes de montagne à conserver leur population ou à attirer de nouveaux habitants va à l'encontre de certains constats sur la tendance à la résidentialisation. Ph. Bourdeau observait par exemple en 2007 :

«Cette résidentialisation concerne tous les types de stations qu'il s'agisse de villages de montagne les plus propices à une périurbanisation à la périphérie des grandes agglomérations, des stations moyennes facilement accessibles, mais aussi de grandes stations où s'amorce l'implantation de résidents effectuant des trajets pendulaires vers les métropoles alpines. $»^{20}$

Ce qui vaut peut-être pour les moyennes montagnes autour de Grenoble ne peut plus aujourd'hui être généralisé à ce point, et l'évolution que nous avons décelée met en évidence la spécificité des stations de sports d'hiver des montagnes françaises, dont le succès touristique ne s'est pas traduit par une attractivité résidentielle durable. La résidentialisation des stations de tourisme est souvent perçue de façon plutôt positive :

"Ces nouveaux résidents contribuent à renforcer et valider la dimension peuplante des lieux touristiques et à favoriser le recul relatif de l'activité touristique du lieu en faveur d'une fonction résidentielle et ludique. $»^{21}$

Mais lorsque le foncier est rare et les procédures d'aménagement très contraignantes, l'installation d'une population résidente peut aussi se substituer à la capacité d'hébergement touristique. L'occupation permanente de logements se solderait alors par une baisse de l'activité et des recettes des opérateurs touristiques.

Les dynamiques migratoires observables aujourd'hui dans les communes-supports de stations des Alpes du Nord signalent-elles la fin d'un cycle? Dans les décennies qui ont suivi leur création, les stations ont atteint les objectifs démographiques qui leur avaient été fixés par les concepteurs de ces aménagements: l'hôtellerie, le commerce, les remontées mécaniques, le bâtiment et les travaux publics, les services destinés aux touristes ont fixé et souvent attiré de nouveaux habitants en montagne. Mais 30 ou 40 ans après, force est de constater que cette attractivité s'est bien affaiblie et qu'elle ne suffit plus, dans de nombreux cas, à compenser les départs.

37 Au bout d'une ou deux générations, cet « effet peuplant », s'il a pu exister, a atteint ses limites, sans que la résidentialisation vienne ici prendre le relais. À savoir s'il s'agit d'une force ou d'une faiblesse... Car globalement, ces stations de sports d'hiver, dont 
nous avons retenu ici les plus importantes, ont su trouver, conserver et faire évoluer leurs clientèles; les taux de remplissage en saison sont satisfaisants aux yeux des acteurs du tourisme et l'on peut aussi estimer que la situation démographique n'est pas le meilleur indicateur de la santé d'une station touristique...

Mais la situation actuelle résulte aussi d'une très grande spécialisation de l'économie touristique en montagne dont les acteurs ont du mal à envisager la diversification. L'évolution vers la résidentialisation n'est pas forcément souhaitée. Le renouvellement de la population sera aussi, à terme, une condition nécessaire à la pérennisation de ce modèle économique; d'autant plus que la montée en gamme, dans laquelle de nombreuses stations se sont engagées, suppose la présence en stations d'une importante population d'actifs. La variable démographique peut-elle brider les ambitions des promoteurs du tourisme? Ou s'achemine-t-on vers des peuplements de plus en plus saisonniers de ces « archipels d'altitude » monofonctionnels?

\section{BIBLIOGRAPHIE}

A. A., « Dossier Top 100 : une saison qui souffle le chaud et le froid », Montagne Leaders, n $^{\circ} 257$, septembre-octobre 2016, p. 50-72.

AMREIN Thierry, «Parcours de migrants et recomposition des sociétés d'accueil : le palimpseste des identités collectives en Bas-Valais ", Revue de Géographie alpine, vol. 102, n 3, 2014.

ANGUIER Caroline et LAVERGNE Henri, « Savoie : la population du nord-ouest augmente, celle de la Maurienne diminue », La Lettre analyses, INSEE Rhône-Alpes, $\mathrm{n}^{\circ}$ 219, 2014.

APTV, Charte de Développement Durable Rhône-Alpes, Tarentaise-Vanoise, vol. I : diagnostic, août 2013. BLACHE Jules, L'homme et la montagne, Gallimard, 1934, 192 p.

BOESCH Martin, RENNER Erich et SIEGRIST Dominik, « Stratégies contre le déclin des zones périphériques ", Revue de Géographie alpine, vol. 99, nº 1, 2011.

BOURDEAU Philippe (dir.), Les sports d'hiver en mutation : crise ou révolution géoculturelle?, co-éd. Hermes-Lavoisier, 2007, 250 p.

CAMENISCH Martin et DEBARBIEUX Bernard, « Les migrations inter-communales en Suisse : un "effetmontagne" ? », Revue de Géographie alpine vol. 99, n 1, 2011.

CORRADO Federica, « Les territoires fragiles dans la région alpine : une proposition de lecture entre innovation et marginalité », Revue de Géographie alpine, vol. 98, nº 3, 2010.

CORRADO Federica, « Processes of re-settlement in mountain areas », Revue de Géographie alpine, vol. 102, $\mathrm{n}^{\circ} 3,2014$.

DEWAILLY Jean-Michel et FLAMENT Émile, Géographie du tourisme et des loisirs, Sedes, D.I.E.M., 1993, $288 \mathrm{p}$.

DOMENGE Mireille, « Savoie : plus de 480000 habitants à l'horizon 2031 », La Lettre analyses, INSEE Rhône-Alpes, $\mathrm{n}^{\circ}$ 132, 2010. 
DUHAMEL Philippe, Le tourisme, lectures géographiques, Documentation photographique, $\mathrm{n}^{\circ} 8094$, 2013, 64 p.

ELMI Marianna et PERLIK Manfred, « From tourism to multilocal residence? Unequal transformation processes in the Dolomite area ", Revue de Géographie alpine, vol. 102, n 3, 2014.

Euromontana, Déclaration de Chambéry: Améliorer l'attractivité des montagnes pour les nouvelles générations, 2012, 5 p. [URL : http://www.euromontana.org/wp-content/uploads/2014/08/ declaration_de_chambery_fr_final.pdf]

FERRARIO Elena et PRICE Martin, « Should I stay or should I go? Les facteurs de décision d'un retour dans la région montagnarde d'origine des jeunes diplômés alpins ", Revue de Géographie alpine, vol. 102, n 4, 2014.

FOREST Nicolas et BERTRAND Philippe, « Pays du Mont-Blanc : des enjeux liés au logement et au développement durable ", La Lettre analyses, INSEE Rhône-Alpes, nº 208, 2013.

FRANÇOIS Hugues et MARCELPOIL Emmanuelle, « Mutations touristiques, mutations foncières : vers un renouvellement des formes d'ancrage territorial des stations ", dans CLARIMONT Sylvie et VLÈs Vincent (dir.), Tourisme durable en montagne : entre discours et pratiques, éd. Afnor, 2008, p. 177-195. HITAL Mohamed, BARCZAK Aleksandra, TOURNEUX François-Pierre, SCHAEFFER Yves, HOUDART Marie et CREMER-SCHULTE Dominik, Typologie des campagnes françaises et des espaces à enjeu spécifique, DATAR, $2012,80 \mathrm{p}$.

MARTIN Niels, BOURDEAU Philippe et DALLER Jean-François (dir.), Les migrations d'agrément : $d u$ tourisme à l'habiter, L'Harmattan, 2012.

MESSERLI Paul, SCHEURER Thomas et VELT Heinz, « Entre nostalgie et fuite - processus de migration dans les régions de montagne, et en particulier dans les Alpes ", Revue de Géographie alpine, vol. 99, $\mathrm{n}^{\circ} 1,2011$.

POINSARD Michel et BERTRAND Philippe, « Tarentaise-Vanoise : un territoire autonome dont l'activité découle du tourisme de stations ", La Lettre analyses, INSEE Rhône-Alpes, $\mathrm{n}^{\circ}$ 221, 2014. VEYRET Paul et Germaine, «Essai de définition de la Montagne », dans Études montagnardes, 1962, p. 30.

VIAZZo Pier Paolo et ZANINI Roberta Clara, « Taking advantage of emptiness? », Revue de Géographie alpine, vol. 102, $\mathrm{n}^{\circ} 3,2014$.

\section{NOTES}

1. P. et G. Veyret, « Essai de définition de la Montagne », p. 30.

2. Ph. Duhamel, Le tourisme, lectures géographiques, p. 54.

3. J.-M. Dewailly et E. Flament, Géographie du tourisme et des loisirs, p. 196.

4. Par exemple F. Cognard in Martin et al., 2012.

5. F. Corrado, 2010.

6. M. Camenisch et B. Debarbieux, 2011.

7. M. Elmi et M. Perlik, 2014.

8. A. A., 2016.

9. H. François et E. Marcelpoil, 2008. 
10. M. Poinsard et P. Bertrand, 2014.

11. N. Forest et P. Bertrand, 2013.

12. J.-M. Dewailly et E. Flament, 1993.

13. E. Ferrario et M. Price, 2014.

14. T. Amrein, 2014.

15. M. Domenge, 2010.

16. M. Hital et al., 2012.

17. Idem.

18. C. Anguier et H. Lavergne, 2014.

19. APTV, 2013, p. 70.

20. Ph. Bourdeau, 2007, p. 223-224.

21. Ph. Duhamel, 2013, p. 16.

\section{RÉSUMÉS}

Lorsque les politiques d'aménagement touristique de la montagne ont été lancées dans les décennies 1950-1960, elles visaient à développer les activités économiques, mais aussi à enrayer le déclin démographique. Ces buts ont d'abord semblé être atteints. Mais depuis une vingtaine d'années, de nombreuses communes-supports de stations enregistrent des soldes migratoires négatifs : sur un échantillon de 88 communes-supports de stations de sports d'hiver des Alpes du Nord (Isère, Savoie, Haute-Savoie), 55 ont été dans cette situation entre 2009 et 2014. Contrairement à de nombreuses stations littorales, l'attractivité touristique en montagne ne s'est pas accompagnée d'une attractivité résidentielle ; et les populations permanentes installées dans les stations d'altitude ont du mal à faire souche au-delà de la génération des pionniers. L'augmentation des prix du foncier et l'hyperspécialisation de cette économie touristique engendrent pour les jeunes actifs une difficulté à s'installer et à vivre en station.

\section{AUTEUR}

\section{CHRISTOPHE GAUCHON}

Professeur de Géographie, Université Savoie - Mont-Blanc 